\title{
Spatially and Temporally Explicit Water Footprint Accounting
}

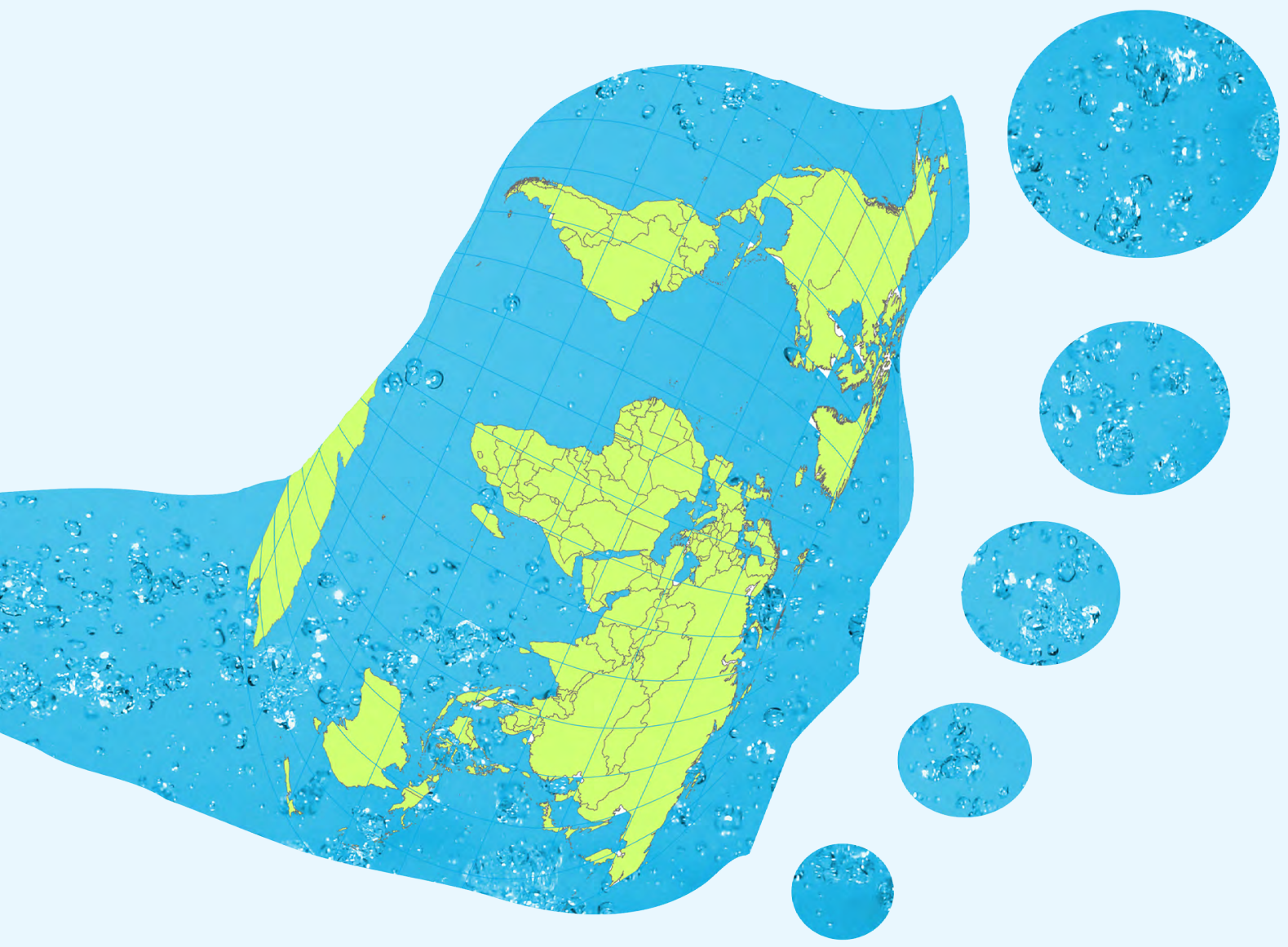

Mesfin Mergia Mekonnen 
SPATIALLY AND TEMPORALLY EXPLICIT WATER FOOTPRINT ACCOUNTING 
Members of the Awarding Committee:

Prof. dr. F. Eising

Prof. dr. ir. A. Y. Hoekstra

Prof. dr. C. Kroeze

Prof. Junguo Liu

Prof. ir. E. van Beek

Prof. dr. A. van der Veen
University of Twente, chairman and secretary

University of Twente, promoter

Open Universiteit Heerlen

Beijing Forestry University

University of Twente

University of Twente

Cover image: Background 'Water Texture' $\odot$ Jiri Vaclavek / Dreamstime.com

Copyright $(\mathcal{C}$ by Mesfin Mergia Mekonnen, Enschede, the Netherlands

Printed by Wöhrmann Print Service, Zutphen, the Netherlands

ISBN 978-90-365-3221-1 


\title{
SPATIALLY AND TEMPORALLY EXPLICIT WATER FOOTPRINT ACCOUNTING
}

\author{
DISSERTATION \\ to obtain \\ the degree of doctor at the University of Twente, \\ on the authority of the rector magnificus, \\ prof.dr. H. Brinksma, \\ on account of the decision of the graduation committee, \\ to be publicly defended \\ on Friday 16 September at 16.45
}

by

Mesfin Mergia Mekonnen

born on 23 November 1966

in Addis Ababa, Ethiopia 
This dissertation has been approved by:

prof. dr. ir. A.Y Hoekstra

promoter 


\section{Contents}

Acknowledgements $\quad$ xi

Summary xiii

1. Introduction 1

2. The green, blue and grey water of crops and derived crop products 9

2.1 Introduction 10

2.2 Method and data $\quad 12$

$\begin{array}{lll}2.3 & \text { Result } & 18\end{array}$

$\begin{array}{ll}\text { 2.3.1 The global picture } & 18\end{array}$

2.3.2 The water footprint of primary crops and derived crop products per ton 19

2.3.3 The water footprint of biofuels per GJ and per litre 29

2.3.4 The total water footprint of crop production at national and sub-national level $\quad 30$

2.3.5 The total water footprint of crop production at river basin level 32

2.3.6 The water footprint in irrigated versus rain-fed agriculture 34

2.4 Discussion $\quad 34$

2.5 Conclusion $\quad 41$

3. The green, blue and grey water footprint of farm animals and animal products 45

3.1 Introduction $\quad 45$

$\begin{array}{lll}3.2 & \text { Method } & 48\end{array}$

3.3 Data 54

3.4 Results 56

3.4.1 Quantity and composition of animal feed 56

3.4.2 The water footprint of live animals at the end of their lifetime and animal $\begin{array}{ll}\text { products per ton } & 58\end{array}$

3.4.3 Water footprint of animal vs crop products per unit of nutritional value 64

3.4.4 The total water footprint of animal production 68

$\begin{array}{lll}3.5 & \text { Discussion } & 71\end{array}$

$\begin{array}{lll}3.6 & \text { Conclusion } & 75\end{array}$ 
4. National water footprint accounts: the green, blue and grey water footprint of production and consumption

$\begin{array}{lll}4.1 & \text { Introduction } & 78\end{array}$

4.2 Method and data $\quad 81$

$\begin{array}{lll}4.3 & \text { Results } & 87\end{array}$

$\begin{array}{ll}\text { 4.3.1 The water footprint of national production } & 87\end{array}$

4.3.2 International virtual water flows related to trade in agricultural and $\begin{array}{ll}\text { industrial products } & 89\end{array}$

4.3.3 National water saving per country as a result of trade 93

4.3.4 Global water saving related to trade in agricultural and industrial products 94

4.3.5 The water footprint of national consumption 98

$\begin{array}{ll}\text { 4.3.6 External water dependency of countries } & 101\end{array}$

4.3.7 Mapping the global water footprint of national consumption: an example from the US 105

$\begin{array}{lll}4.4 & \text { Discussion } & 109\end{array}$

$\begin{array}{lll}4.5 & \text { Conclusion } & 111\end{array}$

5. Global water scarcity: The monthly blue water footprint compared to blue water availability for the world's major river basins 113

$\begin{array}{lll}5.1 & \text { Introduction } & 114\end{array}$

5.2 Method and data 117

$\begin{array}{lll}5.3 \text { Results } & 119\end{array}$

5.3.1 Monthly natural runoff and blue water availability 119

$\begin{array}{ll}\text { 5.3.2 Monthly blue water footprint } & 120\end{array}$

$\begin{array}{ll}\text { 5.3.3 Monthly blue water scarcity per river basin } & 120\end{array}$

5.3.4 Annual average monthly blue water scarcity per river basin 126

$\begin{array}{ll}\text { 5.3.5 Global blue water scarcity } & 129\end{array}$

5.3.6 Blue water footprint vs blue water availability in selected river basins $\quad 130$

$\begin{array}{lll}5.4 & \text { Discussion and conclusion } & 136\end{array}$

Appendix 5A. Global river basin map $\quad 138$

Appendix 5B. Global maps of monthly natural runoff in the world's major river basins 139

Appendix 5C. Global maps of monthly blue water availability in the world's major river

basins 
Appendix 5D. Global maps of the monthly blue water footprint in the world's major river basins. Period 1996-2005.

6. A global and high-resolution assessment of the green, blue and grey water footprint of wheat

6.1 Introduction 144

$\begin{array}{lll}6.2 \text { Method } & 146\end{array}$

$\begin{array}{lll}6.3 \text { Data } & 150\end{array}$

6.4 The water footprint of wheat from the production perspective 152

6.5 International virtual water flows related to trade in wheat products 156

6.6 The water footprint of wheat from the consumption perspective 158

$\begin{array}{lll}6.7 & \text { Case studies } & 160\end{array}$

6.7.1 The water footprint of wheat production in the Ogallala area (USA) $\quad 160$

6.7.2 The water footprint of wheat production in the Ganges and Indus river basins 164

6.7.3 The external water footprint of wheat consumption in Italy and Japan 165

$\begin{array}{lll}6.8 & \text { Discussion } & 167\end{array}$

$\begin{array}{lll}6.9 \text { Conclusion } & 171\end{array}$

7. The water footprint of electricity from hydropower 173

$\begin{array}{lll}7.1 & \text { Introduction } & 174\end{array}$

$\begin{array}{lll}7.2 & \text { Method and data } & 176\end{array}$

7.3 Results: the water footprint of hydroelectricity 184

$\begin{array}{lll}7.4 & \text { Discussion } & 189\end{array}$

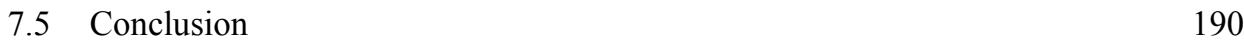

8. The external water footprint of the Netherlands: geographically-explicit quantification

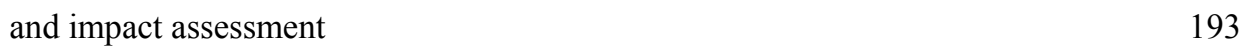

$\begin{array}{lll}8.1 & \text { Introduction } & 193\end{array}$

$\begin{array}{lll}8.2 \text { Method } & 195\end{array}$

$\begin{array}{ll}\text { 8.2.1 Bottom-up approach } & 197\end{array}$

$\begin{array}{ll}\text { 8.2.2 Top-down approach } & 199\end{array}$

8.2.3 Impact of the water footprint 202

8.2.4 Green, blue and grey water footprint 203

$\begin{array}{ll}\text { 8.2.5 Methodological innovation } & 205\end{array}$ 
$\begin{array}{lll}8.3 \text { Results } & 206\end{array}$

8.3.1 The water footprint of Dutch consumers 206

8.3.2 The external water footprint of Dutch consumers 207

8.3.3 The total virtual-water import to the Netherlands 212

8.3.4 Hotspots 214

$\begin{array}{lll}8.4 & \text { Conclusion } & 217\end{array}$

9. The relation between national water management and international trade: A case study $\begin{array}{ll}\text { for Kenya } & 219\end{array}$

$\begin{array}{lll}9.1 & \text { Introduction } & 220\end{array}$

9.2 Method and data 221

9.3 Results 223

9.3.1 Water footprint of crop production 223

9.3.2 Virtual water flow related to trade in agricultural products 225

9.3.3 The water footprint of national consumption 231

9.4 Water resource scarcity in Kenya 233

9.5 Water management in Kenya - the role of virtual water 236

9.6 Conclusion 242

10. Mitigating the water footprint of export cut flowers from the lake Naivasha basin,

Kenya 245

10.1 Introduction 246

10.2 Method 248

$\begin{array}{ll}10.3 \text { Data } & 249\end{array}$

10.4 Water use within the Lake Naivasha Basin related to cut-flower production 251

10.4.1 The water footprint within the Lake Naivasha Basin related to crop production 251

10.4.2 The water footprint per cut flower 253

10.4.3 Virtual water export from the Lake Naivasha Basin 254

10.5 Sustainability of water use in the Lake Naivasha Basin 255

10.6 Reducing the water footprint in the Lake Naivasha Basin: involving consumers, retailers and traders along the supply chain 260

10.6.1 Current water regulations in the Lake Naivasha Basin 260 
10.6.2 A sustainable-flower agreement between major agents along the cut-flower supply-chain 262

10.7 Discussion 266

11. Discussion and conclusion 269

References 277

List of publications 307

About the author 311 



\section{Acknowledgements}

Let us thank God for his priceless gift!

-2 Corinthians 9:15

This $\mathrm{PhD}$ thesis is the result of four years of research at the Water Engineering and Management group in the faculty of Engineering Technology of University of Twente. I greatly appreciate all who have contributed directly or indirectly to the content of the thesis, to the underlying work, and to my personal life during this period.

First and foremost, I express my gratitude to my supervisor and promoter prof.dr.ir Arjen Y. Hoekstra who has shaped my thesis with his invaluable guidance and support throughout the four years. I still remember my excitement when I received your email four years ago asking if I am interested to do my $\mathrm{PhD}$ research with you. Arjen, thank you for giving me the opportunity to do my $\mathrm{PhD}$, for your seemingly never ending enthusiasm about our work, creative inputs and your patients to hear me out while I was struggling to explain myself. My work has greatly benefited from your critical comments and the discussion we had. Thank you!

I am also indebted to Ashok Chapagain who has been my daily supervisor during my MSc work at UNESCO-IHE, Delft and still remains a good friend. Ashok, your enthusiasm, support and advices during my MSc work and to this date has greatly helped me. It was a challenge to improve upon Arjen and your work but I have benefited from the clear documentations of your works. Thank you!

I would like to thank all my current and former colleagues at the WEM department. Pieter van Oel, it was a joyful and learning experience working with you on the Netherland's case study. Winnie, I have enjoyed sharing a room with you and the discussion we had from time to time. Bert Kort, the discussion we had and your dedication during your MSc thesis project has helped me to counter check how the crop model works. I am thankful to Anke and Brigitte who were always cheerful when I visited them but most of all, to Joke who was always willing to arrange whatever had to be arranged. Erica and Mehmet, thank you for 
accepting to be my paranymphs. I am very happy to have you beside me at my defence. Special thanks to Maite, Blanca, Tanya, Ertug, Guoping, Michel, Ruth and many others. Thanks also to Rene and Arthur for your technical support with ArcGIS and other computer related problems.

Many thanks are also given to a dozen friends who are in Ethiopia or in other parts of the world. Dr. Getahun Merga, Shiferaw Alemu, Mulugeta Asamnew, Andualem Tsegaye, Getinet Beshah, Melis Teka, Tadesse Kifle, Solomon Teshome, Fiseha W/Gabriel, Daniel Hailu, Yohannes Kahsay, Getachew Lemma and many others, your friendship over the years and the occasional long distance call was source of joy and strength.

My family has always provided all the love, advice and support that I needed. I couldn't thank you enough. Grandma - I couldn't formulate meaningful words to show my feelings and thank you. You have given me everything - I wish you could have witnessed this day. Grandma, this book is dedicated to you!

Meron, you are my source of love and strength. I couldn't imagine how the four years would have passed without your love, patience and full support. I couldn't say enough to thank you except quoting the 'wise man's' words (Proverbs 31:10-11): “Who can find a virtuous and capable wife? She is worth more than precious rubies. Her husband can trust her, and she will greatly enrich his life”. Thank you for enriching my life!!

Mesfin M. Mekonnen

Enschede, 12 August 2011 


\section{Summary}

The earth's freshwater resources are subject to increasing pressure in the form of consumptive water use and pollution (Postel, 2000; WWAP, 2003, 2006, 2009). Quantitative assessment of the green, blue and grey water footprint of global production and consumption can be regarded as a key in understanding the pressure put on the global freshwater resources. The overall objective of this thesis is, therefore, to analyse the spatial and temporal pattern of the water footprint of humans from both a production perspective and a consumption perspective. The study quantifies in a spatially explicit way and with a worldwide coverage the green, blue and grey water footprint of agricultural and industrial production, and domestic water supply. The green, blue and grey water footprint of national consumption is quantified and mapped for each country of the world. The study further estimates virtual water flows and national and global water savings related to international trade in agricultural and industrial goods. Next, the study assesses the blue water scarcity for the major river basins of the world for the first time on a month-by-month basis, thus providing more useful guidance on water scarcity than the usual annual estimates of water scarcity. The study also contains five case studies: two specific product water footprint studies, two specific country water footprint studies and one water footprint study on a specific product from a specific region. The main findings are summarised below, following the chapter-setup of the thesis.

Water footprint of crop production: The agricultural sector, in particular crop production, accounts for the largest share of global freshwater consumption. This study quantifies the green, blue and grey water footprint of crop production by using a grid-based dynamic water balance model that takes into account local climate and soil conditions at a high spatial resolution. The global water footprint related to crop production in the period 1996-2005 was 7404 billion cubic meters per year (78\% green, 12\% blue, 10\% grey). Wheat and rice have the largest blue water footprints, together accounting for $45 \%$ of the global blue water footprint. At country level, the total water footprint was largest for India $\left(1047 \mathrm{Gm}^{3} / \mathrm{yr}\right)$, China $\left(967 \mathrm{Gm}^{3} / \mathrm{yr}\right)$ and the USA $\left(826 \mathrm{Gm}^{3} / \mathrm{yr}\right)$. The Indus and Ganges river basins together account for $25 \%$ of the blue water footprint related to global crop production. Globally, rain-fed agriculture has a water footprint of $5173 \mathrm{Gm}^{3} / \mathrm{yr}(91 \%$ green, 
$x i v$

$9 \%$ grey); irrigated agriculture has a water footprint of $2230 \mathrm{Gm}^{3} / \mathrm{yr}(48 \%$ green, $40 \%$ blue, $12 \%$ grey).

Water footprint of farm animals: Animal production requires large volumes of water for feed production and relatively much smaller volumes for drinking water and servicing animals. The current study provides a comprehensive account of the global green, blue and grey water footprints of different sorts of farm animals and animal products, distinguishing between different production systems and considering the conditions in all countries of the world separately. The study shows that about $29 \%$ of the total water footprint of the agricultural sector in the world is related to the production of animal products. One third of the global water footprint of animal production is related to beef cattle. The size and characteristics of the water footprint vary across animal types and production systems. The blue and grey water footprints of animal products are largest for industrial systems (with an exception for chicken products). Per ton of product, animal products generally have a larger water footprint than crop products. The same is true when we look at the water footprint per calorie. The average water footprint per calorie for beef is twenty times larger than for cereals and starchy roots. The study shows that from a freshwater resource perspective, it is more efficient to obtain calories, protein and fat through crop products than animal products.

National water footprint: In order to quantify and visualize the effect of global production and consumption on freshwater resources, the study quantifies and maps the water footprints of nations from both a production and consumption perspective. The study also estimates virtual water flows and national and global water savings as a result of international trade. The global water footprint in the period 1996-2005 was $9087 \mathrm{Gm}^{3} / \mathrm{yr}$ (74\% green, $11 \%$ blue, $15 \%$ grey). Agricultural production contributes $92 \%$ to this total footprint and about one fifth of the global water footprint relates to production for export. The total volume of international virtual water flows related to trade in agricultural and industrial products was $2320 \mathrm{Gm}^{3} / \mathrm{yr}$ (68\% green, $13 \%$ blue, $19 \%$ grey). The water footprint of the global average consumer in the period 1996-2005 was $1385 \mathrm{~m}^{3} / \mathrm{yr}$. About $92 \%$ of the water footprint is related to the consumption of agricultural products, $5 \%$ to the consumption of industrial goods, and $4 \%$ to domestic water use. The average consumer in 
the US has a water footprint of $2842 \mathrm{~m}^{3} / \mathrm{yr}$, while the average citizens in China and India have water footprints of $1071 \mathrm{~m}^{3} / \mathrm{yr}$ and $1089 \mathrm{~m}^{3} / \mathrm{yr}$ respectively. The volume and pattern of consumption and the water footprint per ton of product of the products consumed are the main factors determining the water footprint of a consumer. The study illustrates the global dimension of water consumption and pollution by showing that several countries heavily rely on water resources elsewhere with significant impacts on water consumption and pollution elsewhere.

Blue water scarcity: The shortcomings of conventional blue water scarcity indicators are solved by defining blue water scarcity as the ratio of blue water footprint to blue water availability - where the latter is taken as natural runoff minus environmental flow requirement - and by estimating all underlying variables on a monthly basis. This study assesses the intra-annual variability of blue water scarcity for the world's major river basins for the period 1996-2005. In 223 river basins (55\% of the basins studied) with in total 2.72 billion inhabitants ( $69 \%$ of the total population living in the basins included in this study), the blue water scarcity level exceeded one hundred per cent, which means environmental flow requirements were violated during at least one month of the year. In 201 river basins with 2.67 billion people there was severe water scarcity, which means that the blue water footprint was more than twice the blue water availability during at least one month per year. The average blue water consumer in the world experiences a water scarcity of $244 \%$, i.e. operates in a month in a basin in which the blue water footprint is 2.44 times the blue water availability and in which presumptive environmental flow requirements are thus strongly violated.

Water footprint of wheat: The global water footprint of crop production and consumption has been elaborated in a case study for wheat with the aim to estimate the green, blue and grey water footprint of wheat in a spatially-explicit way, both from a production and consumption perspective. The global wheat production in the period 1996-2005 required about 1088 billion cubic meters of water per year (70\% green, 19\% blue and $11 \%$ grey). About $18 \%$ of the water footprint related to the production of wheat relates to production for export. About $55 \%$ of the virtual water export comes from the USA, Canada and Australia alone. A relatively large total blue water footprint as a result of wheat production 
$x v i$

is observed in the Ganges and Indus river basins, which are known for their water stress problems. The two basins alone account for about $47 \%$ of the blue water footprint related to global wheat production. About $93 \%$ of the water footprint of wheat consumption in Japan lies in other countries, particularly the USA, Australia and Canada. In Italy, with an average wheat consumption of $150 \mathrm{~kg} / \mathrm{yr}$ per person, more than two times the word average, about $44 \%$ of the total water footprint related to wheat consumption lies outside Italy. The major part of this external water footprint of Italy lies in France and the USA.

Water footprint of hydroelectricity: The water footprint of hydroelectricity - the water evaporated from manmade reservoirs to produce electric energy $\left(\mathrm{m}^{3} / \mathrm{GJ}\right)$ was assessed for 35 selected hydropower plants. The average water footprint of the selected hydropower plants is $68 \mathrm{~m}^{3} / \mathrm{GJ}$. Great differences in water footprint among hydropower plants exist, due to differences in climate in the places where the plants are situated, but more importantly as a result of large differences in the area flooded per unit of installed hydroelectric capacity.

Water footprint of the Netherlands: The effect of national consumption on the global water resources is visualised in a case study for the Netherlands. The impact of the external water footprint of the Netherlands on water resources in the exporting countries is assessed by comparing the geographically explicit water footprint with the water scarcity in the different parts of the world. About $67 \%$ of the total water footprint of Dutch consumption relates to the consumption of agricultural goods, $31 \%$ to the consumption of industrial goods, and $2 \%$ to domestic water use. About $11 \%$ of the water footprint of the Netherlands is internal and $89 \%$ is external. About $48 \%$ of the external water footprint of the Netherlands is located within European countries (mainly in Germany, France and Belgium) and $20 \%$ in Latin American countries (mainly in Brazil and Argentina). For industrial products $53 \%$ of the consumed products originate from European countries and about 33\% originates from Asian countries (mainly China, Taiwan, Hong Kong and Viet Nam). The study shows that Dutch consumption implies the use of water resources throughout the world, with significant impacts at specified locations.

Water footprint of Kenya: The relation between national water management and virtual water transfer is assessed in a case study for Kenya. It is estimated that during the period 
1996-2005, the water footprint of Kenya related to crop production was $18.1 \mathrm{Gm}^{3} / \mathrm{yr}(97 \%$ green, $1 \%$ blue and $2 \%$ grey). During the same period Kenya's virtual water import and export were $3.96 \mathrm{Gm}^{3} / \mathrm{yr}$ and $4.1 \mathrm{Gm}^{3} / \mathrm{yr}$ respectively. Over $78 \%$ of the virtual water export was related to the export of coffee, tea and cotton products. The average export earning related to trade in agricultural product was US\$ 0.25 per cubic meter of water, whereas the average cost of imported commodities per unit of virtual water imported was $(0.10$ $\left.\mathrm{US} \$ / \mathrm{m}^{3}\right)$. Through its trade, Kenya has reduced the pressure on its domestic water resources through importing water-intensive low-value products such as cereals and exporting of high-value products such as cut flower and vegetables. This is a smart strategy provided that exports are based on sustainable use of water resources, which can be improved in some cases as shown in the cut-flower case study for Lake Naivasha.

Cut flowers from Lake Naivasha Basin, Kenya: The study quantifies the water footprint within the Lake Naivasha Basin related to production of cut flowers and assesses the potential for mitigating this footprint by involving cut-flower traders, retailers and consumers overseas. The water footprint of one rose flower is estimated to be 7-13 litres. The total virtual water export related to export of cut flowers from the Lake Naivasha Basin was $16 \mathrm{Mm}^{3} / \mathrm{yr}$ during the period 1996-2005 (22\% green water; $45 \%$ blue water; $33 \%$ grey water). Although the commercial farms around the lake have contributed to the decline in the lake level through water abstractions, both the commercial farms and the smallholder farms in the upper catchment are responsible for the lake pollution due to nutrient loads. In order to address the problem of implementing full-cost water pricing under current socioeconomic and political conditions in Kenya, the study proposes a water-sustainability agreement between major agents along the cut-flower supply chain that includes a premium to the final product at the retailer end of the supply chain.

Conclusion: The data presented in this research are derived on the basis of a great number of underlying statistics, maps and assumptions, so that the presented water footprint estimates should be taken and interpreted with extreme caution, particularly when zooming in on specific locations on a map or when focussing on specific products. Recommendations for future research are done in the concluding chapter of the thesis. Despite the large number of uncertainties, the result of the thesis provides a good basis for 
xviii

rough comparisons and to guide further analysis. An integrated analysis of the spatial and temporal patterns of the green, blue and grey water footprint of humanity from both a production perspective and a consumption perspective as was done in this thesis, can eventually help to identify hot-spots and opportunities, both globally and for individual regions and basins. 


\section{Introduction}

Freshwater is a renewable but finite and therefore scarce resource. Its availability and quality show enormous temporal and spatial variations. Freshwater systems are sensitive to human influence and environmental degradation. An increasing population coupled with continued socio-economic development put an increasing pressure on the world's freshwater resources. In many parts of the world there are signs that water use exceeds a sustainable level. The reported incidents of groundwater depletion, rivers running dry and worsening pollution levels are signs of the growing water problem (Gleick, 1993; Postel, 2000; Shiklomanov and Rodda, 2003; Vörösmarty et al., 2010, Wada et al., 2010).

Addressing the scarcity of the world's finite freshwater resources entails either supply-side or demand-side management or a combination of both. Because of the limited water availability in many areas and the high cost of increasing its supply, there is a growing emphasis on increasing water use efficiency (Gleick, 1998; Postel, 2000; Wallace and Gregory, 2002; Falkenmark, et al. 2007). According to Hoekstra and Hung (2005), there are three levels at which water use efficiency can be increased. At a local level, that of the water user, water use efficiency can be increased by charging prices based on full marginal cost, stimulating water-saving technology, and creating awareness among the water users on the detrimental impacts of excessive water abstractions. At the river basin level, water use efficiency can be enhanced by reallocating water to those purposes with the highest marginal benefits. At this level we speak of 'water allocation efficiency'. Finally, at the global level, water use efficiency can be increased if nations use their relative water abundance or scarcity to either encourage or discourage the use of domestic water resources for producing export commodities.

Much research efforts have been dedicated to study water use efficiency at the local and river basin level. In most parts of the world, the efficiency level is low in both irrigated and rain-fed agriculture. Postel (1993) has estimated the global average irrigation efficiency to be only $37 \%$. After accounting for the water lost by evaporation from the field and the water surface where the crop is grown, Wallace (2000) estimated that globally only $13-18$ $\%$ of the initial water resource in irrigated agriculture is transpired by the crop, i.e. used by the crop to produce biomass. In sub-Saharan conditions, transpiration from rain-fed crops has been estimated to be $15-30 \%$ of the rainfall (Wallace, 2000). Based on these analyses, 


\section{2 / Chapter 1. Introduction}

Wallace and Batchelor (1997) and Wallace (2000) argue that there is plenty of scope for improving the efficiency level in agriculture, since normally in both rain-fed and irrigated agriculture only about one third of the available water is used to grow food.

However, other researchers argue that although the potential for water saving through increased efficiency is large, it is not as large as may be thought (Seckler et al. 2003). The reason is that the classical definition of irrigation efficiency ignores the value of return flows, i.e. irrigation water runoff and seepage that re-enters the water supply system (Keller and Keller 1995; Seckler et al. 2003). When the return flow is reused, the overall efficiency increases. Thus, while the individual systems could have a low level of efficiency, the actual basin-wide efficiencies can be much higher. Therefore, taking steps to increase water use efficiency at local level based on the classical efficiency calculations will often not result in real water savings. Perry (2007) and Perry et al. (2009) also have arrived at the conclusion that the classical definition of irrigation efficiency is wrong and even misleading.

This limitation of the classical definition of irrigation efficiency gave rise to the development of the 'water productivity' concept as a measure of performance of water use for economic activities (Kijne et al., 2003; Zwart and Bastiaanssen, 2004). Water productivity can have different meanings depending on the aims, stakeholders' interest and scale of analysis (Molden et al., 2003). In its broadest definition, increasing water productivity means getting more value or benefit from the use of water. At the farm level, it refers to more crop per drop of water. At the basin or national level, it refers to the allocative efficiency, i.e. to get more value per unit of water used in all economic activities including the environment (Molden et al., 2003). Increases in water productivity in the agricultural sector result in higher outputs with marginal or even without additional water requirements. Raising water productivity in agriculture will require improvements in crop yields and a reduction in the non-productive loss of water from the plant root zone through better matching of the pattern of water supply to the development of the crop (Rockström 2003; Passioura, 2006). The potential water saving by increasing water productivities in regions that currently still have low water productivities is very large (Rockström et al., 2003; Rockström et al., 2007b; Falkenmark et al., 2009). 


\section{Real versus virtual water transfers}

In addressing water scarcity problems most governments have traditionally focused on expanding supply through dams, reservoirs, and inter-basin transfers. Currently there are about 155 inter-basin water transfer schemes in 26 countries with a total capacity to transfer around $490 \mathrm{Gm}^{3} / \mathrm{yr}$ of water. There exist plans for around 60 additional proposed schemes with a total capacity to transfer $1150 \mathrm{Gm}^{3} / \mathrm{yr}$ (ICID, 2006). The south to north inter-basin transfer in China and the River Interlinking Projects in India are typical examples of large and expensive inter-basin water transfer schemes (Liu and Zheng, 2002; Gupta and Deshpande, 2004; Ma et al., 2006; Verma et al., 2009). As stressed by the 2006 Human Development Report, river diversion offers a short-term solution for what is a more fundamental long-term problem: people invest in water-intensive activities in places without accounting for the limitations in local water availability (UNDP, 2006).

While real water transfers over long distances are generally economically infeasible, transfers of water in the form of virtual water can offer a more efficient way of easing water stress problems in water-scarce areas (Allan, 2003; Earle and Turton, 2003; Hoekstra and Hung, 2005; Hoekstra and Chapagain, 2008). The idea of 'virtual water import' as a means of easing the pressure on domestic water resources was introduced by Allan (1998, 2001). Virtual water imports generate water saving for importing countries and global water saving if water-intensive products are traded internationally from highly water productive areas to areas where water productivity is low. Various studies have shown that large amounts of virtual flows occur as a result of global trade in agricultural and industrial products (Hoekstra and Hung, 2005; Zimmer and Renault, 2003; De Fraiture et al., 2004; Oki and Kanae, 2004; Chapagain et al., 2006a; Yang et al., 2006; Hoekstra and Chapagain, 2008). These studies also show that North and South America, Australia, most of Asia and Central Africa have net virtual water export, while Europe, Japan, North and Southern Africa, the Middle East, Mexico and Indonesia have net virtual water import. From a water resources point of view one may expect that all countries with net virtual water import have purposely adopted this as a strategy to alleviate their water scarcity problem. However, trade in agricultural goods is driven largely by factors other than water, therefore, import of virtual water is often not related to a country's water scarcity (Yang et al., 2003; De Fraiture et al., 2004; Oki and Kanae, 2004; Wichelns, 2004; Chapagain and Hoekstra, 2008; Yang and Zehnder, 2008). Besides, the water saved might not always be reallocated to 


\section{4 / Chapter 1. Introduction}

other beneficial uses (De Fraiture et al. 2004). Nonetheless, it is clear from the different studies that virtual water flows between nations could be used as a means to improve global water use efficiency and to achieve water security in water stressed countries (Allan, 2003; Hoekstra, 2003; Hoekstra and Chapagain, 2008; Hoekstra, 2011).

\section{Water footprint}

The recognition that freshwater resources are subject to global changes and globalization has led many researchers to argue for the importance of putting freshwater issues in a global context (Postel et al., 1996; Vörösmarty et al., 2000; Hoekstra and Hung, 2005; Hoekstra and Chapagain, 2008; Hoff, 2009; Hoekstra, 2011). Since its introduction by Hoekstra in 2002, the 'water footprint' concept has emphasized the global dimension of water use and the importance of considering the water use along the supply chain (Hoekstra, 2003).

As a result of global trade in both agricultural and industrial goods, many consumers have no longer any idea about the natural resource use and environmental impacts associated with the products they consume. Consumers are spatially disconnected from the processes necessary to produce the products (Hoekstra and Chapagain, 2008; Hoekstra and Hung, 2005; Hoekstra, 2011; Hoekstra et al., 2011). The concept of 'water footprint' provides a framework of analysis to study the link between the consumption of goods and services and the use of water resources. The water footprint is an indicator of freshwater appropriation that looks at both the direct and indirect use of water by consumers and producers. The water footprint of a product (alternatively known as 'virtual water content') expressed in water volume per unit of product (usually $\mathrm{m}^{3} / \mathrm{ton}$ ) is the sum of the water footprints of the process steps taken to produce the product. The water footprint of an individual or community is the sum of the water footprints of the various products consumed by the individual or community. The water footprint of a producer or a business is equal to the sum of the water footprints of the products that the producer or business delivers. The water footprint within a geographically delineated area (e.g. a province, nation, catchment area or river basin) is equal to the sum of the water footprints of all processes taking place in that area (Hoekstra et al., 2011).

The water footprint of a product, producer or consumer comprises of three colour coded components: the green, blue and grey water footprint (Hoekstra et al., 2011). Green 
water is the rain water temporarily stored in the unsaturated soil, on the soil or on the vegetation. Green water is either productively used for plant transpiration or unproductively evaporated from the soil or from vegetation canopies (Savenije, 2000; Falkenmark and Rockström, 2004). Blue water refers to water in rivers, lakes, wetlands and aquifers, which can be withdrawn for irrigation and other purposes. The conventional measure of water resource availability considers only blue water as available for human use. Green water has generally been given little attention and only just recently green water has been recognized as an important resource that is beneficial for society. Globally, about $60 \%$ of all food is produced from rain-fed agriculture, and hence from green water (Cosgrove and Rijsberman, 2000b; Savenije, 2000). Even on irrigated land, green water is important as blue water is supplied only to the extent to fill the precipitation deficit for optimal plant growth. As shown by Rockström et al. (2009) and Hoff et al. (2010), the global green water consumption for crop production is about four to five times larger than blue water consumption. It has also been recognized that green water sustains all terrestrial nonagricultural ecosystems (Rockström et al. 1999; Rockström and Gordon, 2001; Rockström, 2003; Falkenmark and Rockström, 2004). The inclusion of the green water component in water footprint analysis has been debated and it has even been suggested to speak only about 'net green water footprint' to refer to the difference between the evapotranspiration from the crop and the natural conditions (SABMiller and WWF-UK, 2009). In this approach, green water use in itself would be ignored, but only considered insofar it would affect blue water resources availability. Such conventional approach of considering the blue water as the only freshwater resource upon which humans depend is 'extremely narrow' (Rockström, 2003). Therefore, an integrated green and blue water footprint assessment in global food production is required.

The argument for including the grey component in water footprint accounting is that not only water quantity but also quality plays an important role in the availability of water for human use (UNDP, 2006). As stressed by Falkenmark and Rockström (2004), when water use results in contamination of water, the polluted water has to be considered as consumed water. The grey water footprint has been introduced in order to express water pollution in terms of water volume polluted (Hoekstra and Chapagain, 2008). Water pollution not only poses a threat to environmental sustainability and public health but also 


\section{6 / Chapter 1. Introduction}

increases the competition for freshwater resources (Pimentel et al., 1997; Pimentel et al., 2004; UNDP, 2006; UNEP GEMS/Water Programme, 2008; Vörösmarty et al., 2010).

For an improved analysis of the pressure put by both producers and consumers on freshwater resources a clear distinction and quantitative assessment of the green, blue and grey water footprint both from the production and consumption perspective is relevant. The variability of water resources in space and time also requires a spatially and temporally explicit water footprint analysis.

\section{Water scarcity indicators}

Until recently water scarcity indicators have focused on blue water resources and on annual averages. However, as shown by Savenije (2000) the existing indicators of water scarcity and water availability per capita are deceptive in the sense that these earlier studies fail to incorporate the green water into the analysis and to account for temporal (both intra- and inter-annual) variability of water availability.

The recent advances in geographic information systems (GIS) technology and availability of global GIS data sets such as crop growing areas, soil characteristics, irrigation coverage and climatic data have made it possible to assess the spatial and temporal patterns of availability and consumption of green and blue water. This possibility also offers new opportunities to take into account the heterogeneity in climate and other parameters within a large geographic area (e.g. a country) which was not possible in the earlier water footprint studies which used country average data (Chapagain and Hoekstra, 2004). More recently, a number of important research works have started to appear showing both the green and blue water use in global crop production at a high spatial resolution. Rost et al. (2008), Liu et al. (2009), Liu and Yang (2010), Hanasaki et al. (2010) and Fader et al. (2011) have made global estimates of agricultural green and blue water consumption with a spatial-resolution of 30 by 30 arc minute; Siebert and Döll (2010) have done similar study but with a spatial-resolution of 5 by 5 arc minute.

\section{Objective}

The overall objective of this thesis is to analyse the spatial and temporal pattern of global water footprint from both a production and consumption perspective. More specifically, the study is guided with the following specific objectives: (a) quantify at high spatial resolution 
the worldwide green, blue and grey water footprint of agricultural and industrial production, and domestic water supply; (b) quantify the spatially explicit green, blue and grey water footprint of national consumption for all countries of the world; (c) estimate global virtual water flows and water savings related to international trade in agricultural and industrial goods; (d) assess the temporal and spatial pattern of global blue water scarcity; and (e) carry out a few case studies from either a specific product or geographic point of view.

\section{Structure of the thesis}

The thesis consists of two parts: global studies (Chapters 2-5) and case studies (Chapters 610). Chapter 2 estimates the green, blue and grey water footprint of global crop production based on a crop water use model at high spatial resolution. The green, blue and grey water footprint in $\mathrm{m}^{3}$ /ton for over 146 primary crops and over two hundred derived crop products is presented at sub-national and national level. The total production water footprint in $\mathrm{Mm}^{3} / \mathrm{yr}$ is provided at national and river basin level. Chapter 3 presents a comprehensive account of the global green, blue and grey water footprint of different sorts of farm animals and animal products, distinguishing between different production systems and considering the conditions in all countries of the world separately. The water footprints of the various feed components, which form an important input into the estimation of the water footprint of animal products, are taken from Chapter 2. Chapter 4 builds on the previous two chapters and estimates the national green, blue and grey water footprint from both production and consumption perspective. The national water footprint of consumption was estimated for the first time using the bottom-up approach at a global scale. This chapter also estimates international virtual water flows and associated national and global water savings. In Chapter 5 the temporal pattern of global blue water scarcity is analyzed for the first time by comparing blue water footprint and blue water availability for major river basins of the world at monthly time step. The chapter is innovative by estimating blue water scarcity worldwide at a monthly time step at river basin level while accounting for environmental flow requirements.

The second part of the thesis contains two specific product water footprint studies (for wheat and hydroelectricity), two specific geographic water footprint studies (for the Netherlands and Kenya) and one study in which the water footprint of one specific product 


\section{8 / Chapter 1. Introduction}

(flowers) from a specific region (Lake Naivasha basin, Kenya) is analysed. Chapter 6 presents the first case study on the global water footprint related to wheat production and consumption. The chapter provides a number of case studies at country and basin level to show the link between consumption in one place and pressure on freshwater resources in other places through production for export. Chapter 7 presents the first detailed study on the water footprint of electricity from hydropower. The evaporation from the reservoirs of selected hydropower plants is estimated using the Penman-Monteith model with the inclusion of water body heat storage. In Chapter 8 a case study on the external water footprint of the Netherlands is presented. The study provides geographically-explicit quantification and impact assessment of the external water footprint of the Netherlands. It further compares the top-down and bottom-up approach in estimating national water footprint related to consumption. This case study was carried out before the global studies reported in the first part of the thesis. Since a number of improvements could be implemented in the global studies, the precise figures presented in the Dutch case study are different from the Dutch data presented in the global studies, so that as for the precise numbers the reader is advised to use the numbers from the global studies. The Dutch case study, however, remains very illustrative of how national water footprint assessment can enrich the understanding of how the consumption pattern of a national community can influence the water resources outside its own territory. In Chapter 9 the relation between national water management and international trade is analysed for Kenya. This case study fundamentally differs from the Dutch case study, not only because of the difference in the climate and level of development between the two countries, but also the two studies have an opposite perspective. While, the Dutch case study focuses on the sustainability of its external water footprint and virtual water imports, the Kenyan case study focuses on the sustainability of the water footprint within its own territory related to virtual water exports. Chapter 10 offers a final case study, in which an international arrangement is proposed to involve consumers, retailers and traders overseas to address the problem of the observed lake level decline and pollution of Lake Naivasha in Kenya, which is related to water use by the flower farmers around the lake. The study first quantifies the water footprint of cut flowers from Lake Naivasha Basin and assesses its sustainability and then proposes some mechanisms to address the problem. The last chapter concludes the thesis by putting the main findings in the previous chapters into perspective. 


\section{The green, blue and grey water of crops and derived crop products $^{1}$}

\section{Abstract}

This study quantifies the green, blue and grey water footprint of global crop production in a spatially-explicit way for the period 1996-2005. The assessment improves upon earlier research by taking a high-resolution approach, estimating the water footprint of 126 crops at a 5 by 5 arc minute grid. We have used a grid-based dynamic water balance model to calculate crop water use over time, with a time step of one day. The model takes into account the daily soil water balance and climatic conditions for each grid cell. In addition, the water pollution associated with the use of nitrogen fertilizer in crop production is estimated for each grid cell. The crop evapotranspiration of additional 20 minor crops is calculated with the CROPWAT model. In addition, we have calculated the water footprint of more than two hundred derived crop products, including various flours, beverages, fibres and biofuels. We have used the water footprint assessment framework as in the guideline of the Water Footprint Network.

Considering the water footprints of primary crops, we see that the global average water footprint per ton of crop increases from sugar crops (roughly $200 \mathrm{~m}^{3} / \mathrm{ton}$ ), vegetables (300 $\mathrm{m}^{3} /$ ton), roots and tubers $\left(400 \mathrm{~m}^{3} /\right.$ ton $)$, fruits $\left(1000 \mathrm{~m}^{3} /\right.$ ton $)$, cereals $\left(1600 \mathrm{~m}^{3} /\right.$ ton $)$, oil crops $\left(2400 \mathrm{~m}^{3} /\right.$ ton $)$ to pulses $\left(4000 \mathrm{~m}^{3} /\right.$ ton $)$. The water footprint varies, however, across different crops per crop category and per production region as well. Besides, if one considers the water footprint per kcal, the picture changes as well. When considered per ton of product, commodities with relatively large water footprints are: coffee, tea, cocoa, tobacco, spices, nuts, rubber and fibres. The analysis of water footprints of different biofuels shows that bio-ethanol has a lower water footprint (in $\mathrm{m}^{3} / \mathrm{GJ}$ ) than biodiesel, which supports earlier analyses. The crop used matters significantly as well: the global average water footprint of bio-ethanol based on sugar beet amounts to $51 \mathrm{~m}^{3} / \mathrm{GJ}$, while this is 121 $\mathrm{m}^{3} / \mathrm{GJ}$ for maize.

The global water footprint related to crop production in the period 1996-2005 was 7404 billion cubic meters per year (78\% green, $12 \%$ blue, $10 \%$ grey). A large total water

\footnotetext{
${ }^{1}$ Based on Mekonnen and Hoekstra (2010d, 2011a)
} 


\section{0 / Chapter 2. The green, blue and grey water footprint of crops}

footprint was calculated for wheat $\left(1087 \mathrm{Gm}^{3} / \mathrm{yr}\right)$, rice $\left(992 \mathrm{Gm}^{3} / \mathrm{yr}\right)$ and maize $(770$ $\mathrm{Gm}^{3} / \mathrm{yr}$ ). Wheat and rice have the largest blue water footprints, together accounting for $45 \%$ of the global blue water footprint. At country level, the total water footprint was largest for India $\left(1047 \mathrm{Gm}^{3} / \mathrm{yr}\right)$, China $\left(967 \mathrm{Gm}^{3} / \mathrm{yr}\right)$ and the USA $\left(826 \mathrm{Gm}^{3} / \mathrm{yr}\right)$. A relatively large total blue water footprint as a result of crop production is observed in the Indus river basin $\left(117 \mathrm{Gm}^{3} / \mathrm{yr}\right)$ and the Ganges river basin $\left(108 \mathrm{Gm}^{3} / \mathrm{yr}\right)$. The two basins together account for $25 \%$ of the blue water footprint related to global crop production. Globally, rain-fed agriculture has a water footprint of $5173 \mathrm{Gm}^{3} / \mathrm{yr}$ (91\% green, $9 \%$ grey); irrigated agriculture has a water footprint of $2230 \mathrm{Gm}^{3} / \mathrm{yr}$ (48\% green, $40 \%$ blue, $12 \%$ grey).

\subsection{Introduction}

Global freshwater withdrawal has increased nearly seven-fold in the past century (Gleick, 2000). With a growing population, coupled with changing diet preferences, water withdrawals are expected to continue to increase in the coming decades (Rosegrant and Ringler, 2000; Liu et al., 2008). With increasing withdrawals, also consumptive water use is likely to increase. Consumptive water use in a certain period in a certain river basin refers to water that after use is no longer available for other purposes, because it evaporated (Perry, 2007). Currently, the agricultural sector accounts for about $85 \%$ of global blue water consumption (Shiklomanov, 2000).

The aim of this study is to estimate the green, blue and grey water footprint of crops and crop products in a spatially-explicit way. We quantify the green, blue and grey water footprint of crop production by using a grid-based dynamic water balance model that takes into account local climate and soil conditions and nitrogen fertilizer application rates and calculates the crop water requirements, actual crop water use and yields and finally the green, blue and grey water footprint at grid level. The model has been applied at a spatial resolution of 5 by 5 arc minute. The model's conceptual framework is based on the CROPWAT approach (Allen et al., 1998).

The concept of 'water footprint' introduced by Hoekstra (2003) and subsequently elaborated by Hoekstra and Chapagain (2008) provides a framework to analyse the link between human consumption and the appropriation of the globe's freshwater. The water 
footprint of a product (alternatively known as 'virtual water content') expressed in water volume per unit of product (usually $\mathrm{m}^{3} / \mathrm{ton}$ ) is the sum of the water footprints of the process steps taken to produce the product. The water footprint within a geographically delineated area (e.g. a province, nation, catchment area or river basin) is equal to the sum of the water footprints of all processes taking place in that area (Hoekstra et al., 2011). The blue water footprint refers to the volume of surface and groundwater consumed (evaporated) as a result of the production of a good; the green water footprint refers to the rainwater consumed. The grey water footprint of a product refers to the volume of freshwater that is required to assimilate the load of pollutants based on existing ambient water quality standards.

The water footprint is an indicator of direct and indirect appropriation of freshwater resources. The term 'freshwater appropriation' includes both consumptive water use (the green and blue water footprint) and the water required to assimilate pollution (the grey water footprint). The grey water footprint, expressed as a dilution water requirement, has been recognised earlier by for example Postel et al. (1996) and Chapagain et al. (2006b). Including the grey water footprint is relatively new in water use studies, but justified when considering the relevance of pollution as a driver of water scarcity. As stressed in UNDP's Human Development Report 2006, which was devoted to water, water consumption is not the only factor causing water scarcity; pollution plays an important role as well (UNDP, 2006). Pollution of freshwater resources does not only pose a threat to environmental sustainability and public health but also increases the competition for freshwater (Pimentel et al., 1997; Pimentel et al., 2004; UNEP GEMS/Water Programme, 2008). Vörösmarty et al. (2010) further argue that water pollution together with other factors pose a threat to global water security and river biodiversity.

There are various previous studies on global water use for different sectors of the economy, most of which focus on water withdrawals. Studies of global water consumption (evaporative water use) are scarcer. There are no previous global studies on the grey water footprint in agriculture. L'vovich et al. (1990) and Shiklomanov (1993) estimated blue water consumption at a continental level. Postel et al. (1996) made a global estimate of consumptive use of both blue and green water. Seckler et al. (1998) made a first global estimate of consumptive use of blue water in agriculture at country level. Rockström et al. (1999) and Rockström and Gordon (2001) made some first global estimates of green water 


\section{2 / Chapter 2. The green, blue and grey water footprint of crops}

consumption. Shiklomanov and Rodda (2003) estimated consumptive use of blue water at county level. Hoekstra and Hung (2002) were the first to make a global estimate of the consumptive water use for a number of crops per country, but they did not explicitly distinguish consumptive water use into a green and blue component. Chapagain and Hoekstra (2004) and Hoekstra and Chapagain (2007a, 2008) improved this study in a number of respects, but still did not explicitly distinguish between green and blue water consumption.

All the above studies are based on coarse spatial resolutions that treat the entire world, continents or countries as a whole. In recent years, there have been various attempts to assess global water consumption in agriculture at high spatial resolution. The earlier estimates focus on the estimation of blue water withdrawal (Gleick, 1993; Alcamo et al., 2007) and irrigation water requirements (Döll and Siebert, 2002). More recently, a few studies have separated global water consumption for crop production into green and blue water. Rost et al. (2008) made a global estimate of agricultural green and blue water consumption with a spatial-resolution of 30 by 30 arc minute without showing the water use per crop, but applying 11 crop categories in the underlying model. Siebert and Döll (2008, 2010) have estimated the global green and blue water consumption for 24 crops and 2 additional broader crop categories applying a grid-based approach with a spatialresolution of 5 by 5 arc minute. Liu et al. (2009) and Liu and Yang (2010) made a global estimate of green and blue water consumption for crop production with a spatial-resolution of 30 by 30 arc minute. Liu et al. (2009) distinguished 17 major crops, while Liu and Yang (2010) considered 20 crops and 2 additional broader crop categories. Hanasaki et al. (2010) present the global green and blue water consumption for all crops but assume one dominant crop per grid cell at a 30 by 30 arc minute resolution. In a recent study, Fader et al. (2011) made a global estimate of agricultural green and blue water consumption with a spatialresolution of 30 by 30 arc minute, distinguishing 11 crop functional types.

\subsection{Method and data}

The green, blue and grey water footprints of crop production were estimated following the calculation framework of Hoekstra et al. (2011). The computations of crop evapotranspiration and yield, required for the estimation of the green and blue water 
footprint in crop production, have been done following the method and assumptions provided by Allen et al. (1998) for the case of crop growth under non-optimal conditions. The grid-based dynamic water balance model used in this study computes a daily soil water balance and calculates crop water requirements, actual crop water use (both green and blue) and actual yields. The model is applied at a global scale using a resolution of 5 by 5 arc minute (Mekonnen and Hoekstra, 2010a). We estimated the water footprint of 146 primary crops and more than two hundred derived products. The grid-based water balance model was used to estimate the crop water use for 126 primary crops; for the other 20 crops, which are grown in only few countries, the CROPWAT 8.0 model was used.

The actual crop evapotranspiration $\left(E T_{a}, \mathrm{~mm} /\right.$ day $)$ depends on climate parameters (which determine potential evapotranspiration), crop characteristics and soil water availability (Allen et al., 1998):

$$
E T_{a}[t]=K_{c}[t] \times K_{s}[t] \times E T_{o}[t]
$$

where $K_{c}$ is the crop coefficient, $K_{s}[t]$ a dimensionless transpiration reduction factor dependent on available soil water with a value between zero and one and $E T_{o}[t]$ the reference evapotranspiration ( $\mathrm{mm} /$ day). The crop coefficient varies in time, as a function of the plant growth stage. During the initial and mid-season stages, $K_{c}$ is a constant and equals $K_{c, \text { ini }}$ and $K_{c, \text { mid }}$ respectively. During the crop development stage, $K_{c}$ is assumed to linearly increase from $K_{c, i n i}$ to $K_{c, m i d}$. In the late season stage, $K_{c}$ is assumed to decrease linearly from $K_{c, \text { mid }}$ to $K_{c, \text { end }}$. Crop coefficients $\left(K_{c}\right.$ 's) were obtained from Chapagain and Hoekstra (2004). Crop planting dates and lengths of cropping seasons were obtained from FAO (2010e), Sacks et al. (2010), Portmann et al. (2010) and USDA (1994). For some crops, values from Chapagain and Hoekstra (2004) were used. We have not considered multicropping practices. Monthly long-term average reference evapotranspiration data at 10 by 10 arc minute resolution were obtained from FAO (2010d). The 10 by 10 arc minute data were converted to 5 by 5 arc minute resolution by assigning the 10 by 10 minute data to each of the four 5 by 5 minute grid cells. Following the CROPWAT approach, the monthly average data were converted to daily values by curve fitting to the monthly average through polynomial interpolation. 


\section{4 / Chapter 2. The green, blue and grey water footprint of crops}

The value of $K_{s}$ is calculated on a daily basis as a function of the maximum and actual available soil moisture in the root zone.

$$
K_{s}[t]=\left\{\begin{array}{ccc}
\frac{S[t]}{(1-p) \times S_{\max }[t]} & \text { if } & S[t]<(1-p) \times S_{\max }[t] \\
1 & \text { Otherwise }
\end{array}\right.
$$

where $S[t]$ is the actual available soil moisture at time $t$ (in $\mathrm{mm}$ ); $S_{\max }[t]$ the maximum available soil water in the root zone, i.e., the available soil water in the root zone when soil water content is at field capacity ( $\mathrm{mm})$; and $p$ the fraction of $S_{\max }$ that a crop can extract from the root zone without suffering water stress (dimensionless). Grid-based data on total available water capacity of the soil (TAWC) at a 5 by 5 arc minute resolution were taken from ISRIC-WISE (Batjes, 2006). An average value of TAWC of the five soil layers was used in the model.

In the case of rain-fed crop production, blue crop water use is zero and green crop water use $\left(\mathrm{m}^{3} / \mathrm{ha}\right)$ is calculated by summing up the daily values of $E T_{a}(\mathrm{~mm} /$ day $)$ over the length of the growing period. In the case of irrigated crop production, the green and blue water use is calculated by performing two different soil water balance scenarios as proposed in Hoekstra et al. (2011) and also applied by FAO (2005a), Siebert and Döll (2010) and Liu and Yang (2010). The first soil water balance scenario is carried out based on the assumption that the soil does not receive any irrigation, but using crop parameters of irrigated crops (such as rooting depth as under irrigation conditions). The second soil water balance scenario is carried out with the assumption that the amount of actual irrigation is sufficient to meet the irrigation requirement, applying the same crop parameters as in the first scenario. The green crop water use of irrigated crops is assumed to be equal to the actual crop evapotranspiration as was calculated in the first scenario. The blue crop water use is then equal to the crop water use over the growing period as simulated in the second scenario minus the green crop water use as estimated in the first scenario.

Crop growth and yield are affected by water stress. To account for the effect of water stress, a linear relationship between yield and crop evapotranspiration was proposed by Doorenbos and Kassam (1979): 


$$
\left(1-\frac{Y_{a}}{Y_{m}}\right)=K_{y} \times\left(1-\frac{\sum E T_{a}[t]}{\sum C W R[t]}\right)
$$

where $K_{y}$ is a yield response factor (water stress coefficient), $Y_{a}$ the actual harvested yield (kg/ha), $Y_{m}$ the maximum yield $(\mathrm{kg} / \mathrm{ha}), E T_{a}$ the actual crop evapotranspiration in $\mathrm{mm} /$ period and CWR the crop water requirement in $\mathrm{mm} /$ period (which is equal to $K_{c} \times$ $\left.E T_{0}\right) . K_{y}$ values for individual periods and the complete growing period are given in Doorenbos and Kassam (1979). The maximum yield values for each crop were obtained by multiplying the corresponding national average yield values by a factor of 1.2 (Reynolds et al., 2000). The actual yields, which are calculated per grid cell, are averaged over the nation and compared with the national average yield data (for the period 1996-2005) obtained from FAO (2010a). The calculated yield values are scaled to fit the national average FAO yield data.

The green and blue water footprints of primary crops $\left(\mathrm{m}^{3} / \mathrm{ton}\right)$ are calculated by dividing the total volume of green and blue water use $\left(\mathrm{m}^{3} / \mathrm{yr}\right)$, respectively, by the quantity of the production (ton/yr).

The grey water footprint is calculated by quantifying the volume of water needed to assimilate the nutrients that reach ground- or surface water. Nutrients leaching from agricultural fields are a main cause of non-point source pollution of surface and subsurface water bodies. In this study we have quantified the grey water footprint related to nitrogen use only. The grey component of the water footprint $\left(\mathrm{m}^{3} / \mathrm{ton}\right)$ is calculated by multiplying the fraction of nitrogen that leaches or runs off by the nitrogen application rate $(\mathrm{kg} / \mathrm{ha})$ and dividing this by the difference between the maximum acceptable concentration of nitrogen $\left(\mathrm{kg} / \mathrm{m}^{3}\right)$ and the natural concentration of nitrogen in the receiving water body $\left(\mathrm{kg} / \mathrm{m}^{3}\right)$ and by the actual crop yield (ton/ha). Country-specific nitrogen fertilizer application rates by crop have been estimated based on Heffer (2009), FAO (2006, 2010c) and IFA (2009). Since grid-based fertilizer application rates are not available, we have assumed that crops receive the same amount of nitrogen fertilizer per hectare in all grid cells in a country. We have further assumed that on average $10 \%$ of the applied nitrogen fertilizer is lost through leaching, following Chapagain et al. (2006b). The recommended maximum value of nitrate in surface and groundwater by the World Health Organization and the European Union is 


\section{6 / Chapter 2. The green, blue and grey water footprint of crops}

$50 \mathrm{mg}$ nitrate $\left(\mathrm{NO}_{3}\right)$ per litre and the maximum value recommended by US-EPA is $10 \mathrm{mg}$ per litre measured as nitrate-nitrogen $\left(\mathrm{NO}_{3}-\mathrm{N}\right)$. In this study we have used the standard of $10 \mathrm{mg}$ per litre of nitrate-nitrogen $\left(\mathrm{NO}_{3}-\mathrm{N}\right)$, following again Chapagain et al. (2006b). Because of lack of data, the natural nitrogen concentrations were assumed to be zero.

The water footprints of crops as harvested have been used as a basis to calculate the water footprints of derived crop products based on product and value fractions and water footprints of processing steps following the method as in Hoekstra et al. (2011). For the calculation of the water footprints of derived crop products we used product and value fraction. Most of these fractions have been taken from FAO (2003) and Chapagain and Hoekstra (2004). The product fraction of a product is defined as the quantity of output product obtained per quantity of the primary input product. The value fraction of a product is the ratio of the market value of the product to the aggregated market value of all the products obtained from the input product (Hoekstra et al., 2011). Products and by-products have both a product fraction and value fraction. On the other hand, residues (e.g. bran of crops) have only a product fraction and we have assumed their value fraction to be close to zero.

The water footprint per unit of energy for ethanol and biodiesel producing crops was calculated following the method as applied in Gerbens-Leenes et al. (2009a). Data on the dry mass of crops, the carbohydrate content of ethanol providing crops, the fat content of biodiesel providing crops and the higher heating value of ethanol and biodiesel were taken from Gerbens-Leenes et al. (2008a, 2008b) and summarized in Table 2.1.

Monthly values for precipitation, number of wet days and minimum and maximum temperature for the period 1996-2002 with a spatial resolution of 30 by 30 arc minute were obtained from CRU-TS-2.1 (Mitchell and Jones, 2005). The 30 by 30 arc minute data were assigned to each of the thirty-six 5 by 5 arc minute grid cells contained in the 30 by 30 arc minute grid cell. Daily precipitation values were generated from the monthly average values using the CRU-dGen daily weather generator model (Schuol and Abbaspour, 2007).

Crop growing areas on a 5 by 5 arc minute grid cell resolution were obtained from Monfreda et al. (2008). For countries missing grid data in Monfreda et al. (2008), the MICRA2000 grid database as described in Portmann et al. (2010) was used to fill the gap. The harvested crop areas as available in grid format were aggregated to a national level and 
scaled to fit national average crop harvest areas for the period 1996-2005 obtained from FAO (2010a).

Table 2.1. Characteristics of ten ethanol providing and seven biodiesel providing crops.

\begin{tabular}{|c|c|c|c|c|c|}
\hline $\begin{array}{l}\text { Sugar and } \\
\text { starch crops }\end{array}$ & $\begin{array}{r}\text { Dry mass } \\
\text { fraction }(\%)\end{array}$ & $\begin{array}{r}\text { Fraction of } \\
\text { carbohydrates } \\
\text { in dry mass } \\
(\mathrm{g} / \mathrm{g})\end{array}$ & $\begin{array}{r}\text { Ethanol per } \\
\text { unit of } \\
\text { carbohydrate } \\
(\mathrm{g} / \mathrm{g})\end{array}$ & $\begin{array}{r}\text { Energy } \\
\text { yield* } \\
\text { (GJ/ton) }\end{array}$ & $\begin{array}{r}\text { Bio-ethanol } \\
\text { yield ** } \\
\text { (litre/ton) }\end{array}$ \\
\hline Barley & $85 \%$ & 0.76 & 0.53 & 10.2 & 434 \\
\hline Cassava & $38 \%$ & 0.87 & 0.53 & 5.20 & 222 \\
\hline Maize & $85 \%$ & 0.75 & 0.53 & 10.0 & 428 \\
\hline Potatoes & $25 \%$ & 0.78 & 0.53 & 3.07 & 131 \\
\hline Rice, paddy & $85 \%$ & 0.76 & 0.53 & 10.2 & 434 \\
\hline Rye & $85 \%$ & 0.76 & 0.53 & 10.2 & 434 \\
\hline Sorghum & $85 \%$ & 0.76 & 0.53 & 10.2 & 434 \\
\hline Sugar beet & $21 \%$ & 0.82 & 0.51 & 2.61 & 111 \\
\hline Sugar cane & $27 \%$ & 0.57 & 0.51 & 2.33 & 99 \\
\hline Wheat & $85 \%$ & 0.76 & 0.53 & 10.17 & 434 \\
\hline Oil crops & $\begin{array}{c}\text { Dry mass } \\
\text { fraction } \\
(\%)\end{array}$ & $\begin{array}{r}\text { Fraction of fat } \\
\text { in dry mass } \\
(\mathrm{g} / \mathrm{g})\end{array}$ & $\begin{array}{r}\text { Biodiesel per } \\
\text { unit of fat } \\
(\mathrm{g} / \mathrm{g})\end{array}$ & $\begin{array}{r}\text { Energy } \\
\text { yield* } \\
\text { (GJ/ton) }\end{array}$ & $\begin{array}{r}\text { Biodiesel } \\
\text { yield ** } \\
\text { (litre/ton) }\end{array}$ \\
\hline Coconuts & $50 \%$ & 0.03 & 1 & 0.57 & 17 \\
\hline $\begin{array}{l}\text { Groundnuts, } \\
\text { with shell }\end{array}$ & $95 \%$ & 0.39 & 1 & 14.0 & 421 \\
\hline Oil palm fruit & $85 \%$ & 0.22 & 1 & 7.05 & 213 \\
\hline Rapeseed & $74 \%$ & 0.42 & 1 & 11.7 & 353 \\
\hline Seed cotton & $85 \%$ & 0.23 & 1 & 7.37 & 222 \\
\hline Soybeans & $92 \%$ & 0.18 & 1 & 6.24 & 188 \\
\hline Sunflower seed & $85 \%$ & 0.22 & 1 & 7.05 & 213 \\
\hline
\end{tabular}

* Based on a higher heating value of $29.7 \mathrm{~kJ} / \mathrm{gram}$ for ethanol and $37.7 \mathrm{~kJ} / \mathrm{gram}$ for biodiesel.

** Based on a density of $0.789 \mathrm{~kg} / \mathrm{litre}$ for ethanol and $0.88 \mathrm{~kg} / \mathrm{litre}$ for biodiesel (Alptekin and Canakci, 2008).

Grid data on the irrigated fraction of harvested crop areas for 24 major crops were obtained from the MICRA2000 database (Portmann et al., 2010). For the other 102 crops considered in the current study, we used the data for 'other perennial' and 'other annual crops' as in the 
$18 /$ Chapter 2. The green, blue and grey water footprint of crops

MICRA2000 database, depending on whether the crop is categorised under 'perennial' or 'annual' crops.

\subsection{Result}

\subsubsection{The global picture}

The global water footprint of crop production in the period 1996-2005 was $7404 \mathrm{Gm}^{3} /$ year ( $78 \%$ green, $12 \%$ blue, and $10 \%$ grey). Wheat takes the largest share in this total volume; it consumed $1087 \mathrm{Gm}^{3} / \mathrm{yr}$ (70\% green, 19\% blue, $11 \%$ grey). The other crops with a large total water footprint are rice $\left(992 \mathrm{Gm}^{3} / \mathrm{yr}\right)$ and maize $\left(770 \mathrm{Gm}^{3} / \mathrm{yr}\right)$. The contribution of the major crops to the global water footprint related to crop production is presented in Figure 2.1. The global average green water footprint related to crop production was $5771 \mathrm{Gm}^{3} / \mathrm{yr}$, of which rain-fed crops use $4701 \mathrm{Gm}^{3} / \mathrm{yr}$ and irrigated crops use $1070 \mathrm{Gm}^{3} / \mathrm{yr}$. For most of the crops, the contribution of green water footprint toward the total consumptive water footprint (green and blue) is more than $80 \%$. Among the major crops, the contribution of green water toward the total consumptive water footprint is lowest for date palm (43\%) and cotton (64\%). The global average blue water footprint related to crop production was 899 $\mathrm{Gm}^{3} / \mathrm{yr}$. Wheat $\left(204 \mathrm{Gm}^{3} / \mathrm{yr}\right)$ and rice $\left(202 \mathrm{Gm}^{3} / \mathrm{yr}\right)$ have large blue water footprint together accounting for $45 \%$ of the global blue water footprint. The grey water footprint related to the use of nitrogen fertilizer in crops cultivation was $733 \mathrm{Gm}^{3} / \mathrm{yr}$. Wheat $\left(123 \mathrm{Gm}^{3} / \mathrm{yr}\right)$, maize $\left(122 \mathrm{Gm}^{3} / \mathrm{yr}\right)$ and rice $\left(111 \mathrm{Gm}^{3} / \mathrm{yr}\right)$ have large grey water footprint together accounting for about $56 \%$ of the global grey water footprint.

The green, blue, grey and total water footprints of crop production per grid cell are shown in Figure 2.2. Large water footprints per grid cell $(>400 \mathrm{~mm} / \mathrm{yr})$ are found in the Ganges and Indus river basins (India, Pakistan and Bangladesh), in eastern China and in the Mississippi river basin (USA). These locations are the same locations as where the harvested crop area takes a relative large share in the total area (Monfreda et al., 2008).

Globally, $86.5 \%$ of the water consumed in crop production is green water. Even in irrigated agriculture, green water often has a very significant contribution to total water consumption. The share of the blue water footprint in total water consumption (green plus blue water footprint) is shown in Figure 2.3. The share of the blue water footprint is largest 
in arid and semi-arid regions. Regions with a large blue water proportion are located, for example, in the western part of the USA, in a relatively narrow strip of land along the west coast of South America (Peru-Chile), in southern Europe, North Africa, the Arabian peninsula, Central Asia, Pakistan and northern India, northeast China and parts of Australia.

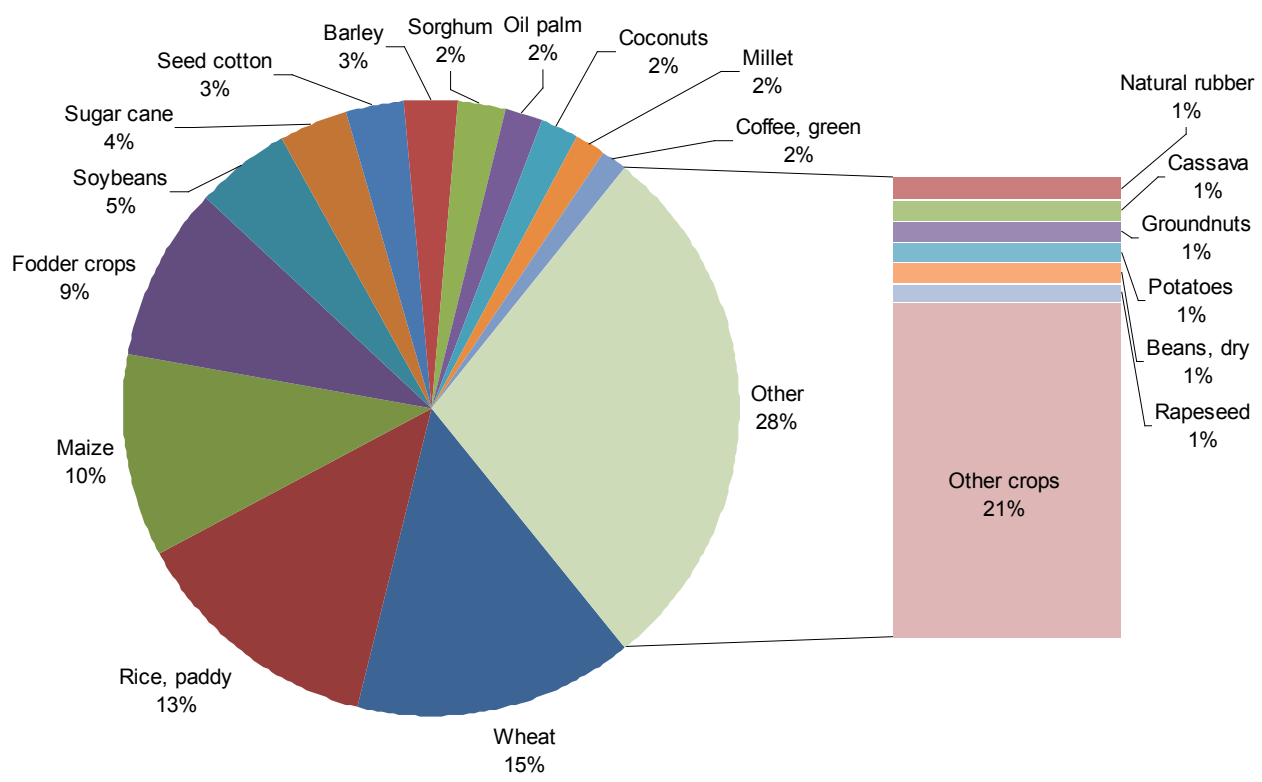

Figure 2.1. Contribution of different crops to the total water footprint of crop production. Period: 1996-2005.

\subsubsection{The water footprint of primary crops and derived crop products per ton}

The average water footprint per ton of primary crop differs significantly among crops and across production regions. Crops with a high yield or large fraction of crop biomass that is harvested generally have a smaller water footprint per ton than crops with a low yield or small fraction of crop biomass harvested. When considered per ton of product, commodities with relatively large water footprints are: coffee, tea, cocoa, tobacco, spices, nuts, rubber and fibres (Table 2.2). For food crops, the global average water footprint per ton of crop increases from sugar crops (roughly $200 \mathrm{~m}^{3} /$ ton), vegetables $\left(\sim 300 \mathrm{~m}^{3} /\right.$ ton), roots and tubers $\left(\sim 400 \mathrm{~m}^{3} /\right.$ ton $)$, fruits $\left(\sim 1000 \mathrm{~m}^{3} /\right.$ ton $)$, cereals $\left(\sim 1600 \mathrm{~m}^{3} /\right.$ ton $)$, oil crops $(\sim 2400$ $\mathrm{m}^{3} /$ ton), pulses $\left(\sim 4000 \mathrm{~m}^{3} /\right.$ ton $)$, spices $\left(\sim 7000 \mathrm{~m}^{3} /\right.$ ton $)$ to nuts $\left(\sim 9000 \mathrm{~m}^{3} /\right.$ ton $)$. The water 
footprint varies, however, across different crops per crop category. Besides, if one considers the water footprint per kcal, the picture changes as well. Vegetables and fruits, which have a relatively small water footprint per $\mathrm{kg}$ but a low caloric content, have a relatively large water footprint per kcal.

Table 2.2.Global average water footprint of 14 primary crop categories. Period: 1996-2005.

\begin{tabular}{|c|c|c|c|c|c|c|}
\hline \multirow{2}{*}{ Primary crop category } & \multicolumn{4}{|c|}{ Water footprint $\left(\mathrm{m}^{3} / \mathrm{ton}\right)$} & \multirow{2}{*}{$\begin{array}{r}\text { Caloric } \\
\text { value* }^{*} \\
(\mathrm{kcal} / \mathrm{kg})\end{array}$} & \multirow{2}{*}{$\begin{array}{r}\text { Water footprint } \\
\text { (litre/kcal) }\end{array}$} \\
\hline & Green & Blue & Grey & Total & & \\
\hline Sugar crops & 130 & 52 & 15 & 197 & 290 & 0.68 \\
\hline Fodder crops & 207 & 27 & 20 & 253 & & \\
\hline Vegetables & 194 & 43 & 85 & 322 & 240 & 1.34 \\
\hline Roots and tubers & 327 & 16 & 43 & 387 & 830 & 0.47 \\
\hline Fruits & 727 & 147 & 93 & 967 & 460 & 2.10 \\
\hline Cereals & 1232 & 228 & 184 & 1644 & 3200 & 0.51 \\
\hline Oil crops & 2023 & 220 & 121 & 2364 & 2900 & 0.81 \\
\hline Tobacco & 2021 & 205 & 700 & 2925 & & \\
\hline Fibres, vegetal origin & 3375 & 163 & 300 & 3837 & & \\
\hline Pulses & 3180 & 141 & 734 & 4055 & 3400 & 1.19 \\
\hline Spices & 5872 & 744 & 432 & 7048 & 3000 & 2.35 \\
\hline Nuts & 7016 & 1367 & 680 & 9063 & 2500 & 3.63 \\
\hline Rubber, gums, waxes & 12964 & 361 & 422 & 13748 & & \\
\hline Stimulants & 13731 & 252 & 460 & 14443 & 880 & 16.4 \\
\hline
\end{tabular}

* Source: FAO (2010a).

Global average water footprint of selected primary crops and their derived products are presented in Table 2.3. The results allow us to compare the water footprints of different products:

- The average water footprint for cereal crops is $1644 \mathrm{~m}^{3} / \mathrm{ton}$, but the footprint for wheat is relatively large $\left(1827 \mathrm{~m}^{3} /\right.$ ton$)$, while for maize it is relatively small $\left(1222 \mathrm{~m}^{3} /\right.$ ton $)$. The average water footprint of rice is close to the average for all cereals together. 
- Sugar obtained from sugar beet has a smaller water footprint than sugar from sugar cane. Besides, the blue component in the total water footprint of beet sugar $(20 \%)$ is smaller than for cane sugar (27\%).

- For vegetable oils we find a large variation in water footprints: maize oil $2600 \mathrm{~m}^{3} /$ ton; cotton-seed oil $3800 \mathrm{~m}^{3} /$ ton; soybean oil $4200 \mathrm{~m}^{3} /$ ton; rapeseed oil $4300 \mathrm{~m}^{3} /$ ton; palm oil $5000 \mathrm{~m}^{3} /$ ton; sunflower oil $6800 \mathrm{~m}^{3} /$ ton; groundnut oil $7500 \mathrm{~m}^{3} /$ ton; linseed oil $9400 \mathrm{~m}^{3} /$ ton; olive oil $14500 \mathrm{~m}^{3} /$ ton; castor oil $24700 \mathrm{~m}^{3} /$ ton.

- For fruits we find a similar variation in water footprints: water melon $235 \mathrm{~m}^{3} /$ ton; pineapple $255 \mathrm{~m}^{3} /$ ton; papaya $460 \mathrm{~m}^{3} /$ ton; orange $560 \mathrm{~m}^{3} /$ ton; banana $790 \mathrm{~m}^{3} /$ ton; apple $820 \mathrm{~m}^{3} /$ ton; peach $910 \mathrm{~m}^{3} /$ ton; pear $920 \mathrm{~m}^{3} /$ ton; apricot $1300 \mathrm{~m}^{3} /$ ton; plums 2200 $\mathrm{m}^{3} /$ ton; dates $2300 \mathrm{~m}^{3} /$ ton; grapes $2400 \mathrm{~m}^{3} /$ ton; figs $3350 \mathrm{~m}^{3} /$ ton.

- For alcoholic beverages we find: a water footprint of $300 \mathrm{~m}^{3} /$ ton for beer and 870 $\mathrm{m}^{3} /$ ton for wine.

- The water footprints of juices vary from tomato juice $\left(270 \mathrm{~m}^{3} / \mathrm{ton}\right)$, grapefruit juice $\left(675 \mathrm{~m}^{3} /\right.$ ton $)$, orange juice $\left(1000 \mathrm{~m}^{3} /\right.$ ton $)$ and apple juice $\left(1100 \mathrm{~m}^{3} /\right.$ ton $)$ to pineapple juice $\left(1300 \mathrm{~m}^{3} /\right.$ ton $)$.

- The water footprint of coffee (130 litre/cup, based on use of 7 gram of roasted coffee per cup) is much larger than the water footprint of tea (27 litre/cup, based on use of 3 gram of black tea per cup).

- The water footprint of cotton fibres is substantially larger than the water footprints of sisal and flax fibres, which are again larger than the water footprints of jute and hemp fibres.

One should be careful in drawing conclusions from the above product comparisons. Although the global average water footprint of one product may be larger than the global average water footprint of another product, the comparison may turn out quite differently for specific regions. 
22 / Chapter 2. The green, blue and grey water footprint of crops
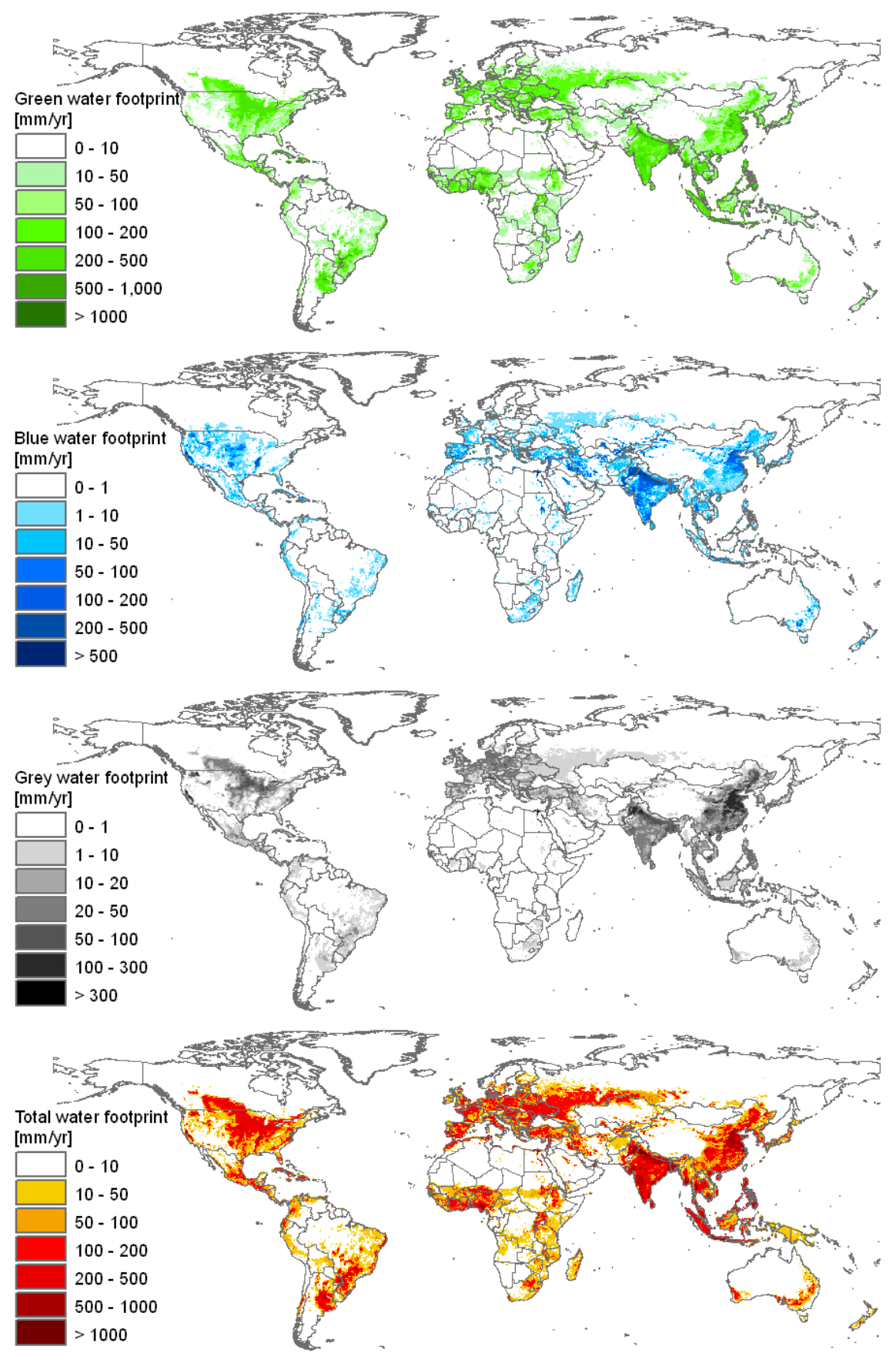

Figure 2.2. The green, blue, grey and total water footprint of crop production estimated at a 5 by 5 arc minute resolution. The data are shown in $\mathrm{mm} / \mathrm{yr}$ and have been calculated as the aggregated water footprint per grid cell (in $\mathrm{m}^{3} / \mathrm{yr}$ ) divided by the area of the grid cell. Period: 1996-2005. 
Table 2.3. Global average water footprint of primary crops and derived crop products. Period: 1996-2005.

\begin{tabular}{|c|c|c|c|c|c|}
\hline \multirow{2}{*}{$\begin{array}{l}\text { FAOSTAT } \\
\text { crop code }\end{array}$} & \multirow{2}{*}{ Product description } & \multicolumn{4}{|c|}{ Global average water footprint ( $\mathrm{m}^{3} /$ ton $)$} \\
\hline & & Green & Blue & Grey & Total \\
\hline \multirow[t]{7}{*}{$\overline{15}$} & Wheat & 1277 & 342 & 207 & 1827 \\
\hline & Wheat flour & 1292 & 347 & 210 & 1849 \\
\hline & Wheat bread & 1124 & 301 & 183 & 1608 \\
\hline & Dry pasta & 1292 & 347 & 210 & 1849 \\
\hline & Wheat pellets & 1423 & 382 & 231 & 2036 \\
\hline & Wheat, starch & 1004 & 269 & 163 & 1436 \\
\hline & Wheat gluten & 2928 & 785 & 476 & 4189 \\
\hline \multirow[t]{5}{*}{27} & Rice, paddy & 1146 & 341 & 187 & 1673 \\
\hline & Rice, husked (brown) & 1488 & 443 & 242 & 2172 \\
\hline & Rice, broken & 1710 & 509 & 278 & 2497 \\
\hline & Rice flour & 1800 & 535 & 293 & 2628 \\
\hline & Rice groats and meal & 1527 & 454 & 249 & 2230 \\
\hline \multirow[t]{5}{*}{44} & Barley & 1213 & 79 & 131 & 1423 \\
\hline & Barley, rolled or flaked grains & 1685 & 110 & 182 & 1977 \\
\hline & Malt, not roasted & 1662 & 108 & 180 & 1950 \\
\hline & Malt, roasted & 2078 & 135 & 225 & 2437 \\
\hline & Beer made from malt & 254 & 16 & 27 & 298 \\
\hline \multirow[t]{6}{*}{56} & Maize (corn) & 947 & 81 & 194 & 1222 \\
\hline & Maize (corn) flour & 971 & 83 & 199 & 1253 \\
\hline & Maize (corn) groats and meal & 837 & 72 & 171 & 1081 \\
\hline & Maize (corn), hulled/pearled/sliced/ kibbled & 1018 & 87 & 209 & 1314 \\
\hline & Maize (corn) starch & 1295 & 111 & 265 & 1671 \\
\hline & Maize (corn) oil & 1996 & 171 & 409 & 2575 \\
\hline \multirow[t]{2}{*}{71} & Rye & 1419 & 25 & 99 & 1544 \\
\hline & Rye flour & 1774 & 32 & 124 & 1930 \\
\hline \multirow[t]{3}{*}{75} & Oats & 1479 & 181 & 128 & 1788 \\
\hline & Oat groats and meal & 2098 & 257 & 182 & 2536 \\
\hline & Oats, rolled or flaked grains & 1998 & 245 & 173 & 2416 \\
\hline 79 & Millet & 4306 & 57 & 115 & 4478 \\
\hline 83 & Sorghum & 2857 & 103 & 87 & 3048 \\
\hline 89 & Buckwheat & 2769 & 144 & 229 & 3142 \\
\hline \multirow[t]{5}{*}{116} & Potatoes & 191 & 33 & 63 & 287 \\
\hline & Tapioca of potatoes & 955 & 165 & 317 & 1436 \\
\hline & Potato flour and meal & 955 & 165 & 317 & 1436 \\
\hline & Potato flakes & 694 & 120 & 230 & 1044 \\
\hline & Potato starch & 1005 & 173 & 333 & 1512 \\
\hline 122 & Sweet potatoes & 324 & 5 & 53 & 383 \\
\hline \multirow[t]{5}{*}{125} & Manioc (cassava) & 550 & 0 & 13 & 564 \\
\hline & Tapioca of cassava & 2750 & 1 & 66 & 2818 \\
\hline & Flour of cassava & 1833 & 1 & 44 & 1878 \\
\hline & Dried cassava & 1571 & 1 & 38 & 1610 \\
\hline & Manioc (cassava) starch & 2200 & 1 & 53 & 2254 \\
\hline 136 & Taro (coco yam) & 587 & 3 & 15 & 606 \\
\hline
\end{tabular}


24 / Chapter 2. The green, blue and grey water footprint of crops

\begin{tabular}{|c|c|c|c|c|c|}
\hline \multirow{2}{*}{$\begin{array}{l}\text { FAOSTAT } \\
\text { crop code }\end{array}$} & \multirow{2}{*}{ Product description } & \multicolumn{4}{|c|}{ Global average water footprint $\left(\mathrm{m}^{3} / \mathrm{ton}\right)$} \\
\hline & & Green & Blue & Grey & Total \\
\hline$\overline{137}$ & Yams & 341 & 0 & 1 & 343 \\
\hline \multirow[t]{4}{*}{156} & Sugar cane & 139 & 57 & 13 & 210 \\
\hline & Raw sugar, cane & 1107 & 455 & 104 & 1666 \\
\hline & Refined sugar & 1184 & 487 & 111 & 1782 \\
\hline & Cane molasses & 350 & 144 & 33 & 527 \\
\hline \multirow[t]{2}{*}{157} & Sugar beet & 82 & 26 & 25 & 132 \\
\hline & Raw sugar, beet & 535 & 167 & 162 & 865 \\
\hline 176 & Beans, dry & 3945 & 125 & 983 & 5053 \\
\hline 181 & Broad beans, horse beans, dry & 1317 & 205 & 496 & 2018 \\
\hline 187 & Peas, dry & 1453 & 33 & 493 & 1979 \\
\hline 191 & Chick peas & 2972 & 224 & 981 & 4177 \\
\hline 195 & Cow peas, dry & 6841 & 10 & 55 & 6906 \\
\hline 197 & Pigeon peas & 4739 & 72 & 683 & 5494 \\
\hline 201 & Lentils & 4324 & 489 & 1060 & 5874 \\
\hline 217 & Cashew nuts & 12853 & 921 & 444 & 14218 \\
\hline 220 & Chestnuts & 2432 & 174 & 144 & 2750 \\
\hline \multirow[t]{2}{*}{221} & Almonds, with shell & 4632 & 1908 & 1507 & 8047 \\
\hline & Almonds, shelled or peeled & 9264 & 3816 & 3015 & 16095 \\
\hline \multirow[t]{2}{*}{222} & Walnuts, with shell & 2805 & 1299 & 814 & 4918 \\
\hline & Walnuts, shelled or peeled & 5293 & 2451 & 1536 & 9280 \\
\hline 223 & Pistachios & 3095 & 7602 & 666 & 11363 \\
\hline 224 & Kola nuts & 23345 & 26 & 19 & 23391 \\
\hline \multirow[t]{2}{*}{225} & Hazelnuts, with shell & 3813 & 1090 & 354 & 5258 \\
\hline & Hazelnuts, shelled or peeled & 7627 & 2180 & 709 & 10515 \\
\hline 226 & Areca nuts & 10621 & 139 & 406 & 11165 \\
\hline \multirow[t]{8}{*}{236} & Soya beans & 2037 & 70 & 37 & 2145 \\
\hline & Soya sauce & 582 & 20 & 11 & 613 \\
\hline & Soya paste & 543 & 19 & 10 & 572 \\
\hline & Soya curd & 2397 & 83 & 44 & 2523 \\
\hline & Soy milk & 3574 & 123 & 65 & 3763 \\
\hline & Soya bean flour and meals & 2397 & 83 & 44 & 2523 \\
\hline & Soybean oil, refined & 3980 & 137 & 73 & 4190 \\
\hline & Soybean oilcake & 1690 & 58 & 31 & 1779 \\
\hline \multirow[t]{4}{*}{242} & Groundnuts in shell & 2469 & 150 & 163 & 2782 \\
\hline & Groundnuts shelled & 3526 & 214 & 234 & 3974 \\
\hline & Groundnut oil, refined & 6681 & 405 & 442 & 7529 \\
\hline & Groundnut oilcake & 1317 & 80 & 87 & 1484 \\
\hline \multirow[t]{6}{*}{249} & Coconuts & 2669 & 2 & 16 & 2687 \\
\hline & Copra & 2079 & 1 & 12 & 2093 \\
\hline & Coconut (husked) & 1247 & 1 & 7 & 1256 \\
\hline & Coconut (copra) oil , refined & 4461 & 3 & 27 & 4490 \\
\hline & Coconut/copra oilcake & 829 & 1 & 5 & 834 \\
\hline & Coconut (coir) fibre, processed & 2433 & 2 & 15 & 2449 \\
\hline \multirow[t]{2}{*}{254} & Oil palm & 1057 & 0 & 40 & 1098 \\
\hline & Palm nuts and kernels & 2762 & 1 & 105 & 2868 \\
\hline
\end{tabular}




\begin{tabular}{|c|c|c|c|c|c|}
\hline \multirow{2}{*}{$\begin{array}{l}\text { FAOSTAT } \\
\text { crop code }\end{array}$} & \multirow{2}{*}{ Product description } & \multicolumn{4}{|c|}{ Global average water footprint $\left(\mathrm{m}^{3} /\right.$ ton $)$} \\
\hline & & Green & Blue & Grey & Total \\
\hline & Palm oil, refined & 4787 & 1 & 182 & 4971 \\
\hline & Palm kernel/babassu oil, refined & 5202 & 1 & 198 & 5401 \\
\hline & Palm nut/kernel oilcake & 802 & 0 & 31 & 833 \\
\hline \multirow[t]{3}{*}{260} & Olives & 2470 & 499 & 45 & 3015 \\
\hline & Olive oil, virgin & 11826 & 2388 & 217 & 14431 \\
\hline & Olive oil, refined & 12067 & 2437 & 221 & 14726 \\
\hline \multirow[t]{2}{*}{265} & Castor oil seeds & 8423 & 1175 & 298 & 9896 \\
\hline & Castor oil & 21058 & 2938 & 744 & 24740 \\
\hline \multirow[t]{3}{*}{267} & Sunflower seeds & 3017 & 148 & 201 & 3366 \\
\hline & Sunflower seed oil, refined & 6088 & 299 & 405 & 6792 \\
\hline & Sunflower seed oilcake & 1215 & 60 & 81 & 1356 \\
\hline \multirow[t]{3}{*}{270} & Rapeseed & 1703 & 231 & 336 & 2271 \\
\hline & Rape oil, refined & 3226 & 438 & 636 & 4301 \\
\hline & Rape seed oilcake & 837 & 114 & 165 & 1115 \\
\hline 280 & Safflower seeds & 6000 & 938 & 283 & 7221 \\
\hline \multirow[t]{2}{*}{289} & Sesame seed & 8460 & 509 & 403 & 9371 \\
\hline & Sesame oil & 19674 & 1183 & 936 & 21793 \\
\hline 292 & Mustard seeds & 2463 & 1 & 345 & 2809 \\
\hline 296 & Poppy seeds & 1723 & 0 & 464 & 2188 \\
\hline 299 & Melon seed & 5087 & 56 & 41 & 5184 \\
\hline \multirow[t]{11}{*}{328} & Seed cotton & 2282 & 1306 & 440 & 4029 \\
\hline & Cotton seeds & 755 & 432 & 146 & 1332 \\
\hline & Cotton lint & 5163 & 2955 & 996 & 9113 \\
\hline & Cotton linters & 1474 & 844 & 284 & 2602 \\
\hline & Cotton-seed oil, refined & 2242 & 1283 & 432 & 3957 \\
\hline & Cotton seed oilcake & 487 & 279 & 94 & 860 \\
\hline & Cotton, not carded or combed & 5163 & 2955 & 996 & 9113 \\
\hline & Cotton yarn \& thread waste & 950 & 544 & 183 & 1677 \\
\hline & Garneted stock of cotton & 1426 & 816 & 275 & 2517 \\
\hline & Cotton, carded or combed & 5359 & 3067 & 1034 & 9460 \\
\hline & Cotton fabric, finished textile & 5384 & 3253 & 1344 & 9982 \\
\hline \multirow[t]{3}{*}{333} & Linseed & 4730 & 268 & 170 & 5168 \\
\hline & Linseed oil, refined & 8618 & 488 & 310 & 9415 \\
\hline & Linseed oilcake & 2816 & 160 & 101 & 3077 \\
\hline 336 & Hempseed & 3257 & 12 & 417 & 3685 \\
\hline 358 & Cabbages and other brassicas & 181 & 26 & 73 & 280 \\
\hline 366 & Artichokes & 478 & 242 & 98 & 818 \\
\hline 367 & Asparagus & 1524 & 119 & 507 & 2150 \\
\hline 372 & Lettuce & 133 & 28 & 77 & 237 \\
\hline 373 & Spinach & 118 & 14 & 160 & 292 \\
\hline \multirow[t]{5}{*}{388} & Tomatoes & 108 & 63 & 43 & 214 \\
\hline & Tomato juice unfermented/not spirited & 135 & 79 & 53 & 267 \\
\hline & Tomato juice, concentrated & 539 & 316 & 213 & 1069 \\
\hline & Tomato paste & 431 & 253 & 171 & 855 \\
\hline & Tomato ketchup & 270 & 158 & 107 & 534 \\
\hline
\end{tabular}


26 / Chapter 2. The green, blue and grey water footprint of crops

\begin{tabular}{|c|c|c|c|c|c|}
\hline \multirow{2}{*}{$\begin{array}{l}\text { FAOSTAT } \\
\text { crop code }\end{array}$} & \multirow{2}{*}{ Product description } & \multicolumn{4}{|c|}{ Global average water footprint ( $\mathrm{m}^{3} /$ ton) } \\
\hline & & Green & Blue & Grey & Total \\
\hline & Tomato puree & 360 & 211 & 142 & 713 \\
\hline & Peeled tomatoes & 135 & 79 & 53 & 267 \\
\hline & Tomato, dried & 2157 & 1265 & 853 & 4276 \\
\hline \multirow[t]{2}{*}{393} & Cauliflowers and broccoli & 189 & 21 & 75 & 285 \\
\hline & Brussels sprouts & 189 & 21 & 75 & 285 \\
\hline 394 & Pumpkins, squash and gourds & 228 & 24 & 84 & 336 \\
\hline 397 & Cucumbers and gherkins & 206 & 42 & 105 & 353 \\
\hline 399 & Eggplants (aubergines) & 234 & 33 & 95 & 362 \\
\hline 401 & Chillies and peppers, green & 240 & 42 & 97 & 379 \\
\hline 402 & Onions (incl. shallots), green & 176 & 44 & 51 & 272 \\
\hline 403 & Onions, dry & 192 & 88 & 65 & 345 \\
\hline \multirow[t]{2}{*}{406} & Garlic & 337 & 81 & 170 & 589 \\
\hline & Garlic powder & 1297 & 313 & 655 & 2265 \\
\hline 414 & Beans, green & 320 & 54 & 188 & 561 \\
\hline 417 & Peas, green & 382 & 63 & 150 & 595 \\
\hline 423 & String beans & 301 & 104 & 143 & 547 \\
\hline 426 & Carrots and turnips & 106 & 28 & 61 & 195 \\
\hline 430 & Okra & 474 & 36 & 65 & 576 \\
\hline 446 & Maize, green & 455 & 157 & 88 & 700 \\
\hline 461 & Carobs & 4557 & 334 & 703 & 5594 \\
\hline 486 & Bananas & 660 & 97 & 33 & 790 \\
\hline 489 & Plantains & 1570 & 27 & 6 & 1602 \\
\hline \multirow[t]{2}{*}{490} & Oranges & 401 & 110 & 49 & 560 \\
\hline & Orange juice & 729 & 199 & 90 & 1018 \\
\hline 495 & Tangerines, mandarins, clement & 479 & 118 & 152 & 748 \\
\hline 497 & Lemons and limes & 432 & 152 & 58 & 642 \\
\hline 507 & Grapefruit & 367 & 85 & 54 & 506 \\
\hline \multirow[t]{3}{*}{515} & Apples, fresh & 561 & 133 & 127 & 822 \\
\hline & Apples, dried & 4678 & 1111 & 1058 & 6847 \\
\hline & Apple juice unfermented/ not spirited & 780 & 185 & 176 & 1141 \\
\hline 521 & Pears & 645 & 94 & 183 & 922 \\
\hline 526 & Apricots & 694 & 502 & 92 & 1287 \\
\hline 530 & Sour cherries & 1098 & 213 & 99 & 1411 \\
\hline 531 & Cherries & 961 & 531 & 112 & 1604 \\
\hline 534 & Peaches and nectarines & 583 & 188 & 139 & 910 \\
\hline 536 & Plums and sloes & 1570 & 188 & 422 & 2180 \\
\hline 544 & Strawberries & 201 & 109 & 37 & 347 \\
\hline 547 & Raspberries & 293 & 53 & 67 & 413 \\
\hline 549 & Gooseberries & 487 & 8 & 31 & 526 \\
\hline 550 & Currants & 457 & 19 & 23 & 499 \\
\hline 552 & Blueberries & 341 & 334 & 170 & 845 \\
\hline 554 & Cranberries & 91 & 108 & 77 & 276 \\
\hline \multirow[t]{3}{*}{560} & Grapes & 425 & 97 & 87 & 608 \\
\hline & Grapes, dried & 1700 & 386 & 347 & 2433 \\
\hline & Grapefruit juice & 490 & 114 & 71 & 675 \\
\hline
\end{tabular}




\begin{tabular}{|c|c|c|c|c|c|}
\hline \multirow{2}{*}{$\begin{array}{l}\text { FAOSTAT } \\
\text { crop code }\end{array}$} & \multirow{2}{*}{ Product description } & \multicolumn{4}{|c|}{ Global average water footprint $\left(\mathrm{m}^{3} /\right.$ ton $)$} \\
\hline & & Green & Blue & Grey & Total \\
\hline & Grape wines, sparkling & 607 & 138 & 124 & 869 \\
\hline 567 & Watermelons & 147 & 25 & 63 & 235 \\
\hline 569 & Figs & 1527 & 1595 & 228 & 3350 \\
\hline 571 & Mangoes, mangosteens, guavas & 1314 & 362 & 124 & 1800 \\
\hline 572 & Avocados & 849 & 283 & 849 & 1981 \\
\hline \multirow[t]{2}{*}{574} & Pineapples & 215 & 9 & 31 & 255 \\
\hline & Pineapple juice & 1075 & 45 & 153 & 1273 \\
\hline 577 & Dates & 930 & 1250 & 98 & 2277 \\
\hline 591 & Cashew apple & 3638 & 34 & 121 & 3793 \\
\hline 592 & Kiwi fruit & 307 & 168 & 38 & 514 \\
\hline 600 & Papayas & 399 & 40 & 21 & 460 \\
\hline \multirow[t]{2}{*}{656} & Coffee, green & 15249 & 116 & 532 & 15897 \\
\hline & Coffee, roasted & 18153 & 139 & 633 & 18925 \\
\hline \multirow[t]{5}{*}{661} & Cocoa beans & 19745 & 4 & 179 & 19928 \\
\hline & Cocoa paste & 24015 & 5 & 218 & 24238 \\
\hline & Cocoa butter, fat and oil & 33626 & 7 & 305 & 33938 \\
\hline & Cocoa powder & 15492 & 3 & 141 & 15636 \\
\hline & Chocolate & 16805 & 198 & 193 & 17196 \\
\hline 667 & Green and black tea & 7232 & 898 & 726 & 8856 \\
\hline \multirow[t]{2}{*}{677} & Hop cones & 2382 & 269 & 1414 & 4065 \\
\hline & Hop extract & 9528 & 1077 & 5654 & 16259 \\
\hline 687 & Pepper of the genus Piper & 6540 & 467 & 604 & 7611 \\
\hline 689 & Chillies and peppers, dry & 5869 & 1125 & 371 & 7365 \\
\hline 692 & Vanilla beans & 86392 & 39048 & 1065 & 126505 \\
\hline 693 & Cinnamon (canella) & 14853 & 41 & 632 & 15526 \\
\hline 698 & Cloves & 59834 & 30 & 1341 & 61205 \\
\hline 702 & Nutmeg, mace and cardamoms & 30683 & 2623 & 1014 & 34319 \\
\hline \multirow[t]{2}{*}{711} & Anise, badian, fennel, coriander & 5369 & 1865 & 1046 & 8280 \\
\hline & Coriander seeds & 5369 & 1865 & 1046 & 8280 \\
\hline 720 & Ginger & 1525 & 40 & 92 & 1657 \\
\hline 748 & Peppermint & 206 & 63 & 19 & 288 \\
\hline \multirow[t]{3}{*}{773} & Flax fibre and tow & 2637 & 443 & 401 & 3481 \\
\hline & Flax fibre, otherwise processed/ not spun & 2866 & 481 & 436 & 3783 \\
\hline & Flax tow and waste & 581 & 98 & 88 & 767 \\
\hline \multirow[t]{2}{*}{777} & Hemp fibre and tow & 1824 & & 624 & 2447 \\
\hline & True hemp fibre processed/ not spun & 2026 & & 693 & 2719 \\
\hline 780 & Jute and other textile bast fibres & 2356 & 33 & 217 & 2605 \\
\hline 788 & Ramie & 3712 & 201 & 595 & 4507 \\
\hline \multirow[t]{2}{*}{789} & Sisal & 6112 & 708 & 222 & 7041 \\
\hline & Sisal textile fibres processed/ not spun & 6791 & 787 & 246 & 7824 \\
\hline 800 & Agave fibres & 6434 & 9 & 106 & 6549 \\
\hline \multirow[t]{2}{*}{809} & Manila fibre (Abaca) & 19376 & 246 & 766 & 20388 \\
\hline & Abaca fibre, processed but not spun & 21529 & 273 & 851 & 22654 \\
\hline 826 & Tobacco, unmanufactured & 2021 & 205 & 700 & 2925 \\
\hline 836 & Natural rubber & 12964 & 361 & 422 & 13748 \\
\hline
\end{tabular}




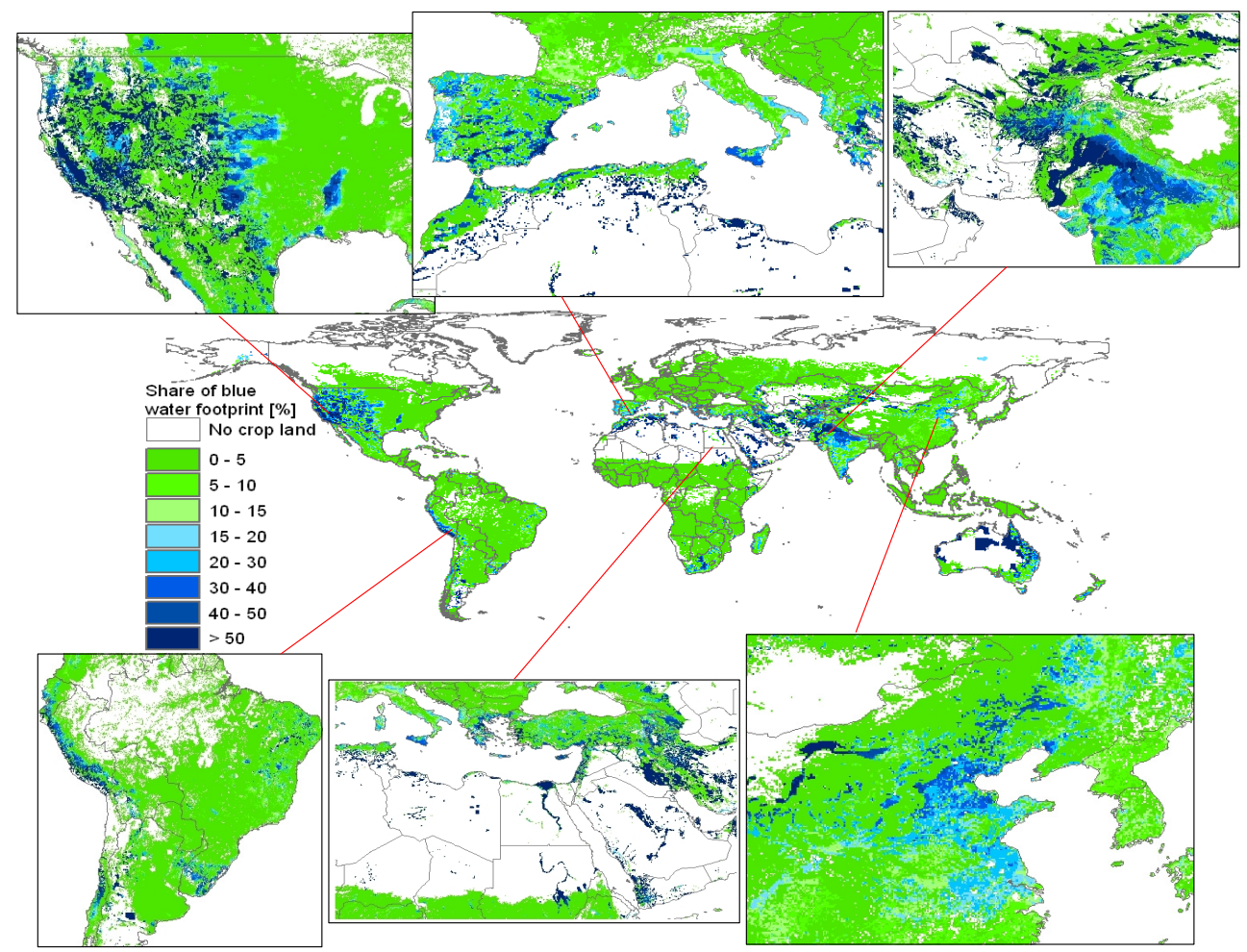

Figure 2.3. Contribution of the blue water footprint to the total consumptive (green and blue) water footprint of crop production. Period: 1996-2005.

The water footprints of crops vary across countries and regions as well. This is mainly due to differences in crop yields, as shown in Table 2.4 for the case of cereal crops. Relatively small water footprints per ton of cereal crops were calculated for Northern Europe (637 $\mathrm{m}^{3} /$ ton) and Western Europe $\left(654 \mathrm{~m}^{3} /\right.$ ton). On the other hand, with the exception of Southern Africa, the water footprints of cereal crops are quite large in most parts of Africa. While the average crop water requirement in Europe was only 11\% lower to that observed in Africa, the average water footprint of cereal crops in Europe was about three times smaller than in Africa, which can mainly be explained by the higher average yield in Europe (3.4 ton/ha) compared to that observed in Africa (1.3 ton/ha). A similar observation can be made for other regions as well: while crop water requirements in America, on average, are higher than in Asia, due to a higher yield, the average water footprint of cereals in America is smaller compared to the value calculated for Asia. Figure 2.4 shows the relationship between cereal yield and water footprint, where the dots represent country 
averages. From the figure we can observe a general trend between the water footprint and yield of cereals which follows a logarithmic function. This suggests that the water footprint of a crop, to a large extent, is influenced by agricultural management rather than by the agro-climate under which the crop is grown and that cannot be influenced by the farmer. This provides an opportunity to improve water productivity, i.e., to produce more food per unit of water consumption. According to Rockström et al. (2003), this opportunity is particularly large in the range of low crop yields, due to the current large losses in nonproductive green water evaporation.

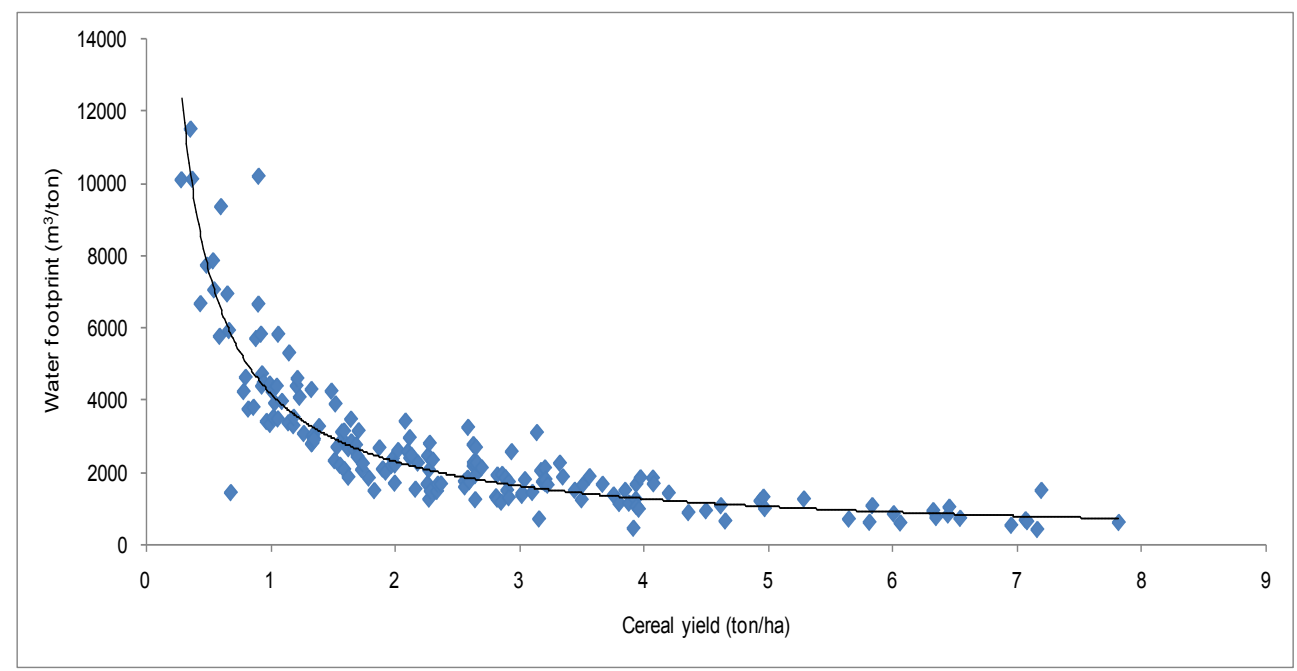

Figure 2.4. The relationship between average cereal yield and water footprint per ton of cereal. Period: 1996-2005. The dots represent average country data.

\subsubsection{The water footprint of biofuels per GJ and per litre}

The water footprint of biofuel varies across both crops and countries. The variation is due to differences in crop yields across countries and crops, differences in energy yields across crops and differences in climate and agricultural practices across countries. Table 2.5 shows the global average water footprint of biofuel for a number of crops providing ethanol and some other crops providing biodiesel. Among the crops providing ethanol, sorghum has the largest water footprint, with 7000 litre of water per litre of ethanol, which is equivalent to $300 \mathrm{~m}^{3} /$ GJ. Bio-ethanol based on sugar beet has the smallest global average water footprint, 
with 1200 litre of water per litre of ethanol, equivalent to $50 \mathrm{~m}^{3} / \mathrm{GJ}$. In general, biodiesel has a larger water footprint per unit of energy obtained than bio-ethanol, a finding that is consistent with Gerbens-Leenes et al. (2009a). Among the crops studied here, biodiesel from coconuts has the largest water footprint: $4750 \mathrm{~m}^{3} / \mathrm{GJ}$. Biodiesels from oil palm, rapeseed and groundnuts are more efficient, with water footprints in the range 150-200 $\mathrm{m}^{3} / \mathrm{GJ}$. The largest blue water footprint is observed for biodiesel from cotton: $177 \mathrm{~m}^{3} / \mathrm{GJ}$ ( $32 \%$ of the total water footprint).

\subsubsection{The total water footprint of crop production at national and sub-national level}

At the country level, the largest total water footprints were estimated for India, China, the USA, Brazil, Russia and Indonesia. These six countries together account for about half of the global total water footprint related to crop production. The largest green water footprints are also found in these six countries: India, China, the USA, Russia, Brazil and Indonesia. Data per country are shown in Table 2.6 for the largest producers. At subnational level (state or province level), the largest green water footprints can be found in Uttar Pradesh (88 $\mathrm{Gm}^{3} / \mathrm{yr}$ ), Maharashtra (86 Gm³/yr), Karnataka (65 $\mathrm{Gm}^{3} / \mathrm{yr}$ ), Andhra Pradesh $\left(61 \mathrm{Gm}^{3} / \mathrm{yr}\right)$, and Madhya Pradesh $\left(60 \mathrm{Gm}^{3} / \mathrm{yr}\right)$, all in India. The largest blue water footprints were calculated for India, China, the USA and Pakistan. These four countries together account for $58 \%$ of the total blue water footprint related to crop production. At sub-national level, the largest blue water footprints were found in: Uttar Pradesh (59 $\left.\mathrm{Gm}^{3} / \mathrm{yr}\right)$ and Madhya Pradesh $\left(24 \mathrm{Gm}^{3} / \mathrm{yr}\right)$ in India; Punjab $\left(50 \mathrm{Gm}^{3} / \mathrm{yr}\right)$ in Pakistan; and California $\left(20 \mathrm{Gm}^{3} / \mathrm{yr}\right)$ in the USA. Large grey water footprints were estimated for China, the USA and India. 
Table 2.4. Crop water requirement, production, area, yield and water footprint per ton per region for cereal crops (1996-2005)

\begin{tabular}{|c|c|c|c|c|c|c|c|c|c|c|c|c|}
\hline \multirow[b]{2}{*}{ Region } & \multirow{2}{*}{$\begin{array}{r}\text { Crop water } \\
\text { requirement } \\
(\mathrm{mm} / \\
\text { period })\end{array}$} & \multirow{2}{*}{$\begin{array}{r}\text { Total } \\
\text { production } \\
\left(10^{6} \text { ton/yr }\right)\end{array}$} & \multirow{2}{*}{$\begin{array}{l}\% \text { irrigated } \\
\text { production }\end{array}$} & \multirow{2}{*}{$\begin{array}{l}\text { Total area } \\
\left(10^{6} \mathrm{ha} / \mathrm{yr}\right)\end{array}$} & \multirow{2}{*}{$\begin{array}{r}\% \\
\text { irrigated } \\
\text { area }\end{array}$} & \multicolumn{3}{|c|}{ Yield (ton/ha) } & \multicolumn{4}{|c|}{ Water footprint ( $\left.\mathrm{m}^{3} / \mathrm{ton}\right)$} \\
\hline & & & & & & Rain-fed & Irrigated & average & Green & Blue & Grey & Total \\
\hline Africa & 527 & 122 & 23 & 94 & 7 & 1.08 & 4.25 & 1.30 & 3044 & 243 & 101 & 3388 \\
\hline Central Africa & 448 & 5 & 2 & 6 & 1 & 0.84 & 1.72 & 0.84 & 4616 & 25 & 17 & 4658 \\
\hline Eastern Africa & 561 & 30 & 13 & 24 & 7 & 1.20 & 2.21 & 1.27 & 3572 & 118 & 56 & 3746 \\
\hline Northern Africa & 602 & 35 & 62 & 21 & 19 & 0.80 & 5.36 & 1.68 & 1897 & 672 & 242 & 2811 \\
\hline Southern Africa & 614 & 13 & 13 & 5 & 8 & 2.21 & 3.68 & 2.32 & 1727 & 80 & 119 & 1926 \\
\hline Western Africa & 465 & 39 & 3 & 38 & 1 & 1.02 & 2.82 & 1.03 & 3846 & 40 & 17 & 3903 \\
\hline Asia & 546 & 1014 & 67 & 320 & 53 & 2.22 & 3.99 & 3.17 & 1166 & 379 & 228 & 1774 \\
\hline Central Asia & 492 & 22 & 26 & 17 & 14 & 1.12 & 2.40 & 1.30 & 2272 & 289 & 13 & 2574 \\
\hline Eastern Asia & 475 & 447 & 81 & 91 & 76 & 3.89 & 5.26 & 4.94 & 707 & 238 & 250 & 1195 \\
\hline Middle East & 613 & 6 & 47 & 4 & 25 & 1.07 & 2.87 & 1.53 & 2123 & 543 & 325 & 2991 \\
\hline South-Eastern Asia & 665 & 174 & 47 & 51 & 39 & 2.91 & 4.12 & 3.38 & 1578 & 180 & 154 & 1912 \\
\hline Southern Asia & 549 & 326 & 67 & 139 & 54 & 1.67 & 2.93 & 2.35 & 1421 & 678 & 255 & 2354 \\
\hline Western Asia & 576 & 40 & 28 & 19 & 22 & 1.96 & 2.61 & 2.11 & 1698 & 413 & 189 & 2300 \\
\hline America & 578 & 535 & 19 & 125 & 13 & 3.97 & 6.39 & 4.28 & 1028 & 92 & 174 & 1294 \\
\hline Caribbean & 555 & 2 & 50 & 1 & 32 & 1.51 & 3.17 & 2.04 & 2021 & 325 & 14 & 2359 \\
\hline Central America & 483 & 33 & 34 & 13 & 27 & 2.39 & 3.31 & 2.64 & 1598 & 149 & 261 & 2008 \\
\hline Northern America & 589 & 392 & 19 & 76 & 11 & 4.70 & 8.60 & 5.14 & 828 & 85 & 182 & 1094 \\
\hline South America & 589 & 108 & 15 & 35 & 11 & 2.91 & 4.40 & 3.07 & 1558 & 96 & 123 & 1778 \\
\hline Europe & 470 & 418 & 10 & 125 & 6 & 3.21 & 5.63 & 3.36 & 1054 & 41 & 119 & 1214 \\
\hline Eastern Europe & 492 & 180 & 5 & 79 & 4 & 2.25 & 2.95 & 2.27 & 1645 & 38 & 113 & 1795 \\
\hline Northern Europe & 284 & 47 & 2 & 9 & 2 & 5.16 & 5.73 & 5.17 & 522 & 1 & 114 & 637 \\
\hline Southern Europe & 516 & 70 & 29 & 18 & 16 & 3.18 & 7.07 & 3.81 & 907 & 140 & 170 & 1217 \\
\hline Western Europe & 421 & 121 & 9 & 18 & 6 & 6.62 & 8.99 & 6.77 & 528 & 14 & 111 & 654 \\
\hline Oceania & 624 & 35 & 7 & 18 & 3 & 1.87 & 5.21 & 1.96 & 1787 & 66 & 116 & 1969 \\
\hline World & 538 & 2117 & 41 & 679 & 30 & 2.63 & 4.26 & 3.11 & 1232 & 228 & 184 & 1644 \\
\hline
\end{tabular}


Table 2.5. Global average water footprint of biofuel for ten crops providing ethanol and seven crops providing biodiesel. Period: 1996-2005.

\begin{tabular}{|c|c|c|c|c|c|c|}
\hline \multirow{2}{*}{ Crop } & \multicolumn{3}{|c|}{ Water footprint per unit of energy } & \multicolumn{3}{|c|}{ Water footprint per litre of biofue } \\
\hline & Green & Blue & Grey & Green & Blue & Grey \\
\hline Crops for ethanol & \multicolumn{3}{|c|}{$\mathrm{m}^{3}$ per GJ ethanol } & \multicolumn{3}{|c|}{ litres water per litre ethanol } \\
\hline Barley & 119 & 8 & 13 & 2796 & 182 & 302 \\
\hline Cassava & 106 & 0 & 3 & 2477 & 1 & 60 \\
\hline Maize & 94 & 8 & 19 & 2212 & 190 & 453 \\
\hline Potatoes & 62 & 11 & 21 & 1458 & 251 & 483 \\
\hline Rice, paddy & 113 & 34 & 18 & 2640 & 785 & 430 \\
\hline Rye & 140 & 2 & 10 & 3271 & 58 & 229 \\
\hline Sorghum & 281 & 10 & 9 & 6585 & 237 & 201 \\
\hline Sugar beet & 31 & 10 & 10 & 736 & 229 & 223 \\
\hline Sugar cane & 60 & 25 & 6 & 1400 & 575 & 132 \\
\hline Wheat & 126 & 34 & 20 & 2943 & 789 & 478 \\
\hline Crops for biodiesel & \multicolumn{3}{|c|}{$\mathrm{m}^{3}$ per GJ biodiesel } & \multicolumn{3}{|c|}{ litres water per litre biodiesel } \\
\hline Coconuts & 4720 & 3 & 28 & 156585 & 97 & 935 \\
\hline Groundnuts & 177 & 11 & 12 & 5863 & 356 & 388 \\
\hline Oil palm & 150 & 0 & 6 & 4975 & 1 & 190 \\
\hline Rapeseed & 145 & 20 & 29 & 4823 & 655 & 951 \\
\hline Seed cotton & 310 & 177 & 60 & 10274 & 5879 & 1981 \\
\hline Soybeans & 326 & 11 & 6 & 10825 & 374 & 198 \\
\hline Sunflower & 428 & 21 & 28 & 14200 & 696 & 945 \\
\hline
\end{tabular}

\subsubsection{The total water footprint of crop production at river basin level}

At the river basin level, large water footprints were calculated for the Mississippi, Ganges, Yangtze, Indus and Parana river basins (Table 2.7). These five river basins together account for $23 \%$ of the global water footprint related to crop production. The largest green water footprint was calculated for the Mississippi river basin $\left(424 \mathrm{Gm}^{3} / \mathrm{yr}\right)$. The largest blue water footprints were found in the basins of the Indus $\left(117 \mathrm{Gm}^{3} / \mathrm{yr}\right)$ and Ganges $\left(108 \mathrm{Gm}^{3} / \mathrm{yr}\right)$. These two river basins together account for $25 \%$ of the global blue water footprint. Both basins are under severe water stress (Alcamo et al., 2007). 
Table 2.6. The water footprint of crop production in selected countries (1996-2005).

\begin{tabular}{lrrrr}
\hline \multirow{2}{*}{ Country } & \multicolumn{4}{c}{ Water footprint of crop production $\left(\mathrm{Gm}^{3} / \mathrm{yr}\right)$} \\
\cline { 2 - 5 } India & Green & Blue & Grey & Total \\
China & 716.0 & 231.4 & 99.4 & 1047 \\
USA & 623.9 & 118.9 & 223.8 & 967 \\
Brazil & 612.0 & 95.9 & 118.2 & 826 \\
Russia & 303.7 & 8.9 & 16.0 & 329 \\
Indonesia & 304.8 & 10.4 & 11.6 & 327 \\
Nigeria & 285.5 & 11.5 & 20.9 & 318 \\
Argentina & 190.6 & 1.1 & 0.6 & 192 \\
Canada & 157.6 & 4.3 & 5.0 & 167 \\
Pakistan & 120.3 & 1.6 & 18.2 & 140 \\
\hline World & 40.6 & 74.3 & 21.8 & 137 \\
\hline
\end{tabular}

Table 2.7. The water footprint of crop production in selected river basins (1996-2005).

\begin{tabular}{lrrrr}
\hline \multirow{2}{*}{ River basin* } & \multicolumn{3}{c}{ Water footprint of crop production $\left(\mathrm{Gm}^{3} / \mathrm{yr}\right)$} & \\
\cline { 2 - 5 } Mississippi & Green & Blue & Grey & Total \\
Ganges & 424 & 40 & 70 & 534 \\
Yangtze (Chang Jiang) & 260 & 108 & 39 & 408 \\
Indus & 177 & 18 & 61 & 256 \\
Parana & 102 & 117 & 34 & 253 \\
Niger & 237 & 3.2 & 9.4 & 250 \\
Nile & 186 & 1.7 & 0.5 & 188 \\
Huang He (Yellow River) & 131 & 29 & 6.9 & 167 \\
Nelson & 80 & 21 & 31 & 132 \\
Danube & 108 & 1.5 & 18 & 128 \\
Krishna & 106 & 1.8 & 11 & 119 \\
Volga & 89 & 21 & 8.7 & 118 \\
Ob & 101 & 3.4 & 3.9 & 108 \\
World & 92 & 1.8 & 1.8 & 95 \\
\hline
\end{tabular}

* River basins grid data from GRDC (2007). 


\section{4 / Chapter 2. The green, blue and grey water footprint of crops}

\subsubsection{The water footprint in irrigated versus rain-fed agriculture}

For most of the crops, the global average consumptive water footprint (blue plus green water footprint) per ton of crop was lower for irrigated crops than for rain-fed crops (Table 2.8). This is because, on average, irrigated yields are larger than rain-fed yields. For wheat, the water footprint per ton in irrigated and rain-fed agriculture are very similar at the global scale. For soybean, sugarcane and rapeseed, the water footprints per ton were substantially smaller in rain-fed production. The reason is that, although yields are higher under irrigation for soybean and sugarcane, there is more water available to meet crop water requirements, leading to an actual evapotranspiration that will approach or equal potential evapotranspiration. Under rain-fed conditions, the actual evapotranspiration over the growing period is generally lower than the potential evapotranspiration. In the case of rapeseed, the global average rain-fed yield is larger than global average irrigated yield which results in a smaller water footprint under rain-fed compared to irrigated crops. The reason for this is that those countries with a high yield happen to be countries with a large share of rain-fed harvested crop area. For example, a high crop yield is observed for rapeseed in most parts of Western Europe, where rapeseed is almost completely rain-fed. On the other hand, in countries such as Algeria, Pakistan and India, where the share of irrigated crop is high, the irrigated yield is quite low compared to the rain-fed yield in Western Europe. Globally, rain-fed agriculture has a water footprint of $5173 \mathrm{Gm}^{3} / \mathrm{yr}(91 \%$ green, $9 \%$ grey); irrigated agriculture has a water footprint of $2230 \mathrm{Gm}^{3} / \mathrm{yr}(48 \%$ green, $40 \%$ blue, $12 \%$ grey).

\subsection{Discussion}

In order to compare our estimates with previous studies, we have selected those studies which estimated the water footprint in global crop production and made an explicit distinction between green and blue water (Table 2.9). The study by Chapagain and Hoekstra (2004) did not take a grid-based approach and also did not make the green-blue distinction per crop and per country, unlike the current study and the studies by Rost et al. (2008), Liu and Yang (2010), Siebert and Döll (2010) and Hanasaki et al. (2010). 
Table 2.8. The water footprint of rain-fed and irrigated agriculture for selected crops (19962005).

\begin{tabular}{|c|c|c|c|c|c|c|c|c|c|}
\hline \multirow[t]{2}{*}{ Crop } & \multirow[t]{2}{*}{$\begin{array}{l}\text { Farming } \\
\text { system }\end{array}$} & \multirow[t]{2}{*}{$\begin{array}{l}\text { Yield } \\
\text { (ton/ha) }\end{array}$} & \multicolumn{4}{|c|}{$\begin{array}{l}\text { Total water footprint related to } \\
\text { crop production }\left(\mathrm{Gm}^{3} / \mathrm{yr}\right)\end{array}$} & \multicolumn{3}{|c|}{$\begin{array}{l}\text { Water footprint per ton of } \\
\text { crop }\left(\mathrm{m}^{3} / \text { ton }\right)\end{array}$} \\
\hline & & & Green & Blue & Grey & Total & Green & Blue & Grey \\
\hline \multirow{3}{*}{ Wheat } & Rain-fed & 2.48 & 610 & 0 & 65 & 676 & 1629 & 0 & 175 \\
\hline & Irrigated & 3.31 & 150 & 204 & 58 & 411 & 679 & 926 & 263 \\
\hline & Global & 2.74 & 760 & 204 & 123 & 1087 & 1278 & 342 & 208 \\
\hline \multirow{3}{*}{ Maize } & Rain-fed & 4.07 & 493 & 0 & 85 & 579 & 1082 & 0 & 187 \\
\hline & Irrigated & 6.01 & 104 & 51 & 37 & 192 & 595 & 294 & 212 \\
\hline & Global & 4.47 & 597 & 51 & 122 & 770 & 947 & 81 & 194 \\
\hline \multirow{3}{*}{ Rice } & Rain-fed & 2.69 & 301 & 0 & 30 & 331 & 1912 & 0 & 190 \\
\hline & Irrigated & 4.67 & 378 & 202 & 81 & 661 & 869 & 464 & 185 \\
\hline & Global & 3.90 & 679 & 202 & 111 & 992 & 1146 & 341 & 187 \\
\hline \multirow{3}{*}{ Apples } & Rain-fed & 8.93 & 24 & 0 & 6 & 30 & 717 & 0 & 167 \\
\hline & Irrigated & 15.91 & 8 & 8 & 2 & 18 & 343 & 321 & 71 \\
\hline & Global & 10.92 & 33 & 8 & 7 & 48 & 561 & 133 & 127 \\
\hline \multirow{3}{*}{ Soybean } & Rain-fed & 2.22 & 328 & 0 & 5 & 333 & 2079 & 0 & 33 \\
\hline & Irrigated & 2.48 & 24 & 12 & 1 & 37 & 1590 & 926 & 85 \\
\hline & Global & 2.24 & 351 & 12 & 6 & 370 & 2037 & 70 & 37 \\
\hline \multirow{3}{*}{ Sugarcane } & Rain-fed & 58.70 & 95 & 0 & 7 & 102 & 164 & 0 & 13 \\
\hline & Irrigated & 71.17 & 85 & 74 & 10 & 169 & 120 & 104 & 14 \\
\hline & Global & 64.96 & 180 & 74 & 17 & 271 & 139 & 57 & 13 \\
\hline \multirow{3}{*}{ Coffee } & Rain-fed & 0.68 & 106 & 0 & 4 & 110 & 15251 & 0 & 523 \\
\hline & Irrigated & 0.98 & 1 & 1 & 0 & 2 & 8668 & 4974 & 329 \\
\hline & Global & 0.69 & 108 & 1 & 4 & 112 & 15249 & 116 & 532 \\
\hline \multirow{3}{*}{ Rapeseed } & Rain-fed & 1.63 & 62 & 0 & 12 & 74 & 1783 & 0 & 356 \\
\hline & Irrigated & 1.23 & 4 & 9 & 1 & 14 & 1062 & 2150 & 181 \\
\hline & Global & 1.57 & 66 & 9 & 13 & 88 & 1703 & 231 & 336 \\
\hline \multirow{3}{*}{ Cotton } & Rain-fed & 1.35 & 90 & 0 & 13 & 103 & 3790 & 0 & 532 \\
\hline & Irrigated & 2.16 & 41 & 75 & 13 & 129 & 1221 & 2227 & 376 \\
\hline & Global & 1.73 & 132 & 75 & 25 & 233 & 2282 & 1306 & 440 \\
\hline \multirow{3}{*}{ All crops } & Rain-fed & - & 4701 & 0 & 472 & 5173 & - & - & - \\
\hline & Irrigated & - & 1070 & 899 & 261 & 2230 & - & - & - \\
\hline & Global & - & 5771 & 899 & 733 & 7404 & - & - & . \\
\hline
\end{tabular}

A comparison of our estimates with earlier studies shows that the order of magnitude is similar in all studies. The estimate of the total water footprint related to crop production by Hanasaki et al. (2010) is 6\% higher than our estimate, while the estimate of Liu and Yang (2010) is $11 \%$ lower. Our study is at the high side regarding the estimation of the global green water footprint and at the low side regarding the blue water footprint. Although there are major differences in applied models and assumptions, the models agree on the dominant role of green water in global crop production. The study by Rost et al. (2008) gives a higher green water footprint than the other studies, but this can be explained by the fact that 


\section{6 / Chapter 2. The green, blue and grey water footprint of crops}

evapotranspiration from croplands is estimated here over the whole year, instead of over the growing periods of the crops. The estimate of the total water footprint related to crop production by Fader et al. (2011) is only 4\% higher than our estimate. The differences in the outcomes of the various studies can be due to a variety of causes, including: type of model, spatial resolution, period considered and data regarding cultivated and irrigated areas, growing periods, crop parameters, soil and climate.

Table 2.9. Comparison between the results from the current study and the results from previous studies.

\begin{tabular}{lcccc}
\hline \multirow{2}{*}{$\begin{array}{l}\text { Study } \\
\text { Phapagain and Hoekstra (2004), }\end{array}$} & Period & \multicolumn{3}{c}{$\begin{array}{c}\text { Global water footprint related to crop } \\
\left.\text { production (Gm }{ }^{3} / \mathrm{yr}\right)\end{array}$} \\
\cline { 3 - 5 } $\begin{array}{l}\text { Choekstra and Chapagain (2007), } \\
\text { Hoekstra and Chapagain (2008) }\end{array}$ & $1997-2001$ & 5330 & 1060 & 6390 \\
\hline Rost et al. (2008) & $1971-2000$ & $7250^{*}$ & $600-1258$ & $7850-8508^{*}$ \\
\hline Liu and Yang (2010) & $1998-2002$ & 4987 & 951 & 5938 \\
\hline Siebert and Döll (2010) & $1998-2002$ & 5505 & 1180 & 6685 \\
\hline Hanasaki et al. (2010) & $1985-1999$ & 5550 & 1530 & 7080 \\
\hline Fader et al. (2011) & $1998-2002$ & 6000 & 923 & 6923 \\
\hline Current study, green \& blue only & $1996-2005$ & 5771 & 899 & 6670 \\
\hline
\end{tabular}

* Unlike the other values, this value includes the evapotranspiration from cropland outside the growing period.

Chapagain and Hoekstra (2004) have estimated the global water footprint of crop production distinguishing between green and blue only at the global level, but not per country and per crop. Our estimate of the total (green plus blue) water footprint is $4 \%$ higher than that of Chapagain and Hoekstra (2004). The total water footprint per country estimated in the current study compares reasonably well with the estimates by Chapagain and Hoekstra (2004), with an $r^{2}$ value of 0.96 (Figure 2.5a). The trend line almost fits the 1:1 line. The close agreement between the two studies and the slightly higher estimate in the current study is surprising. Due to limited data availability at the time, Chapagain and Hoekstra (2004) estimated crop water consumption based on the assumption of no water stress, so that actual equals potential evapotranspiration and their estimate is expected to be 
at the high side. There could be a number of reasons for the lower estimate in Chapagain and Hoekstra (2004). Some of the differences are observed in the larger countries such as the USA, Russia, China and Brazil. Chapagain and Hoekstra (2004) have taken national average climatic data to calculate crop evapotranspiration, which in particular for the large countries mentioned above has led to a different estimate compared to the current study. There are also differences between the two studies in the planting and harvesting dates and thus the length of growing period for the different crops considered.

The estimate of the total water footprint by Liu and Yang (2010) is 11\% lower than our estimate. The reason for the difference probably lies in the number of crops explicitly considered in the two studies: in the current study we have considered 146 crops explicitly while Liu and Yang (2010) have considered 20 crops and grouped the rest into 2 broad crop categories. In Figure 2.5b, the total (green plus blue) water footprints by country as estimated in the current study are plotted against the results from Liu and Yang (2010). There is a close agreement between the two studies with an $r^{2}$ value of 0.96 . The differences between the two studies can be partially explained by differences in the method used to estimate reference evapotranspiration. The blue water footprint per country as computed in this study compares to the result from Liu and Yang (2010) as shown in Figure 2.6a. The correlation is reasonably well, with an $\mathrm{r}^{2}$ value of 0.78 .

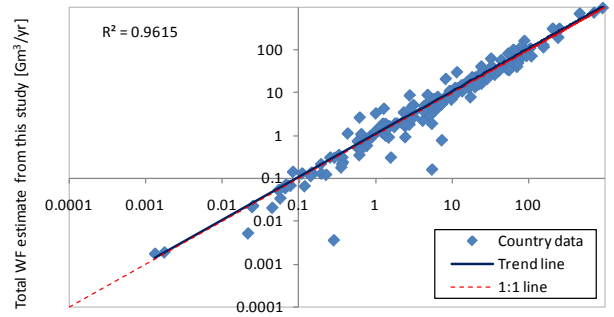

(a)

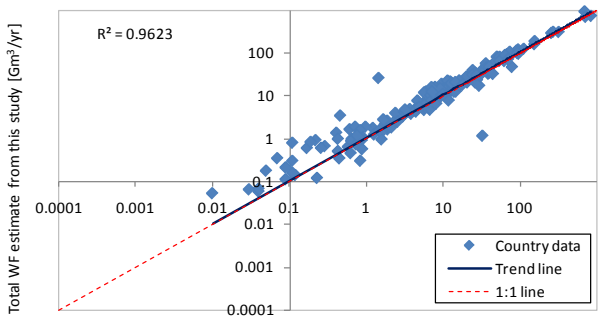

(b)

Total WF estimate by Liu and Yang $(2010)\left[\mathrm{Gm}^{3} / \mathrm{yr}\right]$

Figure 2.5. Comparison of national (green plus blue) water footprints related to crop production as estimated in the current study with results from (a) Chapagain and Hoekstra (2004), and (b) Liu and Yang (2010).

The computed total (green plus blue) water footprint is almost the same as the value found by Siebert and Döll (2010). However, the green water footprint estimated by Siebert and Döll (2010) is $4.6 \%$ lower than in the current study, while their blue water footprint 
estimate is $31 \%$ higher. At country level, the blue water footprint estimates in the two studies correlate well, with an $\mathrm{r}^{2}$ value of 0.99 , but our estimates are consistently lower (Figure 2.6b). For most crops there is a good agreement between the current estimate of the total blue water footprint and the one by Siebert and Döll (2010). However, their total blue water footprint estimate for rice $\left(307 \mathrm{Gm}^{3} / \mathrm{yr}\right)$ is $52 \%$ higher than our estimate (202 $\mathrm{Gm}^{3} / \mathrm{yr}$ ). The reason for the difference could be differences in the planting and harvesting dates and thus the length of the growing period in the two studies.

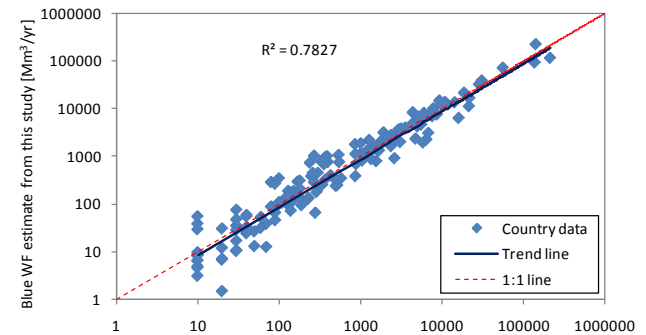

(a)

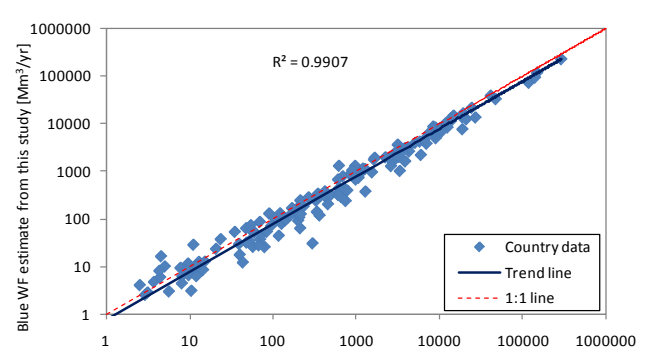

(b)

Figure 2.6. Comparison of national blue water footprints related to crop production as estimated in the current study with results from (a) Liu and Yang (2010) and (b) Siebert and Döll (2008).

The national blue water footprints estimated in the current study were further compared with statistics on agricultural water withdrawals per country as available from AQUASTAT (FAO, 2010b). Since water withdrawals are higher than actual blue water consumption, we first estimated the latter by multiplying the water withdrawal per country by the irrigation efficiency. Overall irrigation efficiency data per country were obtained from Rohwer et al. (2007), whereby irrigation efficiency refers here to the fraction of water diverted from the water source that is available for beneficial crop evapotranspiration. The blue water footprint per country computed in the current study generally compares well with the derived values based on AQUASTAT and Rohwer et al. (2007), with an $\mathrm{r}^{2}$ value of 0.94 (Figure 2.7a). Compared to the AQUASTAT values, our estimates are slightly lower (6\%). A reason may be that water withdrawals in agriculture do not refer to withdrawals alone; water withdrawn for domestic needs and animal breeding may constitute $5-8 \%$ of the agricultural water withdrawal (Shiklomanov, 2000). Assuming that water withdrawal for 
irrigation equals agricultural water withdrawal may thus lead to a slight overestimation of the blue water footprint from the statistics.

The blue water footprints estimated in the current study can also be compared with consumptive water use in irrigation on the level of federal states in the USA. Hutson et al. (2004) provide irrigation water withdrawal at federal state level for the year 2000. Consumptive blue water use for the year 2000 was derived using the ratio of consumptive water use to water withdrawal for irrigation at state level for the year 1995 (Solley et al., 1998). Our estimated blue water footprints at federal state level correlate well with the statistic data, at least for states with high irrigation water use. The blue water footprints at the state level obtained in the current study, however, are generally lower than the values obtained from the statistics (Figure 2.7b).

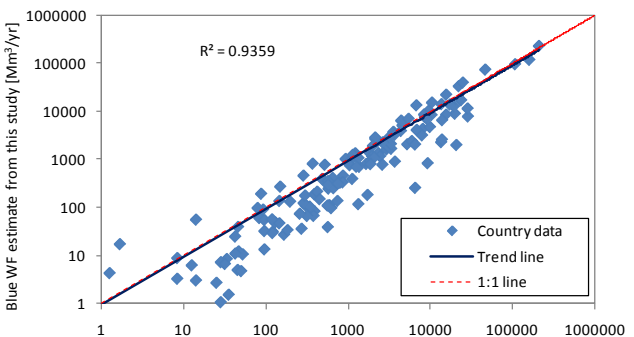

(a)

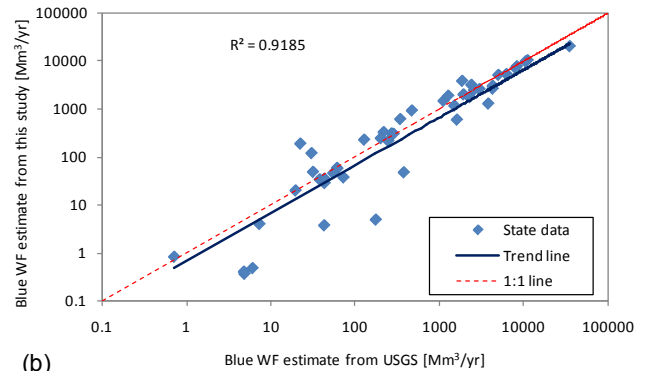

(b)

Figure 2.7. Comparison of blue water footprints related to crop production as estimated in the current study with results from (a) AQUASTAT (FAO, 2010b) for developing countries, and (b) USGS (Hutson et al., 2004; Solley et al., 1998) for the states in the USA.

The calculated national blue water footprints were further compared to the irrigation water requirements for 90 developing countries as estimated by FAO (2005a) for the year 2000 . As can be seen in Figure 2.8, the calculated national blue water footprints are consistently lower than the national irrigation requirements from FAO (2005a), which can be explained by the use of different land use data and differences in model set-up in the two studies. In the current study, the soil water balance was made on a daily basis while in FAO (2005a) the soil water balance was done with a monthly time step. Besides, for rice irrigation water requirements, FAO (2005a) added an additional $250 \mathrm{~mm}$ of water to flood the paddy fields.

The water footprint per ton of crop has been compared with results from Chapagain and Hoekstra (2004) and Siebert and Döll (2010). The global average water footprint per 
40 / Chapter 2. The green, blue and grey water footprint of crops

ton of crop correlates well with Chapagain and Hoekstra (2004), with an $\mathrm{r}^{2}$ value of 0.97 (Figure 2.9a). The comparison with Siebert and Döll (2010) also shows a good agreement, with an $r^{2}$ value of 0.995 (Figure 2.9b). Out of the 22 crops compared, for 13 crops (including wheat, rice, maize, barley and sugar cane) the difference is within $\pm 10 \%$. Large differences $( \pm 20 \%)$ were observed for rye, cassava and millet. The reason for the larger differences probably lies in the average yield used in the two studies. We used national average yield data from FAOSTAT, which apparently differ from the yield data from Monfreda et al. (2008) which were used by Siebert and Döll (2010).

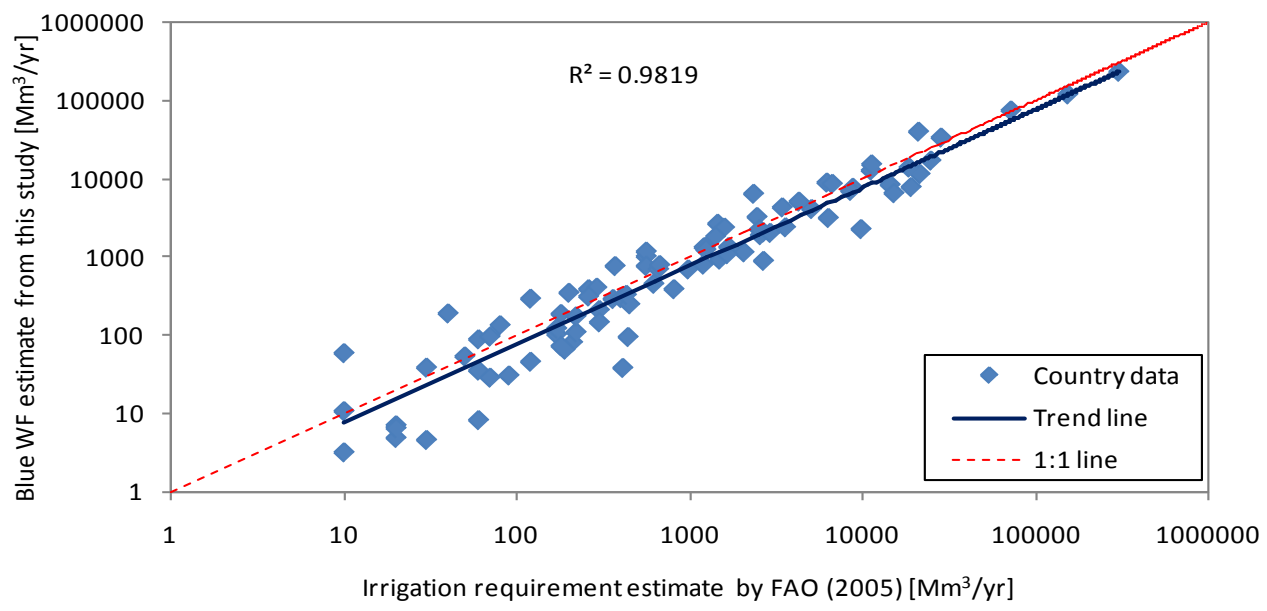

Figure 2.8. Comparison of national blue water footprints related to crop production as estimated in the current study with national irrigation requirements as estimated by FAO (2005a).
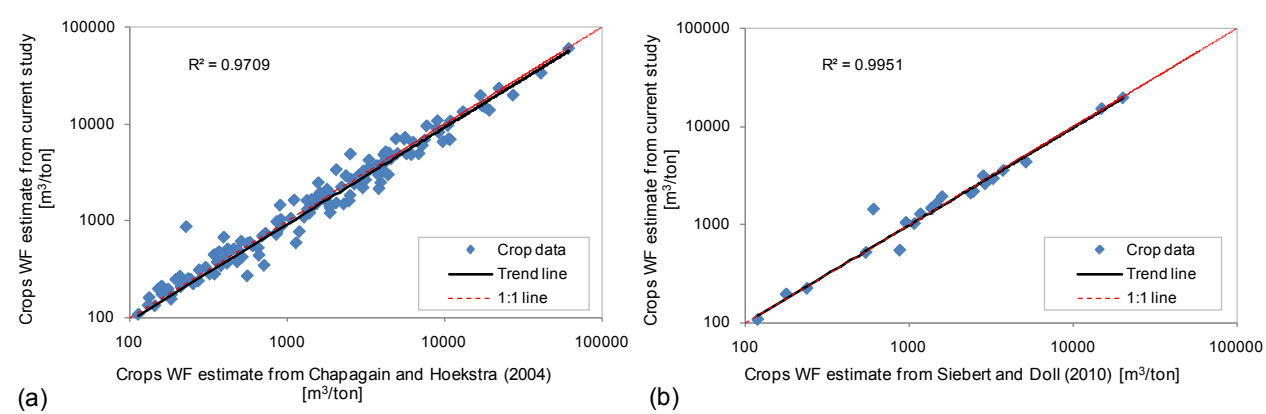

(b)

Figure 2.9. Comparison of global average crops water footprint (green plus blue) as estimated in the current study with results from (a) Chapagain and Hoekstra (2004), and (b) Siebert and Döll (2008). 
Since all studies depend on a large set of assumptions with respect to modelling structure, parameter values and datasets used, as it was already pointed out by Mekonnen and Hoekstra (2010a), it is difficult to attribute differences in estimates from the various studies to specific factors; also it is difficult to assess the quality of our new estimates relative to the quality of earlier estimates. The quality of data used defines the accuracy of the model output. All studies suffer the same sorts of limitations in terms of data availability and quality and deal with that in different ways. In future studies it would be useful to spend more effort in studying the sensitivity of the model outcomes to assumptions and parameters and assessing the uncertainties in the final outcome.

\subsection{Conclusion}

The study shows that the global water footprint of crop production for the period 19962005 was $7404 \mathrm{Gm}^{3} / \mathrm{yr}$. The large fraction of green water $(78 \%)$ confirms the importance of green water in global food production. The fraction of blue water is smaller (12\%), but as the spatial analysis shows, the regions where blue water footprints are large are often arid and semi-arid regions where water scarcity is high. The share of the grey water footprint is relatively small as well $(10 \%)$, but this is a conservative estimate, because we have analysed the required assimilation volume for leached nitrogen fertilizers only, leaving out relevant pollutants such as phosphorus and pesticides.

The finding in this study agrees with earlier studies that green water plays a prominent role in the global crop production. As shown by Rockström et al. (2009), most countries in theory have a green water based self-sufficiency potential and are in a position to produce their entire food requirement locally. Rockström et al. (2003) showed that there is great opportunity to improve water productivity through improving yield levels as much as four folds within the available water balance in rain-fed agriculture. This offers a good opportunity to increase food production from rain-fed agriculture by raising water productivity without requiring additional blue water resources (Critchely and Siegert, 1991; Rockström and Barron, 2007; Rockström et al., 2003, 2007a, 2007b). However, the marginal benefit of additional blue water in semi-arid and arid regions is quite large in terms of raising productivity. Globally, the current cereal production would be significantly lower if no blue water is applied (Hoff et al., 2010; Rost et al., 2009; Siebert and Döll, 


\section{2 / Chapter 2. The green, blue and grey water footprint of crops}

2010). Therefore, a carefully balanced green-blue water use strategy would be required to address the issue of increasing water demand in a world of limited freshwater resources. For further research it is important to assess the spatiotemporal variability of blue water availability and how much blue water can sustainably be used in a certain catchment without adversely affecting the ecosystem.

There are a number of uncertainties in the estimation of the green, blue and grey water footprints. In particular, the uncertainties related to the input data used in the model are high. A number of assumptions were made due to a lack of data. The uncertainties include:

- Crop-specific irrigation maps are available only for a limited number of crops. Irrigation maps for the other crops were derived from the MICRA2000 database through the simple assumption that all crops in a country belonging to a certain crop category (annuals/perennials) would have the same fraction of irrigated area out of the total harvested area. This assumption will lead to an underestimation of the irrigated area and thus the blue water footprint of crops which are most likely to be irrigated and an overestimation of the blue water footprint for those minor crops which are actually not irrigated.

- The planting and harvesting dates and thus the length of the growing period used in the study are available only at country level, thus do not reflect possible variation within a country and across varieties of the same crop. Crop planting and harvesting dates are provided in the literature as a range of dates (FAO, 2010e; USDA, 1994). The choice of the planting and harvesting dates out of these ranges obviously influences the final crop water footprint estimate.

- The rooting depths for both rain-fed and irrigated crops are defined based on the crop characteristics. However, such assumption neglects the fact that actual rooting depth depends also on the soil type.

- The soil water holding capacity is derived based on the dominant soil type. However, farmers may plant in the parts of the grid cell with better soils, which may have a different water holding capacity to that defined for the dominant soil type.

- For irrigated agriculture, the irrigation is assumed to be sufficient to meet the irrigation requirement. However, farmers may decide to supply irrigation water below the level of 
optimal yield, in particular in those regions where water is scarce. The assumption of sufficient irrigation may lead to an overestimation of the blue water footprint.

- Fertilizer application rates per crop per country are not available for most crops. The rates used in this study are based on different sources and a number of assumptions. All grid cells of the same crop in a country are assumed to receive the same fertilizer application rate. However, irrigated crops generally receive more fertilizer than rain-fed ones. Besides, most small subsistence farmers likely use no or less fertilizer.

- The grey water footprint is estimated based on a simplified approach, which gives a rough estimate; it leaves out local factors that influence the precise leaching and runoff rates, such as rainfall intensity, soil property, slopes and the amount of already mineralized nitrogen in the upper soil layer. Systematic comparison of the estimate from such simplified approach with other regression models (De Willigen, 2000; Roy et al., 2003; Liu et al., 2010) might be required to test the uncertainties and limitation of our approach. Liu et al. (2010) estimated, for the first time, global nitrogen flows of 6 nitrogen inputs and 5 nitrogen outputs including nitrogen leaching at high resolution (5 by 5 arc minute grid). Their approach is very innovative and could be useful to conduct in-depth grey water assessment in the future.

- The model used to estimate the yield at grid level is a simplified linear model which accounts for the effect of water deficit on yield reduction only, leaving out other factors, such as fertilizer application rate, soil salinity and crop growing characteristics.

- Although intercropping and multi-cropping are practiced in most part of the world, we have not considered those practices explicitly.

In a global study like this one, because of lack of data, several assumptions and expert guesses were made. At this stage it seems difficult to reduce the uncertainties. Therefore, the water footprint values at a smaller spatial scale, in particular at the grid cell level, should be interpreted with care. 



\section{The green, blue and grey water footprint of farm animals and animal products ${ }^{2}$}

\section{Abstract}

The projected increase in the production and consumption of animal products is likely to put further pressure on the globe's freshwater resources. This paper provides a comprehensive account of the global green, blue and grey water footprints of different sorts of farm animals and animal products, distinguishing between different production systems (grazing, mixed and industrial) and considering the conditions in all countries of the world separately. The result shows that: The blue and grey water footprints of animal products are largest for industrial systems (with an exception for chicken products). From a freshwater perspective, animal products from grazing systems are therefore to be preferred above products from industrial systems; The water footprint of any animal product is larger than the water footprint of a wisely chosen crop product with equivalent nutritional value; $29 \%$ of the total water footprint of the agricultural sector in the world is related to the production of animal products. One third of the global water footprint of animal production is related to beef cattle.

\subsection{Introduction}

The global meat production has almost doubled in the period 1980-2004 (FAO, 2005b) and this trend is likely to continue given the projected doubling of meat production in the period 2000-2050 (Steinfeld et al., 2006). To meet this rising demand for animal products, the ongoing shift from traditional extensive and mixed farming to industrial farming systems is likely to continue (Bouwman et al., 2005, Naylor et al., 2005, Galloway et al., 2007). There is a rich literature on the expected environmental consequences of increased consumption of animal products (Naylor et al., 2005; Myers and Kent, 2003; McAlpine et al., 2009; Pelletier and Tyedmers, 2010; Sutton et al., 2011) and on the pros and cons of industrial versus conventional farming systems (Lewis and others 1990; Capper et al., 2009). Specific fields of interest include, amongst others, animal welfare (Fraser, 2008; Thompson, 2008),

\footnotetext{
${ }^{2}$ Based on Mekonnen and Hoekstra (2010e)
} 
excessive use of antibiotics (Gustafson and Bowen, 1997; Witte, 1998; Smith et al., 2002; McEwen, 2006), the demand for scarce lands to produce the required feed (Naylor et al., 2005; Keyzer et al., 2005; Nepstad et al., 2006) and the contribution of livestock to the emission of greenhouse gases (Pelletier and Tyedmers, 2010; Tilman et al., 2001; Bouwman et al., 2011). Although it is known that animal products are very water intensive (Pimentel et al., 2004; Chapagain and Hoekstra, 2003), little attention has been paid thus far to the total impact of the livestock sector on the global demand for freshwater resources. Because of the larger dependence on concentrate feed in industrial systems, the intensification of animal production systems will result in increasing blue and grey water footprints per unit of animal product. The pressure on the global freshwater resources will thus increase both because of the increasing meat consumption and the increasing blue and grey water footprint per unit of meat consumed.

As a result of the increasing global trade in feed crops and animal products and the growth of meat preservation over longer periods, consumers of animal products are spatially disconnected from the processes necessary to produce the products (Naylor et al., 2005; Hoekstra, 2010). The concept of 'water footprint' provides an appropriate framework of analysis to find the link between the consumption of animal products and the use of the global water resources. The water footprint is defined as the total volume of freshwater that is used to produce the goods and services consumed by an individual or community (Hoekstra and Chapagain, 2008). The blue water footprint refers to the volume of surface and groundwater consumed (evaporated) as a result of the production of a good; the green water footprint refers to the rainwater consumed. The grey water footprint of a product refers to the volume of freshwater that is required to assimilate the load of pollutants based on existing ambient water quality standards.

There are a few earlier publications on water use in animal production. The first and most comprehensive assessment of the water footprint of farm animals and animal products was carried out by Chapagain and Hoekstra (2003) and later updated by the same authors in their water footprint of nation's publication (Chapagain and Hoekstra, 2004). A study by FAO has quantified the global blue water use for feed production, animal drinking and servicing (Steinfeld et al., 2006). De Fraiture et al. (2007) have estimated the global water use for animal feed production, both green and blue but not distinguishing between the two. Galloway et al. (2007) produced a study on the water consumption for chicken and pig for 
four countries. Peden et al. (2007) made an estimate of the global water consumption for producing the feed for farm animals. In addition to the studies mentioned there have been a few more specific studies for the Nile River Basin (Van Breugel et al., 2010) and for the USA (Renault and Wallender, 2000; Pimentel et al., 2004).

With the exception of Chapagain and Hoekstra $(2003,2004)$, none of the studies have estimated the water footprint of animal products by product and country at a global level. Although Chapagain and Hoekstra $(2003,2004)$ were able to estimate the water footprint of farm animals and animal products per country, they have taken a very crude assumption on the composition and amount of feed consumed by the different animals. Besides, the water footprints of feed crops were estimated based on national average climatic data. We have tried to improve the estimation of feed composition and feed amount per animal category and have used better estimates for the water footprints of feed crops:

- We have estimated the amount of feed consumed per animal category, per production system and per country based on estimates of feed conversion efficiencies and statistics on the annual production of animal products. Chapagain and Hoekstra $(2003,2004)$ have taken rough assumptions on the quantities of feed consumed per animal category based on incidental data.

- We reckon with the relative occurrence of the three production systems (grazing, mixed and industrial) in each country, using the studies of Seré and Steinfeld (1996) and Wint and Robinson (2007).

- We have estimated the green, blue and grey water footprints of the feed crops using a spatially explicit crop water use model able to estimate actual crop water use (Mekonnen and Hoekstra, 2010a, 2010d).

The objective of the study is to assess the water footprint of farm animals and the various derived animal products per animal production systems for the period 1996-2005. We consider eight animal categories: beef and dairy cattle, pig, sheep, goat, broiler and layer chicken and horses. 


\subsection{Method}

We follow the water footprint definitions and methodology as set out in Hoekstra et al. (2009). The blue water footprint refers to consumption of blue water resources (surface and groundwater) along the supply chain of a product. 'Consumption' refers to loss of water from the available ground-surface water body in a catchment area. Losses occur when water evaporates, returns to another catchment area or the sea or is incorporated into a product. The green water footprint refers to consumption of green water resources (rainwater in so far as it does not become run-off). The grey water footprint refers to pollution and is defined as the volume of freshwater that is required to assimilate the load of pollutants given natural background concentrations and existing ambient water quality standards.

We consider eight farm animal categories: beef and dairy cattle, pig, sheep, goat, broiler and layer chicken and horses. When estimating total feed amounts and total water footprints per category, we include 'buffaloes' in the category of 'beef cattle' and 'asses and mules' in the category of 'horses'.

The water footprint of a live animal consists of different components: the indirect water footprint of the feed and the direct water footprint related to the drinking water and service water consumed (Chapagain and Hoekstra, 2003, 2004). The water footprint of an animal is expressed as:

$$
W F[a, c, s]=W F_{\text {feed }}[a, c, s]+W F_{d r i n k}[a, c, s]+W F_{\text {serv }}[a, c, s]
$$

where $W F_{\text {feed }}[a, c, s], W F_{\text {drink }}[a, c, s]$ and $W F_{\text {serv }}[a, c, s]$ represent the water footprint of an animal for animal category $a$ in country $c$ in production systems $s$ related to feed, drinking water and service water consumption, respectively. Service water refers to the water used to clean the farmyard, wash the animal and carry out other services necessary to maintain the environment. The water footprint of an animal and its three components can be expressed in terms of $\mathrm{m}^{3} / \mathrm{yr} / \mathrm{animal}$, or, when summed over the lifetime of the animal, in terms of $\mathrm{m}^{3} /$ animal. For beef cattle, pig, sheep, goat and broiler chicken - animals that provide their products after they have been slaughtered - it is most useful to look at the water footprint of the animal at the end of its lifetime, because it is this total that will be allocated to the 
various products (e.g. meat, leather). For dairy cattle and layer chicken, it is most straightforward to look at the water footprint of the animal per year (averaged over its lifetime), because one can easily relate this annual animal water footprint to its average annual production (milk, eggs).

The water footprint of an animal related to the feed consumed consists of two parts: the water footprint of the various feed ingredients and the water that is used to mix the feed:

$W F_{\text {feed }}[a, c, s]=\frac{\sum_{p=1}^{n}\left(\text { Feed }[a, c, s, p] \times W F_{\text {prod }}^{*}[p]\right)+W F_{\text {mixing }}[a, c, s]}{\operatorname{Pop}^{*}[a, c, s]}$

Feed $[a, c, s, p]$ represents the annual amount of feed ingredient $p$ consumed by animal category $a$ in country $c$ and production system $s$ (ton/yr), $W F_{p r o d}^{*}[p]$ the water footprint of feed ingredient $p\left(\mathrm{~m}^{3} /\right.$ ton $), W F_{\text {mixing }}[a, c, s]$ the volume of water consumed for mixing the feed for animal category $a$ in country $c$ and production system $s\left(\mathrm{~m}^{3} / \mathrm{yr} / \mathrm{animal}\right)$ and $\operatorname{Pop}^{*}[a, c, s]$ the number of slaughtered animals per year or the number of milk or egg producing animals in a year for animal category $a$ in country $c$ and production system $s$.

\section{The water footprint of feed ingredients}

The water footprints of the different crops, roughages and crop by-products $\left(W F_{p r o d}^{*}[p]\right.$, $\mathrm{m}^{3} /$ ton) that are eaten by the various farm animals have been calculated following the methodology developed by Hoekstra and Chapagain (2008) and Hoekstra et al. (2009). The water footprints of feed crops were estimated using a crop water use model that estimates crop water footprints at a 5 by 5 arc minute spatial resolution globally (Mekonnen and Hoekstra, 2010a, 2010d). Grey water footprints were estimated by looking at leaching and runoff of nitrogen fertilisers only, following Mekonnen and Hoekstra (2010a,d). Since animal feed in a country originates from domestic production and imported products, for the calculation of the water footprint of animal feed in a country, we have taken a weighted average water footprint according to the relative volumes of domestic production and import: 


$$
W F_{\text {prod }}^{*}[p]=\frac{P[p] \times W F_{\text {prod }}[p]+\sum_{n_{e}}\left(T_{i}\left[n_{e}, p\right] \times W F_{\text {prod }}\left[n_{e}, p\right]\right)}{P[p]+\sum_{n_{e}} T_{i}\left[n_{e}, p\right]}
$$

in which $P[p]$ is the production quantity of feed product $p$ in a country (ton/yr), $T_{i}\left[n_{e}, p\right]$ the imported quantity of feed product $p$ from exporting nation $n_{e}$ (ton/yr), $W F_{p r o d}[p]$ the water footprint of feed product $p$ when produced in the nation considered $\left(\mathrm{m}^{3} /\right.$ ton $)$ and $W F_{\text {prod }}\left[n_{e}, p\right]$ the water footprint of feed product $p$ as in the exporting nation $n_{e}\left(\mathrm{~m}^{3} /\right.$ ton). The water footprint of crop residues such as bran, straw, chaff and leaves and tops from sugar beet have already been accounted for in the main product, therefore their water footprint was set equal to zero.

\section{Volume and composition of feed}

The volume and composition of the feed consumed vary depending on the type of animal, the production system and the country. The amount of feed consumed is estimated following the approach of Hendy et al. (1995), in which the total annual feed consumption (including both concentrates and roughages) is calculated based on annual production of animal products and feed conversion efficiencies. Only for horses we have used the approach as in Chapagain and Hoekstra (2003), which means that we multiplied the estimated feed consumption per animal by the number of animals, thus arriving at an estimate of the total feed consumed by horses.

The total feed per production system for both ruminants and non-ruminants animals is calculated as follows:

Feed $[a, c, s]=F C E[a, c, s] \times P[a, c, s]$

where Feed $[a, c, s]$ is the total amount of feed consumed by animal category $a$ (ton/yr) in country $c$ and production system $s, F C E[a, c, s]$ the feed conversion efficiency (kg dry mass of feed / $\mathrm{kg}$ of product) for animal category $a$ in country $c$ and production system $s$, and 
$P[a, c, s]$ the total amount of product (meat, milk, or egg) produced by animal category $a$ (ton/yr) in country $c$ and production system $s$.

\section{Estimating feed conversion efficiencies}

Feed conversion efficiency is defined as the amount of feed consumed per unit of produced animal product (e.g. meat, milk, egg). Feed conversion efficiencies were estimated separately for each animal category (beef cattle, dairy cattle, sheep, goat, pig, broiler chicken and egg layer chicken), for each animal production system and per country. Although the term used may suggest precisely the opposite, animals that have a low 'feed conversion efficiency' are efficient users of feed. We use the term here as generally used in livestock studies. The feed conversion efficiencies (FCE, $\mathrm{kg}$ dry mass/kg product) for nonruminants (pig and chicken) were adopted from Hendy et al. (1995). For ruminants (cattle, goat, sheep), feed conversion efficiencies were estimated through dividing feed intake per capita by annual production (of beef, milk, sheep and goat meat) per capita:

$$
F C E[a, c, s]=\frac{F I[a, c, s]}{P O[a, c, s]}
$$

where $F I[a, c, s]$ is the feed intake per head by ruminant animal category $a$ in country $c$ and production system $s$ (kg dry mass/yr/animal), and $P O[a, c, s]$ the product output per head for ruminant animal category $a$ in country $c$ and production system $s$ (kg product/yr/animal). The product output (beef, milk, sheep and goat meat) per animal for ruminants is calculated as:

$$
P O[a, c, s]=\frac{P[a, c, s]}{\operatorname{Pop}[a, c, s]}
$$

in which $P[a, c, s]$ is the total annual production of beef, milk, sheep meat or goat meat in country $c$ in production system $s(\mathrm{~kg} / \mathrm{yr})$ and $P o p[a, c, s]$ the total population of beef cattle, dairy cattle, sheep or goat in that country and production system. 


\section{2 / Chapter 3. The green, blue and grey water footprint of animal products}

\section{Estimating the total annual production of animal products}

The meat production $\left(P_{\text {meat }}\right.$, ton/yr) per animal category a (beef cattle, pig, sheep and goat) in country $c$ and production system $s$ is estimated by multiplying the carcass yield per slaughtered animal by the annual number of animals slaughtered:

$$
P_{\text {meat }}[a, c, s]=C Y[a, c, s] \times S A[a, c, s]
$$

The carcass yield ( $C Y, \mathrm{~kg} /$ animal) for each animal category per production system was estimated by combining country average carcass yield data from FAO (2010a) with data on animal live weight per production system per economic region (Hendy et al. 1995) and data on carcass weight as percentage of live weight (FAO, 2003). The obtained carcass yields were scaled such that the total meat production per animal category equals the value provided by FAO (2010a). The number of slaughtered animals per production system ( $S A$, number of animal/yr) was calculated by multiplying the total animal number by the animal off-take rate per production system:

$S A[a, c, s]=\operatorname{Pop}[a, c, s] \times \operatorname{OR}[a, c, s]$

where Pop $[a, c, s]$ is the population of animal category $a$ in country $c$ for production system $s$ and $O R[a, c, s]$ the off-take rate, which is the fraction of the animal population that is taken out in a given year for slaughter (dimensionless).

Milk and egg production per production system and country were calculated as:

$$
\begin{aligned}
& P_{\text {milk }}[a, c, s]=M Y[a, c, s] \times D C[a, c, s] \\
& P_{e g g}[a, c, s]=f_{e g g}[a, c, s] \times P_{e g g}[a, c]
\end{aligned}
$$

where $P_{\text {milk }}[a, c, s]$ and $P_{\text {egg }}[a, c, s]$ represent production of milk and egg in country $c$ and production system $s$ respectively (ton/yr), $M Y[a, c, s]$ milk yield per dairy cow in country $c$ and production system $s$ (ton/dairy cow), $D C[a, c, s]$ the number of dairy cows in country $c$ 
and production system $s, f_{\text {egg }}[a, c, s]$ the fraction of egg produced in country $c$ and production system $s$ and $P_{\text {egg }}[a, c]$ the total amount of egg produced in country $c$ (ton/yr).

\section{Estimating the feed composition}

Animal feeds are generally divided into 'concentrates' and 'roughages'. The volume of concentrate feed has been estimated per animal category and per production system as:

Concentrate $[a, c, s]=$ Feed $[a, c, s] \times f_{c}[a, c, s]$

where Concentrate $[a, c, s]$ is the volume of concentrate feed consumed by animal category $a$ in country $c$ and production system $s$ (ton/yr) and $f_{c}[a, c, s]$ the fraction of concentrate in the total feed for animal category $a$ in country $c$ and production system $s$. For the latter variable, data have been obtained from Hendy et al. (1995) and Bouwman et al. (2005).

The composition of concentrate feeds varies across animal species and regions of the world. To our knowledge, there are no datasets with global coverage on the composition of feed for the different animals per country. Therefore, we have made a number of assumptions concerning the concentrate feed composition of the different animal species. According to Hendy et al. (1995), the diets of pig and poultry include, on average, 50-60\% cereals, 10 $20 \%$ oil meals and 15-25\% 'other concentrates' (grain substitutes, milling by-products, non-conventional concentrates). Wheeler et al. (1981) provide the feed composition in terms of major crop categories for the different animal categories. We have used these and other sources in combination with FAOSTAT country average concentrate feed values for the period 1996-2003 (FAO, 2010a) to estimate the diet composition of the different animal species. In order to estimate the feed in terms of specific crops per animal, we first estimated the feed in terms of major crop categories following Wheeler et al. (1981). The feed in terms of major crop categories is further distributed to each crop proportional to the crop's share in its crops category as obtained from FAOSTAT (FAO, 2010a). The roughage feed is divided into fodder, grass and crop residues using the data obtained from Bouwman et al. (2005). 


\subsection{Data}

A large amount of data has been collected from different sources. A major data source for animal stocks, numbers of animals slaughtered each year, annual production of animal products, and concentrate feed per country is FAOSTAT (FAO, 2010a). Other important sources that have been used are: Seré and Steinfeld (1996), Hendy et al. (1995), Bouwman et al. (2005), Wint and Robinson (2007), Wheeler et al. (1981) and FAO (2003). Box 3.1 summarizes how specific data have been obtained from these different sources.

\section{Box 3.1. Overview of data sources.}

- Animal production systems: Seré and Steinfeld (1996) have developed a classification of animal production systems based on agro-ecology, the distinction between pastoral, mixed and landless systems and on the presence of irrigation or not. They distinguish eleven animal production systems grouped under three headings: grazing (extensive), mixed and industrial (intensive). In this study we use the schematization into these three production systems.

- Feed conversion efficiencies: For ruminants, the feed conversion efficiencies were estimated as explained in Supplementary method section. For non-ruminants (pig, broiler and egg laying chicken), feed conversion efficiencies per animal category, per production system and per economic region were obtained from Hendy et al. (1995). For both ruminants and non-ruminants, the feed conversion efficiency data were scaled such that at the level of world regions they match the efficiencies as reported in Bouwman et al. (2005).

- Annual production of animal products: Data on the annual production of animal products (beef, pig meat, sheep meat, goat meat, chicken meat, milk and egg) per production system for different economic regions were obtained from Seré and Steinfeld (1996). Production data per product and country for the period 1996-2005 were obtained from FAOSTAT (FAO, 2010a). The two data sources have been combined to derive production data per animal category, production system and per country for the period 1996-2005. We scaled the production data per production system such that at national level, the production aggregated over the different production systems equals the production as reported in FAO (2010a) for the period 1996-2005.

- Number of animals: Seré and Steinfeld (1996) provide the total animal population for the different production systems for the year 1995 for a number of geographic regions in the world. Wint and Robinson (2007) provide the total animal population for the year 2005 for the different production systems for developing countries. We have combined the two sources to obtain number of animals per animal category, per production system and per country. We scaled the numbers such that at national level, the number of animals aggregated over the different production systems equal the numbers as reported in FAO (2010a) for the period 1996-2005.

Continued next page...... 
Box 3.1 continued ...

- Number of slaughtered animals and animal off-take rates: The annual number of slaughtered animals for beef cattle, pig, sheep, goat and broiler chicken per country have been taken from FAO (2010a). The animal off-take rates at national level have been derived from the same source by dividing the annual number of slaughtered animals by the total population. The off-take rate for the grazing system was assumed to be $90 \%$ of the national average off-take rate for the animal category considered (Bouwman, et al., 2005). Per country, the off-take rate for the mixed and industrial production systems were scaled until the total number of slaughtered animals per animal category equalled the value provided by FAO (2010a).

- Animal live weight: Hendy et al. (1995) provide live weight of ruminant animals (beef cattle, dairy cattle, sheep and goat) by production system and economic region. FAO (2003) give animal live weight for cattle, pig, sheep, goat and chicken. We combined these two sources, taking advantage of the fact that Hendy et al. (1995) specify data per production system (but not per country) and FAO (2003) provides data per country (but not per system).

- Carcass weight as percentage of live weight: FAO (2003) provides carcass weight as percentage of live weight for the different animal categories per country.

- Ruminant animals daily feed intake rate: Daily feed intake rate for ruminant animals (beef cattle, dairy cattle, sheep and goat) was obtained from Hendy et al. (1995).

- Share of concentrate feed in total animal feed: The contribution of concentrate feeds such as cereals, oilmeals, roots and other crop products in the total feed composition was obtained from Hendy et al. (1995) and Bouwman et al. (2005).

- Composition of the concentrate feed: The composition of concentrate feed per animal category was estimated following mainly Wheeler et al. (1981). In addition, we used Steinfeld et al. (2006) for data on the relative composition of poultry and pig feed for major countries. The data available in Wheeler et al. (1981) and Steinfeld et al. (2006) are not sufficient to specify the feed composition at the level of specific crops or crop products. In order to come to that level of detail we use the Supply and Utilization Accounts of FAOSTAT (FAO, 2010a), which provide the total concentrate feed utilization per country per crop and crop product.

- Composition of the roughage feed: We used Bouwman et al. (2005) to estimate the composition of the roughage feed (grass, fodder crops, crop residues).

- Water use for drinking and animal servicing: Data were obtained from Chapagain and Hoekstra (2003).

- Water use for mixing feed: Following Chapagain and Hoekstra (2003), the water use for feed mixing is assumed to be $50 \%$ of total concentrate feed intake (or 0.5 litre per $\mathrm{kg}$ of concentrate feed intake). 


\subsection{Results}

\subsubsection{Quantity and composition of animal feed}

Table 3.1 provides global average feed conversion efficiencies for different animal categories and production systems. Ruminants (cattle, sheep, goat) are less efficient in converting feed into meat than non-ruminants (pig, chicken), amongst other due to the lower quality of feed they consume. Particularly meat production from cattle costs a lot of feed per unit of product obtained. Although ruminants need more feed, their feed largely consists of forage and other materials that humans cannot eat, while non-ruminants consume large amounts of concentrate feed that could be used for human consumption. Non-ruminants thus most obviously compete with humans for food, but in an indirect way ruminants also compete for food with humans. In some cases the roughages eaten by ruminants are produced with land and water resources that cannot alternatively be allocated to crop production for human consumption (e.g. in the case of grazing in dry or wetlands), but often the land and water resources used for roughages supply can alternatively be used for crop growth for human consumption, so that ruminants compete with humans for food also through consumption of roughages.

Table 3.1. Global average feed conversion efficiency per animal category and production system.

\begin{tabular}{lrrrr}
\hline \multirow{2}{*}{ Animal category } & \multicolumn{3}{c}{ Feed conversion efficiency $(\mathrm{kg}$ dry mass feed/kg output) } \\
\cline { 2 - 5 } & Grazing & Mixed & Industrial & Overall \\
\hline Beef cattle & 70.1 & 51.8 & 19.2 & 46.9 \\
Dairy cattle & 3.5 & 1.6 & 1.1 & 1.9 \\
Broiler chicken & 9.0 & 4.9 & 2.8 & 4.2 \\
Layer chicken & 9.3 & 4.4 & 2.3 & 3.1 \\
Pig & 11.3 & 6.5 & 3.9 & 5.8 \\
Sheep and goat & 49.6 & 25.8 & 13.3 & 30.2 \\
\hline
\end{tabular}

Non-ruminants are responsible for $60 \%$ of the global consumption of concentrate feeds; ruminants account for $40 \%$. Figure 3.1 shows the consumption of different concentrates by different animal categories. Chickens take the largest share in total concentrate feed 
consumption $(30 \%)$. Three fifth of the concentrate feed consumption by chicken in the world is for broiler chicken and two fifth for layer chicken. Pig meat production takes nearly the same share (29\%) in global concentrate feed consumption, while dairy cattle are responsible for $25 \%$ and beef cattle $14 \%$. Our estimated shares of different animal categories in the total concentrate feed consumption is very close to the estimates made by Hendy et al. (1995).

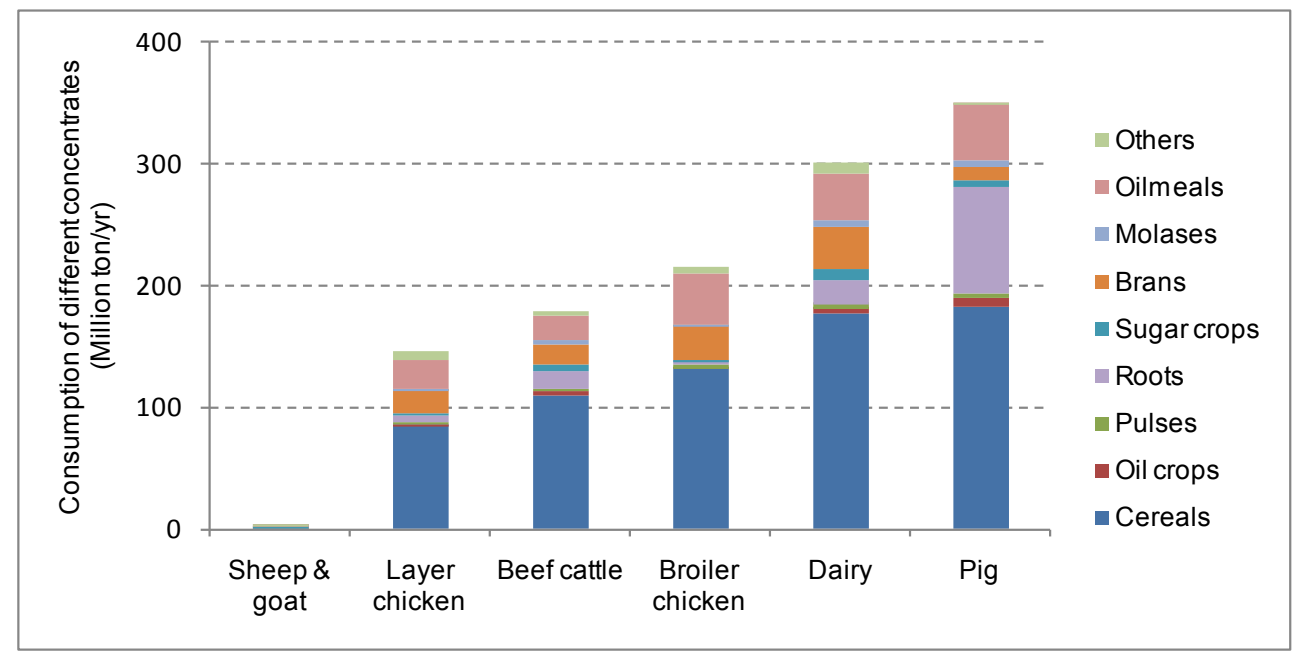

Figure 3.1. Global consumption of different concentrates per animal category.

Annual concentrate feed consumption averaged over the period 1996-2005 expressed in commodity fresh weight amounted to 1195 million tons per year. This value is very close to the feed data provided by FAO (2010a) for the period 1996-2003 (1229 million ton/yr). The feed data analysed and presented here focus on commodities derived from crop production. Figure 3.2 presents a summary of the global total feed utilization of cereals, oil meals and cakes, roots and tubers, bran and others. Cereals make up the largest percentage of the total concentrate feed use (57\%), followed by oil meals (15\%), roots $(11 \%)$ and brans $(10 \%)$.

The total feed consumption over the period 1996-2005 was 4996 million ton feed in dry matter per year, on average. Roughages account for the largest share out of this total, accounting for $80 \%$, and feeds derived from crop production account for the remaining $20 \%$. Considering only plant-based feed materials, our global estimate of total feed in dry matter (4996 Mton dry mass/yr) is about 6\% lower than the estimate of Wirsenius (2000) 
(5300 Mton dry mass/yr) and 8\% more than the estimate of Bouwman et al. (2005) for 1995 (4637 Mton dry mass/yr). Our estimate of global utilization of roughages (4010 Mton dry mass/yr), which includes pasture, forages, straws, sugar crops tops and leaves, oil crops stalks and husks is 15\% lower than the estimate of Wirsenius (2000) (4740 Mton dry mass $/ y r$ ) and 5\% larger than the estimate of Bouwman et al. (2005) for 1995 (3832 Mton dry mass/yr).

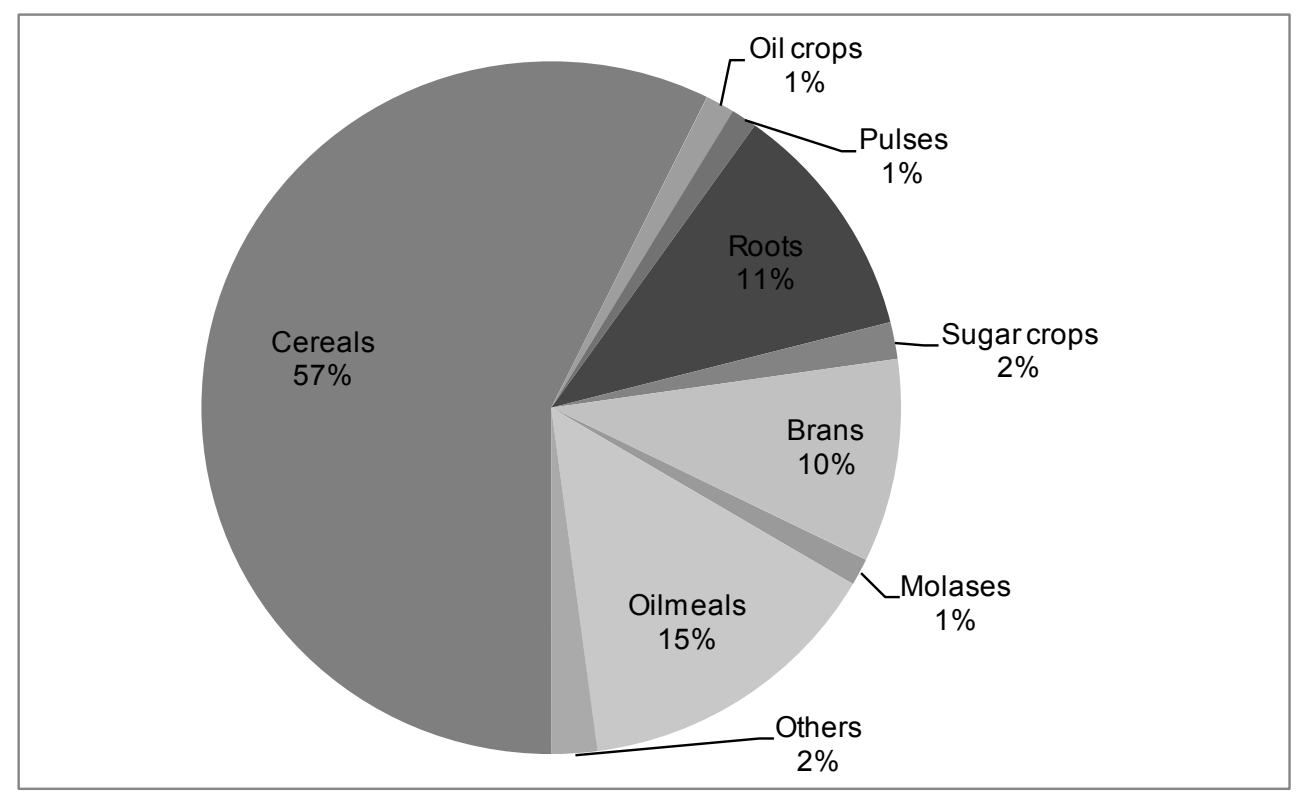

Figure 3.2. Contribution of different crops (on fresh weight basis) toward global total concentrate feed utilization. Period 1996-2005.

\subsubsection{The water footprint of live animals at the end of their lifetime and animal products perton}

Table 3.2 shows, for each animal category, the average water footprint of an animal at the end of its life time and the annual water footprint of an animal. Dairy cows have the largest annual water footprint $\left(2056 \mathrm{~m}^{3} / \mathrm{yr} / \mathrm{animal}\right)$, which is more than the average human being. Broiler chicken have the smallest footprint $\left(26 \mathrm{~m}^{3} / \mathrm{yr} / \mathrm{animal}\right)$. 
Table 3.2. Average annual water footprint of one animal, per animal category (1996-2005).

\begin{tabular}{lrrrrr}
\hline $\begin{array}{l}\text { Animal } \\
\text { category }\end{array}$ & $\begin{array}{r}\text { Water } \\
\text { footprint of } \\
\text { live animal at } \\
\begin{array}{r}\text { end of life } \\
\text { time }\left(\mathrm{m}^{3} / \mathrm{ton}\right)\end{array}\end{array}$ & $\begin{array}{r}\text { Average } \\
\text { animal weight } \\
\text { at end of life } \\
\text { time }(\mathrm{kg})\end{array}$ & $\begin{array}{r}\text { Average water } \\
\text { footprint at end } \\
\text { of life time } \\
\left(\mathrm{m}^{3} / \text { animal }\right)\end{array}$ & $\begin{array}{r}\text { Average } \\
\text { life time } \\
(\mathrm{yr})\end{array}$ & $\begin{array}{r}\begin{array}{r}\text { Average } \\
\text { annual water } \\
\text { footprint of one } \\
\text { animal }\end{array} \\
\left(\mathrm{m}^{3} / \mathrm{yr} / \text { animal }\right)\end{array}$ \\
\hline Dairy cattle & & & 20558 & 10 & 2056 \\
Horse & 40612 & 473 & 19189 & 12 & 1599 \\
Beef cattle & 7477 & 253 & 1889 & 3.0 & 630 \\
Pig & 3831 & 102 & 390 & 0.75 & 520 \\
Sheep & 4519 & 31.3 & 141 & 2.1 & 68 \\
Layer chicken & & & 47 & 1.4 & 33 \\
Goat & 3079 & 24.6 & 76 & 2.3 & 32 \\
Broiler chicken & 3364 & 1.90 & 6 & 0.25 & 26 \\
\hline
\end{tabular}

Table 3.3 presents the green, blue and grey water footprints of some selected animal products per production system for selected countries. The water footprints of animals and animal products vary greatly across countries and production systems. In general terms, one can say that the type of production system is highly relevant for the size, composition and geographic spread of the water footprint of an animal product, because it determines feed conversion efficiency, feed composition and origin of feed. Similarly we observe that the country of production influences the water footprint of animal products related to existing country differences in feed conversion efficiencies, but also to the fact that water footprints of feed crops vary across countries as a function of differences in climate and agricultural practice. When we look at global averages, however, we see that the water footprint of meat increases from chicken meat $\left(4300 \mathrm{~m}^{3} /\right.$ ton $)$, goat meat $\left(5500 \mathrm{~m}^{3} /\right.$ ton $)$, pig meat $(6000$ $\mathrm{m}^{3} /$ ton $)$, sheep meat $\left(10400 \mathrm{~m}^{3} /\right.$ ton $)$ to beef $\left(15400 \mathrm{~m}^{3} /\right.$ ton $)$. The differences can be partly explained from the different feed conversion efficiencies of the animals. Beef production, for example, requires eight times more feed (in dry matter) per kilogram of meat compared to producing pig meat, and eleven times if compared to the case of chicken meat. This is not the only factor, however, that can explain the differences. Another important factor is the feed composition. Particularly the fraction of concentrate feed in the total feed is important, because concentrate feed generally has a larger water footprint than roughages. Chicken, which are efficient from a total feed point of view, are no longer that efficient 


\section{0 / Chapter 3. The green, blue and grey water footprint of animal products}

when we look at the fraction of concentrates in their feed. This fraction is $73 \%$ for broiler chicken (global average), while it is only $5 \%$ for beef cattle.

\section{Total water footprint per ton of product}

For all farm animal products, except dairy products, the total water footprint per unit of product declines from the grazing to the mixed production system and then again from the mixed to the industrial production system. The reason is that, when moving from grazing to industrial production systems, feed conversion efficiencies gets better. Per unit of product, about three to four times more feed is required for grazing systems when compared to industrial systems (see Table 3.1). More feed implies that more water is needed to produce the feed. However, the fact that feed conversion efficiencies in grazing and industrial production systems differ by a factor 3 to 4 does not mean that the water footprints of animal products are 3 to 4 times larger when derived from a grazing instead of an industrial system. This is because the feed composition of animals raised in grazing systems is generally more favourable from a water resources point of view. For all animal categories, the fraction of concentrate feed in the total feed is larger for industrial systems if compared to mixed production systems and larger for mixed systems if compared to grazing systems. The water footprint per $\mathrm{kg}$ of concentrate feed is generally larger than for roughages, so that this works to the disadvantage of the total water footprint of animals raised in industrial systems and to the advantage of the total water footprint of animals raised in grazing systems. This effect, however, does not fully compensate for the unfavourable feed conversion efficiencies in grazing systems. An exception is in dairy farming, where the total water footprint per unit of product is comparable in all three production systems. For dairy products, the water footprint happens to be smallest when they are derived from a mixed system and a bit larger but comparable when obtained from a grazing or industrial system.

\section{Blue and grey water footprints per ton of product}

All the above is about comparing the total water footprints of animal products. The picture changes when we focus on the blue and grey water footprint components. With the exception of chicken products, blue and grey water footprints always increase from grazing to industrial production systems. Figure 3.3 illustrates this by showing the blue water 
footprint of a number of animal products across the three productions systems. For the grey water footprint similar pictures can be obtained. The larger blue and grey water footprints for products obtained from industrial production systems are caused by the fact that concentrate feed takes a larger share in the total feed in industrial systems when compared to grazing systems. For beef cattle in grazing systems, the global average share of concentrate feed in total feed is $2 \%$, while in industrial systems it is $21 \%$. Mixed systems are generally somewhere in between. Although the feed crops that are contained in the concentrate feed are often to a great extent based on green water, there is a blue water footprint component as well, and the larger the consumption of feed crops compared to roughages, the larger the total amount of blue water consumed. This explains the larger blue water footprint per ton of product in industrial production systems for beef, milk, cheese, and pig, sheep and goat meat. The application and leaching of fertilizers and other agro-chemicals in feed crop production results in the fact that the grey water footprint of animal products from industrial systems, where the dependence on feed crops is greatest, is larger than for grazing systems. Given the fact that freshwater problems generally relate to blue water scarcity and water pollution and to a lesser extent to competition over green water, this means that - from a water resources point of view - grazing systems are preferable over industrial production systems for cattle, pig, sheep and goat.

In the case of chicken products (chicken meat and egg), the industrial production system has, on average, a smaller blue and grey water footprint per ton of product compared to the other two production systems. The reason is that chicken strongly rely on concentrate feed in all production systems, intensive or extensive. Broiler chickens in extensive systems have a share of concentrate feed in total feed of $63 \%$, while this is $81 \%$ in intensive industrial systems. There is still a difference, but the differences in feed composition for both broiler and layer chicken is less outspoken if compared to the other animal categories. As a result, the relatively unfavourable feed conversion efficiency in extensive systems is not compensated by a more favourable composition of the feed as is the case in the other animal categories. 
62 / Chapter 3. The green, blue and grey water footprint of animal products

Table 3.3. The green, blue and grey water footprint of selected animal products for selected countries $\left(m^{3} /\right.$ ton).

\begin{tabular}{|c|c|c|c|c|c|c|c|c|c|c|c|c|c|c|c|c|c|c|c|c|c|c|}
\hline \multirow{2}{*}{$\begin{array}{l}\text { Animal } \\
\text { products }\end{array}$} & \multirow{2}{*}{ Farming system } & \multicolumn{3}{|c|}{ Australia } & \multicolumn{3}{|c|}{ Brazil } & \multicolumn{3}{|c|}{ China } & \multicolumn{3}{|c|}{ India } & \multicolumn{3}{|c|}{ Netherlands } & \multicolumn{3}{|c|}{ USA } & \multicolumn{3}{|c|}{ Global average } \\
\hline & & Green & Blue & Grey & Green & Blue & Grey & Green & Blue & Grey & Green & Blue & Grey & Green & Blue & Grey & Green & Blue & Grey & Green & Blue & Grey \\
\hline \multirow[t]{4}{*}{ Beef } & Grazing & 18056 & 745 & 55 & 23729 & 150 & 16 & 16140 & 213 & 0 & 25913 & 242 & 0 & & & & 19102 & 525 & 590 & 21121 & 465 & 243 \\
\hline & Mixed & 14455 & 623 & 61 & 20604 & 187 & 61 & 13227 & 339 & 103 & 16192 & 533 & 144 & 10319 & 761 & 664 & 12726 & 546 & 768 & 14803 & 508 & 401 \\
\hline & \begin{tabular}{|l|} 
Industrial \\
\end{tabular} & 4730 & 304 & 96 & 8421 & 147 & 244 & 10922 & 933 & 1234 & 12412 & 1471 & 866 & 3934 & 349 & 225 & 2949 & 356 & 551 & 8849 & 683 & 712 \\
\hline & Weighted average & 14507 & 613 & 62 & 19228 & 178 & 82 & 12795 & 495 & 398 & 15537 & 722 & 288 & 5684 & 484 & 345 & 12933 & 525 & 733 & 14414 & 550 & 451 \\
\hline \multirow{4}{*}{$\begin{array}{l}\text { Sheep } \\
\text { meat }\end{array}$} & Grazing & 13236 & 438 & 9 & 19440 & 372 & 1 & 9606 & 388 & 0 & 11441 & 489 & 0 & & & & 11910 & 312 & 18 & 15870 & 421 & 20 \\
\hline & Mixed & 6554 & 427 & 22 & 10649 & 421 & 9 & 5337 & 454 & 14 & 7528 & 582 & 316 & 8248 & 422 & 35 & 9842 & 318 & 74 & 7784 & 484 & 67 \\
\hline & \begin{tabular}{|l|} 
Industrial \\
\end{tabular} & & & & 4747 & 445 & 12 & 2366 & 451 & 22 & 4523 & 593 & 484 & & & & 0 & 0 & 0 & 4607 & 800 & 216 \\
\hline & Weighted average & 10151 & 434 & 15 & 11772 & 421 & 7 & 5347 & 452 & 14 & 7416 & 582 & 314 & 8248 & 422 & 35 & 10948 & 315 & 44 & 9813 & 522 & 76 \\
\hline \multirow[t]{4}{*}{ Goat meat } & Grazing & 4809 & 245 & 0 & 15860 & 328 & 0 & 5073 & 272 & 0 & 8081 & 374 & 0 & & & & & & & 9277 & 285 & 0 \\
\hline & Mixed & 2435 & 233 & 0 & 8745 & 349 & 0 & 2765 & 283 & 0 & 4544 & 381 & 9 & 2443 & 453 & 4 & & & & 4691 & 313 & 4 \\
\hline & Industrial & & & & 3754 & 406 & 0 & 1187 & 437 & 0 & 2046 & 436 & 30 & & & & & & & 2431 & 413 & 18 \\
\hline & Weighted average & 3733 & 240 & 0 & 8144 & 372 & 0 & 2958 & 312 & 0 & 4194 & 393 & 13 & 2443 & 454 & 4 & & & & 5185 & 330 & 6 \\
\hline \multirow[t]{4}{*}{ Pig meat } & Grazing & 4299 & 3721 & 247 & 5482 & 1689 & 318 & 11134 & 205 & 738 & 3732 & 391 & 325 & 4048 & 479 & 587 & 5118 & 870 & 890 & 7660 & 431 & 632 \\
\hline & Mixed & 2056 & 1909 & 118 & 5109 & 828 & 316 & 5401 & 356 & 542 & 4068 & 893 & 390 & 3653 & 306 & 451 & 4953 & 743 & 916 & 5210 & 435 & 582 \\
\hline & \begin{tabular}{|l|} 
Industrial \\
\end{tabular} & 7908 & 651 & 656 & 8184 & 215 & 525 & 3477 & 538 & 925 & 9236 & 2014 & 1021 & 3776 & 236 & 427 & 3404 & 563 & 634 & 4050 & 487 & 687 \\
\hline & Weighted average & 5284 & 1226 & 414 & 6080 & 749 & 379 & 5050 & 405 & 648 & 5415 & 1191 & 554 & 3723 & 268 & 438 & 4102 & 645 & 761 & 4907 & 459 & 622 \\
\hline \multirow{4}{*}{$\begin{array}{l}\text { Chicken } \\
\text { meat }\end{array}$} & \multirow{4}{*}{$\begin{array}{l}\text { Grazing } \\
\text { Mixed } \\
\text { Industrial } \\
\text { Weighted average } \\
\end{array}$} & 4862 & 276 & 336 & 6363 & 35 & 364 & 4695 & 448 & 1414 & 11993 & 1536 & 1369 & 2535 & 113 & 271 & 2836 & 294 & 497 & 7919 & 734 & 718 \\
\hline & & 2893 & 173 & 200 & 4073 & 32 & 233 & 3005 & 297 & 905 & 7676 & 995 & 876 & 1509 & 76 & 161 & 1688 & 183 & 296 & 4065 & 348 & 574 \\
\hline & & 2968 & 176 & 205 & 3723 & 24 & 213 & 1940 & 195 & 584 & 3787 & 496 & 432 & 1548 & 77 & 165 & 1731 & 187 & 303 & 2337 & 210 & 325 \\
\hline & & 2962 & 176 & 205 & 4204 & 30 & 240 & 2836 & 281 & 854 & 6726 & 873 & 768 & 1545 & 77 & 165 & 1728 & 187 & 303 & 3545 & 313 & 467 \\
\hline \multirow[t]{4}{*}{ Egg } & Grazing & 2243 & 146 & 173 & 432 & 24 & 25 & 3952 & 375 & 1189 & 10604 & 1360 & 1176 & 1695 & 76 & 161 & 1740 & 183 & 331 & 6781 & 418 & 446 \\
\hline & Mixed & 1435 & 99 & 111 & 257 & 24 & 15 & 2351 & 230 & 708 & 6309 & 815 & 699 & 1085 & 51 & 103 & 1113 & 121 & 212 & 3006 & 312 & 545 \\
\hline & \begin{tabular}{|l|} 
Industrial \\
\end{tabular} & 1570 & 107 & 121 & 3625 & 28 & 213 & 2086 & 206 & 628 & 3611 & 472 & 400 & 1187 & 55 & 113 & 1218 & 132 & 232 & 2298 & 205 & 369 \\
\hline & Weighted average & 1555 & 106 & 120 & 2737 & 27 & 161 & 2211 & 217 & 666 & 4888 & 635 & 542 & 1175 & 55 & 111 & 1206 & 130 & 230 & 2592 & 244 & 429 \\
\hline \multirow[t]{4}{*}{ Milk } & Grazing & 780 & 74 & 20 & 1046 & 22 & 7 & 1580 & 106 & 128 & 1185 & 105 & 34 & 572 & 50 & 32 & 1106 & 69 & 89 & 1087 & 56 & 49 \\
\hline & Mixed & 700 & 64 & 35 & 1254 & 42 & 36 & 897 & 147 & 213 & 863 & 132 & 65 & 431 & 40 & 23 & 582 & 59 & 88 & 790 & 90 & 76 \\
\hline & \begin{tabular}{|l|} 
Industrial \\
\end{tabular} & 517 & 48 & 43 & & & & & & & & & & 500 & 43 & 25 & 444 & 61 & 100 & 1027 & 98 & 82 \\
\hline & Weighted average & 704 & 63 & 33 & 1149 & 33 & 22 & 927 & 145 & 210 & 885 & 130 & 63 & 462 & 41 & 25 & 647 & 60 & 89 & 863 & 86 & 72 \\
\hline \multirow[t]{4}{*}{ Butter } & Grazing & 4246 & 400 & 107 & 5691 & 122 & 39 & 8600 & 577 & 696 & 6448 & 572 & 188 & 3111 & 272 & 176 & 6022 & 373 & 482 & 5913 & 305 & 265 \\
\hline & Mixed & 3808 & 347 & 192 & 6822 & 230 & 196 & 4880 & 799 & 1161 & 4697 & 716 & 352 & 2345 & 218 & 123 & 3169 & 321 & 478 & 4297 & 492 & 415 \\
\hline & Industrial & 2814 & 261 & 231 & & & & & & & & & & 2720 & 233 & 136 & 2417 & 330 & 543 & 5591 & 532 & 448 \\
\hline & Weighted average & 3829 & 344 & 178 & 6254 & 179 & 117 & 5044 & 789 & 1141 & 4819 & 706 & 341 & 2513 & 224 & 134 & 3519 & 324 & 483 & 4695 & 465 & 393 \\
\hline
\end{tabular}




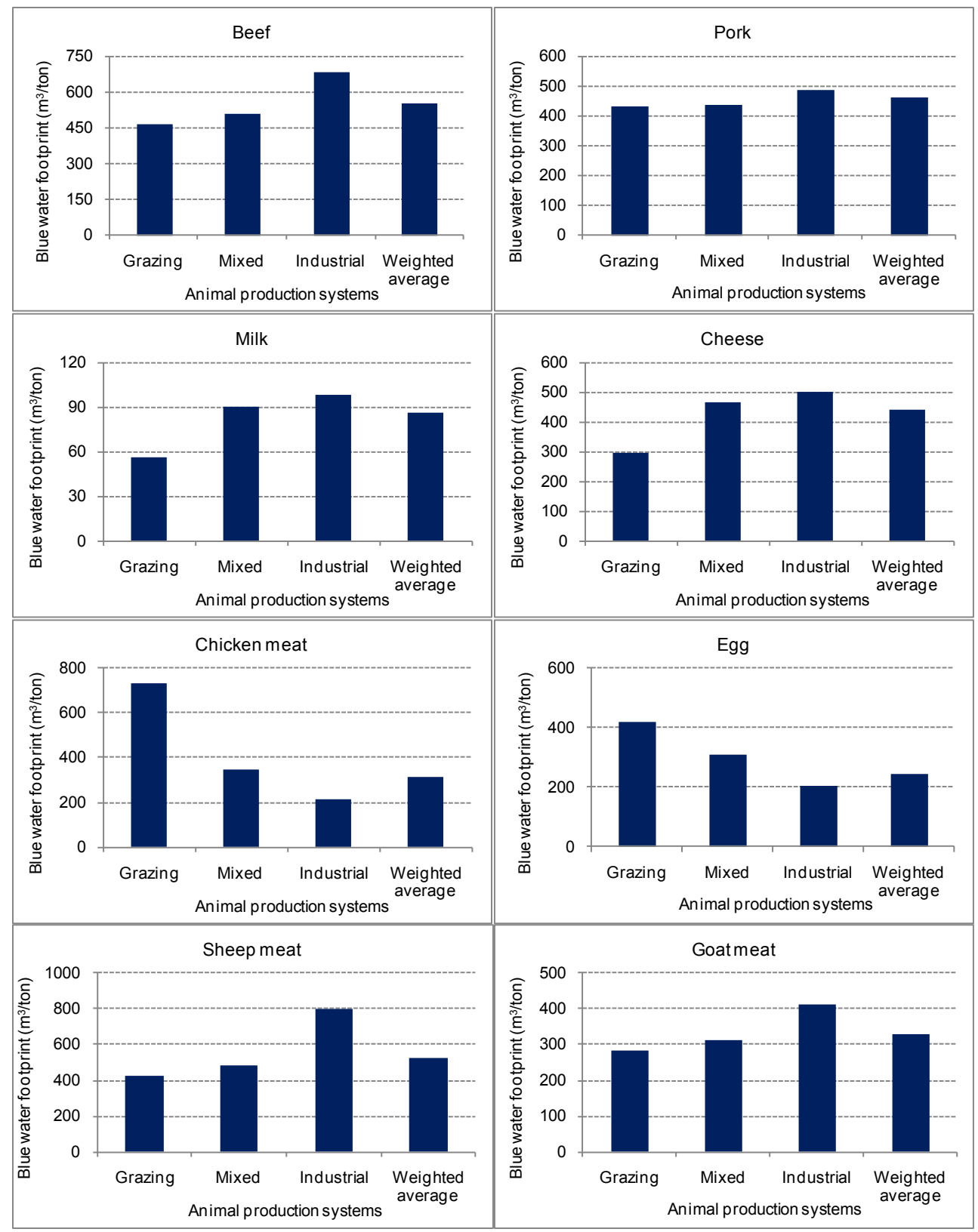

Figure 3.3. Global average blue water footprint per production system for selected animal products (1996-2005). 


\section{Country differences}

In general terms, one can say that the type of production system is highly relevant for the size, composition and geographic spread of the water footprint of an animal product, because the type of production system determines feed conversion efficiency, feed composition and origin of feed. Similarly we observe that the country of production influences the water footprint of animal products in general terms as well. The Netherlands, for example, shows lower total water footprints for most animal products if compared to the USA. The USA, in turn, generally shows lower total water footprints for animal products than India. These crude general differences between countries are related to existing country differences in feed conversion efficiencies, but also to the fact that water footprints of feed crops vary across countries as a function of differences in climate and agricultural practice.

\section{Water footprint components - example for beef}

For all animal products, the water footprint related to the animal feed takes by far the largest share in the total water footprint. Further one can say that the green water footprint is always much larger than the blue and grey water footprints. As an example, Table 3.4 shows in detail the components of the water footprint of producing a kilogram of beef. The water footprint is dominantly green water (94\%) and the largest share comes from the feed the cattle consume (99\%). Drinking and service water contribute only $1 \%$ toward the total water footprint, but $30 \%$ to the blue water footprint. The major fraction $(83 \%)$ of the water footprint of a beef cow is attributed to the derived beef, but smaller fractions go to the other products: offal, leather and semen.

\subsubsection{Water footprint of animal versus crop products per unit of nutritional value}

As a general picture we find that animal products have a larger water footprint per ton of product than crop products. As we see from Table 3.5, the global average water footprint per ton of crop increases from sugar crops (roughly $200 \mathrm{~m}^{3} /$ ton) and vegetables $(\sim 300$ $\mathrm{m}^{3} /$ ton $)$ to pulses $\left(\sim 4000 \mathrm{~m}^{3} /\right.$ ton $)$ and nuts $\left(\sim 9000 \mathrm{~m}^{3} /\right.$ ton $)$. For animal products, the water footprint increases from milk $\left(\sim 1000 \mathrm{~m}^{3} /\right.$ ton $)$ and egg $\left(\sim 3300 \mathrm{~m}^{3} /\right.$ ton $)$ to beef $(\sim 15400$ $\mathrm{m}^{3} /$ ton). Also when viewed from a caloric standpoint, the water footprint of animal 
products is larger than for crop products. The average water footprint per calorie for beef is twenty times larger than for cereals and starchy roots. When we look at the water requirements for protein, we find that the water footprint per gram of protein for milk, eggs and chicken meat is about 1.5 times larger than for pulses. For beef, the water footprint per gram of protein is 6 times larger than for pulses. In the case of fat, we find that butter has a relatively small water footprint per gram of fat, even lower than for oil crops. All other animal products, however, have larger water footprints per gram of fat when compared to oil crops. The general conclusion is that from a freshwater resource perspective, it is more efficient to obtain calories, protein and fat through crop products than animal products. A note should be made here, however, that types of proteins and fats differ across the different products.

In order to reduce the pressure on the world's water resource associated with their consumption pattern, individuals have the option of shifting from a meat-rich to a vegetarian diet. The water footprint of an individual consumer depends to a large extent on the type of diet of the individual. Meat-based diets have a larger water footprint compared to a vegetarian diet. The average USA citizen consumes almost four times the amount of protein compared to the global average (FAO, 2010a). About 63\% of the daily protein intake comes from animal based products. This high level of consumption of animal-based products is directly reflected in the relative large water footprint of the average American citizen (Hoekstra and Chapagain, 2007). Replacing 50\% of all animal products by an equivalent amount of high nutritious crop products such as pulses, groundnuts and potatoes will result a $30 \%$ reduction of the food-related water footprint. A vegetarian diet compared with the average current per capita food intake in the USA can reduce the water footprint of an individual by as much as $58 \%$. 
Table 3.4. The components of the water footprint of a beef cow and its derived products.

\begin{tabular}{|c|c|c|c|c|c|c|c|c|}
\hline \multirow[t]{2}{*}{ Feed crop* } & \multirow{2}{*}{$\begin{array}{l}\text { Feed } \\
\text { amount } \\
(\mathrm{kg} / \mathrm{kg} \\
\text { carcass) }\end{array}$} & \multicolumn{3}{|c|}{$\begin{array}{l}\text { Weighted average } \\
\text { water footprint of } \\
\text { feed (litre/kg) }\end{array}$} & \multicolumn{4}{|c|}{$\begin{array}{l}\text { Water footprint (litre/kg } \\
\text { carcass) }\end{array}$} \\
\hline & & Green & Blue & Grey & Green & Blue & Grey & Total \\
\hline Maize & 1.0102 & 695 & 111 & 181 & 702 & 112 & 182 & 996 \\
\hline Wheat & 0.2441 & 1322 & 77 & 140 & 323 & 18.8 & 34.0 & 375 \\
\hline Barley & 0.2657 & 1143 & 59 & 126 & 304 & 15.6 & 33.4 & 353 \\
\hline Soya bean cake & 0.1858 & 1451 & 72 & 19 & 270 & 13.4 & 3.6 & 286 \\
\hline Sorghum & 0.1028 & 1228 & 130 & 92 & 126 & 13.4 & 9.5 & 149 \\
\hline Oats & 0.0603 & 1457 & 212 & 125 & 87.8 & 12.8 & 7.6 & 108 \\
\hline Rice, paddy & 0.0754 & 997 & 259 & 165 & 75.1 & 19.6 & 12.4 & 107 \\
\hline Cassava & 0.1451 & 498 & 0 & 12 & 72.3 & 0.0 & 1.8 & 74.1 \\
\hline Oilseed cakes, other & 0.0275 & 2158 & 37 & 50 & 59.4 & 1.0 & 1.4 & 61.7 \\
\hline Rape and mustard cake & 0.0479 & 977 & 132 & 151 & 46.8 & 6.3 & 7.2 & 60.4 \\
\hline Rye & 0.0233 & 1573 & 38 & 109 & 36.7 & 0.9 & 2.5 & 40.1 \\
\hline Millet & 0.0107 & 2718 & 130 & 172 & 29.0 & 1.4 & 1.8 & 32.2 \\
\hline Cereals, not specified & 0.0308 & 874 & 66 & 41 & 26.9 & 2.0 & 1.3 & 30.2 \\
\hline Sunflower seed cake & 0.0249 & 968 & 63 & 98 & 24.1 & 1.6 & 2.4 & 28.1 \\
\hline Pulses, not specified & 0.0132 & 1133 & 307 & 618 & 15.0 & 4.1 & 8.2 & 27.2 \\
\hline Molasses & 0.0597 & 311 & 110 & 29 & 18.6 & 6.6 & 1.7 & 26.9 \\
\hline Groundnut cake & 0.0171 & 1265 & 121 & 106 & 21.7 & 2.1 & 1.8 & 25.6 \\
\hline Soybeans & 0.0140 & 1744 & 41 & 24 & 24.5 & 0.6 & 0.3 & 25.4 \\
\hline Potatoes & 0.0796 & 254 & 10 & 48 & 20.2 & 0.8 & 3.8 & 24.9 \\
\hline Cottonseed cake & 0.0280 & 481 & 259 & 86 & 13.5 & 7.3 & 2.4 & 23.1 \\
\hline Cottonseed & 0.0181 & 618 & 353 & 124 & 11.2 & 6.4 & 2.2 & 19.8 \\
\hline Peas, dry & 0.0126 & 1149 & 21 & 336 & 14.4 & 0.3 & 4.2 & 18.9 \\
\hline Sunflower seed & 0.0054 & 2744 & 144 & 234 & 14.8 & 0.8 & 1.3 & 16.9 \\
\hline Sugar cane & 0.0698 & 171 & 35 & 16 & 11.9 & 2.5 & 1.1 & 15.5 \\
\hline Plantains & 0.0091 & 1392 & 27 & 3 & 12.7 & 0.2 & 0.0 & 13.0 \\
\hline Beans, dry & 0.0029 & 3270 & 48 & 575 & 9.4 & 0.1 & 1.6 & 11.1 \\
\hline Rapeseed & 0.0049 & 1877 & 3 & 305 & 9.3 & 0.0 & 1.5 & 10.8 \\
\hline $\begin{array}{l}\text { Vegetables fresh not } \\
\text { specified }\end{array}$ & 0.0369 & 152 & 49 & 69 & 5.6 & 1.8 & 2.5 & 10.0 \\
\hline Copra cake & 0.0046 & 1567 & 2 & 10 & 7.2 & 0.0 & 0.0 & 7.2 \\
\hline Sweet potatoes & 0.0170 & 285 & 7 & 57 & 4.8 & 0.1 & 1.0 & 5.9 \\
\hline Yams & 0.0166 & 326 & 0 & 1 & 5.4 & 0.0 & 0.0 & 5.5 \\
\hline Palm kernel cake & 0.0075 & 659 & 0 & 27 & 4.9 & 0.0 & 0.2 & 5.2 \\
\hline \multirow[t]{2}{*}{ Dates } & 0.0009 & 2397 & 2074 & 97 & 2.1 & 1.8 & 0.1 & 4.0 \\
\hline & & & & & \multicolumn{4}{|c|}{ continued on next page } \\
\hline
\end{tabular}




\begin{tabular}{|c|c|c|c|c|c|c|c|c|}
\hline \multirow[t]{2}{*}{ Feed crop* } & \multirow{2}{*}{$\begin{array}{c}\text { Feed } \\
\text { amount } \\
(\mathrm{kg} / \mathrm{kg} \\
\text { carcass) }\end{array}$} & \multicolumn{3}{|c|}{$\begin{array}{l}\text { Weighted average } \\
\text { water footprint of } \\
\text { feed (litre/kg) }\end{array}$} & \multicolumn{4}{|c|}{$\begin{array}{l}\text { Water footprint (litre/kg } \\
\text { carcass) }\end{array}$} \\
\hline & & Green & Blue & Grey & Green & Blue & Grey & Total \\
\hline Sesame seed cake & 0.0015 & 2111 & 53 & 53 & 3.1 & 0.1 & 0.1 & 3.3 \\
\hline Sugar beet & 0.0165 & 154 & 16 & 30 & 2.5 & 0.3 & 0.5 & 3.3 \\
\hline Oilseeds, not specified & 0.0024 & 802 & 94 & 35 & 2.0 & 0.2 & 0.1 & 2.3 \\
\hline Other minor feed crops & 0.0122 & 325 & 66 & 40 & 3.9 & 0.8 & 0.5 & 5.2 \\
\hline Crop residues & 21.943 & 0 & 0 & 0 & 0.0 & 0.0 & 0.0 & 0.0 \\
\hline Fodder crops & 2.4632 & 168 & 29 & 21 & 415 & 71.8 & 50.7 & 537 \\
\hline Pasture (grass) & 31.525 & 303 & 0 & 0 & 9556 & 0.0 & 0.0 & 9556 \\
\hline Water for feed mixing & & & & & & 1.5 & & 1.5 \\
\hline \multicolumn{2}{|c|}{ Water footprint related to feed } & & & & 12391 & 314 & 388 & 13107 \\
\hline \multicolumn{2}{|l|}{ Drinking water } & & & & & 110 & & 110 \\
\hline \multicolumn{2}{|l|}{ Service water } & & & & & 29 & & 29 \\
\hline \multicolumn{5}{|c|}{ Total water footprint of beef cattle (litre/kg carcass) } & 12391 & 453 & 388 & 13246 \\
\hline
\end{tabular}

Total water footprint of a $253 \mathrm{~kg}$ beef cow (in litre)

(assuming a total carcass weight of $143 \mathrm{~kg}$ )

$1769000 \quad 64600 \quad 55300 \quad 889000$

... of which $83 \%$ is attributed to the $101 \mathrm{~kg}$ of resultant

beef, so that

the WF of beef ${ }^{\star *}$ (litre/kg beef) amounts to:

$\begin{array}{llll}14400 & 550 \quad 450 \quad 15400\end{array}$

$\ldots$ of which $10 \%$ is attributed to the $18 \mathrm{~kg}$ of resultant offal, so that

the WF of offal ${ }^{* *}$ (litre $/ \mathrm{kg}$ offal) amounts to:

$\begin{array}{llll}10400 \quad 400 \quad 330 & 11200\end{array}$

... of which $5 \%$ is attributed to the $6.1 \mathrm{~kg}$ of resultant leather, so that

the WF of leather** (litre/kg leather) amounts to: $\begin{array}{llll}15900 & 680 & 500 & 17100\end{array}$

... of which $2 \%$ is attributed to the $0.03 \mathrm{~kg}$ of resultant semen, so that

the WF of semen ${ }^{* *}$ (litre/kg semen) amounts to: $1069000 \quad 40600 \quad 33400143000$

* The feed amounts included here represent the global average feed intake of beef cattle. Obviously, the feed composition of individual cows will deviate based on the production system and composition of the concentrate feed applied.

** The percentage of the total water footprint of a beef cow attributed to each product refers to the 'value fraction' for that product. The amount of a certain product (in $\mathrm{kg}$ ) coming from the total animal is based on the 'product fraction' for that product. In the blue water footprint, we added the water footprint of processing the slaughtered cow into the derived products. 
68 / Chapter 3. The green, blue and grey water footprint of animal products

Table 3.5. The water footprint of some selected food products from vegetable and animal origin.

\begin{tabular}{|c|c|c|c|c|c|c|c|c|c|c|}
\hline \multirow[b]{2}{*}{ Food item } & \multicolumn{4}{|c|}{$\begin{array}{l}\text { Water footprint per ton } \\
\qquad\left(\mathrm{m}^{3} / \text { ton }\right)\end{array}$} & \multicolumn{3}{|c|}{ Nutritional content } & \multicolumn{3}{|c|}{$\begin{array}{l}\text { Water footprint per unit } \\
\text { of nutritional value }\end{array}$} \\
\hline & Green & Blue & Grey & Total & $\begin{array}{c}\text { Calorie } \\
(\mathrm{kcal} / \mathrm{kg})\end{array}$ & $\begin{array}{r}\text { Protein } \\
(\mathrm{g} / \mathrm{kg})\end{array}$ & $\begin{array}{r}\text { Fat } \\
(\mathrm{g} / \mathrm{kg})\end{array}$ & $\begin{array}{r}\text { Calorie } \\
\text { (litre/kcal) }\end{array}$ & $\begin{array}{r}\text { Protein } \\
\text { (litre/g } \\
\text { protein) }\end{array}$ & $\begin{array}{r}\text { Fat } \\
\text { (litre/ } \\
\text { g fat) }\end{array}$ \\
\hline Sugar crops & 130 & 52 & 15 & 197 & 285 & 0.0 & 0.0 & 0.69 & 0.0 & 0.0 \\
\hline Vegetables & 194 & 43 & 85 & 322 & 240 & 12 & 2.1 & 1.34 & 26 & 154 \\
\hline Starchy roots & 327 & 16 & 43 & 387 & 827 & 13 & 1.7 & 0.47 & 31 & 226 \\
\hline Fruits & 726 & 147 & 89 & 962 & 460 & 5.3 & 2.8 & 2.09 & 180 & 348 \\
\hline Cereals & 1232 & 228 & 184 & 1644 & 3208 & 80 & 15 & 0.51 & 21 & 112 \\
\hline Oil crops & 2023 & 220 & 121 & 2364 & 2908 & 146 & 209 & 0.81 & 16 & 11 \\
\hline Pulses & 3180 & 141 & 734 & 4055 & 3412 & 215 & 23 & 1.19 & 19 & 180 \\
\hline Nuts & 7016 & 1367 & 680 & 9063 & 2500 & 65 & 193 & 3.63 & 139 & 47 \\
\hline Milk & 863 & 86 & 72 & 1020 & 560 & 33 & 31 & 1.82 & 31 & 33 \\
\hline Eggs & 2592 & 244 & 429 & 3265 & 1425 & 111 & 100 & 2.29 & 29 & 33 \\
\hline Chicken meat & 3545 & 313 & 467 & 4325 & 1440 & 127 & 100 & 3.00 & 34 & 43 \\
\hline Butter & 4695 & 465 & 393 & 5553 & 7692 & 0.0 & 872 & 0.72 & 0.0 & 6.4 \\
\hline Pig meat & 4907 & 459 & 622 & 5988 & 2786 & 105 & 259 & 2.15 & 57 & 23 \\
\hline $\begin{array}{l}\text { Sheep/goat } \\
\text { meat }\end{array}$ & 8253 & 457 & 53 & 8763 & 2059 & 139 & 163 & 4.25 & 63 & 54 \\
\hline Bovine meat & 14414 & 550 & 4511 & 15415 & 1513 & 138 & 101 & 10.19 & 112 & 153 \\
\hline
\end{tabular}

\subsubsection{The total water footprint of animal production}

During the period 1996-2005, the total water footprint for global animal production was $2422 \mathrm{Gm}^{3} / \mathrm{yr}$ (87.2\% green, $6.2 \%$ blue and $6.6 \%$ grey water). The largest water footprint for the animal production comes from the feed they consume, which accounts for $98 \%$ of the total water footprint. Drinking water, service water and feed mixing water further account only for $1.1 \%, 0.8 \%$ and $0.03 \%$ of the total water footprint, respectively. Grazing accounts for the largest share (38\%), followed by maize (17\%) and fodder crops $(8 \%)$.

The global water footprint of feed production is $2376 \mathrm{Gm}^{3} / \mathrm{yr}$, of which $1463 \mathrm{Gm}^{3} / \mathrm{yr}$ refers to crops and the remainder to grazing (Table 3.6). This estimate is consistent with the values reported in De Fraiture et al. (2007). The total water footprint of feed crops amounts 
to $20 \%$ of the water footprint of total crop production in the world, which is $7404 \mathrm{Gm}^{3} / \mathrm{yr}$ (Mekonnen and Hoekstra, 2010d). The globally aggregated blue water footprint of feed crop production is $105 \mathrm{Gm}^{3} / \mathrm{yr}$, which is $12 \%$ of the blue water footprint of total crop production in the world (Mekonnen and Hoekstra, 2010d). This means that an estimated $12 \%$ of the global consumption of groundwater and surface water for irrigation is for feed, not for food, fibres or other crop products. Globally, the total water footprint of animal production $\left(2422 \mathrm{Gm}^{3} / \mathrm{yr}\right)$ constitutes $29 \%$ of the water footprint of total agricultural production.

Table 3.6. The global water footprint of animal production compared to the global water footprint of total agricultural production for the period 1996-2005 $\left(\mathrm{Gm}^{3} / \mathrm{yr}\right)$.

\begin{tabular}{lrrrr}
\hline & Green & Blue & Grey & Total \\
\hline Water footprint of total agricultural production & & & & \\
Water footprint of crop production* & 5771 & 899 & 733 & 7404 \\
Water footprint of grazing & 913 & - & - & 913 \\
Direct water footprint of livestock** & - & 46 & - & 46 \\
Total & 6684 & 899 & 733 & 8317 \\
\hline Water footprint of animal production & & & & \\
Water footprint of feed crop production & 1199 & 105 & 159 & 1463 \\
Water footprint of grazing & 913 & - & - & 913 \\
Direct water footprint of livestock ${ }^{* *}$ & - & 46 & - & 46 \\
Total & 2112 & 151 & 159 & 2422 \\
\hline Water footprint of animal production as a percentage of the & $32 \%$ & $17 \%$ & $22 \%$ & $29 \%$ \\
$\quad$ total water footprint in agricultural production & & &
\end{tabular}

* Source: Mekonnen and Hoekstra (2010d).

${ }^{* *}$ Water footprint of drinking, servicing and feed mixing.

When we consider the total water footprint per animal category (Table 3.7), we find that beef cattle have the largest contribution $(33 \%)$ to the global water footprint of farm animal production, followed by dairy cattle $(19 \%)$, pig (19\%) and broiler chicken $(11 \%)$. The green, blue and grey water footprints per animal category and production system are shown in Table 3.8. Altogether, mixed production systems account for the largest share $(57.4 \%)$ in the total water footprint of animal production. Grazing and industrial production systems 


\section{0 / Chapter 3. The green, blue and grey water footprint of animal products}

account for $20.3 \%$ and $22.3 \%$, respectively. In the grazing system, over $97 \%$ of the water footprint related to feed comes from grazing and fodder crops and the water footprint is dominantly (94\%) green. In the mixed and industrial production systems, the green water footprint forms $87 \%$ and $82 \%$ of the total footprint, respectively. The blue water footprint in the grazing system accounts for $3.6 \%$ of the total water footprint and about $33 \%$ of this comes from the drinking and service water use. In the industrial system, the blue water footprint accounts for $8 \%$ of the total water footprint.

A substantial part of the water footprint of an animal product produced in one country often resides outside that country. This is most in particular the case for products originating from industrial production systems, because those systems use the largest fraction of concentrate feed. Feed crops are often imported rather than produced domestically. Soybean cake, for example, which is an important feed ingredient in industrial livestock raising, is often imported. In the period 1996-2005, 49\% of global soybean production was exported, either in the form of soybean or in the form of soybean cake (FAO, 2010a).

Table 3.7. The total water footprint per animal category (1996-2005).

\begin{tabular}{|c|c|c|c|c|}
\hline $\begin{array}{l}\text { Animal } \\
\text { category }\end{array}$ & $\begin{array}{r}\text { Global total } \\
\text { number of } \\
\text { animals* } \\
\text { (millions) }\end{array}$ & $\begin{array}{r}\text { Average annual water } \\
\text { footprint per animal } \\
\left(\mathrm{m}^{3} / \mathrm{yr} \text { per animal }\right)\end{array}$ & $\begin{array}{r}\text { Annual water } \\
\text { footprint of animal } \\
\text { category }\left(\mathrm{Gm}^{3} / \mathrm{yr}\right)\end{array}$ & $\%$ \\
\hline Beef cattle & 1267 & 630 & 798 & 33 \\
\hline Dairy cattle & 228 & 2056 & 469 & 19 \\
\hline Pig & 880 & 520 & 458 & 19 \\
\hline Broiler chicken & 9923 & 26 & 255 & 11 \\
\hline Horse & 112 & 1599 & 180 & 7 \\
\hline Layer Chicken & 5046 & 33 & 167 & 7 \\
\hline Sheep & 1052 & 68 & 71 & 3 \\
\hline Goat & 750 & 32 & 24 & 1 \\
\hline Total & 19258 & & 2422 & 100 \\
\hline
\end{tabular}

* Source: FAO (2010a).

** See Table 3.2 . 
Table 3.8. The green, blue and grey water footprints per animal category and production system $\left(\mathrm{Gm}^{3} / \mathrm{yr}\right)$ for the period 1996-2005.

\begin{tabular}{|c|c|c|c|c|c|c|c|c|c|c|c|c|}
\hline \multirow{2}{*}{$\begin{array}{l}\text { Animal } \\
\text { category }\end{array}$} & \multicolumn{3}{|c|}{$\begin{array}{c}\text { Grazing production } \\
\text { system }\end{array}$} & \multicolumn{3}{|c|}{$\begin{array}{l}\text { Mixed production } \\
\text { system }\end{array}$} & \multicolumn{3}{|c|}{$\begin{array}{c}\text { Industrial } \\
\text { production system }\end{array}$} & \multicolumn{3}{|c|}{ World total } \\
\hline & Green & Blue & Grey & Green & Blue & Grey & Green & Blue & Grey & Green & Blue & Grey \\
\hline Beef cattle & 185 & 4.5 & 2.1 & 443 & 20 & 12 & 112 & 10 & 9.0 & 740 & 35 & 23 \\
\hline Dairy cattle & 83 & 3.6 & 3.7 & 269 & 27 & 26 & 48 & 4.1 & 3.8 & 400 & 35 & 34 \\
\hline Pig & 27 & 1.5 & 2.2 & 237 & 19 & 27 & 111 & 14 & 19 & 376 & 34 & 48 \\
\hline $\begin{array}{l}\text { Broiler } \\
\text { chicken }\end{array}$ & 37 & 3.4 & 3.3 & 100 & 8.3 & 14 & 73 & 6.3 & 10 & 210 & 18 & 28 \\
\hline Horse & 82 & 3.0 & 1.4 & 69 & 7.1 & 2.4 & 13 & 0.8 & 0.6 & 164 & 11 & 4 \\
\hline $\begin{array}{l}\text { Layer } \\
\text { chicken }\end{array}$ & 4.5 & 0.3 & 0.3 & 52 & 5.4 & 9.4 & 77 & 6.5 & 12 & 133 & 12 & 22 \\
\hline Sheep & 34 & 1.2 & 0.0 & 28 & 2.0 & 0.2 & 5.0 & 1.0 & 0.2 & 66.5 & 4.3 & 0.5 \\
\hline Goat & 8.2 & 0.3 & 0.0 & 13 & 0.9 & 0.0 & 2.0 & 0.4 & 0.0 & 22.7 & 1.5 & 0.0 \\
\hline Total & 461 & 17.8 & 13.2 & 1210 & 90 & 90 & 442 & 43 & 55 & 2112 & 151 & 159 \\
\hline
\end{tabular}

\subsection{Discussion}

The result of the current study can be compared with results from earlier studies. However, only a few other studies on the water footprint per unit of animal product and the total water footprint of animal production are available. We will first compare our estimates of the water footprints per ton of animal product with two earlier studies and subsequently we will compare the total water footprint related to animal feed production with five earlier studies.

The rough estimates made by Pimentel et al. (2004) for the water footprints of beef and meat from sheep, pig and chicken are partly very close to our global estimates but partly also quite different. They report a water footprint of chicken meat of $3500 \mathrm{~m}^{3} /$ ton, which is only a bit lower than our global average estimate of $4300 \mathrm{~m}^{3} /$ ton, and even closer if we subtract the grey water footprint component from our estimate (which is not included in Pimentel's studies). They report a water footprint of pig meat of $6000 \mathrm{~m}^{3} /$ ton, which happens to coincide with our global average estimate (but our estimate includes the grey water footprint component). For sheep meat, they report a water footprint of $51000 \mathrm{~m}^{3} /$ ton and for beef $43000 \mathrm{~m}^{3} /$ ton, values that are very high when compared to our estimates 


\section{2 / Chapter 3. The green, blue and grey water footprint of animal products}

$\left(10,400 \mathrm{~m}^{3} /\right.$ ton for sheep meat and $15400 \mathrm{~m}^{3} /$ ton for beef). We consider the values reported by Pimentel as crude first estimates, for which the underlying assumptions have not been spelled out, so that it is difficult to explain differences with our estimates.

The study of Chapagain and Hoekstra (2004) is the only publication with global estimates of the water footprint of animal products with specifications by country. At a global level, the estimated water footprints per ton of animal and animal product compare very well with the estimates from Chapagain and Hoekstra (2004), with an $r^{2}$ of 0.88 (Figure 3.4a). The good agreement at the global level between the two studies is probably that the global average water footprints for various feed ingredients are very close in the two studies. The trend line in Figure 3.4a is slightly above 1, which is caused by our higher estimates for the water footprints of sheep and goat meat. For most other animal products, the current study gives a bit lower estimates than the earlier study.

When we compare our estimates with Chapagain and Hoekstra (2004) at a country level, more differences are found (Figure 3.4b-f). The two studies show a relatively good agreement for pig meat, chicken meat and egg - although for egg the earlier study systematically gives higher numbers - but little agreement for beef and dairy products. In general we find that Chapagain and Hoekstra (2004) underestimated the water footprints for African countries and overestimated the water footprints for OECD countries. As already pointed out in the introductory chapter, there are three main reasons why the estimates from the current study can differ from the 2004-study and are considered more accurate. First, the current study is based on better data for the estimation of the quantity and composition of animal feed. Second, the current study reckons with the relative presence of the three production systems per country and accounts for the differences between those systems. Third, we have estimated the water footprints of the various feed ingredients more accurately by using a high-resolution grid-based crop water use model, including the effect of water deficits where they occur, making explicit distinction between the green and blue water footprint components and including the grey water footprint component. 

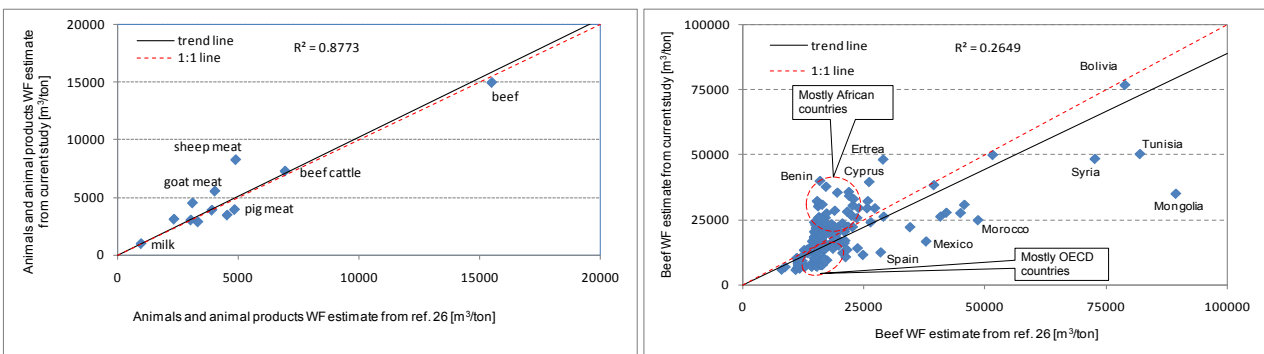

(a)

(b)
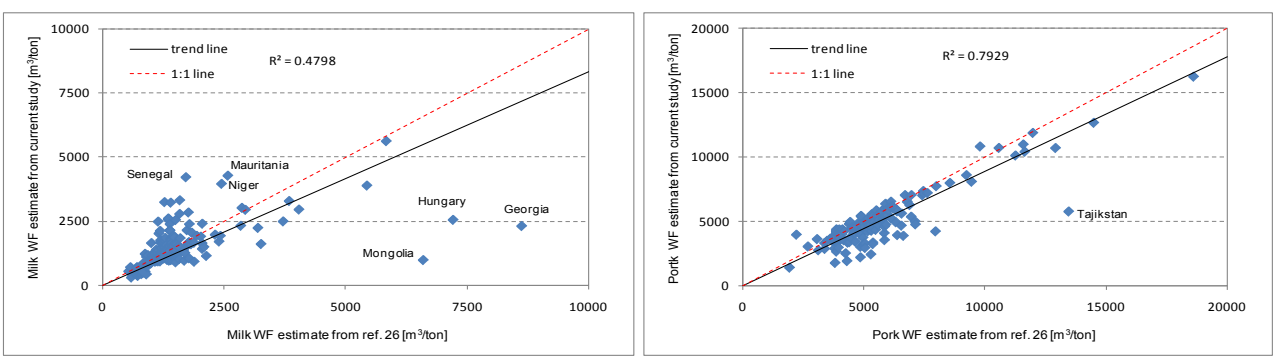

(c)

(d)

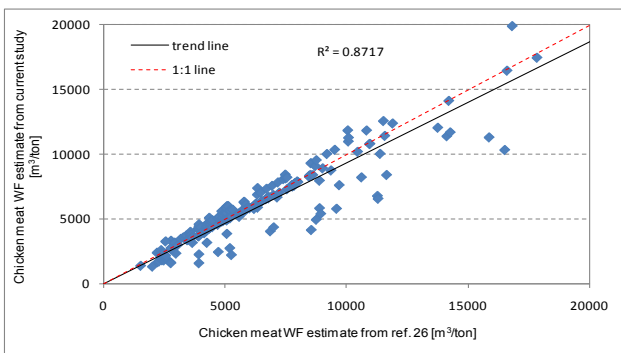

(e)

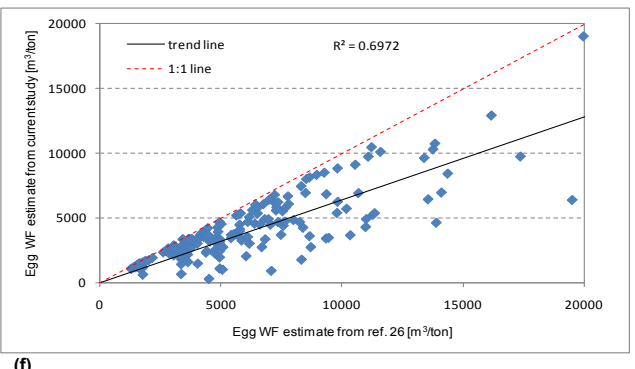

Figure 3.4. Comparison of average water footprint of (a) animals and animal products at global level, and (b) beef (c) milk, (d) pig meat, (e) chicken meat and (f) egg at the country level as estimated in the current study and Chapagain and Hoekstra (2004). From the current study we show here the sum of green and blue water footprints, excluding the grey water footprint, because that component was excluded in the 2004-study.

As one can see in the overview presented in Table 3.9, our estimate of the total evaporative water use (green plus blue water footprint) for producing animal feed $\left(2217 \mathrm{Gm}^{3} / \mathrm{yr}\right)$ is $3 \%$ larger than the estimate by De Fraiture et al. (2007) and 5\% smaller than the estimate by Zimmer and Renault (2003). Our estimate of the global consumptive water use for producing feed crops $\left(1312 \mathrm{Gm}^{3} / \mathrm{yr}\right)$ does not significantly differ from the estimate by De Fraiture et al. (2007). Our estimate of global consumptive water use for grazing (913 $\mathrm{Gm}^{3} / \mathrm{yr}$ ) is $9 \%$ larger than the estimate by De Fraiture et al. (2007). The differences with three other studies that reported on the consumptive water use related to grazing are much 


\section{4 / Chapter 3. The green, blue and grey water footprint of animal products}

larger, which is cause by another definition applied. Postel et al. (1996) estimated the water evaporated from grazing land to be $5800 \mathrm{Gm}^{3} / \mathrm{yr}$. In more recent studies, Rost et al. (2008) and Hanasaki et al. (2010) estimate the total evapotranspiration from grazing land to be $8258 \mathrm{Gm}^{3} / \mathrm{yr}$ and $12960 \mathrm{Gm}^{3} / \mathrm{yr}$, respectively. However, unlike the current study, the estimates in these three studies refer to the total evapotranspiration from grazing lands rather than to the evaporation related to the grass actually consumed. According to De Fraiture et al. (2007), reported 'grazing lands' are only partly actually grazed. Besides, the harvest efficiency - the fraction of grass actually consumed by the animal compared to the standing biomass - is quite small. In a recent study in the USA, Smart et al. (2010) showed that, depending on the animal stocking density, harvest efficiencies reach between $14-38 \%$.

Table 3.9. Comparison of the results of the current study with the results from previous studies.

\begin{tabular}{lllll}
\hline \multirow{2}{*}{ Study } & Period & \multicolumn{3}{c}{$\begin{array}{c}\text { Global water footprint related to animal feed } \\
\text { production }\left(\mathrm{Gm}^{3} / \mathrm{yr}\right)^{*}\end{array}$} \\
\cline { 3 - 5 } & & Grazing & Crops & Total \\
\hline Postel et al. (1996) & 1995 & 5800 & - & - \\
Zimmer and Renault (2003) & 2000 & - & - & 2340 \\
De Fraiture et al. (2007) & 2000 & 840 & 1312 & 2152 \\
Rost et al. (2008) & $1971-2002$ & 8258 & - & - \\
Hanasaki et al. (2010) & $1985-1999$ & 12960 & - & - \\
\hline Current study* & $1996-2005$ & 913 & 1304 & 2217 \\
\hline
\end{tabular}

* The numbers in the table, also the ones from the current study, refer to the green plus blue water footprint. None of the previous studies included the grey water footprint component.

There are several uncertainties in this study in the quantification of the water footprint of animals and animal products. Due to a lack of data, many assumptions have to be made. There are a number of uncertainties in the study, but particularly two types of uncertainty may have a major effect on the final output of the study. First, data on animal distribution per production system per country for OECD countries is not available. Wint and Robinson (2007) provide livestock distributions per production system per country for developing countries but not for OECD countries. For these countries we are forced to use the data from Seré and Steinfeld (1996), who provide livestock distribution per economic region. These data have the limitation that they are not country-specific and may lead to wrong 
distribution of animals into the different production system for some countries. The second major uncertainty is related to the precise composition of feed per animal category per country. Such data are not directly available so that we had to infer these data by combining different data sources and a number of assumptions.

Although the scope of this study is very comprehensive, there are many issues that have been left out. One issue is that we neglected the indirect water footprints of materials used in feed production and animal raising. We expect that this may add at most a few per cents to the water footprint estimates found in this study (based on Hoekstra et al., 2009). In the grey water footprint estimations we have looked at the water pollution by nitrogenfertilisers only, excluding the potential pollution by other fertiliser components or by pesticides or other agro-chemicals. Besides, we have not quantified the grey water footprint coming from animal wastes, which is particularly relevant for industrial production systems. Intensive animal production often generates an amount of waste that cannot be fully recycled on the nearby land. The large amount of waste generated in a concentrated place can seriously affect freshwater systems (FAO, 2005b; Steinfeld et al., 2006; Galloway et al., 2007). Finally, by focusing on freshwater appropriation, the study obviously excludes many other relevant issues in farm animal production, such as microand macro-cost of production, livelihood of smallholder farmers, animal welfare, public health and environmental issues other than freshwater.

\subsection{Conclusion}

The present study estimates the water footprint of farm animals and animal products per production system and per country. The results show that:

- The blue and grey water footprints of animal products are largest for industrial systems (with an exception for chicken products). From a freshwater perspective, animal products from grazing systems are therefore to be preferred above products from industrial systems.

- The water footprint of any animal product is larger than the water footprint of a wisely chosen crop product with equivalent nutritional value. 
- $29 \%$ of the total water footprint of the agricultural sector in the world is related to the production of animal products. One third of the global water footprint of animal production is related to beef cattle.

Managing the demand for animal products by promoting a dietary shift away from a meatrich diet will be an inevitable component in the environmental policy of governments. In countries where the consumption of animal products is still quickly rising, one should critically look how this growing demand can be moderated. On the production side, it would be wise to include freshwater implications in the development of animal farming policies, which means that particularly feed composition, feed water requirements and feed origin need to receive attention. Animal farming puts the lowest pressure on freshwater systems when dominantly based on crop residues, waste and roughages. Policies aimed to influence either the consumption or production side of farm animal products will generally entail various sorts of socio-economic and environmental trade-offs (Herrero et al., 2009; Pelletier and Tyedmers, 2010). Therefore, policies aimed at reducing the negative impacts of animal production and consumption should be able to address these potential tradeoffs. Policies should not affect the required increase in food security in less developed countries neither the livelihood of the rural poor should be put in danger through intensification of animal farming.

This study provides a rich data source for further studies on the factors that determine how animal products put pressure on the global water resources. The reported incidents of groundwater depletion, rivers running dry and increasing levels of pollution form an indication of the growing water scarcity (UNESCO, 2009; Postel, 2000; Gleick, 1993). Since animal production and consumption play an important role in depleting and polluting the world's scarce freshwater resources, information on the water footprint of animal products will help us understand how we can sustain the scarce freshwater resources. 


\section{National water footprint accounts: the green, blue and grey water footprint of production and consumption ${ }^{3}$}

\section{Abstract}

This study quantifies and maps the water footprints of nations from both a production and consumption perspective and estimates international virtual water flows and national and global water savings as a result of trade. The entire estimate includes a breakdown of water footprints, virtual water flows and water savings into their green, blue and grey components. The main finding of the study can be summarized as:

- The global water footprint in the period $1996-2005$ was $9087 \mathrm{Gm}^{3} / \mathrm{yr}(74 \%$ green, $11 \%$ blue, $15 \%$ grey). Agricultural production contributes $92 \%$ to this total footprint.

- About one fifth of the global water footprint relates to production for export.

- The total volume of international virtual water flows related to trade in agricultural and industrial products was $2320 \mathrm{Gm}^{3} / \mathrm{yr}$ (68\% green, $13 \%$ blue, $19 \%$ grey). Trade in crop products contributes $76 \%$ to the total volume of international virtual water flows; trade in animal and industrial products contribute $12 \%$ each. As a global average, the blue and grey shares in the total water footprint of internationally traded products are slightly larger than in the case of domestically consumed products.

- Mexico and Spain are the two countries with the largest national blue water savings as a result of trade.

- The global water saving as a result of trade in agricultural products in the period 19962005 was $369 \mathrm{Gm}^{3} / \mathrm{yr}$ (59\% green, $27 \%$ blue, $15 \%$ grey), which is equivalent to $4 \%$ of the global water footprint related to agricultural production. The global blue water saving is equivalent to $10 \%$ of the global blue water footprint related to agricultural production, which indicates that virtual water importing countries generally depend more strongly on blue water for crop production than the virtual water exporting countries. The largest global water saving (53\%) is due to trade in cereal crops, followed by oil crops (22\%) and animal products (15\%).

\footnotetext{
${ }^{3}$ Based on Mekonnen and Hoekstra (2011b)
} 


\section{8 / Chapter 4. National water footprint accounts}

- International trade in industrial products can be associated with an increased global water footprint that is equivalent to $4 \%$ of the global water footprint related to industrial production.

- The water footprint of the global average consumer in the period 1996-2005 was 1385 $\mathrm{m}^{3} / \mathrm{yr}$. About $92 \%$ of the water footprint is related to the consumption of agricultural products, $5 \%$ to the consumption of industrial goods, and $4 \%$ to domestic water use.

- The average consumer in the US has a water footprint of $2842 \mathrm{~m}^{3} / \mathrm{yr}$, while the average citizens in China and India have water footprints of $1071 \mathrm{~m}^{3} / \mathrm{yr}$ and $1089 \mathrm{~m}^{3} / \mathrm{yr}$ respectively.

- Consumption of cereal products gives the largest contribution to the water footprint of the average consumer $(27 \%)$, followed by meat $(22 \%)$ and milk products $(7 \%)$. The contribution of different consumption categories to the total water footprint varies across countries.

- The volume and pattern of consumption and the water footprint per ton of product of the products consumed are the main factors determining the water footprint of a consumer.

The study illustrates the global dimension of water consumption and pollution by showing that several countries heavily rely on water resources elsewhere (for example Mexico depending on virtual water imports from the US) and that many countries have significant impacts on water consumption and pollution elsewhere (for example Japan and many European countries due to their large external water footprints).

\subsection{Introduction}

The earth's freshwater resources are subject to increasing pressure in the form of consumptive water use and pollution (Postel, 2000; WWAP, 2003, 2006, 2009). Until recently, issues of freshwater availability, use and management have been addressed at a local, national and river basin scale. The recognition that freshwater resources are subject to global changes and globalization have led a number of researchers to argue for the importance of putting freshwater issues in a global context (Postel et al., 1996; Vörösmarty et al., 2000; Hoekstra and Hung, 2005; Hoekstra and Chapagain, 2008; Hoff, 2009). 
Appreciating the global dimension of freshwater resources can be regarded as a key to solving some of today's most urgent water problems (Hoekstra, 2011).

In formulating national water plans, governments have traditionally taken a purely national perspective, aiming at matching national water supplies to national water demands. Governments have looked for ways to satisfy water users without questioning the total amount of water demands. Even though governments nowadays consider options to reduce water demands, in addition to options to increase supplies, they generally do not consider the global dimension of water demand patterns. All countries trade water-intensive commodities, but few governments explicitly consider options to save water through import of water-intensive products or to make use of relative water abundance to produce waterintensive commodities for export. In addition, by looking at water use within only their own country, governments do not have a comprehensive view of the sustainability of national consumption. Many countries have significantly externalized their water footprint without looking at whether the imported products are related to water depletion or pollution in the producing countries. Knowledge of the dependency on water resources elsewhere is relevant for a national government, not only when evaluating its environmental policy but also when assessing national food security.

Understanding the water footprint of a nation is highly relevant for developing wellinformed national policy. Conventional national water use accounts are restricted to statistics on water withdrawals within their own territory (Van der Leeden et al., 1990; Gleick, 1993; FAO, 2010b). National water footprint accounts extend these statistics by including data on green water use and volumes of water use for waste assimilation and by adding data on water use in other countries for producing imported products as well as data on water use within the country for making export products (Hoekstra et al., 2011).

Quantifying and mapping 'national water footprints' is an evolving field of study since the introduction of the water footprint concept in the beginning of this century (Hoekstra, 2003). The first global study on the water footprints of nations was carried out by Hoekstra and Hung (2002); a second, much more comprehensive study, was done by Hoekstra and Chapagain and reported in a number of subsequent publications: Chapagain and Hoekstra (2004, 2008), Chapagain et al. (2006a) and Hoekstra and Chapagain (2007a, 2008). The current study is the third global assessment of national water footprints, which 
improves upon the previous assessments in a number of respects as will be elaborated below.

The objective of this study is to estimate the water footprints of nations from both a production and consumption perspective. First, the green, blue and grey water footprints within countries associated with agricultural production, industrial production and domestic water supply is quantified and mapped at a high spatial resolution. Second, international virtual water flows related to trade in agricultural and industrial commodities is estimated. Finally, the water footprint of consumption for all countries of the world distinguishing for each country between the internal and the external water footprint of national consumption is quantified and mapped. Throughout the study, the green, blue and grey water footprints are explicitly distinguished.

The current study is more comprehensive and detailed than the earlier two global water footprint studies (Hoekstra and Hung, 2002; Hoekstra and Chapagain, 2008). It is also more comprehensive than the contemporary study by Fader et al. (2011), who estimate the global green and blue water footprint of consumption showing the internal and external water footprint per country. This study excludes the grey water footprint component and is restricted to an analysis of the water footprint of consuming crop products, leaving out the water footprints of farm animal products, industrial products and domestic water supply.

Apart from the global water footprint studies mentioned, several water footprint studies with a focus on a specific country were published in the past few years: Vincent et al. (2011) for Belgium; Ma et al. (2006), Liu and Savenije (2008), Hubacek et al. (2009) and Zhao et al. (2009) for China; Sonnenberg et al. (2009) for Germany; Kampman et al. (2008) for India; Bulsink et al. (2009) for Indonesia; Hoekstra and Chapagain (2007b) for Morocco; Hoekstra and Chapagain (2007b) and Van Oel et al. (2009) for the Netherlands; Aldaya et al. (2010a) and Garrido et al. (2010) for Spain; Sonnenberg et al. (2010) for Switzerland; Chahed et al. (2008) for Tunisia; and Chapagain and Orr (2008), Yu et al. (2010) and Feng et al. (2011) for the UK. The scope, assumptions and data sources in these country studies vary widely, so these studies cannot be used to make comparisons between countries.

The study improves upon the previous global water footprint study - Hoekstra and Chapagain (2008) - in a number of respects: applied a high spatial resolution in estimating the water footprint in crop production, industrial production and domestic water supply. In 
the case of crop production, made an explicit distinction between the green, blue and grey water footprint; used better estimates of the feed composition of farm animals and distinguished three different animal production systems (grazing, mixed and industrial) in each country, accounting for the relative presence of those three systems; explicitly distinguished between the blue and grey water footprint in industrial production and domestic water supply and account for wastewater treatment coverage per country; applied the bottom-up approach in estimating the water footprint of national consumption of agricultural products, which is less sensitive to trade data than the top-down approach.

The study builds on two earlier studies by the same authors. In Mekonnen and Hoekstra (2010d, 2011a) we have reported the green, blue and grey water footprints of crops and derived crop products. In Mekonnen and Hoekstra (2010e) we documented the green, blue and grey water footprints of farm animals and animal products.

\subsection{Method and data}

\section{Accounting framework}

In this study we adopt the terminology and calculation methodology as set out in The Water Footprint Assessment Manual, which contains the global standard for water footprint assessment developed by the Water Footprint Network (Hoekstra et al., 2011). The 'water footprint' is a measure of human's appropriation of freshwater resources. Freshwater appropriation is measured in terms of water volumes consumed (evaporated or incorporated into a product) or polluted per unit of time. A water footprint has three components: green, blue and grey. The blue water footprint refers to consumption of blue water resources (surface and ground water). The green water footprint is the volume of green water (rainwater) consumed, which is particularly relevant in crop production. The grey water footprint is an indicator of the degree of freshwater pollution and is defined as the volume of freshwater that is required to assimilate the load of pollutants based on existing ambient water quality standards. The water footprint is a geographically explicit indicator, showing not only volumes of water consumption and pollution, but also the locations.

The framework for national water footprint accounting is shown in Figure 4.1. One can see that 'the water footprint of national consumption' is different from 'the water footprint within the area of the nation'. The latter is the water footprint of national 


\section{2 / Chapter 4. National water footprint accounts}

production, defined as the total freshwater volume consumed or polluted within the territory of the nation as a result of activities within the different sectors of the economy. It can be calculated by summing the water footprints of all water consuming or polluting processes taking place in the nation. Generally, one can distinguish three main water using sectors: the agricultural sector, the industrial sector and the domestic water supply sector. On the other hand, the water footprint of national consumption is defined as the total volume of freshwater that is used to produce the goods and services consumed by the inhabitant of the nation. It consists of two components: the internal and external water footprint of national consumption. The internal water footprint is defined as the use of domestic water resources to produce goods and services consumed by the nation's population. It is the sum of the water footprint within the nation minus the volume of virtual-water export to other nations related to the export of products produced with domestic water resources. The external water footprint is defined as the volume of water resources used in other nations to produce goods and services consumed by the population in the nation under consideration. It is equal to the virtual-water import into the nation minus the volume of virtual-water export to other nations as a result of re-export of imported products. The virtual-water export from a nation consists of exported water of domestic origin and re-exported water of foreign origin. The virtual-water import into a nation will partly be consumed, thus constituting the external water footprint of national consumption, and may partly be re-exported. The sum of the virtual water import into a country and the water footprint within the area of the nation is equal to the sum of the virtual water export from the nation and the water footprint of national consumption. This sum is called the virtual-water budget of a nation.

\section{Water footprints of national production}

The water footprints within nations related to crop production were obtained from Mekonnen and Hoekstra (2010b, 2010d, 2011a), who estimated the global water footprint of crop production with a crop water use model at a 5 by 5 arc minute spatial resolution. The water footprints within nations related to water use in livestock farming, were obtained from Mekonnen and Hoekstra (2010e). The water footprints within nations related to industrial production and domestic water supply were estimated in this study using water withdrawal data from the AQUASTAT database (FAO, 2010b). For some countries, water 
withdrawal data were taken from EUROSTAT (2011). We have assumed that $5 \%$ of the water withdrawn for industrial purposes is actual consumption (blue water footprint) and that the remaining fraction is return flow; for the domestic water supply sector we assumed a consumptive portion of $10 \%$ (FAO, 2010b). The part of the return flow which is disposed into the environment without prior treatment has been taken as a measure of the grey water footprint, thus assuming a dilution factor of 1 . Data on the wastewater treatment coverage per country were obtained from the United Nations Statistical Division database (UNSD, 2010a). For countries for which we could not find data, we assumed zero wastewater treatment coverage. Domestic wastewater treatment coverage data are generally specified for urban areas only; we used data on urban populations per country from FAO (2010a) to estimate the grey water footprint from domestic water supply in urban areas. For rural areas we assumed zero treatment. For treatment coverage in the industrial sector per country we used data on municipal treatment coverage in urban areas as an indicator. Water footprints related to industrial production and domestic water supply were mapped using the global population density map from CIESIN and CIAT (2005).

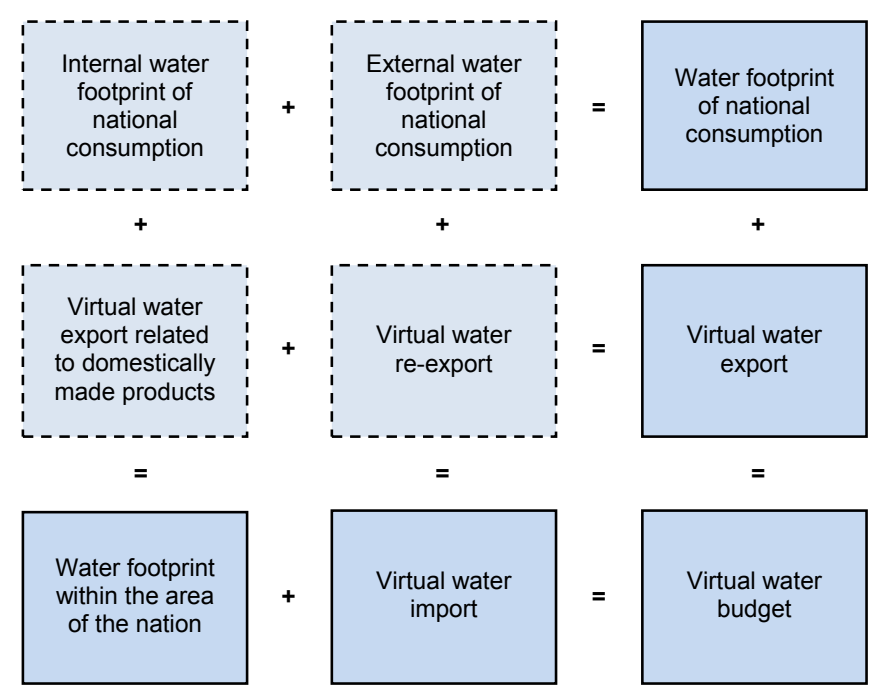

Figure 4.1. The national water footprint accounting scheme. Source: Hoekstra et al. (2011). 


\section{International virtual water flows}

International virtual-water flows are calculated by multiplying, per trade commodity, the volume of trade by the respective average water footprint per ton of product in the exporting nation. When a product is exported from a country that does not produce the product we have assumed the global average product water footprint for that trade flow.

Data on international trade in agricultural and industrial products have been taken from the SITA database (Statistics for International Trade Analysis) available from the International Trade Centre (ITC, 2007). This database covers trade data over ten years (1996-2005) from 230 reporting countries disaggregated by product and partner countries. Country-specific estimates on the green, blue and grey water footprints of 146 crops and more than two hundred derived crop products per ton of product were taken from Mekonnen and Hoekstra (2010d). Estimates on the water footprints of farm animals (beef cattle, dairy cattle, pig, sheep, goat, broiler chicken, layer chicken and horses) and animal products per ton of product were taken from Mekonnen and Hoekstra (2010e). The national average water footprint per dollar of industrial product was calculated per country by dividing the total national water footprint in the industrial sector by the value added in industrial sector. The latter was obtained from the United Nations Statistical Division database (UNSD, 2010b).

\section{Water footprints of national consumption}

The water footprint of national consumption (in $\mathrm{m}^{3} / \mathrm{yr}$ ) is calculated by adding the direct water footprint of consumers and two indirect water footprint components:

$$
W F_{\text {cons }}=W F_{\text {cons,dir }}+W F_{\text {cons,indir }}(\text { agri. commod. })+W F_{\text {cons,indir }}(\text { ind. commod. })
$$

The direct water footprint of consumers within the nation $\left(W F_{c o n s, d i r}\right)$ refers to consumption and pollution of water related to domestic water supply. The indirect water footprint of consumers $\left(W F_{\text {cons,indir }}\right)$ refers to the water use by others to make the commodities consumed, whereby we distinguish between agricultural and industrial commodities.

The water footprint of national consumption of agricultural and industrial commodities can be calculated through either the top-down or the bottom-up approach (Hoekstra et al., 2011). In the top-down approach, the water footprint of national consumption is calculated as the water footprint within the nation plus the virtual-water 
import minus the virtual-water export. The gross virtual-water import is calculated by multiplying import volumes of various products by their respective product water footprint in the nation of origin. The gross virtual-water export is found by multiplying the export volumes of the various export products by their respective product water footprint. In the bottom-up approach, the water footprint of national consumption is calculated by adding the direct and indirect water footprints of consumers within the nation.

For agricultural commodities, the water footprint of national consumption is calculated in this study based on the bottom-up approach. It is calculated by multiplying all agricultural products consumed by the inhabitants of the nation by their respective product water footprint:

$W F_{\text {cons,indir }}($ agri.commod. $)=\sum_{p} C[p] \times W F_{\text {prod }}^{*}[p]$

$C[p]$ is consumption of agricultural product $p$ by consumers within the nation (ton/yr) and $W F^{*}{ }_{p r o d}[p]$ the water footprint of this product $\left(\mathrm{m}^{3} /\right.$ ton $)$. We consider the full range of final agricultural goods. Data on national consumption of agricultural products per country for the period 1996-2005 were taken from the Supply and Utilization Accounts (SUA) of the Food and Agriculture Organization of the United Nations (FAO, 2010a). For edible products, we have taken the "food" column multiplied by a certain factor representing seed and waste. For fibre, hide and skin products, we took the "other utilization" column, again multiplied by a certain factor representing seed and waste. The multiplication factor was calculated per product as the global production divided by the difference between the global production and volume of seed and waste.

The volume of agricultural product $p$ consumed in a nation will generally originate in part from the nation itself and in part from other nations. The average water footprint of a product $p$ consumed in a nation is:

$$
W F_{p r o d}^{*}[p]=\frac{P[p] \times W F_{\text {prod }}[p]+\sum_{n_{e}}\left(T_{i}\left[n_{e}, p\right] \times W F_{p r o d}\left[n_{e}, p\right]\right)}{P[p]+\sum_{n_{e}} T_{i}\left[n_{e}, p\right]}
$$


in which $P[p]$ represents the production quantity of product $p$ in the nation, $T_{i}\left[n_{e}, p\right]$ the imported quantity of product $p$ from exporting nation $n_{e}, W F_{p r o d}[p]$ the water footprint of product $p$ when produced in the nation considered and $W F_{\text {prod }}\left[n_{e}, p\right]$ the water footprint of product $p$ as in the exporting nation $n_{e}$. The assumption made here is that the total consumption volume originates from domestic production and imports according to their relative volumes. The water footprints of agricultural products were taken from Mekonnen and Hoekstra (2010d, 2010e).

For industrial commodities, the water footprint of national consumption is calculated based on the top-down approach as the water footprint of industrial processes taking place within the nation plus the virtual-water import related to import of industrial commodities minus the virtual-water export.

The external water footprint of national consumption $\left(W F_{\text {cons,ext }}\right)$ is estimated based on the relative share of the virtual water import to the total water budget:

$$
W F_{\text {cons }, e x t}=\frac{V_{i}}{W F_{\text {area }}+V_{i}} \times W F_{\text {cons }}
$$

in which $W F_{\text {area }}$ is the water footprint within a nation and $V_{i}$ the virtual water import. We apply this formula separately for the category of agricultural products (crop and animal products) and for the category of the industrial products. The internal water footprint of national consumption $\left(W F_{\text {cons,int }}\right)$ is calculated as:

$$
W F_{\text {cons }, \text { int }}=\frac{W F_{\text {area }}}{W F_{\text {area }}+V_{i}} \times W F_{\text {cons }}
$$

For mapping the global water footprint of the consumption of a certain country at a high spatial resolution, we distinguish between mapping the internal and the external water footprint. The internal water footprint is mapped by taking the shares of the water footprints within the different grid cells in the country that contribute to the water footprint of national consumption. Mapping the external water footprint is done in two steps. First, we quantify the external water footprint per product category per trade partner country based on the relative import from different trade partners. Second, within each trade partner country we 
map the external water footprint by taking the shares of the water footprints within the different grid cells in the trade partner country that contribute to the water footprint of consumption in our country under consideration. We could not trace the external water footprint of imported animal products at grid level because of data limitations.

In a case study for the US, we applied the above approach but took a more refined, though laborious, approach by applying the whole procedure separately for each crop type and animal type. For (domestically produced and consumed) animal products we identify the feed volumes from the country itself and from abroad, and for each feed crop we map the internal and external water footprints using the same approach as for food crops. The category of the industrial products was still treated as one category. The mapping of the external water footprint is slightly improved this way, but more importantly, it enabled us to trace the external water footprint not only by location but also by crop.

\subsection{Results}

\subsubsection{The water footprint of national production}

Figure 4.2 shows world maps with the green, blue and grey water footprints within nations in the period 1996-2005. China, India and the US are the countries with the largest total water footprints within their territory, with total water footprints of 1207, 1182 and 1053 $\mathrm{Mm}^{3} / \mathrm{yr}$, respectively. About $38 \%$ of the water footprint of global production lies within these three countries. The next country in the ranking is Brazil, with total water footprint within its territory of $482 \mathrm{Mm}^{3} / \mathrm{yr}$. India is the country with the largest blue water footprint within its territory: $243 \mathrm{Mm}^{3} / \mathrm{yr}$, which is $24 \%$ of the global blue water footprint. Irrigation of wheat is the process that takes the largest share (33\%) in India's blue water footprint, followed by irrigation of rice $(24 \%)$ and irrigation of sugarcane $(16 \%)$. China is the country with the largest grey water footprint within its borders: $360 \mathrm{Mm}^{3} / \mathrm{yr}$, which is $26 \%$ of the global grey water footprint.

Figure 4.3 shows world maps with the water footprints of agricultural production, industrial production and related to domestic water supply. In all countries of the world, the water footprint related to agricultural production takes the largest share in the total water footprint within the country. China and the US have the largest water footprints in their 
territory related to industrial production; $22 \%$ of the global water footprint related to industrial production lies in China and $18 \%$ in the US. Belgium is the country in which industrial production takes the largest share in the total water footprint in the country. The water footprint of industries in Belgium contributes $41 \%$ to the total water footprint in the country; agricultural production still contributes 53\% here.

The global water footprint related to agricultural and industrial production and domestic water supply for the period 1996-2005 was $9087 \mathrm{Gm}^{3} / \mathrm{yr}(74 \%$ green, $11 \%$ blue, 15\% grey; see Table 4.1). Agricultural production takes the largest share, accounting for $92 \%$ of the global water footprint. Industrial production contributes $4.4 \%$ to the total water footprint and domestic water supply $3.6 \%$.

Table 4.1. Global water footprint of production (1996-2005).

\begin{tabular}{|c|c|c|c|c|c|c|}
\hline & \multicolumn{3}{|c|}{ Agricultural production } & \multirow[b]{2}{*}{$\begin{array}{l}\text { Industrial } \\
\text { production }\end{array}$} & \multirow[b]{2}{*}{$\begin{array}{l}\text { Domestic } \\
\text { water } \\
\text { supply }\end{array}$} & \multirow[b]{2}{*}{ Total } \\
\hline & $\begin{array}{l}\text { Crop } \\
\text { production }\end{array}$ & Pasture & $\begin{array}{l}\text { Water } \\
\text { supply in } \\
\text { animal } \\
\text { raising }\end{array}$ & & & \\
\hline \multicolumn{7}{|c|}{$\begin{array}{l}\text { Global water footprint of } \\
\text { production }\left(\mathrm{Gm}^{3} / \mathrm{yr}\right)\end{array}$} \\
\hline - Green & $5771^{*}$ & $913^{* *}$ & - & - & - & 6684 \\
\hline - Blue & $899^{*}$ & - & $46^{* *}$ & 38 & 42 & 1025 \\
\hline - Grey & $733^{*}$ & - & - & 363 & 282 & 1378 \\
\hline - Total & 7404 & 913 & 46 & 400 & 324 & 9087 \\
\hline $\begin{array}{l}\text { Water footprint for } \\
\text { export }\left(\mathrm{Gm}^{3} / \mathrm{yr}\right)\end{array}$ & \multicolumn{3}{|c|}{ 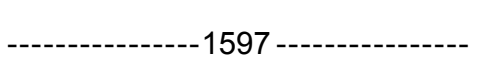 } & 165 & 0 & 1762 \\
\hline $\begin{array}{l}\text { Water footprint for } \\
\text { export compared to } \\
\text { total }(\%)\end{array}$ & \multicolumn{3}{|c|}{ 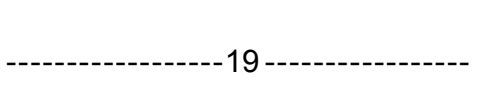 } & 41 & 0 & 19 \\
\hline
\end{tabular}

* Source: Mekonnen and Hoekstra (2010d; 2011a).

** Source: Mekonnen and Hoekstra (2010e).

The global water footprint related to producing goods for export is $1762 \mathrm{Gm}^{3} / \mathrm{yr}$. In the agricultural sector, $19 \%$ of the total water footprint relates to production for export; in the industrial sector this is $41 \%$. The water footprint related to domestic water supply does not 
relate to export at all. Taken as an average over the three water-using sectors, we find that $19 \%$ of the global water footprint is not for domestic consumption but for export.

\subsubsection{International virtual water flows related to trade in agricultural and industrial products}

The global sum of international virtual water flows for the period 1996-2005 was 2320 $\mathrm{Gm}^{3} / \mathrm{yr}$ (68\% green, $13 \%$ blue and $19 \%$ grey). The largest share $(76 \%)$ of the virtual water flows between countries is related to international trade in crops and derived crop products. Trade in animal products and industrial products contributed $12 \%$ each to the global virtual water flows. The volume of global virtual water flows related to domestically produced products was $1762 \mathrm{Gm}^{3} / \mathrm{yr}$. The gross international virtual water flows are presented in Table 4.2.

Table 4.2. Gross international virtual water flows (Gm³/yr). Period 1996-2005.

\begin{tabular}{lrrr}
\hline & $\begin{array}{r}\text { Related to trade } \\
\text { in agricultural } \\
\text { products }\end{array}$ & $\begin{array}{r}\text { Related to trade } \\
\text { in industrial } \\
\text { products }\end{array}$ & Total \\
\hline $\begin{array}{l}\text { Related to export of domestically } \\
\text { produced goods }\end{array}$ & 1597 & 165 & 1762 \\
Related to re-export of imported goods & 441 & 117 & 558 \\
\hline Total & 2038 & 282 & 2320 \\
\hline
\end{tabular}

As a global average, the blue and grey shares in the total water footprint of internationally traded products are slightly larger than in the case of domestically consumed products. This means that export goods are more strongly related to water consumption from and pollution of surface and groundwater than non-export goods. The green component in the total water footprint of internationally traded products is $68 \%$, while it is $74 \%$ for total global production. 

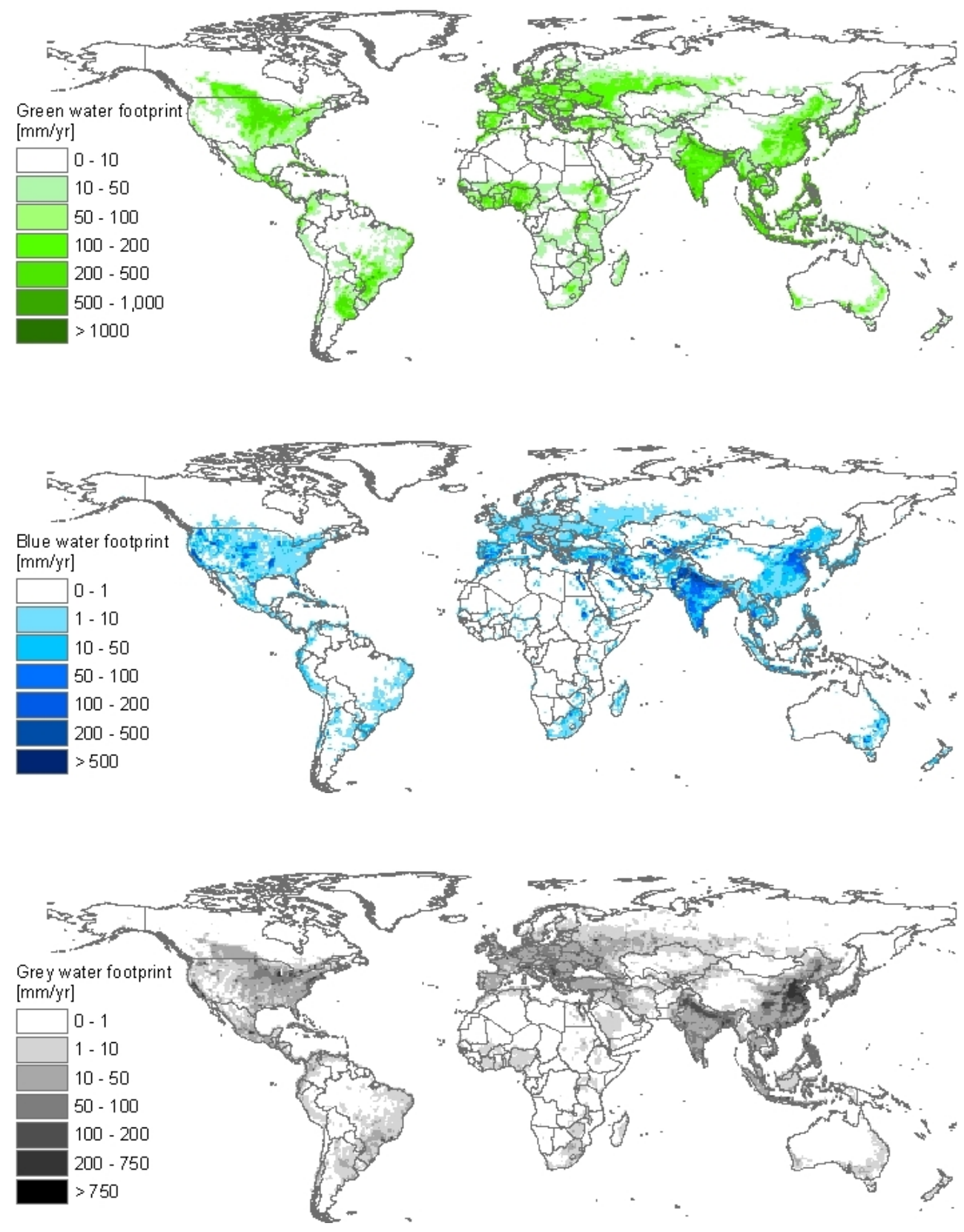

Figure 4.2. The green, blue and grey water footprints within nations in the period 1996-2005. The data are shown in $\mathrm{mm} / \mathrm{yr}$ on a 5 by 5 arc minute grid. Data per grid cell have been calculated as the water footprint within a grid cell (in $\mathrm{m}^{3} / \mathrm{yr}$ ) divided by the area of the grid cell (in $10^{3} \mathrm{~m}^{2}$ ). 

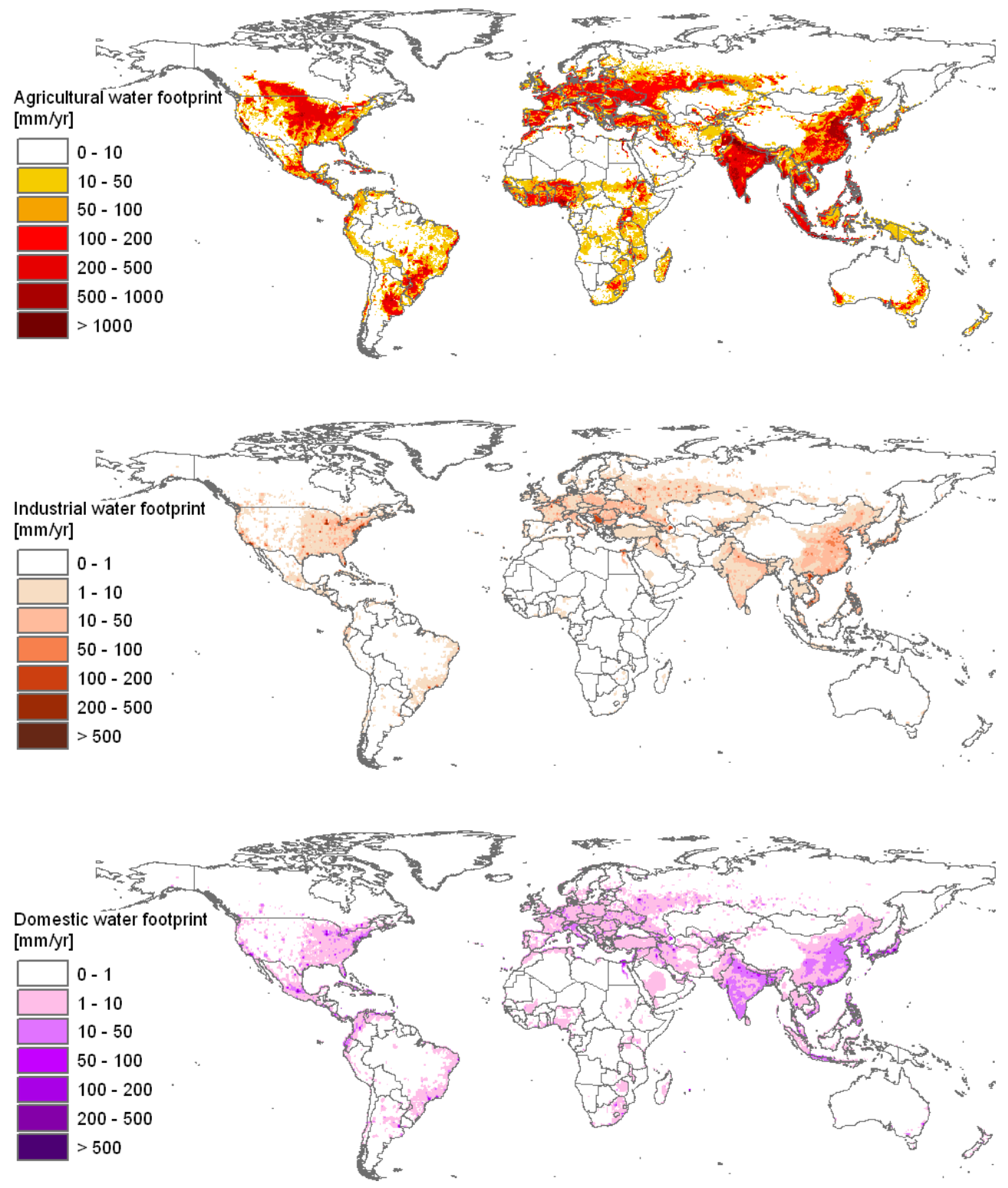

Figure 4.3. The water footprint within nations in the period 1996-2005, shown by sector: the total water footprint of agricultural production (above), the total water footprint of industrial production (middle) and the total water footprint related to domestic water supply (below). The data are shown in $\mathrm{mm} / \mathrm{yr}$ on a 5 by 5 arc minute grid. Data per grid cell have been calculated as the water footprint within a grid cell (in $\mathrm{m}^{3} / \mathrm{yr}$ ) divided by the area of the grid cell (in $10^{3} \mathrm{~m}^{2}$ ). 
The major gross virtual water exporters, which together account for more than half of the global virtual water export, are the US $\left(314 \mathrm{Gm}^{3} / \mathrm{yr}\right)$, China $\left(143 \mathrm{Gm}^{3} / \mathrm{yr}\right)$, India (125 $\mathrm{Gm}^{3} / \mathrm{yr}$ ), Brazil (112 $\left.\mathrm{Gm}^{3} / \mathrm{yr}\right)$, Argentina $\left(98 \mathrm{Gm}^{3} / \mathrm{yr}\right)$, Canada $\left(91 \mathrm{Gm}^{3} / \mathrm{yr}\right)$, Australia (89 $\left.\mathrm{Gm}^{3} / \mathrm{yr}\right)$, Indonesia $\left(72 \mathrm{Gm}^{3} / \mathrm{yr}\right)$, France $\left(65 \mathrm{Gm}^{3} / \mathrm{yr}\right)$ and Germany $\left(64 \mathrm{Gm}^{3} / \mathrm{yr}\right)$. The US, Pakistan, India, Australia, Uzbekistan, China and Turkey are the largest blue virtual water exporters, accounting for $49 \%$ of the global blue virtual water export. All of these countries are partially under water stress (Alcamo and Henrichs, 2002; Alcamo et al. 2003b; Smakhtin et al., 2004a). This raises the question whether the implicit or explicit choice to consume the limited national blue water resources for export products is sustainable and most efficient. Closely related to this is the question to what extent the scarcity is reflected in the price of water in these countries. Given the fact that all the externalities and a scarcity rent are seldom included in the price of water, most particular in agriculture, one cannot expect that production and trade patterns automatically account for regional water scarcity patterns.

The major gross virtual water importers are the US (234 $\left.\mathrm{Gm}^{3} / \mathrm{yr}\right)$, Japan (127 $\mathrm{Gm}^{3} / \mathrm{yr}$ ), Germany $\left(125 \mathrm{Gm}^{3} / \mathrm{yr}\right)$, China (121 Gm $\left.\mathrm{Gm}^{3} / \mathrm{yr}\right)$, Italy (101 $\left.\mathrm{Gm}^{3} / \mathrm{yr}\right)$, Mexico (92 $\left.\mathrm{Gm}^{3} / \mathrm{yr}\right)$, France $\left(78 \mathrm{Gm}^{3} / \mathrm{yr}\right)$, the UK $\left(77 \mathrm{Gm}^{3} / \mathrm{yr}\right)$ and the Netherlands $\left(71 \mathrm{Gm}^{3} / \mathrm{yr}\right)$.

Figure 4.4 shows the virtual water balance per country and the largest international gross virtual water flows. The countries shown in green colour have a negative balance, which means that they have net virtual water export. The countries shown in yellow to red have net virtual water import. The biggest net exporters of virtual water are found in North and South America (the US, Canada, Brazil and Argentina), Southern Asia (India, Pakistan, Indonesia, Thailand) and Australia. The biggest net virtual water importers are North Africa and the Middle East, Mexico, Europe, Japan and South Korea.

The largest share of the international virtual water flows relates to trade in oil crops (including cotton, soybean, oil palm, sunflower, rapeseed and others) and derived products. This category accounts for $43 \%$ of the total sum of international virtual water flows. More than half of this amount relates to trade in cotton products; about one fifth relates to trade in soybean. The other products with a large share in the global virtual water flows are cereals $(17 \%)$, industrial products $(12.2 \%)$, stimulants $(7.9 \%)$ and beef cattle products $(6.7 \%)$. Figure 4.5 shows the contribution of different product categories to the global sum of international virtual water flows. 


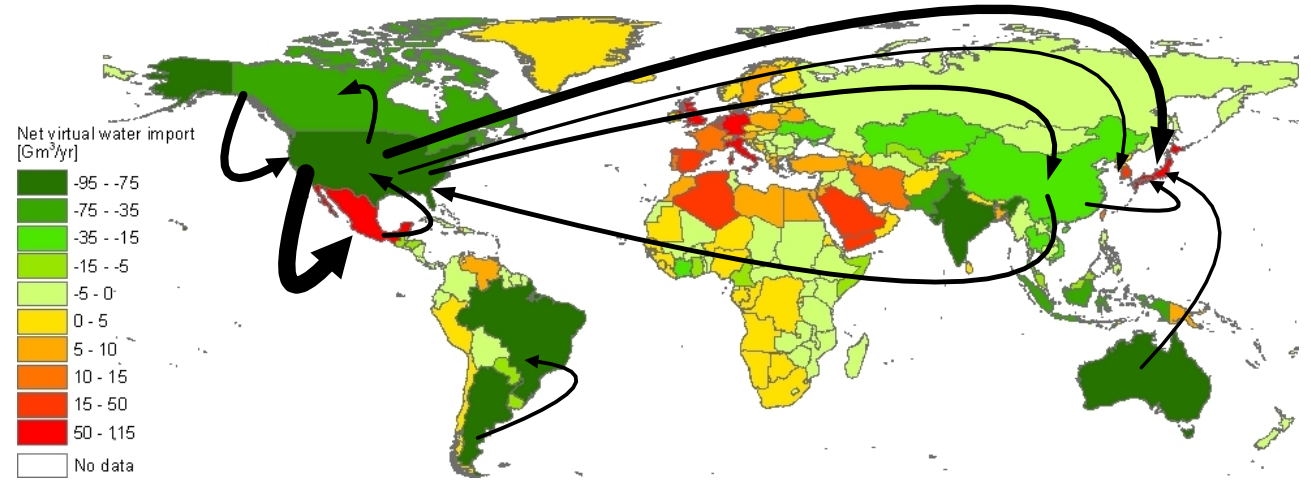

Figure 4.4. Virtual water balance per country and direction of gross virtual water flows related to trade in agricultural and industrial products over the period 1996-2005. Only the biggest gross flows (> $15 \mathrm{Gm}^{3} / \mathrm{yr}$ ) are shown; the fatter the arrow, the bigger the virtual water flow.

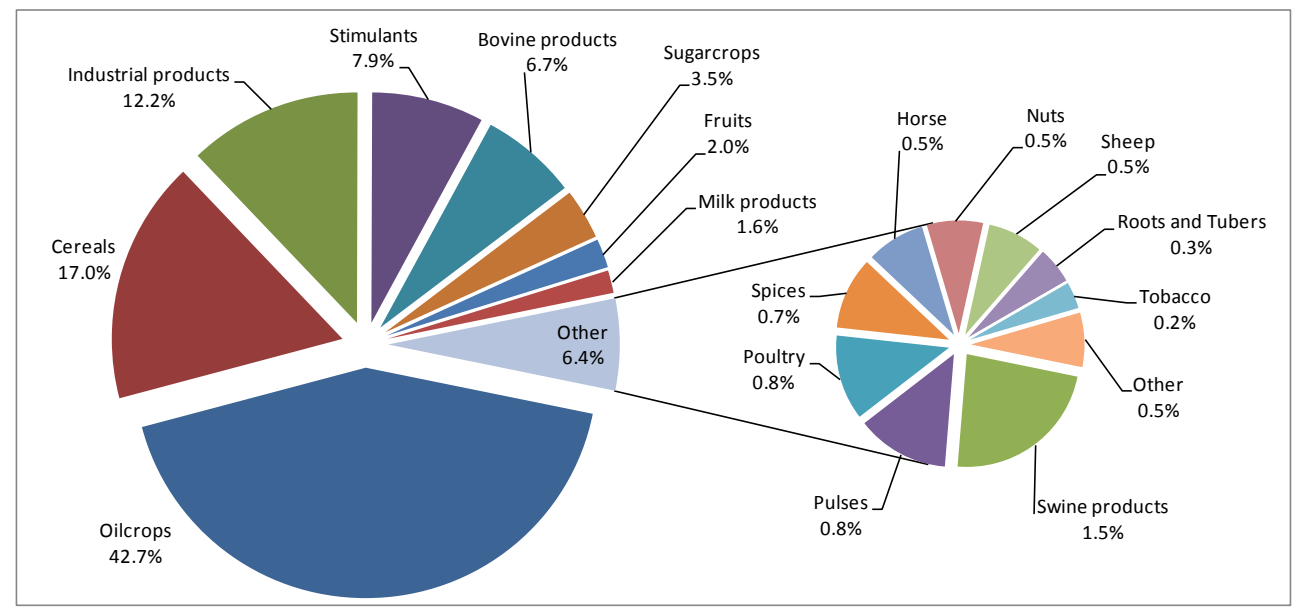

Figure 4.5. Contribution of different product categories to the global virtual water flows

\subsubsection{National water saving per country as a result of trade}

A number of countries reduce the use of their national water resources through the import of agricultural products. Japan saves $134 \mathrm{Gm}^{3} / \mathrm{yr}(80 \%$ green, $9 \%$ blue, $12 \%$ grey) of its domestic water resources, Mexico $83 \mathrm{Gm}^{3} / \mathrm{yr}$ (69\% green, 26\% blue, 6\% grey), Italy 54 $\mathrm{Gm}^{3} / \mathrm{yr}\left(83 \%\right.$ green, $10 \%$ blue, $7 \%$ grey), the UK $53 \mathrm{Gm}^{3} / \mathrm{yr}(75 \%$ green, $15 \%$ blue, $9 \%$ 
grey) and Germany $50 \mathrm{Gm}^{3} / \mathrm{yr}$ ( $83 \%$ green, $14 \%$ blue, $3 \%$ grey). In terms of blue water saved, Mexico, Spain, Japan, the UK and a number of countries in the Middle East come on top of the list. The figures on 'national water saving' presented here should be merely understood as 'volumes of domestic water resources not necessary to be used for production because the commodities are imported'. The term 'saving' is used in a physical, not economic sense. Besides, the 'water saving' does not necessarily imply that the water saved is allocated to other beneficial uses (De Fraiture et al. 2004). In water-scarce countries, however, 'water saving' is likely to have positive environmental, social and economic implications.

From a water resources point of view, one would expect that countries facing water stress adopt a trade strategy that alleviates their water scarcity problem. However, international trade in agricultural goods is driven largely by factors other than water. Therefore, import of virtual water is often unrelated to relative water scarcity in a country (Yang et al., 2003; De Fraiture et al., 2004; Oki and Kanae, 2004; Chapagain and Hoekstra, 2008; Yang and Zehnder, 2008). As shown by Yang et al. (2003), only below a certain threshold in water availability can a relationship be established between the country's per capita water availability and its cereal import. For most relatively water-scarce countries like in North Africa, Middle East, Southern Europe and Mexico - we find indeed net virtual water imports and related national water savings. The national water savings found for Northern European countries, however, cannot be understood from a water scarcity perspective.

\subsubsection{Global water saving related to trade in agricultural and industrial products}

The global water saving related to trade in agricultural products in the period 1996-2005 was $369 \mathrm{Gm}^{3} / \mathrm{yr}$ (58.7\% green, $26.6 \%$ blue and $14.7 \%$ grey). This volume is equivalent to $4 \%$ of the global water footprint related to agricultural production (which is $8363 \mathrm{Gm}^{3} / \mathrm{yr}$, see Table 4.1). Looking only at the blue water saving, it would have required an additional $98 \mathrm{Gm}^{3} / \mathrm{yr}$ of blue water to produce the same amount of goods without virtual water trade. This volume is equivalent to $10 \%$ of the global blue water footprint related to agricultural production (which is $945 \mathrm{Gm}^{3} / \mathrm{yr}$, see again Table 4.1). More than a quarter (98/369=27\%) of the global water saving related to agricultural trade is blue water, which indicates that 
virtual water importing countries generally depend more strongly on blue water for crop production than the virtual water exporting countries. Figure 4.6 shows trade flows that save more than $5 \mathrm{Gm}^{3} / \mathrm{yr}$. Export of agricultural products (mainly maize and soybean products) from the US to Mexico and Japan comprise the biggest global water savings, contributing over $11 \%$ toward the total global water saving.

The largest water saving is due to trade in cereal crops with a global water saving of $196 \mathrm{Gm}^{3} / \mathrm{yr}$, followed by oil crops $\left(82 \mathrm{Gm}^{3} / \mathrm{yr}\right.$, mainly soybean) and animal products (56 $\mathrm{Gm}^{3} / \mathrm{yr}$ ). Among the cereal crops, trade in maize has resulted in the largest saving (71 $\left.\mathrm{Gm}^{3} / \mathrm{yr}\right)$, followed by wheat $\left(67 \mathrm{Gm}^{3} / \mathrm{yr}\right)$, rice $\left(27 \mathrm{Gm}^{3} / \mathrm{yr}\right)$, barley $\left(21 \mathrm{Gm}^{3} / \mathrm{yr}\right)$ and other cereals $\left(10 \mathrm{Gm}^{3} / \mathrm{yr}\right)$. In the case of rice, there is net global water saving if we look at the sum of green, blue and grey, but when we focus on the blue component we find a global blue water loss associated with trade in rice. Among the animal products, international trade in poultry products $\left(25 \mathrm{Gm}^{3} / \mathrm{yr}\right)$, dairy products $\left(16 \mathrm{Gm}^{3} / \mathrm{yr}\right)$, bovine products (16 $\left.\mathrm{Gm}^{3} / \mathrm{yr}\right)$ and pig products $\left(2 \mathrm{Gm}^{3} / \mathrm{yr}\right)$ result in significant global water savings, but trade flows in horse, sheep and goat products are accompanied with a total global water loss of 3 $\mathrm{Gm}^{3} / \mathrm{yr}$. Figure 4.7 shows the contribution of different product groups to the total global water saving.

Trade in industrial products has resulted in a net global water loss of $16.4 \mathrm{Gm}^{3} / \mathrm{yr}$ ( $2 \%$ blue and $98 \%$ grey). This volume is equivalent to $4 \%$ of the global water footprint related to industrial production (which is $400 \mathrm{Gm}^{3} / \mathrm{yr}$, see Table 4.1). Exports of industrial products from China and Russia are the major trade flows contributing to this global water loss related to industrial product trade. This is mainly due to the large grey water footprints per unit of value added in the industrial sectors in those two countries, which in turn relate to the low wastewater treatment coverage in those countries.

When we consider the global water saving related to trade in both agricultural and industrial products, we come to a net saving of $353 \mathrm{Gm}^{3} / \mathrm{yr}(61.5 \%$ green, $27.7 \%$ blue and $10.8 \%$ grey). Global water savings due to international trade in crop products are specified by crop type; global water savings related to trade in animal products are given by animal type. 


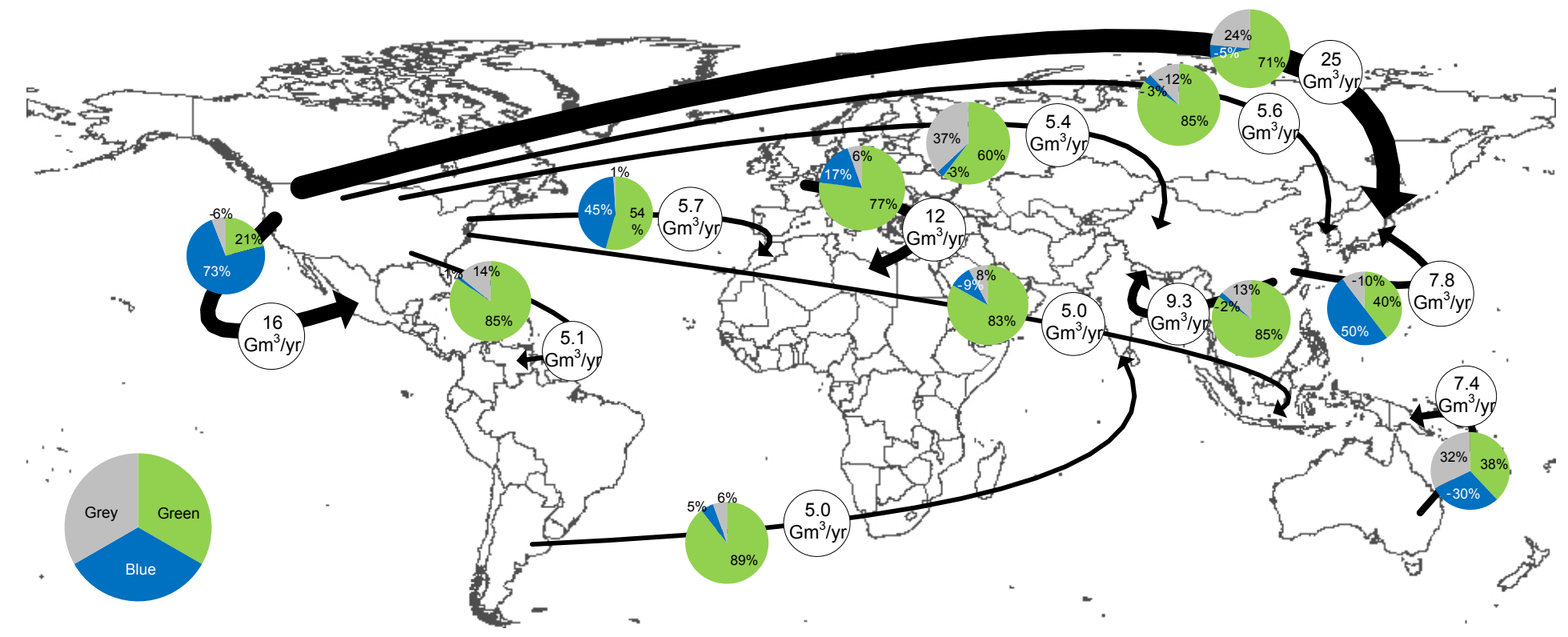

Figure 4.6. Global water savings associated with international trade in agricultural products (1996-2005). Only the biggest water savings (> $5 \mathrm{Gm}^{3} / \mathrm{yr}$ ) are shown. 


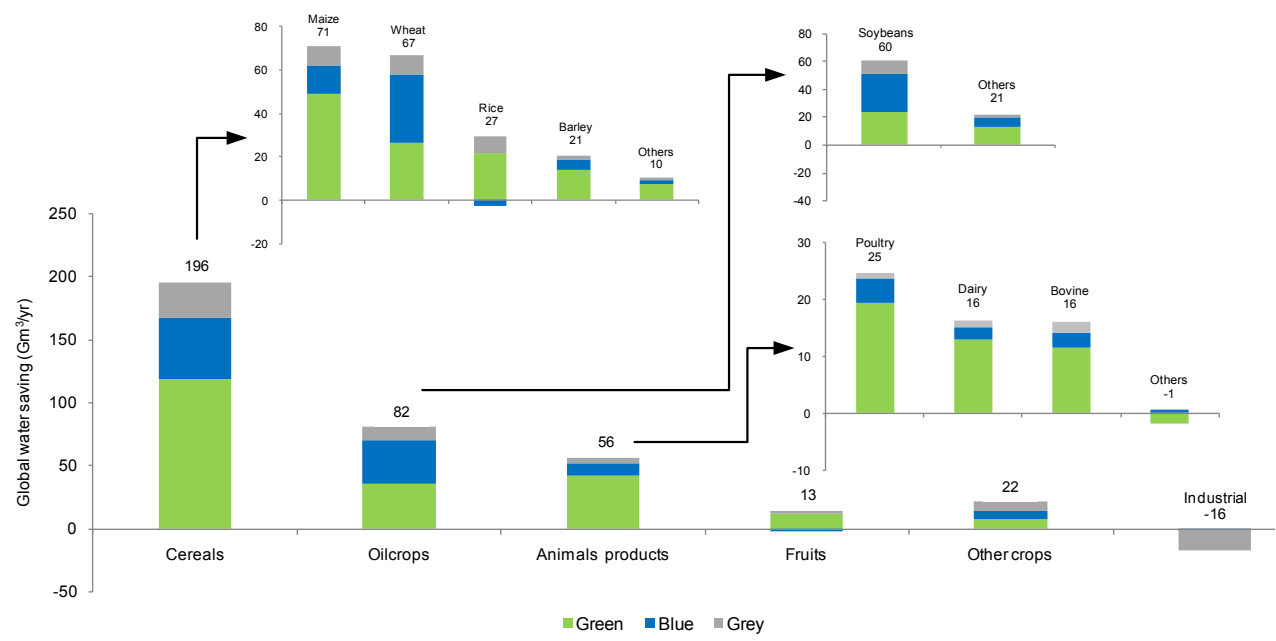

Figure 4.7. Contribution of different product categories to the total global water saving (19962005).

The calculated trade-related water savings are based on the crop yields and corresponding water footprints as they currently exist in the exporting and importing countries. One should therefore be careful in extrapolating water savings when trade flows would intensify. Water scarcity will stimulate countries to improve their water productivities, particularly in countries with low yields (Appelgren and Klohn, 1999; Keller et al., 1998; Molle, 2003; Ohlsson, 2000). Current global water savings resulting from trade in waterintensive products from countries with high water productivity to countries with low water productivity will diminish once the latter countries have increased their water productivity.

The presented global water saving related to international trade may seem significant: the global water footprint of agricultural and industrial production would be $4 \%$ higher if countries would produce all commodities within their own territory based on existing domestic productivities instead of partially import them from other countries. The potential of optimising international trade for further global water savings is probably small once the most important importing countries with low water productivities increase their productivity. The global water footprint can be reduced more significantly by achieving high water productivities across the globe than by optimising trade from high to low productivity regions. Supported by the assessment by Falkenmark et al. (2009), we estimate that the potential global water saving by increasing water productivities in regions that 
currently still have low productivities will be of an order of magnitude larger than the current global water saving achieved by trade. Therefore, for water scarce countries the first priority should be to raise their water productivity as much as possible before turning to virtual water import as an option to address their water scarcity problem.

\subsubsection{The water footprint of national consumption}

The global average water footprint related to consumption is $1385 \mathrm{~m}^{3} / \mathrm{yr}$ per capita over the period 1996-2005. Consumption of agricultural products largely determines the global water footprint related to consumption, contributing $92 \%$ to the total water footprint. Consumption of industrial products and domestic water use contribute $4.7 \%$ and $3.8 \%$ respectively. When we look at the level of product categories, cereals consumption contribute the largest share to the global water footprint $(27 \%)$, followed by meat $(22 \%)$ and milk products $(7 \%)$. The contribution of different product categories to the global average water footprint of consumption is presented in Figure 4.8.

The water footprint of consumption in a country depends on two factors: what and how much do consumers consume and what are the water footprints of the commodities consumed. The latter depends on the production circumstances in the places of origin of the various commodities. A certain product as available on the shelves within a country generally comes from different places, with different production circumstances and thus a different water footprint in each place. To calculate the average water footprint of a product in a country, the water footprints for all locations the product originates from are multiplied by the proportional share of the product coming from those locations.

The relative contribution of different countries to the total water footprint of consumption is given in Figure 4.9. The green, blue, grey and total water footprint per capita for all countries are mapped in Figure 4.10. The water footprint of national consumption by product category for countries with a population size above 5 million is shown in Figure 4.11.

In total terms, China is the country with the largest water footprint of consumption in the world, with a total footprint of $1368 \mathrm{Gm}^{3} / \mathrm{yr}$, followed by India and the US with 1145 $\mathrm{Gm}^{3} / \mathrm{yr}$ and $821 \mathrm{Gm}^{3} / \mathrm{yr}$ respectively. Obviously, countries with large populations have a 
large water footprint. Therefore it is more interesting to look at the water footprint per capita.

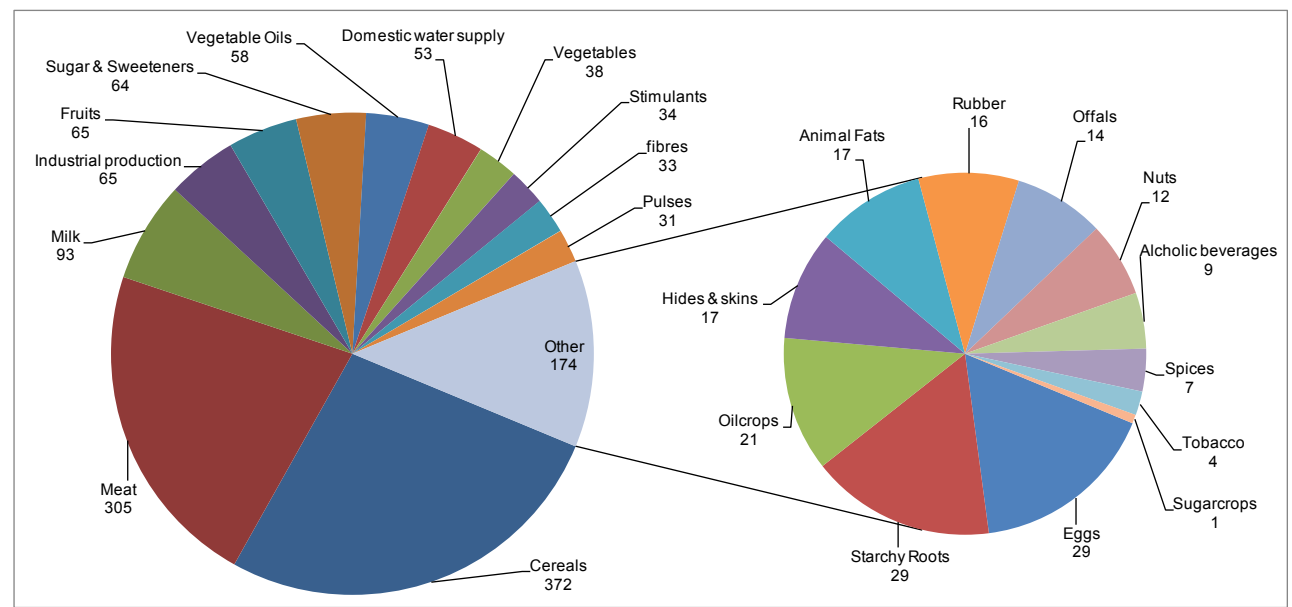

Figure 4.8. Contribution of different product categories to the global water footprint of consumption (in $\mathrm{m}^{3} / \mathrm{yr} / \mathrm{cap}$ ).

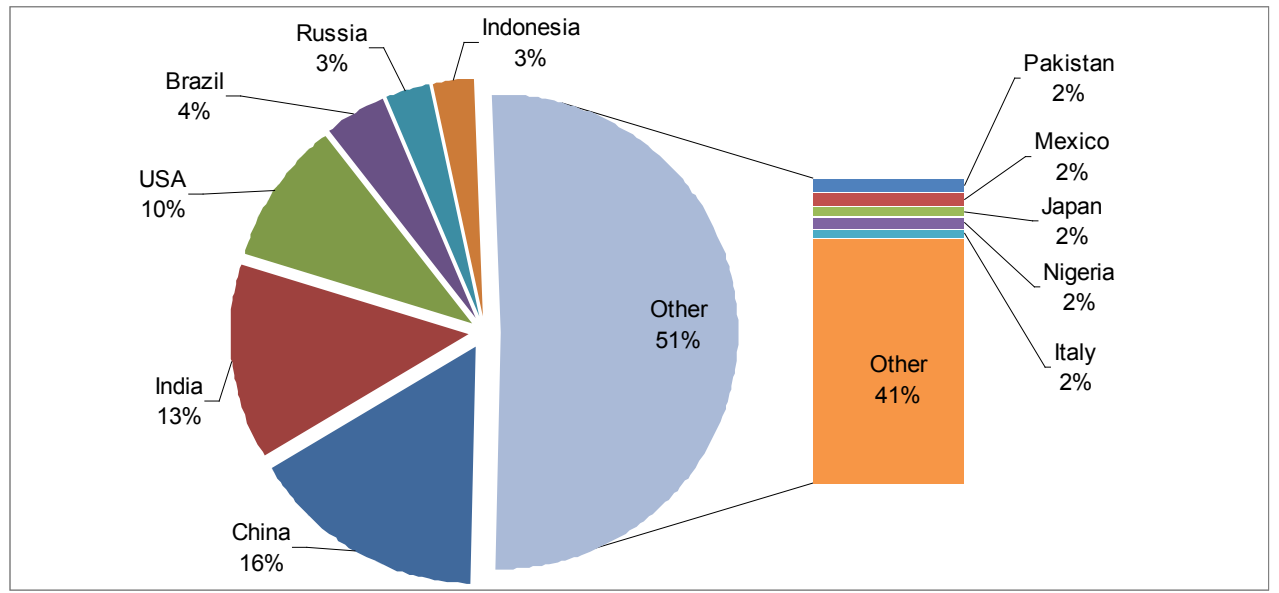

Figure 4.9. Contribution of different countries to the global water footprint of consumption.

The ranking of countries in Figure 4.11 shows that industrialised countries have water footprints per capita in the range of $1250-2850 \mathrm{~m}^{3} / \mathrm{yr}$. The UK, with a water footprint of $1258 \mathrm{~m}^{3} / \mathrm{yr}$, is at the low end of this range, while the USA, with a footprint of $2842 \mathrm{~m}^{3} / \mathrm{yr}$, is at the high end. The differences can be partially explained by differences in consumption 
pattern. In the USA, for example, average consumption of bovine meat - one of the highly water-intensive commodities - was $43 \mathrm{~kg} / \mathrm{yr}$ per capita, about 4.5 times the global average, while in the UK this was $18 \mathrm{~kg} / \mathrm{yr}$ per capita, about two times the global average. Another factor behind the differences in the water footprints is the water consumption and pollution per unit of product per country. In the USA, the average water footprint of one $\mathrm{kg}$ of consumed bovine meat is $14500 \mathrm{~m}^{3} /$ ton, while in the UK this is $9900 \mathrm{~m}^{3} /$ ton.

The water footprint per capita for developing countries varies much more than for industrialised countries. We find values in a range $550-3800 \mathrm{~m}^{3} / \mathrm{yr}$ per capita. At the low end is the Democratic Republic of Congo, with $552 \mathrm{~m}^{3} / \mathrm{yr}$ per capita. At the high end we

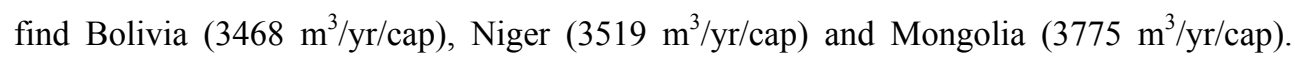
With the disclaimer that the extreme values can also partially relate to weak basic data on consumption and water productivity in those countries, the differences can be traced back to differences in consumptions patterns on the one hand and differences in the water footprints of the products consumed on the other hand. What the ranking in Figure 4.11 shows is that in the range of relatively large water footprints per capita we find both industrialised and developing countries. The latter are in that range generally not because of their relatively large consumption - although relatively large meat consumption can play a role - but because of their low water productivities, i.e. large water footprints per ton of product consumed. In Bolivia, for example, consumption of meat is 1.3 times the global average, but the water footprint per ton of meat is five times the global average. For Niger, the consumption of cereals per capita is 1.4 times the global average, but the water footprint of cereals per ton is six times the world average.

When we look at the blue water footprint per capita, countries in Central and Southwest Asia and North Africa appear on top. Consumers in Turkmenistan have the largest blue water footprint of all countries, namely $740 \mathrm{~m}^{3} / \mathrm{yr}$ per capita on average. Other countries with a large blue water footprint are (in descending order): Iran (589 $\mathrm{m}^{3} / \mathrm{yr} / \mathrm{cap}$ ), the United Arab Emirates (571), Egypt (527), Libya (511), Tajikistan (474), Saudi Arabia (447) and Pakistan (422). The global average blue water footprint of consumption is 153 $\mathrm{m}^{3} / \mathrm{yr}$ per capita, which is $11 \%$ of the total water footprint. As can be seen in Figure 4.12, the variation in blue water footprint per capita across countries is huge, much larger than the variation in total water footprint per capita (Figure 4.11). Whereas the largest total water footprint per capita (Mongolia) is about seven times the smallest total water footprint 
per capita (DR Congo), the difference in case of the blue water footprint is more than a factor hundred.

\subsubsection{External water dependency of countries}

All external water footprints of nations together constitute $22 \%$ of the total global water footprint (Figure 4.13). The share of external water footprint, however, varies from country to country. Some European countries, such as Italy, Germany, the UK and the Netherlands have external water footprints contributing $60 \%$ to $95 \%$ to the total water footprint. On the other hand, some countries such as Chad, Ethiopia, India, Niger, DR Congo, Mali, Argentina and Sudan have very small external water footprints, smaller than $4 \%$ of the total footprint.

Countries with a large external water footprint apparently depend upon freshwater resources in other countries. Highly water-scarce countries that have a large external water dependency are for example: Malta (dependency 92\%), Kuwait (90\%), Jordan (86\%), Israel (82\%), United Arab Emirates (76\%), Yemen (76\%), Mauritius (74\%), Lebanon (73\%) and Cyprus (71\%). Not all countries that have a large external water footprint, however, are water scarce. In this category are many Northern European countries like the Netherlands and the UK. They depend upon freshwater resources elsewhere, but the high dependence is not by necessity, since these countries have ample room for expanding agricultural production and thus reduce their external water dependency. 


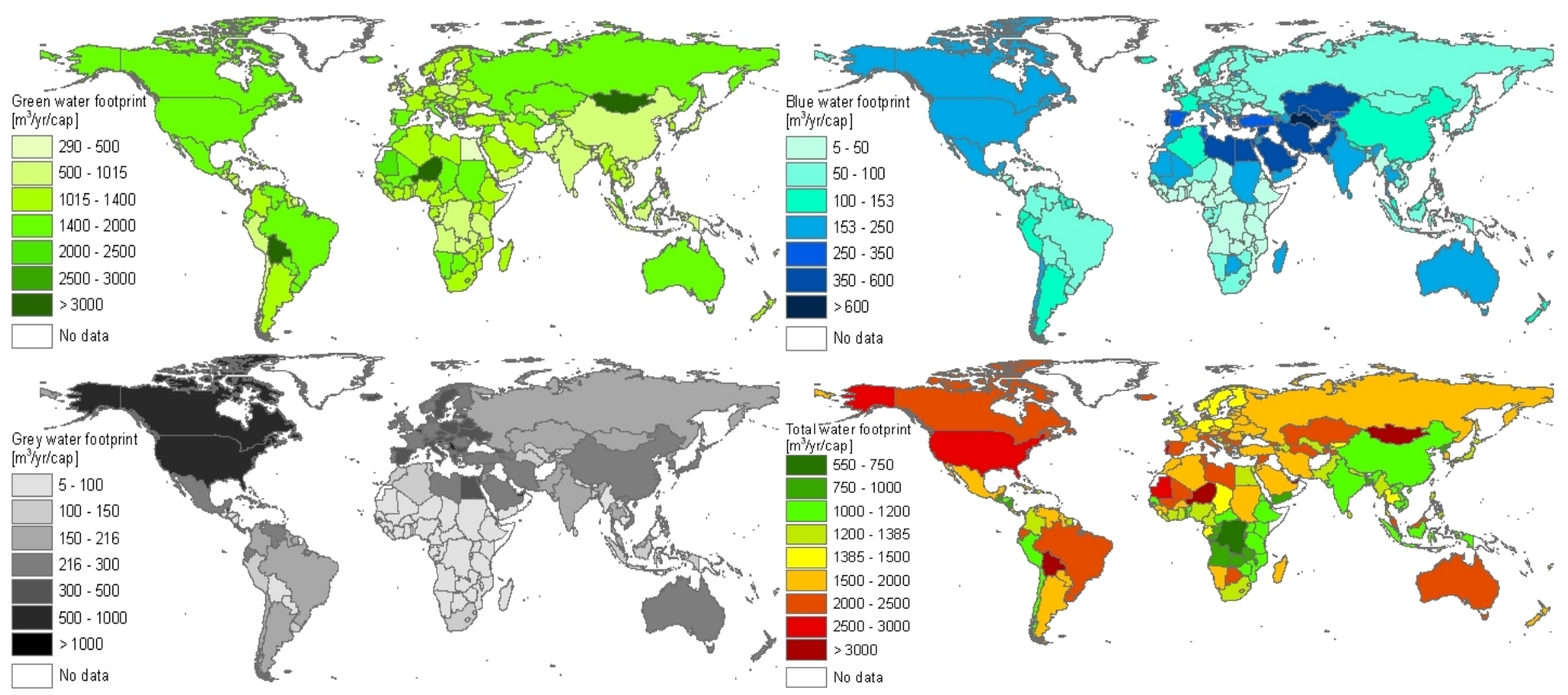

Figure 4.10. The green, blue, grey and total water footprint of consumption per country in the period 1996-2005 ( $\mathrm{m}^{3} / \mathrm{yr}$ per capita). In the map showing the total water footprint of consumption per country (bottom-right), countries shown in green have a water footprint that is smaller than the global average; countries shown in yellow-red have a water footprint larger than the global average. 


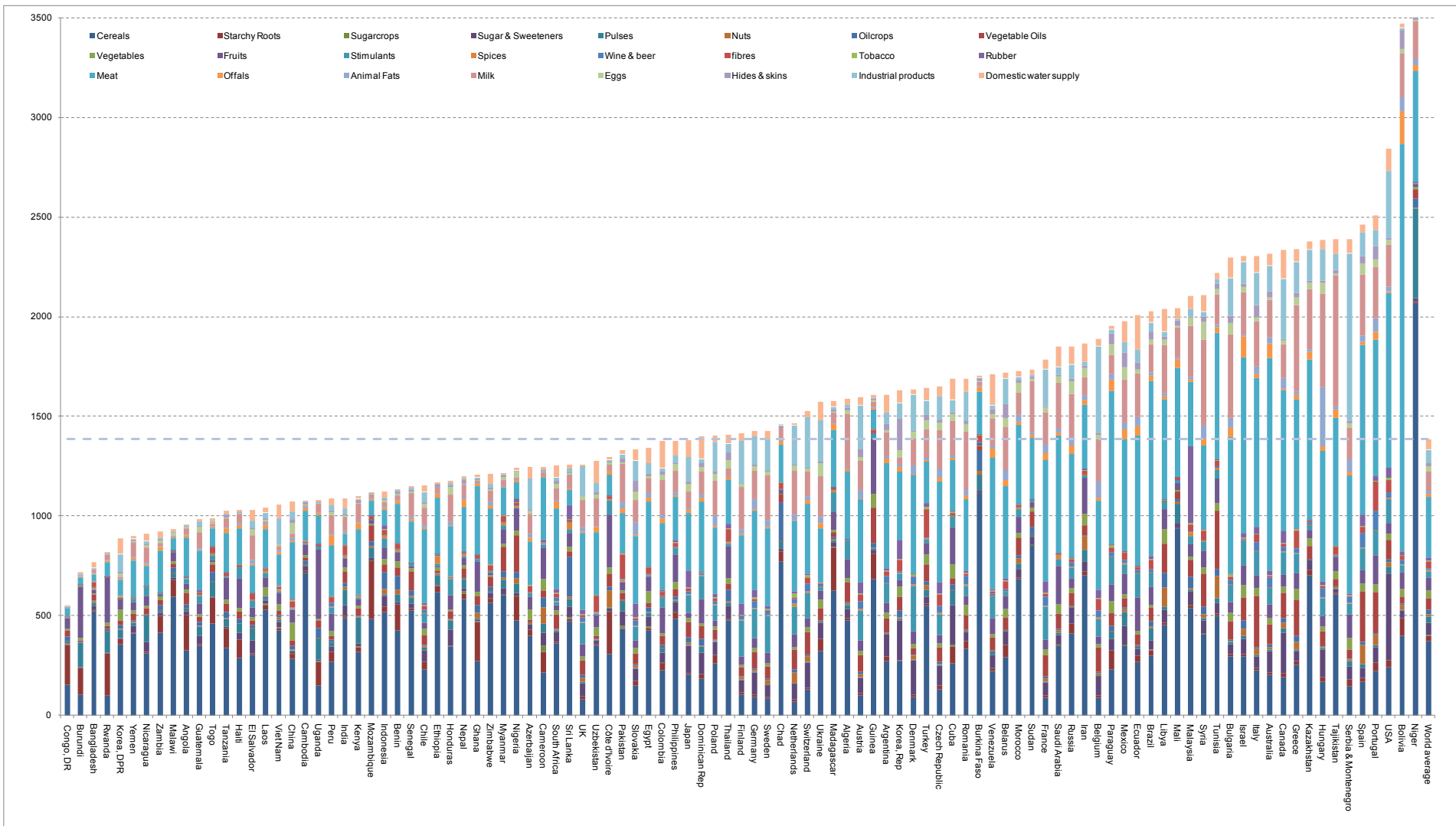

Figure 4.11. Water footprint of national consumption for countries with a population larger than 5 million, shown by product category ( $\left.\mathrm{m}^{3} / \mathrm{yr} / \mathrm{cap}\right)(1996-2005)$. 


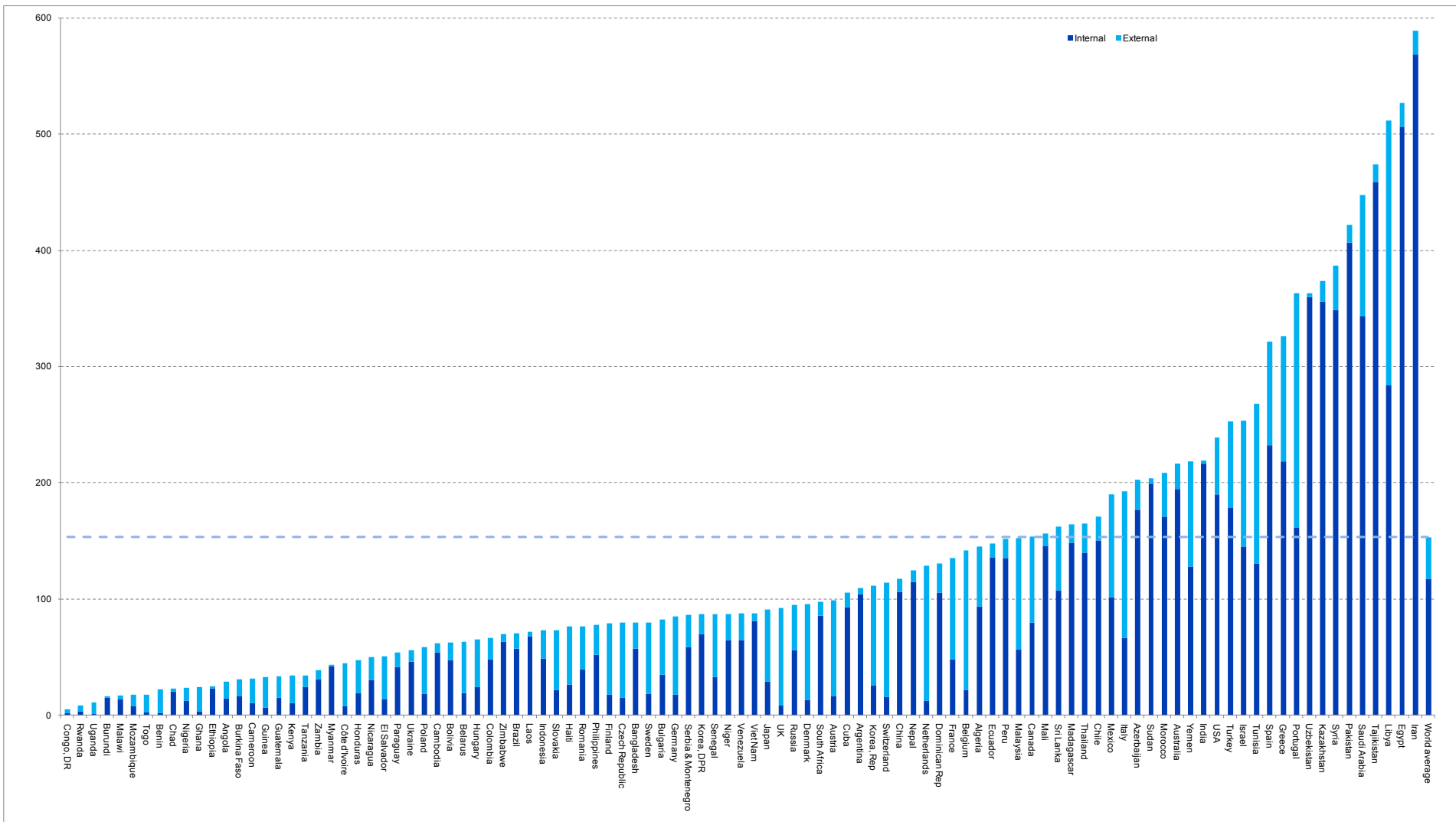

Figure 4.12. Blue water footprint of national consumption for countries with a population larger than 5 million, shown by internal and external component ( $\left.\mathrm{m}^{3} / \mathrm{yr} / \mathrm{cap}\right)$ (1996-2005). 


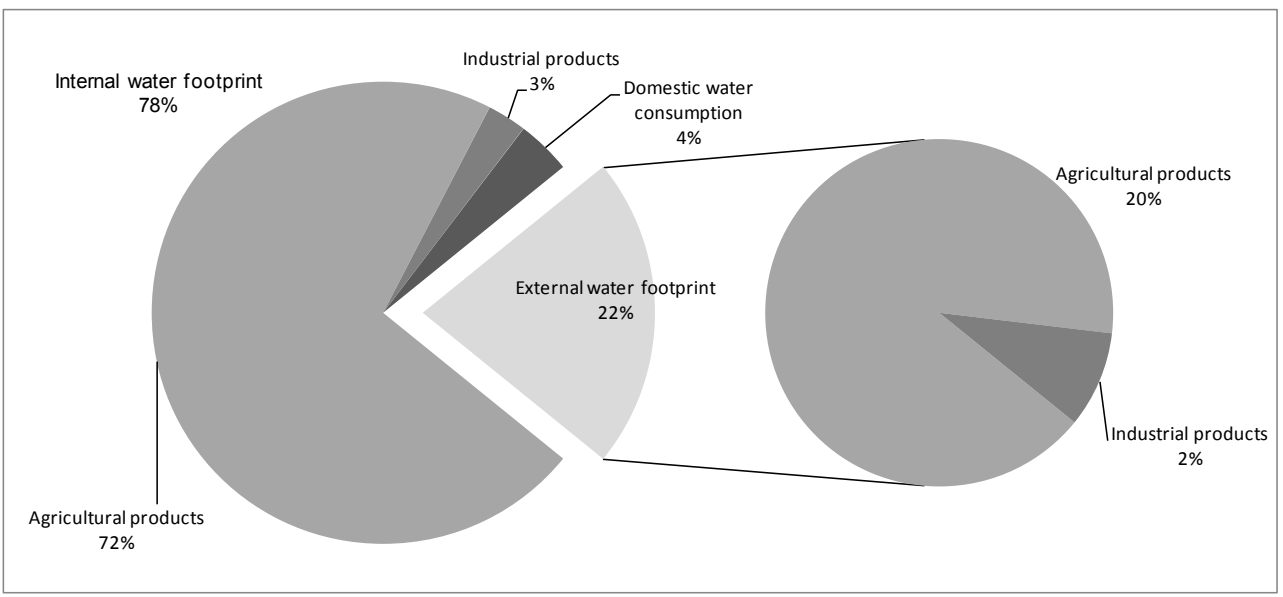

Figure 4.13. Contribution of different consumption categories to the global water footprint, split into internal and external water footprint.

\subsubsection{Mapping the global water footprint of national consumption: an example from the US}

The water footprint statistics presented in the previous section hide the fact that water footprints have a spatial dimension. In this section we illustrate this spatial dimension with an example from the US.

The global water footprint of US citizens related to the consumption of agricultural products is mapped at a fine scale resolution ( 5 by 5 arc minute grid) in Figure 4.14. The map shows the water footprint of crops consumed directly by US consumers and the water footprint of animal feed crops (domestic and imported) used to produce the animal products that are both produced and consumed within the US. It excludes the water footprint of imported animal products consumed within the US because tracing the origin of the feed of imported animal products on grid level would require a very laborious additional step of analysis.

The global water footprint of US consumption of industrial products is mapped in Figure 4.15. The water footprint of US domestic water consumption is fully within the US itself and shown in Figure 4.16. We ignore here the water footprint of imported bottled water, but in terms of volumes this is very small compared to the water volumes consumed in households from domestic water supply (Gleick, 2010). 


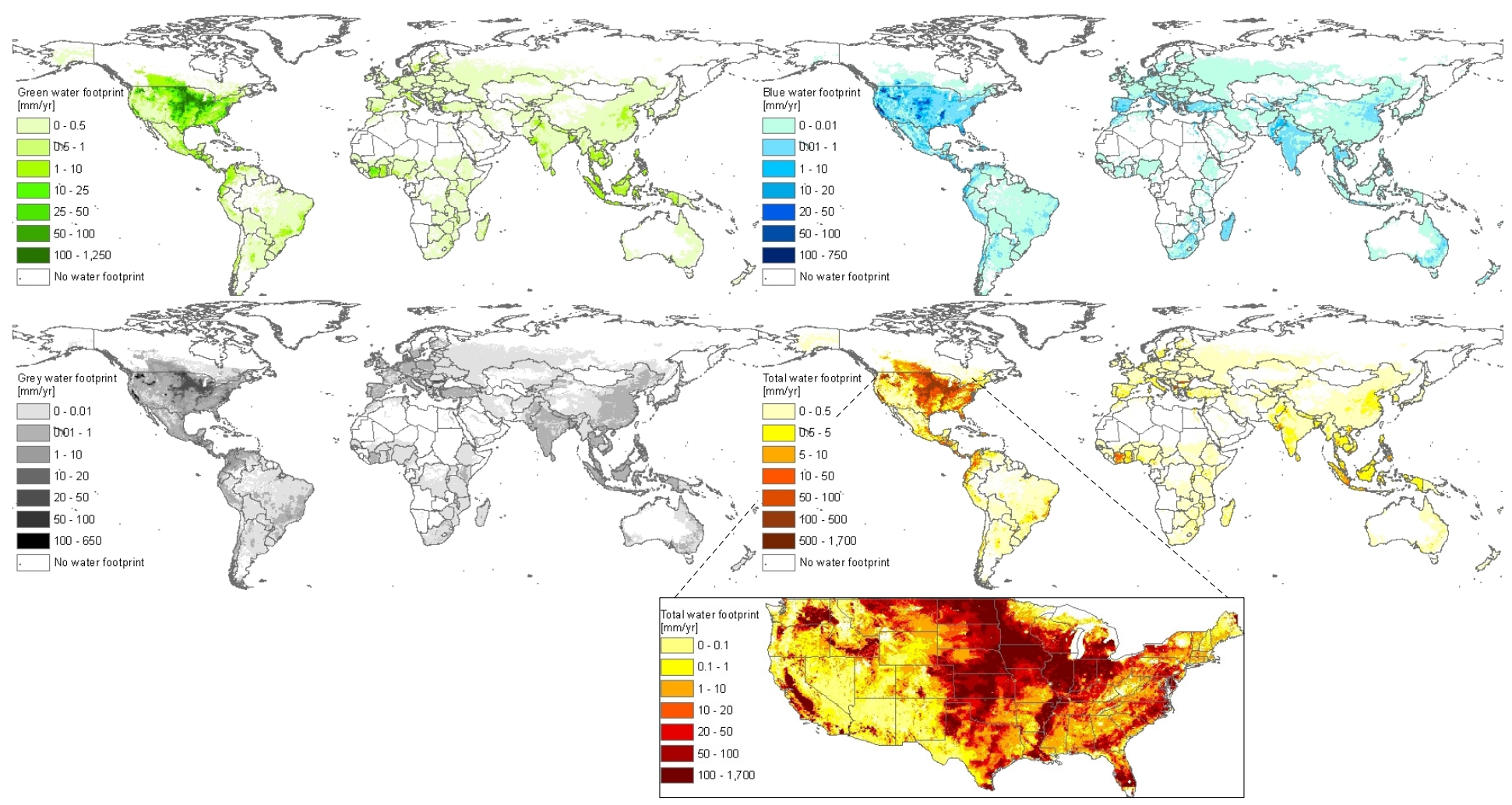

Figure 4.14. The global water footprint of US citizens related to the consumption of crop and animal products (1996-2005). 


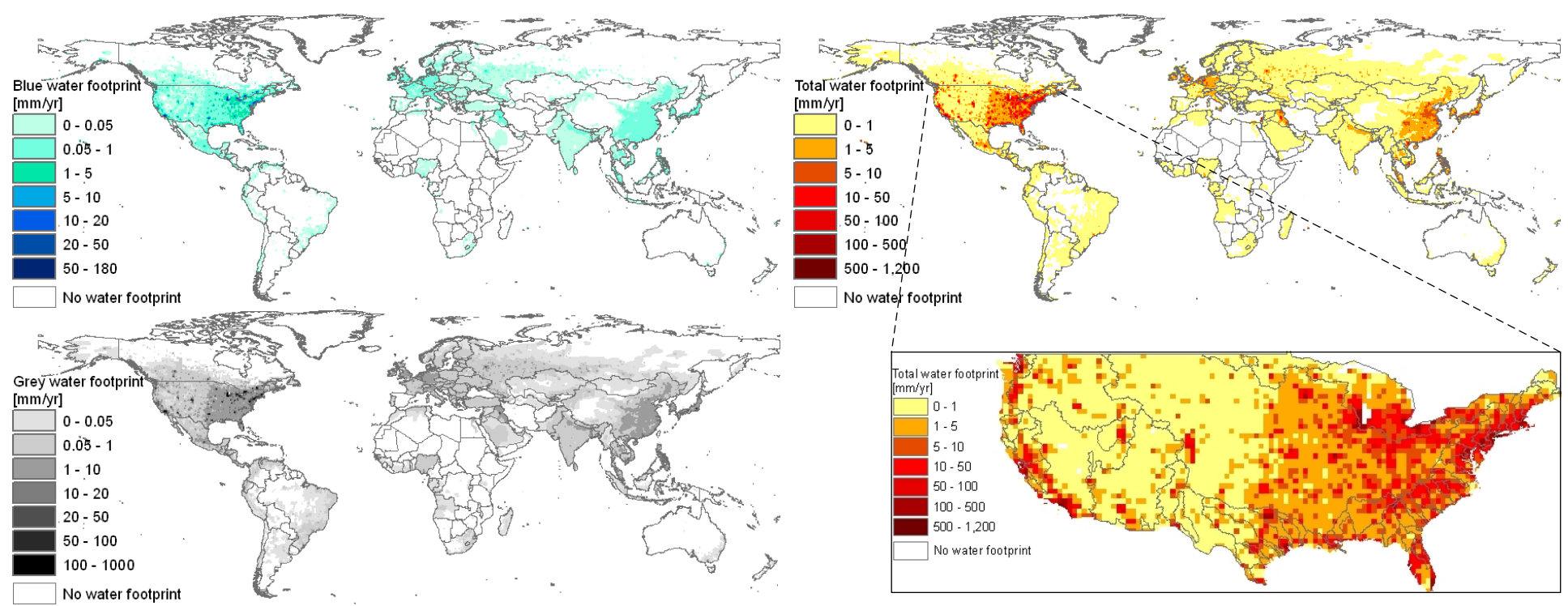

Figure 4.15. The global water footprint of US citizens related to the consumption of industrial products (1996-2005). 

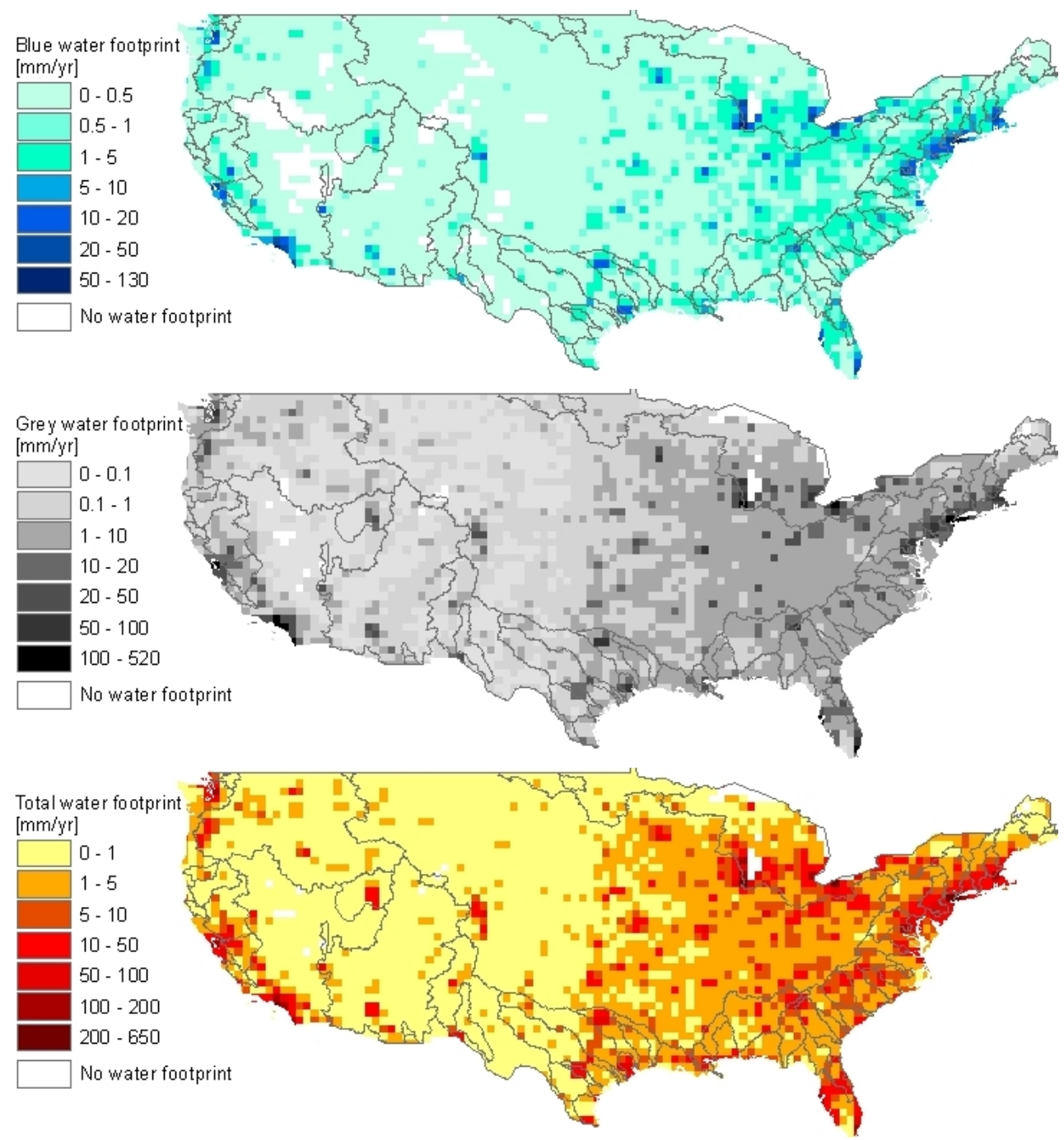

Figure 4.16. The water footprint of US citizens related to domestic water supply (19962005). The boundaries shown are river basin boundaries.

Most of the US water footprint lies within the US, mainly in the Mississippi basin (more than $50 \%$ ). About $20 \%$ of the water footprint of US citizens lies outside the US. The largest water footprint outside the US is in the Yangtze basin (China). 


\subsection{Discussion}

The global water footprint related to agricultural and industrial production and domestic water supply for the period 1996-2005 was found to be $9087 \mathrm{Gm}^{3} / \mathrm{yr}$ (Section 4.3.1). If we calculate the global sum of estimated national water footprints of consumption (Section 4.3.5), we arrive at a $6 \%$ lower figure, namely $8525 \mathrm{Gm}^{3} / \mathrm{yr}$. An explanation is that the latter figure is conservative, because in the estimation of the water footprint of national consumption of agricultural products based on the bottom-up approach we only partially accounted for the water footprint of waste and seeds. We multiplied all consumption figures by a certain factor to account for waste and seeds where applicable (see method and data section) for all crop and animal products consumed but we could not account for the water footprint of waste and seeds in the production of animal feed. Another reason for the difference between the two global water footprint estimates is that in the water footprint of global production we could account for all countries, while in the estimation of the water footprint of national consumption we had to exclude a few countries due to the absence of consumption data (most notably Iraq and Afghanistan). Another explanation of the difference is that in the estimation of the national water footprint related to consumption we could not include all consumer categories (like for example some alcoholic beverages). When it was not clear which crops underlie certain products, we could not calculate the water footprint per ton of those products. A final explanation for differences between the two global water footprint figures could be that stock changes reported in the Supply and Utilization Accounts of the Food and Agriculture Organization (FAO, 2010a) create a difference between 'production plus imports' and 'utilization' in a certain period.

This study is the first to use the bottom-up approach to estimate the water footprint of national consumption of agricultural commodities at a global scale. As shown by Van Oel et al. (2009), the advantage of using the bottom-up approach is that it is more stable. The bottom-up approach depends on the quality of consumption data, while the top-downapproach relies on the quality of production and trade data. The outcome of the top-down approach can be vulnerable to relatively small errors in the trade data when the import and export of a country are large relative to its domestic production. Relatively small errors in the estimates of virtual-water import and export can then translate into a relatively large error in the water footprint estimate. In such a case, the bottom-up approach yields a more 


\section{0 / Chapter 4. National water footprint accounts}

reliable estimate than the top-down approach. Another advantage of the bottom-up approach is that it allows for showing the composition of the water footprint by commodity or product category in a very straightforward manner (because this is the way the overall estimate is built up), which in the top-down approach is difficult to achieve.

A limitation in the study is that the origin of products has been traced only by one step. If a product is imported from another country, we assume that the product has been produced in that country and we take the water footprint of the imported product accordingly. If the trade partner country does not produce that commodity, we do not trace further back but assume a global average water footprint. But even if the country produces the product, it could have been the case that the product was in part imported from somewhere else and re-exported. Tracing of products by more than one step has been done for example by Chapagain and Orr (2008) for the UK but this was too laborious for this global study. Besides, such continued tracing effort is necessarily based on assumptions because export data in trade statistics are not connected to import data, therefore the added value of tracing can be questioned. Finally, in a global study, tracing back more than one step would create the problem of circularity in the calculations. Common products are traded in all directions between all countries, so that a strategy of tracing products will soon lead to the situation in which a small fraction of a product imported to a country $\mathrm{X}$ is estimated to originate, through a detour, from the same country $\mathrm{X}$. This leads to a mathematical circularity in the calculation of the average water footprint of the product in country $\mathrm{X}$ - see equation (17).

The grey water footprint estimates in this study are to be considered as conservative. In the case of agricultural production, the grey water footprint estimates are based on leaching and runoff of nitrogen fertilisers, excluding the potential effect of other fertiliser components and pesticides (Mekonnen and Hoekstra, 2010d, 2011a). In the cases of industrial production and domestic water supply, a very conservative dilution factor of 1 has been applied for all untreated return flows.

While in the estimation of the water footprint of consumer products we considered a huge amount of different agricultural commodities separately, industrial commodities were treated as one whole category. Although in this way the study shows no detail within the estimation of the water footprint of production and consumption of industrial products, we 
justify the choice in this global study based on the fact that most of the water footprint of humanity is within the agricultural sector.

We have analysed a ten-year period, but we do not show annual variations or trends in time. The reason is that the data do not allow for that. Many of the databases that we used show data for every individual year within our ten-year period (e.g. production, consumption, trade, rainfall and yield data), but not all global databases show year-specific data (e.g. reference evapotranspiration, crop growing area and irrigation data). The estimated water footprints of agricultural products are necessarily ten-year averages, because they have been based on climate data, which are by definition multi-year averages (Mekonnen and Hoekstra, 2010d, 2011a). Even if we would have been able to estimate water footprints by year, a trend analysis over a ten-year period would have been difficult due to the natural inter-annual variability of rainfall and temperature.

The data presented in this paper are derived on the basis of a great number of underlying statistics, maps and assumptions. Since all basic sources include uncertainties and possible errors, the presented water footprint data should be taken and interpreted with extreme caution, particularly when zooming in on specific locations on a map or when focussing on specific products. Basic sources of uncertainties are for example the global precipitation, temperature, crop and irrigation maps that we have used and the yield, production, consumption, trade and wastewater treatment statistics that we had to rely on. Underlying assumptions refer, for example, to planting and harvesting dates per crop per region and feed composition per farm animal type per country and production system. Another assumption has been that water footprints of industrial production and domestic water supply are geographically spread according to population densities. Despite the plethora of uncertainties, we think that the current study forms a good basis for rough comparisons and to guide further analysis.

\subsection{Conclusion}

The study shows that about one fifth of the global water footprint in the period 1996-2005 was not related to production for domestic consumption but for export. The global volume of water saving from international trade in agricultural products was equivalent to $4 \%$ of the global water footprint for agricultural production. The relatively large volume of 


\section{2 / Chapter 4. National water footprint accounts}

international virtual water flows and the associated national water savings and external water dependencies strengthen the argument to consider issues of local water scarcity in a global context (Hoekstra and Chapagain, 2008; Hoekstra, 2011).

Two factors determine the magnitude of the water footprint of national consumption: (1) the volume and pattern of consumption and (2) the water footprint per ton of consumed products. The latter, in the case of agricultural products, depends on climate, irrigation and fertilization practice and crop yield. The global average water footprint related to consumption is $1385 \mathrm{~m}^{3} / \mathrm{yr}$ per capita over the period 1996-2005. Industrialised countries have water footprints in the range of $1250-2850 \mathrm{~m}^{3} / \mathrm{yr} / \mathrm{cap}$, while developing countries show a much larger range of 550-3800 $\mathrm{m}^{3} / \mathrm{yr} / \mathrm{cap}$. The low values for developing countries relate to low consumption volumes; the large values refer to very large water footprints per unit of consumption.

The study provides important information on the water footprints of nations, disaggregated into the type of water footprint (green, blue or grey) and mapped at a high spatial resolution. The paper shows how different products and national communities contribute to water consumption and pollution in different places. The figures can thus form an important basis for further assessment of how products and consumers contribute to the global problem of increasing freshwater appropriation against the background of limited supplies and to local problems of overexploitation and deterioration of freshwater bodies or conflict over water. Once one starts overlaying localised water footprints of products or consumers with maps that show environmental or social water conflict, a link has been established between final products and consumers on the one hand and local water problems on the other hand. Establishing such links can help the dialogue between consumers, producers, intermediates (like food processors and retailers) and governments about how to share responsibility for reducing water footprints where most necessary. 


\section{Global water scarcity: The monthly blue water footprint compared to blue water availability for the world's major river basins ${ }^{4}$}

\section{Abstract}

Conventional blue water scarcity indicators suffer from four weaknesses: they measure water withdrawal instead of consumptive water use, they compare water use with actual runoff rather than natural (undepleted) runoff, they ignore environmental flow requirements and they evaluate scarcity on an annual rather than a monthly time scale. In the current study, these shortcomings are solved by defining blue water scarcity as the ratio of blue water footprint to blue water availability - where the latter is taken as natural runoff minus environmental flow requirement - and by estimating all underlying variables on a monthly basis.

The objective of this study is to assess the intra-annual variability of blue water scarcity for the world's major river basins. Monthly blue water footprints were estimated based on Mekonnen and Hoekstra (2011b). Natural runoff per river basin was estimated by adding estimates of actual runoff from Fekete et al. (2002) and estimates of water volumes already consumed. Environmental flow requirements were estimated based on the presumptive standard for environmental flow protection as proposed by Richter et al. (2011), which can be regarded as a precautionary estimate of environmental flow requirements.

Within the study period 1996-2005, in 223 river basins (55\% of the basins studied) with in total 2.72 billion inhabitants $(69 \%$ of the total population living in the basins included in this study), the blue water scarcity level exceeded one hundred per cent during at least one month of the year, which means that environmental flow requirements were violated during at least one month of the year. In 201 river basins with in total 2.67 billion people there was severe water scarcity during at least one month per year, which means that the blue water footprint was more than twice the blue water availability during at least one month per year.

\footnotetext{
${ }^{4}$ Based on Hoekstra and Mekonnen (2011)
} 


\section{4 / Chapter 5. Global blue water scarcity}

Global average blue water scarcity - estimated by averaging the annual average monthly blue water scarcity values per river basin weighted by basin area - is $85 \%$. This is the average blue water scarcity over the year within the total land area considered in this study. When we weight the annual average monthly blue water scarcity values per river basin according to population number per basin, global average blue water scarcity is $133 \%$. This is the average scarcity as experienced by the people in the world. This population-weighted average scarcity is higher than the area-weighted scarcity because the water scarcity values in densely populated areas - which are often higher than in sparsely populated areas - get more weight. Yet another way of expressing water scarcity is to take the perspective of the average water consumer. The global water consumption pattern is different from the population density pattern, because intensive water consumption in agriculture is not specifically related to where most people live. If we estimate global blue water scarcity by averaging monthly blue water scarcity values per river basin weighted based on the blue water footprint in the respective month and basin, we calculate a global blue water scarcity at $244 \%$. This means that the average blue water consumer in the world experiences a water scarcity of $244 \%$, i.e. operates in a month in a basin in which the blue water footprint is 2.44 times the blue water availability and in which presumptive environmental flow requirements are thus strongly violated.

\subsection{Introduction}

Water is a ubiquitous natural resource covering approximately three-quarters of the Earth's surface, but 97.5 per cent of the water on the planet is saline water (Shiklomanov and Rodda, 2003). Only 2.5 per cent of the global water stock is fresh water, but more than twothirds of that is locked in the form of ice and snow in the Antarctic, Greenland, arctic islands and mountainous regions. This leaves less than one per cent of the global water resources as freshwater accessible for meeting human needs. Fortunately, however, freshwater is a renewable resource, which means that it is continually replenished through precipitation over land. Renewable, though, does not mean that supply is unlimited. The availability of freshwater is primarily limited by the replenishment rate, not by the existing stocks. Moreover, availability is strongly dependent upon location and time. Globally and on an annual basis there is enough freshwater to meet human needs but the problem is that 
its spatial and temporal distribution is uneven. Spatial and temporal variation of freshwater availability is often a major determining factor for water scarcity (Postel et al., 1996; Savenije, 2000).

There have been various studies developing water-scarcity indicators and assessing global water scarcity. Water-scarcity indicators are always based on two basic ingredients: a measure of water demand or use and a measure of water availability. One commonly used indicator of water scarcity is population of an area divided by total runoff in that area, called the water competition level (Falkenmark, 1989; Falkenmark et al., 1989) or water dependency (Kulshreshtha, 1993). Many authors take the inverse ratio, thus getting a measure of the per capita water availability. Falkenmark proposes to consider regions with more than $1700 \mathrm{~m}^{3}$ per year per capita as 'water sufficient', which means that only general water management problems occur. Between 1000-1700 $\mathrm{m}^{3} / \mathrm{yr}$ per capita would indicate 'water stress', 500-1000 m³/yr 'chronic water scarcity' and less than $500 \mathrm{~m}^{3} / \mathrm{yr}$ 'absolute water scarcity'. This classification is based on the idea that $1700 \mathrm{~m}^{3}$ of water per year per capita is sufficient to produce the food and other goods and services consumed by one person. This approach ignores the fact that water resources in a certain area do not necessarily need to be sufficient to feed the people in the area, since people can also import food (Hoekstra and Hung, 2005). Falkenmark's water scarcity indicator is not related to the actual consumption of the people in an area, nor to the efficiency of water use or the way in which the people obtain their water-intensive goods (through self-production or import). When the production of water-intensive goods for the people in a country is for a significant part localised abroad, it may well happen that a country with much less than $1700 \mathrm{~m}^{3} / \mathrm{yr}$ per capita does not experience serious water problems. And $1700 \mathrm{~m}^{3} / \mathrm{yr}$ per capita means much more in a country that uses it water in a highly efficient way and has reduced demand than in an inefficient country that lacks any demand management.

Another common indicator of water scarcity is the ratio of annual water use in a certain area to total annual runoff in that area, called variously the water utilization level (Falkenmark, 1989; Falkenmark et al., 1989), the use-availability ratio (Kulshreshtha, 1993), withdrawal-to-availability ratio (Alcamo and Henrichs, 2002; Oki and Kanae, 2006; Vörösmarty et al., 2000), use-to-resource ratio (Raskin et al., 1996) or criticality ratio (Alcamo et al., 1997, 2000; Cosgrove and Rijsberman, 2000a, 200b). As a measure of water use, the total water withdrawal is taken. There are four critiques to this approach. First, 


\section{6 / Chapter 5. Global blue water scarcity}

water withdrawal is not the best indicator of water use when one is interested in the effect of the withdrawal at the scale of the catchment as a whole, because water withdrawals partly return to the catchment (Perry, 2007). Therefore it makes more sense to express blue water use in terms of consumptive water use, i.e. by considering the blue water footprint (Hoekstra et al., 2011). Second, total runoff is not the best indicator of water availability, because it ignores the fact that part of the runoff needs to be maintained for the environment. Therefore it is better to subtract the environmental flow requirement from total runoff (Smakhtin et al., 2004a; Poff et al., 2010). Third, comparing water use to actual runoff from a catchment becomes problematic when runoff has been substantially lowered due to the water use within the catchment. It makes more sense to compare water use to natural or undepleted runoff from the catchment, i.e. the runoff that would occur without consumptive water use within the catchment. Finally, it is not accurate to consider water scarcity by comparing annual values of water use and availability (Savenije, 2000). In reality, water scarcity manifests itself at monthly rather than annual scale, due to the intraannual variations of both water use and availability. In the context of water footprint studies, the 'blue water scarcity' in a catchment is defined such that the four weaknesses are repaired. Blue water scarcity in a river basin is defined here as the ratio of blue water footprint to blue water availability, whereby the latter is defined as natural runoff (through groundwater and rivers) from the basin minus environmental flow requirements (Hoekstra et al., 2011). The blue water scarcity indicator can be calculated over any time period, but in order to capture variability of both the blue water footprint and blue water availability, a time step of a month is much better than a time step of a year. The blue water scarcity as defined here is a physical and environmental concept. It is physical because it compares appropriated to available volumes and environmental because it accounts for environmental flow needs. It is not an economic scarcity indicator, which would use monetary values to express scarcity.

The objective of this study is to assess the intra-annual variability of blue water scarcity for the world's major river basins. We compare the monthly blue water footprint with monthly blue water availability, where the latter is taken as natural runoff minus environmental flow requirement. Monthly blue water footprints were estimated based on Mekonnen and Hoekstra (2011b). Natural runoff per river basin was estimated by adding estimates of actual runoff from Fekete et al. (2002) and estimates of water volumes already 
consumed. Environmental flow requirements were estimated based on the presumptive standard for environmental flow protection as proposed by Richter et al. (2011), which can be regarded as a precautionary estimate of environmental flow requirements.

\subsection{Method and data}

Following Hoekstra et al. (2011), the blue water scarcity in a river basin in a certain period is defined as the ratio of the total 'blue water footprint' in the river basin in that period to the 'blue water availability' in the catchment and that period. A blue water scarcity of one hundred per cent means that the available blue water has been fully consumed. The blue water scarcity is time-dependent; it varies within the year and from year to year. In this study, we calculate blue water scarcity per river basin on a monthly basis. Blue water footprint and blue water availability are expressed in $\mathrm{mm} / \mathrm{month}$. For each month of the year we consider the ten-year average for the period 1996-2005.

The blue water footprint per river basin for the period 1996-2005 has been obtained from Mekonnen and Hoekstra (2011b), who estimated the global blue water footprint at a 5 by 5 arc minute spatial resolution. Their blue water footprint assessment comprises the blue water footprint by three water-consuming sectors: agriculture, industry and domestic water supply. The blue water footprint of crop production was calculated using a daily soil water balance model at the mentioned resolution level as reported in Mekonnen and Hoekstra (2010a,d, 2011a). The blue water footprints of industries and domestic water supply were obtained by spatially distributing national data on industrial and domestic water withdrawals from FAO (2010b) according to population densities around the world as given by CIESIN and CIAT (2005) and by assuming that $5 \%$ of the industrial withdrawals and $10 \%$ of the domestic withdrawals are ultimately consumed, i.e. evaporated, crude estimates based on FAO (2010b). Due to a lack of data we have distributed the annual water withdrawal figures equally over the twelve months of the year without accounting for the possible monthly variation.

The monthly blue water availability in a river basin in a certain period was calculated as the 'natural runoff' in the basin minus 'environmental flow requirement'. The natural runoff was estimated by adding the actual runoff and the total blue water footprint within the river basin. Monthly actual runoff data at a 30 by 30 arc minute resolution were 


\section{8 / Chapter 5. Global blue water scarcity}

obtained from the Composite Runoff V1.0 database (Fekete et al., 2002). These data are based on model estimates that were calibrated against runoff measurements for different periods, with the year 1975 as the mean central year. In order to get the natural (undepleted) runoff, we added the aggregated blue water footprint per basin as in 1975. The latter was estimated to be $74 \%$ of the blue water footprint per basin as was estimated by Mekonnen and Hoekstra (2011b) for the central year 2000. The 74\% refers to the ratio of global water consumption in 1975 to the global water consumption in 2000 (Shiklomanov and Rodda, 2003).

In order to establish the environmental flow requirement we have adopted the ' 20 per cent rule' as proposed by Richter et al. (2011) and Hoekstra et al. (2011). Under this rule, 80 per cent of the natural run-off is allocated as 'environmental flow requirement' and the remaining 20 per cent can be considered as blue water available for human use without affecting the integrity of the water-dependent ecosystems. The 20 per cent rule is considered as a general precautionary guideline.

Blue water scarcity values have been classified into four levels of water scarcity:

- low blue water scarcity ( $<100 \%)$ : the blue water footprint is lower than $20 \%$ of natural runoff and does not exceed blue water availability; river runoff is unmodified or slightly modified; environmental flow requirements are not violated.

- moderate blue water scarcity (100-150\%): the blue water footprint is between 20 and $30 \%$ of natural runoff; runoff is moderately modified; environmental flow requirements are not met.

- significant blue water scarcity (150-200\%): the blue water footprint is between 30 and $40 \%$ of natural runoff; runoff is significantly modified; environmental flow requirements are not met.

- severe water scarcity ( $>200 \%$ ). The monthly blue water footprint exceeds $40 \%$ of natural runoff, so runoff is seriously modified; environmental flow requirements are not met.

We considered 405 river basins, which together cover $66 \%$ of the global land area (excluding Antarctica) and represent 65\% of the global population in 2000 (estimate based 
on database of CIESIN and CIAT, 2005). We applied river basin boundaries and names as provided by GRDC (2007) (Appendix 5A). The land areas not covered include for example Greenland, the Sahara desert in North Africa, the Arabian peninsula, the Iranian, Afghan and Gobi deserts in Asia, the Mojave desert in North America and the Australian desert. Also excluded are many smaller pieces of land, often along the coasts, that do not fall within major river basins.

\subsection{Results}

\subsubsection{Monthly natural runoff and blue water availability}

Natural runoff and blue water availability vary across basins and over the year as shown on the global maps in Appendices 5B-5C. At a global level, monthly runoff is beyond average in the months of January and April to August and below average during the other months of the year. When we look at the runoff per region, we find that most of the runoff in North America occurs in the period of April to June, in Europe from March to June, in Asia between May and September, in Africa in January, August and September, and in South America from January to May (Figure 5.1). While the Amazon and Congo river basins display relatively low variability over the year, much sharper gradients are apparent in other basins. In some parts of the world, a large portion of the annual runoff occurs within a few weeks or months, generating floods during one part of the year and drought during the other part. Even in otherwise water abundant areas, intra-annual variability can severely limit blue water availability. Under such conditions, considering blue water availability on an annual basis provides an incomplete view of blue water availability per basin. Not only temporal variability of blue water availability is important, but also the spatial variability. The Amazon and Congo River Basins together account for $28 \%$ of the natural runoff in the 405 river basins considered in this study. These two basins, however, are sparsely populated, which illustrates how important it is to analyse blue water scarcity at river basin rather than global level. 


\section{0 / Chapter 5. Global blue water scarcity}

\subsubsection{Monthly blue water footprint}

The current study has taken the blue water footprint (consumptive use of ground or surface water) as a measure of freshwater use instead of water withdrawal as used in all earlier water scarcity studies. Agriculture accounts for $92 \%$ of the global blue water footprint; the remainder is equally shared between industrial production and domestic water supply (Mekonnen and Hoekstra, 2011b). However, this share varies across river basins and within the year. While the blue water footprint in agriculture varies from month to month depending on the timing and intensity of irrigation, the domestic water supply and industrial production were assumed to remain constant throughout the year. Therefore, for particular months in certain basins one hundred per cent of the blue water footprint can be attributed to industry and domestic water supply. The intra-annual variability of the total blue water footprint for the major river basins is mapped in Appendix 5D. The values on the maps are shown in mm per month and can thus directly be compared. A large blue water footprint throughout the year is observed for the Indus and Ganges river basins, because irrigation occurs here throughout the year. A large blue water footprint during part of the year is estimated for basins such as the Tigris-Euphrates, Huang He (Yellow River), Murray, Guadiana, Colorado (Pacific Ocean) and Krishna. When we consider Europe and North America as a whole, we see a clear peak in the blue water footprint in the months May to September (around the northern summer). In Australia, we see a blue water footprint peak in the months October to March (around the southern summer). One cannot find such profound patterns if one consider the blue water footprint throughout the year in South America, Africa or Asia, because these continents are more heterogeneous (Figure $5.2)$.

\subsubsection{Monthly blue water scarcity per river basin}

The blue water scarcity for each of the twelve months of the year for the major river basins in the world is presented in global maps in Figures 5.3a-5.3b. In each month that a river basin is coloured in some shade of green, the monthly blue water scarcity is low (smaller than $100 \%$ ). The blue water footprint does not exceed blue water availability, which means that environmental flow requirements are not violated. River runoff in that month is 
unmodified or slightly modified. In each month that a river basin is coloured yellow, blue water scarcity is moderate (100-150\%). The blue water footprint is between 20 and $30 \%$ of natural runoff. Runoff is moderately modified; environmental flow requirements are not met. When a river basin is coloured orange, water scarcity is significant (150-200\%). The blue water footprint is between 30 and $40 \%$ of natural runoff. Monthly runoff is significantly modified. In each month that a river basin is coloured red, water scarcity is severe $(>200 \%)$. The monthly blue water footprint exceeds $40 \%$ of natural runoff, so runoff is seriously modified.

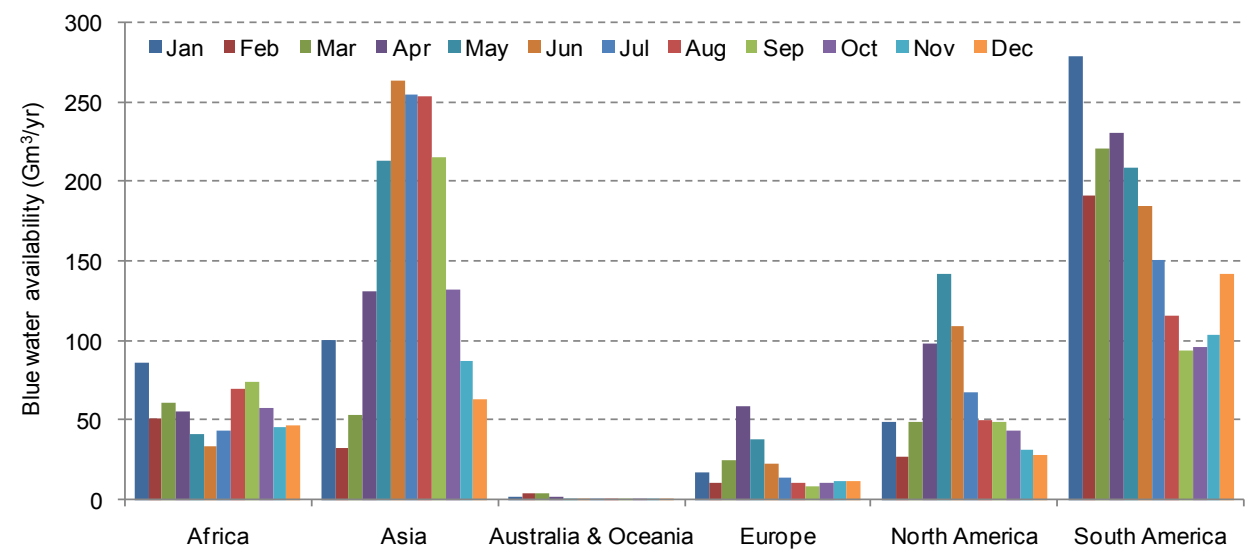

Figure 5.1. Monthly blue water availability per continent.

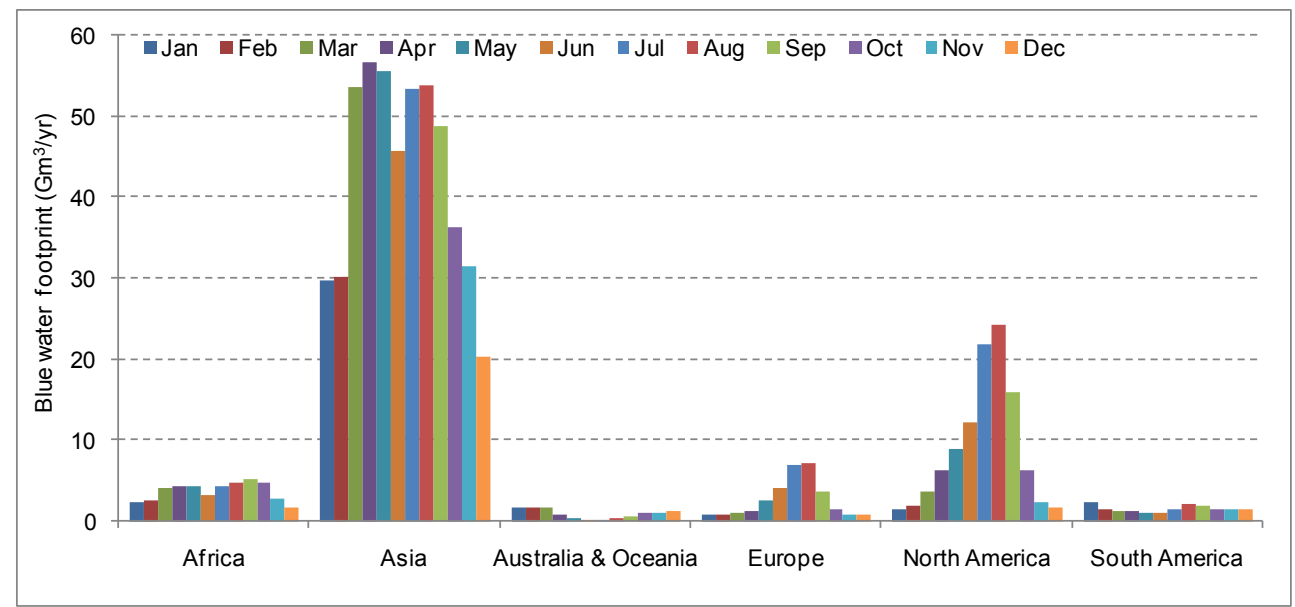

Figure 5.2. Monthly blue water footprint per continent. 


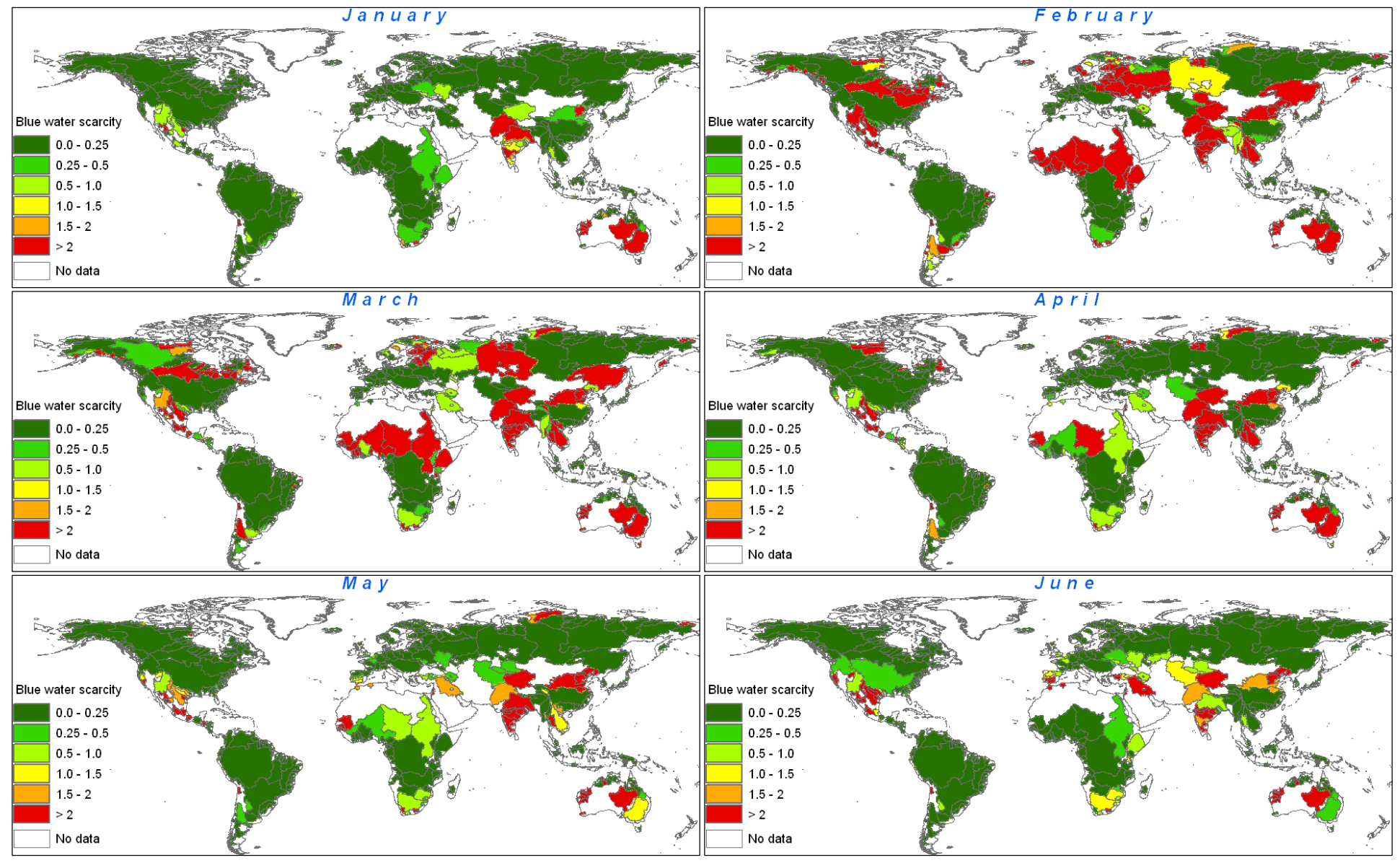

Figure 5.3a. Monthly blue water scarcity in the world's major river basins (January-June). Period: 1996-2005. 


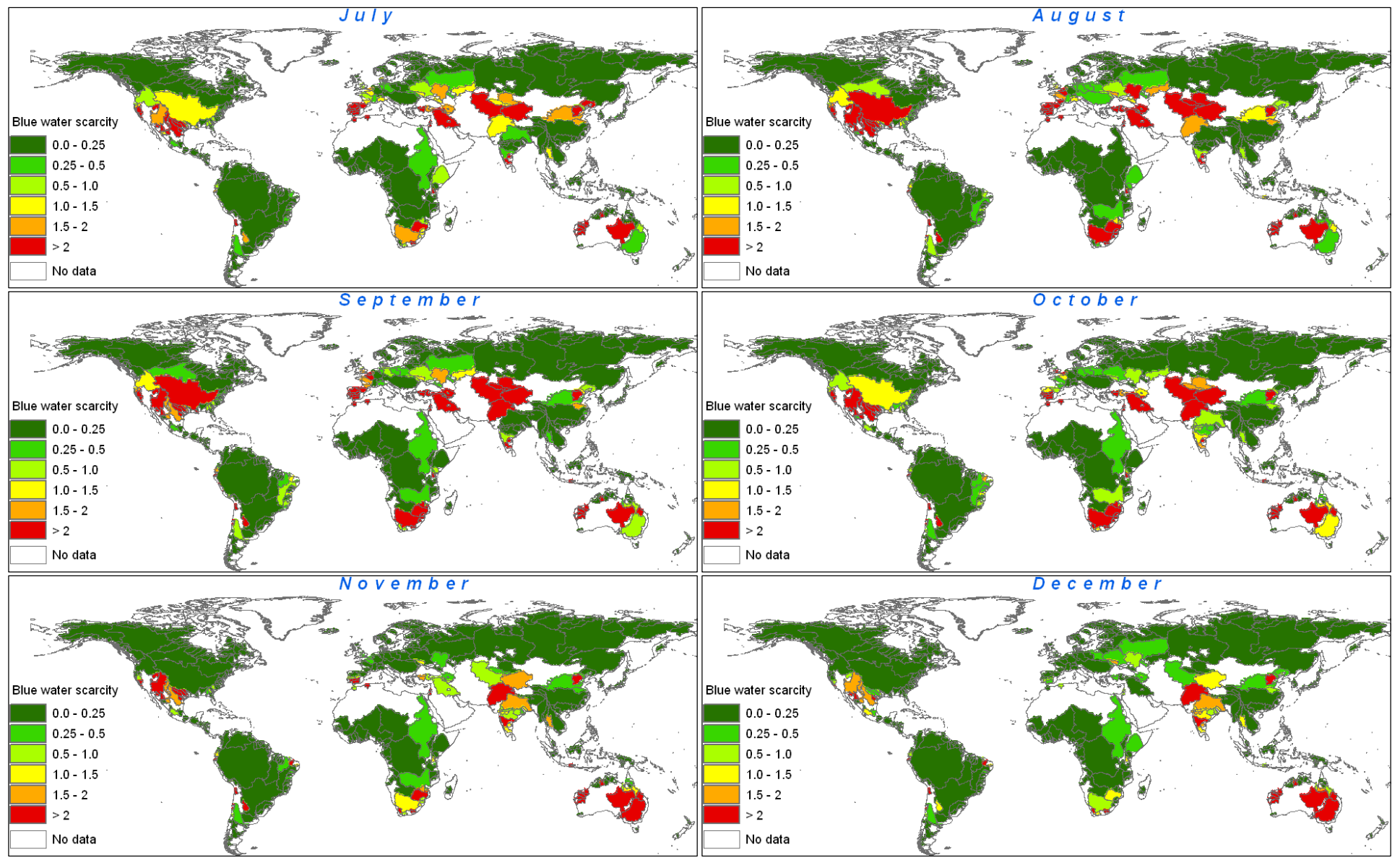

Figure 5.3b. Monthly blue water scarcity in the world's major river basins (July-December). Period: 1996-2005. 


\section{4 / Chapter 5. Global blue water scarcity}

Table 5.1 gives an overview of the number of basins and number of people facing low, moderate, significant and severe water scarcity during a given number of months per year. Our analysis shows that $31 \%$ of the people living in the river basins analysed in this study have low water scarcity throughout the year, i.e. in every month of the year. About $32 \%$ of the people living in the river basins analysed in this study face moderate water scarcity during at least one month per year; $34 \%$ of the people face significant water scarcity during at least one month per year; and $67 \%$ of the people face severe water scarcity during at least one month per year.

Table 5.1. Number of basins and number of people facing low, moderate, significant and severe water scarcity during a given number of months per year.

\begin{tabular}{|c|c|c|c|c|c|c|c|c|}
\hline \multirow{2}{*}{$\begin{array}{l}\text { Number } \\
\text { of } \\
\text { months } \\
\text { per year } \\
(n)\end{array}$} & \multicolumn{4}{|c|}{$\begin{array}{l}\text { Number of basins facing low, moderate, } \\
\text { significant and severe water scarcity during } n \\
\text { months per year }\end{array}$} & \multicolumn{4}{|c|}{$\begin{array}{l}\text { Number of people (millions) facing low, } \\
\text { moderate, significant and severe water } \\
\text { scarcity during } n \text { months per year }\end{array}$} \\
\hline & $\begin{array}{l}\text { Low } \\
\text { water } \\
\text { scarcity }\end{array}$ & $\begin{array}{l}\text { Moderate } \\
\text { water } \\
\text { scarcity }\end{array}$ & $\begin{array}{l}\text { Significant } \\
\text { water } \\
\text { scarcity }\end{array}$ & $\begin{array}{l}\text { Severe } \\
\text { water } \\
\text { scarcity }\end{array}$ & $\begin{array}{l}\text { Low } \\
\text { water } \\
\text { scarcity }\end{array}$ & $\begin{array}{l}\text { Moderate } \\
\text { water } \\
\text { scarcity }\end{array}$ & $\begin{array}{l}\text { Significant } \\
\text { water } \\
\text { scarcity }\end{array}$ & $\begin{array}{l}\text { Severe } \\
\text { water } \\
\text { scarcity }\end{array}$ \\
\hline 0 & 17 & 319 & 344 & 204 & 353 & 2690 & 2600 & 1289 \\
\hline 1 & 2 & 55 & 45 & 46 & 18.6 & 894 & 357 & 440 \\
\hline 2 & 1 & 26 & 12 & 49 & 0.002 & 302 & 672 & 512 \\
\hline 3 & 4 & 4 & 2 & 33 & 79.6 & 69.2 & 220 & 182 \\
\hline 4 & 6 & 1 & 1 & 22 & 35.0 & 0.14 & 9.2 & 345 \\
\hline 5 & 18 & 0 & 1 & 16 & 897 & 0 & 97.8 & 706 \\
\hline 6 & 9 & 0 & 0 & 10 & 111 & 0 & 0 & 25.6 \\
\hline 7 & 17 & 0 & 0 & 4 & 144 & 0 & 0 & 88.0 \\
\hline 8 & 29 & 0 & 0 & 4 & 293 & 0 & 0 & 254 \\
\hline 9 & 29 & 0 & 0 & 3 & 66.8 & 0 & 0 & 20.2 \\
\hline 10 & 52 & 0 & 0 & 0 & 428 & 0 & 0 & 0 \\
\hline 11 & 39 & 0 & 0 & 2 & 296 & 0 & 0 & 1.8 \\
\hline 12 & 182 & 0 & 0 & 12 & 1233 & 0 & 0 & 93.3 \\
\hline Total & 405 & 405 & 405 & 405 & 3956 & 3956 & 3956 & 3956 \\
\hline
\end{tabular}

In 223 river basins (55\% of the basins studied) with in total 2.72 billion inhabitants $(69 \%$ of the total population living in the basins included in this study), the blue water scarcity level exceeded hundred per cent during at least one month of the year, which means that environmental flow requirements were violated during at least one month of the year. 
Figure 5.4 shows per basin how many months per year environmental flow requirements are violated (water scarcity $>100 \%$ ). In 201 river basins with in total 2.67 billion people there is severe water scarcity during at least one month per year, which means that the blue water footprint is more than twice the blue water availability during at least one month per year.

Twelve of the river basins included in this study experience severe water scarcity during twelve months per year. The largest of those basins is the Eyre Lake Basin in Australia, one of the largest endorheic basins in the world, arid and inhabited by only about 86,000 people, but covering about 1.2 million $\mathrm{km}^{2}$. The basin that faces severe water scarcity during twelve months a year that inhabits most people is the Yongding He Basin in northern China (serving water to Beijing), with an area of $214,000 \mathrm{~km}^{2}$ and a population density of 425 persons per $\mathrm{km}^{2}$. The next most populated basins with severe water scarcity during the whole year are the Yaqui River Basin in north-western Mexico $\left(76,000 \mathrm{~km}^{2}\right.$, 651,000 people), followed by the Nueces River Basin in Texas, US $\left(44,000 \mathrm{~km}^{2}, 614,000\right.$ people), the Groot-Vis (Great Fish) River Basin in Eastern Cape, South Africa $\left(30,000 \mathrm{~km}^{2}\right.$, 299,000 people), the Loa River Basin, the main water course in the Atacama Desert in northern Chile $\left(50,000 \mathrm{~km}^{2}, 196,000\right.$ people) and the Conception River Basin in northern Mexico (26,000 km², 193,000 people). Finally, a number of small river basins in Western Australia experience year-round severe water scarcity (De Grey, Fortescue, Ashburton, Gascoyne and Murchison). Eleven months of severe water scarcity occurs in the San Antonio River Basin in Texas, US $\left(11,000 \mathrm{~km}^{2}, 915,000\right.$ people) and the Groot-Kei River Basin in Eastern Cape, South Africa (19,000 km², 874,000 people). Nine months of severe water scarcity occurs in the Penner River Basin in southern India, a basin with a dry tropical monsoon climate $\left(55,000 \mathrm{~km}^{2}, 10.9\right.$ million people), the Tarim River Basin in China, which includes the Taklamakan Desert $\left(1052,000 \mathrm{~km}^{2}, 9.3\right.$ million people) and the Ord River Basin, a sparsely populated basin in the Kimberley region of Western Australia. Four basins face severe water scarcity during eight months a year: the Indus, Cauvery and Salinas River Basins and the Dead Sea Basin. Among these, the Indus River basin is the largest $\left(1,139,000 \mathrm{~km}^{2}, 212\right.$ million people). Next come the very densely populated Cauvery River Basin in India (91,000 km², 35 million people), the Dead Sea Basin, which includes the Jordan River and extends over parts of Jordan, Israel, West Bank and minor parts of Lebanon and Egypt $\left(35,000 \mathrm{~km}^{2}, 6.1\right.$ million people) and the Salinas River Basin in 


\section{6 / Chapter 5. Global blue water scarcity}

California in the US $\left(13,000 \mathrm{~km}^{2}, 308,000\right.$ people). Four other river basins experience severe water scarcity during seven months of the year: the Krishna, Bravo, San Joaquin and Doring River Basins. The largest and most densely populated of those is the Krishna River Basin in India $\left(270,000 \mathrm{~km}^{2}, 77\right.$ million people). The Bravo River Basin is situated partly in the US and partly in Mexico (510,000 km², 9.2 million people); the San Joaquin River Basin lies in California, US (34,000 km², 1.7 million people). The Doring River Basin is a relatively sparsely populated basin in South Africa, where it is irrigation of agricultural lands that causes the scarcity of water.

Figure 5.5 shows per river basin the blue water scarcity in the month of the year in which scarcity is highest and also shows the month in which this occurs. In a range of basins in Africa north of the Equator (Senegal, Volta, Niger, Lake Chad, Nile and Shebelle), the most severe blue water scarcity occurs in February or March due to low runoff. In all of these basins, water is not scarce if considered on an annual basis; scarcity occurs only during a limited period of low runoff. In a number of river basins in Eastern Europe and Asia (Dniepr, Don, Volga, Ural, Ob, Balkhash and Amur), the most severe water scarcity occurs in the months February or March as well. The blue water footprint is not yet large in these months, because the growing period is yet to start, but natural runoff is very low in this period and puts limits to industrial and domestic water supply if environmental flow requirements are to be maintained. In the Yellow and Tarim River Basins, most severe water scarcity is in early spring because runoff is low while water demand for irrigation starts to increase. In the Orange and Limpopo River Basins in South Africa, most severe water scarcity occurs in September-October, in the period in which the blue water footprint is highest while runoff is lowest. In the Mississippi River Basin in the US, severe water scarcity occurs in August-September, when the blue water footprint is largest but runoff low.

\subsubsection{Annual average monthly blue water scarcity per river basin}

In order to get an overall picture of blue water scarcity per basin we have combined the monthly scarcity values into an annual average (Figure 5.6). Considering the annual average monthly blue water scarcity in the 405 river basins considered, we find that in 264 basins a total number of 2.05 billion people experience low water scarcity $(<100 \%)$, but in 
55 basins 0.38 billion people face moderate water scarcity (100-150\%), in 27 basins 0.15 billion people face significant water scarcity (150-200\%) and in 59 basins a total of 1.37 billion people face severe water scarcity $(>200 \%)$. The largest basins in the latter category (in terms of inhabitants) are: the Ganges River Basin (situated mainly in India and Pakistan, inhabiting 454 million people), the Indus River Basin (mainly in Pakistan and India, 212 million people), the Huang He (Yellow River) Basin in China (161 million people), the Yongding He Basin in China (91 million) and the Krishna River Basin in India (77 million people).

Instead of quantifying the overall blue water scarcity in a basin by taking the average of the twelve monthly blue water scarcity values, one could also do that by taking the total annual blue water footprint over the total annual blue water availability. This is the way in which traditionally water scarcity indicators are calculated. For a large number of basins, this water scarcity indicator masks the fact that during part of the year environmental flow requirements are violated. This is for example the case for the Senegal, Lake Chad, Shebelle, Limpopo and Orange river basins in Africa and the Ural, Don and Balkhash basins in Asia. 


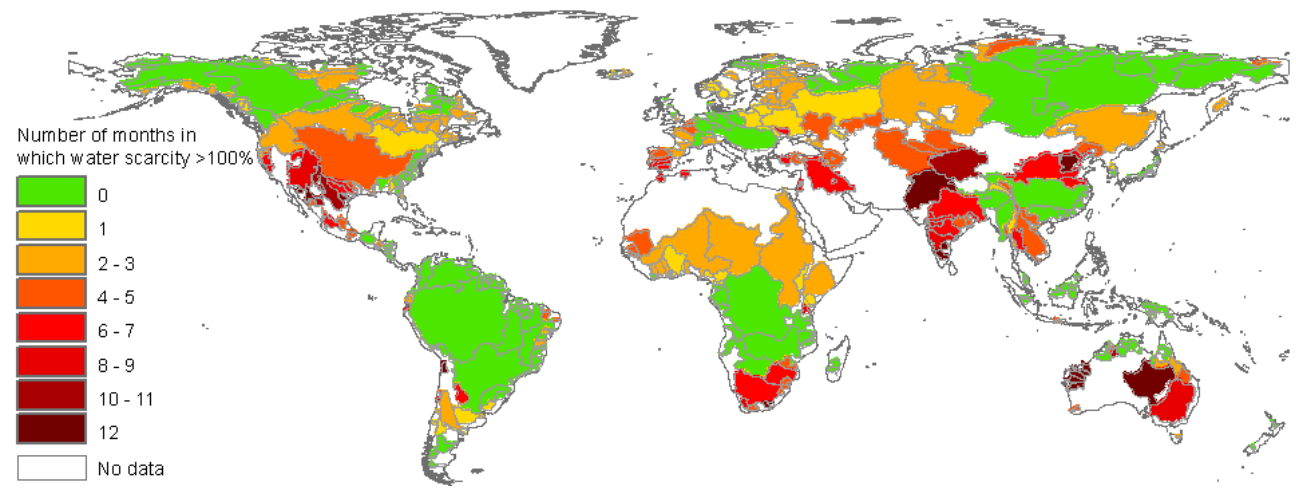

Figure 5.4. Number of months during the year in which blue water scarcity exceeds $100 \%$ for the world's major river basins. Period 1996-2005.

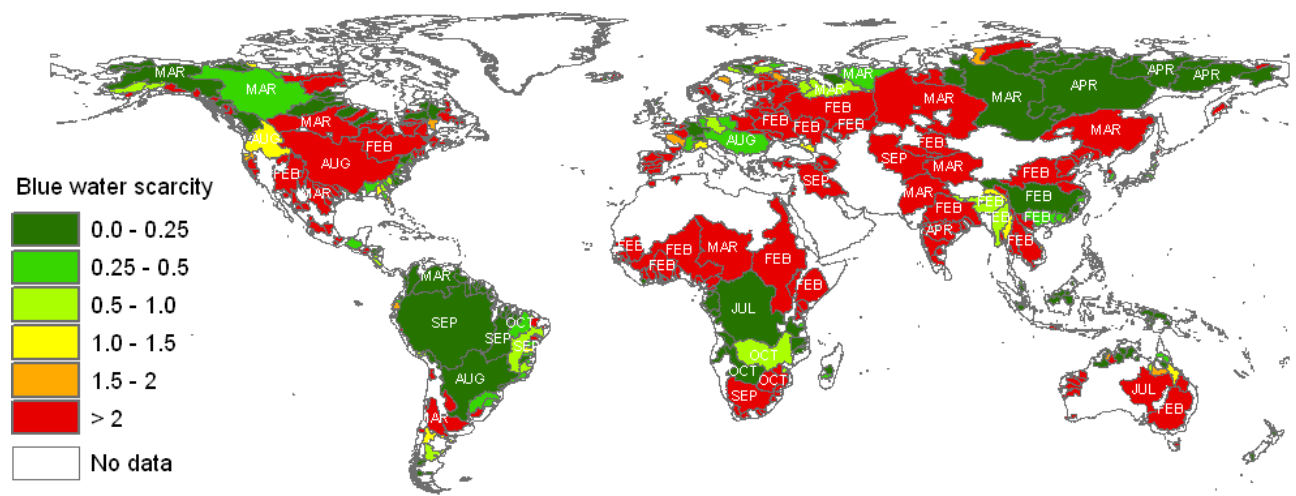

Figure 5.5. The blue water scarcity per river basin in the month in which blue water scarcity is highest, together with the month in which this highest scarcity occurs. Months are shown only for the largest river basins (with an area $>300,000 \mathrm{~km}^{2}$ ). Period 1996-2005.

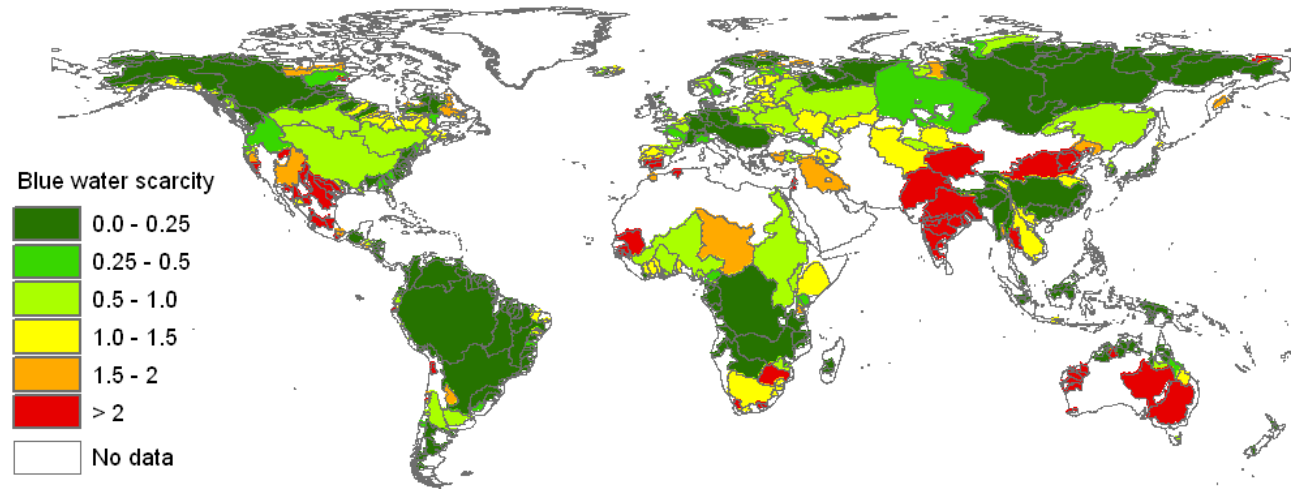

Figure 5.6. Annual average monthly blue water scarcity in the world's major river basins (calculated by equal weighting the twelve monthly blue water scarcity values per basin). Period 1996-2005. 


\subsubsection{Global blue water scarcity}

Global annual runoff from the 405 river basins studied is estimated to be $27,545 \mathrm{Gm}^{3} / \mathrm{yr}$. Global annual blue water availability is $20 \%$ of that, i.e. $5,509 \mathrm{Gm}^{3} / \mathrm{yr}$. The aggregated annual blue water footprint in the basins considered amounts to $731 \mathrm{Gm}^{3} / \mathrm{yr}$. Based on these annual global values one would calculate a global blue water scarcity of $13 \%$. If, however, we estimate global blue water scarcity by averaging the annual average monthly blue water scarcity values per river basin, weighting basin data based on basin area, we calculate a global average blue water scarcity of $85 \%$. This means that, sampling over the full year and over the total land area considered in this study, one will measure a blue water scarcity of $85 \%$ on average. Since some areas are more densely populated than others, this is not the same as the scarcity experienced by people. When we estimate global blue water scarcity by averaging the annual average monthly blue water scarcity values per river basin weighted based on population number per basin, we calculate a global blue water scarcity at $133 \%$. This figure reflects the blue water scarcity that people in the world on average experience. Yet another way of expressing water scarcity is to take the perspective of the average water consumer. The global water consumption pattern is different from the population density pattern, because intensive water consumption in agriculture is not specifically related to where most people live. If we estimate global blue water scarcity by averaging monthly blue water scarcity values per river basin weighted based on the blue water footprint in the respective month and basin, we calculate a global blue water scarcity at $244 \%$. This means that the average blue water consumer in the world experiences a water scarcity of $244 \%$, i.e. operates in a month in a basin in which the blue water footprint is 2.44 times the blue water availability and in which presumptive environmental flow requirements are thus strongly violated.

From the above it is clear that the $13 \%$ scarcity value (global annual blue water footprint over global annual blue water availability) is highly misleading because it is based on the implicit assumption that all blue water available in the world at any point in the year is available for all people in the world - wherever they live - at any (other) point in the year, which is not the case. 


\subsubsection{Blue water footprint versus blue water availability in selected river basins}

Figures 5.7a-5.7c compare the blue water footprint with the blue water availability within the course of the year for nine selected basins: the Tigris-Euphrates, Indus, Ganges, Huang He, Tarim, Murray, Colorado, Guadiana and Limpopo. The blue water footprints refer to the average over the period 1996-2005. The natural runoff and blue water availability refer to climate averages. The figures show per river basin which parts of the blue water footprint result in slight, moderate, significant and severe hydrological modification of the river. The categories beyond slight modification mean that presumptive environmental flow requirements are violated. Moderate hydrological modification occurs when blue water footprint varies between 20 and 30 per cent of natural runoff; significant modification happens when blue water footprint is 30-40 per cent of natural runoff; and severe modification occurs when blue water footprint exceeds 40 per cent of natural runoff.

The Tigris-Euphrates River Basin extends over four countries: Turkey, Syria, Iraq and Iran. Almost all of the runoff in the two rivers is generated in the highlands of the northern and eastern parts of the basin in Turkey, Iraq and Iran. Precipitation in the basin is largely confined to the winter months from October through April. The high waters occur during the months of March through May as the snows melts on the highlands. The typical low water season occurs from June to December. The basin faces severe water scarcity for five months of the year (June-October). Most of the blue water footprint in the basin is due to evaporation of irrigation water in agriculture, mostly for wheat, barley and cotton, which together account for $52 \%$ of the total blue water footprint in the basin.

The Indus River Basin is a densely populated basin (186 persons $/ \mathrm{km}^{2}$ ) facing severe water scarcity almost three quarters of the year (September-April). The basin receives around $70 \%$ of its precipitation during the months of June to October (Thenkabail et al., 2005). The low-water period in the Indus River Basin is from November through February. The high waters begin in June and continue through October as the snow and glaciers melt from the Tibetan plateau. Over $93 \%$ of the blue water footprint related to crop production in Pakistan occurs in the two major agricultural provinces of Punjab and Sindh which lie fully (Punjab) and mostly (Sindh) in the basin. Irrigation of wheat, rice and cotton crops account for $77 \%$ of the blue water footprint in the basin. Groundwater abstraction, mainly for 
irrigation, goes beyond the natural recharge leading to depletion of the groundwater in the basin (Wada et al., 2010).

The Ganges River Basin is one of the most densely populated basins in the world (443 persons $/ \mathrm{km}^{2}$ ). The basin is fed by two main headwaters in the Himalayas - the Bhagirathi and Alaknanda - and many other tributaries that drain the Himalayas and the Vindhya and Satpura ranges. The basin faces severe water scarcity for five months of the year (January-May). Most of the blue water footprint in the basin is due to evaporation of irrigation water in agriculture, mostly for wheat, rice and sugar cane. These three crops together are responsible for $85 \%$ of the total blue water footprint in the basin. Overexploitation of the aquifers for irrigation is leading to depletion of the groundwater in the basin (Wada et al., 2010).

The Huang He (Yellow River) Basin in China faces severe water scarcity for four months of the year (February-May). The low-water period in the Huang He River Basin is from December through March. The river originates in the Bayankela Mountains of the Tibetan Plateau. The high waters begin in April and continue through October. Most of the blue water footprint in the basin is due to irrigation water use in agriculture, mostly for wheat, maize and rice, which together account for $79 \%$ of the blue water footprint in the basin. The dry conditions during part of the year coupled with the large water footprint related to agricultural and industrial production and domestic water supply is leading to a great pressure on the water resources of the basin.

The Tarim River Basin faces severe water scarcity during three quarters of the year (February-October). The low-water period in the Tarim Basin is from October through April. The spring and summer high waters begin in May and continue through September as the snows melts on the Tian Shan and Kunlun Shan mountains. Most of the blue water footprint in the basin is due to evaporation of irrigation water in agriculture, mostly for wheat, rice and maize. These three crops are responsible for $78 \%$ of the blue water footprint in the Tarim River Basin.

The Murray River Basin, often called the Murray-Darling River Basin because of the importance of the Darling River that joins the Murray River at Wentworth, is a very important basin for agriculture in Australia. About 78\% of the blue water footprint related to crop production in Australia is in the Murray River Basin. Most of the blue water footprint in the basin is due to evaporation of irrigation water in agriculture, mostly for 


\section{2 / Chapter 5. Global blue water scarcity}

fodder crops, cotton and rice, which together constitute $77 \%$ of the blue water footprint within the basin. The basin faces severe water scarcity for half of the year (NovemberApril).

The Colorado River Basin draining into the Pacific Ocean is a basin in the Southwestern US (with a minor fraction in North-western Mexico). About $75 \%$ of the runoff in the basin occurs during the months of April through July. During five months of year (August-November and February) the basin faces severe water scarcity. Most of the blue water footprint in the basin is due to evaporation of irrigation water in agriculture, mostly for fodder crops and cotton, which make $73 \%$ of the blue water footprint in the Colorado Basin. The Colorado River is considered the life line of the South-western US providing water to millions of people both within and outside the basin, for irrigated land and hydroelectricity generation (Pontius, 1997). Colorado River water is diverted for use both in and outside of the basin. Annually, more than one third of the river's supply is diverted from the basin, including diversions to cities such as Denver, Colorado Springs, Salt Lake City, Albuquerque, Los Angeles, and San Diego (Pontius, 1997). Due to its overexploitation, little or no freshwater is discharged to the sea in dry years (Postel, 1998).

The Guadiana River Basin is shared by Spain and Portugal but mainly lies in SouthEastern Spain. The basin faces severe water scarcity during half of the year (JuneNovember). The high-water period in the Guadiana Basin is from February through April. Irrigation of maize, grapes and other perennial crops (mainly olives) account for the largest share of the blue water footprint in the basin (55\%). Overexploitation of the aquifer for irrigation purposes is a major problem (Wada et al., 2010), occurring mainly in the upper basin (Aldaya and Llamas, 2008).

The Limpopo River Basin faces severe water scarcity during five months of the year (July-November). The low-water period in the Limpopo Basin is from May through December. Most of the blue water footprint in the basin is due to evaporation of irrigation water in agriculture, mostly for fodder crops, cotton and sugar cane, which together account for $52 \%$ of the total blue water footprint in the basin. 

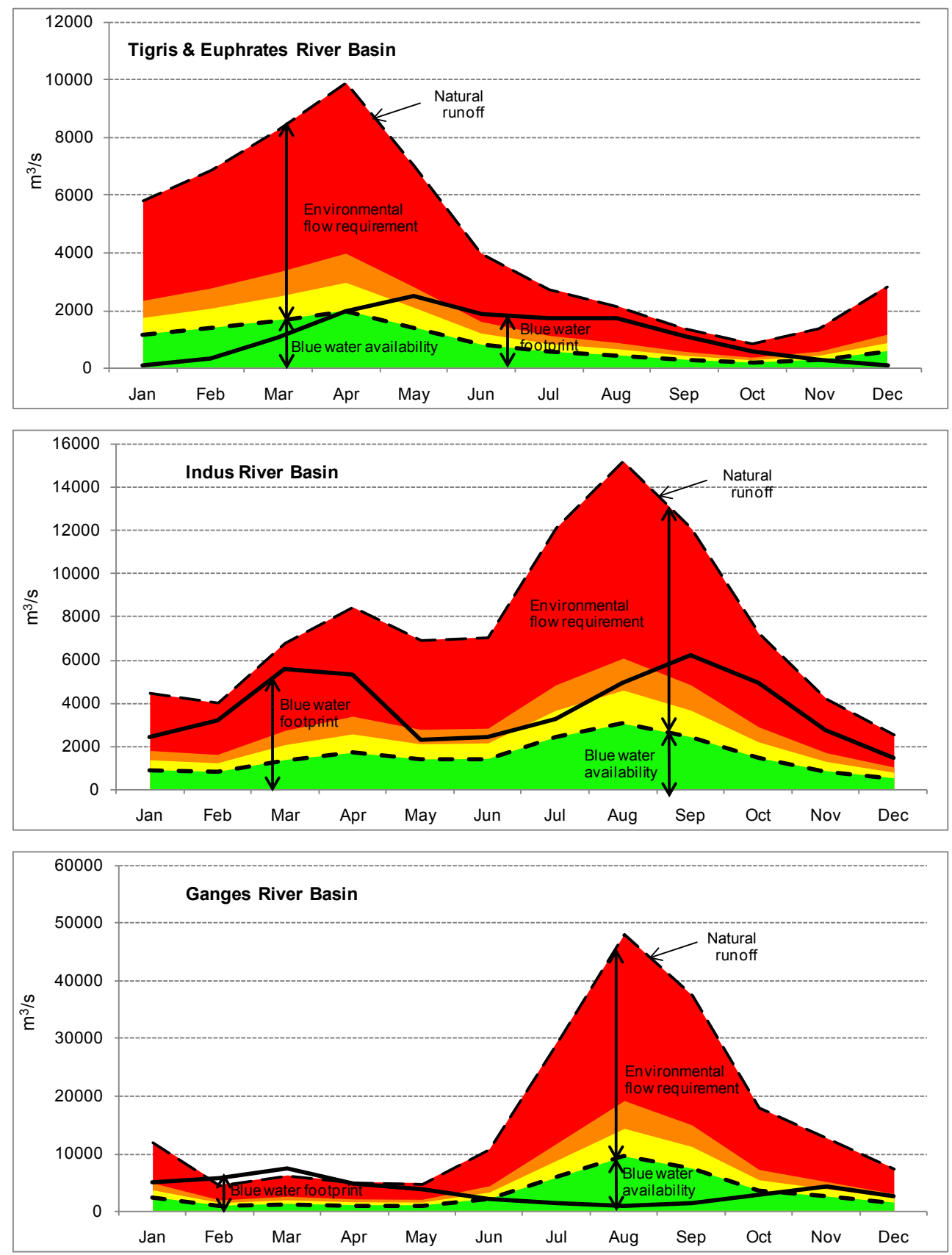

Figure 5.7a. The blue water footprint over the year compared to blue water availability for selected river basins. Period 1996-2005. Blue water availability - that is natural runoff minus environmental flow requirement - is shown in green. When water consumption moves into the yellow, orange and red colours, water scarcity is moderate, significant and severe, respectively. 

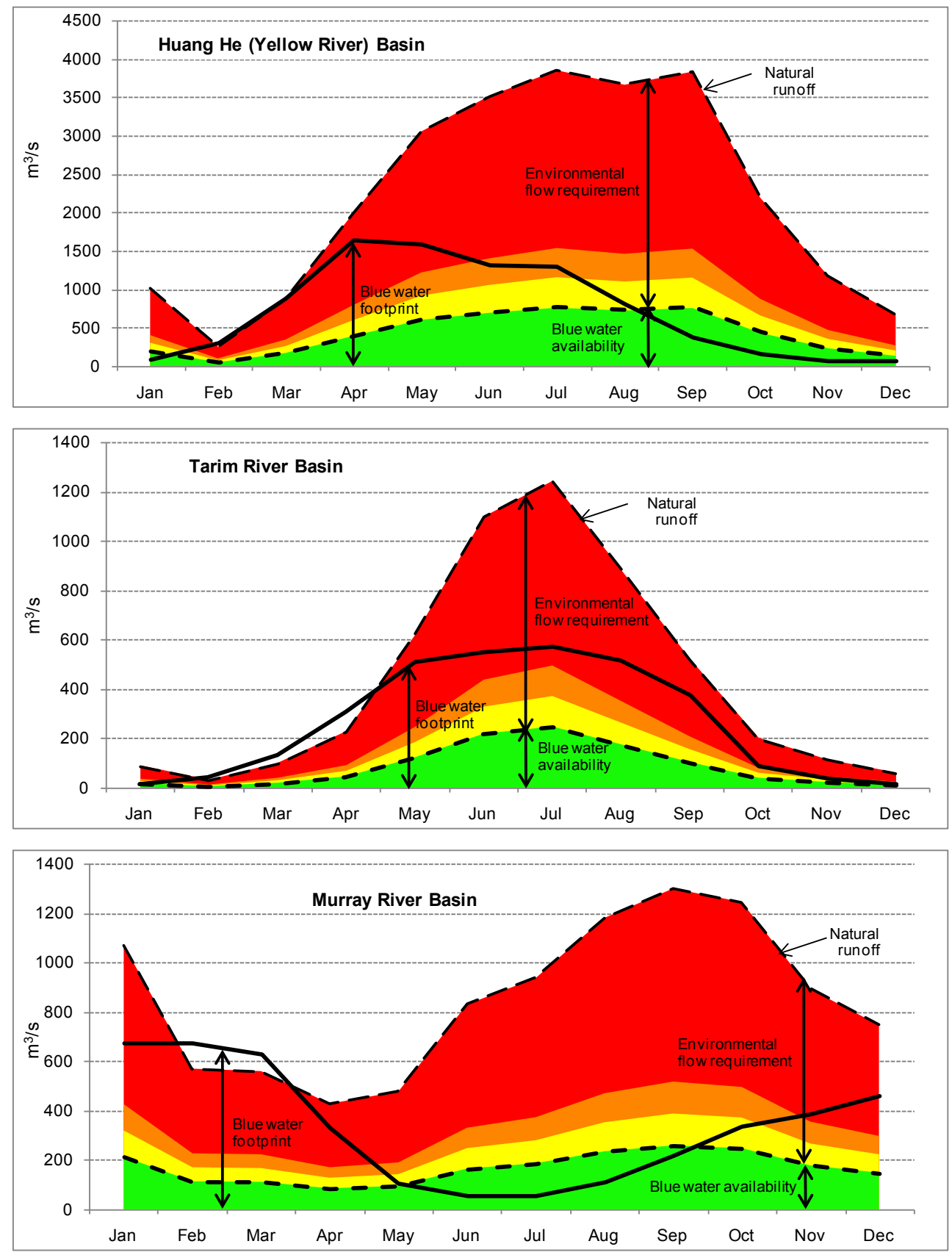

Figure 5.7b. The blue water footprint over the year compared to blue water availability for selected river basins. Period 1996-2005. Blue water availability - that is natural runoff minus environmental flow requirement - is shown in green. When water consumption moves into the yellow, orange and red colours, water scarcity is moderate, significant and severe, respectively. 

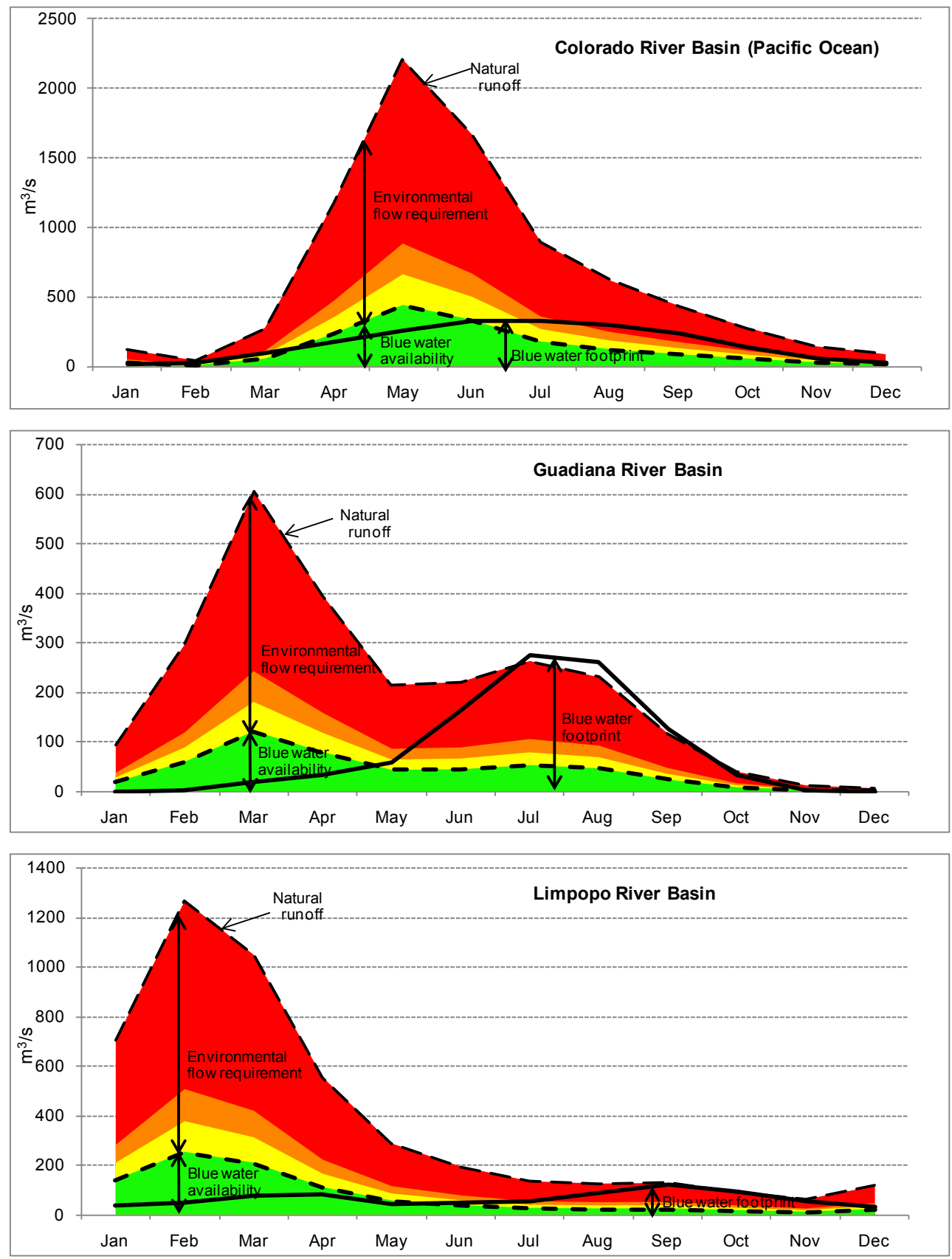

Figure 5.7c. The blue water footprint over the year compared to blue water availability for selected river basins. Period 1996-2005. Blue water availability - that is natural runoff minus environmental flow requirement - is shown in green. When water consumption moves into the yellow, orange and red colours, water scarcity is moderate, significant and severe, respectively. 


\section{6 / Chapter 5. Global blue water scarcity}

\subsection{Discussion and conclusion}

The blue water scarcity estimates presented include uncertainties that reflect the uncertainties in input data used and the assumptions that were made. The data on actual runoff used are model-based estimates calibrated against long-term runoff measurements (Fekete et al., 2002); the model outcomes include an error of 5\% at the scale of large river basins or beyond for smaller river basins. The runoff measurements against which the model is calibrated include uncertainties as well; discharge measurements have an accuracy on the order of \pm 10 -20 per cent (Fekete et al., 2002). Estimates used for the blue water footprints can easily contain an uncertainty of $\pm 20 \%$ (Hoff et al., 2010; Mekonnen and Hoekstra, 2010a,d); uncertainties for relatively small river basins are generally bigger than for large river basins. An important assumption in the study is the presumptive standard on environmental flow requirements based on Richter et al. (2011). Obviously, different estimates of environmental flow requirements will affect the estimates of blue water availability and thus scarcity.

In order to estimate natural runoff in each river basin, we have added the estimated blue water footprint (from Mekonnen and Hoekstra, 2011b) to the estimated actual runoff (from Fekete et al., 2002). In doing so, we overestimate natural runoff in those months in which the blue water footprint (partially) originates from depleting the total water stock in the basin rather than from runoff depletion. At the same time we underestimate the natural runoff in the months in which water is being stored for later consumption. Further, as a result of our approach we overestimate natural runoff in those months and basins in which the blue water footprint (partially) originates from fossil (non-renewable) groundwater, because that part should not be added to actual runoff to get natural runoff. However, data on consumption of renewable versus fossil groundwater are hard to obtain at a global scale.

Given the uncertainties and the sensitivity of the outcomes of this study to the assumptions made, the quantitative results presented in this study should be taken with caution. However, the spatial and temporal water scarcity patterns and the order of magnitudes of the results presented in this paper give a good indication of when and where blue water scarcity is relatively low or high.

The calculated blue water scarcity values per river basin and month are conservative estimates of actual scarcity for two reasons. First, by evaluating water scarcity at the level 
of whole river basins, we do not capture spatial variations within the basins, so that the blue water footprint may match blue water availability at the basin level while it does not at subcatchment level. Second, we consider an average year regarding both blue water availability and footprint, while in many basins inter-annual variations can be substantial, aggravating the scarcity problem in the dryer years.

The water scarcity values presented refer to the period 1996-2005. Continued growth of the water footprint due to growing populations, changing food patterns (for instance in the direction of more meat) and increasing demand for biomass for bio-energy combined with the effects of climate change, are likely to result in growing blue water scarcity in the future (Vörösmarty et al., 2000).

This study has quantified freshwater scarcity only in terms of blue water. For a complete picture of the extent of freshwater scarcity one should also consider the use and availability of green water and water pollution (Savenije, 2000; Rijsberman, 2006; Rockstrom et al., 2009; Hoekstra et al., 2011). Therefore, future research should focus on the development of a complete picture of water scarcity, including green water scarcity and water pollution levels over time.

The current study provides the first global assessment of blue water scarcity in a spatially and temporally explicit way. Water scarcity analysis at a monthly time step provides insight into the real degree of water scarcity that is not revealed in existing annual water scarcity indicators like those employed by for example Vörösmarty et al. (2000), Alcamo and Henrichs (2002), Smakthin et al. (2004) and Oki and Kanae (2006). Ignoring temporal variability in estimating blue water scarcity obscures the fact that scarcity occurs in certain periods of the year and not in others. A similar problem occurs if one would compare the global blue water footprint with global blue water availability. In this case one obscures the fact that scarcity happens in certain basins, generally where most people live, and not equally throughout the world. 


\section{Appendix 5A. Global river basin map}

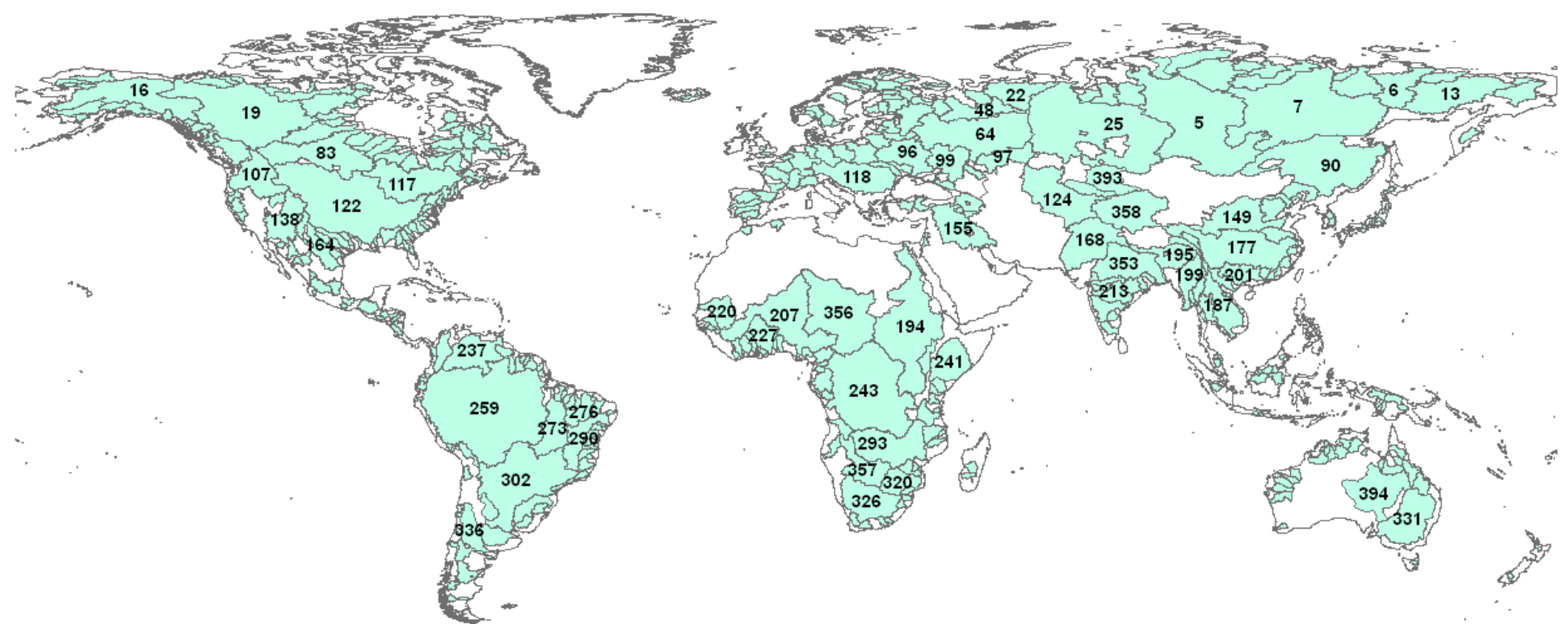

The map shows the basin ID for the largest river basins (area $>300,000 \mathrm{~km}^{2}$ ). Data source: GRDC (2007).

\begin{tabular}{|c|c|c|c|c|c|c|c|c|c|c|c|}
\hline $\begin{array}{r}\text { Basin } \\
\text { ID }\end{array}$ & Basin & $\begin{array}{r}\text { Basin } \\
\text { ID }\end{array}$ & Basin & $\begin{array}{r}\text { Basin } \\
\text { ID }\end{array}$ & Basin & $\begin{array}{r}\text { Basin } \\
\text { ID }\end{array}$ & Basin & $\begin{array}{r}\text { Basin } \\
\text { ID }\end{array}$ & Basin & $\begin{array}{r}\text { Basin } \\
\text { ID }\end{array}$ & Basin \\
\hline 5 & Yenisei & 64 & Volga & 122 & Mississippi & 194 & Nile & 241 & Shebelle & 326 & Orange \\
\hline 6 & Indigirka & 83 & Nelson & 124 & Aral Drainage & 195 & Brahmaputra & 243 & Congo & 331 & Murray \\
\hline 7 & Lena & 90 & Amur & 138 & Colorado (Pacific Ocean) & 199 & $\begin{array}{l}\text { Irrawaddy } \\
\text { Ind }\end{array}$ & 259 & Amazonas & 336 & Colorado (Argentina) \\
\hline 13 & Kolyma & 96 & Dniepr & 149 & Huang He (Yellow River) & 201 & Xi Jiang & 273 & Tocantins & 353 & Ganges \\
\hline 16 & Yukon & 97 & Ural & 155 & Tigris \& Euphrates & 207 & Niger & 276 & Rio Parnaiba & 356 & Lake Chad \\
\hline 19 & Mackenzie & 99 & Don & 164 & Bravo & 213 & Godavari & 290 & Sao Francisco & 357 & Okavango \\
\hline 22 & Pechora & 107 & Columbia & 168 & Indus & 220 & Senegal & 293 & Zambezi & 358 & Tarim \\
\hline 25 & $\mathrm{Ob}$ & 117 & St.Lawrence & 177 & Yangtze(Chang Jiang) & 227 & Volta & 302 & Parana & 393 & Balkhash \\
\hline 48 & Northern Dvina (Severnaya Dvina) & 118 & Danube & 187 & Mekong & 237 & Orinoco & 320 & Limpopo & 394 & Eyre Lake \\
\hline
\end{tabular}




\section{Appendix 5B. Global maps of monthly natural runoff in the world's major river basins}

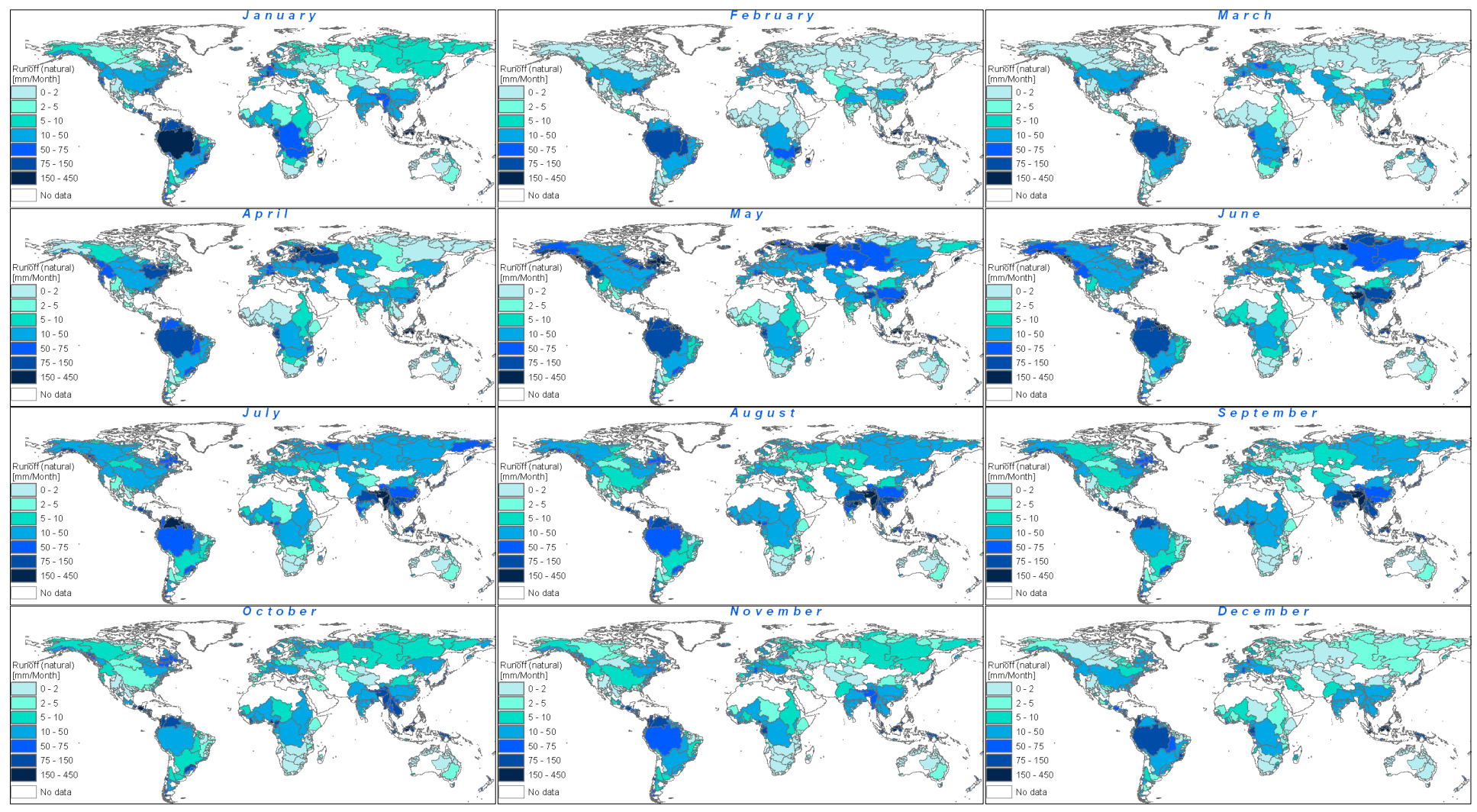


140 / Chapter 5. Global blue water scarcity

Appendix 5C. Global maps of monthly blue water availability in the world's major river basins

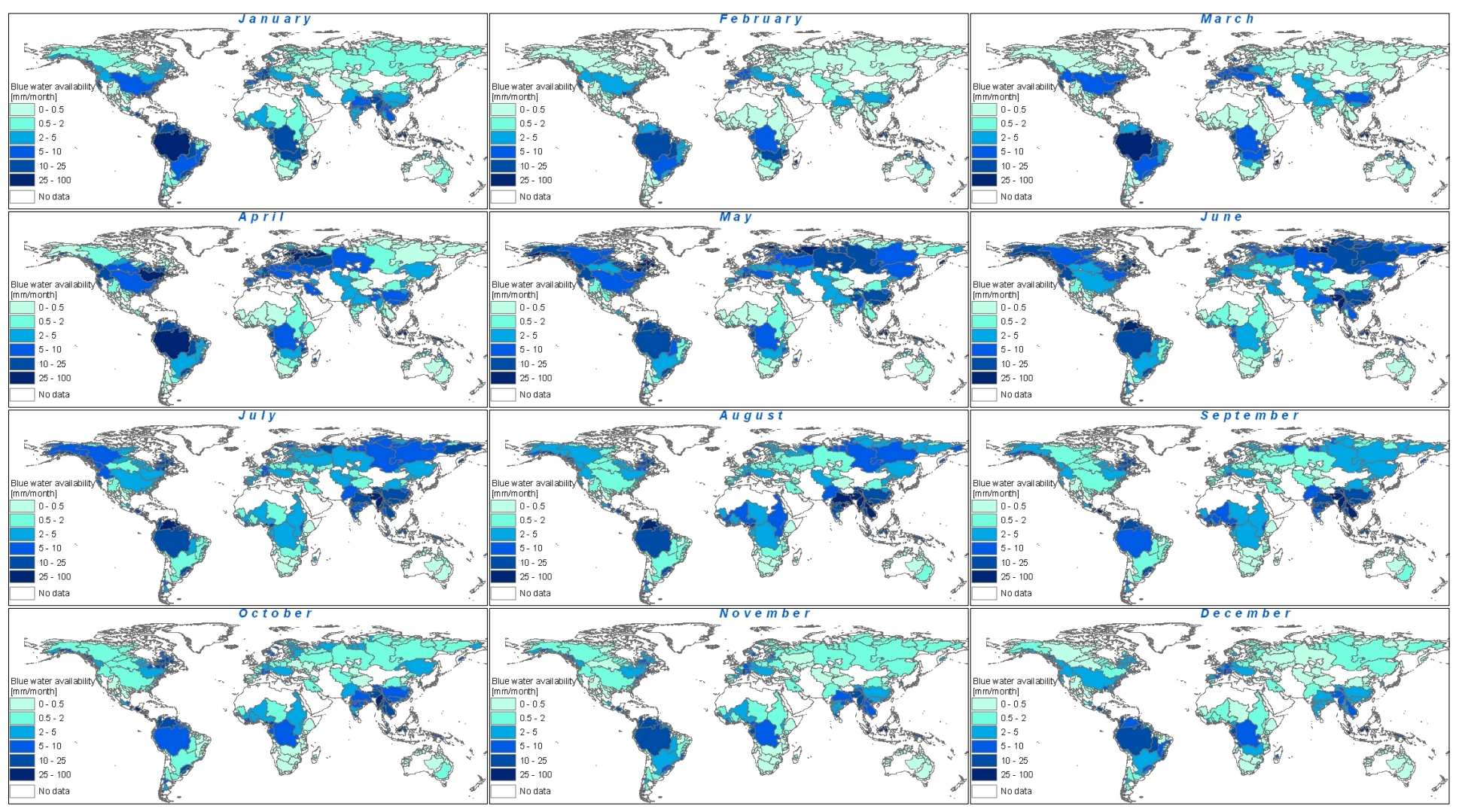


Appendix 5D. Global maps of the monthly blue water footprint in the world's major river basins. Period 1996-2005.

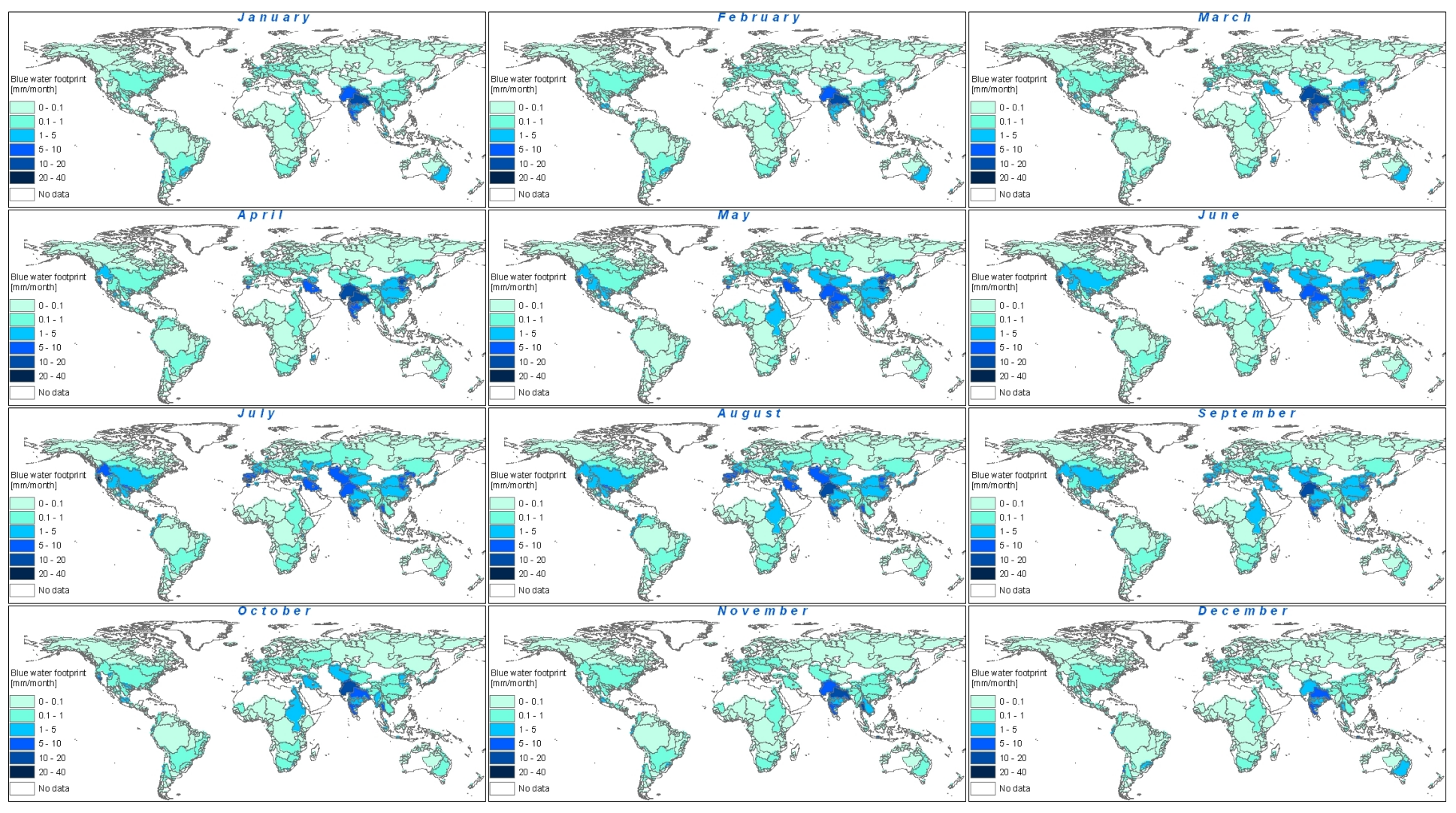





\section{A global and high-resolution assessment of the green, blue and grey water footprint of wheat $^{5}$}

\section{Abstract}

The aim of this study is to estimate the green, blue and grey water footprint of wheat in a spatially-explicit way, both from a production and consumption perspective. The assessment is global and improves upon earlier research by taking a high-resolution approach, estimating the water footprint of the crop at a 5 by 5 arc minute grid. We have used a grid-based dynamic water balance model to calculate crop water use over time, with a time step of one day. The model takes into account the daily soil water balance and climatic conditions for each grid cell. In addition, the water pollution associated with the use of nitrogen fertilizer in wheat production is estimated for each grid cell. We have used the water footprint and virtual water flow assessment framework as in the guideline of the Water Footprint Network.

The global wheat production in the period 1996-2005 required about 1088 billion cubic meters of water per year. The major portion of this water $(70 \%)$ comes from green water, about $19 \%$ comes from blue water, and the remaining $11 \%$ is grey water. The global average water footprint of wheat per ton of crop was $1830 \mathrm{~m}^{3} /$ ton. About $18 \%$ of the water footprint related to the production of wheat is meant not for domestic consumption but for export. About 55\% of the virtual water export comes from the USA, Canada and Australia alone. For the period 1996-2005, the global average water saving from international trade in wheat products was $65 \mathrm{Gm}^{3} / \mathrm{yr}$.

A relatively large total blue water footprint as a result of wheat production is observed in the Ganges and Indus river basins, which are known for their water stress problems. The two basins alone account for about $47 \%$ of the blue water footprint related to global wheat production. About $93 \%$ of the water footprint of wheat consumption in Japan lies in other countries, particularly the USA, Australia and Canada. In Italy, with an average wheat consumption of $150 \mathrm{~kg} / \mathrm{yr}$ per person, more than two times the word average, about

\footnotetext{
${ }^{5}$ Based on Mekonnen and Hoekstra (2010a,b)
} 


\section{4 / Chapter 6. A global assessment of water footprint of wheat}

$44 \%$ of the total water footprint related to this wheat consumption lies outside Italy. The major part of this external water footprint of Italy lies in France and the USA.

\subsection{Introduction}

Fresh water is a renewable but finite resource. Both freshwater availability and quality vary enormously in time and space. Growing populations coupled with continued socioeconomic developments put pressure on the globe's scarce water resources. In many parts of the world, there are signs that water consumption and pollution exceed a sustainable level. The reported incidents of groundwater depletion, rivers running dry and worsening pollution levels form an indication of the growing water scarcity (Gleick, 1993; Postel, 2000; WWAP, 2009). Molden (2007) argues that to meet the acute freshwater challenges facing humankind over the coming fifty years requires substantial reduction of water use in agriculture.

The concept of 'water footprint' introduced by Hoekstra (2003) and subsequently elaborated by Hoekstra and Chapagain (2008) provides a framework to analyse the link between human consumption and the appropriation of the globe's freshwater. The water footprint of a product is defined as the total volume of freshwater that is used to produce the product (Hoekstra et al., 2009). The blue water footprint refers to the volume of surface and groundwater consumed (evaporated) as a result of the production of a good; the green water footprint refers to the rainwater consumed. The grey water footprint of a product refers to the volume of freshwater that is required to assimilate the load of pollutants based on existing ambient water quality standards. The water footprint of national consumption is defined as the total amount of freshwater that is used to produce the goods consumed by the inhabitants of the nation. The water footprint of national consumption always has two components: the internal and the external footprint. The latter refers to the appropriation of water resources in other nations for the production of goods and services that are imported into and consumed within the nation considered. Externalising the water footprint reduces the pressure on domestic water resources, but increases the pressure on the water resources in other countries. Virtual water transfer in the form of international trade in agricultural goods is increasingly recognized as a mechanism to save domestic water resources and achieve national water security (Allan, 2003; Hoekstra, 2003; De Fraiture et al., 2004; Liu 
et al., 2007; Oki and Kanae, 2004; Chapagain et al., 2006a; Yang et al., 2006; Hoekstra and Chapagain, 2008). Virtual water import is an instrument that enables nations to save scarce domestic water resources by importing water-intensive products and exporting commodities that require less water. On the other hand, water-abundant countries can profit by exporting water-intensive commodities.

In this paper, we focus on the water footprint of wheat, which is one of the most widely cultivated cereal grains globally. It is grown on more land area than any other commercial crop and is the second most produced cereal crop after maize and a little above rice. It is believed to originate in Southwest Asia and the most likely site of its first domestication is near Diyarbakir in Turkey (Dubcovsky and Dvorak, 2007). About 90 to 95 percent of the wheat produced is the common wheat or bread wheat followed by durum wheat which accounts less than 5\% of world wheat production (Pena, 2002; Ekboir, 2002). Based on the growing period, wheat can be subdivided into spring and winter wheat. The difference between spring and winter wheat is accounted for by taking specific crop parameters, rooting depth and growing period.

A number of previous studies on global water use for wheat are already available. Hoekstra and Hung $(2002,2005)$ were the first to make a global estimate of the water use in wheat production. They analysed the period 1995-99 and looked at total evapotranspiration, not distinguishing between green and blue water consumption. Hoekstra and Chapagain (2007a, 2008) improved this first study in a number of respects and studied the period 1997-2001. Still, no distinction between green and blue water consumption was made. Liu et al. (2007) made a global estimate of water consumption in wheat production for the period 1998-2002 without making the green-blue water distinction, but for the first time grid-based. Liu et al. (2009) and Liu and Yang (2010) present similar results, but now they show the green-blue water distinction. Siebert and Döll $(2008,2010)$ have estimated the global water consumption for wheat production for the same period as Liu et al. (2007, 2009), showing the green-blue water distinction and applying a grid-based approach as well. Gerbens et al. (2009a) estimated the green and blue water footprint for wheat in the 25 largest producing countries. Aldaya et al. (2010b) have calculated the green and blue water components for wheat in four major producing countries and also estimate international virtual water flows related to wheat trade. Aldaya and Hoekstra (2010) made an assessment 


\section{6 / Chapter 6. A global assessment of water footprint of wheat}

of the water footprint of wheat in different regions of Italy, for the first time specifying not only the green and blue, but the grey water footprint as well.

The aim of this study is to estimate the green, blue and grey water footprint of wheat in a spatially-explicit way, both from a production and consumption perspective. We quantify the green, blue and grey water footprint of wheat production by using a grid-based dynamic water balance model that takes into account local climate and soil conditions and nitrogen fertilizer application rates and calculates the crop water requirements, actual crop water use and yields and finally the green, blue and grey water footprint at grid level. The model has been applied at a spatial resolution of 5 arc minutes by 5 arc minutes. The model's conceptual framework is based on the FAO CROPWAT approach (Doorenbos and Pruitt, 1977; Doorenbos and Kassam, 1979; Allen et al., 1998). The water footprint of wheat consumption per country is estimated by tracing the different sources of wheat consumed in a country and considering the specific water footprints of wheat production in the producing regions.

\subsection{Method}

In this study the global green, blue and grey water footprint of wheat production and consumption and the international virtual water flows related to wheat trade were estimated following the calculation framework of Hoekstra and Chapagain (2008) and Hoekstra et al. (2009). The computations of crop evapotranspiration and yield, required for the estimation of the green and blue water footprint in wheat production, have been done following the method and assumptions provided by Allen et al. (1998) for the case of crop growth under non-optimal conditions (Chapter 8). The grid-based dynamic water balance model developed in this study for estimating the crop evapotranspiration and yield computes a daily soil water balance and calculates crop water requirements, actual crop water use (both green and blue) and actual yields. The model is applied at a global scale using a resolution level of 5 by 5 arc minute grid size (about $10 \mathrm{~km}$ by $10 \mathrm{~km}$ around the Equator). The water balance model is largely written in Python language and embedded in a computational framework where input and output data are in grid-format. The input data available in gridformat (like precipitation, reference evapotranspiration, soil, crop parameters) are converted 
to text-format to feed the Python code. Output data from the Python code are converted back to grid-format.

The actual crop evapotranspiration $\left(E T_{a}, \mathrm{~mm} /\right.$ day $)$ depends on climate parameters (which determine potential evapotranspiration), crop characteristics and soil water availability (Allen et al., 1998):

$$
E T_{a}[t]=K_{c}[t] \times K_{s}[t] \times E T_{o}[t]
$$

where $K_{c}$ is the crop coefficient, $K_{s}[t]$ a dimensionless transpiration reduction factor dependent on available soil water and $E T_{o}[t]$ the reference evapotranspiration ( $\mathrm{mm} /$ day). The crop coefficient varies in time, as a function of the plant growth stage. During the initial and mid-season stages of the crop development, $K_{c}$ is a constant and equals $K_{c, i n i}$ and $K_{c, \text { mid }}$ respectively. During the crop development and late season stages, $K_{c}$ varies linearly and linear interpolation is applied for days within the development and late growing seasons. The value of $K_{s}$ is calculated on a daily basis as a function of the maximum and actual available soil moisture in the root zone.

Following the approach as in the HBV model (Bergström, 1995; Lidén and Harlin, 2000) the amount of rainfall lost through runoff is computed as:

$$
R O[t]=(P[t]+I[t]) \times\left(\frac{S[t-1]}{S_{\max }[t-1]}\right)^{\gamma}
$$

in which $R O[t]$ is runoff on day $t[\mathrm{~mm}] ; P[t]$ precipitation on day $t[\mathrm{~mm}] ; I[t]$ the net irrigation depth on day $t$ that infiltrates the soil [mm]. The value of the parameter $\gamma$ is adopted from Siebert and Döll (2010) and was set to 3 for irrigated land and to 2 for rainfed areas.

The irrigation requirement is determined based on the root zone depletion. The actual irrigation $I[t]$ depends on the extent to which the irrigation requirement is met:

$$
I[t]=\alpha \times I R[t]
$$




\section{8 / Chapter 6. A global assessment of water footprint of wheat}

where $\alpha$ is the fraction of the irrigation requirement that is actually met. Following the method as proposed in Hoekstra et al. (2009) and also applied by Siebert and Döll (2010), we run two scenarios, one with $\alpha=0$ (no application of irrigation, i.e. rain-fed conditions) and the other with $\alpha=1$ (full irrigation). In the second scenario we have assumed that the amount of actual irrigation is sufficient to meet the irrigation requirement. In the case of rain-fed wheat production, blue crop water use is zero and green crop water use $\left(\mathrm{m}^{3} / \mathrm{ha}\right)$ is calculated by summing up the daily values of $E T_{a}(\mathrm{~mm} /$ day) over the length of the growing period. In the case of irrigated wheat production, the green crop water use is assumed to be equal to the green crop water use as was calculated for the rain-fed case. The blue crop water use is then equal to the total $E T_{a}$ over the growing period as simulated under the case $\alpha=1$ (full irrigation) minus the green crop water use.

The crop growth and yield are affected by the water stress. To account for the effect of water stress, a linear relationship between yield and crop evapotranspiration was proposed by Doorenbos and Kassam (1979):

$$
\left(1-\frac{Y_{a}}{Y_{m}}\right)=K_{y}\left(1-\frac{\sum E T_{a}[t]}{\sum C W R[t]}\right)
$$

where $K_{y}$ is a yield response factor (water stress coefficient), $Y_{a}$ the actual harvested yield $[\mathrm{kg} / \mathrm{ha}], Y_{m}$ the maximum yield [kg/ha], $E T_{a}$ the actual crop evapotranspiration in $\mathrm{mm} /$ period and $C W R$ the crop water requirement in $\mathrm{mm} /$ period (which is equal to $K_{c} \times E T_{0}$ ). $K_{y}$ values for individual periods and the complete growing period are given in Doorenbos and Kassam (1979). The $K_{y}$ values for the total growing period for winter wheat and spring wheat are 1.0 and 1.15 respectively. The maximum yield value for a number of countries is obtained from Ekboir (2002) and Pingali (1999). For countries with no such data the regional average value is taken. The actual yields which are calculated per grid cell are averaged over the nation and compared with the national average yield data (for the period 1996-2005) obtained from FAO (2010a). The calculated yield values are scaled to fit the national average $\mathrm{FAO}$ yield data.

The green and blue water footprints $\left(\mathrm{m}^{3} / \mathrm{ton}\right)$ are calculated by dividing the green and blue crop water use $\left(\mathrm{m}^{3} / \mathrm{ha}\right)$, respectively, by the actual crop yield (ton/ha). Both the total 
green and the total blue water footprint in each grid cell are calculated as the weighted average of the (green, respectively blue) water footprints under the two scenarios:

$W F=\beta \times W F(\alpha=1)+(1-\beta) \times W F(\alpha=0)$

where $\beta$ refers to the fraction of wheat area in the grid cell that is irrigated.

The grey water footprint of wheat production is calculated by quantifying the volume of water needed to assimilate the fertilisers that reach ground- or surface water. Nutrients leaching or running off from agricultural fields are the main cause of non-point source pollution of surface and subsurface water bodies. In this study we have quantified the grey water footprint related to nitrogen use only. The grey component of the water footprint of wheat $\left(W F_{g y}, \mathrm{~m}^{3} /\right.$ ton $)$ is calculated by multiplying the leaching-runoff fraction $(\delta, \%)$ by the nitrogen application rate $(A R, \mathrm{~kg} / \mathrm{ha})$ and dividing this by the difference between the maximum acceptable concentration of nitrogen $\left(c_{\max }, \mathrm{kg} / \mathrm{m}^{3}\right)$ and the natural concentration of nitrogen in the receiving water body $\left(c_{n a t}, \mathrm{~kg} / \mathrm{m}^{3}\right)$ and by the actual wheat yield $\left(Y_{a}\right.$, ton/ha):

$$
W F_{g y}=\left(\frac{\delta \times A R}{c_{\max }-c_{n a t}}\right) \times \frac{1}{Y_{a}}
$$

The average green, blue and grey water footprints of wheat in a whole nation or river basin were estimated by taking the area-weighted average of the water footprint $\left(\mathrm{m}^{3} / \mathrm{ton}\right)$ over the relevant grid cells.

The water footprints of wheat as harvested (unmilled wheat) have been used as a basis to calculate the water footprints of derived wheat products (wheat flour, wheat groats and meal, wheat starch and gluten) based on product and value fractions following the method as in Hoekstra et al. (2009).

International virtual water flows $\left(\mathrm{m}^{3} / \mathrm{yr}\right)$ related to trade in wheat products were calculated by multiplying the trade volumes (tons/yr) by their respective water footprint $\left(\mathrm{m}^{3} /\right.$ ton $)$. The global water saving $\left(\mathrm{m}^{3} / \mathrm{yr}\right)$ through international trade in wheat products is 


\section{0 / Chapter 6. A global assessment of water footprint of wheat}

calculated by multiplying the volume of trade (ton/yr) between two countries by the difference between the water footprint of the traded product in the importing country and the water footprint of the product in the exporting country.

The water footprint of national wheat consumption can be distinguished into an internal and external component. The internal water footprint is defined as the use of domestic water resources to produce goods and services consumed by inhabitants of the country. It is the water footprint related to production within the country minus the volume of virtual water export to other countries insofar as related to export of domestically produced products. The external water footprint is the part of the water footprint of national consumption that falls outside the nation considered. It refers to the appropriation of water resources in other nations for the production of goods and services that are imported into and consumed within the nation considered

\subsection{Data}

Average monthly reference evapotranspiration data at 10 arc minute resolution were obtained from FAO (2010d). The 10 minute data were converted to 5 arc minute resolution by assigning the 10 minute data to each of the four 5 minute grid cells. Following the CROPWAT approach, the monthly average data were converted to daily values by curve fitting to the monthly average through polynomial interpolation.

Monthly values for precipitation, wet days and minimum and maximum temperature with a spatial resolution of 30 arc minute were obtained from CRU-TS-2.1 (Mitchell and Jones, 2005). The 30 arc minute data were assigned to each of the thirty-six 5 arc minute grid cells contained in the 30 arc minute grid cell. Daily precipitation values were generated from these monthly average values using the CRU-dGen daily weather generator model (Schuol and Abbaspour, 2007).

Wheat growing areas on a 5 arc minute grid cell resolution were obtained from Monfreda et al. (2008). For countries missing grid data in Monfreda et al. (2008) the MICRA grid database as described in Portmann et al. (2010) was used to fill the gap. The harvested wheat areas as available in grid format were aggregated to a national level and scaled to fit national average wheat harvest areas for the period 1996-2005 obtained from 
FAO (2010a). Grid data on irrigated wheat area per country were obtained from Portmann et al. (2010).

Crop coefficients $\left(K_{c}\right.$ 's) for wheat were obtained from Chapagain and Hoekstra (2004). Wheat planting dates and lengths of cropping seasons for most wheat producing countries and regions were obtained from Sacks et al. (2010) and Portmann et al. (2010). For some countries, values from Chapagain and Hoekstra (2004) were used. We have not considered multi-cropping practices.

Grid based data on total available water capacity of the soil (TAWC) at a 5 arc minute resolution were taken from ISRIC-WISE (Batjes, 2006). An average value of TAWC of the five soil layers was used in the model.

Country-specific nitrogen fertilizer application rates for wheat have been based on Heffer (2009), FAO (2006, 2010c) and IFA (2009). Globally, wheat accounts for about $17 \%$ of total fertilizer use and $19 \%$ of the total nitrogen fertilizer consumption. A number of authors show that about $45-85 \%$ of the applied nitrogen fertilizer is recovered by the plant (Addiscot, 1996, King et al., 2001, Ma et al., 2009, Noulas et al., 2004). On average, about $16 \%$ of the applied nitrogen is presumed to be lost either by denitrification or leaching (Addiscot, 1996). The reported value of nitrogen leaching varies between 2-13\% (Addiscot, 1996, Goulding et al., 2000, Riley et al., 2001, Webster et al., 1999). In this study we have assumed that on average $10 \%$ of the applied nitrogen fertilizer is lost through leaching or runoff, following Chapagain et al. (2006b). The recommended standard value of nitrate in surface and groundwater by the World Health Organization and the European Union is $50 \mathrm{mg}$ nitrate $\left(\mathrm{NO}_{3}\right)$ per litre and the standard recommended by USEPA is $10 \mathrm{mg}$ per litre measured as nitrate-nitrogen $\left(\mathrm{NO}_{3}-\mathrm{N}\right)$. In this study we have used the standard of $10 \mathrm{mg} /$ litre of nitrate-nitrogen $\left(\mathrm{NO}_{3}-\mathrm{N}\right)$, following again Chapagain et al. (2006b). Because of a lack of data, the natural nitrogen concentrations were assumed to be zero.

Data on international trade in wheat products have been taken from the SITA database (Statistics for International Trade Analysis) available from the International Trade Centre (ITC, 2007). This database covers trade data over ten years (1996-2005) from 230 reporting countries disaggregated by product and partner countries. We have taken the average for the period 1996-2005 in wheat products trade. 


\section{2 / Chapter 6. A global assessment of water footprint of wheat}

\subsection{The water footprint of wheat from the production perspective}

The global water footprint of wheat production for the period 1996-2005 is $1088 \mathrm{Gm}^{3} /$ year ( $70 \%$ green, $19 \%$ blue, and $11 \%$ grey). Data per country are shown in Table 6.1 for the largest producers. The global green water footprint related to wheat production was 760 $\mathrm{Gm}^{3} / \mathrm{yr}$. At a country level, large green water footprints can be found in the USA (112 $\mathrm{Gm}^{3} / \mathrm{yr}$ ), China $\left(83 \mathrm{Gm}^{3} / \mathrm{yr}\right.$ ), Russia $\left(91 \mathrm{Gm}^{3} / \mathrm{yr}\right)$, Australia (44 $\mathrm{Gm}^{3} / \mathrm{yr}$ ), and India (44 $\mathrm{Gm}^{3} / \mathrm{yr}$ ). About $49 \%$ of the global green water footprint related to wheat production is in these five countries. At sub-national level (state or province level), the largest green water footprints can be found in Kansas in the USA $\left(21 \mathrm{Gm}^{3} / \mathrm{yr}\right)$, Saskatchewan in Canada (18 $\mathrm{Gm}^{3} / \mathrm{yr}$ ), Western Australia (15 $\left.\mathrm{Gm}^{3} / \mathrm{yr}\right)$, and North Dakota in the USA (15 $\left.\mathrm{Gm}^{3} / \mathrm{yr}\right)$. The global blue water footprint was estimated to be $204 \mathrm{Gm}^{3} / \mathrm{yr}$. The largest blue water footprints were calculated for India $\left(81 \mathrm{Gm}^{3} / \mathrm{yr}\right)$, China $\left(47 \mathrm{Gm}^{3} / \mathrm{yr}\right)$, Pakistan $\left(28 \mathrm{Gm}^{3} / \mathrm{yr}\right)$, Iran $\left(11 \mathrm{Gm}^{3} / \mathrm{yr}\right)$, Egypt $\left(5.9 \mathrm{Gm}^{3} / \mathrm{yr}\right)$ and the USA $\left(5.5 \mathrm{Gm}^{3} / \mathrm{yr}\right)$. These six countries together account for $88 \%$ of the total blue water footprint related to wheat production. At sub-national level, the largest blue water footprints can be found in Uttar Pradesh (24 $\left.\mathrm{Gm}^{3} / \mathrm{yr}\right)$ and Madhya Pradesh $\left(21 \mathrm{Gm}^{3} / \mathrm{yr}\right)$ in the India and Punjab in Pakistan $\left(20 \mathrm{Gm}^{3} / \mathrm{yr}\right)$. These three states in the two countries alone account about $32 \%$ of the global blue water footprint related to wheat production. The grey water footprint related to the use of nitrogen fertilizer in wheat cultivation was $124 \mathrm{Gm}^{3} / \mathrm{yr}$. The largest grey water footprint was observed for China $\left(32 \mathrm{Gm}^{3} / \mathrm{yr}\right)$, India $\left(20 \mathrm{Gm}^{3} / \mathrm{yr}\right)$ the USA $\left(14 \mathrm{Gm}^{3} / \mathrm{yr}\right)$ and Pakistan $(8$ $\left.\mathrm{Gm}^{3} / \mathrm{yr}\right)$.

The calculated global average water footprint per ton of wheat was $1830 \mathrm{~m}^{3} /$ ton. The results show a great variation, however, both within a country and among countries (Figure 6.1). Among the major wheat producers, the highest total water footprint per ton of wheat was found for Morocco, Iran and Kazakhstan. On the other side of the spectrum, there are countries like the UK and France with a wheat water footprint of around $560-600 \mathrm{~m}^{3} /$ ton.

The global average blue water footprint per ton of wheat amounts to $343 \mathrm{~m}^{3} /$ ton. For a few countries, including Pakistan, India, Iran and Egypt, the blue water footprint is much higher, up to $1478 \mathrm{~m}^{3} /$ ton in Pakistan. In Pakistan, the blue water component in the total water footprint is nearly $58 \%$. The grey water footprint per ton of wheat is $208 \mathrm{~m}^{3} /$ ton as a global average, but in Poland it is 2.5 times higher than the global average. 
Table 6.1. Water footprint of wheat production for the major wheat producing countries.

Period: 1996-2005.

\begin{tabular}{|c|c|c|c|c|c|c|c|c|c|}
\hline \multirow{2}{*}{ Country } & \multirow{2}{*}{$\begin{array}{c}\text { Contribution } \\
\text { to global } \\
\text { wheat } \\
\text { production } \\
(\%)\end{array}$} & \multicolumn{4}{|c|}{$\begin{array}{l}\text { Total water footprint of production } \\
\qquad\left(\mathrm{Mm}^{3} / \mathrm{yr}\right)\end{array}$} & \multicolumn{4}{|c|}{$\begin{array}{l}\text { Water footprint per ton of } \\
\text { wheat }\left(\mathrm{m}^{3} / \text { ton) }\right.\end{array}$} \\
\hline & & Green & Blue & Grey & Total & Green & Blue & Grey & Total \\
\hline Argentina & 2.5 & 25905 & 162 & 1601 & 27668 & 1777 & 11 & 110 & 1898 \\
\hline Australia & 3.6 & 44057 & 363 & 2246 & 46666 & 2130 & 18 & 109 & 2256 \\
\hline Canada & 3.9 & 32320 & 114 & 4852 & 37286 & 1358 & 5 & 204 & 1567 \\
\hline China & 17.4 & 83459 & 47370 & 31626 & 162455 & 820 & 466 & 311 & 1597 \\
\hline $\begin{array}{l}\text { Czech } \\
\text { Republic }\end{array}$ & 0.6 & 2834 & 0 & 900 & 3734 & 726 & 0 & 231 & 957 \\
\hline Denmark & 0.8 & 2486 & 30 & 533 & 3049 & 530 & 6 & 114 & 651 \\
\hline Egypt & 1.1 & 1410 & 5930 & 2695 & 10034 & 216 & 907 & 412 & 1536 \\
\hline France & 6.0 & 21014 & 48 & 199 & 21261 & 584 & 1 & 6 & 591 \\
\hline Germany & 3.5 & 12717 & 0 & 3914 & 16631 & 602 & 0 & 185 & 787 \\
\hline Hungary & 0.7 & 4078 & 8 & 1389 & 5476 & 973 & 2 & 331 & 1306 \\
\hline India & 11.9 & 44025 & 81335 & 20491 & 145851 & 635 & 1173 & 296 & 2104 \\
\hline Iran & 1.8 & 26699 & 10940 & 3208 & 40847 & 2412 & 988 & 290 & 3690 \\
\hline Italy & 1.2 & 8890 & 120 & 1399 & 10409 & 1200 & 16 & 189 & 1405 \\
\hline Kazakhstan & 1.7 & 33724 & 241 & 1 & 33966 & 3604 & 26 & 0 & 3629 \\
\hline Morocco & 0.5 & 10081 & 894 & 387 & 11362 & 3291 & 292 & 126 & 3710 \\
\hline Pakistan & 3.2 & 12083 & 27733 & 8000 & 47816 & 644 & 1478 & 426 & 2548 \\
\hline Poland & 1.5 & 9922 & 4 & 4591 & 14517 & 1120 & 0 & 518 & 1639 \\
\hline Romania & 0.9 & 9066 & 247 & 428 & 9741 & 1799 & 49 & 85 & 1933 \\
\hline Russia & 6.5 & 91117 & 1207 & 3430 & 95754 & 2359 & 31 & 89 & 2479 \\
\hline Spain & 1.0 & 8053 & 275 & 1615 & 9943 & 1441 & 49 & 289 & 1779 \\
\hline Syria & 0.7 & 5913 & 1790 & 842 & 8544 & 1511 & 457 & 215 & 2184 \\
\hline Turkey & 3.3 & 40898 & 2570 & 3857 & 47325 & 2081 & 131 & 196 & 2408 \\
\hline UK & 2.5 & 6188 & 2 & 2292 & 8482 & 413 & 0 & 153 & 566 \\
\hline Ukraine & 2.5 & 26288 & 287 & 1149 & 27724 & 1884 & 21 & 82 & 1987 \\
\hline USA & 10.2 & 111926 & 5503 & 13723 & 131152 & 1879 & 92 & 230 & 2202 \\
\hline Uzbekistan & 0.7 & 3713 & 399 & 0 & 4112 & 939 & 101 & 0 & 1039 \\
\hline World & & 760301 & 203744 & 123533 & 1087578 & 1279 & 343 & 208 & 1830 \\
\hline
\end{tabular}

Table 6.2 shows the water footprint related to production of wheat for some selected river basins. About $59 \%$ of the global water footprint related to wheat production is located in 
this limited number of basins. Large blue water footprints can be found in the GangesBrahmaputra-Meghna (53 $\mathrm{Gm}^{3} / \mathrm{yr}$ ), Indus (42 $\left.\mathrm{Gm}^{3} / \mathrm{yr}\right)$, Yellow (13 $\left.\mathrm{Gm}^{3} / \mathrm{yr}\right)$, TigrisEuphrates $\left(10 \mathrm{Gm}^{3} / \mathrm{yr}\right)$, Amur $\left(3.1 \mathrm{Gm}^{3} / \mathrm{yr}\right)$ and Yangtze river basins $\left(2.7 \mathrm{Gm}^{3} / \mathrm{yr}\right)$. The Ganges-Brahmaputra-Meghna and Indus river basins together account for about $47 \%$ of the global blue and $21 \%$ of the global grey water footprint.

Table 6.2. The water footprint of wheat production for some selected river basins (19962005).

\begin{tabular}{|c|c|c|c|c|c|c|c|c|}
\hline \multirow[t]{2}{*}{ River basin } & \multicolumn{4}{|c|}{$\begin{array}{l}\text { Total water footprint of production } \\
\qquad\left(\mathrm{Mm}^{3} / \mathrm{yr}\right)\end{array}$} & \multicolumn{4}{|c|}{$\begin{array}{l}\text { Water footprint per ton of } \\
\text { wheat }\left(\mathrm{m}^{3} / \text { ton }\right)\end{array}$} \\
\hline & Green & Blue & Grey & Total & Green & Blue & Grey & Total \\
\hline $\begin{array}{l}\text { Ganges- } \\
\text { Brahmaputra-Meghna }\end{array}$ & 30288 & 53009 & 12653 & 95950 & 665 & 1164 & 278 & 2107 \\
\hline Mississippi & 79484 & 2339 & 9413 & 91236 & 1979 & 58 & 234 & 2271 \\
\hline Indus & 22897 & 42145 & 13326 & 78368 & 604 & 1111 & 351 & 2066 \\
\hline $\mathrm{Ob}$ & 51984 & 225 & 511 & 52721 & 2680 & 12 & 26 & 2718 \\
\hline $\begin{array}{l}\text { Nelson- } \\
\text { Saskatchewan }\end{array}$ & 38486 & 118 & 5691 & 44294 & 1275 & 4 & 189 & 1468 \\
\hline Tigris-Euphrates & 29219 & 10282 & 2670 & 42170 & 2893 & 1018 & 264 & 4175 \\
\hline Yellow & 17012 & 13127 & 7592 & 37731 & 695 & 536 & 310 & 1541 \\
\hline Danube & 27884 & 273 & 3579 & 31735 & 1298 & 13 & 167 & 1477 \\
\hline Volga & 25078 & 272 & 955 & 26305 & 2315 & 25 & 88 & 2429 \\
\hline Don & 24834 & 384 & 927 & 26144 & 2658 & 41 & 99 & 2799 \\
\hline Yangtze & 17436 & 2700 & 4855 & 24991 & 1112 & 172 & 310 & 1594 \\
\hline Murray-Darling & 20673 & 343 & 987 & 22003 & 2061 & 34 & 98 & 2193 \\
\hline La Plata & 17127 & 73 & 1070 & 18271 & 2039 & 9 & 127 & 2175 \\
\hline Amur & 8726 & 3136 & 2355 & 14216 & 985 & 354 & 266 & 1604 \\
\hline Dnieper & 13219 & 68 & 813 & 14100 & 1732 & 9 & 107 & 1847 \\
\hline Columbia & 7238 & 1877 & 1122 & 10236 & 1852 & 480 & 287 & 2620 \\
\hline Oral & 9338 & 94 & 192 & 9624 & 2542 & 26 & 52 & 2620 \\
\hline World & 760301 & 203744 & 123533 & 1087578 & 1279 & 343 & 208 & 1830 \\
\hline
\end{tabular}

The global average water footprint of rain-fed wheat production is $1805 \mathrm{~m}^{3} /$ ton, while in irrigated wheat production it is $1868 \mathrm{~m}^{3} /$ ton (Table 6.3). Obviously, the blue water footprint 
in rain-fed wheat production is zero. In irrigated wheat production, the blue water footprint constitutes $50 \%$ of the total water footprint. Although, on average, wheat yields are $30 \%$ higher in irrigated fields, the water footprint of wheat from irrigated lands is higher than in the case of rain-fed lands. When we consider consumptive water use (blue plus green water footprint) only, the water footprints of wheat from rain-fed and irrigated land are more or less equal, as a global average. The reason is that, although yields are higher under irrigation, water consumption (evapotranspiration) is higher as well. Under rain-fed conditions, the actual evapotranspiration over the growing period is lower than the potential evapotranspiration, while under irrigated conditions there is more water available to meet crop water requirements, leading to an actual evapotranspiration that will approach or equal potential evapotranspiration .

Table 6.3. The global water footprint of wheat production in rain-fed and irrigated lands (1996-2005).

\begin{tabular}{lrrrrrrrrr}
\hline \multirow{2}{*}{$\begin{array}{l}\text { Farming } \\
\text { system }\end{array}$} & $\begin{array}{c}\text { Yield } \\
\text { (ton/ha) }\end{array}$ & \multicolumn{3}{c}{$\begin{array}{c}\text { Total water footprint of } \\
\text { production }\left(\mathrm{Gm}^{3} / \mathrm{yr}\right)\end{array}$} & \multicolumn{4}{c}{$\begin{array}{c}\text { Water footprint per ton of } \\
\text { wheat }\left(\mathrm{m}^{3} / \text { ton }\right)\end{array}$} \\
\cline { 2 - 11 } & & Green & Blue & Grey & Total & Green & Blue & Grey & Total \\
\hline Rain-fed & 2.5 & 611 & 0 & 66 & 676 & 1629 & 0 & 175 & 1805 \\
Irrigated & 3.3 & 150 & 204 & 58 & 411 & 679 & 926 & 263 & 1868 \\
\hline World average & 2.7 & 760 & 204 & 124 & 1088 & 1279 & 343 & 208 & 1830 \\
\hline
\end{tabular}

The green, blue and grey water footprints of global wheat production put pressure on the freshwater system in different ways. Green water generally has a low opportunity cost compared to blue water. There are many river basins in the world where blue water consumption contributes to severe water scarcity and associated environmental problems, like in the Indus and Ganges basins as will be discussed below. Since wheat has relatively low economic water productivity (euro/ $\mathrm{m}^{3}$ ) compared to many other crops (Molden, 2007), one may question to which extent water should be allocated to wheat production in relatively water-scarce basins. The relatively low yields in rain-fed lands show that there is still plenty of room to raise green water productivity in most countries, i.e. lowering the green water footprint. This is particularly relevant in policy aimed at addressing the negative externalities of blue water footprints, because increasing green water productivity and increased production from rain-fed lands will reduce the need for production from 


\section{6 / Chapter 6. A global assessment of water footprint of wheat}

irrigated lands in water-scarce areas, and thus reduce blue water use. The grey water footprint in wheat production can generally be lowered substantially by applying fertilisers in the right amounts at the right time using appropriate application technology (precision farming), so that less fertilisers leach to groundwater or run off to surface water (Jenkinson, 2001; Norse, 2005).

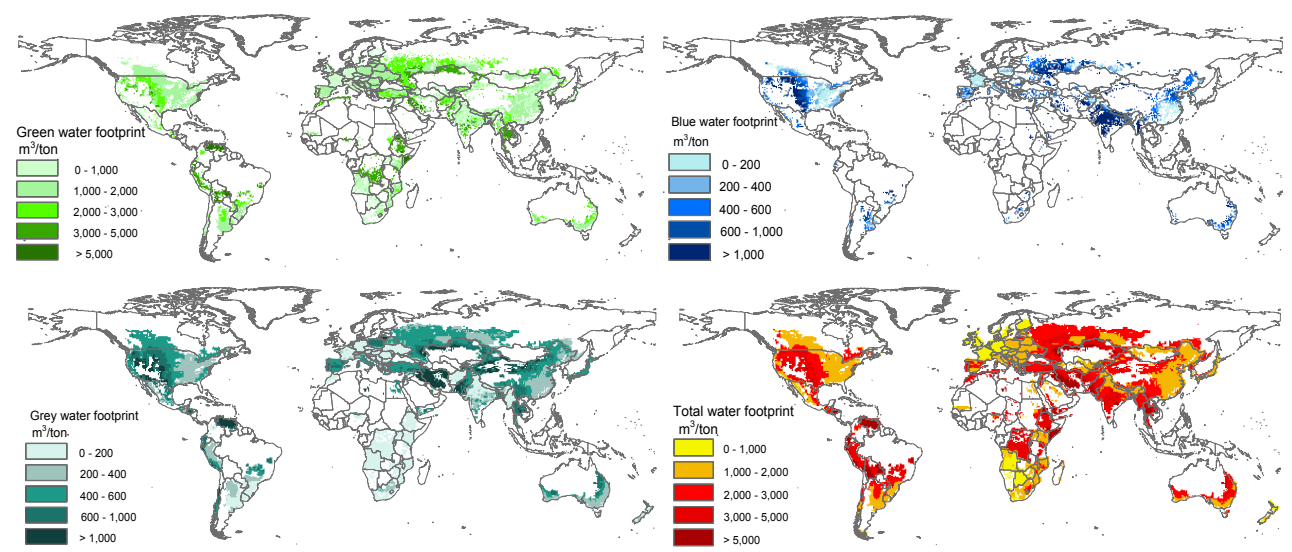

Figure 6.1. The green, blue, grey and total water footprint of wheat production per ton of wheat. Period: 1996-2005.

\subsection{International virtual water flows related to trade in wheat products}

The total global virtual water flow related to trade in wheat products averaged over the period 1996-2005 was $200 \mathrm{Gm}^{3} /$ year. This means that an estimated $18 \%$ of the global water footprint was related to wheat production for export. About $87 \%$ of this amount comes from green water and only $4 \%$ from blue water and the remaining $9 \%$ is grey water. Wheat exports in the world are thus basically from rain-fed agriculture. The world's largest 26 wheat producers, which account for about $90 \%$ of global wheat production (Table 6.1), were responsible for about $94 \%$ of the global virtual water export. The USA, Canada and Australia alone were responsible for about $55 \%$ of the total virtual water export. China, which is the top wheat producer accounting for $17.4 \%$ of the global wheat production, was a net virtual water importer. India and the USA were the largest exporters of blue water, accounting for about $62 \%$ of the total blue water export. A very small fraction $(4 \%)$ of the total blue water consumption in wheat production was traded internationally. Surprisingly, 
some water-scarce regions in the world, relying on irrigation, show a net export of blue water virtually embedded in wheat. Saudi Arabia had a net blue virtual water export of 21 $\mathrm{Mm}^{3} / \mathrm{yr}$ and Iraq exported a net volume of blue water of $6 \mathrm{Mm}^{3} / \mathrm{yr}$. The largest grey water exporters were the USA, Canada, Australia and Germany. Data per country are shown in Table 6.4 for the largest virtual water exporters and importers, respectively. The largest net virtual water flows related to international wheat trade are shown in Figure 6.2.

Table 6.4. Gross virtual water export and import related to the international trade of wheat products in the period 1996-2005.

\begin{tabular}{lrrrllllrr}
\hline \multicolumn{1}{l}{ Largest virtual water exporters $\left(\mathrm{Mm}^{3} / \mathrm{yr}\right)$} & \multicolumn{4}{l}{ Largest virtual water importers $\left(\mathrm{Mm}^{3} / \mathrm{yr}\right)$} \\
\hline USA & Green & Blue & Grey & Total & & Green & Blue & Grey & Total \\
Canada & 48603 & 2389 & 5959 & 56952 & Brazil & 11415 & 88 & 801 & 12304 \\
Australia & 24144 & 85 & 3625 & 27854 & Japan & 10393 & 320 & 1147 & 11860 \\
Argentina & 24396 & 201 & 1244 & 25841 & Italy & 7345 & 174 & 760 & 8279 \\
Kazakhstan & 15973 & 100 & 987 & 17060 & Egypt & 6838 & 274 & 633 & 7745 \\
France & 16490 & 118 & 0 & 16608 & Korea, Rep & 6511 & 398 & 685 & 7594 \\
Russian Fed & 75347 & 21 & 89 & 9457 & Indonesia & 6512 & 364 & 577 & 7453 \\
Ukraine & 4569 & 100 & 285 & 7954 & Iran & 6105 & 60 & 504 & 6670 \\
Germany & 3537 & 0 & 1090 & 4626 & Algeria & 5330 & 323 & 696 & 6350 \\
India & 1266 & 2338 & 589 & 4193 & Mexico & 5155 & 205 & 660 & 6020 \\
Turkey & 2208 & 139 & 208 & 2555 & Russian Fed & 5334 & 69 & 92 & 5495 \\
UK & 1189 & 0 & 441 & 1630 & Philippines & 3923 & 426 & 538 & 4887 \\
Spain & 1242 & 42 & 249 & 1534 & Spain & 4161 & 80 & 493 & 4734 \\
Hungary & 1035 & 2 & 352 & 1389 & China & 4087 & 98 & 453 & 4638 \\
Others & 13107 & 2202 & 2488 & 17797 & Others & 85967 & 4725 & 9131 & 99823 \\
\hline Global flow & 174693 & 7789 & 17807 & 200289 & Global flow & 174693 & 7789 & 17807 & 200289 \\
\hline
\end{tabular}

The global water saving associated with the international trade in wheat products adds up to $65 \mathrm{Gm}^{3} / \mathrm{yr}$ (39\% green, $48 \%$ blue, and 13\% grey). Import of wheat and wheat products by Algeria, Iran, Morocco and Venezuela from Canada, France, the USA and Australia resulted in the largest global water savings. Figure 6.3 illustrates the concept of global water saving through an example of the trade in durum wheat from France to Morocco. 


\subsection{The water footprint of wheat from the consumption perspective}

The global water footprint related to the consumption of wheat products was estimated at $1088 \mathrm{Gm}^{3} / \mathrm{yr}$, which is $177 \mathrm{~m}^{3} / \mathrm{yr}$ per person on average (70\% green, $19 \%$ blue, and $11 \%$ grey). About $82 \%$ of the total water footprint related to consumption was from domestic production while the remaining $18 \%$ was external water footprint (Figure 6.4). In terms of water footprint per capita, Kazakhstan has the largest water footprint, with $1156 \mathrm{~m}^{3} / \mathrm{cap} / \mathrm{yr}$, followed by Australia and Iran with 1082 and $716 \mathrm{~m}^{3} / \mathrm{cap} / \mathrm{yr}$ respectively. Data per country are shown in Table 6.5 for the major wheat consuming countries and in Figure 6.5 all countries of the world. When the water footprint of wheat consumption per capita is relatively high in a country, this can be explained by either one or a combination of two factors: (i) the wheat consumption in the country is relatively high; (ii) the wheat consumed has a high water footprint per $\mathrm{kg}$ of wheat. As one can see in Table 6.5, in the case of Kazakhstan and Iran, both factors play a role. In the case of Australia, the relatively high water footprint related to wheat consumption can be mostly explained by the high wheat consumption per capita alone. Germany has a large wheat consumption per capita - more than twice the world average - so that one would expect that the associated water footprint would be high as well, but this is not the case because, on average, the wheat consumed in Germany has a low water footprint per $\mathrm{kg}$ ( $43 \%$ of the global average).

The countries with the largest external water footprint related to wheat consumption were Brazil, Japan, Egypt, Italy, the Republic of Korea and Iran. Together, these countries account for about $28 \%$ of the total external water footprint. Japan's water footprint related to wheat consumption lies outside the country for about $93 \%$. In Italy, with an average wheat consumption of $150 \mathrm{~kg} / \mathrm{yr}$ per person, more than two times the word average, this was about 44\%. Most African, South-East Asian, Caribbean and Central American countries strongly rely on external water resources for their wheat consumption as shown in Figure 6.6. 


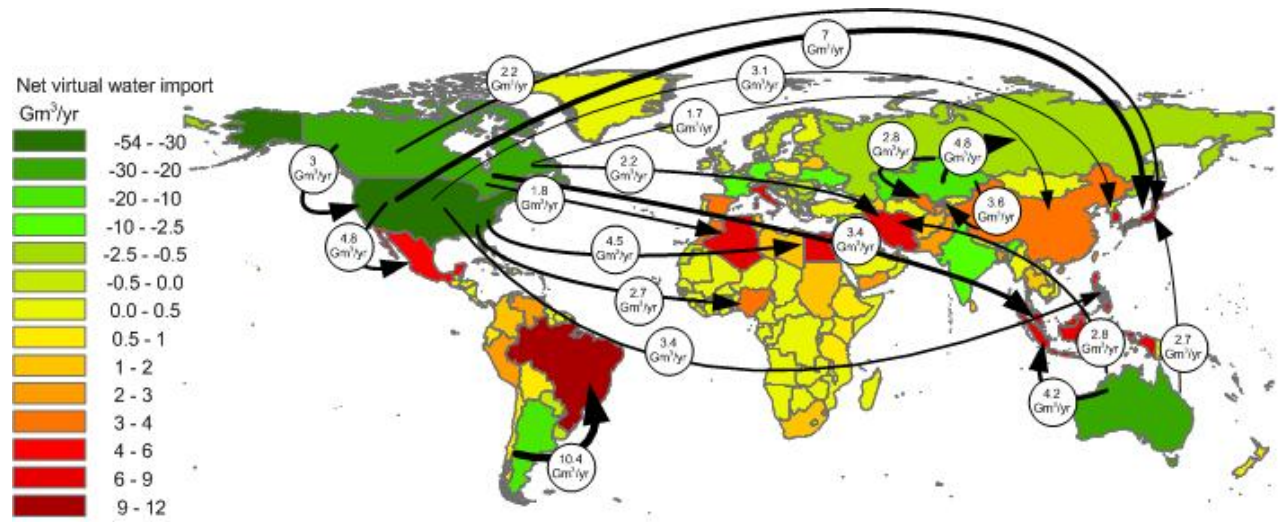

Figure 6.2. National virtual water balances and net virtual water flows related to trade in wheat products in the period 1996-2005. Only the largest net flows (> $2 \mathrm{Gm}^{3} / \mathrm{yr}$ ) are shown.

\section{France}

Water footprint, $\mathrm{WF}_{\mathrm{e}}=591 \mathrm{~m}^{3} /$ ton

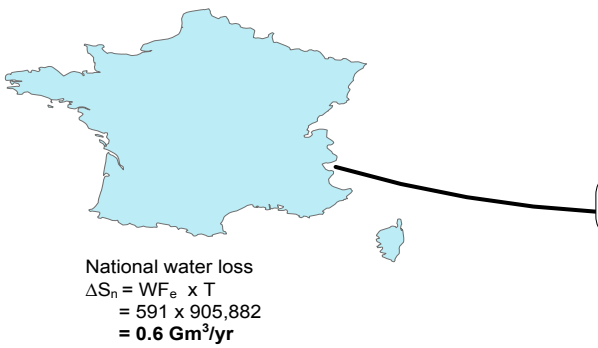
$\mathrm{T}=905,882$ ton $/ \mathrm{yr}$

$$
\begin{aligned}
& \text { Global water saving } \\
& \begin{aligned}
\Delta S_{g} & =T\left(W F_{i}-W F_{e}\right) \\
& =905,882(5710-591) \\
& =\mathbf{3 . 1 7} \mathbf{~ G m}^{3} / \mathbf{y r}
\end{aligned}
\end{aligned}
$$

Morocco

Water footprint , $W_{\mathrm{i}}=5710 \mathrm{~m}^{3} /$ ton

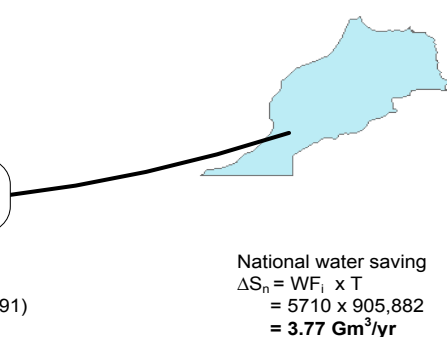

Figure 6.3. Global water saving through the trade in durum wheat from France to Morocco. Period: 1996-2005.

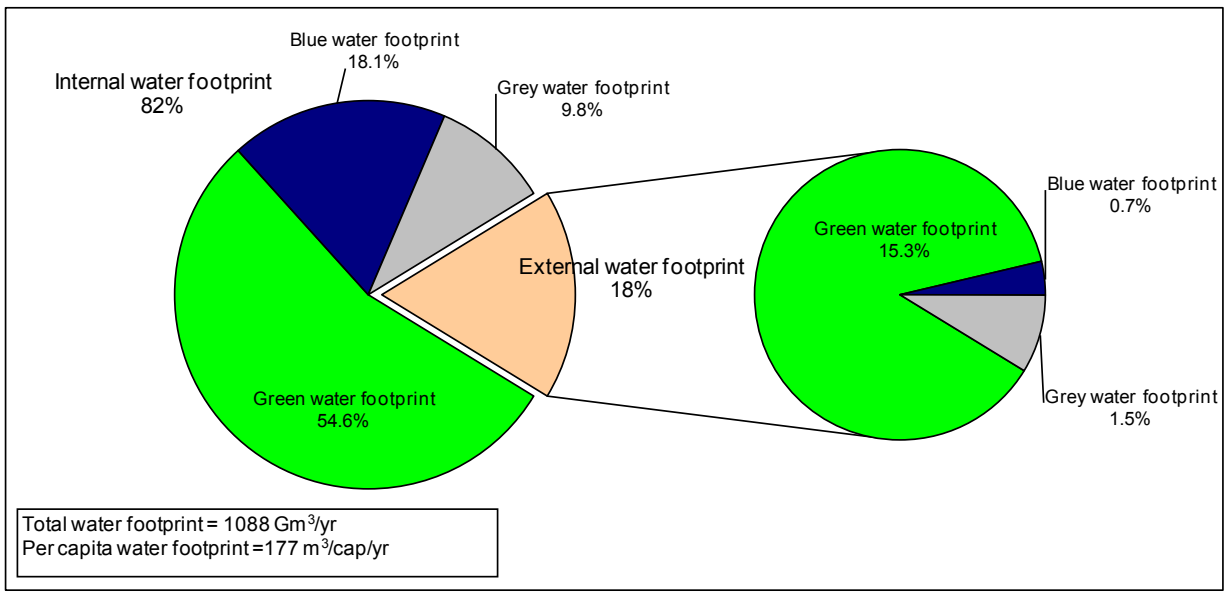

Figure 6.4. Global water footprint related the consumption of wheat products. Period: 19962005 
Table 6.5. Water footprint of wheat consumption for the major wheat consuming countries (1996-2005).

\begin{tabular}{|c|c|c|c|c|c|c|c|c|c|c|c|}
\hline \multirow{2}{*}{ Countries } & \multicolumn{3}{|c|}{$\begin{array}{l}\text { Internal water footprint } \\
\left(\mathrm{Mm}^{3} / \mathrm{yr}\right)\end{array}$} & \multicolumn{3}{|c|}{$\begin{array}{c}\text { External water } \\
\text { footprint }\left(\mathrm{Mm}^{3} / \mathrm{yr}\right)\end{array}$} & \multicolumn{2}{|c|}{ Water footprint } & \multirow{2}{*}{$\begin{array}{l}\text { WF } \\
\text { per } \\
\text { capita } \\
\text { Fraction } \\
\text { of world } \\
\text { average }\end{array}$} & \multirow{2}{*}{$\begin{array}{l}\text { Wheat } \\
\text { consump- } \\
\text { tion per } \\
\text { capita } \\
\text { Fraction } \\
\text { of world } \\
\text { average }\end{array}$} & \multirow{2}{*}{$\begin{array}{l}\text { WF of } \\
\text { wheat } \\
\text { products } \\
\text { Fraction } \\
\text { of world } \\
\text { average }\end{array}$} \\
\hline & Green & Blue & Grey & Green & Blue & Grey & $\begin{array}{l}\text { Total WF } \\
\left(\mathrm{Mm}^{3} / \mathrm{yr}\right)\end{array}$ & $\begin{array}{c}\text { WF } \\
\text { per } \\
\text { capita } \\
\left(\mathrm{m}^{3} / \mathrm{yr}\right)\end{array}$ & & & \\
\hline China & 82990 & 47091 & 31442 & 4064 & 97 & 450 & 166134 & 133 & 0.75 & 0.86 & 0.88 \\
\hline India & 42786 & 78997 & 19903 & 931 & 17 & 64 & 142699 & 135 & 0.76 & 0.66 & 1.15 \\
\hline Russia & 83967 & 1112 & 3152 & 4915 & 63 & 85 & 93295 & 635 & 3.59 & 2.67 & 1.33 \\
\hline USA & 64508 & 3124 & 7941 & 1612 & 15 & 244 & 77444 & 270 & 1.53 & 1.32 & 1.17 \\
\hline Pakistan & 11900 & 27218 & 7856 & 2752 & 90 & 259 & 50075 & 345 & 1.95 & 1.42 & 1.37 \\
\hline Iran & 26693 & 10937 & 3208 & 6104 & 60 & 504 & 47505 & 716 & 4.04 & 2.32 & 1.74 \\
\hline Turkey & 38810 & 2434 & 3659 & 2238 & 54 & 181 & 47376 & 691 & 3.90 & 2.98 & 1.30 \\
\hline Ukraine & 21905 & 239 & 955 & 1021 & 12 & 30 & 24163 & 496 & 2.80 & 2.78 & 1.01 \\
\hline Australia & 19671 & 162 & 1005 & 8 & 1 & 3 & 20851 & 1082 & 6.11 & 5.47 & 1.16 \\
\hline Brazil & 6901 & 3 & 469 & 11224 & 88 & 788 & 19472 & 111 & 0.63 & 0.58 & 1.08 \\
\hline Egypt & 1409 & 5924 & 2692 & 6837 & 274 & 633 & 17768 & 264 & 1.49 & 1.62 & 0.92 \\
\hline Kazakhstan & 17312 & 124 & 1 & 83 & 1 & 7 & 17529 & 1156 & 6.53 & 3.92 & 1.85 \\
\hline Italy & 8274 & 114 & 1284 & 6837 & 165 & 697 & 17372 & 300 & 1.69 & 2.35 & 0.70 \\
\hline Poland & 9687 & 4 & 4478 & 572 & 7 & 94 & 14841 & 386 & 2.18 & 2.48 & 0.87 \\
\hline Morocco & 9923 & 877 & 383 & 3230 & 68 & 306 & 14786 & 505 & 2.85 & 2.21 & 1.29 \\
\hline Germany & 9459 & 0 & 2868 & 810 & 13 & 120 & 13270 & 161 & 0.91 & 2.07 & 0.43 \\
\hline World & 593599 & $19669 x$ & 106972 & 166703 & 7147 & 16586 & 1087696 & 177 & & & \\
\hline
\end{tabular}

\subsection{Case studies}

\subsubsection{The water footprint of wheat production in the Ogallala area (USA)}

The Ogallala Aquifer, also known as the High Plains Aquifer, is a regional aquifer system located beneath the Great Plains in the United States in portions of the eight states of South Dakota, Nebraska, Wyoming, Colorado, Kansas, Oklahoma, New Mexico, and Texas. It covers an area of approximately $451,000 \mathrm{~km}^{2}$, making it the largest area of irrigationsustained cropland in the world (Peterson and Bernardo, 2003). Most of the aquifer underlies parts of three states: Nebraska has $65 \%$ of the aquifer's volume, Texas $12 \%$ and Kansas 10\% (Peck, 2007). About 27 percent of the irrigated land in the United States 
overlies this aquifer system, which yields about 30 percent of the nation's ground water used for irrigation (Dennehy, 2000).

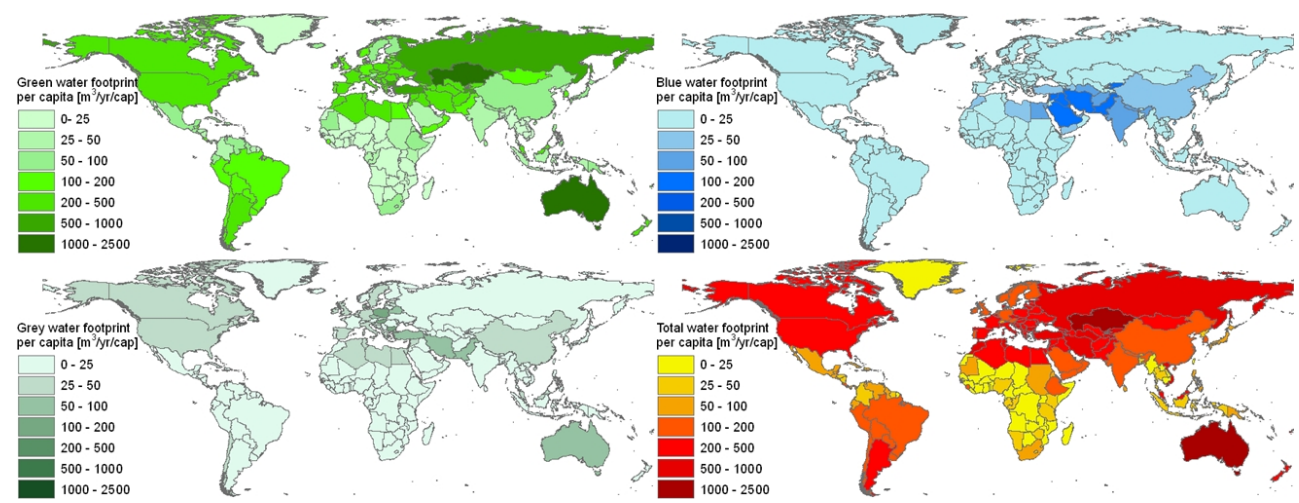

Figure 6.5. Water footprint per capita related to consumption of wheat products in the period 1996-2005.

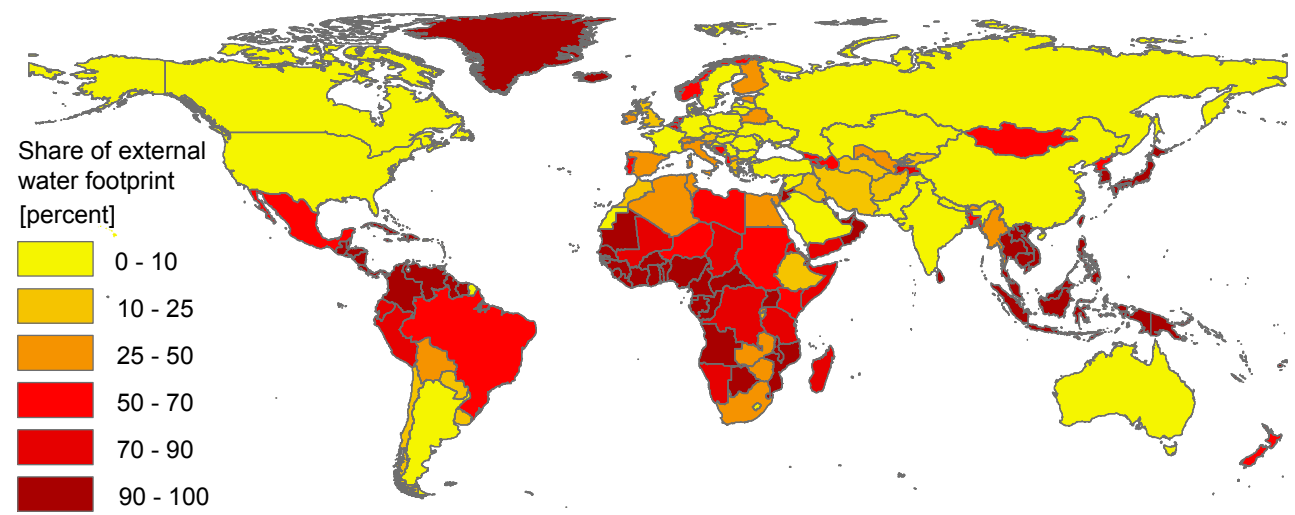

Figure 6.6. The extent to which countries rely on external water resources for their wheat consumption. Period: 1996-2005.

Water from the Ogallala Aquifer is the principal source of supply for irrigated agriculture. In 1995, the Ogallala Aquifer contributed about $81 \%$ of the water supply in the Ogallala area while the remainder was withdrawn from rivers and streams, most of it from the Platte River in Nebraska. Outside of the Platte River Valley, 92\% of water used in the Ogallala area is supplied by ground water (Dennehy, 2000). Since the beginning of extensive irrigation using ground water, the water level of the aquifer has dropped by 3 to 15 meters in most part of the aquifer (McGuire, 2007). 
Within the Ogallala area, Kansas takes the largest share in wheat production $(51 \%)$, followed by Texas and Nebraska (16\% and 15\% respectively). In Kansas, $84 \%$ of the wheat production comes from rain-fed areas. In Nebraska, this is $86 \%$ and in Texas $47 \%$. The Ogallala area accounts for about $14 \%$ of the total wheat production in the USA. Our study shows that $16 \%$ of the total water footprint of wheat production in the country lies in the Ogallala area. About 19\% of the blue water footprint of wheat production in the USA is in the Ogallala area (Table 6.6). The total water footprint in the Ogallala area was $21 \mathrm{Gm}^{3} / \mathrm{yr}$ ( $85 \%$ green, $5 \%$ blue, and $10 \%$ grey).

Table 6.6. Water footprint of wheat production and virtual water export from the Ogallala area (1996-2005).

\begin{tabular}{lrrrrrrrr}
\hline & \multicolumn{3}{c}{$\begin{array}{c}\text { Water footprint related to } \\
\text { States in the }\end{array}$ Ogallala area* } & \multicolumn{4}{c}{$\begin{array}{c}\text { Virtual water export related to } \\
\text { export of wheat products } \\
\left(\mathrm{Mm}^{3} / \mathrm{yr}\right)\end{array}$} \\
\cline { 2 - 10 } & Green & Blue & Grey & Total & Green & Blue & Grey & Total \\
\hline Kansas & 9136 & 368 & 1077 & 10581 & 8914 & 359 & 1051 & 10323 \\
Texas & 1981 & 417 & 301 & 2699 & 1933 & 407 & 294 & 2633 \\
Nebraska & 2952 & 78 & 345 & 3375 & 2880 & 76 & 337 & 3293 \\
Colorado & 2108 & 67 & 281 & 2456 & 2057 & 66 & 274 & 2397 \\
Oklahoma & 693 & 26 & 91 & 809 & 676 & 25 & 88 & 789 \\
New Mexico & 317 & 94 & 45 & 455 & 309 & 91 & 44 & 444 \\
South Dakota & 211 & 0 & 24 & 235 & 206 & 0 & 23 & 229 \\
Wyoming & 299 & 6 & 34 & 338 & 291 & 6 & 33 & 330 \\
\hline Ogallala area total & 17696 & 1056 & 2196 & 20949 & 17266 & 1031 & 2143 & 20439 \\
\hline
\end{tabular}

* Values in the table refer to the part of the states within the Ogallala area only.

Texas takes the largest share (39\%) in the blue water footprint of wheat production in the Ogallala area, followed by Kansas (35\%). There is a considerable variation in the blue water footprint per ton of wheat within the Ogallala area. Besides, the blue water footprint per ton of wheat in the Ogallala area is relatively high if compared to the average in the USA.

In the period 1996-2005, the virtual water export related to export of wheat products from the USA was $57 \mathrm{Gm}^{3} / \mathrm{yr}$. About $98 \%\left(55.6 \mathrm{Gm}^{3} / \mathrm{yr}\right)$ of the virtual water export comes 
from domestic water resources and the remaining $2 \%\left(1.4 \mathrm{Gm}^{3} / \mathrm{yr}\right)$ is from re-export of imported virtual water related to import of wheat products. Taking the per capita wheat consumption in the USA of about $88 \mathrm{~kg} / \mathrm{yr}$ (FAO, 2010a) and a population in the Ogallala area of 2.4 million (CIESIN and CIAT, 2005) we can find that only $2 \%$ of the wheat produced is consumed within the Ogallala area and the surplus (about 98\%) is exported out of the Ogallala area to other areas in the USA or exported to other countries. This surplus of wheat constitutes $33 \%$ of the domestic wheat export from the USA (Table 6.6). Figure 6.7 shows the major foreign destinations of wheat-related virtual water exports from the area of the Ogallala Aquifer.

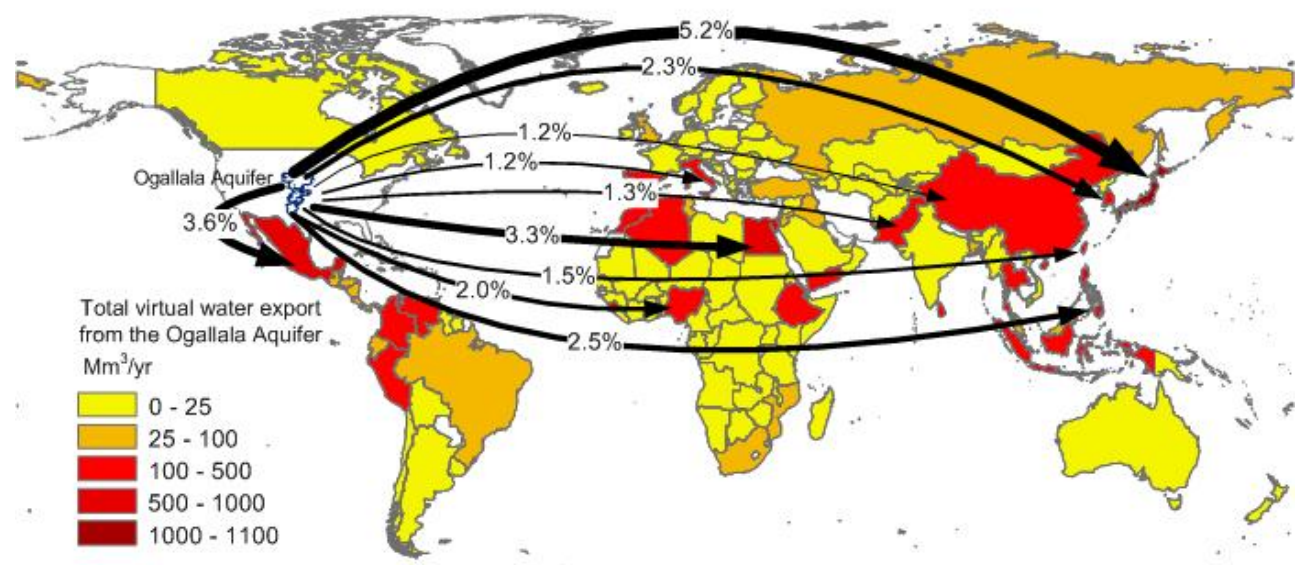

Figure 6.7. Major destinations of wheat-related virtual water exports from the Ogallala area in the USA (1996-2005). About 58\% of the total water footprint of wheat production in the area is for wheat consumption in the USA and $42 \%$ is for export to other nations. Only the largest exports (> 1\%) are shown.

The water footprint related to wheat production for export is putting pressure on the water resources of the Ogallala Aquifer (McGuire, 2007). Visualising the hidden link between the wheat consumer elsewhere and the impact of wheat production on the water resources of the Ogallala Aquifer is quite relevant in policy aimed at internalizing the negative externalities of wheat production and passing such externalities cost to consumers elsewhere. 


\subsubsection{The water footprint of wheat production in the Ganges and Indus river basins}

The Ganges river basin, which is part of the composite Ganges-Brahmaputra-Meghna river basin, is one of most densely populated river basins in the world. It covers about 1 million $\mathrm{km}^{2}$ (Gleick, 1993). The Indus river basin, which extends over four countries (China, India, Pakistan and Afghanistan), is also a highly populated river basin. The area of the Indus basin is a bit smaller than the Ganges basin but covers nearly 1 million $\mathrm{km}^{2}$ as well (Gleick, 1993).

The two river basins together account for about 90 percent of the wheat production in India and Pakistan in the period 1996-2005. Almost all wheat production (98\%) in Pakistan comes from the Indus river basin. About $89 \%$ of India's wheat is produced in the Ganges (62\%) and the Indus basin (27\%). About $87 \%$ of the total water footprint related to wheat production in India and Pakistan lies in these two river basins. The total water footprint of wheat production in the Indian part of the Ganges basin is $92 \mathrm{Gm}^{3} / \mathrm{yr}(32 \%$ green, $54 \%$ blue, $14 \%$ grey). The total water footprint of wheat production in the Pakistani part of the Indus basin is $48 \mathrm{Gm}^{3} / \mathrm{yr}$ (25\% green, $58 \%$ blue, $17 \%$ grey).

In the period 1996-2005, India and Pakistan together had a virtual water export related to wheat export of $5.1 \mathrm{Gm}^{3} / \mathrm{yr}$ (29\% green water, $56 \%$ blue, $15 \%$ grey), which is a small fraction (3\%) of the total water footprint of wheat production in these two countries. About $55 \%$ of this total virtual water export comes from the Ganges basin and $45 \%$ from the Indus basin. The blue water export to other countries from the Ganges and Indus river basins was $1304 \mathrm{Mm}^{3} / \mathrm{yr}$ and $1077 \mathrm{Mm}^{3} / \mathrm{yr}$ respectively.

Based on the water withdrawal-to-availability ratio, which is an indicator of water stress (Alcamo et al., 2003a; Alcamo et al., 2007; Cosgrove and Rijsberman, 2000), most parts of Pakistan and India are highly water stressed (Alcamo et al., 2003b). Both the Ganges and Indus river basins are under severe water stress, in particular the Indus river basin. About $97 \%$ of the water footprint related to wheat production in the two basins is for domestic consumption within the two countries. Since the two basins are the wheat baskets of the two countries, there are substantial virtual water transfers from the Ganges and Indus basins to other areas within India and Pakistan. By looking at the virtual flows both within the country and to other countries, it is possible to link the impacts of wheat consumption in 
other places to the water stress in the Ganges and Indus basins. For the case of India, Kampman et al. (2008) have shown that the states which lie within the Indus and Ganges river basins, such as Punjab, Uttar Pradesh and Haryana are the largest inter-state virtual water exporters within India. The highly subsidized irrigation water in these regions has led to an intensive exploitation of the available water resources in these areas compared to other, more water-abundant regions of India. In order to provide incentives for water protection, negative externalities such as water overexploitation and pollution, and also scarcity rents should be included in the price of the crop. Both basins have a relatively high water productivity, which is shown by a smaller water footprint per ton of wheat, compared to other wheat producing areas in the two countries (Figure 6.8). Since wheat is a low-value crop, one may question whether water allocation to wheat production for export in states such as Punjab, Uttar Pradesh and Haryana is worth the cost. A major destination of wheat exports from India's parts of the Indus and Ganges basins is East India, to states like Bihar. Major foreign destinations of India's virtual water export related to export of wheat products are Bangladesh (22\%), Indonesia (11\%), Philippines (10\%) and Yemen (10\%). Pakistan's export mainly goes to Afghanistan (56\%) and Kenya (11\%).

\subsubsection{The external water footprint of wheat consumption in Italy and Japan}

In the previous two sections we have looked into the water footprint of wheat production in specific areas of the world and analysed how this water footprints could be linked to consumers elsewhere. In this section we will do the reverse: we will consider the wheat consumers in two selected countries - Italy and Japan - and trace where their water footprint lies.

Italy's water footprint related to the consumption of wheat products for the period 1996-2005 was $17.4 \mathrm{Gm}^{3} / \mathrm{yr}$. More than half (56\%) of Italy's water footprint is pressing on domestic water systems. The rest of the water footprint of Italian wheat consumption lies in other countries, mainly the USA (20\%), France (19\%), Canada (11\%) and Russia (10\%). The water footprint of Italy's wheat consumers in the USA lies in different regions of that country, among others in the Ogallala area as earlier shown in Figure 6.7. Italy also imports virtual water from the water-scarce countries of the Middle East, such as Syria $\left(58 \mathrm{Mm}^{3} / \mathrm{yr}\right)$ and Iraq $\left(36 \mathrm{Mm}^{3} / \mathrm{yr}\right)$. 

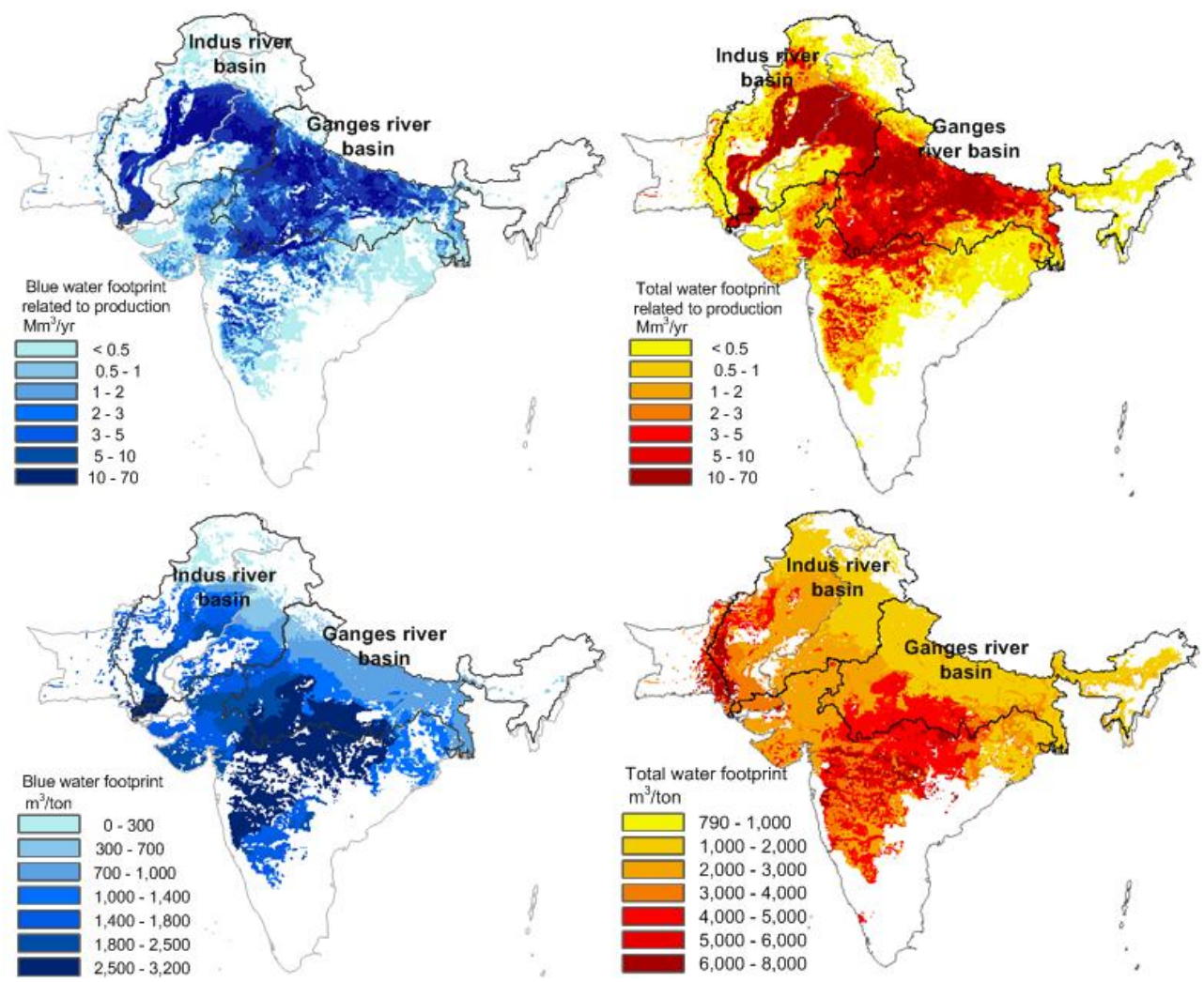

Figure 6.8. The total and blue water footprint related to wheat production in India and Pakistan, both expressed as a total $\left(\mathrm{Mm}^{3} / \mathrm{yr}\right)$ and per ton of wheat ( $\mathrm{m}^{3} /$ ton). Period: 19962005.

About $93 \%$ of the water footprint of wheat consumption in Japan lies in other countries, mainly in the USA (59\%), Australia (22\%) and Canada (19\%). About 87\% of Japan's external water footprint is from green water. Japan's wheat-related water footprint in the USA partly presses on the water resources of the Ogallala area as shown in Figure 6.7. The water footprint in Australia largely lies in Southern Australia where most of the wheat is produced and water scarcity is high. 


\subsection{Discussion}

The results of the current study can be compared to results from earlier studies as shown in Table 6.7. The global average water footprint of wheat in our study comes to $1622 \mathrm{~m}^{3} /$ ton (excluding grey water), while earlier studies gave estimates of $1334 \mathrm{~m}^{3} /$ ton (Chapagain and Hoekstra, 2004), $1253 \mathrm{~m}^{3} /$ ton (Liu et al., 2007) and $1469 \mathrm{~m}^{3} /$ ton (Siebert and Döll, 2010). A variety of factors differ in the various studies, so that it is difficult to identify the main reason for the different results. The model results with respect to the wheat water footprint per ton can also be compared for a number of specific locations to the inverse of the measured crop water productivity values as collected by Zwart and Bastiaanssen (2004). The comparison shows that out of 28 measured sites, for 17 sites (61\% of the time) the simulated water footprint lies within the range of measured values.

Table 6.7. Comparison between the results from the current study with the results from previous studies.

\begin{tabular}{lccccc}
\hline Study & Period & $\begin{array}{c}\text { Global } \\
\text { average } \\
\text { water } \\
\text { footprint of } \\
\text { wheat }\end{array}$ & $\begin{array}{c}\text { Global } \\
\text { water } \\
\text { footprint } \\
\text { related to } \\
\text { wheat } \\
\text { production }\end{array}$ & $\begin{array}{c}\text { International } \\
\text { virtual water } \\
\text { flows related } \\
\text { to wheat } \\
\text { trade }\end{array}$ & $\begin{array}{c}\text { Global } \\
\text { water } \\
\text { saving } \\
\text { due to } \\
\text { wheat } \\
\text { trade }\end{array}$ \\
\hline $\begin{array}{l}\text { Hoekstra and Hung (2002, } \\
\text { 2005) }\end{array}$ & $1995-1999$ & - & - & 210 & $\mathrm{~m}^{3} / \mathrm{ton}$ \\
$\begin{array}{l}\text { Chapagain and Hoekstra } \\
\text { (2004), Chapagain et al. }\end{array}$ & $1997-2001$ & 1334 & 793 & 114 & 103 \\
$\begin{array}{l}\text { (2006a), Hoekstra and } \\
\text { Chapagain (2008) }\end{array}$ & 2000 & - & - & 271 & 193 \\
$\begin{array}{l}\text { Oki and Kanae (2004) } \\
\text { Yang et al. (2006) }\end{array}$ & $1997-2001$ & - & - & 188 & 130 \\
$\begin{array}{l}\text { Liu et al. (2007), Liu et al. } \\
\text { (2009) }\end{array}$ & $1998-2002$ & 1253 & 688 & 159 & 77 \\
$\begin{array}{l}\text { Siebert and Döll (2010) } \\
\text { Hanasaki et al. (2010) }\end{array}$ & $1998-2002$ & 1469 & 858 & - & - \\
\hline $\begin{array}{l}\text { Current study, green \& blue } \\
\text { only }\end{array}$ & 2000 & - & - & 122 & - \\
\hline $\begin{array}{l}\text { Current study incl. grey } \\
\text { water * }\end{array}$ & $1996-2005$ & 1622 & 964 & 182 & 57 \\
\hline
\end{tabular}

* None of the previous studies included grey water, so these figures are for information only, not for comparison. 


\section{8 / Chapter 6. A global assessment of water footprint of wheat}

The model results with respect to the total global water footprint of wheat production can be compared to three previous global wheat studies. The study by Chapagain and Hoekstra (2004) did not take a grid-based approach and also did not make the green-blue distinction, unlike the current study and the studies by Siebert and Döll (2010) and Liu et al. (2009), therefore we will compare here only with the latter two. When we compare the computed green and blue water footprints to the computation by Siebert and Döll (2010), we find that their estimate of the total water footprint of global wheat production is $11 \%$ lower, which is completely due to their lower estimate of the green water footprint component. The estimate of the total water footprint by Liu et al. (2009) is $29 \%$ lower than our estimate, again due to the difference in the estimate of the green component. The relatively low value presented by Liu et al. (2009) is not a surprise given the fact that their estimate is based on the GEPIC model, which has been shown to give low estimates of evapotranspiration compared to other models (Hoff et al., 2010). Our estimate of the total green water footprint in global wheat production is $760 \mathrm{Gm}^{3} / \mathrm{yr}$ (period 1996-2005), whereas Siebert and Döll (2010) give an estimation of $650 \mathrm{Gm}^{3} / \mathrm{yr}$ (period 1998-2002) and Liu et al. (2009) 540 $\mathrm{Gm}^{3} / \mathrm{yr}$ (1998-2002). Our estimate of the total blue water footprint in global wheat production is $204 \mathrm{Gm}^{3} / \mathrm{yr}$, whereas Siebert and Döll (2010) give an estimation of 208 $\mathrm{Gm}^{3} / \mathrm{yr}$ and Liu et al. (2009) $150 \mathrm{Gm}^{3} / \mathrm{yr}$.

Liu et al. (2009) use another water balance model than applied in the current study. As a basis, they use the EPIC model (Williams et al., 1989), whereas we apply the model of Allen et al. (1998). Although both models compute the same variables, EPIC has been developed as a crop growth model, whereas the model of Allen et al. (1998) has been developed as a water balance model, which makes that the two models have a different structure and different parameters. One of the differences is the runoff model applied, which affects the soil water balance and thus soil water availability and finally the green water footprint. Besides, Liu et al. (2009) estimate water footprints $\left(\mathrm{m}^{3} / \mathrm{ton}\right.$ ) based on computed yields, whereas we use computed yields, but scale them according to FAO statistics. Siebert and Döll (2010) basically apply the same modelling approach as in the current study. Both studies have the same spatial resolution, carry out a soil water balance with a daily time step, use the same CRU TS-2.1 climate data source to generate the daily precipitation and use the same crop, soil and irrigation maps. Although there are many similarities, the studies differ in some respects. For estimating daily reference 
evapotranspiration data, Siebert and Döll (2010) applied the cubic splin method to generate daily climate data from the monthly data as provided in the available database. In contrast, we have used long-term monthly average reference evapotranspiration global spatial data obtained from FAO (2010d) and converted these data to daily values by polynomial interpolation. Further, Siebert and Döll (2010) have considered multi-cropping based on a number of assumptions and generated their own cropping calendar based on climatic data, while in our study we have neglected multi-cropping and adopted cropping calendars as provided in literature at country level. Siebert and Döll (2010) compute local yields and scale them later on, like in the current study, but scaling is done in different manner. Finally, in our study we include the grey water footprint and study international virtual water flows, which is not done by Siebert and Döll (2010).

It is difficult to make a conclusion about the accuracy or reliability of our estimates vice versa the quality of the data presented in the other two modelling studies cited. All studies depend on a large set of assumptions with respect to modelling structure, parameter values, datasets used and period considered. For the time being, it is probably best to conclude that the divergence in outcomes is a reflection of the uncertainties involved. It implies that all estimates - both from the current and the previous studies - should be interpreted with care. Assuming that the different study periods are comparable, the three studies together give an estimation of the total water footprint of wheat production of about $830 \mathrm{Gm}^{3} / \mathrm{yr} \pm 17 \%$. This uncertainty range is probably still a conservative estimate, because it is based on the central estimates of three different modelling studies only. Furthermore, locally, differences and uncertainty ranges can be larger.

The green water footprint estimate is sensitive to a variety of assumptions, including: (a) the daily rain pattern (b) the modelling of runoff, (c) the rooting depth, (d) the soil type, which determines the soil water holding capacity, (e) the planting and harvesting dates and thus the length of the growing period, (f) the moisture content in the soil at the moment of planting, $(\mathrm{g})$ the modelling of yield. The blue water footprint estimate depends on the same assumptions, plus it depends on data on actual irrigation. In a global study, given the limitations in global databases, it seems very difficult in this stage to reduce the uncertainties. Higher resolution maps of all input parameters and variables, based on either local measurements or remote sensing (Romaguera et al., 2010) may finally help to reduce the uncertainties in a global assessment like this one. In local studies, it will generally be 
less time-consuming to find better estimates for the various parameters and data involved and better be able to validate the model used for the specific local conditions, so that uncertainties can be reduced more easily.

The estimation of the grey water footprint in this study is based on a simplified approach, assuming a certain leaching-runoff fraction and a maximum acceptable concentration of nitrogen in the receiving water body. This approach gives a rough estimate; it leaves out local factors that influence the precise leaching rates, such as rainfall intensity, soil property and the amount of the already mineralized nitrogen in the upper soil layer. A possible improvement in estimating the amount of nitrogen lost through leaching would be to use more advanced models such as De Willigen (2000) regression model. This model has been used by a number of studies including FAO (Roy et al. 2003), Smaling et al. (2008) in the Brazilian soybean agriculture study, Haileslassie et al. (2007) in the nutrient flows and balance study in the central highland of Ethiopia, and Lesschen et al. (2007) in the soil nutrient balance study in Burkina Faso. Most recently, Liu et al. (2010) have shown the application of the model in a high-resolution assessment of global nitrogen flows in cropland.

Estimating water footprints of crops at national level and estimating international virtual water flows based on those national estimates - as done in all previous global water footprint studies until date - hides the existing variation at sub-national level in climatic conditions, water resources availability and crop yields. Therefore, the present study is an attempt to improve water footprint accounting through implementing the calculations at a grid basis, which takes into account the existing heterogeneity at grid level. Such approach has the advantage of being able to pinpoint precisely in space where the water footprint of wheat consumption is located. We have combined the water footprint assessment framework as provided in Hoekstra and Chapagain (2008) and Hoekstra et al. (2009) with a grid-based approach to estimating crop evapotranspiration as applied by for example Liu et al. (2009) and Siebert and Döll (2010). 


\subsection{Conclusion}

The major findings of the current study are that: (i) the green water footprint related to global wheat production is about four times larger than the blue water footprint, (ii) a large amount of global water saving occurs as a result of international trade in wheat products without trade the global wheat-related water footprint would be $6 \%$ higher than under current conditions, (iii) the high share of blue water (48\%) in the global water saving indicates that the water footprint of wheat in the largest virtual water export regions is dominated by green water while virtual water import regions depend more strongly on blue water for wheat production. The study agrees with earlier studies in the importance of green water in global wheat production and the relevance of virtual water trade in global water savings. It is observed that the costs of water consumption and pollution are not yet properly factored into the price of traded wheat, so that export countries bear the cost related to wheat consumption in the importing countries.

The study showed that the global water footprint of wheat production for the period $1996-2005$ was $1088 \mathrm{Gm}^{3} / \mathrm{yr}$ (70\% green, $19 \%$ blue, $11 \%$ grey). Since about $18 \%$ of the global water footprint related to wheat production is for making products for export, the importance of mapping the impact of global wheat consumption on local water resources with the help of the water footprint and virtual water trade accounting framework is quite clear. Quantifying the water footprint of wheat consumption and visualizing the hidden link between wheat consumers and their associated appropriation of water resources elsewhere (in the wheat producing areas) is quite relevant. The study shows that countries such as Italy and Japan, with high external water footprints related to wheat consumption, put pressure on the water resources of their trading partners. Including a water scarcity rent and the external costs of water depletion and pollution in the price of the wheat traded is crucial in order to provide an incentive within the global economy to enhance the efficiency and sustainability of water use and allocation.

The model result was compared with measured water productivity values found in the literature and outputs of previous studies. It appears very difficult to attribute differences in estimates from the various studies to specific factors; also it is difficult to assess the quality of our new estimates relative to the quality of earlier estimates. Our gridbased estimates of the water footprint of wheat production are better than the earlier 
national estimates as provided by Chapagain and Hoekstra (2004), but it is not possible to claim that they are better than the results from similar grid-based estimates as presented by Liu et al. (2009) and Siebert and Döll (2010). The quality of input data used defines the accuracy of the model output; all studies suffer the same sorts of limitations in terms of data availability and quality and deal with that in different ways. It has been observed that the model output is sensitive for example to the soil data and crop calendar, which are parameters about which no accurate data are available. A slight change in the planting date and length of cropping has a significant impact on the crop water footprint. In future studies it would be useful to spend more effort in structurally studying the sensitivity of the model outcomes to assumptions and parameters and assessing the uncertainties in the final outcome. 


\section{The water footprint of electricity from hydropower 6}

\section{Abstract}

Hydropower accounts for about $16 \%$ of the world's electricity supply. Although dams often have big environmental and social impacts, proponents of hydropower regard it as a comparatively clean, low-cost and renewable form of energy. It has been debated whether hydroelectric generation is merely an in-stream water user or whether it also consumes water, in the sense of effectively taking away water from the river. In this paper we provide scientific support for the argument that hydroelectric generation is in most cases a significant water consumer.

The study assesses the blue water footprint of hydroelectricity - the water evaporated from manmade reservoirs to produce electric energy - for 35 selected sites. The aggregated blue water footprint of the selected hydropower plants is $90 \mathrm{Gm}^{3} / \mathrm{yr}$, which is equivalent to $10 \%$ of the blue water footprint of global crop production in the year 2000 . The total blue water footprint of hydroelectric generation in the world must be considerably larger if one considers the fact that this study covers only $8 \%$ of the global installed hydroelectric capacity. Hydroelectric generation is thus a significant water consumer.

The average water footprint of the selected hydropower plants is $68 \mathrm{~m}^{3} / \mathrm{GJ}$. Great differences in water footprint among hydropower plants exist, due to differences in climate in the places where the plants are situated, but more importantly as a result of large differences in the area flooded per unit of installed hydroelectric capacity.

We recommend that water footprint assessment is added as a component in evaluations of newly proposed hydropower plants as well as in the evaluation of existing hydroelectric dams, so that the consequences of the water footprint of hydroelectric generation on downstream environmental flows and other water users can be evaluated. Sustainable development of hydropower requires the accounting and internalization of all external costs including water consumption. Internalization means that the economic and environmental costs of the water consumed are charged to the operator of a hydropower plant and included in the price of hydroelectricity. It should thereby be acknowledged that

\footnotetext{
${ }^{6}$ Based on Mekonnen and Hoekstra (2011c).
} 


\section{4 / Chapter 7. The water footprint of electricity from hydropower}

water consumption costs vary within the year and across river basins, since the degree of water scarcity and competition over water depend on the period within the year and local circumstances.

\subsection{Introduction}

The need to supply a growing population with sufficient fresh water in the context of increasing water scarcity and declining water quality has brought sustainable water resources management to the forefront of the global development agenda. For centuries, dams have played a key role in human development, bringing about significant social and economic improvements. About 30-40\% of irrigated land worldwide relies on water stored behind dams (World Commission on Dams, 2000) and hydropower accounted for 16\% of world electricity in 2008 (IEA, 2010).

Large hydropower dams have both positive and negative effects (Sternberg, 2008, 2010). Dams have been built to regulate river flows, store water to guarantee adequate supply of water in dry periods, control floods, irrigate agricultural lands, provide for navigation and to generate electricity. Negative impacts associated with the building of large dams include displacement of people, loss of land and alteration of river flows and water quality affecting downstream people and ecosystems (Gleick, 1993; Rosenberg et al., 1995; Poff et al., 1997; Scudder, 1997; Lerer and Scudder, 1999; Tilt et al., 2009). Worldwide, many countries are likely to continue depending on hydroelectric dams as their source of electricity. But such development should be in a manner which addresses environmental concerns and the question how water resources can best be allocated.

It has been debated whether hydroelectric generation is merely an in-stream water user or whether it also consumes water, in the sense of effectively taking away water from the river. In World Congress organised by the International Hydropower Association, 14-17 June 2011 in Brazil, a special session was even devoted to the question: Does hydropower consume water? The session explored different interpretations of water 'consumption' in an attempt to recognise the energy impacts on water. In this paper we provide scientific support for the argument that the production of hydroelectricity is in most cases a significant water consumer. 
As an indicator of water consumption of hydroelectricity we use the concept of the water footprint, which measures the volume of freshwater consumed and polluted to produce the product along its supply chain. The water footprint of a product is equal to the sum of freshwater consumed or polluted divided by the quantity of production of the product (Hoekstra and Chapagain, 2008; Hoekstra et al., 2011). The water footprint consists of three components: the green water footprint (consumptive use of rainwater), the blue water footprint (consumptive use of ground or surface water) and the grey water footprint (the volume of water polluted). The analysis in this paper is restricted to the quantification of the blue water footprint of hydroelectricity and focuses on the consumptive use of water that relates to the evaporation from the artificial reservoirs that are created behind hydroelectric dams.

Storage of water behind large hydropower dams leads to consumptive water use through evaporation from the open water surface of the artificial lake. Gleick (1993) has shown that on average $1.5 \mathrm{~m}^{3}$ of water per GJ of electricity produced is evaporated from hydroelectric facilities in California. By combining the estimate of global evaporation from artificial water reservoirs in the world from Shiklomanov (2000) with data on global hydroelectric generation from Gleick (1993), Gerbens-Leenes et al. (2009b) estimated that the global average blue water footprint of electricity from hydropower is $22 \mathrm{~m}^{3} / \mathrm{GJ}$.

The objective of the current study is to estimate the blue water footprint of hydroelectricity for 35 selected reservoirs. First we estimate the evaporation throughout the year for the selected reservoirs. Next, we calculate the water footprint of hydropower based on the annual evaporation rate and energy generated. We have considered both the theoretical maximum and the actual hydroelectric generation of the plant. The theoretical maximum hydroelectric generation refers to the energy that could be generated with $100 \%$ hydropower availability. Since this theoretical maximum is not realistically attainable, comparisons among the hydropower plants and further discussion of the water footprint will be based on the actual energy generation.

The selection of the hydropower plants has been largely arbitrary and mostly based on the availability of data. All plants selected have been primarily built for the purpose of hydroelectric generation, although some serve other purposes as well. With the exception of the largest hydropower plants such as Itaipu, Tucurui, Sayano Shushenskaya, RobertBourossa, Yacyreta and Cahora Bassa all hydropower plants selected are the ones included 
in World Bank (1996). The 35 hydropower plants have a total capacity of about $72 \mathrm{GW}$ and represent $8 \%$ of the global installed hydroelectric capacity of $924 \mathrm{GW}$ in 2007 (IEA, 2010).

\subsection{Method and data}

The water footprint of electricity $\left(W F, \mathrm{~m}^{3} / \mathrm{GJ}\right)$ generated from hydropower is calculated by dividing the amount of water evaporated from the reservoir annually ( $\left.W E, \mathrm{~m}^{3} / \mathrm{yr}\right)$ by the amount of energy generated ( $E G, \mathrm{GJ} / \mathrm{yr})$ :

$$
W F=\frac{W E}{E G}
$$

The total volume of evaporated water $\left(W E, \mathrm{~m}^{3} / \mathrm{yr}\right)$ from the hydropower reservoir over the year is:

$$
W E=\left(10 \times \sum_{t=1}^{365} E\right) \times A
$$

where $E$ is the daily evaporation (mm/day) and $A$ the area of the reservoir (ha).

There are a number of methods for the measurement or estimation of evaporation. These methods can be grouped into several categories including (Singh and Xu, 1997): (i) empirical, (ii) water budget, (iii) energy budget, (iv) mass transfer and (v) a combination of the previous methods.

Empirical methods relate pan evaporation, actual lake evaporation or lysimeter measurements to meteorological factors using regression analyses. The weakness of these empirical methods is that they have a limited range of applicability. The water budget methods are simple and can potentially provide a more reliable estimate of evaporation, as long as each water budget component is accurately measured. However, owing to difficulties in measuring some of the variables such as the seepage rate in a water system the water budget methods rarely produce reliable results in practice (Lenters et al., 2005, Singh and $\mathrm{Xu}, 1997)$. In the energy budget method, the evaporation from a water body is estimated as the difference between energy inputs and outputs measured at a site. Energy 
budget methods are considered to be the most reliable in theory (Lenters et al., 2005, Singh and $\mathrm{Xu}, 1997)$, but require costly instrumentation and a large commitment of personnel for field work and data processing (Winter et al., 1995). The mass-transfer (aerodynamic) based methods utilize the concept of eddy motion transfer of water vapour from an evaporating surface to the atmosphere. The mass-transfer methods normally use easily measurable variables and give satisfactory results in many cases. However, measurement of wind speed and air temperature at inconsistent heights, have resulted in a large number of equations with similar or identical structure (Singh and $\mathrm{Xu}$, 1997). The combination methods combine the mass transfer and energy budget principles in a single equation. Two of the most commonly known combination methods are the Penman equation and the Penman-Monteith equation.

Owing to its limited empirical basis, the Penman-Monteith equation is more readily applicable to a variety of water bodies. In addition, the model takes into account heat storage within water bodies. Therefore, for the purpose of the current study the PenmanMonteith equation with heat storage is considered suitable for the estimation of evaporation from the selected hydropower reservoirs.

The evaporation from the water surface $(E, \mathrm{~mm} / \mathrm{day})$ is estimated using the PenmanMonteith equation with an inclusion of water body heat storage. This equation is written as (McJannet et al., 2008):

$$
E=\frac{1}{\lambda} \times\left(\frac{\Delta_{w} \times\left(R_{n}-G\right)+\gamma \times f(u) \times\left(e_{w}-e_{a}\right)}{\Delta_{w}+\gamma}\right)
$$

where $E$ is open water evaporation ( $\mathrm{mm} /$ day); $\lambda$ the latent heat of vaporization $(\mathrm{MJ} / \mathrm{kg}) ; \Delta_{w}$ the slope of the temperature saturation water vapour curve at water temperature $\left(\mathrm{kPa} /{ }^{\circ} \mathrm{C}\right)$; $R_{n}$ net radiation $\left(\mathrm{MJ} / \mathrm{m}^{2} /\right.$ day); $G$ the change in heat storage in the water body $\left(\mathrm{MJ} / \mathrm{m}^{2} /\right.$ day); $f(u)$ the wind function $\left(\mathrm{MJ} / \mathrm{m}^{2} / \mathrm{day} / \mathrm{kPa}\right) ; e_{w}$ the saturated vapour pressure at water temperature $(\mathrm{kPa}) ; e_{a}$ the vapour pressure at air temperature $(\mathrm{kPa})$; and $\gamma$ the psychometric constant $\left(\mathrm{kPa} /{ }^{\circ} \mathrm{C}\right)$.

The latent heat of vaporisation $(\lambda, \mathrm{MJ} / \mathrm{kg})$ at air temperature $\left(T_{a},{ }^{\circ} \mathrm{C}\right)$ is calculated as (McJannet et al., 2008): 
$\lambda=2.501-2.361 \times 10^{-3} T_{a}$

The psychometric constant $\left(\gamma, \mathrm{kPa} /{ }^{\circ} \mathrm{C}\right)$ is calculated from (Allen et al., 1998):

$\gamma=\frac{c_{p} \times P}{\varepsilon \times \lambda}=\frac{1.63 \times 10^{-3} P}{\lambda}$

in which $P$ is the atmospheric pressure $(\mathrm{kPa}) ; c_{p}$ the specific heat of air at constant pressure (which is equal to $1.013 \times 10^{-3} \mathrm{MJ} / \mathrm{kg} /{ }^{\circ} \mathrm{C}$ ) and $\varepsilon$ the ratio of molecular weight of water vapour to dry air and is equal to 0.622 (dimensionless).

The atmospheric pressure $(P, \mathrm{kPa})$ varies with elevation above sea level $(\psi, \mathrm{m})$ and is expressed as (Allen et al., 1998):

$P=101.3 \times\left(\frac{293-0.0065 \psi}{293}\right)^{5.26}$

The wind function $f(u)\left(\mathrm{MJ} / \mathrm{m}^{2} /\right.$ day $\left./ \mathrm{kPa}\right)$ is calculated from wind speed at $10 \mathrm{~m}\left(u_{10}, \mathrm{~m} / \mathrm{s}\right)$ and the so-called equivalent area $\left(A_{e}, \mathrm{~km}^{2}\right)$ (Sweers, 1976):

$f(u)=\left(\frac{5}{A_{e}}\right)^{0.05} \times\left(3.80+1.57 u_{10}\right)$

The equivalent area $\left(A_{e}, \mathrm{~km}^{2}\right)$ is equal to the total surface area for regularly shaped reservoirs, but for irregularly shaped reservoirs, it can be taken equal to the square of the mean width.

Saturated vapour pressure at air temperature $\left(e_{a}, \mathrm{kPa}\right)$ is calculated from:

$e_{a}=0.6108 \times \exp \left(\frac{17.27 T_{a}}{\left(T_{a}+237.3\right)}\right)$ 
Net radiation $\left(R_{n}, \mathrm{MJ} / \mathrm{m}^{2} /\right.$ day) is the difference between the net incoming short-wave radiation $\left(R_{n s}, \mathrm{MJ} / \mathrm{m}^{2} /\right.$ day) and the net outgoing long-wave radiation $\left(R_{n l}, \mathrm{MJ} / \mathrm{m}^{2} / \mathrm{day}\right)$ (Allen et al., 1998):

$$
R_{n}=R_{n s}-R_{n l}
$$

The net incoming short-wave radiation $\left(R_{n s}, \mathrm{MJ} / \mathrm{m}^{2} /\right.$ day $)$ resulting from the balance between incoming and reflected solar radiation is given by (Allen et al., 1998):

$$
R_{n s}=(1-\alpha) \times R_{s}
$$

where $\alpha$ is the albedo coefficient for open water (dimensionless), which has a value of 0.07 (Lenters et al., 2005), and $R_{s}$ the incoming solar radiation $\left(\mathrm{MJ} / \mathrm{m}^{2} /\right.$ day).

Solar radiation $\left(R_{s}, \mathrm{MJ} / \mathrm{m}^{2} /\right.$ day) can be calculated with the Angstrom formula, which relates solar radiation to extraterrestrial radiation and relative sunshine duration:

$$
R_{s}=\left(a_{s}+b_{s} \times \frac{n}{N}\right) \times R_{a}
$$

where $n$ is the actual duration of sunshine (hours); $N$ the maximum possible duration of sunshine or daylight hours (hours); $n / N$ the relative sunshine duration (which is equal to one minus the cloud cover fraction, dimensionless); $R_{a}$ extraterrestrial radiation ( $\left.\mathrm{MJ} / \mathrm{m}^{2} / \mathrm{day}\right) ; a_{s}$ a regression constant, expressing the fraction of extraterrestrial radiation reaching the earth on overcast days $(\mathrm{n}=0)$ and $a_{s}+b_{s}$ the fraction of extraterrestrial radiation reaching the earth on clear days (when $\mathrm{n}=\mathrm{N}$ ).

Depending on atmospheric conditions (humidity, dust) and solar declination (latitude and month), the Angstrom values $a_{s}$ and $b_{s}$ will vary. Where no actual solar radiation data are available and no calibration has been carried out for improved $a_{s}$ and $b_{s}$ parameters, the values $a_{s}=0.25$ and $b_{s}=0.50$ are taken as recommended by Allen et al. (1998). 
180 / Chapter 7. The water footprint of electricity from hydropower

The extraterrestrial radiation, $R_{a}$, for each day of the year and for different latitudes, can be estimated from the solar constant, the solar declination and the time of the year.

$$
R_{a}=\frac{24 \times 60}{\pi} G_{s c} \times d_{r}\left[\omega_{s} \times \sin (\varphi) \times \sin (\delta)+\cos (\varphi) \times \cos (\delta) \times \sin \left(\omega_{s}\right)\right]
$$

where $G_{s c}$ is the solar constant (which is equal to $0.0820 \mathrm{MJ} / \mathrm{m}^{2} /$ day); $d_{r}$ the inverse relative distance Earth-Sun; $\omega_{s}$ the sunset hour angle (rad); $\varphi$ the latitude (rad) and $\delta$ the solar decimation (rad).

The inverse relative distance Earth-Sun, $d_{r}$, and the solar declination, $\delta$, are given by:

$$
\begin{aligned}
& d_{r}=1+0.033 \cos \left(\frac{2 \pi}{365} \times J\right) \\
& \delta=0.409 \sin \left(\frac{2 \pi}{365} \times J-1.39\right)
\end{aligned}
$$

where $J$ is the number of the day in the year between 1 ( 1 January) and 365 or 366 (31 December). The latitude $\varphi$, expressed in radians, is positive for the northern hemisphere and negative for the southern hemisphere.

The sunset hour angle, $\omega_{s}$, is given by:

$$
\omega_{s}=\arccos [-\tan (\varphi) \times \tan (\delta)]
$$

The net outgoing long-wave radiation $\left(R_{n l}, \mathrm{MJ} / \mathrm{m}^{2} /\right.$ day $)$ is the difference between the outgoing long-wave radiation $\left(R_{l} \uparrow, \mathrm{MJ} / \mathrm{m}^{2} /\right.$ day $)$ and the incoming long-wave radiation $\left(R_{l} \downarrow\right.$, $\mathrm{MJ} / \mathrm{m}^{2} /$ day):

$$
R_{n l}=R_{l} \uparrow-R_{l} \downarrow
$$


The incoming long-wave radiation $\left(R_{l} \downarrow, \mathrm{MJ} / \mathrm{m}^{2} /\right.$ day) is calculated from (Fischer et al., 1979; Henderson-Sellers, 1986):

$R_{l} \downarrow=\varepsilon_{a} \times \sigma \times\left(T_{a}+273.15\right)^{4}\left(1+0.17 C_{f}^{2}\right)\left(1-r_{l w}\right)$

where $\varepsilon_{a}$ is the emissivity of air (dimensionless); $\sigma$ the Stefan-Boltzmann constant ( $4.903 \times 10^{-9} \mathrm{MJ} / \mathrm{K}^{4} / \mathrm{m}^{2} /$ day); $C_{f}$ the fractional cloud cover (dimensionless); and $r_{l w}$ the total reflectivity of the water surface for long wave radiation, taken as a constant with a value of 0.03 (Henderson-Sellers, 1986).

The emissivity of air is calculated as (Swinbank, 1963):

$\varepsilon_{a}=C_{\varepsilon} \times\left(T_{a}+273.15\right)^{2}$

where $C_{\varepsilon}=9.37 \times 10^{-6} \mathrm{~K}^{-2}$.

The outgoing long-wave radiation at water temperature $\left(R_{l} \uparrow, \mathrm{MJ} / \mathrm{m}^{2} /\right.$ day $)$ is calculated as (Henderson-Sellers, 1986):

$R_{l} \uparrow=\varepsilon_{w} \times \sigma \times\left(T_{w}+273.15\right)^{4}$

where $\sigma$ is the Stefan-Boltzmann constant $\left(\mathrm{MJ} / \mathrm{m}^{2} / \mathrm{K}^{4} /\right.$ day $) ; T_{w}$ the water surface temperature $\left({ }^{\circ} \mathrm{C}\right)$; and $\varepsilon_{w}$ the emissivity of water, equal to 0.97 .

The water temperature at day $i\left(T_{w i},{ }^{\circ} \mathrm{C}\right)$ is calculated from the following equation (De Bruin, 1982):

$T_{w, i}=T_{e}+\left(T_{w, i-1}-T_{e}\right) \times \exp (-1 / \tau)$

where $T_{w, i-1}$ is the water temperature at day $i-1\left({ }^{\circ} \mathrm{C}\right) ; T_{e}$ the equilibrium temperature $\left({ }^{\circ} \mathrm{C}\right)$; and $\tau$ the time constant (day). 
The equilibrium temperature $\left(T_{e},{ }^{\circ} \mathrm{C}\right)$ is calculated as follows (De Bruin, 1982):

$$
T_{e}=T_{n}+\frac{R_{n}^{*}}{4 \sigma \times\left(T_{n}+273.15\right)^{3}+f(u) \times\left(\Delta_{n}+\gamma\right)}
$$

Wet-bulb temperature $\left(T_{n},{ }^{\circ} \mathrm{C}\right)$ is calculated using vapour pressure $\left(e_{a}, \mathrm{kPa}\right)$ and dew point temperature $\left(T_{d},{ }^{\circ} \mathrm{C}\right)$ as follows (McJannet et al., 2008):

$$
T_{n}=\frac{0.00066 \times 100 T_{a}+\left(4098 e_{a} /\left(T_{d}+237.3\right)^{2}\right) \times T_{d}}{0.00066 \times 100+\left(4098 e_{a} /\left(T_{d}+237.3\right)^{2}\right)}
$$

The slope of the temperature saturation water vapour curve at wet bulb temperature $\left(\Delta_{n}\right.$, $\mathrm{kPa} / \mathrm{K})$ is:

$$
\Delta_{n}=\frac{4098 \times\left[0.6108 \times \exp \left(\frac{17.27 T_{n}}{\left(T_{n}+237.3\right)}\right)\right]}{\left(T_{n}+237.3\right)^{2}}
$$

Net radiation at wet-bulb temperature $\left(R_{n}^{*}, \mathrm{MJ} / \mathrm{m}^{2} /\right.$ day) is calculated using albedo $(\alpha)$ as follows:

$$
R_{n}^{*}=(1-\alpha) \times R_{s}+\left(R_{l} \downarrow-R_{l} \uparrow_{n}\right)
$$

Outgoing long-wave radiation at wet-bulb temperature $\left(R_{l} \uparrow_{n}, \mathrm{MJ} / \mathrm{m}^{2} /\right.$ day $)$ is calculated, based on Finch and Gash (2002):

$$
R_{l} \uparrow_{n}=C_{f} \times\left(\sigma \times\left(T_{a}+273.15\right)^{4}+4 \sigma \times\left(T_{a}+273.15\right)^{3} \times\left(T_{n}-T_{a}\right)\right)
$$

where $C_{f}$ is fractional cloud cover. 
The time constant ( $\tau$, day) is given as (De Bruin, 1982):

$$
\tau=\frac{\rho_{w} \times c_{w} \times h}{4 \sigma \times\left(T_{n}+273.15\right)^{3}+f(u) \times\left(\Delta_{n}+\gamma\right)}
$$

where $\rho_{w}$ is the density of water $\left(=1000 \mathrm{~kg} / \mathrm{m}^{3}\right) ; c_{w}$ the specific heat of water $(=0.0042$ $\mathrm{MJ} / \mathrm{kg} / \mathrm{K}$ ); and $h$ the depth of water (m), estimated from reservoir volume capacity and area.

Change in the heat storage in the water body $\left(G, \mathrm{MJ} / \mathrm{m}^{2} /\right.$ day) is calculated from Finch (2001):

$G=\rho_{w} \times c_{w} \times h \times\left(T_{w, i}-T_{w, i-1}\right)$

Saturated vapour pressure at water temperature $\left(e_{w}, \mathrm{kPa}\right)$ is calculated from:

$$
e_{w}=0.6108 \times \exp \left(\frac{17.27 T_{w}}{\left(T_{w}+237.3\right)}\right)
$$

Finally, the slope of the temperature saturation water vapour curve at water temperature $\left(\Delta_{w}, \mathrm{kPa}^{\circ} \mathrm{C}^{-1}\right)$ is:

$$
\Delta_{w}=\frac{4098 \times\left[0.6108 \times \exp \left(\frac{17.27 T_{w}}{\left(T_{w}+237.3\right)}\right)\right]}{\left(T_{w}+237.3\right)^{2}}
$$

The water footprint of electricity from hydropower is compared with the water footprint of electricity from combustion of primary crops. The latter has been calculated per type of crop by first multiplying the water footprint of the primary crop in $\mathrm{m}^{3} /$ ton from Mekonnen and Hoekstra (2011a) by the harvest index for that crop to get the water footprint in $\mathrm{m}^{3}$ per 
ton of total biomass harvested. Harvest indices were taken from Gerbens-Leenes et al. (2009a,b). Next, the water footprint of total biomass was divided by the bio-electricity output per unit of crop (GJ/ton) as reported by Gerbens-Leenes et al. (2008a).

Data on installed hydroelectric capacity, actual hydroelectric generation and reservoir area were obtained from the World Bank (1996). For some hydropower plants data were obtained from Dorcey et al. (1997) and other sources. Data on reservoir water holding capacity were obtained mainly from Chao et al. (2008).

Daily values of mean air temperature, dew point temperature and wind speed for the selected meteorological stations were obtained from NCDC (2009). The daily data for the years 1996-2005 were averaged in order to fill missing values and smooth out some inconsistencies in the data. Monthly values of cloud cover and percentage of maximum possible sunshine with a spatial resolution of 10 arc minute were obtained from the CRU CL-2.0 database (New et al., 2002). The cloud cover and sunshine duration were available only as monthly averages for the period 1961-1990. Therefore the monthly average values were used as daily values for each month of the year.

\subsection{Results: the water footprint of hydroelectricity}

The aggregated blue water footprint of the 35 selected hydropower plants is $90 \mathrm{Gm}^{3} / \mathrm{yr}$, which is equivalent to $10 \%$ of the blue water footprint of global crop production in the year 2000 (Mekonnen and Hoekstra, 2011a; Fader et al., 2011). The total blue water footprint of hydroelectric generation in the world must be considerably larger if one considers the fact that this study covers only $8 \%$ of the global installed hydroelectric capacity. The annual evaporation from hydropower reservoirs depends on both climate (which determines the evaporation from the water surface in $\mathrm{mm} / \mathrm{yr}$ ) and reservoir area.

The water footprint of electricity from hydropower for the 35 selected hydropower plants is presented in Table 7.1. The average water footprint of electricity from hydropower for the selected plants is $68 \mathrm{~m}^{3} / \mathrm{GJ}$. There is a large variation in water footprint among the different power plants, ranging from $0.3 \mathrm{~m}^{3} / \mathrm{GJ}$ for San Carlos in Colombia to $846 \mathrm{~m}^{3} / \mathrm{GJ}$ for Akosombo-Kpong in Ghana. 
Table 7.1. Water footprint of electricity for selected hydropower plants

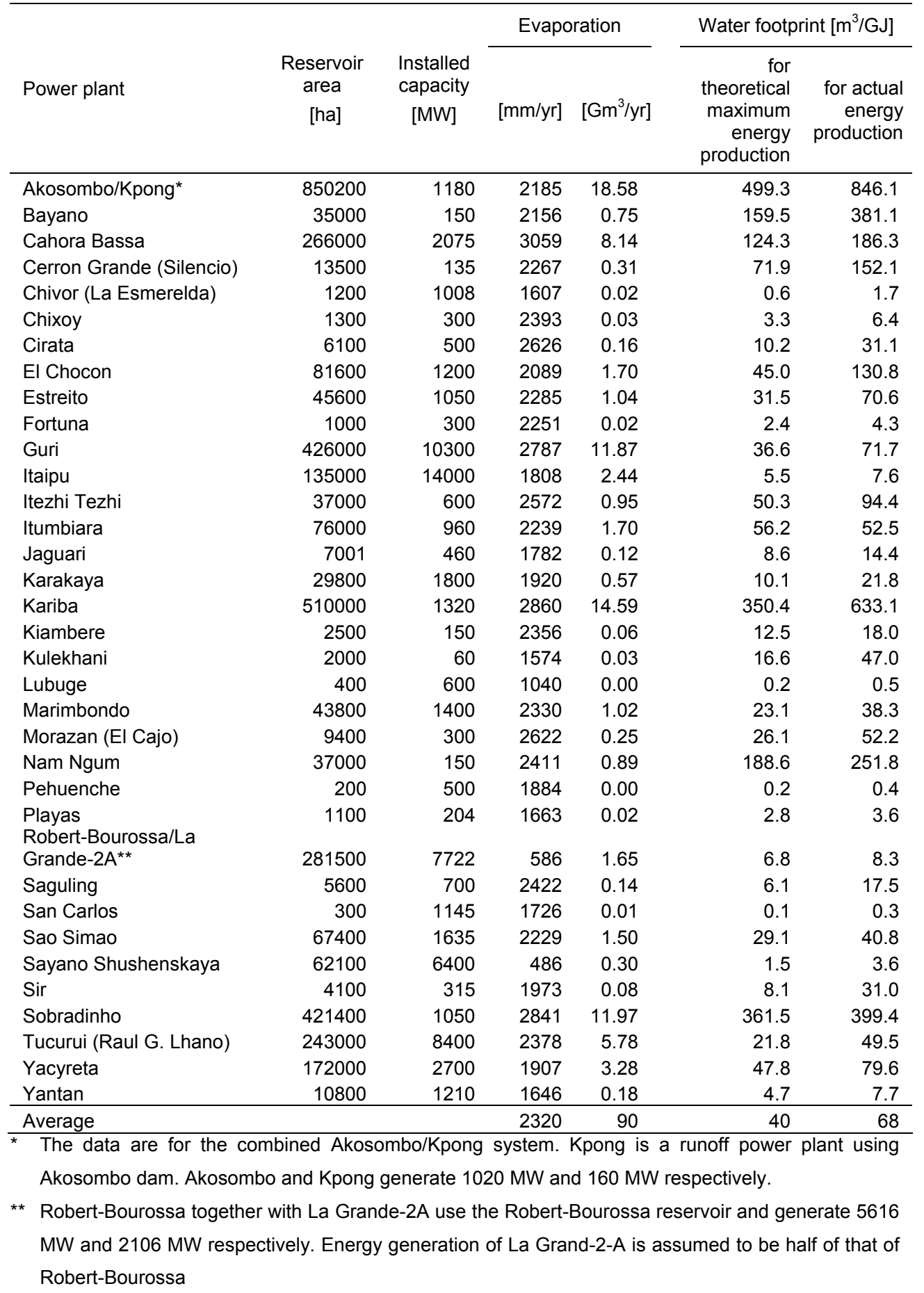


Most of the reservoirs show an evaporation rate between 2000 and $3000 \mathrm{~mm} / \mathrm{yr}$. Reservoirs in the tropics have generally a higher evaporation rate than reservoirs in temperate and subtropic climatic regions. The surface water evaporation varies from no more than $486 \mathrm{~mm} / \mathrm{yr}$ from the Sayano Shushenskaya reservoir in Russia to $3059 \mathrm{~mm} / \mathrm{yr}$ from the Cahora Bassa reservoir in the Zambezi River in Mozambique (Table 7.1). Minimum and maximum evaporation rates thus differ by a factor of six, which partially explains the differences between the water footprints of different hydropower reservoirs. The size of the reservoir surface in relation to the installed hydroelectric capacity, however, has a much bigger impact on the ultimate water footprint of hydroelectricity. While the average reservoir area per unit of installed capacity in the reservoirs studied is $83 \mathrm{ha} / \mathrm{MW}$, the minimum is 0.26 ha/MW (San Carlos reservoir, Colombia) and the maximum 720 ha/MW (AkosomboKpong in the Volta River, Ghana). The total evaporation from a hydropower reservoir thus depends more on its size than on climate. This is illustrated in Figure 7.1, which shows a more or less linear relationship between the water footprint of the power plants and ha/MW. Hydropower plants that inundate a large area per unit of installed capacity have in general a larger water footprint per unit of electricity generated than those that flood a small area per unit of installed capacity.

The largest hydropower plant in terms of installed hydroelectric capacity in this study, the Itaipu dam in the Paraná River at the border of Brazil and Paraguay, has a water footprint of $7.6 \mathrm{~m}^{3} / \mathrm{GJ}$. The second-largest studied hydropower plant in terms of MW, the Guri reservoir in Venezuela, has a water footprint that is close to the global average of 68 $\mathrm{m}^{3} / \mathrm{GJ}$ found in this study. The largest plant in terms of MW that has a water footprint far beyond the average found in this study is the Cahora Bassa dam in the Zambezi River in Mozambique, with a water footprint of $186 \mathrm{~m}^{3} / \mathrm{GJ}$.

When we compare the water footprint of electricity from hydropower with the water footprint of electricity from other renewable sources, it appears that hydroelectricity has a relatively large water footprint per GJ. The blue water footprint of electricity from wind and solar energy is estimated to be well below $1 \mathrm{~m}^{3} / \mathrm{GJ}$ (Gerbens-Leenes et al., 2009a). The blue water footprint of bio-electricity - when derived from combustion of the full biomass of primary crops - ranges from zero to $40 \mathrm{~m}^{3} / \mathrm{GJ}$, depending on which crop is used for comparison and to which extent it is irrigated. The $40 \mathrm{~m}^{3} / \mathrm{GJ}$ refers to bio-electricity from combustion of cotton, which is a rather theoretical example, because cotton is in practice 
not used for the purpose of electricity generation. Also other crops are rarely used for that purpose. More common feedstock for the generation of bio-electricity are crop residues, animal manure, wood wastes from forestry and industry, residues from food and paper industries, municipal green wastes and sewage sludge. In all those cases, the water footprint of bio-electricity will be much lower than the water footprint of bio-electricity from combustion of primary crops, because the water footprint of biomass is largely attributed to the primary product and not to the residues and waste (Hoekstra et al., 2011).

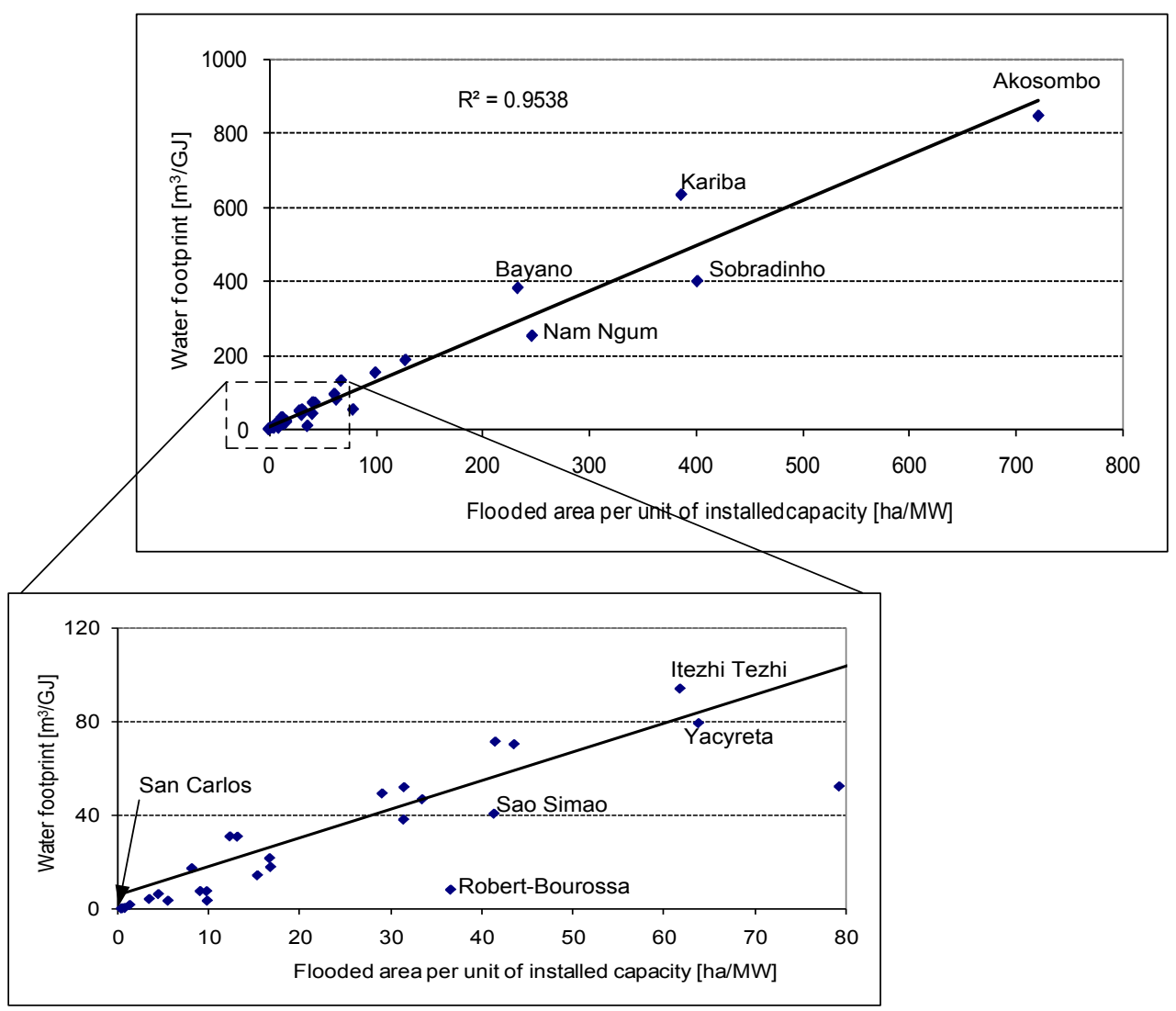

Figure 7.1. Relation between water footprint of hydroelectricity and flooded area per unit of installed hydroelectric capacity.

Figure 7.2 compares the blue water footprint of electricity from hydropower with the total (green+blue+grey) water footprint of electricity from combustion of primary crops. For a fair comparison one should compare the blue water footprints. But even when comparing 
the total water footprints, bioelectricity from a number of crops - including sugar beet, sugar cane and maize - will have a smaller water footprint than hydroelectricity. In other words, one drop of blue water allocated for consumption for hydroelectric generation generally yields much less energy than one drop of blue water allocated for consumption in crop production for generating feedstock for bioelectricity. This is not to suggest that in general it is advisable to allocate water to grow crops for producing bioelectricity rather than to generate a much lower amount of hydroelectricity at the cost of the same volume of water. In many cases this alternative allocation is not a reasonable choice, or even impossible (e.g. due to the unavailability of suitable land). Besides, for such broad decisions as investing in different sectors, one needs to take into account all relevant economic, social and environmental factors, not the factor of water productivity alone. Also one should account for the fact that many hydroelectric dams are designed to serve other purposes as well. What we do want to argue, however, is that hydroelectric generation is generally a large water consumer and that in allocating water to hydroelectric generation it is advisable to explore the foregone costs by not allocating the water to alternative uses, either upstream or downstream of the location of a planned hydropower reservoir. Alternative uses include crop growing for bioelectricity, but more common alternatives are to allocate the blue water to grow crops for food, feed, fibres or biofuel or to let the blue water in the river to maintain environmental flows.

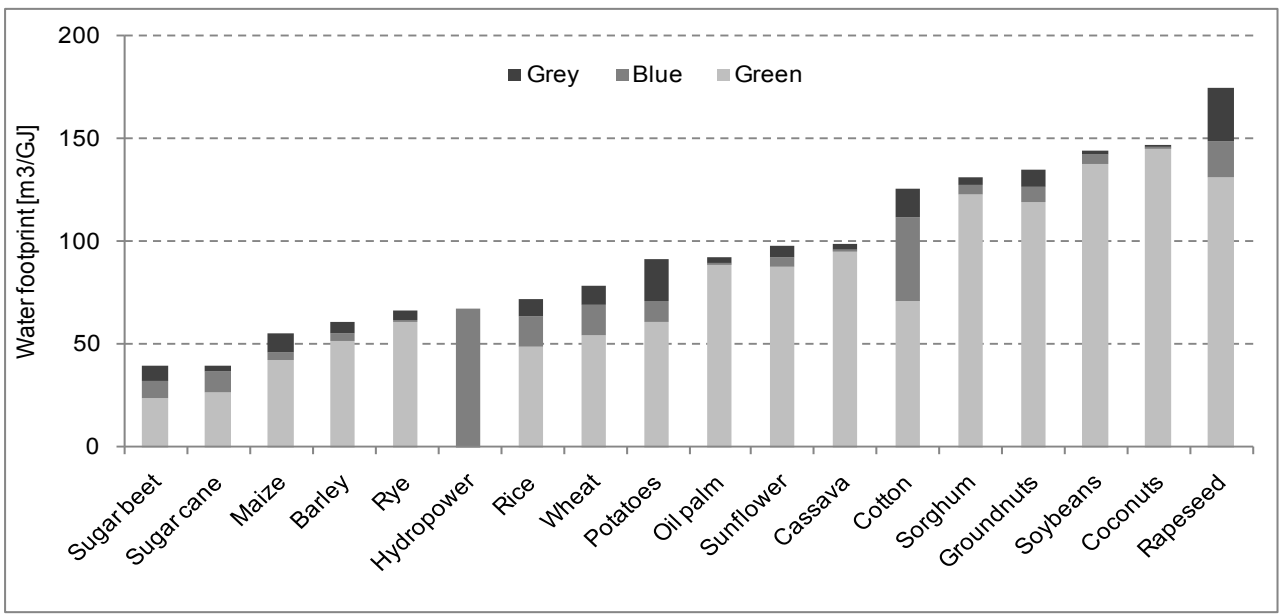

Figure 7.2. Global average water footprint of electricity from hydropower compared to the water footprint of electricity from combustion of primary crops. 


\subsection{Discussion}

The water footprints of the artificial reservoirs analysed in this study were fully attributed to hydroelectric generation, even though some of the reservoirs serve other purposes as well, such as flood control and irrigation. We justify this choice by the fact that all selected hydropower dams and associated reservoirs were primarily created for hydroelectric generation. Future research could be directed towards the analysis of the water footprint of reservoirs created for storing water for irrigation or other purposes and on tackling the water footprint attribution issue when reservoirs are used for multiple purposes.

The model output is sensitive to a number of input parameters such as air temperature, wind speed and water body depth. Since climatic data at the dam site are available only for a few plants, data from the most nearby climatic stations have been used, some of which are a bit far from the reservoir. Due to the uncertainties in the input data, the data presented should be seen as indicative. The order of magnitude of the results, however, will not change with better data, so that the results are good enough to compare the water footprint of hydroelectricity with the water footprint of other forms of electricity and to make rough comparisons between the water footprints of different hydropower sites.

Most reservoirs have a varying water surface area over time, as a result of changes in water volume during the year and between years. The difference between minimum and maximum area relative to the maximum area over a multi-year period differs greatly across reservoirs. In this study we have used a fixed reservoir area as provided by World Bank (1997) and Dorcey et al. (1997). Since reported areas generally refer to the maximum, this can lead to some overestimation of evaporation over the year. It is very difficult to find good data of area changes over the year; future studies devoted to particular sites could improve this.

We have estimated the water footprint per reservoir by considering the total evaporation from the reservoir, whereas one could argue that before the reservoir was created there was evaporation from the area as well, probably not so much from the original flowing river (since in most cases the reservoir area is much larger than the original river water area) but possibly significant from the inundated land. However, here it is relevant to recall the definition and meaning of the water footprint. The water footprint is not meant to refer to additional evaporation (compared to some reference situation), but for quantifying 
the volume of water consumption that can be associated with a specific human purpose (Hoekstra et al., 2011). From this perspective, the full reservoir evaporation can be attributed to the purpose of the reservoir.

The study has been limited to the estimation of the evaporation from reservoirs, i.e. the so-called operational water footprint of hydroelectric generation. The study does not include an assessment of the supply-chain water footprint of hydroelectric generation, which is expected to be much smaller than the operational water footprint. The supplychain water footprint refers to the water footprint of producing the materials used in the construction and the operation and maintenance of the site.

The current study does not claim to be exhaustive in terms of showing both the beneficial and negative effects of hydropower. The study has been restricted to the estimation of the water footprint of different hydropower plants. Environmental issues surrounding hydropower dams relate to, for example: physical, chemical, biological and geomorphological aspects of blocking a river; flooding of natural habitats and related loss of plants and animals; alteration of water flow regimes; and water quality problems due to the decay of submerged vegetations. On the other hand, hydropower is often perceived as a clean and cost-effective source of renewable energy. Many countries rely upon hydropower for a substantial portion of their electricity supply. Between 1973 and 2008, hydroelectric generation grew from $1295 \mathrm{TWh}$ to $3288 \mathrm{TWh}$, which is a growth by a factor 2.5 (IEA, 2010). Further development of hydropower should take into account all the associated environmental and social costs. In this respect, the water footprint of hydroelectricity, i.e. the consumptive use of water, should be considered as one item in environmental impact assessment studies for newly proposed hydroelectric dams.

\subsection{Conclusion}

Hydroelectric generation has historically been considered as a non-consumptive water user; however, through the estimation of the blue water footprint of hydroelectricity at 35 sites, this study finds that hydropower is a large consumptive user of water. The amount of water lost through evaporation annually from the selected reservoirs is equivalent to $10 \%$ of the global blue water footprint related to crop production. The 35 sites represent only $8 \%$ of the global installed hydroelectric capacity. The study shows that the range of water footprint 
values for the different hydropower plants is very wide. Although local climate has an influence, the water footprint of hydroelectricity is largely influenced by the area flooded per unit of installed capacity. The water footprint linearly increases with the area flooded per unit of installed capacity.

The water evaporated from the reservoir is seldom taken into account in assessing the pros and cons of constructing dams for hydroelectric generation. This study demonstrates that accounting for water loss through evaporation is an additional consideration when evaluating the environmental, social and economic sustainability of a proposed dam or in the evaluation of hydropower as an energy source. We recommend that water footprint assessment is added as a component in evaluations of newly proposed hydropower plants as well as in the evaluation of existing hydroelectric dams, so that the consequences of the water footprint of hydroelectric generation on downstream environmental flows and other water users can be evaluated.

The water footprint of hydroelectric dams should be considered in the context of the river basin in which this water footprint occurs, because competition over water and possible alternative uses of water differ per basin. This study contributes new information that can be used in river basin planning and water allocation decisions.

Sustainable development of hydropower requires the accounting and internalization of all external costs including water consumption. Internalization means that the economic and environmental costs of the water consumed are charged to the operator of a hydropower plant and included in the price of hydroelectricity. It should thereby be acknowledged that water consumption costs vary within the year and across river basins, since the degree of water scarcity and competition over water depend on the period within the year and local circumstances. 



\section{The external water footprint of the Netherlands: geographically- explicit quantification and impact assessment ${ }^{7}$}

\section{Abstract}

This study quantifies the external water footprint of the Netherlands by partner country and import product and assesses the impact of this footprint by contrasting the geographically explicit water footprint with water scarcity in the different parts of the world. The total water footprint of the Netherlands is estimated to be about $2300 \mathrm{~m}^{3} / \mathrm{yr} / \mathrm{cap}$, of which $67 \%$ relates to the consumption of agricultural goods, $31 \%$ to the consumption of industrial goods, and $2 \%$ to domestic water use. The Dutch water footprint related to the consumption of agricultural goods, is composed as follows: $46 \%$ related to livestock products; $17 \%$ oil crops and oil from oil crops; $12 \%$ coffee, tea, cocoa and tobacco; $8 \%$ cereals and beer; $6 \%$ cotton products; $5 \%$ fruits; and $6 \%$ other agricultural products. About $11 \%$ of the water footprint of the Netherlands is internal and $89 \%$ is external. Only $44 \%$ of the virtual-water import relates to products consumed in the Netherlands, thus constituting the external water footprint. For agricultural products this is $40 \%$ and for industrial products this is $60 \%$. The remaining $56 \%$ of the virtual-water import to the Netherlands is re-exported. The impact of the external water footprint of Dutch consumers is highest in countries that experience serious water scarcity. Based on indicators for water scarcity the following eight countries have been identified as hotspots: China; India; Spain; Turkey; Pakistan; Sudan; South Africa; and Mexico. The study shows that Dutch consumption implies the use of water resources throughout the world, with significant impacts at specified locations.

\subsection{Introduction}

The background of this study is the recognition that there is a relation between consumption by Dutch consumers and impacts on water systems elsewhere in the world. Many of the goods consumed in the Netherlands are not produced in the Netherlands, but abroad. Some goods, most in particular agriculture-based products, require a lot of water during

\footnotetext{
${ }^{7}$ Based on Van Oel, P.R. et al. (2008, 2009).
} 


\section{4 / Chapter 8. The external water footprint of the Netherlands}

production. These water-intensive production processes are accompanied by impacts on the water systems at the various locations where the production processes take place. The impacts vary from reduced river water flows, declined lake levels and declined ground water tables to increased salt intrusion in coastal areas and pollution of freshwater bodies. As an indicator of the water use related to consumption we use the water footprint concept. The water footprint of a nation is defined as the total amount of freshwater that is used to produce the goods and services consumed by the inhabitants of the nation (Hoekstra and Chapagain, 2007a, 2008). The total water footprint of a country includes two components: the part of the footprint that falls inside the country (internal water footprint) and the part of the footprint that presses on other countries in the world (external water footprint). In this study, we focus on the external water footprint of the Netherlands.

The external water footprint of the Netherlands is the volume of water used in other countries to produce goods and services imported and consumed by the inhabitants of the Netherlands. The water footprint is a quantitative measure of the amount of water consumed. It breaks down into three components: the blue, green and grey water footprint. The blue water footprint is the volume of freshwater that evaporated from the global blue water resources (surface water and ground water) to produce the goods and services consumed by the people in a nation. The green water footprint is the volume of water evaporated from the global green water resources (rainwater stored in the soil as soil moisture). The grey water footprint is the volume of polluted water that associates with the production of all goods consumed in the nation. The latter is calculated as the volume of water that is required to dilute pollutants to such an extent that the quality of the water remains above agreed water quality standards. Analysis of the grey water footprint of the Dutch community will be done in this study only in the last phase, when analyzing the impacts at hotspots.

The external water footprint of the Netherlands is specified according to (i) partner countries and (ii) imported products. The results of the country and product analyses are confronted with water scarcity indicators. In this way, hotspots are identified where the external water footprint of the Netherlands expectedly has the largest impacts. For a number of selected hotspots the impact on the affected local water systems will be further analyzed. The research is driven by the following research questions: What is the water use outside of the Dutch borders in effect of Dutch consumption? In which countries is the 
external footprint concentrated? What are the main products related to this external footprint? What is the external water footprint related to total water use behind imports into the Netherlands? In which countries is the impact of the external water footprint most serious (hotspots)? What are the impacts of the external water footprint on local water systems in the identified hotspots?

We have considered the period 1996-2005, which is long enough to get a good impression of average Dutch trade and its effects on the Dutch water footprint, excluding the effects of deviations in specific years, but which is not long enough to carry out trendanalyses, which was out of the scope of the current study. In quantifying the total external water footprint of the Netherlands it was not feasible to distinguish between the green, blue and grey components of the water footprint, but in the analysis of the identified hotspots, a specification of the green, blue and grey water footprint was made.

\subsection{Method}

As defined by Hoekstra and Chapagain (2007a, 2008), the water footprint ( $\left.W F_{\text {cons }}\right)$ of Dutch consumers has two components: the internal water footprint $\left(W F_{\text {cons, int }}\right)$ and the external water footprint $\left(W F_{\text {cons, ext }}\right)$ :

$W F[N L]=W F_{\text {cons,int }}[N L]+W F_{\text {cons,ext }}[N L]$

The internal water footprint is defined as the annual use of domestic water sources to produce goods and services consumed by the Dutch population. It is the sum of the total water volume used from the domestic water resources in the national economy $\left(W F_{\text {area }}\right)$ minus the volume of virtual-water export to other countries insofar as related to the export of products produced with national water resources $\left(V_{e, d}\right)$ :

$$
W F_{\text {cons,int }}[N L]=W F_{\text {area }}[N L]-V_{e, d}[N L]
$$

The external water footprint is defined as the annual volume of freshwater resources used in other countries to produce goods and services consumed by the population of these 
196 / Chapter 8. The external water footprint of the Netherlands

countries. It is equal to the virtual-water import into the country $\left(V_{i}\right)$ minus the volume of virtual-water exported to other countries as a result of re-export of imported products $\left(V_{e, r}\right)$ :

$W F_{\text {cons,ext }}[N L]=V_{i}[N L]-V_{e, r}[N L]$

As Figure 8.1 shows, the virtual-water export $\left(V_{e}\right)$ consists of exported water of domestic origin $\left(V_{e, d}\right)$ and re-exported water of foreign origin $\left(V_{e, r}\right)$ :

$V_{e}[N L]=V_{e, d}[N L]+V_{e, r}[N L]$
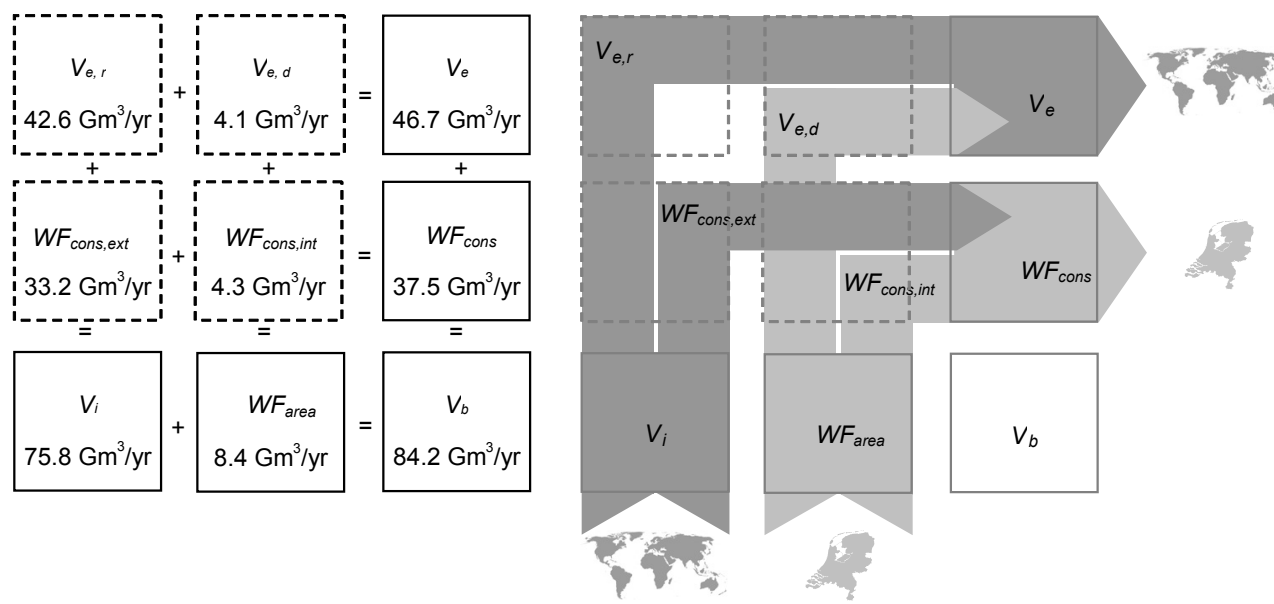

Figure 8.1 The relation between virtual-water import $\left(V_{i}\right)$, virtual-water export $\left(V_{e}\right)$, use of national water resources (WF area) and the water footprint $\left(W F_{\text {cons }}\right)$ of a country. The numbers in the boxes are average values for the Netherlands for the period 1996-2005.

The virtual-water import will partly be consumed, thus constituting the external water footprint of the country $\left(W F_{\text {cons,ext }}\right)$, and partly be re-exported $\left(V_{e, r}\right)$ :

$V_{i}[N L]=W F_{\text {cons,ext }}[N L]+V_{e, r}[N L]$ 
Finally, we see in Figure 8.1 that the sum of $V_{i}$ and $W F_{\text {area }}$ is equal to the sum of $V_{e}$ and $W F_{\text {cons }}$. We call this sum the virtual-water budget $\left(V_{b}\right)$ of a country (Ma et al., 2006; Hoekstra and Chapagain, 2008).

$$
\begin{aligned}
V_{b}[N L] & =V_{i}[N L]+W F_{\text {area }}[N L] \\
& =V_{e}[N L]+W F_{\text {cons }}[N L]
\end{aligned}
$$

The water footprint $\left(W F_{\text {cons }}\right)$ of a country can be estimated through a bottom-up or topdown approach. In this study both approaches are applied in order to be able to compare the outcomes. As will become clear, however, the bottom-up approach gives more reliable results in the case of the Netherlands, so that in the rest of the study, after the comparison of the outcomes of both approaches, we will work with the outcomes of the bottom-up approach.

\subsubsection{Bottom-up approach}

In the bottom-up approach, the water footprint $\left(W F_{\text {cons }}\right)$ of the Netherlands $(N L)$ is calculated by adding the direct water use by people and their indirect water use:

$$
W F_{\text {cons }}[N L]=W F_{\text {cons,dir }}[N L]+W F_{\text {cons,indir }}[N L]
$$

The direct water use refers to the water that people consume at home. The indirect water use of people refers to the water use by others to make the goods and services consumed. It refers to the water that was used to produce for example the food, clothes, paper, energy and industrial goods consumed. The indirect water use is calculated by multiplying all goods and services consumed by the inhabitants of the Netherlands by the respective water needs for those goods and services:

$$
W F_{\text {cons,indir }}[N L, p]=\sum_{p=1}^{n}\left(C[N L, p] \times W F^{*}[N L, p]\right)
$$


$C[N L, p]$ is Dutch consumption of product $p$ (unit/yr) and $W F^{*}[N L, p]$ the water footprint (virtual water content) of this product ( $\mathrm{m}^{3} / \mathrm{unit}$ ). The set of products considered refers to the full range of final consumer goods and services. The water footprint (virtual water content) of a product is the volume of freshwater used to produce the product, measured at the place where the product was actually produced. The water footprint of a product thus varies as a function of place and conditions of production. It refers to the sum of the water use in the various steps of the production chain. The adjective 'virtual' refers to the fact that most of the water used to produce a product is not contained in the product. The real-water content of products is generally negligible if compared to the virtual water content. The water footprint of individual primary and processed products is calculated (per country) based on the method described in Hoekstra and Chapagain (2008).

In the case of agricultural products, the water footprint is expressed in terms of $\mathrm{m}^{3} /$ ton and consumption is expressed in ton/yr. In the case of industrial products, the water footprint is, for practical reasons, expressed in terms of $\mathrm{m}^{3} / \mathrm{US} \$$ instead of $\mathrm{m}^{3} /$ ton. Industrial products show a relatively high heterogeneity and there are often different production methods for one type of product. As a result, the weight of an industrial product is not an as obvious indicator of underlying water use as in the case of an agricultural product. Since industrial production in a sector as a whole is generally expressed in monetary terms, it is easiest to consider water use in a sector per monetary unit as well.

The total volume of a product $(p)$ consumed in a country will generally originate from different nations $\left(n_{e}\right)$. The average water footprint of a product consumed in the Netherlands is estimated by assuming that:

$$
W F^{*}[N L, p]=\frac{P[N L, p] \times W F[N L, p]+\sum_{c=1}^{m}\left(T_{i}\left[n_{e}, p\right] \times W F[c, p]\right)}{P[N L, p]+\sum_{c=1}^{m} T_{i}\left[n_{e}, p\right]}
$$

The assumption here is that consumption originates from domestic production $(P$, tons/yr) and imports $\left(T_{i}\right.$, tons/yr) according to their relative volumes. 


\subsubsection{Top-down approach}

Another way of assessing the water footprint of a country $\left(W F_{\text {cons }}, \mathrm{m}^{3} / \mathrm{yr}\right)$ is the top-down approach, which takes the total water footprint $\left(W F_{\text {area }}\right)$ in the country as starting point and then adds the incoming virtual-water flow $\left(V_{i}\right)$ and subtracts the virtual-water export $\left(V_{e}\right)$ :

$W F_{\text {cons }}[N L]=W F_{\text {area }}[N L]+V_{i}[N L]-V_{e}[N L]$

The water use in the Netherlands is calculated as follows:

$W F_{\text {area }}[N L]=\sum_{p=1}^{n} P[N L, p] \times W F[N L, p]$

The gross virtual-water import is calculated based on the imported quantity and the water footprint of all products and countries:

$V_{i}[N L]=\sum_{p=1}^{n} \sum_{c=1}^{m} T_{i}\left[n_{e}, p\right] \times W F\left[n_{e}, p\right]$

The gross virtual-water export is calculated based on the exported quantity ( $T_{e}$, tons/yr) and the average water footprint of all products exported from the Netherlands:

$V_{e}[N L]=\sum_{p=1}^{n} T_{e}[N L, p] \times W F^{*}[N L, p]$

The average water footprint of an exported product is estimated by applying the same assumption that was used in the bottom-up approach (equation (63)).

The bottom-up and top-down calculations of the water footprint of a country for a particular year theoretically result in the same figure, provided that there is no product stock change over a year. The top-down calculation can theoretically give a slightly higher 
(lower) figure if the stocks of water-intensive products increase (decrease) over the year. The reason is that the top-down approach presupposes a balance $\left(V_{i}\right.$ plus $W F_{\text {area }}$ becomes $W F_{\text {cons }}$ and $V_{e}$ ) which is an approximation only (to be more precise: $V_{i}$ plus $W F_{\text {area }}$ becomes $W F_{\text {cons }}$ plus $V_{e}$ plus virtual-water stock increase). Another drawback of the top-down approach is that there can be delays between the moment of water use for production and the moment of trade. For instance in the case of trade in livestock products this may happen: beef or leather products traded in one year originate from livestock raised and fed in previous years. Part of the water virtually embedded in beef or leather refers to water that was used to grow feed crops in previous years. As a result of this, the virtual-water balance presumed in the top-down approach $\left(W F_{\text {area }}[N L]+V_{i}[N L]=W F_{\text {cons }}[N L]+V_{e}[N L]\right)$ will hold over a period of a few years, but not necessarily over one year.

Next to theoretical differences between the two approaches, differences can result from the use of different types of data as inputs of the calculations. The bottom-up approach depends on the quality of consumption data, while the top-down-approach relies on the quality of trade data. When the different databases are not consistent with one another, the results of both approaches will differ.

In one particular type of case the outcome of the top-down can be very vulnerable to relatively small errors in the input data. This happens when the import and export of a country are large relative to its domestic production, which is typical for a trade nation as the Netherlands. In this case the water footprint, calculated in the top-down approach as the domestic water use plus the virtual-water import minus the virtual-water export, will be sensitive to the import and export data used. Relative small errors in the estimates of virtual-water import and export translate into a relatively large error in the water footprint estimate. In such a case, the bottom-up approach will yield a more reliable estimate than the top-down approach. In countries where trade is relatively small compared to domestic production, the reliability of the outcomes of both approaches will depend on the relative quality of the databases used for each approach. In the case of agricultural products, both calculations are carried out in this study. However, the water footprint outcomes from the bottom-up approach are used as a basis for further analysis. For industrial products only top-down calculations are carried out. In the case of industrial products, no distinction between different types of industrial commodities is made, thus effectively industrial 
products are regarded as one homogeneous category with an average water footprint per dollar.

In the present study we are interested in the external water footprint of Dutch consumers $\left(W F_{\text {cons,ext }}\right)$ and the re-exported virtual-water $\left(V_{e, r}\right)$. To determine these terms we use the following assumption, which we apply separately for the category of agricultural products and for the category of the industrial products:

$$
W F_{\text {cons,ext }}[N L]=\frac{W F_{\text {cons }}[N L]}{V_{i}[N L]+W F_{\text {area }}[N L]} \times V_{i}[N L]
$$

This formula says that only a fraction of the gross virtual-water import can be said to be the external water footprint of the Dutch consumers and that this fraction is equal to the portion of virtual-water import plus use of domestic water that is to be attributed to consumption within the country ${ }^{8}$.The other portion of virtual-water import plus use of domestic water is exported and is therefore not part of the Dutch footprint. The term $W F_{\text {cons }}$ in above equation refers to the water footprint of the Dutch consumers. When calculating the external water footprint, the total water footprint as earlier calculated with the bottom-up approach has been taken. The external water footprint can be estimated for specific countries and products by assuming that the national ratio between the external water footprint and the total virtual-water import applies to all partner countries and imported products ${ }^{9,10}$ :

$$
W F_{\text {cons,ext }}\left[N L, n_{e}, p\right]=\frac{W F_{\text {cons,ext }}[N L]}{V_{i}[N L]} \times V_{i}\left[N L, n_{e}, p\right]
$$

The external water footprint of Dutch consumers for an individual country and an individual product are respectively:

8 This assumption implies that $\frac{W F_{\text {cons,ext }}}{V_{e, r}}=\frac{W F_{\text {cons,int }}}{V_{e, d}}=\frac{W F_{\text {cons }}}{V_{e}}$ and $\frac{W F_{\text {cons,ext }}}{W F_{\text {cons,int }}}=\frac{V_{e, r}}{V_{e, d}}=\frac{V_{i}}{W F_{\text {area }}}$.

9 We have made an exception for cocoa products and derivates, because of the exceptionally high volumes that are imported and re-exported again. The national ratio between $W F_{\text {cons, ext }}$ and $V_{i}$ is not a good assumption here. Instead, we have applied a specific ratio of $W F_{\text {cons,ext }}$ to $V_{i}$ valid to the cocoa product category.

${ }^{10}$ For cotton we applied the top-down approach for estimating the water footprint, because data on cotton product consumption are not available in the consumption database used in this study (FAO, 2007b). Because the Netherlands does not have cotton production, we could now assume that $W F_{\text {cons, ext }}=V_{i}-V_{e}$. 


$$
\begin{aligned}
& W F_{\text {cons,ext }}\left[N L, n_{e}\right]=\sum_{p=1}^{n} W F_{\text {cons,ext }}\left[N L, n_{e}, p\right] \\
& W F_{\text {cons }, e x t}[N L, p]=\sum_{n_{e}=1}^{m} W F_{c o n s, e x t}\left[N L, n_{e}, p\right]
\end{aligned}
$$

Many products are imported from countries in which they are not produced. Examples are cocoa products from Belgium and cotton products from Germany. For some product groups, world production is concentrated in specific regions. For these products we can estimate the ultimate place of origin based on world production data (FAO, 2010a). We do this for cotton, cocoa and coffee. For these products it is assumed that the water footprint in a non-producing country should be distributed over producing countries according to the same distribution of the world production. We only include producing countries from which the Netherlands is already importing directly.

\subsubsection{Impact of the water footprint}

In order to gather insight into the impacts of both Dutch consumption and re-exported virtual-water, both $W F_{\text {cons,ext, }}$ and $V_{i}$ as a whole are compared to indicators of water scarcity or stress. Water-scarcity indicators are always based on two basic ingredients: a measure of water demand or use and a measure of water availability.

The first commonly used indicator of water scarcity is population of an area divided by total runoff in that area, called the water competition level (Falkenmark, 1989) or water dependency (Kulshreshtha, 1993). Many authors take the inverse ratio, thus getting a measure of the per capita water availability. Falkenmark proposed to consider regions with more than $1700 \mathrm{~m}^{3}$ per capita per year as 'water sufficient', which means that only general water management problems occur. Between 1000-1700 $\mathrm{m}^{3} / \mathrm{cap} / \mathrm{yr}$ would indicate 'water stress', 500-1000 m³/cap/yr 'chronic water scarcity' and less than $500 \mathrm{~m}^{3} / \mathrm{cap} / \mathrm{yr}$ 'absolute water scarcity'. This classification is based on the idea that $1700 \mathrm{~m}^{3}$ of water per capita per year is sufficient to produce the food and other goods and services consumed by one person. In Falkenmark's indicator 'runoff' is taken as a measure of water availability. 
Runoff can refer to locally generated runoff (in FAO terminology then called the internal renewable water resources, IRWR), but it can also include inflows from other areas (in FAO terminology then called the total renewable water resources, TRWR).

A second common indicator of water scarcity is the ratio of water withdrawal in a certain area to total runoff in that area, called variously the water utilization level (Falkenmark, 1989; Falkenmark et al., 1989), the withdrawal-to-availability ratio (Alcamo et al., 2000, 2002) or the use-to-resource ratio (Raskin et al., 1996).

The third indicator has been proposed by Smakhtin et al. (2004a; 2004b), who have determined the withdrawal-to-availability ratio by basin.

All three water scarcity indicators can be applied to either countries or river basins. The indicators of water scarcity enable us to estimate the Dutch share in the creation of water stress in a country. On weak soil the imprint of a footstep is deeper than that it is on solid ground, so the impact of a water footprint in a water-scarce area is larger than in an area where water is more abundant.

\subsubsection{Green, blue and grey water footprint}

For the products with the largest contribution to the external water footprint of the Netherlands in the identified hotspots we estimate the size of the green, blue and grey components in the total water footprint.

In the case of agricultural products, we estimate the volume of green water use by taking the minimum of the crop water requirement and the precipitation available to the crop over the cropping season. We assume that $60 \%$ of the rainfall in the cropping season is available to the crop. The difference between crop water requirement and the precipitation available to the crop over the cropping season gives an indication of the irrigation water requirement (i.e. blue water requirement). For the areas equipped for irrigation it is assumed that the irrigation water requirements were actually met. For estimating the green versus blue water footprint in agriculture, the following spatial-explicit data have been used:

- $\quad$ The main locations where specific crops are cultivated (e.g. Leff et al., 2004);

- The percentage of land equipped for irrigation (Döll and Siebert 2000);

- Crop water requirements (Hoekstra and Chapagain, 2008). 
- Monthly precipitation at meteorological station (Müller and Hennings, 2000).

In the case of agricultural products, estimation of the grey water footprint is done as follows. It is assumed that the quantity of nitrogen that reaches free flowing water bodies is $10 \%$ of the applied fertilization rate (in $\mathrm{kg} / \mathrm{ha} / \mathrm{yr}$ ), presuming a steady state balance at root zone in the long run (Hoekstra and Chapagain, 2008). The effect of the use of other nutrients, pesticides and herbicides to the environment has not been analyzed. The total volume of water required per ton $\mathrm{N}$ is calculated considering the volume of nitrogen leached (ton/ton) and the maximum allowable concentration in the free flowing surface water bodies. The standard recommended by EPA (2005) for nitrate in drinking water is 10 milligrams per litre (measured as nitrogen) and has been taken to calculate the necessary dilution water volume. This is a conservative approach, since natural background concentration of $\mathrm{N}$ in the water used for dilution has been assumed negligible. Data on the application of fertilizers has been obtained from the FERTISTAT database of FAO (FAO, 2010c).

In the case of industrial products data on water withdrawals from FAO (2010b) have been used. Part of this volume evaporates (blue water footprint), while the other part generally returns as polluted water to the water system (grey water footprint). In the cases where industrial wastewater flows are partially treated, we have thus overestimated the grey water footprint. On the other hand, the effect of pollution has been underestimated, because one cubic meter of wastewater generally does not result in one cubic metre of polluted water, but much more (Postel et al., 1996). On average, ten percent of industrial water withdrawals are lost through evaporation (Shiklomanov and Rodda, 2003). In this paper we assume that in the estimated water footprints related to industrial products, ten percent is a blue water footprint and ninety percent is a grey water footprint.

Results of this study are based on data for the period of 1996-2005. Most results are presented as 10-year averages, although in some cases specific annual data are shown. The product coverage of the study is comprehensive: the trade analysis covers all agricultural and industrial product categories as represented in the trade database of ITC (2007) and the consumption analysis covers all consumption categories available within the food balance sheets of the FAO (2010a). Table 8.1 gives an overview of all input sources used in this study. 
Table 8.10verview of input variables and sources used.

\begin{tabular}{|c|c|}
\hline Input variable & Source \\
\hline \multicolumn{2}{|l|}{ Agricultural water use } \\
\hline $\begin{array}{l}\text { Crop water requirement per crop per } \\
\text { country }\end{array}$ & Hoekstra \& Chapagain (2008) \\
\hline - Agricultural yield per crop per country & FAOSTAT (FAO, 2010a) \\
\hline \multirow{2}{*}{$\begin{array}{l}\text { - Livestock feed composition in the } \\
\text { Netherlands }\end{array}$} & $\begin{array}{l}\text { CBS (2007), Elferink et al. (2007), LEI } \\
\text { (2007), }\end{array}$ \\
\hline & PDV (2005) \\
\hline $\begin{array}{l}\text { - Livestock feed composition in other } \\
\text { countries }\end{array}$ & Hoekstra \& Chapagain (2008) \\
\hline - Consumption per product & $\begin{array}{l}\text { FAO's food balance sheets, which are } \\
\text { part of FAOSTAT (FAO, 2010a); data } \\
\text { available for 1996-2003; average for this } \\
\text { period assumed for 2004-05. }\end{array}$ \\
\hline - Agricultural production & FAO PRODSTAT (FAO, 2010a) \\
\hline $\begin{array}{l}\text { - Use of fertilizer for important crops in } \\
\text { hotspots }\end{array}$ & FAO FERTISTAT (FAO, 2010c) \\
\hline \multicolumn{2}{|l|}{ Domestic water use } \\
\hline $\begin{array}{l}\text { Domestic water withdrawal in the } \\
\text { Netherlands }\end{array}$ & AQUASTAT (FAO, 2010b); Vitens (2008) \\
\hline \multicolumn{2}{|l|}{ Industrial water use } \\
\hline - Industrial water withdrawal per country & AQUASTAT (FAO, 2010b) \\
\hline $\begin{array}{l}\text { - Added value in the industrial sector per } \\
\text { country }\end{array}$ & UNSD (2010b) \\
\hline $\begin{array}{l}\text { Import and export of agricultural and } \\
\text { industrial products }\end{array}$ & ITC (2007) \\
\hline $\begin{array}{l}\text { Precipitation and renewable water resources } \\
\text { per country }\end{array}$ & AQUASTAT (FAO, 2010b) \\
\hline
\end{tabular}

\subsubsection{Methodological innovation}

The calculation methods applied in this study are the same as in earlier world-wide studies on virtual water trade and water footprints (Hoekstra and Chapagain, 2007a, 2008; Chapagain and Hoekstra, 2008; Chapagain et al., 2006a) and one that was applied to the Netherlands in more specific terms (Hoekstra and Chapagain, 2007b). There are, however, two methodological improvements when compared to this earlier study. Firstly, the bottom- 
up approach is applied to calculate the water footprint which is more accurate for a country as the Netherlands, where trade flows are large if compared to domestic production. This approach has been tested earlier in a pre-study for the Netherlands; see Gerbens-Leenes and Hoekstra (2007). Secondly the water footprint of consumed and exported goods is calculated as a weighted average of domestically produced and imported products (the variable $W F^{*}$ ) instead of taking the water footprint of the domestically produced products or the global average water footprint in the case that there is no domestic production.

Apart from the methodological improvements, there are differences between the earlier study and the current one in terms of the data used. In the current study we analyze the ten-year period 1996-2005 instead of a five-year period 1997-2001, which diminishes the influence of inter-annual differences due to trade flow delays. Besides, more accurate data in the current study with respect to livestock feed composition are used. Finally, the current study extends the earlier study by making a first step from water footprint estimation towards impact assessment by comparing water footprints to water-scarcity indicators for the identification of hotspots.

\subsection{Results}

\subsubsection{The water footprint of Dutch consumers}

The total water footprint of Dutch consumers is about $2300 \mathrm{~m}^{3}$ per capita per year for the period 1996-2005. Agricultural goods are responsible for the largest part of the footprint (67\%), industrial goods are responsible for $31 \%$ and domestic water use accounts for about 2\% (Figure 8.2).

The water footprint due to the consumption of agricultural products is specified further into product categories. Livestock products make up $31 \%$ of the water footprint. Oil crops and oil from oil crops are large contributors as well (12\%). The consumption of coffee, tea, cocoa and tobacco contributes another $8 \%$ and cereals and beer, which is made from barley, contribute 5\%. Cotton products and fruit contribute $4 \%$ and $3 \%$ respectively. The remainder of the footprint is related to other agricultural products (4\%). A more detailed overview of the individual contribution of product categories to the water footprint of Dutch consumers is given in Table 8.2. In Table 8.3 the results of both the bottom-up 
and the top-down approach for the water footprint due to the consumption of agricultural products are given.

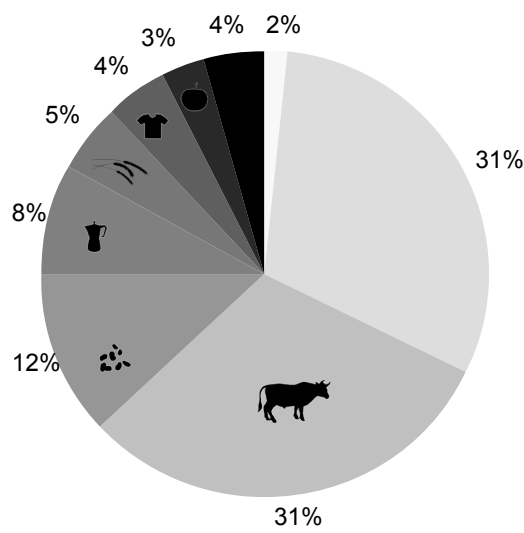

$$
\begin{aligned}
& \square \text { Domestic water use } \\
& \text { Industrial products } \\
& \text { Livestock products } \\
& \square \text { Oil crops and oil from oil crops } \\
& \text { Coffee, tea, cocoa and tobacco } \\
& \square \text { Cereals and beer } \\
& \text { Cotton products } \\
& \text { - Fruit, nuts and wine } \\
& \text { - Other agricultural products }
\end{aligned}
$$

Figure 8.2. The water footprint of Dutch consumers by product category. The total water footprint is $2300 \mathrm{~m}^{3}$ per capita per year (population 16.3 million) for the period 1996-2005.

\subsubsection{The external water footprint of Dutch consumers}

About $11 \%$ of the water footprint of the Netherlands is internal and $89 \%$ is external. For the water footprint due to the consumption of agricultural products the external part is even $97 \%$. For agricultural products, about $48 \%$ of the external water footprint is located within Europe (mainly in Germany, France and Belgium) and 20\% in Latin America (mainly in Brazil and Argentina). For industrial products, 53\% of the external water footprint is in Europe and about 33\% in Asia (mainly China, Taiwan, Hong Kong and Viet Nam). Figure 8.3 summarizes the results per continent, where Latin America includes Mexico, and Europe includes Turkey and the Russian Federation. During the period 1996-2005, the external water footprint in Latin America steadily increased, while the external water footprint in North America decreased. Figure 8.3 also shows the external water footprint of the Dutch consumers per agricultural product category. The product categories and the percentages refer to products as imported, not as consumed. This partly explains the difference with Figure 8.2, which shows the total water footprint (internal + external) by product as consumed. For instance, the product categories of 'cereals' and 'oil crops' in Figure 8.3 include imported feed for the Dutch livestock sector. 
The water footprint of Dutch consumers is one variable out of a set of nine variables that together give an overview of the Dutch water accounts. As can be seen from the numbers in Figure 8.1, the Netherlands, as a trade nation, imports not only for the purpose of domestic consumption. More than half of the virtual water import is re-exported again. Part of the re-export of virtual-water is done after having processed imported raw materials. An example of such processing is related to the Dutch livestock sector. Crops are imported from Asia and Latin America to be used as feed for Dutch livestock, while large volumes of cheese, eggs and meat are exported.
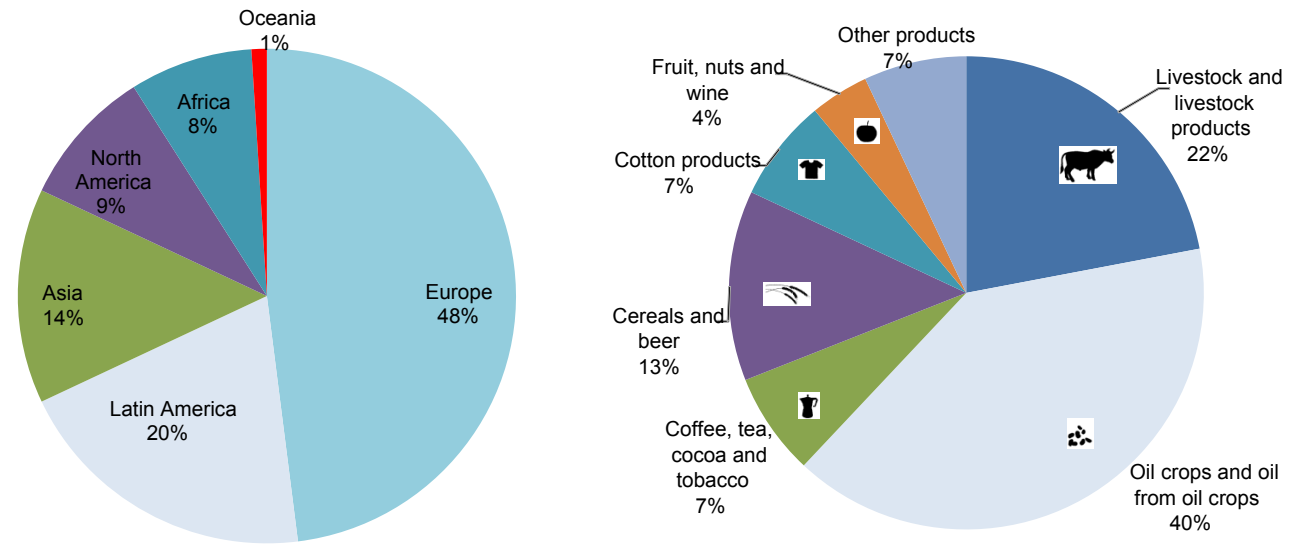

Figure 8.3. Distribution of the external water footprint of Dutch consumption due to the consumption of agricultural products by continent (left) and by product (right). The product categories and the percentages refer to products as imported, not as consumed. 
Table 8.2. Water footprint of the Dutch consumers related to consumption of agricultural products.

\begin{tabular}{|c|c|c|c|c|c|}
\hline Product category & $\begin{array}{l}\text { Water } \\
\left(\mathrm{Gm}^{3}\right)\end{array}$ & Dotprint & Product category & $\begin{array}{l}\text { Water } \\
\left(\mathrm{Gm}^{3}\right)\end{array}$ & footprint \\
\hline Livestock products & 11.58 & $45.60 \%$ & Fruits continued & & \\
\hline Pig meat & 2.24 & $8.80 \%$ & Grapes & 0.08 & $0.30 \%$ \\
\hline $\begin{array}{l}\text { Milk - Excluding } \\
\text { Butter }\end{array}$ & 2.1 & $8.30 \%$ & Bananas & 0.08 & $0.30 \%$ \\
\hline Bovine Meat & 1.88 & $7.40 \%$ & Grapefruit & 0.05 & $0.20 \%$ \\
\hline Fats, Animals, Raw & 1.85 & $7.30 \%$ & Pineapples & 0.03 & $0.10 \%$ \\
\hline Eggs & 1.5 & $5.90 \%$ & Lemons, Limes & 0.01 & $<0.1 \%$ \\
\hline Poultry Meat & 1.47 & $5.80 \%$ & Dates & 0 & $<0.1 \%$ \\
\hline Mutton \& Goat Meat & 0.14 & $0.50 \%$ & Plantains & 0 & $<0.1 \%$ \\
\hline Offals, Edible & 0.13 & $0.50 \%$ & Citrus, Other & 0 & $<0.1 \%$ \\
\hline Butter, Ghee & 0.02 & $0.10 \%$ & Fruits, Other & 0.31 & $1.20 \%$ \\
\hline Honey & 0 & $<0.1 \%$ & Sweeteners & 0.73 & $2.90 \%$ \\
\hline Cream & 0 & $<0.1 \%$ & $\begin{array}{l}\text { Sugar (Raw } \\
\text { Equivalent) }\end{array}$ & 0.32 & $1.20 \%$ \\
\hline Meat, Other & 0.24 & $1.00 \%$ & Sweeteners, Other & 0.42 & $1.60 \%$ \\
\hline Oil from oil crops & 4.57 & $16.80 \%$ & Beverages & 0.38 & $1.50 \%$ \\
\hline Palm Oil & 1.04 & $4.10 \%$ & Beer & 0.22 & $0.90 \%$ \\
\hline Coconut Oil & 0.48 & $1.90 \%$ & Wine & 0.15 & $0.60 \%$ \\
\hline Sunflower seed Oil & 0.38 & $1.50 \%$ & $\begin{array}{l}\text { Beverages, } \\
\text { Alcoholic }\end{array}$ & 0.01 & $<0.1 \%$ \\
\hline Soya bean Oil & 0.19 & $0.80 \%$ & $\begin{array}{l}\text { Beverages, } \\
\text { Fermented }\end{array}$ & 0 & $<0.1 \%$ \\
\hline Palm kernel Oil & 0.15 & $0.60 \%$ & Tree nuts & 0.3 & $1.20 \%$ \\
\hline $\begin{array}{l}\text { Rape and Mustard } \\
\text { Oil }\end{array}$ & 0.14 & $0.60 \%$ & Roots and Tubers & 0.24 & $1.00 \%$ \\
\hline Olive Oil & 0.12 & $0.50 \%$ & Potatoes & 0.24 & $1.00 \%$ \\
\hline Groundnut Oil & 0.09 & $0.40 \%$ & Oil crops & 0.15 & $0.60 \%$ \\
\hline Maize Germ Oil & 0.09 & $0.30 \%$ & $\begin{array}{l}\text { Coconuts - Incl. } \\
\text { Copra }\end{array}$ & 0.08 & $0.30 \%$ \\
\hline Cottonseed Oil & 0.01 & $<0.1 \%$ & Olives & 0.02 & $0.10 \%$ \\
\hline Sesame seed Oil & 0.01 & $<0.1 \%$ & $\begin{array}{l}\text { Groundnuts (shelled } \\
\text { eq.) }\end{array}$ & 0.02 & $0.10 \%$ \\
\hline Oil crops Oil, Other & 1.57 & $6.30 \%$ & $\begin{array}{l}\text { Rape and Mustard } \\
\text { seed }\end{array}$ & 0.01 & $<0.1 \%$ \\
\hline $\begin{array}{l}\text { Coffee, tea, cocoa } \\
\text { beans }\end{array}$ & 2.98 & $11.70 \%$ & Soya beans & 0 & $<0.1 \%$ \\
\hline Coffee & 2.38 & $9.40 \%$ & Cottonseed & 0 & $<0.1 \%$ \\
\hline \multirow[t]{2}{*}{ Tea } & 0.46 & $1.80 \%$ & Oil crops, Other & 0.02 & $0.10 \%$ \\
\hline & & & \multicolumn{3}{|c|}{ Continued next page } \\
\hline
\end{tabular}




\begin{tabular}{lcclccc}
\hline Product category & \multicolumn{2}{c}{$\begin{array}{l}\text { Water footprint } \\
\left(\mathrm{Gm}^{3}\right)\end{array}$} & Product category & \multicolumn{3}{c}{$\begin{array}{l}\text { Water footprint } \\
\left(\mathrm{Gm}^{3}\right)\end{array}$} \\
\hline Cocoa Beans & 0.14 & $0.50 \%$ & Vegetables & $\mathbf{0 . 1 4}$ & $\mathbf{0 . 6 0 \%}$ \\
Cereals & $\mathbf{1 . 7 4}$ & $\mathbf{6 . 9 0 \%}$ & Onions & 0.02 & $0.10 \%$ \\
Wheat & 1.46 & $5.70 \%$ & Tomatoes & 0.01 & $0.1 \%$ \\
Rice (milled & & & & & \\
equivalent) & 0.15 & $0.60 \%$ & Vegetables, Other & 0.12 & $0.50 \%$ \\
Maize & 0.07 & $0.30 \%$ & Spices & $\mathbf{0 . 1 4}$ & $\mathbf{0 . 6 0 \%}$ \\
Oats & 0.02 & $0.10 \%$ & Pepper & 0.04 & $0.20 \%$ \\
Barley & 0.01 & $0.10 \%$ & Cloves & 0.04 & $0.10 \%$ \\
Rye & 0.01 & $<0.1 \%$ & Pimento & 0.03 & $0.10 \%$ \\
Cereals, Other & 0.01 & $<0.1 \%$ & Spices, Other & 0.03 & $0.10 \%$ \\
Cotton products & $\mathbf{1 . 6 5}$ & $\mathbf{6 . 5 0 \%}$ & Pulses & $\mathbf{0 . 0 5}$ & $\mathbf{0 . 2 0 \%}$ \\
Fruits & $\mathbf{1 . 0 3}$ & $\mathbf{4 . 0 0 \%}$ & Beans & 0.02 & $0.10 \%$ \\
Oranges, Mandarins & 0.36 & $1.40 \%$ & Peas & 0.02 & $0.10 \%$ \\
Apples & 0.11 & $0.40 \%$ & Pulses, Other & 0.02 & $0.10 \%$ \\
\hline
\end{tabular}

The sector-specific water accounts are given in Table 8.4. The geographical spreading of the external water footprint in so far related to the consumption of industrial products differs considerably from the geographical distribution of the external water footprint related to the consumption of agricultural products. Tables 8.5 and 8.6 show the ten largest contributors to the external footprint of agricultural and the external footprint of industrial products, respectively. In Figure 8.4 country-specific contributions to the external footprint are presented geographically by product category: agricultural products, industrial products, feed for livestock products, oil crops and oil from oil crops, coffee, cereals and beer, cotton products and fruit, nuts and wine. To show the external water footprint due to the consumption of livestock products the origin of crops used for feeding livestock in the Netherlands are analyzed. Therefore, the foreign water use for a number of these crops and derivates, including soybeans, soybean scrap, cassava, sugar cane molasses, and citrus pulp are aggregated. For coffee, cocoa and cotton products we have redistributed virtual-water imports from non-producing countries over producing countries taking into account the share of these producing countries in world production of these products. 
Table 8.3. Water footprint of Dutch consumers related to consumption of agricultural products, estimated according to the top-down and bottom-up approach.

\begin{tabular}{|c|c|c|c|c|c|c|c|c|}
\hline & \multicolumn{4}{|c|}{$\begin{array}{l}\text { Top-down approach } \\
\text { (water footprint as the closing entry) }\end{array}$} & \multicolumn{4}{|c|}{$\begin{array}{c}\text { Bottom-up approach } \\
\text { (virtual-water export as the closing } \\
\text { entry) }\end{array}$} \\
\hline & A & B & C & $D=A+B-C$ & $A$ & B & $E=A+B-F$ & $F$ \\
\hline Year & $\begin{array}{l}\text { Virtual- } \\
\text { water } \\
\text { import } \\
\left(\mathrm{Gm}^{3} / \mathrm{yr}\right)\end{array}$ & $\begin{array}{l}\text { Water } \\
\text { use } \\
\left(\mathrm{Gm}^{3} / \mathrm{yr}\right)\end{array}$ & $\begin{array}{l}\text { Virtual- } \\
\text { water } \\
\text { export } \\
\left(\mathrm{Gm}^{3} / \mathrm{yr}\right)\end{array}$ & $\begin{array}{l}\text { Water } \\
\text { footprint } \\
\left(\mathrm{Gm}^{3} / \mathrm{yr}\right)\end{array}$ & $\begin{array}{l}\text { Virtual- } \\
\text { water } \\
\text { import } \\
\left(\mathrm{Gm}^{3} / \mathrm{yr}\right)\end{array}$ & $\begin{array}{l}\text { Water } \\
\text { use } \\
\left(\mathrm{Gm}^{3} / \mathrm{yr}\right)\end{array}$ & $\begin{array}{l}\text { Virtual- } \\
\text { water } \\
\text { export } \\
\left(\mathrm{Gm}^{3} / \mathrm{yr}\right)\end{array}$ & $\begin{array}{l}\text { Water } \\
\text { footprint } \\
\left(\mathrm{Gm}^{3} / \mathrm{yr}\right)\end{array}$ \\
\hline 1996 & 60.1 & 3.1 & 34.5 & 28.7 & 60.1 & 3.1 & 39.7 & 23.5 \\
\hline 1997 & 47.7 & 3.1 & 39.9 & 10.9 & 47.7 & 3.1 & 28.0 & 22.8 \\
\hline 1998 & 54.4 & 2.9 & 38.1 & 19.2 & 54.4 & 2.9 & 33.3 & 23.9 \\
\hline 1999 & 65.6 & 3.0 & 41.5 & 27.2 & 65.6 & 3.0 & 42.0 & 26.7 \\
\hline 2000 & 64.1 & 3.1 & 42.3 & 24.8 & 64.1 & 3.1 & 41.5 & 25.7 \\
\hline 2001 & 69.3 & 3.0 & 43.2 & 29.2 & 69.3 & 3.0 & 44.8 & 27.5 \\
\hline 2002 & 42.4 & 3.1 & 34.7 & 10.7 & 42.4 & 3.1 & 18.5 & 27.0 \\
\hline 2003 & 70.5 & 3.0 & 40.2 & 33.3 & 70.5 & 3.0 & 47.5 & 26.0 \\
\hline 2004 & 70.1 & 3.1 & 44.1 & 29.1 & 70.1 & 3.1 & 47.3 & 25.9 \\
\hline 2005 & 71.2 & 3.0 & 45.4 & 28.8 & 71.2 & 3.0 & 49.4 & 24.8 \\
\hline Average & 61.5 & 3.0 & 40.4 & 24.2 & 61.5 & 3.0 & 39.1 & 25.4 \\
\hline
\end{tabular}

Table 8.4. The Dutch water accounts specified by consumption category. Period 1996-2005.

\begin{tabular}{|c|c|c|c|c|}
\hline & $\begin{array}{l}\text { Related to } \\
\text { domestic } \\
\text { water use } \\
\left(\mathrm{Gm}^{3} / \mathrm{yr}\right) \\
\end{array}$ & $\begin{array}{l}\text { Related to } \\
\text { agricultural } \\
\text { products } \\
\left(\mathrm{Gm}^{3} / \mathrm{yr}\right) \\
\end{array}$ & $\begin{array}{l}\text { Related to } \\
\text { industrial } \\
\text { products } \\
\left(\mathrm{Gm}^{3} / \mathrm{yr}\right)\end{array}$ & $\begin{array}{c}\text { Total } \\
\left(\mathrm{Gm}^{3} / \mathrm{yr}\right)\end{array}$ \\
\hline $\begin{array}{l}\text { Use of domestic water resources } \\
(W U)\end{array}$ & 0.6 & 3.0 & 4.8 & 8.4 \\
\hline Virtual-water import $\left(V_{i}\right)$ & - & 61.5 & 14.3 & 75.8 \\
\hline Virtual-water export $\left(V_{e}\right)$ & - & 39.1 & 7.6 & 46.7 \\
\hline $\begin{array}{l}\text { related to export of } \\
\text { domestically produced } \\
\text { products }\left(V_{e, d}\right)\end{array}$ & - & 2.2 & 1.9 & 4.1 \\
\hline $\begin{array}{l}\text { related to re-export of } \\
\text { imported products }\left(V_{e, r}\right)\end{array}$ & - & 36.9 & 5.7 & 42.6 \\
\hline Water footprint (WF) & 0.6 & 25.4 & 11.5 & 37.5 \\
\hline - Internal water footprint $\left(W F_{i}\right)$ & 0.6 & 0.8 & 2.9 & 4.3 \\
\hline - External water footprint $\left(W F_{e}\right)$ & - & 24.6 & 8.6 & 33.2 \\
\hline
\end{tabular}


Table 8.5. The largest contributors to the external water footprint related to Dutch consumption of agricultural products.

\begin{tabular}{lr}
\hline Country & $\begin{array}{r}\text { Part of external water footprint } \\
\text { the consumption of agricultural products) }\end{array}$ \\
\hline Germany & $18.3 \%$ \\
Brazil & $9.7 \%$ \\
France & $8.7 \%$ \\
United States & $8.6 \%$ \\
Belgium- & $8.2 \%$ \\
Luxembourg & $5.4 \%$ \\
Argentina & $4.1 \%$ \\
Indonesia & $2.5 \%$ \\
Malaysia & $2.2 \%$ \\
India & $1.9 \%$ \\
Thailand & \\
\hline
\end{tabular}

\subsubsection{The total virtual-water import to the Netherlands}

About $44 \%$ of the virtual-water import to the Netherlands relates to products consumed in the Netherlands, thus constituting the external water footprint. This means that the other $56 \%$ of the virtual-water imported to the Netherlands is re-exported $(60 \%$ in the case of agricultural products and $40 \%$ in the case of industrial products). Figure 8.5 shows, for agricultural products, the distribution of virtual-water import over the six continents. Not all imports are for Dutch consumption; virtual water re-export concerns for instance cocoa beans from Africa (mainly Cote d'Ivoire, Ghana, Cameroon and Nigeria). After processing in the Netherlands into cocoa butter, cocoa powder or cocoa paste, the cocoa is re-exported to other European countries (mainly Germany, the United Kingdom, Belgium and Switzerland).

When the water footprint of the Netherlands over time (as estimated with the bottom-up approach, see Table 8.3 ) is compared to the virtual-water import to the country, it is found that the latter is much more variable over time. Where consumption over time is rather constant, the trade balance, domestic production and over-year storage vary more significantly. Figure 8.5 shows that the virtual-water import was incidentally low in the 
year 2002, which is mainly due to a low import volume for various water-intensive products in that particular year.
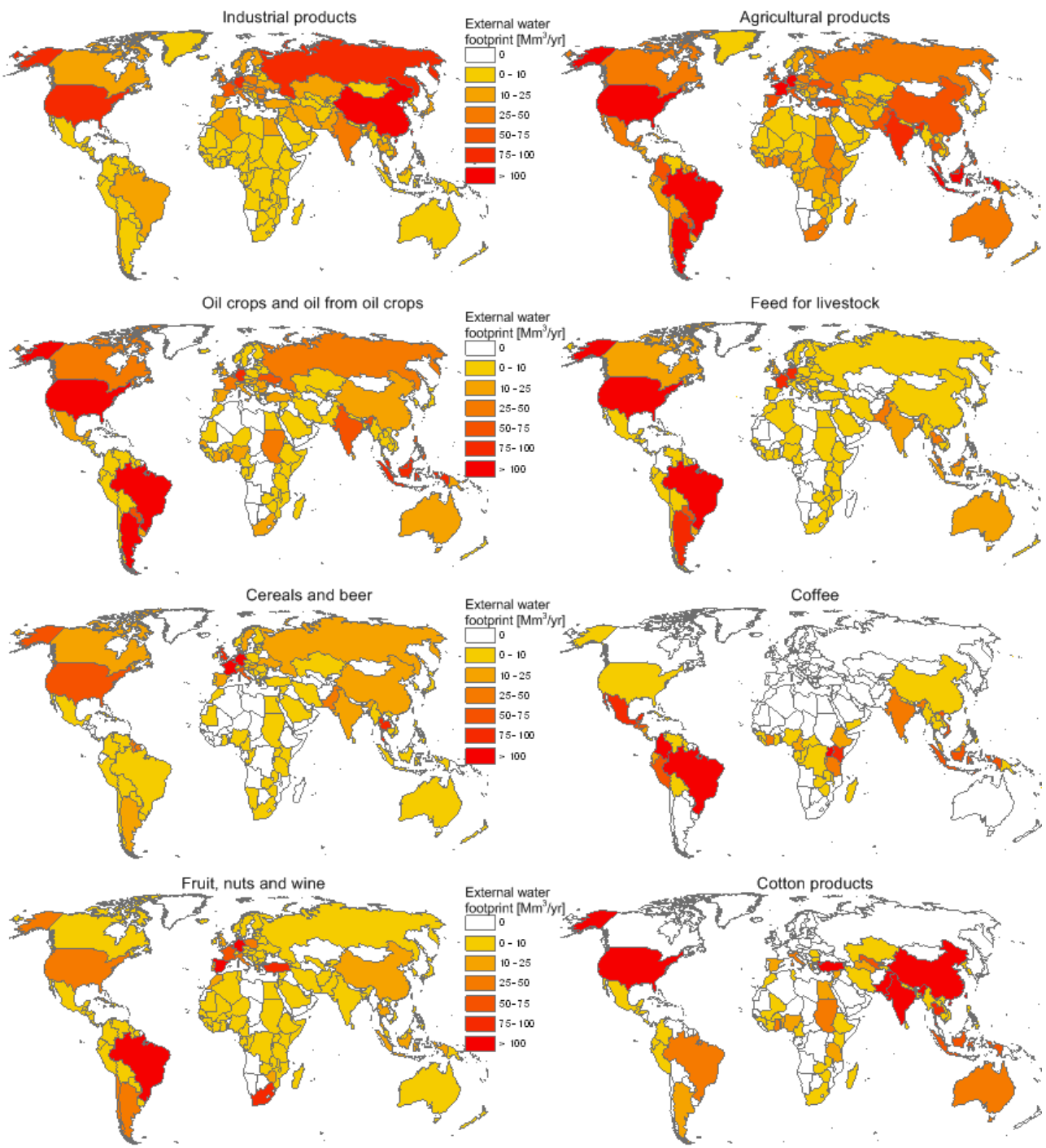

Figure 8.4.Geographical distribution of the external water footprint of the Netherlands for selected product categories. 
Table 8.6 The largest contributors to the external water footprint related to Dutch consumption of industrial products.

\begin{tabular}{lr}
\hline Country & $\begin{array}{r}\text { Part of external water footprint (related to } \\
\text { the consumption of industrial products) }\end{array}$ \\
\hline China & $15.2 \%$ \\
United States & $11.0 \%$ \\
Germany & $10.6 \%$ \\
Russian Federation & $10.6 \%$ \\
Belgium-Luxembourg & $9.9 \%$ \\
Taiwan (POC) & $6.6 \%$ \\
France & $5.6 \%$ \\
Hong Kong & $3.3 \%$ \\
Viet Nam & $2.4 \%$ \\
Poland & $2.1 \%$ \\
\hline
\end{tabular}

\subsubsection{Hotspots}

Hotspots - i.e. countries where the impact of the Dutch external water footprint is relatively large - have been selected based on a country's share in the total external water footprint of Dutch consumers and the three indicators of water scarcity. The impact is obviously larger when the footprint is relatively large in a place where water scarcity is relatively large as well. The selection of hotspots has been done at country level, which implies that local hotspots, where impacts at national level are not among the most significant, have been ignored. The countries that turn out as hotspots are: China; India; Spain; Turkey; Pakistan; Sudan; South Africa; and Mexico. Table 8.7 and 8.8 summarize the most important findings with respect to the selected hotspots. With the exception of China, the external water footprint in these countries is mainly due to the consumption of agricultural products (Figure 8.6). In China, the water footprint is to a large extent related to the production of industrial goods for the Dutch consumer market. The water footprint related to industrial goods consists mostly (90\%) of a grey water footprint (pollution), the remainder (10\%) being a blue water footprint (evaporation of ground and surface water). In the other hotspots, the water footprint is dominated by agricultural products. The type of agricultural 
products in the hotspots varies greatly as is shown in Figure 8.6. The ratio of the blue to the green water footprint per hotspot depends on the degree of irrigation at these hotspots.
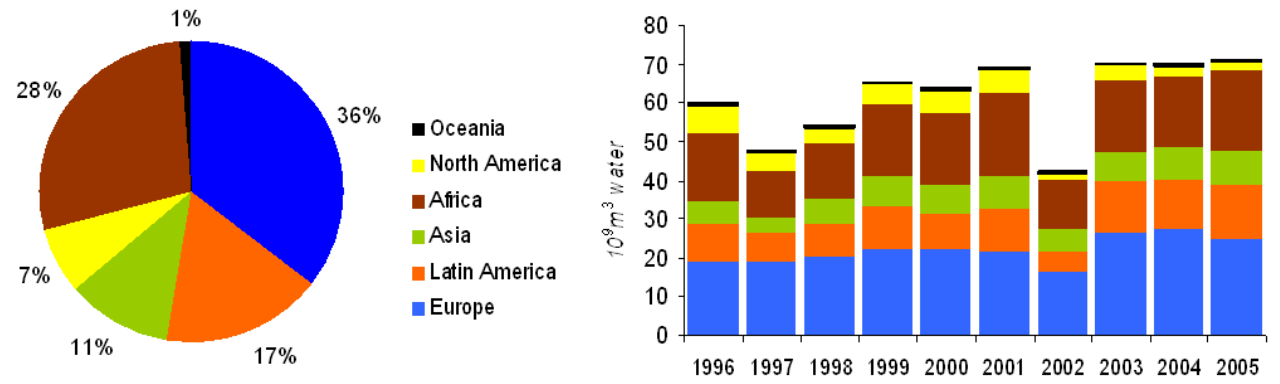

Figure 8.5. Geographical distribution of the virtual-water import in so far related to the import of agricultural products specified by continent. Left: average over the period 1996-2005.

Right: variation over this period.
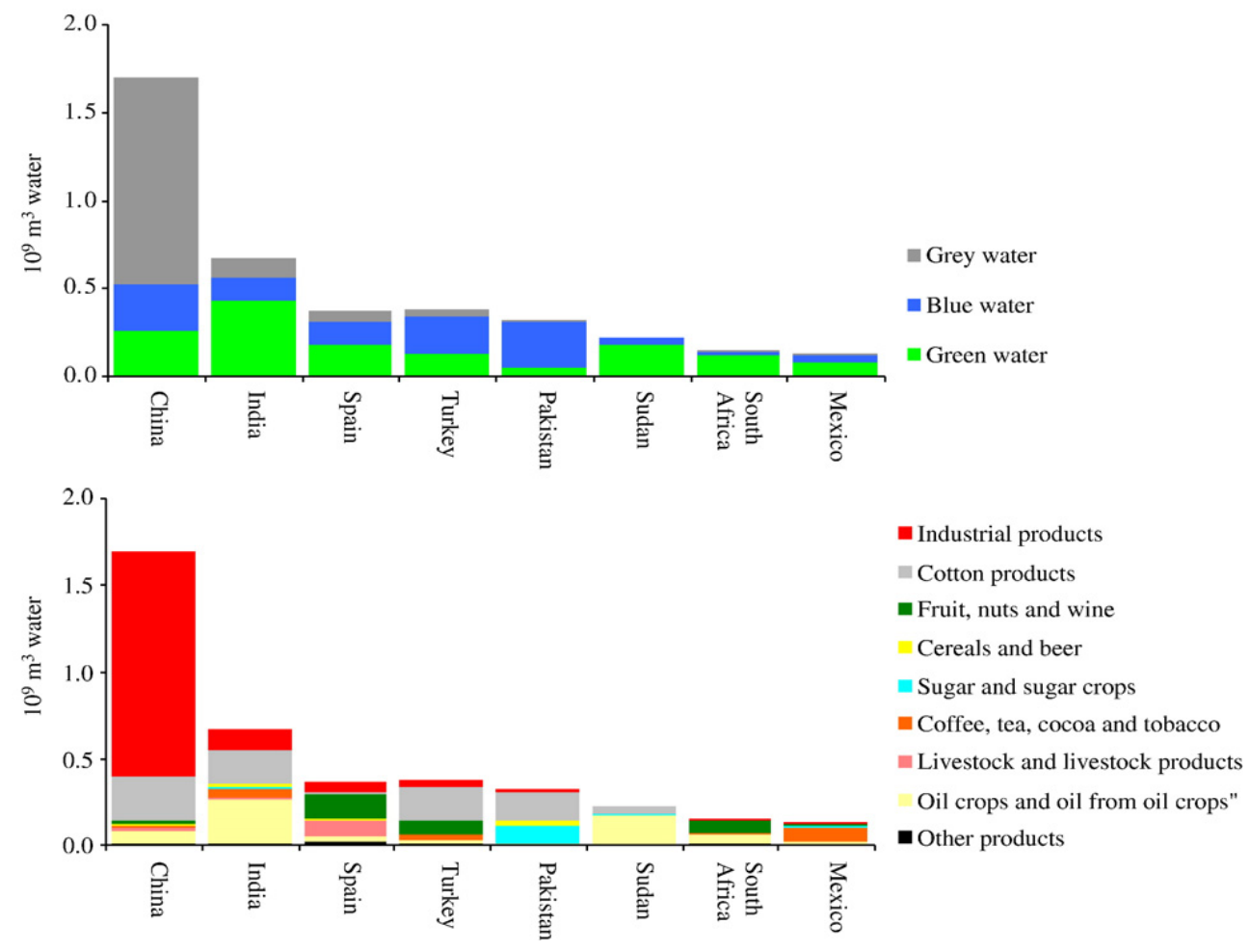

Figure 8.6. Composition of the external water footprint of Dutch consumers per hotspot country and by type of water footprint (left) and product category (right). 
Table 8.7. Hotspots and the products contributing to the external water footprint of Dutch consumers.

\begin{tabular}{|c|c|c|c|c|c|c|c|}
\hline \multirow[b]{2}{*}{ Country } & \multirow{2}{*}{$\begin{array}{c}\text { External } \\
\text { water } \\
\text { footprint } \\
\text { related to } \\
\text { industrial } \\
\text { products } \\
\left(10^{6} \mathrm{~m}^{3} / \mathrm{yr}\right)^{*}\end{array}$} & \multicolumn{6}{|c|}{ External water footprint related to agricultural products $\left(\mathrm{m}^{3} / \mathrm{yr}\right)$} \\
\hline & & $\begin{array}{l}\text { Total } \\
\left(10^{6}\right. \\
\left.\mathrm{m}^{3} / \mathrm{yr}\right)\end{array}$ & $\begin{array}{l}\text { Product category with } \\
\text { largest contribution }\end{array}$ & $\begin{array}{l}\text { Contribution } \\
\text { of the } \\
\text { product } \\
\text { category }\end{array}$ & $\begin{array}{l}\text { Main product within } \\
\text { product category }\end{array}$ & Green & Blue \\
\hline \multirow[t]{3}{*}{ China } & 1307 & 393 & Fibres (including cotton) & $65 \%$ & Cotton $(100 \%)$ & $62 \%$ & $38 \%{ }^{* *}$ \\
\hline & & & $\begin{array}{l}\text { Oil crops and oil from } \\
\text { oil crops }\end{array}$ & $16 \%$ & Groundnuts (74\%) & $90 \%$ & $10 \%$ \\
\hline & & & Livestock products & $7 \%$ & $\begin{array}{l}\text { Skin and hair of pigs } \\
(90 \%)\end{array}$ & & \\
\hline \multirow[t]{3}{*}{ India } & 123 & 547 & $\begin{array}{l}\text { Oil crops and oil from } \\
\text { oil crops }\end{array}$ & $46 \%$ & Castor oil seed $(72 \%)$ & $82 \%$ & $18 \%$ \\
\hline & & & Fibres (including cotton) & $35 \%$ & Cotton $(100 \%)$ & $75 \%$ & $25 \%{ }^{* *}$ \\
\hline & & & $\begin{array}{l}\text { Coffee, tea, cocoa and } \\
\text { tobacco }\end{array}$ & $10 \%$ & Coffee $(72 \%)$ & $79 \%$ & $21 \%$ \\
\hline \multirow[t]{2}{*}{ Spain } & 63 & 305 & Fruits (including wine) & $46 \%$ & $\begin{array}{l}\text { Citrus fruit }(36 \%) \text {, } \\
\text { wine, grapes, raisins } \\
(28 \%)\end{array}$ & $60 \%$ & $40 \%$ \\
\hline & & & Livestock products & $27 \%$ & $\begin{array}{l}\text { Cattle ( } 42 \%) \text {, pig } \\
(27 \%) \text { and goat }(20 \%)\end{array}$ & & \\
\hline \multirow[t]{3}{*}{ Turkey } & 39 & 340 & Fibres (including cotton) & $60 \%$ & Cotton $(99 \%)$ & $9 \%$ & $91 \%{ }^{* *}$ \\
\hline & & & Fruits (including wine) & $23 \%$ & Raisins (81\%) & $91 \%$ & $9 \%$ \\
\hline & & & $\begin{array}{l}\text { Coffee, tea, cocoa and } \\
\text { tobacco }\end{array}$ & $7 \%$ & Tobacco $(84 \%)$ & $93 \%$ & $7 \%$ \\
\hline \multirow[t]{2}{*}{ Pakistan } & 17 & 305 & Fibres (including cotton) & $54 \%$ & Cotton $(100 \%)$ & $21 \%$ & $79 \%{ }^{* *}$ \\
\hline & & & $\begin{array}{l}\text { Sugar (including sugar } \\
\text { crops) }\end{array}$ & $33 \%$ & $\begin{array}{l}\text { Cane molasses } \\
(100 \%)\end{array}$ & $8 \%$ & $92 \%$ \\
\hline Sudan & $<1$ & 218 & $\begin{array}{l}\text { Oil crops and oil from } \\
\text { oil crops }\end{array}$ & $79 \%$ & Sesame seed $(89 \%)$ & $81 \%$ & $19 \%$ \\
\hline \multirow[t]{2}{*}{$\begin{array}{l}\text { South } \\
\text { Africa }\end{array}$} & 6 & 145 & Fruits (including wine) & $49 \%$ & $\begin{array}{l}\text { Citrus fruit }(35 \%) \text {, } \\
\text { grapes, wine, raisins } \\
(29 \%)\end{array}$ & $80 \%$ & $20 \%$ \\
\hline & & & $\begin{array}{l}\text { Oil crops and oil from } \\
\text { oil crops }\end{array}$ & $34 \%$ & $\begin{array}{l}\text { Groundnut/oil }(56 \%) \\
\text { sunflower seed }(40 \%)\end{array}$ & $81 \%$ & $19 \%$ \\
\hline \multirow[t]{2}{*}{ Mexico } & 7 & 123 & $\begin{array}{l}\text { Coffee, tea, cocoa and } \\
\text { tobacco }\end{array}$ & $66 \%$ & Coffee $(100 \%)$ & $57 \%$ & $43 \%$ \\
\hline & & & $\begin{array}{l}\text { Oil crops and oil from } \\
\text { oil crops }\end{array}$ & $16 \%$ & Sunflower oil $(75 \%)$ & $100 \%$ & $0 \%$ \\
\hline
\end{tabular}

\footnotetext{
* Industrial water footprints estimated to be $10 \%$ blue and $90 \%$ grey.

** Based on Chapagain et al. (2006b).
} 
Table 8.8. Estimated grey water footprint for specific crops at the hotspots.

\begin{tabular}{|c|c|c|c|c|c|c|c|}
\hline & & $\begin{array}{l}\text { Area } \\
\left(\mathrm{km}^{2}\right)^{*}\end{array}$ & $\begin{array}{c}\text { Area } \\
\text { with } \\
\text { fertilizer } \\
(\%)^{*}\end{array}$ & $\begin{array}{l}\text { Rate N } \\
(\mathrm{kg} / \mathrm{ha})^{*}\end{array}$ & $\begin{array}{l}\text { Rate P } \\
\text { (kg/ha) * }\end{array}$ & $\begin{array}{l}\text { Rate K } \\
(\mathrm{kg} / \mathrm{ha})^{*}\end{array}$ & $\begin{array}{c}\text { Grey } \\
\text { water } \\
\text { footprint } \\
\left(\mathrm{m}^{3} / \mathrm{ha}\right)^{* *}\end{array}$ \\
\hline \multirow{2}{*}{$\begin{array}{l}\text { China, } \\
\text { Mainland } \\
\text { (1997) }\end{array}$} & Cotton & 5528 & 100 & 120 & 70 & 25 & 1200 \\
\hline & Oil crops & 668 & 95 & 65 & 40 & 30 & 618 \\
\hline \multirow{2}{*}{$\begin{array}{l}\text { India } \\
(2003 / 2004)\end{array}$} & Cotton & 8500 & 6 & 90 & 23 & 5 & 54 \\
\hline & $\begin{array}{l}\text { Other } \\
\text { crops }\end{array}$ & 60400 & 22 & 35 & 19 & 7 & 77 \\
\hline $\begin{array}{l}\text { Spain } \\
(1999 / 2000)\end{array}$ & Fruits & 4975 & n.a. & 57 & 24 & 26 & n.a. \\
\hline \multirow[t]{3}{*}{ Turkey (1999) } & Cotton & 718 & 99 & 127 & 39 & 4 & 1257 \\
\hline & Fruits & 1240 & 70 & $<0.1$ & $<0.1$ & $<0.1$ & 0.4 \\
\hline & Tobacco & 289 & 68 & 3 & 1 & 6 & 20 \\
\hline \multirow{2}{*}{$\begin{array}{l}\text { Pakistan } \\
(2001 / 2002)\end{array}$} & Cotton & n.a. & n.a. & 120 & 50 & 0.1 & n.a. \\
\hline & $\begin{array}{l}\text { Sugar } \\
\text { cane }\end{array}$ & n.a. & n.a. & 125 & 56 & 0.3 & n.a. \\
\hline Sudan ${ }^{*}$ & & n.a. & n.a. & n.a. & n.a. & n.a. & n.a. \\
\hline \multirow[t]{2}{*}{$\begin{array}{l}\text { South Africa } \\
(2004)\end{array}$} & $\begin{array}{l}\text { Citrus } \\
\text { fruits }\end{array}$ & 64 & 100 & 80 & 35 & 60 & 800 \\
\hline & Sunflower & 640 & 85 & 15 & 21 & 2 & 128 \\
\hline \multirow[t]{2}{*}{ Mexico (1998) } & Coffee & 679 & 60 & 60 & 40 & 15 & 360 \\
\hline & Sunflower & 123 & 80 & 75 & 10 & 0 & 600 \\
\hline
\end{tabular}

Source: FAO (2010c). For Sudan, no data on fertiliser use are available.

** Assumptions: nitrogen is the critical factor; $10 \%$ of the nitrogen leaches to the water system; nitrogen water standard $10 \mathrm{mg} / \mathrm{litre}$ (Hoekstra and Chapagain, 2008).

\subsection{Conclusion}

The total water footprint of the Netherlands is estimated to be about $2300 \mathrm{~m}^{3} / \mathrm{yr} / \mathrm{cap}$, which is nearly double the water footprint of an average world citizen. About $67 \%$ of the Dutch water footprint relates to the consumption of agricultural goods, $31 \%$ to the consumption of industrial goods, and $2 \%$ to domestic water use. The Dutch water footprint related to the consumption of agricultural goods, is composed as follows: $46 \%$ related to livestock products; $17 \%$ oil crops and oil from oil crops; $12 \%$ coffee, tea, cocoa and tobacco; $8 \%$ cereals and beer; $6 \%$ cotton products; $5 \%$ fruits; and $6 \%$ other agricultural products. Most agricultural products are related to food consumption, most important exceptions being 


\section{8 / Chapter 8. The external water footprint of the Netherlands}

cotton for textiles and oil crops for cosmetics, pharmaceuticals, soaps, lubricants, paints and bio-energy.

About $89 \%$ of the water footprint of the Netherlands is external. About $48 \%$ of this external footprint is located within European countries (mainly in Germany, France and Belgium) and $20 \%$ in Latin American countries (mainly in Brazil and Argentina). For industrial products $53 \%$ of the consumed products originate from European countries and about 33\% originates from Asian countries (mainly China, Taiwan, Hong Kong and Viet Nam).

As a trade nation, the Netherlands imports not only for the purpose of domestic consumption. Only $44 \%$ of the virtual-water import relates to products consumed in the Netherlands, thus constituting the external water footprint. For agricultural products this is $40 \%$ and for industrial products this is $60 \%$. The remaining $56 \%$ of the virtual-water import to the Netherlands is re-exported. About $41 \%$ of the virtual-water import for re-export comes from Africa (mainly Cote d'Ivoire, Ghana, Cameroon and Nigeria) and mainly concerns the import of cocoa beans, most of which are processed in the Netherlands into cocoa butter, cocoa powder or cocoa paste and re-exported to other European countries (mainly Germany, United Kingdom, Belgium and Switzerland).

The impact of the external water footprint of Dutch consumers is highest in countries that experience serious water scarcity. Based on indicators for water scarcity the following eight countries have been identified as hotspots: China; India; Spain; Turkey; Pakistan; Sudan; South Africa; and Mexico. Although these countries are not the largest contributors to the external water footprint of Dutch consumers in absolute terms, the impact of Dutch consumption in these countries deserves serious attention since in these countries the negative externalities of Dutch consumption are considered to be most serious.

The study shows that Dutch consumption implies the use of water resources throughout the world, with significant impacts at specified locations. This knowledge is relevant for consumers, government and businesses when addressing the sustainability of consumer products and supply chains. The results of this study can be an input to bilateral cooperation between the Netherlands and the Dutch trade partners aimed at the reduction of the negative impacts of Dutch consumption on foreign water resources. Dutch government can also engage with businesses in order to stimulate them to review the sustainability of their supply chains. 


\section{The relation between national water management and international trade: A case study for Kenya ${ }^{11}$}

\section{Abstract}

This study estimates the water footprint of Kenya both from the production and consumption perspective and estimates virtual water import and export flows related to international trade. Both the water footprint and virtual water estimates are broken down into three components: green, blue and grey water. The main findings of the study are:

- During the period 1996-2005, the water footprint of Kenya related to crop production was $18.1 \mathrm{Gm}^{3} / \mathrm{yr}$.

- During the same period, Kenya's virtual water import and export were 3.96 $\mathrm{Gm}^{3} / \mathrm{yr}$ and $4.1 \mathrm{Gm}^{3} / \mathrm{yr}$ respectively. Over $78 \%$ of the virtual water export was related to export of coffee, tea and cotton products. The water use in Kenya for producing flowers for export was $20 \mathrm{Mm}^{3} / \mathrm{yr}$.

- The average export earnings per unit of water consumed or polluted for producing agricultural export products was US\$ 0.25 per cubic metre of water; the average cost of imported commodities per unit of virtual water imported was $0.10 \mathrm{US} \$ / \mathrm{m}^{3}$.

- About 23\% of the water appropriated in the agricultural sector in Kenya is for producing export products, amongst which coffee, tea, cotton, fruits, vegetables and flowers. On the other hand, it imports many other water-intensive goods, primarily cereals and oil crops. As a result of the latter, Kenya is not self-sufficient with respect to its own food supply: $10 \%$ of its maize (the major staple food), $63 \%$ of its wheat and $72 \%$ of its rice are imported.

- The total water footprint related to consumption of both agricultural and industrial goods and domestic water use was $35 \mathrm{Gm}^{3} / \mathrm{yr}$, which is $1100 \mathrm{~m}^{3} / \mathrm{yr}$ per capita on average ( $79 \%$ of the global average).

\footnotetext{
${ }^{11}$ Based on Mekonnen and Hoekstra (2011d)
} 
Kenya could address its water scarcity problem through enhancing its import of waterintensive products such as cereals and export of non water-intensive and high value products such as cut flower and tea. From a water resources point of view, particularly the production and export of green-water based tea and vegetables are positive: water productivities in terms of US\$ per cubic metre are relatively high and the export values in absolute terms are very substantial.

\subsection{Introduction}

There are great disparities in water use and scarcity within and between countries because both people and water resources are unevenly distributed across the globe. Virtual water import in the form of import of agricultural goods is increasingly recognized as a mechanism to improve national water security (Allan, 2003; De Fraiture et al., 2004; Hoekstra, 2003; Chapagain et al., 2006a; Yang et al., 2006; Hoekstra and Chapagain, 2008). Virtual water import enables nations to save scarce domestic water resources by importing water-intensive products and exporting commodities that require little water. On the other hand, water-abundant countries can profit by exporting water-intensive commodities (Hoekstra and Chapagain, 2008).

Kenya's internal renewable water resources are estimated at $20.7 \mathrm{Gm}^{3} / \mathrm{yr}$. Most of this, $20.2 \mathrm{Gm}^{3} / \mathrm{yr}$, is available as surface water. Renewable ground water resources are estimates to be $3.5 \mathrm{Gm}^{3} / \mathrm{yr}$, of which $3.0 \mathrm{Gm}^{3} / \mathrm{yr}$ overlaps with the annual renewable surface water resources. It is estimated that $10 \mathrm{Gm}^{3} / \mathrm{yr}$ of river water flows into the country (FAO, 2005c), which means that the total renewable water resources of Kenya are 30.7 $\mathrm{Gm}^{3} / \mathrm{yr}$.

According to Wong et al. (2005), the available renewable water resources are insufficient to meet Kenya's water needs. Kenya is generally characterized as a waterstressed country (Ohlsson and Appelgren, 1998; FAO, 2005c; UNEP, 2006). This is also the starting point of Kenya's Vision 2030 document (GoK, 2007).

The aim of this paper is to assess the relation between national water management and international trade in a case study for Kenya. We quantify the water consumption and pollution related to the production of agricultural export commodities and put this in the 
context of export earnings. We also consider the import side by quantifying how much water is embedded in imported commodities.

\subsection{Method and data}

The water footprint is an indicator of human appropriation of freshwater resources. The term 'freshwater appropriation' refers to both consumptive water use (water evaporated or incorporated into the product) and water required to assimilate pollutants. The water footprint has three colour coded components: the green, blue and grey water footprint. The green water footprint is the volume of green water (rainwater) consumed. The blue water footprint refers to consumption of blue water resources (surface and ground water). The grey water footprint is an indicator of the degree of freshwater pollution and is defined as the volume of freshwater that is required to assimilate the load of pollutants based on existing ambient water quality standards.

Green, blue and grey water footprints have been estimated following the calculation framework as set out in The Water Footprint Assessment Manual developed by the Water Footprint Network (Hoekstra et al., 2011). The water footprint within a nation is defined as the total freshwater volume consumed or polluted within the territory of the nation as a result of different economic activities. The water footprint of national consumption refers to the total amount of fresh water that is used to produce the goods and services consumed by the inhabitants of the nation. It includes both an internal and an external component. The external water footprint of national consumption is related to the fact that water is consumed or polluted elsewhere to produce commodities imported by Kenya.

The water footprint within a nation is defined as the total freshwater volume consumed or polluted within the territory of the nation as a result of different economic activities. The water footprint related to agricultural production including both crop production and farm animal production were taken from Mekonnen and Hoekstra (2010d,e, 2011a). The water footprints within Kenya related to industrial production and domestic water supply were taken from Mekonnen and Hoekstra (2011b).

The virtual-water export from a nation is the sum of virtual water export from domestic water resources and re-exported virtual water of foreign origin. The gross virtualwater flow is calculated by multiplying the volume of trade by the water footprint per ton of 
product as in the exporting nation. We have taken the average product water footprint as in the exporting country and when a product is imported from a country that does not produce the product we have assumed the global average product water footprint for that import flow. Kenya's virtual water import and export related to trade in industrial products was taken from Mekonnen and Hoekstra (2011b).

The water footprint of national consumption is defined as the total volume of freshwater that is used to produce the goods and services consumed by the inhabitant of the nation. The water footprint of the national consumption can be distinguished between the internal water footprint and the external water footprint. The internal water footprint of national consumption refers to the use of domestic water resources to produce goods and services consumed by the national population. It is the difference between the water footprint within the nation and the volume of virtual-water export to other nations related to export of products produced with domestic water resources. The external water footprint of national consumption, on the other hand, is defined as the volume of water resources used in other nations to produce goods and services consumed by the population in the nation considered. It is the difference between the virtual-water import into the nation and the volume of virtual-water re-exported to other nations as a result of re-export of imported products.

The water footprint of national consumption is calculated by adding the direct and indirect water footprint of consumers within the nation. The direct water footprint of consumers within the nation refers to consumption and pollution of water related to domestic water supply. The indirect water footprint of consumers refers to the water use by others to make the commodities consumed, whereby we distinguish between agricultural and industrial commodities. The water footprint of national consumption of agricultural and industrial commodities can be calculated through either the top-down or the bottom-up approach (Hoekstra et al., 2011). In the top-down approach, the water footprint of national consumption is calculated as the water footprint within the nation plus the virtual-water import minus the virtual-water export. In the bottom-up approach, the water footprint of national consumption is calculated by adding the direct and indirect water footprints of consumers within the nation. The water footprint of national consumption was taken from Mekonnen and Hoekstra (2011b). 
The water productivity of crops was calculated by dividing the total value of crop and the total water footprint related to crop production. The total value of crops was derived based on the unit value of exported products and total production of the product considered. Data on export and import value of agricultural products have been taken from the SITA database (Statistics for International Trade Analysis) available from the International Trade Centre (ITC, 2007).

\subsection{Results}

\subsubsection{Water footprint of crop production}

The water footprint related to crop production in Kenya for the period 1996-2005 was 18.1 $\mathrm{Gm}^{3} / \mathrm{yr}$ (97\% green, $1 \%$ blue and $2 \%$ grey). The largest share of this water footprint is due to the production of maize, which accounts for about $38 \%$ of the total production water footprint. Dry beans, coffee, tea and wheat together account 33\% toward the total production water footprint (Table 9.1).

About $61 \%$ of the total green water footprint is due to the production of maize $(6.8$ $\left.\mathrm{Gm}^{3} / \mathrm{yr}\right)$, dry beans $\left(2.8 \mathrm{Gm}^{3} / \mathrm{yr}\right)$ and coffee $\left(1.5 \mathrm{Gm}^{3} / \mathrm{yr}\right)$. The largest production blue water footprint was estimated for growing coffee $\left(51 \mathrm{Mm}^{3} / \mathrm{yr}\right)$ and rice $\left(35 \mathrm{Mm}^{3} / \mathrm{yr}\right)$, which together account for $40 \%$ of the total blue water footprint related to crop production.

Although the fertilizer application rates are still very low by international standards, Kenya has among the highest fertilizer application rates within Sub-Saharan African countries, excluding South Africa. Fertilizer use has grown on average by more than $30 \%$ over the last few years and in 2004/05 total consumption reached over 350 thousand metric tonnes (Ariga et. al., 2006). Not all fertilizer applied will be absorbed by the plant. A significant amount of nitrogen can remain in the soil and some of this will eventually leach into ground and surface water, causing water pollution. In this study, we have estimated the total volume of water required to dilute the polluted water (the grey water footprint) due to nitrogen fertilizer leaching from crop fields. For the period 1996-2005, the total grey water footprint related to the production of crops was $300 \mathrm{Mm}^{3} / \mathrm{yr}$. A little over half of the grey water footprint is related production of three crops - maize, coffee, and potato. About $23 \%$ of the agricultural water footprint was used for producing export products. The remaining 
$77 \%$ of the water was used for producing products for local consumption. It is worth noting that the exported products yield high foreign currency earnings per unit volume of water used (see Figure 9.11 for crops water productivity).

Table 9.1. The water footprint crop production in Kenya (1996-2005).

\begin{tabular}{|c|c|c|c|c|c|c|c|c|}
\hline \multirow{2}{*}{ Crop } & \multicolumn{4}{|c|}{ Total water footprint $\left(\mathrm{Mm}^{3} / \mathrm{yr}\right)$} & \multicolumn{4}{|c|}{$\begin{array}{l}\text { Water footprint per ton of crop } \\
\qquad\left(\mathrm{m}^{3} / \text { ton }\right)\end{array}$} \\
\hline & Green & Blue & Grey & Total & Green & Blue & Grey & Total \\
\hline Maize & 6688 & 11 & 96 & 6794 & 2703 & 4.4 & 39 & 2746 \\
\hline Beans, dry & 2774 & 0.0 & 0.1 & 2774 & 8319 & 0.0 & 0.3 & 8319 \\
\hline Coffee & 1426 & 51 & 35 & 1513 & 22222 & 802 & 549 & 23573 \\
\hline Tea & 1131 & 1.0 & 25 & 1157 & 4061 & 3.6 & 89 & 4154 \\
\hline Wheat & 439 & 0.0 & 20 & 460 & 1492 & 0.0 & 70 & 1562 \\
\hline Sorghum & 453 & 0.0 & 0.0 & 453 & 4359 & 0.0 & 0.0 & 4359 \\
\hline Sugarcane & 416 & 8.8 & 8.9 & 433 & 95 & 2.0 & 2.0 & 99 \\
\hline Potato & 316 & 0.0 & 29 & 345 & 342 & 0.0 & 31 & 373 \\
\hline Banana & 283 & 6.5 & 5.5 & 295 & 545 & 12 & 11 & 568 \\
\hline Plantains & 284 & 0.0 & 5.5 & 289 & 546 & 0.0 & 11 & 556 \\
\hline Millet & 260 & 0.0 & 0.0 & 260 & 5375 & 0.0 & 0.0 & 5375 \\
\hline Pigeon peas & 240 & 0.0 & 0.0 & 240 & 3200 & 0.0 & 0.3 & 3200 \\
\hline Cassava & 234 & 0.0 & 0.0 & 234 & 431 & 0.0 & 0.0 & 431 \\
\hline Other crops & 2646 & 140 & 75 & 2861 & & & & \\
\hline Total & 17590 & 219 & 300 & 18109 & & & & \\
\hline
\end{tabular}

The water footprint per ton of crop for selected crops is shown in Table 9.1. Among the major crops, the water footprint per ton of crop increases from sugar cane (roughly 100 $\mathrm{m}^{3} /$ ton $)$, potato $\left(\sim 400 \mathrm{~m}^{3} /\right.$ ton $)$, maize $\left(\sim 2800 \mathrm{~m}^{3} /\right.$ ton $)$ to coffee $\left(\sim 23600 \mathrm{~m}^{3} /\right.$ ton $)$. The larges blue and grey water footprint per ton of crop is also calculated for coffee. The water footprint per ton of crop also varies significantly across the country as shown Figure 9.1. While the total water footprint related to crop production is high in western Kenya, water footprint per ton of crop is highest in the northern and eastern Kenya. The water footprint of maize, for example, varies from $1200 \mathrm{~m}^{3} /$ ton in some part of the Rift Valley and Western 
provinces to as high as $6000 \mathrm{~m}^{3} /$ ton in the Eastern province (Figure 9.1). The reason for this difference in water footprint per unit of product between the provinces is due mainly to difference in the climatic condition. The northern and eastern regions of Kenya are arid or semi-arid with annual precipitation as low as $200 \mathrm{~mm}$ which affects crop yield negatively.

The total water footprint of crop production for each province of Kenya is shown in Figure 9.2. The Rift Valley province accounts for about $39 \%$ of the total water footprint related to crop production. The larges blue water footprint is found in Rift Valley (25\%) and Nyanza (20\%) provinces. Rift Valley province alone accounts for $35 \%$ of the grey water footprint. Since most of Kenya's farming system relies heavily on rainfall, the croplands are mainly concentrated in places where rainfall is more reliable, such as the highlands, the Lake Victoria basin, and the narrow coastal strip. The green water footprint dominates $(>95 \%)$ in all provinces reaching up to $98 \%$ in Rift Valley and Western provinces (Figure 9.2). The variation in the total water footprint per grid cell (Figure 9.3) shows similar pattern as the fraction of harvested crop area (Monfreda et al., 2008). This indicates that total water footprint per grid cell is largely determined by the fraction of harvested crop area per grid cell.

\subsubsection{Virtual water flow related to trade in agricultural products}

In the period 1996-2005, Kenya's virtual water export related to agricultural products was $4.1 \mathrm{Gm}^{3} / \mathrm{yr}$ (95\% green, $3 \%$ blue and $2 \%$ grey). About $65 \%$ was related to export of coffee and tea. Cotton products, livestock products and products of oil crops are the other agricultural products responsible for significant virtual water export from Kenya as shown in Table 9.2. Kenya's total export earnings was US\$ 1.02 billion. As shown in Table 9.2, cut flowers generate the highest economic returns per unit of water exported, followed by vegetable products. The major destinations for Kenya's virtual water exports are the US, Germany, the UK, and Pakistan, which together account for about $45 \%$ of Kenya's virtual water exports. 


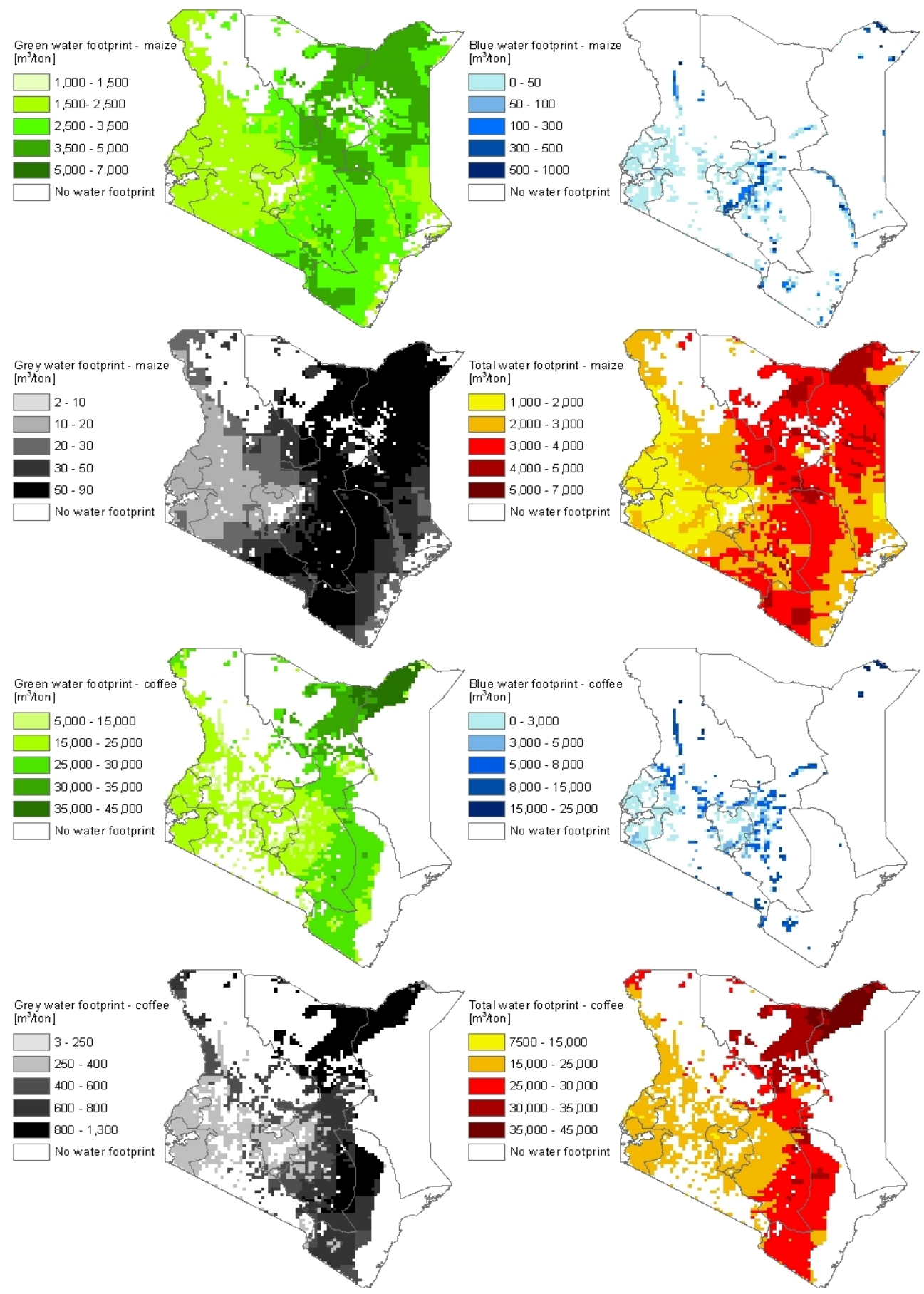

Figure 9.1. The green, blue and grey water footprints per ton of maize (top) and coffee (bottom). Period 1996-2005 


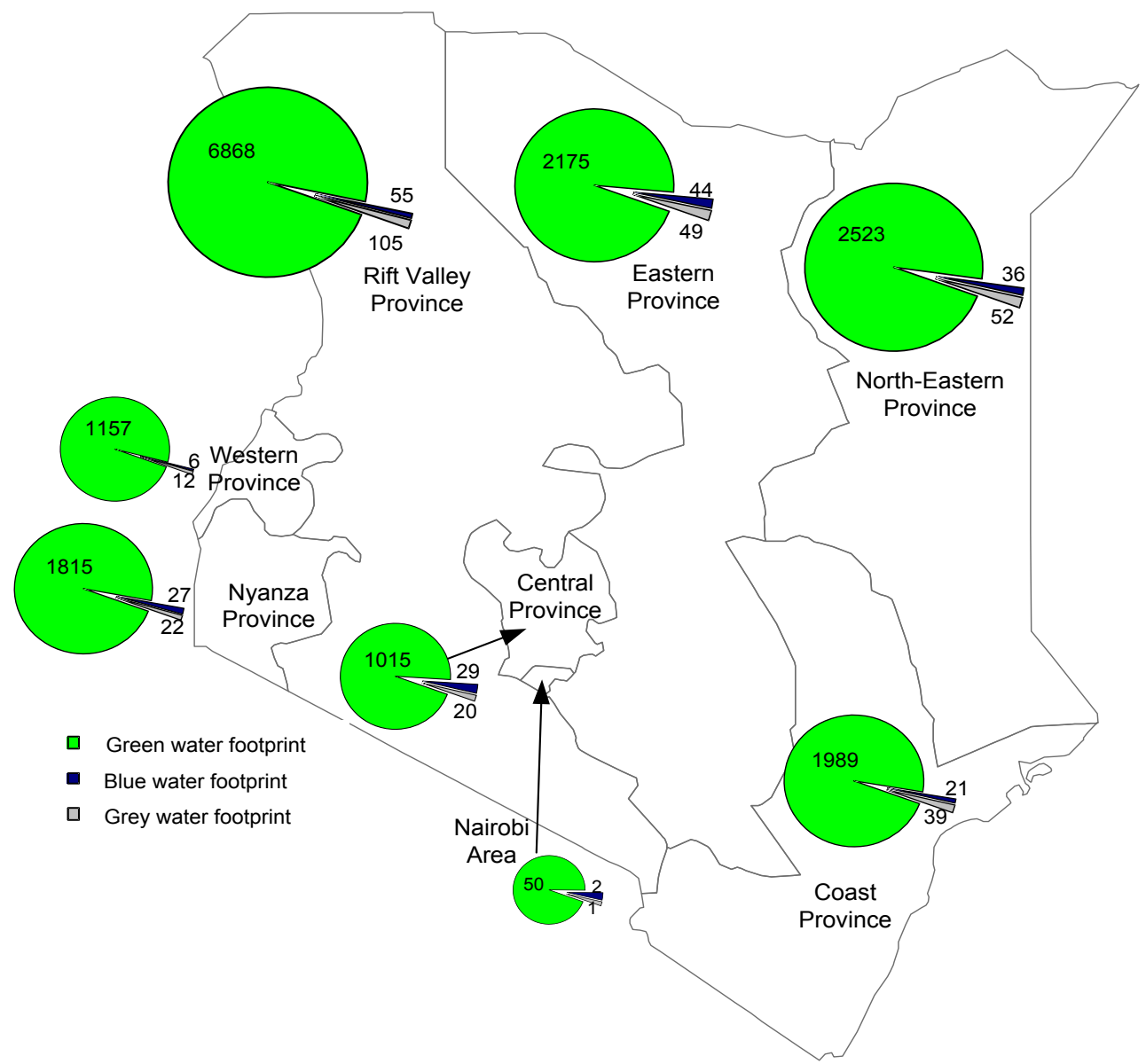

Figure 9.2. Green, blue and grey water footprint related to crop production per province. Values in the chart show water footprint in million $\mathrm{m}^{3} / \mathrm{yr}$. Period 1996-2005.

Coffee and tea are the main agricultural crops, contributing $65 \%$ to Kenya's virtual water export. In the period 1996-2005, the virtual water export in relation to exports of coffee and tea amounted to $2.6 \mathrm{Gm}^{3} / \mathrm{yr}$ (96\% green, $2 \%$ blue and $2 \%$ grey). The main coffee growing regions include the region north of Nairobi, the high plateau surrounding Mount Kenya, and in the Aberdare zone. Tea growing regions in Kenya are located in the Great Rift Valley. To the east of the Rift Valley are the Aberdare highlands (Mt. Kenya and the Nyabene hills). To the west of the Rift Valley are the Nandi hills, and the highlands around Kericho, Mt. Elgon and the Kisii highlands. The rainfall in these regions ranges from 1200 $\mathrm{mm}$ to $2700 \mathrm{~mm}$ annually (EPZA, 2005c). The water footprint for both coffee and tea is predominantly green water $(96 \%)$. 
The contribution of coffee and tea towards Kenya's socio-economic development is vital. Coffee and tea cultivation provides direct and indirect employment to a large proportion of the population. In addition, the combined annual export revenue from coffee and tea accounted for US\$ 581 million, a 57\% share of the total revenue generated from exports of the selected crops and livestock products in the period 1996-2005. Thus, from the loss of its national water resources, Kenya is generating foreign exchange of about $0.25 \mathrm{US} \$ / \mathrm{m}^{3}$. Since trading green water is considered to have a low opportunity cost and to be more efficient compared to trading blue or grey water (Yang et al., 2006; Chapagain et al., 2006b), Kenya's virtual water export related to export of coffee and tea products can be considered more productive in terms of the foreign currency it generates.

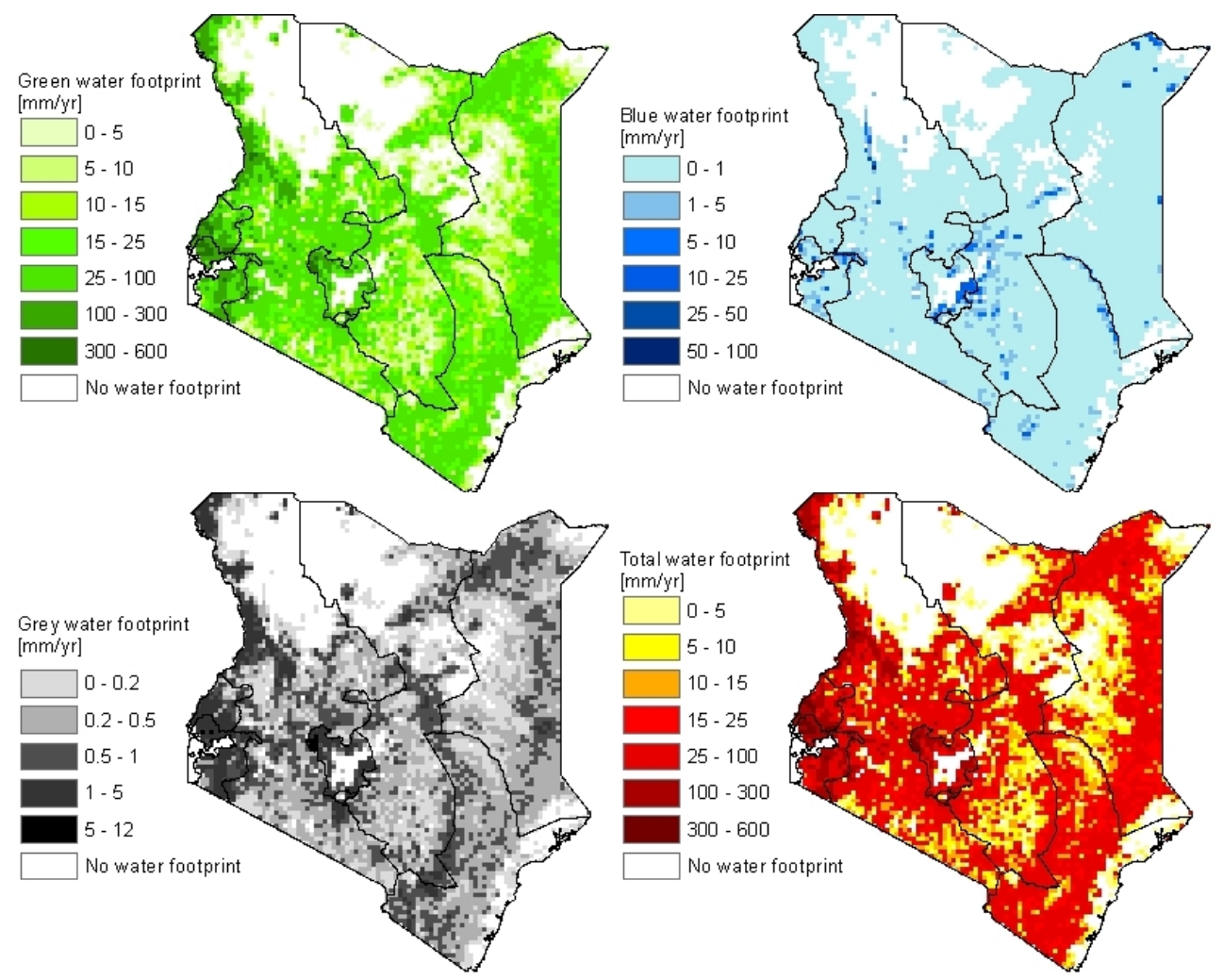

Figure 9.3. Total water footprint of crop production in Kenya. Period 1996-2005 
Kenya's horticulture industry (vegetables, fruits and cut flowers) is the fastest growing agricultural sub-sector and has become the second largest export earner after tea by contributing $13 \%$ to the total exports value in the period 1996-2005. Cut flowers export alone account about $53 \%$ of Kenyan horticultural export value and its overall contribution to the country's export earnings is growing rapidly.

For the period 1996-2005, the virtual water export in relation to the export of cut flowers was $18 \mathrm{Mm}^{3} / \mathrm{yr}$ (22\% green, $45 \%$ blue and 33\% grey) as show in Table 9.2. The virtual water export in relation to the export of cut flowers have shown significant growth, with virtual water export increasing from $14 \mathrm{Mm}^{3} / \mathrm{yr}$ in 1996 almost doubling in 2005 to 27 $\mathrm{Mm}^{3} / \mathrm{yr}$. Over $90 \%$ of the virtual water related to the export of cut flowers is exported to just three countries: the Netherlands (69\%), the UK (18\%) and Germany (7\%). Figure 9.4 shows net virtual water import per country and the major virtual water flows direction related to Kenya's virtual water import and export related to trade in agricultural products.

Table 9.2. Kenya's virtual water export per agricultural products, export earning and water productivity (1996-2005)

\begin{tabular}{|c|c|c|c|c|c|c|}
\hline \multirow{2}{*}{ Products } & \multicolumn{4}{|c|}{ Virtual water export $\left(\mathrm{Mm}^{3} / \mathrm{yr}\right)$} & \multirow{2}{*}{$\begin{array}{r}\text { Export value } \\
\text { (million } \\
\text { US\$/yr) }\end{array}$} & \multirow{2}{*}{$\begin{array}{r}\text { Water } \\
\text { productivity } \\
\left(\mathrm{US} \$ / \mathrm{m}^{3}\right)^{*}\end{array}$} \\
\hline & Green & Blue & Grey & Total & & \\
\hline Coffee & 1568 & 57 & 37 & 1662 & 157 & 0.09 \\
\hline Tea & 960 & 0.9 & 21 & 982 & 424 & 0.43 \\
\hline Cotton products & 552 & 26 & 0.0 & 578 & 42 & 0.07 \\
\hline Livestock products & 292 & 19 & 0.5 & 311 & 22 & 0.07 \\
\hline Oil crop products & 138 & 2.0 & 1.3 & 142 & 25 & 0.17 \\
\hline Fibre products & 99 & 1.1 & 0.2 & 100 & 11 & 0.11 \\
\hline Maize & 84 & 0.1 & 1.2 & 86 & 7.6 & 0.09 \\
\hline Fruits & 35 & 8.0 & 0.7 & 44 & 25 & 0.57 \\
\hline Pulses & 38 & 0.2 & 2.9 & 41 & 2.0 & 0.05 \\
\hline Wheat & 22 & 0.0 & 1.1 & 23 & 6.4 & 0.27 \\
\hline Spices & 20 & 0.9 & 2.6 & 23 & 15 & 0.65 \\
\hline Vegetables & 20 & 1.2 & 1.2 & 22 & 100 & 4.53 \\
\hline Other cereals & 18 & 1.3 & 0.3 & 20 & 6.9 & 0.35 \\
\hline Cut flower & 3.8 & 8.0 & 5.9 & 18 & 141 & 7.98 \\
\hline Other crops & 43 & 0.5 & 0.9 & 44 & 34 & 0.77 \\
\hline Total** & 3892 & 126 & 77 & 4095 & 1018 & 0.25 \\
\hline
\end{tabular}

* water productivity is obtained by dividing total export earnings by the total virtual water export.

${ }^{* *}$ total export earning refers to export earnings from the selected 302 crops and livestock products. 
In the same period, Kenya imported $3.96 \mathrm{Gm}^{3} / \mathrm{yr}$ of virtual water related to its import of agricultural products. The import of cereal products (mainly from Pakistan and South Africa) and palm oil products (mainly from Indonesia and Singapore) were responsible for $2.0 \mathrm{Gm}^{3} / \mathrm{yr}$ and $1.1 \mathrm{Gm}^{3} / \mathrm{yr}$ respectively (Table 9.3). Other key agricultural products responsible for Kenya's virtual water import were sugar products $\left(0.21 \mathrm{Gm}^{3} / \mathrm{yr}\right)$ and cotton products $\left(0.21 \mathrm{Gm}^{3} / \mathrm{yr}\right)$. The total import value of the agricultural products imported by Kenya was 412 million US\$/yr. The average cost of imported commodities per unit of virtual water imported was $0.10 \mathrm{US} \$ / \mathrm{m}^{3}$.

Table 9.3. Kenya's virtual water import and import expenditure related import of agricultural products (1996-2005)

\begin{tabular}{|c|c|c|c|c|c|c|}
\hline \multirow{2}{*}{ Products } & \multicolumn{4}{|c|}{ Virtual water import $\left(\mathrm{Mm}^{3} / \mathrm{yr}\right)$} & \multirow{2}{*}{$\begin{array}{r}\text { Import value } \\
\text { (million } \\
\text { US\$/yr) }\end{array}$} & \multirow{2}{*}{$\begin{array}{l}\text { Import cost per unit } \\
\text { of virtual water } \\
\text { imported }\left(U S \$ / \mathrm{m}^{3}\right)\end{array}$} \\
\hline & Green & Blue & Grey & Total & & \\
\hline Cereals & 1423 & 407 & 174 & 2005 & 167 & 0.08 \\
\hline Oil crops & 1083 & 4 & 58 & 1145 & 121 & 0.11 \\
\hline Sugar products & 114 & 83 & 13 & 210 & 44 & 0.21 \\
\hline Cotton products & 181 & 16 & 9 & 206 & 37 & 0.18 \\
\hline Cocoa products & 149 & 0 & 7 & 156 & 1.8 & 0.01 \\
\hline Pulses & 48 & 1 & 32 & 81 & 6.9 & 0.09 \\
\hline Other products & 133 & 19.6 & 5.6 & 158 & 36 & 0.23 \\
\hline Total & 3132 & 531 & 298 & 3961 & 412 & 0.10 \\
\hline
\end{tabular}

Kenya is not self-sufficient in water for its own food supply: $10 \%$ of its maize (the major staple food), $63 \%$ of its wheat and $72 \%$ of its rice is imported. Although the level of domestic cereal production has remained high, imports have shown significant growth. In the period 1996-2005, the share of imports was significant - reaching over $25 \%$ of the total supply of the main cereal products (maize, rice and wheat). At the same time, its exports of coffee and tea have enjoyed significant growth (Figure 9.5). This is an evidence of the shift in the agricultural sector towards the export of high value crops (tea, coffee and horticulture) and imports of low value crops such as cereals. 


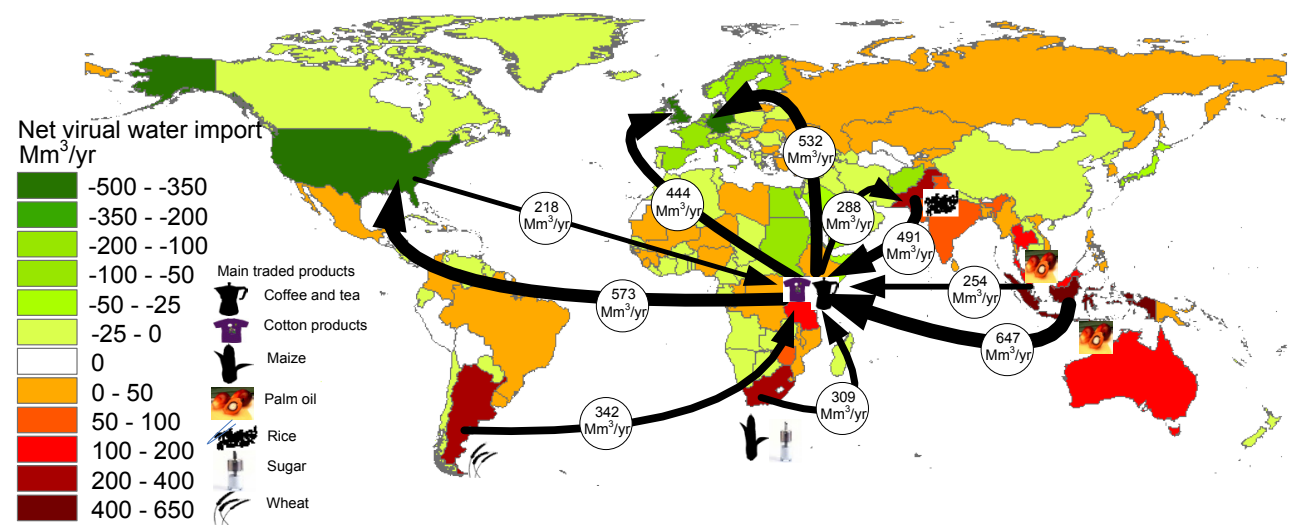

Figure 9.4. Global map showing countries with net virtual water import because of agricultural products imported from Kenya (green) and countries with net virtual water export because of agricultural products exported to Kenya (red). The arrows represent the biggest gross virtual water flows to and from Kenya (> $200 \mathrm{Mm}^{3} / \mathrm{yr}$ ) are shown. Period 1996-2005

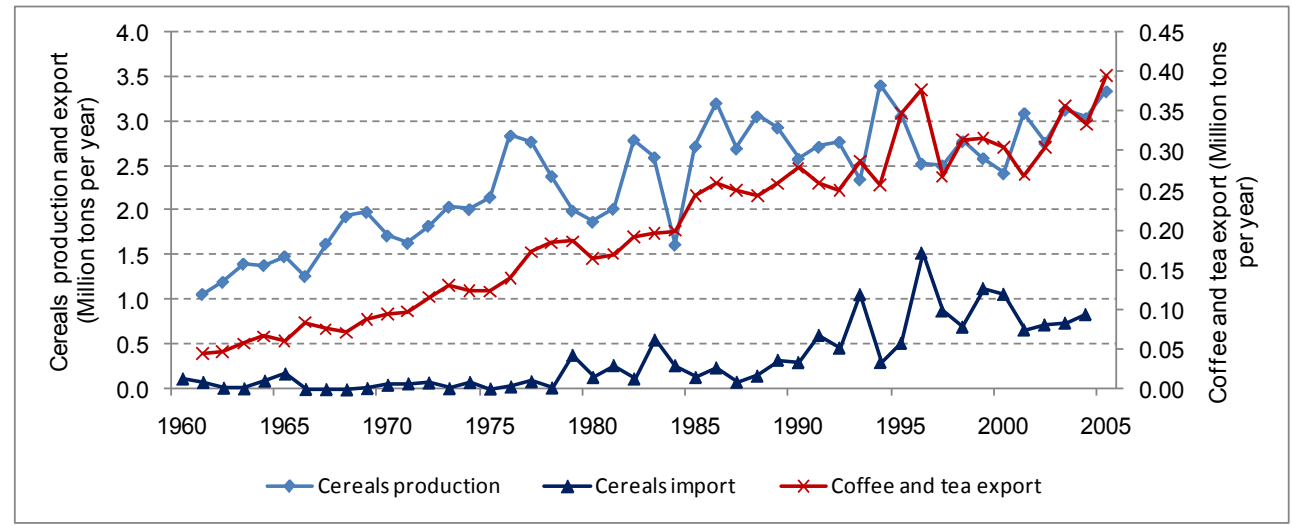

Figure 9.5. Kenya's production and import of cereal (maize, rice and wheat) and export of coffee and tea (Source: FAO, 2010a).

\subsubsection{The water footprint of national consumption}

In the period 1996-2005, the average water footprint of Kenya related to national consumption was $1100 \mathrm{~m}^{3} / \mathrm{yr}$ per capita ( $94 \%$ green, $3 \%$ blue and $3 \%$ grey), which is $79 \%$ of the global average. The water footprint related to consumption per primary product category is presented in Table 9.4. The water footprint is largely determined by the consumption of agricultural goods, contributing $98 \%$ to the total water footprint. When we look at the level of product categories, consumption of meat products contribute the largest 
share to the total water footprint (30\%), followed by cereal products $(29 \%)$ and pulses $(12 \%)$. Among the cereal products category, consumption of maize products contribute the largest share (74\%) to the water footprint related to consumption of cereal products. When we look at the breakdown of the water footprint into internal and external, the external water footprint constitutes $17 \%$ of the total water footprint.

Table 9.4. Water footprint of national consumption, shown by primary product category.

\begin{tabular}{|c|c|c|c|c|c|c|c|}
\hline \multirow[t]{2}{*}{ Product } & \multicolumn{3}{|c|}{$\begin{array}{c}\text { Total water footprint of } \\
\text { national consumption } \\
\left(\mathrm{Mm}^{3} / \mathrm{yr}\right)\end{array}$} & \multicolumn{4}{|c|}{$\begin{array}{l}\text { Water footprint per capita } \\
\qquad\left(\mathrm{m}^{3} / \mathrm{yr} / \mathrm{cap}\right)\end{array}$} \\
\hline & Green & Blue & Grey & Green & Blue & Grey & Total \\
\hline Cereals & 9371 & 523 & 317 & 293.5 & 16.4 & 9.9 & 320 \\
\hline Starchy roots & 744 & 5 & 28 & 23.3 & 0.2 & 0.9 & 24 \\
\hline Sugar crops & 32 & 6 & 1 & 1.0 & 0.2 & 0.0 & 1.2 \\
\hline Sugar \& sweeteners & 443 & 81 & 20 & 13.9 & 2.5 & 0.6 & 17 \\
\hline Pulses & 4139 & 2 & 64 & 130 & 0.1 & 2.0 & 132 \\
\hline Nuts & 18 & 0 & 0 & 0.5 & 0.0 & 0.0 & 0.6 \\
\hline Oil crops & 161 & 2 & 1 & 5.1 & 0.1 & 0.0 & 5.2 \\
\hline Vegetable oils & 1119 & 9 & 48 & 35 & 0.3 & 1.5 & 37 \\
\hline Vegetables & 409 & 51 & 22 & 13 & 1.6 & 0.7 & 15 \\
\hline Fruits & 1052 & 20 & 21 & 33 & 0.6 & 0.6 & 34 \\
\hline Stimulants & 252 & 6 & 7 & 7.9 & 0.2 & 0.2 & 8.3 \\
\hline Spices & 54 & 2 & 0 & 1.7 & 0.1 & 0.0 & 1.7 \\
\hline Alcoholic beverages & 73 & 1 & 3 & 2.3 & 0.0 & 0.1 & 2.4 \\
\hline Fibres & 178 & 9 & 3 & 5.6 & 0.3 & 0.1 & 5.9 \\
\hline Tobacco & 43 & 0 & 1 & 1.4 & 0.0 & 0.0 & 1.4 \\
\hline Rubber & 50 & 1 & 2 & 1.6 & 0.0 & 0.1 & 1.7 \\
\hline Meat & 10345 & 149 & 7 & 324 & 4.7 & 0.2 & 329 \\
\hline Offals & 956 & 12 & 0 & 30 & 0.4 & 0.0 & 30 \\
\hline Animal fats & 73 & 4 & 0 & 2.3 & 0.1 & 0.0 & 2.4 \\
\hline Milk & 2833 & 144 & 3 & 89 & 4.5 & 0.1 & 93 \\
\hline Eggs & 125 & 5 & 2 & 3.9 & 0.1 & 0.1 & 4.1 \\
\hline Hides \& skins & 455 & 8 & 0 & 14 & 0.3 & 0.0 & 14 \\
\hline Industrial production & 0 & 12 & 177 & 0.0 & 0.4 & 5.5 & 5.9 \\
\hline Domestic water supply & 0 & 47 & 419 & 0.0 & 1.5 & 13.1 & 15 \\
\hline Total & 32924 & 1100 & 1146 & 1031 & 34 & 36 & 1101 \\
\hline
\end{tabular}




\subsection{Water resource scarcity in Kenya}

Water scarcity is becoming an increasingly significant problem for Kenya. Based on various water scarcity indicators, Kenya is considered as water scarce country (GoK, 2007; Wong et al., 2005; Ohlsson and Appelgren, 1998; FAO, 2005c; UNEP, 2006). Figure 9.6 shows the water availability per river basin and the water withdrawal-to-availability (WTA) ratio - an indicator of water scarcity. The water withdrawal data has been updated to reflect the current withdrawal levels. As can be seen from the figure, water availability is high in the Tana River drainage area and upper part of Rift Valley drainage area. A water withdrawal-to-availability ratio (WTA) of $20-40 \%$ represents medium water stress, where as a WTA of above 40\% represent sever water stress (Alcamo et al. 2003a,b, 2007; Cosgrove and Rijsberman, 2000a). Based on this measure, only some parts of the NorthEastern and Coastal provinces are under water stress. This might give the wrong impression that most of Kenya is not yet water stressed. However, only a certain proportion of the renewable water resource can be used, while the remainder is either technically inaccessible or needs to be left to meet environmental flow requirements (Molden and Sakhthivadivel, 1999; Smakhtin, 2002; Smakhtin et al., 2004b). If we consider only the water resource that is technically feasible to access and include the environmental flow requirement in the analysis, the result would be quite different and the water scarcity level would be significantly higher.

Kenya's total annual renewable water is estimated at $30.7 \mathrm{Gm}^{3} / \mathrm{yr}$ (FAO, 2005c). Using the 2005 population of 35.6 million (UNSD, 2010b), the total renewable water available per year is therefore $862 \mathrm{~m}^{3}$ per capita. But this is expected to drop due to population growth. When this is compared with the global recommendation of 1000 cubic meter per capita, it suggests that Kenya is water scarce. However, such statistics focus only on the surface and ground water resources (blue water) and fail to take into account the soil water (green water). Much of the worlds' food is grown not from blue water but from green water (Falkenmark and Röckstrom, 2004). As pointed out in the previous sections, agriculture in Kenya is mainly rain-fed and about $90 \%$ of the water footprint related to crop production comes from green water. Therefore, it is quite important to assess the rainfall variability and its impacts on the Kenyan economy. 

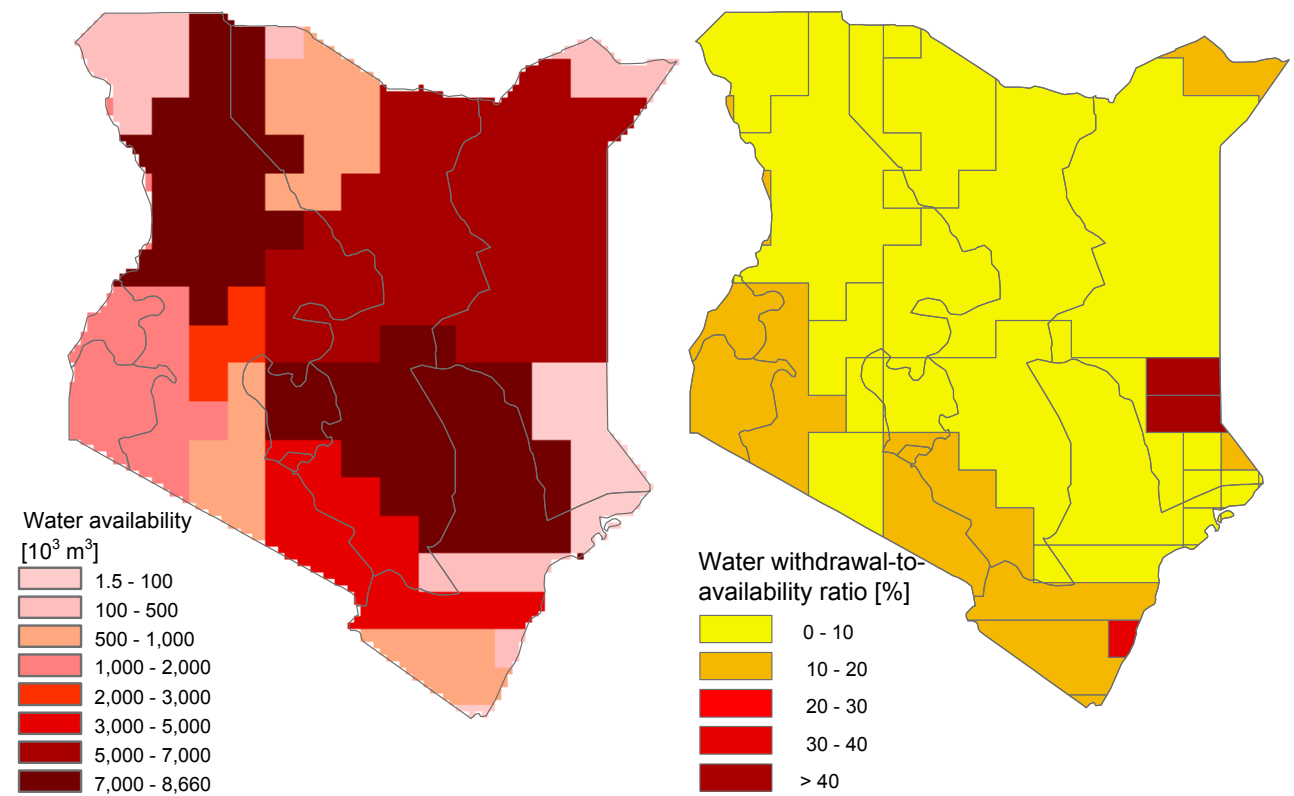

Figure 9.6. Water availability and water stress level. Source: Alcamo et al. (2003a,b). Water withdrawal data was updated based on FAO (2005c) estimate of total withdrawal of 5.8 $\mathrm{Gm}^{3} / \mathrm{yr}$ by 2010. The value is proportionally distributed to the basins based on 1995 estimate of Alcamo et al. $(2003, a, b)$

The average annual rainfall of Kenya is approximately $630 \mathrm{~mm}$. However, there is a significant variation in the annual rainfall across the country ranging from less than 200 $\mathrm{mm}$ in northern Kenya to over $1800 \mathrm{~mm}$ on the slopes of Mt. Kenya (FAO, 2005c). More than $80 \%$ of the country including the northern and eastern regions, is arid or semi-arid, and only $17 \%$ of the country is considered to be land with high agricultural potential which can supports $75 \%$ of the population while generating a significant portion of Kenya's GDP (FAO, 2005c; WRI, 2007).

The annual rainfall amount does not show the pattern of dry and wet seasons of the year or the variations across the country. Figure 9.7 shows the seasonal variability of the Kenya's rainfall, with average statistics for the months of February, April, July and annual average. East of the Rift Valley, "long" rains fall from March to May and the "short" rains fall from October to November (WRI, 2007). The western part of the country bordering Lake Victoria generally experience only one long rainy season from March to September. For most of the country, the "long" rains account for much of the annual rainfall, but the 
"short" rains also play a crucial role in many areas (WRI, 2007). There is also great variation in the rainfall amount and distribution from year to year (Figure 9.8).

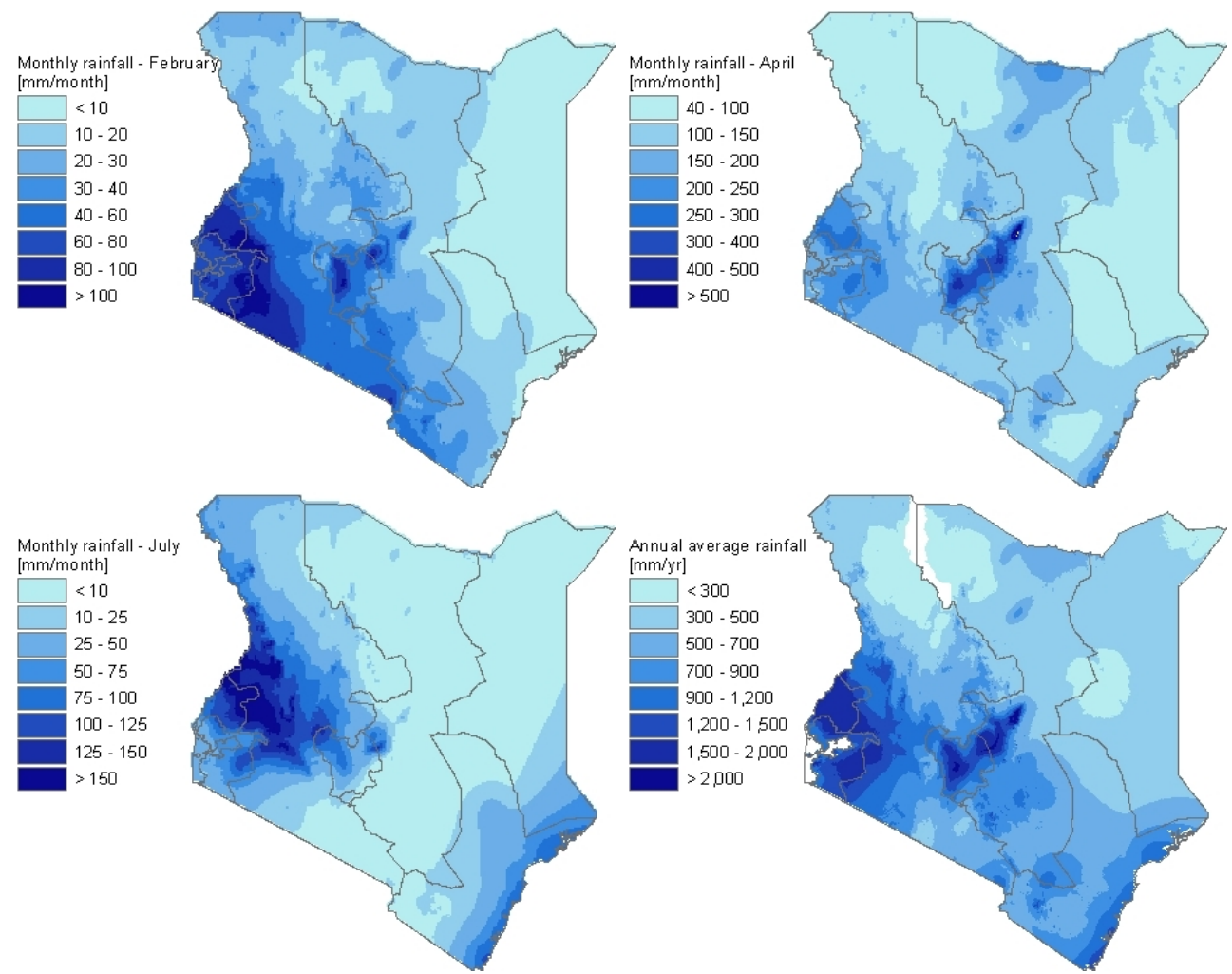

Figure 9.7. Temporal and spatial rainfall variability in Kenya. Source: WRI (2007).

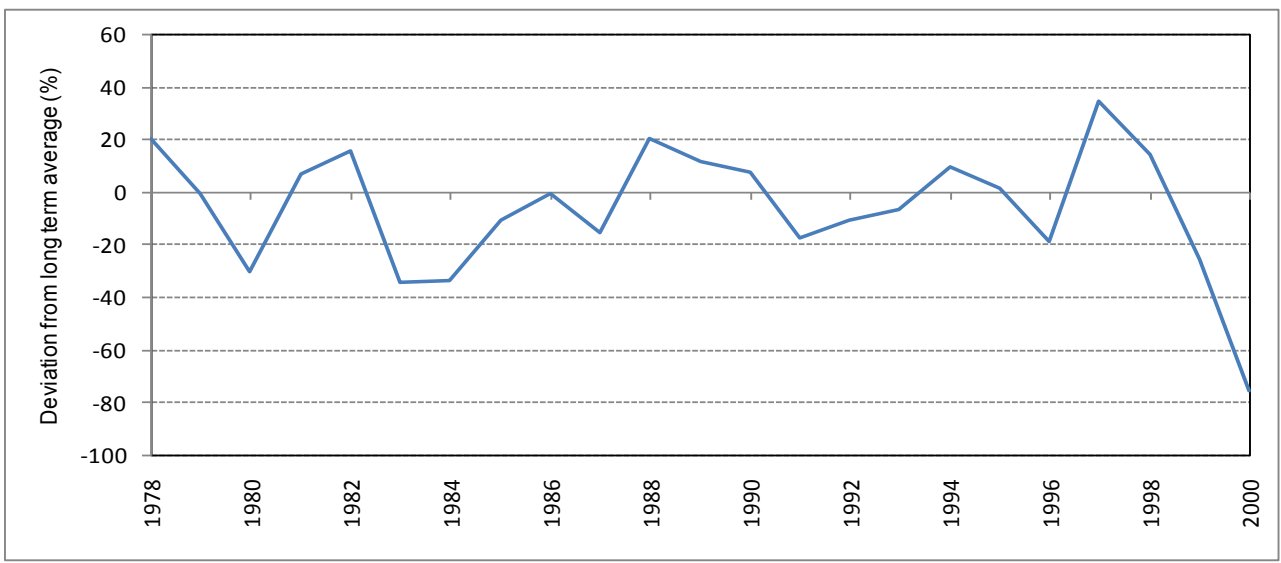

Figure 9.8. Kenya's year to year rainfall variability (adopted from Mogaka et al., 2006) 


\section{6 / Chapter 9. National water management: A case study for Kenya}

Such temporal and spatial variability of rainfall - which most parts of Kenya experiencecombined with high levels of crop water requirement typical in the semi-arid and arid part of the country precludes much of the country from being suited to the growth of rain-fed crops. Thus, policy makers should take effective policy measures to manage the water resource properly in order to avoid future problems with the country's food production and economic development.

\subsection{Water management in Kenya - the role of virtual water}

Managing water scarcity entails either supply-side or demand-side management or a combination of the two. Since the available water supply is limited in many areas and the cost of increasing the water supply is usually high, there is a growing emphasis on increasing water use efficiency (Falkenmark, et al. 2007; Gleick, 1998; Postel, 2000; Wallace and Gregory, 2002). According to Hoekstra and Hung (2005), there are three levels at which water use efficiency can be increased. At a local level, namely that of the water user, water use efficiency can be increased by charging prices based on full marginal cost, stimulating water-saving technologies, and creating awareness among the water users on the detrimental impacts of excessive water abstraction. At the river basin level, water use efficiency can be improved by re-allocating water to those purposes with the highest marginal benefits. At this level, we speak of 'water allocation efficiency'. Finally, at the global level, water use efficiency can be increased if nations use their relative water abundance or scarcity to either encourage or discourage the use of domestic water resources for producing export commodities.

As in most countries, Kenya's irrigation system suffers from poor irrigation efficiency. About $60 \%$ of the irrigated land is irrigated by sprinklers and about $38 \%$ by surface irrigation (FAO, 2005c). Although the potential for water saving through increased efficiency is high, it is not as large as might be thought (Seckler et al., 2003). This is because the classical definition of irrigation efficiency ignores the value of return flows i.e., irrigation water runoff and seepage that re-enters the water supply system (Keller and Keller 1995; Seckler et al. 2003). When the return flow is reused, the overall efficiency increases. Thus, while individual systems could have low levels of efficiency, the basinwide efficiencies can be much higher. Therefore, taking steps to increase water use 
efficiency at the local level based on the classical efficiency calculations often will not result in genuine water savings. The real water savings come not through increasing local level water use efficiency rather from being as productive as possible with each drop of water that is consumed. Growing more crops with less water would alleviate water scarcity. One possible way of increasing water productivity is to raise crop yields at field level.

Figure 9.9 shows that the maize yield in Kenya has shown no improvement over the years. Although Kenya's maize yield is slightly above African countries' average, it is much below the yield obtained in Egypt, the world average and that of South Africa. This low yield level is an indication that there is still much room for improvement in Kenya's agriculture productivity.

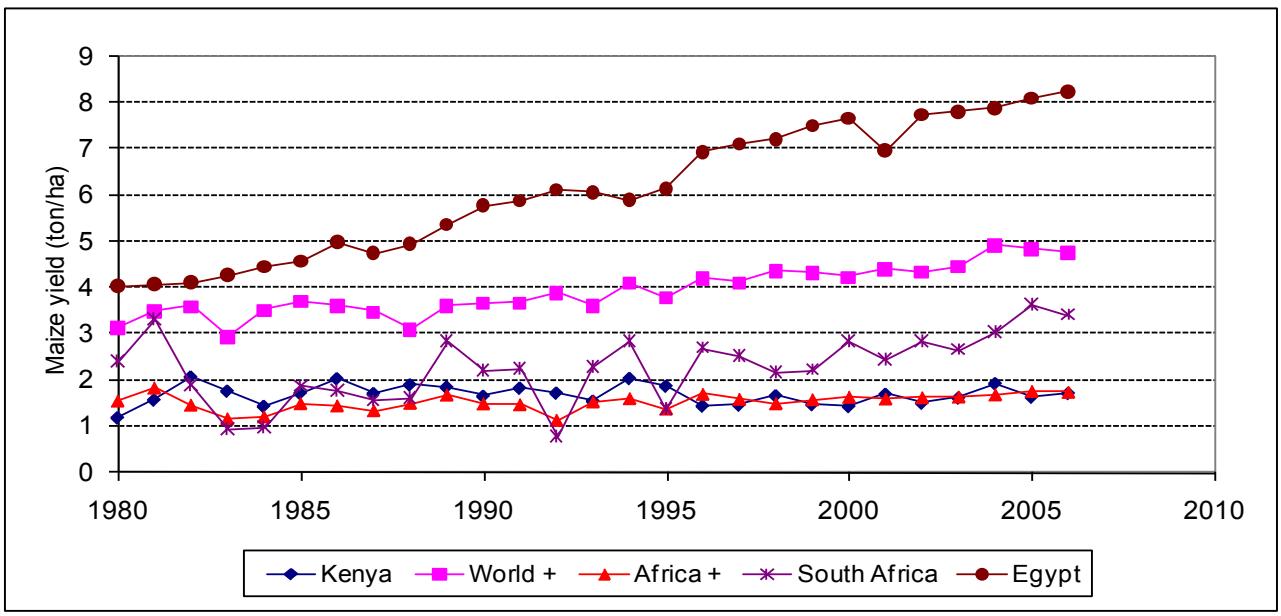

Figure 9.9. Kenya's maize yield compared to maize yields in Egypt, South Africa, the continent of Africa and the world. Source: FAO (2010a)

It is evident from Figure 9.10 that the water footprint per tonne of crop in Kenya increases going from the Western provinces to Eastern and North-Eastern provinces. As pointed out in other sections, the climate in the North-Eastern, Eastern and Coastal provinces is characterized as semi-arid or arid. As such, the crop water requirements in these provinces are quite high compared to the other provinces. The high crop water requirement - coupled with low water availability - has clearly influenced the crop yields in these areas, which is well below the other provinces. It is clear from Figure 9.10 that the Western province in particular has the lowest water footprint per tonne of crop. If crops were to be grown more 


\section{8 / Chapter 9. National water management: A case study for Kenya}

in the Central, Nairobi Area, Nyanza and Western provinces where the water footprint is lower, the water saving from such approach would be quite high. However, the decision about what and where to grow is complex and goes beyond simple water footprint accountings. If we decide to produce most of the crop in areas of low water footprint, provided there is enough land and other means of production beside water, how would the farmers in the marginal areas survive? What alternative means of living would they have? Such important issues need to be addressed before any measure is taken. Farmers in particular low income farmers give priority to producing their own food needs rather than relying on market. Therefore, it is quite important to increase food security, off-farm income and alternative employment options. Beside this, it might be necessary to assist farmers to raise their productivity through providing high yielding and drought resistant crops and improving agricultural techniques so as to obtain more value per unit of water.

Although measures to improve productive efficiency of water as indicated above are important, the effective way of increasing water productivity is through 'allocative efficiency' (Allan, 1999; Dinar, 1998). The 'inter-sectoral allocative efficiency' and the 'intra-sectoral allocative efficiency' are two distinct types of a 'water allocation efficiency' strategy. The intra-sectoral water allocation efficiency is achieved by allocating water within the same economic sector from product with low economic return per unit of water to another product which has a higher economic return per unit of water. This strategy is more relevant in the agricultural sector in which the range of economic returns gained from one crop compared with another can be much higher. Figure 9.11 shows productivity differences among selected crops in Kenya. Cut flowers have a much higher productivity per unit of water; as much as 250 times more productive than pulses or above 120 times more productive than maize. Vegetables also have a high water productivity which is very close to that of cut flower. Spices, fruits and tea also produce more value per unit of water as compared to the least productive crops. This analysis is consistent with results obtained by other researchers. Owuor (1998), for example, showed that horticultural crops are more productive compared to cereal crops such as maize. It is important to stress that the water productivity is calculated based on the assumption that water is the only scarce resource and holding other resources such as land, labour and agricultural inputs constant. Besides, all components of the water footprint (green, blue and grey water) are given equal weight. If we focus on the blue water footprint only, the figures will completely changes, i.e., the 
non-irrigated crops such as wheat, pulses and tea would have a much higher blue water productivity compared to cut flower or vegetables. Provided other factors such as employment opportunities, social equity are addressed, it is beneficial to produce more of the highly productive crops and earn enough money to import the other least productive cereal crops. In other words, there should be a policy shift from food self-sufficiency to food-security. Such decision might involve some form of social stress but not as much as the inter-sectoral allocative efficiency. The economic befits from intra-sectoral water allocation is also not as much as the return per unit of water that would be obtained by inter-sectoral water allocation efficiency.

On the other hand the inter-sectoral water allocation efficiency is achieved through allocating water from an economic sector with a low return per unit of water, usually agriculture, to another economic sector which has a higher return per unit of water, usually industry. Water that is diverted away from agricultural use into industrial and service sectors can produce as much as 1000 times the economic return per unit of water (Allan, 1999). Allocation efficiency - in particular the inter-sectoral allocative efficiency - is a highly politically sensitive strategy (Allan, 1999). In a country such as Kenya where about $74 \%$ of the population (FAO, 2005c) rely on agriculture as their main source of livelihood, allocating water away from agriculture to more the productive industry and service sectors represents a highly socially and politically stressful option (Allan, 1999; Turton and Ohlsson, 1999). Ohlsson (2000) argues that the conflict which might arise because of reallocating water away from agriculture to cities and industries would not be over competition for the amount of water that is diverted, because small portion of the water used in agriculture would be enough to satisfy the water requirement of cities and industries. The possible conflict would rather be about livelihoods of a large population which might have to be displaced from the agriculture sector. Constraints on industrial and service sectors capacity to absorb large labour force which are displaced from the agriculture sector would become highly relevant. The challenge is complex since it would involve creating new jobs in cities and industries to absorb not only the labour force displaced from agriculture but also a rapidly growing population. 


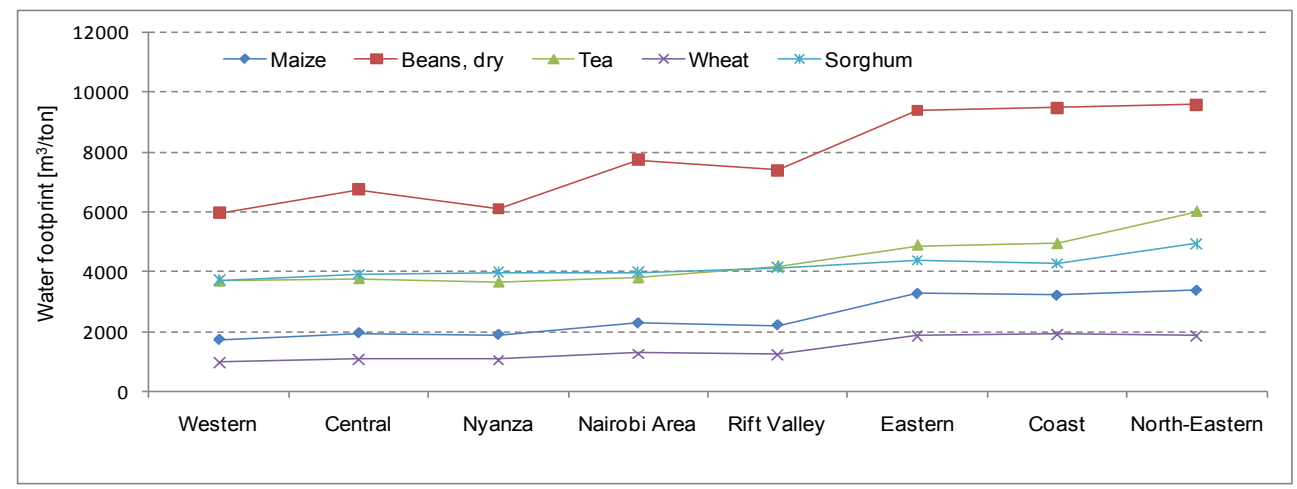

Figure 9.10. Water footprint per ton for selected crops in the 8 provinces of Kenya.

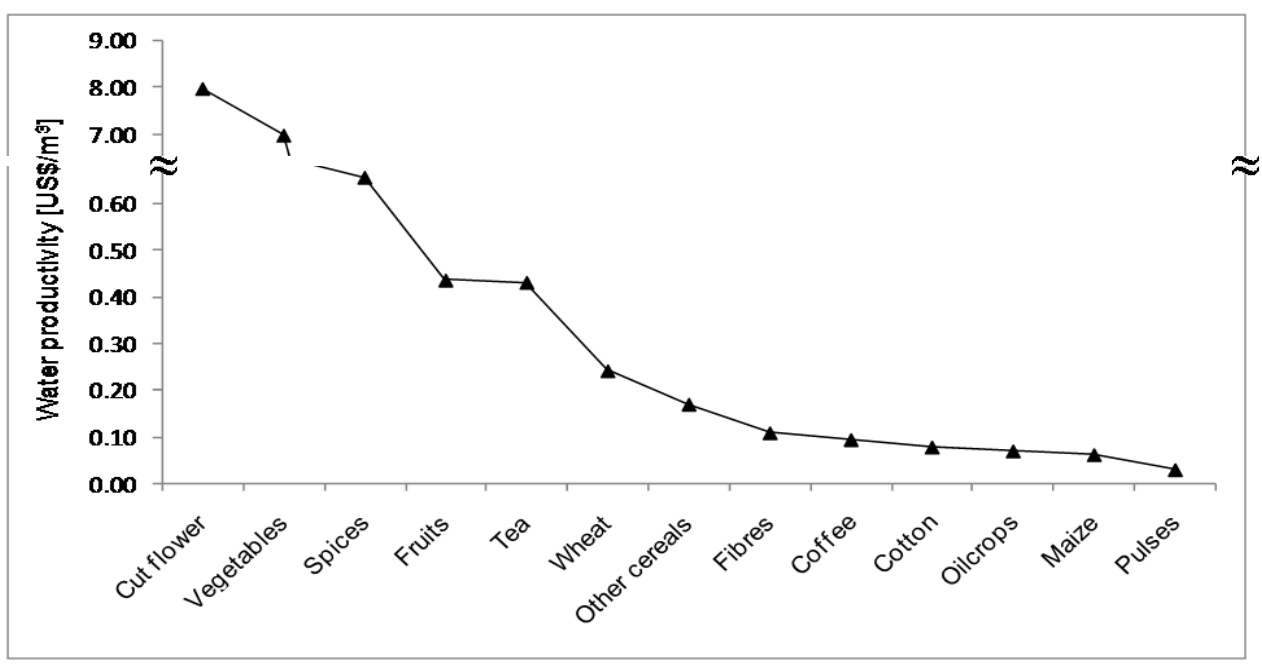

Figure 9.11. Water productivity of selected crops in Kenya [US $\left.\$ / m^{3}\right]$ for the period 19962005.

At the higher level of the ladder of water use efficiency comes virtual water trade or what Hoekstra and Hung (2005) called 'global water use efficiency'. Global virtual water trade can save water if water-intensive products are traded internationally from highly water productive areas to areas where water productivity is low (De Fraiture et al., 2004; Oki and Kanae, 2004; Hoekstra and Chapagain, 2008; Yang et al., 2006). Therefore, water scarce countries such as Kenya can save their domestic water resource through strategic virtual water trade. During the period of 1996-2005, Kenya's national water saving due to agricultural imports was estimated to be about $946 \mathrm{Mm}^{3} / \mathrm{yr}$. One may argue, that since 
Kenya is basically dependent on rainwater (green water) and the opportunity cost of green water is minimal, the water saving that would be gained through virtual water import is minimal. However, as shown in Section 3.2, Kenya's virtual water export is based mainly on high-value crops such as coffee, tea and horticultural crops which generate higher return per unit of water consumed relative to cereal crops such as maize. Its imports, on the other hand, are mainly low water productivity cereal products. Therefore, cultivating high value crops with green water as compared to cultivating cereals would generate higher benefit to Kenya.

Nyoro et al. (2001) showed that Kenya is less competitive compared to its neighbours, Uganda and Tanzania, in producing the major cereals crops, in particular maize. The local production cost of maize, sugar (and in some cases wheat) is much higher than the import parity price. According to Nyoro et al. (2001), the production cost of coffee is among the highest in the world. Under such conditions, a rational economic decision might be that Kenya should produce and export crops in which it has comparative economic advantage and import crops where its comparative advantage is minimal or negative. However, such policy decisions are never straightforward. It requires a policy shift from national food self-sufficiency to food security. Such a policy pre-supposes a strong and diversified economy which provides enough income to pay for the virtual water import in a sustainable manner. Unless there is enough foreign currency earning from the export of high productive crops, from the industry and the service sectors, virtual water import may result in the depletion of the country's foreign currency reserve. In addition the local agricultural sector needs to be in a position to be more competitive, otherwise it will be damaged due to the agricultural goods import. The other important factor which must be addressed is the creation of employment for the unemployed rural population. In a country such as Kenya where the great majority of the population rely on the agriculture sector for their livelihood, a policy shift in the direction of virtual water import may create high social stress (Allan, 1999; Turton and Ohlsson, 1999). Thus, a careful analysis of all available options for water management must be made before embracing virtual water trade as a strategy. 


\subsection{Conclusion}

Kenya is not water self-sufficient with respect to its water needs for its own food supply. In the period 1996-2005, cereal imports contributed $25 \%$ of the total supply of the main cereal products (maize, wheat and rice). On the other hand, a significant part $(23 \%)$ of the freshwater consumption and pollution in Kenya is for producing export products.

Through imports of water-intensive goods, Kenya saves $4 \mathrm{Gm}^{3} / \mathrm{yr}$ of its scarce water resources. However, such water saving, should be seen in the context of the risk of losing food self-sufficiency. It should also be seen in the context of the need to generate foreign exchange for the import of food and the risk of facing rising and fluctuating world food prices. Besides, the water saved may not be allocated to other beneficial uses (De Fraiture et al. 2004).

Over $42 \%$ of Kenya's foreign exchange earnings come from the export of coffee, tea and horticultural products. These products also contributed about $60 \%$ toward the total virtual water export. The increase in the use of scarce water resource for export products may, in the long run, conflict with water use for food self-sufficiency.

The production and export of cash crops from developing countries positively impacts on the socio-economic development of the exporting countries. The water use for coffee and tea production in Kenya's Rift Valley is mainly positive: the impacts on the water system are limited because water use mostly involves the use of rainwater, while the export revenues amount to US\$ 581 million per year, which is $29 \%$ of Kenya's export value. However, the water use for flower production near Lake Naivasha contributes to water scarcity (declining lake level) and pollution problems, but the cut flower export sector is a vital one, contributing US\$ 141 million per year in foreign currency, which is $7 \%$ of Kenya's export value. Therefore, it is necessary to design policies that optimize the trade-offs between the gains from the use of freshwater resources and the high environmental cost.

In order to address its water scarcity problem, Kenya must implement effective policy measures at different spatial levels. Such policy measures include: the improvement of water use efficiency at the user level by charging prices based on full marginal cost, stimulating water-saving technologies, and creating awareness among the water users on the detrimental impacts of excessive water abstraction. Charging prices on full marginal 
cost, besides its positive effect on raising water use efficiency, will force farmers to use water more efficiently and reallocate the limited water to crops which can generate high economic return per unit of water. Besides, improving water productivity to increase the benefit per unit of water has large potential in addressing Kenya's water problem. As shown in the previous sections, Kenya's crop yield level is among the lowest in the world. Raising yields through growing selected seeds and utilization of the available soil moisture through integrated soil and water management could be quite beneficial. At the river basin level, water use efficiency can be improved by re-allocating (both intra- and inter-sectoral) water to those purposes with the highest marginal benefits. Finally, Kenya can use virtual water import and export as a strategy to address its water problem by discouraging the use of domestic water resources for producing export commodities which are highly water intensive and have low economic return per unit of water. Production of crops with high economic return per unit of water and which are less water intensive and produced from rain water can be encouraged. A policy mix of measures could be the best alternative to address Kenya's water scarcity problem. 



\section{Mitigating the water footprint of export cut flowers from the lake Naivasha basin, Kenya ${ }^{12}$}

\section{Abstract}

Kenya's cut-flower industry has been praised as an economic success as it contributed an annual average of US\$ 141 million foreign exchange (7\% of Kenyan export value) over the period 1996-2005 and about US\$ 352 million in 2005 alone. The industry also provides employment, income and infrastructure such as schools and hospitals for a large population around Lake Naivasha. On the other hand, the commercial farms have been blamed for causing a drop in the lake level and for possibly affecting the lake's biodiversity. The objective of this study is to quantify the water footprint within the Lake Naivasha Basin related to cut flowers and assess the potential for mitigating this footprint by involving cutflower traders, retailers and consumers overseas.

The water footprint of one rose flower is estimated to be 7-13 litres. The total virtual water export related to export of cut flowers from the Lake Naivasha Basin was $16 \mathrm{Mm}^{3} / \mathrm{yr}$ during the period 1996-2005 (22\% green water; $45 \%$ blue water; $33 \%$ grey water). Our findings show that, although the commercial farms around the lake have contributed to the decline in the lake level through water abstractions, both the commercial farms and the smallholder farms in the upper catchment are responsible for the lake pollution due to nutrient load. The observed decline in the lake level and deterioration of the lake's biodiversity calls for sustainable management of the basin through pricing water at its full cost and other regulatory measures.

Despite broad international agreement on the need for full-cost water pricing, unilateral efforts to implement it in the agricultural sector are politically difficult, because farmers have difficulty to accept and local competitiveness may be put at risk. More in particular, the conditions in Kenya are unlikely to result in serious steps to full-cost pricing, since many farmers resist even modest water price increases and government is lacking means of enforcement. In addition, little can be expected from international agreements. The implementation of an international protocol on water pricing requires global agreement

\footnotetext{
${ }^{12}$ Based on Mekonnen and Hoekstra (2010c).
} 
among the major players on the global market, which makes it unlikely that such a protocol will be implemented in the near future. As an alternative to an international water-pricing protocol we propose an alternative in this study that can be implemented with a focus on sustainable water use in flower farming around Lake Naivasha alone. The proposal involves a water-sustainability agreement between major agents along the cut-flower supply chain and includes a premium to the final product at the retailer end of the supply chain. Such a 'water sustainability premium' will raise awareness among flower consumers and - when channelled back to the farmers - facilitate the flower farms to install the necessary equipment and implement the right measures to use water in a sustainable manner. The collected premiums will generate a fund that can be used for financing measures to reduce the water footprint and to improve watershed management. The sustainability premium also reduces the risk of the flower farms losing their competitiveness and avoids business migration from Kenya to other countries with less stringent water pricing and environmental regulations.

\subsection{Introduction}

Lake Naivasha is situated $80 \mathrm{~km}$ northwest of Nairobi in the Rift Valley of Kenya (00 45'S, 360 20’E). It is Kenya's second largest freshwater lake without surface outlet and the natural fluctuation in water levels over the last 100 years has been in excess of 12 meters (Mavuti and Harper, 2005). The lake remains fresh due to a significant outflow of groundwater. The lake has international value as a Ramsar wetland. In the last three decades, the area around Lake Naivasha has grown to become the main site of Kenya's horticultural industry (mainly cut flower), which is the third most important foreign exchange earner after tea and tourism. Since the late 1990s, the flower farms started to expand at a faster rate (Becht et al., 2005). The total irrigated commercial farm area around Lake Naivasha is about 4450 ha. Cut flowers account for about $43 \%$ of the irrigated area, followed by vegetables with $41 \%$ and fodder with 15\% (Musota, 2008).

The major flower varieties grown and exported from Kenya are roses, carnation, alstroemeria, lisianthus, statice and cut foliage. Rose flower dominates the export market, accounting for over $70 \%$ of the export volume (HCDA, 2007). The main flower growing 
regions are Lake Naivasha, Thika and Kiambu/Limuru (EPZA, 2005b), with Lake Naivasha accounting for about $95 \%$ of the cultivated area.

The lake has attracted attention and concerns from both national and international organisations. The main stakeholders have shown concern about the health of the lake, mainly related to the decline of the lake level, deterioration of the water quality and reduction of biodiversity. Some of the main stakeholders active around the lake are the Lake Naivasha Riparian Association (LNRA), the Lake Naivasha Growers Group (LNGG) and Kenya Wildlife Services (KWS). The concerns have led to the development of a Management Plan in 1996 by the main stakeholders (Becht et. al., 2005). Around that time, the Lake Naivasha Management Implementation Committee (LNMIC) was formed to execute the management plan. The plan was officially approved by the Government of Kenya in 1997.

There have been many studies regarding the lake water balance and the aquatic ecology of the lake. Most notably, the International Institute of Geo-Information Science and Earth Observation (ITC), based in the Netherlands, has carried out a number of studies regarding the lake water balance and nutrient load to the lake and is active in developing a geo-information system on the land use around the lake. Leicester University and Earthwatch studied the aquatic ecology of the lake since 1985. Many Kenyan scientists, the Kenya Marine and Fisheries Research Institute (KEMFRI), Kenya Wildlife Services (KWS) and Kenya Agricultural Research Institute (KARI) are also doing research on the lake (Becht et. al., 2005).

The objective of the present study is to quantify the water footprint within the Lake Naivasha Basin related to horticulture, in particular the flower farms, and assess the potential for mitigating this footprint by involving cut-flower traders, retailers and consumers overseas. In addition, we will explore the idea of a voluntary sustainable-flower agreement between major agents along the flower supply-chain that involves a watersustainability premium to be paid by the consumers in the countries importing flowers from Kenya. 


\subsection{Method}

The green, blue and grey components of the water footprint of products were calculated following the method of Hoekstra et al. (2009). The green water footprint refers to the volume of rainwater consumed; the blue water footprint refers to the volume of surface and groundwater consumed; the grey water footprint is the volume of freshwater that is required to assimilate the load of pollutants based on the existing water quality standards. The water footprint of a crop $\left(\mathrm{m}^{3} / \mathrm{ton}\right)$ is calculated as the ratio of the volume of water $\left(\mathrm{m}^{3} / \mathrm{ha}\right)$ consumed or polluted during the entire period of crop growth to the corresponding crop yield (ton/ha). Water consumption has two components: green and blue water consumption. The grey component of the water footprint of crops $\left(\mathrm{m}^{3} / \mathrm{ton}\right)$ is calculated by dividing the amount of nitrogen that leaches to the water system $(\mathrm{kg} / \mathrm{ha})$ by the maximum acceptable concentration of nitrogen $\left(\mathrm{kg} / \mathrm{m}^{3}\right)$ and the crop yield (ton/ha).

The crop water requirements, effective rainfall and irrigation requirement for the different vegetables and cut flower grown around Lake Naivasha were estimated using CROPWAT (FAO, 2010f). The calculation was done using climatic data obtained from CLIMWAT (FAO, 2010g) for Naivasha climate station $\left(0.43{ }^{0} \mathrm{~S}\right.$ and $\left.36.26{ }^{0} \mathrm{E}\right)$. The cut flowers are perennial crops and vegetables are grown all over the year with multi-cropping. Therefore, the blue water footprint for vegetables such as cabbages, onions and tomato was calculated by running CROPWAT for each planting cycle.

For the other 22 crops grown in the upper catchment of the Lake Naivasha Basin, a crop water use model (Mekonnen and Hoekstra, 2010a) was used to carry out a daily soil water balance and calculate the green, blue and grey water footprint at grid level. The model was run for the whole of Kenya and later the Lake Naivasha Basin area raster was used to extract data applicable only for the basin.

Virtual water exports $\left(\mathrm{m}^{3} / \mathrm{yr}\right)$ related to exports of cut flowers and vegetables were calculated by multiplying the trade volumes (tons/yr) by their respective water footprint in Kenya ( $\mathrm{m}^{3} /$ ton). 


\subsection{Data}

The Lake Naivasha Basin is schematised here into two parts: the upper catchment with smallholder farms and the area around Lake Naivasha with big farms producing for export. Grid data on type and size of farms around Lake Naivasha was obtained from the ITC Naivasha database (Becht, 2007). For crops grown in the upper catchment, the crop growing areas with 5 arc minute grid cell resolution (which is equivalent to $9.3 \times 9.3 \mathrm{~km}^{2}$ around Naivasha) were obtained from Monfreda et al. (2008). The grid crop area data was aggregated to a national level and compared with and scaled to fit national average crop harvest area for the period 1996-2005 obtained from FAOSTAT (FAO, 2010a).

The cut-flower production for the period 1996-2005 around Lake Naivasha was calculated from the export data assuming that $95 \%$ of the cut-flower production is exported.

The crop parameters (crop coefficients and start and length of cropping seasons) for the different vegetables were taken from Chapagain and Hoekstra (2004). For cut flowers, the crop parameters were adopted from Orr and Chapagain (2006). The evapotranspiration in greenhouse conditions is assumed to be $65 \%$ of the outdoor condition as suggested by various authors (Mpusia, 2006; Baille et al., 1994; Orgaz et al., 2005). The average water footprint of cut flowers was estimated based on the weighted average of indoor and outdoor farm areas. About $62 \%$ of the cut flowers around Lake Naivasha are grown in greenhouses (Musota, 2008). Table 10.1 gives the irrigated area and fertilizer application rate for irrigated crops around Lake Naivasha. A leaching-runoff fraction of $10 \%$ was assumed, following Hoekstra and Chapagain (2008).

Grid-based soil moisture data of total available water capacity (TAWC) at 5 arc minute resolution was taken from ISRIC-WISE (Batjes, 2006). An average value of TAWC of the five soil layers was used in the model. The main data source for nitrogen fertilizer application rate per crop for the upper catchment was FAO (2010c).

Data on irrigated area per crop was obtained mainly from the AQUASTAT country profile database (FAO, 2005c) and Portmann et al. (2008). For rice, data on irrigated area was obtained from EPZA (2005a). The country level irrigated area data is distributed to grid cells according to area equipped for irrigation (AEI). The Global Map of Irrigation Areas version 4.0.1 (Siebert et al., 2007) with spatial resolution of 5 arc minute was used to define the area equipped for irrigation for each grid cell. The distribution was done 
proportional to the harvested area of each cropped grid cell. For cases where there is no AEI data or the AEI does not match with the irrigated area data, the irrigation area data is distributed proportional to the harvest area of each cropped grid cell.

Table 10.1. Irrigated crops around Lake Naivasha. Year 2006.

\begin{tabular}{|c|c|c|c|c|c|}
\hline \multirow[b]{2}{*}{ Crop } & \multicolumn{2}{|c|}{ Irrigated area* } & \multicolumn{3}{|c|}{ Fertilizer application rate $(\mathrm{kg} / \mathrm{ha})^{* *}$} \\
\hline & $\begin{array}{r}\text { Area } \\
\text { (ha) }\end{array}$ & $\%$ & $\mathrm{~N}$ & $\mathrm{P}_{2} \mathrm{O}_{5}$ & $\mathrm{~K}_{2} \mathrm{O}$ \\
\hline Total flowers & 1911 & 42.8 & 325 & 145 & 303 \\
\hline Roses & 1028 & 23.0 & 325 & 145 & 303 \\
\hline Roses \& carnations & 730 & 16.3 & 325 & 145 & 303 \\
\hline Roses, hypercium & 21 & 0.5 & 325 & 145 & 303 \\
\hline Other flowers & 132 & 3.0 & 325 & 145 & 303 \\
\hline Total vegetables & 1824 & 40.8 & 185 & 179 & 55 \\
\hline Babycorn & 205 & 4.6 & 41 & 113 & 0 \\
\hline Babycorn \& beans & 143 & 3.2 & 252 & 141 & 81 \\
\hline Babycorn, beans \& cabbage & 169 & 3.8 & 235 & 141 & 81 \\
\hline Babycorn, beans \& onions & 906 & 20.3 & 244 & 244 & 81 \\
\hline Beans/tomatoes & 21 & 0.5 & 235 & 141 & 81 \\
\hline Cabbage & 374 & 8.4 & 68 & 94 & 0 \\
\hline Cabbage $\&$ beans & 6 & 0.1 & 235 & 141 & 81 \\
\hline Total fodder & 665 & 14.9 & 68 & 94 & 0 \\
\hline Grass & 286 & 6.4 & 68 & 94 & 0 \\
\hline Grass \& lucerne & 40 & 0.9 & 68 & 94 & 0 \\
\hline Lucerne & 163 & 3.7 & 68 & 94 & 0 \\
\hline Lucerne, babycorn, beans & 176 & 3.9 & 68 & 94 & 0 \\
\hline Macadamia & 50 & 1.1 & 68 & 94 & 0 \\
\hline Eucalyptus & 17 & 0.4 & & & \\
\hline Total & 4467 & 100.0 & & & \\
\hline
\end{tabular}

* Musota (2008), ITC Naivasha database (Becht, 2007).

${ }^{* *}$ Tiruneh (2004), Xu (1999), Ariga et al. (2006).

Average monthly reference evapotranspiration data at 10 arc minute resolution were obtained from FAO (2010d). The 10 minute data was converted to 5 arc minute resolution 
by assigning the 10 minute data to each of the four 5 minute grid cells. Following the CROPWAT approach, the monthly average data was converted to daily values by curve fitting to the monthly average through polynomial interpolation.

Monthly values for precipitation, wet days, minimum and maximum temperature with a spatial resolution of 30 arc minute were obtained from CRU through CGIAR-CSI GeoPortal (Mitchell and Jones, 2005). The 30 arc minute data were assigned to each of the thirty-six 5 arc minute grid cells contained in the 30 arc minute grid cell. Daily precipitation values were generated from these monthly average values using the CRU-dGen daily weather generator model (Schuol and Abbaspour, 2007).

Data on trade in cut flowers and vegetable products in the period 1996-2005 have been taken from the SITA (Statistics for International Trade Analysis) database available from the International Trade Centre (ITC, 2007).

\subsection{Water use within the Lake Naivasha Basin related to cut-flower production}

\subsubsection{The water footprint within the Lake Naivasha Basin related to crop production}

The water footprint related to crop production in the Lake Naivasha Basin is presented in Table 10.2. Two groups of crops are shown: fully irrigated crops grown by commercial farms mainly for export and concentrated around Lake Naivasha, and other crops which are cultivated by small farmers in the upper catchment. The total water footprint related to crop production sums up to $102 \mathrm{Mm}^{3} / \mathrm{yr}$. About $68.7 \%$ of the water footprint is related to green water, $18.5 \%$ blue water and $12.8 \%$ grey water. The commercial crops contribute $41 \%$ to the total water footprint related to crop production. About $98 \%\left(18.4 \mathrm{Mm}^{3} / \mathrm{yr}\right)$ of the blue water footprint and about $61 \%$ of the grey water footprint in the catchment area can be attributed to the commercial farms around the lake.

In addition to the irrigated farms which are found around Lake Naivasha, the basin is used mainly for cattle and game rangeland. Smallholder farmers growing mainly maize, vegetables and other crops occupy areas which receive high rainfall. There are about 18,000 ha of farm land in the upper catchment of which only $2 \%$ is irrigated. The average 


\section{2 / Chapter 10. Mitigating the water footprint of export cut flowers}

water footprint related to the production of these crops over the period 1996-2005 was about $60 \mathrm{Mm}^{3} / \mathrm{yr}$ (90.7\% green water, $0.8 \%$ blue water; $8.5 \%$ grey water).

Table 10.2. Water footprint of crops grown in the Lake Naivasha Basin (large irrigated farms). 1996-2005.

\begin{tabular}{|c|c|c|c|c|c|c|}
\hline \multirow[b]{2}{*}{ Land use } & \multicolumn{2}{|c|}{ Area cultivated* } & \multicolumn{4}{|c|}{ Water footprint $\left(1000 \mathrm{~m}^{3} / \mathrm{yr}\right)$} \\
\hline & $\begin{array}{l}\text { Area } \\
\text { (ha) }\end{array}$ & $\begin{array}{l}\text { Irrigated } \\
\quad(\%)\end{array}$ & Green & Blue & Grey & Total \\
\hline \multicolumn{7}{|c|}{ Commercial farms around the lake } \\
\hline Total flower & 1712 & 100 & 3640 & 7576 & 5627 & 16842 \\
\hline Flowers open & 652 & 100 & 3640 & 1770 & 2122 & 7532 \\
\hline Flowers greenhouse & 1076 & 100 & 0 & 5805 & 3504 & 9310 \\
\hline Vegetables & 1885 & 100 & 7887 & 7375 & 1834 & 17097 \\
\hline Fodder & 665 & 100 & 3716 & 3194 & 452 & 7362 \\
\hline Macadamia & 50 & 100 & 278 & 303 & 34 & 615 \\
\hline Total of commercial farms & 4327 & 100 & 15521 & 18448 & 7947 & 41916 \\
\hline \multicolumn{7}{|c|}{ Farms in the upper catchment of the basin } \\
\hline Cereals & 12125 & $1 \%$ & 34776 & 82 & 1655 & 36513 \\
\hline Pulses & 2199 & $0 \%$ & 3958 & 0 & 2673 & 6631 \\
\hline Others & 3813 & $7 \%$ & 15876 & 382 & 809 & 17067 \\
\hline $\begin{array}{l}\text { Total of upper catchment } \\
\text { farms }\end{array}$ & 18137 & $2 \%$ & 54609 & 465 & 5137 & 60211 \\
\hline Grand total & 22465 & $21 \%$ & 70130 & 18913 & 13084 & 102127 \\
\hline
\end{tabular}

Cut flowers take a large share of the water footprint related to crop production around Lake Naivasha, contributing about $98 \%$ and $41 \%$ to the blue and total water footprint respectively. The production water footprint related to cut flowers is about $16.8 \mathrm{Mm}^{3} / \mathrm{yr}$ (Table 10.2). Flowers grown in greenhouses are assumed to be fully supplied with irrigation water, while flowers cultivated in the open field get both rainwater and irrigation water. For flowers grown in the open field the blue water component is only $24 \%$ of the total water footprint, while for flowers grown in greenhouses the evaporative water consumption is met fully from irrigation water (Figure 10.1). The average water footprint 
of cut flowers grown around Lake Naivasha is $367 \mathrm{~m}^{3} /$ ton. About $45 \%\left(165 \mathrm{~m}^{3} /\right.$ ton $)$ of this water footprint refers to blue water, $22 \%\left(79 \mathrm{~m}^{3} /\right.$ ton $)$ to green water and $33 \%\left(123 \mathrm{~m}^{3} /\right.$ ton $)$ to grey water, the volume of water needed to assimilate the nitrogen fertilisers that enter the water systems due to leaching or runoff.

The six big farms - Logonot Horticulture, Delamere, Oserian, Gordon-Miller, Marula Estate and Sher Agencies - account for about $56 \%$ of the total operational water footprint around Lake Naivasha and $60 \%$ of the blue water footprint related to crop production.

\subsubsection{The water footprint per cut flower}

Depending on the yield and weight of a rose flower stem, the water footprint per stem varies from 7 to 13 litre/stem (Table 10.3). If we assume an average rose flower stem weights about 25 gram, its green water footprint would be 2 litre/stem, its blue water footprint 4 litre/stem and its grey water footprint 3 litre/stem, resulting in a total water footprint of 9 litre per stem.

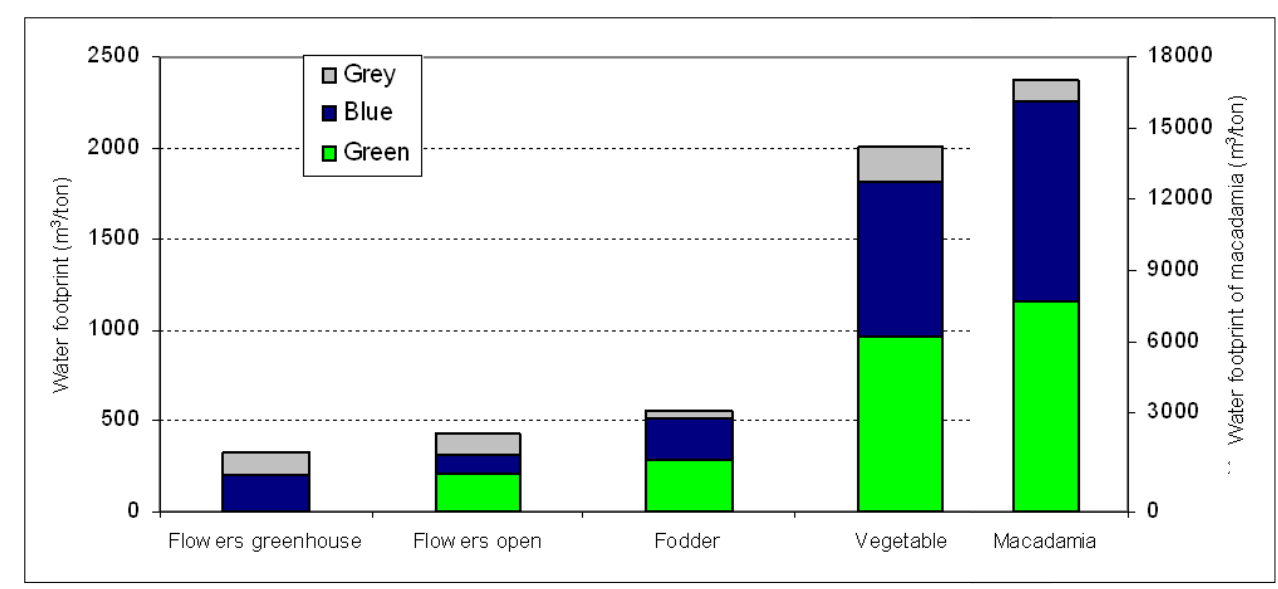

Figure 10.1. Water footprint per ton of crop for crops grown around the lake. Period 19962005 
254 / Chapter 10. Mitigating the water footprint of export cut flowers

Table 10.3. The water footprint of a rose flower. Period 1996-2005.

\begin{tabular}{|c|c|c|c|c|c|}
\hline \multirow{2}{*}{$\begin{array}{l}\text { Weight of rose } \\
\text { (gram/stem) }\end{array}$} & \multirow{2}{*}{$\begin{array}{l}\text { Cut flower } \\
\text { production } \\
\left(\text { stem } / \mathrm{m}^{2}\right)\end{array}$} & \multicolumn{4}{|c|}{ Water footprint by type (litre/stem) } \\
\hline & & Green & Blue & Grey & Total \\
\hline 20 & 134 & 1.6 & 3.3 & 2.5 & 7.3 \\
\hline 25 & 107 & 2.0 & 4.1 & 3.1 & 9.2 \\
\hline 35 & 77 & 2.8 & 5.8 & 4.3 & 12.8 \\
\hline
\end{tabular}

\subsubsection{Virtual water export from the Lake Naivasha Basin}

When we assume that about 95\% of Kenya's cut-flowers export comes from the area around Lake Naivasha, the average virtual water export from the Lake Naivasha Basin related to export of cut flowers was $16 \mathrm{Mm}^{3} / \mathrm{yr}$ in the period 1996-2005 (22\% green water, $45 \%$ blue water and 33\% grey water) (Table 10.4). The European Union is Kenya's principal market for cut flowers; with the Netherlands, the UK, and Germany together taking over 90 percent of the virtual water export due to export of cut flowers. The Netherlands is the principal market, accounting for $69 \%$ of the total export, followed by the UK with $18 \%$ and Germany with $7 \%$. The virtual water export in relation to export of cut flowers has shown a significant growth, with virtual water export almost doubling from 11 $\mathrm{Mm}^{3} / \mathrm{yr}$ in 1996 to $21 \mathrm{Mm}^{3} / \mathrm{yr}$ in 2005 .

In addition to cut flowers, vegetables such as beans, sweet corn, tomato, cabbage and onions are produced for both export and domestic consumption. About $50 \%$ of the vegetable produced around Lake Naivasha is exported and the remaining is supplied to local markets, mainly to Nairobi. The virtual water export related to vegetable products was $8.5 \mathrm{Mm}^{3} / \mathrm{yr}$. Most of the virtual water related to vegetable products was exported to the United Arab Emirates, France and the United Kingdom. Therefore, for the period 19962005 , the total virtual water export related to export of cut flowers and vegetable products was $24.5 \mathrm{Mm}^{3} / \mathrm{yr}$.

The cut-flower industry is an important export sector, which contributed an annual average of US\$ 141 million foreign exchange (7\% of Kenyan export value) over the period 1996-2005, and US\$ 352 in 2005 alone. Hence, Kenya is generating foreign exchange of $(141 / 16=) 8.8 \mathrm{US} \$ / \mathrm{m}^{3}$. 
Table 10.4. Major destinations of virtual water export related to export of cut flowers from the Lake Naivasha Basin. Period 1996-2005.

\begin{tabular}{lrrrr}
\hline \multirow{2}{*}{ Country } & \multicolumn{4}{c}{ Virtual water export (1000 $\left.\mathrm{m}^{3} / \mathrm{yr}\right)$} \\
\cline { 2 - 5 } & Green & Blue & Grey & Total \\
\hline Netherlands & 2399 & 4993 & 3708 & 11100 \\
United Kingdom & 611 & 1272 & 944 & 2827 \\
Germany & 230 & 478 & 355 & 1064 \\
Switzerland & 59 & 122 & 91 & 272 \\
South Africa & 37 & 77 & 57 & 171 \\
France & 33 & 68 & 51 & 152 \\
United Arab Emirates & 16 & 33 & 25 & 74 \\
Italy & 10 & 20 & 15 & 45 \\
Others & 64 & 133 & 98 & 295 \\
\hline Total & 3458 & 7196 & 5345 & 16000 \\
\hline
\end{tabular}

\subsection{Sustainability of water use in the Lake Naivasha Basin}

The horticulture sector in Naivasha employs some 25,000 people directly and the same number of people is indirectly dependent, both as dependents and service providers (Becht et al., 2005). Most of the farms pay more than the legal minimum wage. The farms also provide housing, free medical services, schools for children of farm workers and social and sport facilities. Some of the larger farms also participate in the community development such as provision of clinic and ambulance services, water management and tree planting and watering of the community trees. A continued supply of freshwater to sustain the economy is a concern, however.

Lake Naivasha has been used for irrigation since the 1940s. Water is extracted directly from the lake, but also from groundwater and the rivers feeding the lake. Beside the irrigation water used for crop production, water from the basin is used for drinking water supply and since 1992 a pipeline became operational pumping $20,000 \mathrm{~m}^{3}$ per day from Malewa sub-basin to Gilgil and Nakuru Town (Becht and Nyaoro, 2006; Musota, 2008). The total water use for domestic purposes in the basin is estimated as $1.2 \mathrm{Mm}^{3} / \mathrm{yr}$. .Altogether, the blue water footprint within the Lake Naivasha Basin is estimated to be 27 $\mathrm{Mm}^{3} / \mathrm{yr}$ (Table 10.5). 
The rainfall regime within the Lake Naivasha Basin is influenced by the rain shadow from the surrounding highlands of the Aberdare range to the east and the Mau Escarpment to the west. The long-term rainfall varies from about $600 \mathrm{~mm}$ at Naivasha town to some $1700 \mathrm{~mm}$ on the slopes of the Nyandarua Mountains (Becht et al., 2005). Total basin rainfall and evapotranspiration are estimated at $2790 \mathrm{Mm}^{3} / \mathrm{yr}$ and $2573 \mathrm{Mm}^{3} / \mathrm{yr}$ respectively (Becht, 2007). The annual runoff generated in the Lake Naivasha Basin is estimated at $217 \mathrm{Mm}^{3} / \mathrm{yr}$ (Becht and Harper, 2002). The long-term average annual water balance of the basin is presented in Table 10.6.

Table 10.5. The blue water footprint in the Lake Naivasha Basin.

\begin{tabular}{|c|c|c|c|}
\hline Blue & $\begin{array}{l}\text { water footprint } \\
\left(\mathrm{Mm}^{3} / \mathrm{yr}\right)\end{array}$ & \multicolumn{2}{|c|}{$\begin{array}{l}\text { Contribution to the total } \\
\text { blue water footprint (\%) }\end{array}$} \\
\hline Cut flower & 7.58 & \multicolumn{2}{|c|}{$28 \%$} \\
\hline Vegetable and macadamia & 7.68 & \multicolumn{2}{|c|}{$28 \%$} \\
\hline Grass and fodder & 3.19 & \multicolumn{2}{|c|}{$12 \%$} \\
\hline Upper catchment crops & 0.47 & \multicolumn{2}{|c|}{$2 \%$} \\
\hline Nakuru and Gilgil town ${ }^{*}$ & 7.30 & \multicolumn{2}{|c|}{$27 \%$} \\
\hline $\begin{array}{l}\text { Lake Naivasha Basin potable } \\
\text { water }^{* *}\end{array}$ & 1.19 & \multicolumn{2}{|c|}{4} \\
\hline Total & 27.4 & \multicolumn{2}{|c|}{100} \\
\hline \multicolumn{4}{|c|}{$\begin{array}{l}\text { Source: Becht and Nyaoro (2006); Musota (2008). } \\
\text { the potable water use in the Lake Naivasha Basin is estimated based on a population of } \\
650,000 \text {, a per capita daily consumption of } 50 \text { litre and assuming a } 90 \% \text { return flow and } \\
10 \% \text { of the abstraction actually consumed. }\end{array}$} \\
\hline & \multicolumn{2}{|c|}{$\begin{array}{r}\text { Basin water } \\
\text { balance }\left(\mathrm{Mm}^{3} / \mathrm{yr}\right)\end{array}$} & Fraction (\%) \\
\hline Rainfall & & & 100 \\
\hline Evapotranspiration of rainwater from land & & & 92.2 \\
\hline Evapotranspiration from the lake & & & 9.2 \\
\hline Groundwater outflow & & & 2.0 \\
\hline Blue water footprint & & & 1.0 \\
\hline Closing error & & & -4.4 \\
\hline
\end{tabular}

Source: Becht (2007); blue water footprint own calculation. 
Sustainability of the water footprint related to the production of horticultural and other crops, domestic and industrial water uses in Lake Naivasha Basin can be assessed by comparing the blue water footprint with the available blue water resources. The available blue water for human use is the difference between the annual runoff (R) and the environmental flow requirements (EFR), which is set at $80 \%$ of runoff (Hoekstra et al., 2009). For the Lake Naivasha Basin the total blue water footprint is about $13 \%$ of the annual average runoff, which leaves $87 \%$ of the runoff for meeting environmental flow requirement. When we take the blue and grey water footprint together, they make $19 \%$ of the annual average runoff.

Comparing the blue-grey water footprint with the blue water available for human use at annual basis hides the seasonal variation, which is relevant particularly in basins with highly variable flow regimes. Therefore, it is quite important to do the comparison on a monthly basis. The long-term average monthly runoff and environmental flow requirement and the monthly blue-grey water footprint within the Lake Naivasha Basin are presented in Figure 10.2. The long-term average monthly runoff data for the basin for the period February 1932 to June 1981 was obtained from the ITC Naivasha database (Becht, 2007). The monthly blue-grey water footprints were derived from the current study, taking into account the growth seasons of the various crops. In the dry period Jan-March, the blue plus grey water footprint is double the usable runoff, which means that twice the usable runoff is appropriated for either consumptive water use of assimilation of pollution. In November and December, the blue plus grey water footprint slightly exceeds the environmental flow requirement. There is no violation of the environmental flow requirements in the period April - October.

A fluctuating lake level is a natural phenomenon for Lake Naivasha and a necessity for the functioning of the ecosystem. The climate, physical attributes and geographic context set the background for a hydrological cycle that results in natural lake level variability reaching above 12 meters over the last 100 years (Becht et al., 2005). However, Becht and Harper (2002) and again Becht et al. (2005) show that the more recent decline in the lake level coincides with and can be explained by the commencement of horticulture crops in the area in 1982 (Figure 10.3). Becht and Harper (2002) show that in late 1998, the lake was 3.5 meters lower than it would have been had it followed the hydrological records. On the other hand, according to Harper and Mavuti (2004), the current level of water 
abstraction has not led to a greater lake level fluctuation than as was recorded in the past, and there is no evidence that lake level fluctuations themselves risk biodiversity losses. Becht (2007) suggested that at a constant rate of water abstraction the lake will establish a new equilibrium lake level. He goes further by arguing that the question as to how much a drop in the lake level is acceptable is a societal and political one.

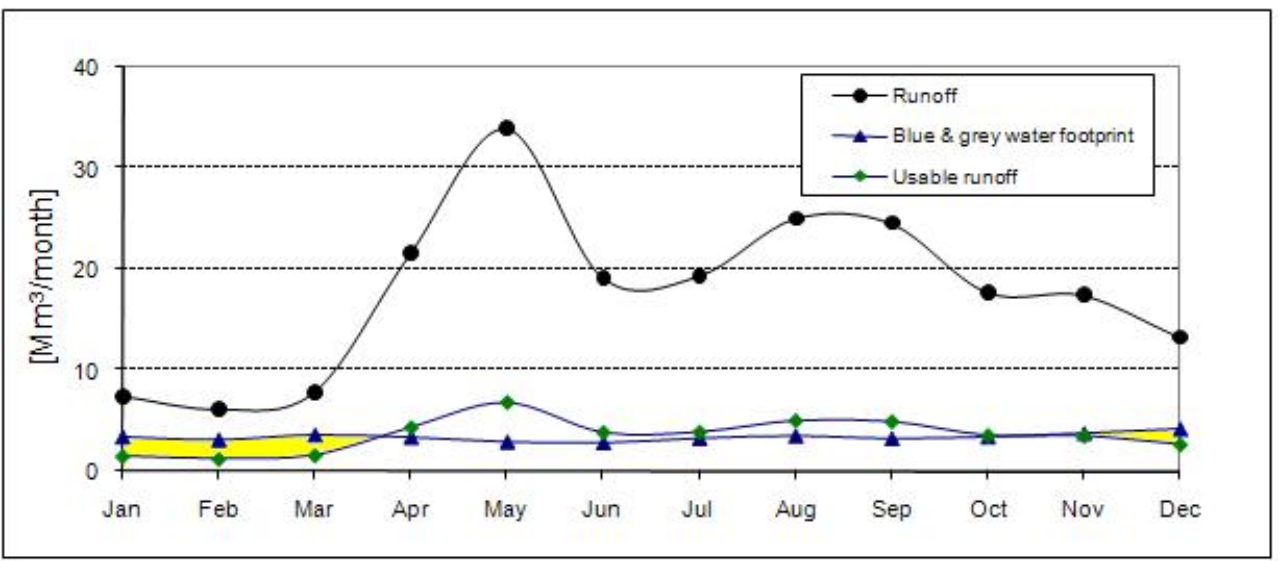

Figure 10.2. Long term average monthly runoff, blue-grey water footprint and environmental flow of the Lake Naivasha Basin. Sources: runoff from the ITC Naivasha database (Becht, 2007); water footprint from own calculation.

Although the recent reduction in the lake's water level can be attributed mainly to the commercial farms around the lake, the deterioration of the lake water quality as a result of the inflow of nutrients is due to both the commercial farms and the farm activities in the upper catchment. This finding is supported by Kitaka et al. (2002) and Gitachi (2005), who also showed that a large amount of nutrient load to the lake originates from the upper catchments and municipal sewage through surface runoff. The nutrient transport from the upper catchments is mainly through surface runoff, while for the riparian agriculture nutrient transport is mainly through leaching to the groundwater.

There is a big and well-founded concern as to whether the lake can sustain a continued increase in irrigation water demand. The long-term protection of the lake ecosystem and the economic and social benefits that depend on the lake require a sustainable use of Lake Naivasha and its catchment. The most pressing issue is the unsustainable water abstraction for horticulture crops and domestic water use which has led 
to a decline in the lake level (Becht and Harper, 2002). There is further the concern about eutrophication of the lake due to an increase in agricultural nutrients inflow both from the commercial farms and from the upper catchment. The increase in nutrients is probably the combined effect of the loss of riparian vegetation, which acts as a buffer to trap sediments, an increase in the sediment flow from the catchment and an increase in fertilisers leaching and running off to the water system. The situation got worse by the increase in subsistence farming even on steep slopes right down to the river edge which destroyed the riparian zone (Everard and Harper 2002).

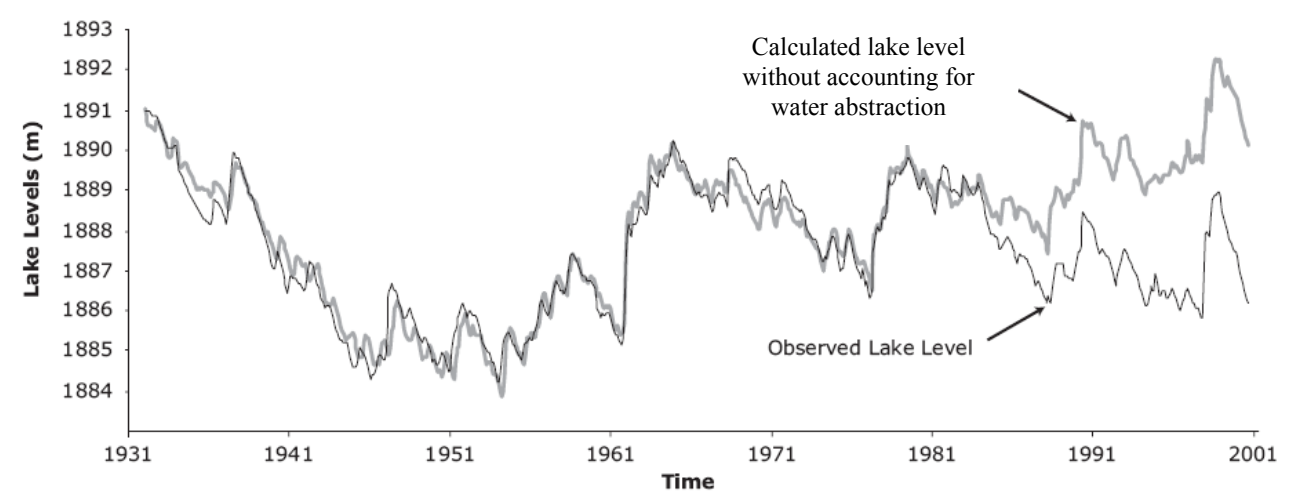

Figure 10.3. Long-term water level change in Lake Naivasha. The calculated lake level represents the case without water abstraction (reproduced from Becht et al, 2005).

Long-term gains from a sustainable and wise use of water require a coordinated action at the catchment scale. There is a need to define the maximum allowable water abstraction level at the basin scale. Although equitable allocation of water is required, decisions should also take into account the difference in economic water productivity among different crops. Cut flowers generate more economic return than the low-value fodder crops and grasses. Indoor flowers are more efficient compared to outdoor flowers; therefore greenhouse cultivation coupled with rainwater harvesting should be encouraged. The use of blue water for the production of water-intensive products such as beans and low-value products such as grass and fodder should be discouraged. Wise use of rainwater, in particular in the upper catchment, for growing fodder and grass needs to be encouraged. Controlling of unlicensed and illegal water abstraction through legal means and community involvement is quite essential. 


\section{0 / Chapter 10. Mitigating the water footprint of export cut flowers}

There is a need to reduce the flow of sediments and agricultural nutrients to the lake both from the commercial farms around the lake and subsistence farmers in the upper catchment. The sedimentation problem is aggravated due to the loss of riparian vegetation that could have acted as a buffer in trapping sediments and increasing infiltration. An urgent and coordinated action is needed to stop the destruction of vegetation along the river banks and lake caused by cultivation and overgrazing. Therefore, prohibition of cultivation in the riparian areas is important.

\subsection{Reducing the water footprint in the Lake Naivasha Basin: involving consumers, retailers and traders along the supply chain}

\subsubsection{Current water regulations in the Lake Naivasha Basin}

Kenya's water sector reform has gone a long way before the adoption of the Water Act in 2002. The first water sector reform in Kenya was in 1974, when the first National Water Master Plan was launched (Kisima, 2007). The publication of the 'Sessional Paper No. 1 of 1999 on National Policy on Water Resources Management and Development' led to a new momentum (Owuor and Foeken, 2009). The Water Act 2002 has introduced comprehensive and, in many instances, radical changes to the legal framework for the management of the water sector in Kenya (Mumma, 2005). The National Water Resources Management Strategy document specifies ten 'specific objectives'. Among these are (Owuor and Foeken, 2009): (a) manage the water demand in a sustainable way, and (b) water pricing that recognizes water as an economic good.

Kenyan government considers water as both a social and economic good, to be available for all Kenyans and at a price reflecting its market value. This principle is reflected in the different water sector strategies and water resource management rules. Among the strategies pursued are demand management, the re-allocation of water to where it has high return and efficient allocation of water through appropriate pricing.

As water is becoming an increasingly scarce resource, full-cost pricing of water is recognized as an effective tool for its management. The need to have full-cost pricing of water has received worldwide acknowledgement since the International Conference on Water and the Environment held in Dublin, 1992. Agenda 21 of the United Nations (UN, 
1992) further supported the internalization of environmental costs and the use of economic instruments for rational use of water resources. The World Water Commission (2000) stated that 'the single most immediate and important measure that we can recommend is the systematic adoption of full-cost pricing for water services'. Hoekstra (2006) and Rogers et al. (2002) argue that sustainable and efficient use of water requires full-cost pricing of water use, including all cost components: the operation and maintenance costs, capital costs, opportunity costs, scarcity rent and externality costs of water use.

However, there are few successful examples of implemented full-cost pricing of water (Cornish et al. 2004; Rosegrant and Cline, 2002; Dinar and Subramanian, 1998). In most OECD countries, let alone in developing countries, the implementation of water pricing policies has been slow and uneven (Molle and Berkoff, 2007; Perry, 2003; Rosergrant and Cline, 2002). The World Bank (2004) acknowledged the complexity of water pricing reform (both in theory and practice) for irrigation. It further advocates a 'pragmatic but principled' approach that respects principles of efficiency, equity and sustainability while recognizing that water resources management is intensely political and that reform requires the articulation of prioritized, sequenced, practical and patient interventions.

Lack of funding is one of the main challenges in the Lake Naivasha Basin for implementing community-based basin rehabilitation and lake conservation (Becht et al. 2005). Under such condition, raising enough funds would be an additional objective of water pricing, besides creation of an incentive for efficient and sustainable use of water. However, the implementation of full marginal-cost pricing under the existing conditions in Kenya and around Naivasha is highly unlikely. The flower farms feel that they are already overtaxed and burdened with a number of remittances and some even have threatened to relocate to Ethiopia if local authorities force them to pay more tax (Riungu, 2007). Attracted by a number of incentives including 10 year tax-holidays, better security, dutyfree import of capital goods and low land price, five major flower companies have already made the switch to Ethiopia with more to follow (ARB, 2007).

According to the 2007 Water Resource Management Rules, domestic water users have to pay 0.50 Kenyan Shilling per $\mathrm{m}^{3}$ and non-domestic water users have to pay 0.50 to 0.75 Kenyan Shilling per $\mathrm{m}^{3}$. Major water users need a license to abstract water and need to install water meters. Implementation of the regulation is actually hampered, however, by 
reluctance of many water users to follow the regulation and difficulties government encounters in enforcing the regulation. The current water pricing policy has several weaknesses. One is that illegal water abstractions from both ground- and surface water are very common. In practice it is difficult for the government to check whether farmers, particularly in the upper catchment, have actually installed water meters as legally required, due to a lack of cars and fuel for the staff responsible for control. Despite the fact that farmers have indicated that the newly introduced water tariff is too high, the tariff actually does by far not cover full economic cost of the water. As a result, the funds generated by the current water pricing scheme are very small. The level of water price increase that would be required to have a significant impact on demand would be politically very difficult to enforce.

Under such conditions, the implementation of full-cost water pricing at the source is not feasible. A unilateral implementation of a stringent water pricing strategy by a country could affect the competitiveness of its local companies in the global market (Hoekstra, 2006; Cornish et al. 2004). To address this problem, Hoekstra (2006) have proposed that national governments negotiate on an international protocol on water pricing. Such scheme would reduce the disadvantage of unilateral implementation of a full-cost pricing strategy. However, the implementation of an international protocol on water pricing requires global agreement among the major players on the global market, which makes it unlikely that such a protocol will be implemented in the near future. As an alternative to the international protocol involving national governments we propose an alternative here that can be implemented with a focus on sustainable water use in flower farming around Lake Naivasha alone. The proposal involves a water-sustainability agreement between major agents along the cut-flower supply chain and includes a premium to the final product at the retailer end of the supply chain.

\subsubsection{A sustainable-flower agreement between major agents along the cut-flower supply-chain}

Given the recent emergence of more environmentally conscious consumers, combined with an increased interest at the side of traders and retailers in providing environmentally sustainable consumer products, involving consumers and other stakeholders forms an 
opportunity to achieve sustainable water use in cut-flower production. Consumers are becoming more and more concerned with how their consumption behaviour is affecting the world around them. This is reflected in the growing consumption of fair-trade products and organic produce. Annual growth rates of 20 percent or more in market volume have been observed for many years for both organic and fair-trade products (Poisot et al. 2007; Krier, 2005). Several studies show that consumers are willing to pay more for products that are environmentally and socially responsible (Aizaki and Sato, 2007; Arnot et al. 2006; Didier and Lucie, 2008; Pelsmacker et al. 2005).

In this section we describe the possible characteristics of a 'sustainable-flower agreement' between major agents along the flower supply-chain focused on sustainable water use. The agreement should include two key ingredients: a fund-raising mechanism at the consumer-end of the supply chain, which will raise the funds for making water use in flower production sustainable, and a labelling or certification scheme, which will provide the guarantee that the funds are properly spent and that the flower production actually moves in the direction of sustainable water use.

Funds. The premium collected when selling cut flowers from the Lake Naivasha Basin to consumers in the Netherlands, the UK etc. should be used to invest in better watershed management and, most in particular, in reducing the water footprint of the flower farmers. Clear criteria need to be formulated for how collected funds can or should be spent. The criteria could be formulated such that also small farmers belong to the beneficiaries of the funds, because particularly smallholder farmers have generally more difficulty than the large farmers to comply with environmental standards or raise funds to be able to comply.

There is a need to provide institutional infrastructure through which the funds could flow back to the basin and be used in environmental protection, watershed management, support of farmers to improve their water management and community development. Fairtrade organisations can be instrumental in making sure that funds raised at the consumer end flow back to the watershed for the support of local programmes for improved watershed management and support to farmers to reduce their water footprint. Figure 10.4 is a visual representation of the cut-flower supply chain and contrasts the current approach of local water pricing with the approach of collecting a water-sustainability premium at the end of the chain. 


\section{4 / Chapter 10. Mitigating the water footprint of export cut flowers}

The funds that can be raised through adding a water-sustainability premium at the end of the supply chain (at the consumer end) are much larger than the funds potentially raised from the current local water-pricing policy (Table 10.7). Currently, the water abstraction fee in Kenya for commercial farmers is 0.50 Kenyan Shillings per cubic meter of water abstracted $\left(0.007 € / \mathrm{m}^{3}\right)$. The total water abstraction by the commercial farms around the lake is estimated at $40 \mathrm{Mm}^{3} / \mathrm{yr}$ and out this the flower farms receive about $50 \%$ (Becht, 2007). With a water abstraction fee of $0.007 € / \mathrm{m}^{3}$, this would raise 0.13 million $€ / \mathrm{yr}$. Given an annual cut-flower export of 1.7 billion stems, they will thus pay, on average, $0.000076 €$ per stem of cut flower for abstracting irrigation water. This is a very optimistic estimate, because as explained before, the conditions are not such that government is actually able to enforce farmers to pay. On the other hand, if we assume a water sustainability premium of $0.01 €$ per stem of cut flower at the retailer, to be paid by the consumer, one would raise 16.9 million $€ / y r$ (Table 10.7). When we look at the capability of generating funds for watershed management, we find that a water-sustainability premium raised at the consumer end of the supply-chain will yield hundred to two hundred times the amount of money potentially raised through local water pricing.

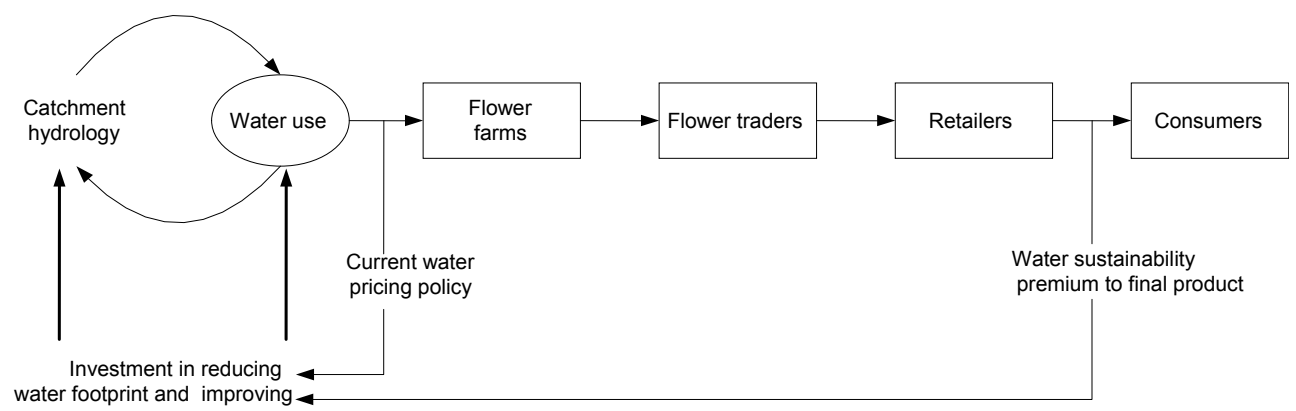

Figure 10.4. Schematization of the flower supply-chain. Local water pricing is a mechanism applied at the beginning of the chain; a water-sustainability premium is raised at the end of the chain. Due to the increase of the price per flower along the supply-chain, generating funds is easier at the end of the chain.

Certification/labelling. Collecting a water-sustainability premium at the lower end of the supply chain needs to go hand in hand with a mechanism for certification of the farmers that deliver the premium-flowers and a mechanism for labelling the premium-flowers. Labelling can be interpreted here in physical sense - where indeed a consumer-oriented 
label is attached to a flower - but it can also get the shape of 'attached information' to whole batches of flowers. Customers can be encouraged to buy flowers from certified farms or labelled flowers and pay an agreed premium to contribute to the sustainability of production and consumption. Certification and labelling would help to segregate environmentally sustainable products from other products and provide consumers with the quality assurance. The success depends on a transparent, credible monitoring and certification systems. Farmers would benefit by having an advantage on the market by achieving standards of production that are internationally recognized.

Table 10.7. Comparison of revenue collection through the current water-pricing policy and through a water-sustainability premium per cut flower sold to the consumer.

\begin{tabular}{l|c|c}
\hline & $\begin{array}{c}\text { Current water } \\
\text { pricing }\end{array}$ & $\begin{array}{c}\text { Water sustainability } \\
\text { premium to final product } \\
\text { at retailer }\end{array}$ \\
\hline $\begin{array}{l}\text { Water abstraction fee }\left(€ / \mathrm{m}^{3}\right) \\
\begin{array}{l}\text { Total blue water abstraction by flower } \\
\left.\text { farms (Mm }{ }^{3} / \mathrm{yr}\right)\end{array}\end{array}$ & 0.007 & 0.01 \\
Revenue per stem of flower $(€ /$ stem) & 0.000076 & 42300 \\
Flower export ${ }^{*}$ (tons/yr) & & $1.69 \mathrm{E}+09$ \\
Flower export ${ }^{* * *}$ (stems/yr) & & $16.9 \mathrm{E}+06$ \\
\hline Estimated revenue $(€ / \mathrm{yr})$ & $0.13 \mathrm{E}+06$ & \\
\hline
\end{tabular}

* Average for the period: 1996-2005.

** Assumed $25 \mathrm{gram} / \mathrm{stem}$.

The certification of farmers and labelling of products could be carried out by the already existing institutional setup of Global Good Agricultural Practices (GlobalGAP). The watersustainability standards can possibly be integrated into the existing standards of GlobalGAP. GAP is already applied in many developed and developing countries including Kenya. Farmers who have complied with the GlobalGAP have benefited in the form of increased access to market, increased productivity and reduced cost of production through careful application of pesticide and fertilizer.

The approach sketched here would encourage flower farmers to comply with criteria on sustainable use of water resources. The costs involved in certification and labelling should be covered by the funds raised, but should be small relative to the funds raised, since 
the funds are primarily meant to promote sustainable water use within the catchment. This is a serious concern when implementing a water-sustainability agreement, because when costs become too high the instrument looses its effectiveness.

Parties involved in the agreement. In its most modest form, a water-sustainability agreement would involve one major retailer in the Netherlands (the most important destination country for Kenyan flowers), one trader and one of the major farmers. In a more ambitious setting, several retailers, traders and farmers could be involved. Retailers, traders or farmers could also be represented by their respective branch organisations. In the case of the flower farmers this could be the Lake Naivasha Growers Group or the Kenyan Flower Council. In the Netherlands, the flower market is organised by FloraHolland, which may take a central role in facilitating an agreement.

Apart from the funds raised to reduce the water footprint in the Lake Naivasha basin, an additional advantage of a water sustainability premium to the final consumer product at the retailer is that it helps to create awareness regarding the value of water along the supply chain down to the consumers. An advantage of raising funds at the consumer end over local full-cost water pricing is that the latter would reduce local competitiveness and diminish profitability. This may lead to a shift of flower farming out of Kenya to other countries, like Ethiopia, which currently experiences a growth in the horticulture sector.

Success of the water-sustainability premium depends on all stakeholders' commitment to reach agreement and effectively implement it. Further, a clearly defined certification procedure and institutional arrangements for the flow of fund back to the basin is required.

\subsection{Discussion}

Cut flowers are an important export sector in Kenya. Next to their contribution to the gross domestic product and foreign exchange earnings, the commercial farms provide employment, housing, schools and hospitals, free to employees and their families. Losing the cut-flower business means over 25,000 workers and their dependence will lose everything. On the other hand, the treatment of Lake Naivasha as a free 'common pool' resource will be at the cost of the lake's sustainability and the corporate image of the 
commercial farms. Therefore, sustainable management of the water resources of the Lake Naivasha Basin is needed. One will need to decide on the maximum allowable drop in the lake water level as a result of water abstractions and on the maximum allowable blue and grey water footprint in the basin. The use of greenhouse flower production (as opposed to production in the open field) needs to be encouraged, coupled with rainwater harvesting. The production of water-intensive products such as beans and low-value products such as fodder and grass around the lake should be discouraged. In the upper catchment, the use of rainwater for the production of fodder and grass should be promoted. The flow of sediments and agricultural nutrients to the lake, both from commercial farms around the lake and farms in the upper catchment, needs to be reduced. The flow of sediment is aggravated due to the loss of riparian vegetation that could have acted as a buffer in trapping sediments. Therefore it is important to create awareness among farmers to protect the riparian zone vegetation and prohibit cultivation in the riparian area.

Pricing water at its full marginal cost is important, but probably difficult to achieve under current and near-future conditions in Kenya. The alternative of a water sustainability premium to flowers sold at the retailer may be more effective. It will generate a larger fund than local water pricing, a fund that can be used for financing improved watershed management and measures that reduce the blue and grey water footprint within the Lake Naivasha Basin. Besides, it would create awareness among consumers on the value of water. The mechanism of a water-sustainability premium will reduce the risk of Kenya losing its business in the long term. An added value of the water-sustainability premium includes the aspect of fairness, since currently the overseas consumers of cut flowers get the benefit but do not cover the environmental cost of the flowers. The mechanism can enhance the green image of the commercial farms and increase chances in the market for sustainable products. Successful implementation of the water-sustainability premium to cut flowers sold by the retailer depends on the commitment of all stakeholders: governments, civil society organizations, private companies and consumers. 



\section{Discussion and conclusion}

The main objective of this thesis was to analyse the spatial and temporal patterns of the global water footprint of humanity both from production and consumption perspective. The work has been based on the calculation framework as set out in The Water Footprint Assessment Manual (Hoekstra et al. 2011).For assessing the water footprint of crop products, the basis was a grid-based dynamic soil water balance model that was developed to estimate the spatially and temporally explicit water footprint related to crop production. For assessing the water footprint of farm animal products, a method was developed to estimate feed composition per animal type, per type of production system and per country. The water footprints of industrial production and domestic water supply were assessed based on a relatively simple approach assuming that the spatial water footprint patterns follows population density within each country. The water footprint assessment framework, the grid-based soil water balance model, the animal-water footprint model and the industrial-domestic water footprint model were successfully applied to assess the spatial and temporal pattern of the water footprint of global agricultural and industrial production and domestic water supply. The study further estimated the international virtual water flows and water savings related to trade in agricultural and industrial products. In order to quantify and visualize the effect of global consumption, the study estimated and mapped the water footprint of nations from the consumption perspective. The entire estimate includes the breakdown of water footprint and virtual water flows into their green, blue and grey components.

The global water footprint related to agricultural and industrial production and domestic water supply for the period 1996-2005 was $9087 \mathrm{Gm}^{3} / \mathrm{yr}(74 \%$ green, $11 \%$ blue, $15 \%$ grey). Agricultural production takes the largest share, accounting for $92 \%$ of the global water footprint. Industrial production contributes $4.4 \%$ to the total water footprint and domestic water supply 3.6\% (Chapter 4). The finding in this study agrees with earlier studies that in many parts of the world blue water use exceeds a sustainable level (Gleick, 1993; Postel, 2000; Smakhtin et al., 2004a; Alcamo et al. 2007; Rondell et al., 2009; Vörösmarty et al., 2010; Wada et al. 2010). The share of the blue water footprint is largest in arid and semi-arid regions. Regions with a large blue water proportion are located, for example, in the western part of the USA, in a relatively narrow strip of land along the west 
coast of South America (Peru-Chile), in southern Europe, North Africa, the Arabian Peninsula, Central Asia, Pakistan, northern India and northeast China (Chapter 2). The use of blue water, in particular for irrigation, has reached a critical stage in many river basins across the globe, by exceeding blue water availability and violating environmental flow requirements (Chapter 5). This means that water has to come either from overexploitation of groundwater resources as it happens in for example the Midwest in the USA (Chapter 6) and places such as the Indian states of Rajasthan, Punjab and Haryana (Rondell et al., 2009; Wada et al. 2010), overexploitation of rivers and lakes as it happens in regions such as the Lake Naivasha basin (Chapter 10) or inter-basin water transfers as for example in China (Ma et al., 2006).

Globally, green water use accounts for $86.5 \%$ of the water consumed (green plus blue water) in crop production. Even in irrigated agriculture, green water often has a very significant contribution to total water consumption. Its contribution further increases to $87.6 \%$ when green water consumption in grazing land is taken into account as well (Chapter 3). Even in regions that according to conventional assessments depend heavily on irrigation, such as the Middle East and North Africa, green water contributes at least half of the total crop water consumption - although in some countries within the regions blue water contribution is larger than $50 \%$. As shown by Rockstrom et al., (2009), in theory most countries have a green water based self-sufficiency potential and there is also great opportunity to increase food production from rain-fed agriculture by raising water productivity without requiring additional blue water resources (Critchely and Siegert, 1991; Rockström and Barron, 2007; Rockström et al., 2003, 2007a, 2007b). Since the marginal benefit of additional blue water in semi-arid and arid regions in terms of raising productivity is quite large, a carefully balanced green-blue water use strategy would be required to address the issue of increasing water demand in a world of limited freshwater resources.

The water footprints of crops vary across countries and regions mainly due to differences in crop yields and much less to differences in climatic conditions. The water footprint and yield of cereals correlate according to a logarithmic function (Figure 2.4), which suggests that the water footprint of a crop, to a large extent, is influenced by agricultural management rather than by the climate under which the crop is grown. Water footprints can thus be lowered by improving water productivity, i.e. producing more food 
per unit of water consumption. According to Rockström et al. (2003), this is particularly possible in the range of low crop yields, due to the current large losses in non-productive green water evaporation.

The global production of animal products accounts for $29 \%$ of the total water footprint of the agricultural sector. Because of the increasing global meat consumption and the on-going shift from traditional extensive and mixed farming to industrial farming systems, the pressure on the global freshwater resources is expected to increase. Therefore, it is relevant to consider from which type of production system an animal product is obtained: from a grazing, mixed or industrial system. The blue and grey water footprints of animal products are largest for industrial systems (with an exception for chicken products). Therefore, from a freshwater perspective, animal products from grazing systems are preferable over products from industrial systems. Further it is more efficient, from a freshwater resource perspective, to obtain calories, protein and fat through crop products than animal products (Chapter 3). Since consumption of animal products plays an important role in depleting and polluting the world's scarce freshwater resources, information on the water footprint of animal products will help us understand how we can sustain the scarce freshwater resources.

The concept of water footprint is used to understand how different products and national communities contribute to water consumption and pollution in different places. The thesis provides information on the water footprints of nations, disaggregated into the type of water footprint (green, blue or grey) and mapped at a high spatial resolution. Such information can form an important basis for further assessment of how products and consumers contribute to the global problem of increasing freshwater appropriation against the background of limited supplies and to local problems of overexploitation and deterioration of freshwater bodies or conflict over water. By overlaying localised blue water footprints of products or consumers with maps that show blue water availability (after accounting for environmental flow requirement), a link has been established between final products and consumers on the one hand and local water problems on the other hand. Establishing such links can help the dialogue between consumers, producers, intermediates (like food processors and retailers) and governments about how to share responsibility for reducing water footprints where most necessary. 


\section{2 / Chapter 11. Discussion and conclusion}

Two factors determine the magnitude of the water footprint of national consumption: the volume and pattern of consumption and the water footprint per ton of consumed products. The latter, in the case of agricultural products, depends on climate and agricultural practice. Therefore, the options available to reduce the water footprint of national consumption include: reducing the volume of products consumed, a shift away from high towards less water-intensive products (for instance from a meat-rich to a vegetarian diet), and reducing the water footprint per ton of product through improvement of water productivity. However, policies aimed at reducing the water footprint of nations should be able to address potential (socio-economic and environmental) trade-offs to be made. For example, the policies should not affect the required increase or maintenance of food security in less developed countries and neither the livelihood of the rural poor should be at risk. Further, a trade-off has to be made in those cases where water footprint and carbon footprint reduction strategies are in conflict.

Countries with a large external water footprint put indirect pressure on the water resources of their trading partners. The research illustrates the global dimension of water consumption and pollution by showing that several countries heavily rely on water resources elsewhere (for example Mexico depending on virtual water imports from the US) and that many countries have significant impacts on water consumption and pollution elsewhere (for example Japan and many European countries due to their large external water footprints). The case study of the external water footprint of the Netherlands helps to visualize the hidden link between Dutch consumers and their associated appropriation of water resources elsewhere (Chapter 8). Dutch consumption implies the use of water resources throughout the world, with significant impacts at specified locations. The impact of the external water footprint of Dutch consumers is greatest in countries that experience serious water scarcity. Based on indicators for water scarcity, eight countries have been identified as hotspots. Although these countries are not the largest contributors to the external water footprint of Dutch consumers in absolute terms, the negative externalities of Dutch consumption in these countries are considered to be most serious. This knowledge is relevant for consumers, government and businesses when addressing the sustainability of consumer products and supply chains.

Measuring blue water scarcity on annual basis masks the intra-annual variability of blue water scarcity. The research presented in this thesis provides the first estimate of blue 
water scarcity in a spatially and temporally explicit way (Chapter 5). Ignoring temporal variability in estimating blue water scarcity obscures the fact that scarcity occurs in certain periods of the year and not in others. Therefore, analysing the blue water scarcity at a monthly time step provides more insight into the degree of water scarcity not revealed in existing annual water scarcity indicators.

The case study of cut flowers from Lake Naivasha, Kenya shows the relation between cut flower production for export to Europe and other countries and its impact on Lake Naivasha (Chapter 10). Over 90 percent of the cut-flower produced in and exported from Kenya comes from the Lake Naivasha basin. The European Union is Kenya's principal market for cut flower, with the Netherlands, the UK, and Germany together importing about $90 \%$ of the cut flowers from Kenya. The use of freshwater in the Lake Naivasha basin for cut-flower production has been blamed for causing a drop in the lake level and for putting the lake's biodiversity at risk. On the other hand, the cut-flower industry has been praised as an economic success as it contributes to the country's economy in the form of foreign exchange earnings and employment opportunity for the population. However, as the water abstraction and pollution level of the lake are unsustainable, the economic benefits will not be sustainable in the long run. The externality costs associated with the decline in the lake level and deteriorating water quality are not included in the price of cut-flowers. Pricing water at its full marginal cost is important, but probably difficult to achieve under current and near-future socio-economic and political conditions in Kenya. The alternative of a water sustainability premium to flowers sold at the retailer may be more effective provided that the funds generated are invested in bringing the water footprint in the Lake Naivasha basin back to a sustainable level. The mechanism of a watersustainability premium will reduce the risk of Kenya losing its business in the long term.

\section{Uncertainties and limitations}

The data presented in this research are derived on the basis of a great number of underlying statistics, maps and assumptions. Basic sources of uncertainties are for example related to global maps of precipitation, temperature, crop and runoff and statistics on yields, production, consumption, trade and wastewater treatment. Other sources of uncertainties in the results presented in this thesis include: lack of crop-specific irrigation data, fertilizer application rates and detailed information on crop parameters, use of simplified models for 


\section{4 / Chapter 11. Discussion and conclusion}

yield and grey water footprint estimations, lack of data on feed composition per farm animal type, country and production system, and uncertainty around the animal distribution per production system per country. An assumption that is not necessarily fully valid has been that water footprints of industrial production and domestic water supply are geographically spread according to population densities.

The grey water footprint estimates in this study are to be considered as conservative. In the case of agricultural production, the grey water footprint estimates are based on leaching and runoff of nitrogen fertilisers, excluding the potential effect of other fertiliser components and pesticides (Chapter 2). Besides, the grey water footprint coming from animal wastes was not quantified, which is particularly relevant for industrial farm animal production systems (Chapter 3). In the cases of industrial production and domestic water supply, a very conservative dilution factor of 1 has been applied for all untreated return flows (Chapter 4).

In this thesis freshwater scarcity was quantified only in terms of blue water. However, as argued by Savenije (2000), Rijsberman (2006) and Rockstrom et al. (2009), considering blue water scarcity only does not provide the whole picture. A complete picture of the extent of water scarcity could be obtained by considering the green and the blue water and the water pollution level together (Savenije, 2000; Rijsberman, 2006; Rockstrom et al., 2009; Hoekstra et al., 2011). Therefore, future research should focus on the development of a complete picture of water scarcity, including green water scarcity and water pollution levels over time.

Since all basic data sources include uncertainties and possible errors, the presented water footprint estimates should be taken and interpreted with extreme caution, particularly when zooming in on specific locations on a map or when focussing on specific products. Higher resolution maps of all input parameters and variables, based on either local measurements or remote sensing (Zwart and Bastiaanssen, 2007; Romaguera et al., 2010) may help to reduce the uncertainties in a global assessment of water consumption in crop production. Besides, in future studies it would be useful to spend more effort in structurally studying the sensitivity of the results to assumptions and parameters and assessing the uncertainties in the final outcome. 


\section{Future outlook}

While meeting water demand in global crop production will remain a key challenge, an integrated analysis of the water needed for other economic sectors and the healthy functioning of ecosystem services is required. An integrated analysis of the spatial and temporal pattern of the green, blue and grey water footprint of humanity both from a production perspective and a consumption perspective as was done in this thesis, can eventually help to identify hot-spots and opportunities, both globally and for individual regions and basins.

Despite the large number of uncertainties, the result of the thesis provides a good basis for rough comparisons and to guide further analysis. The main areas for future analysis as partly elaborated in Hoekstra et al. (2011) are: benchmarking the water footprint of primary crops under different climatic conditions, use of remote sensing images to improve spatial and temporal coverage of data, integrated analysis of green-blue water scarcity, assessment of policies aimed at reducing water footprints and the associated tradeoffs, the splitting up of blue water footprint estimates into surface, renewable-groundwater and fossil-groundwater components, and considering more pollutants in grey water footprint accounting. Developing guidelines on how to define natural and maximum allowable concentration for estimating the grey water footprint is one of the other future challenges. Finally, another important area for future research is detailed uncertainty and sensitivity analysis of the data used in water footprint accounting. 



\section{References}

Addiscott, T.M. (1996) Fertilizers and nitrate leaching, Issues in Environmental Sciences 5: 1-26.

Aizaki, H. and Sato, N. (2007) Consumers' valuation of good agricultural practice by using contingent valuation and contingent ranking methods: A case study of Miyagi Prefecture, Japan, Agricultural Information Research 16 (3): 150-157

Alcamo, J., and Henrichs, T. (2002) Critical regions: A model-based estimation of world water resources sensitive to global changes, Aquatic Sciences 64(4): 352-362.

Alcamo, J., Döll, P., Kaspar, F., and Siebert, S. (1997) Global change and global scenarios of water use and availability: an application of WaterGAP1.0, Centre for Environmental Systems Research, University of Kassel, Kassel.

Alcamo, J., Henrichs, T. and Rösch, T. (2000) World water in 2025: Global modelling and scenario analysis for the World Commission on Water for the $21^{\text {st }}$ century, Kassel World Water Series, Report, No.2, University of Kassel.

Alcamo, J., Döll, P., Henrichs, T., Kaspar, F., Lehner, B., Rösch, T. and Siebert, S. (2003a) Development and testing of the WaterGAP 2 global model of water use and availability, Hydrological Sciences 48(3): 317-337

Alcamo, J., Döll, P., Henrichs, T., Kaspar, F., Lehner, B., Rösch, T. and Siebert, S. (2003b) Global estimates of water withdrawals and availability under current and future “business-as-usual” conditions, Hydrological Sciences Journal 48(3): 339 - 348.

Alcamo, J., Flörke, M., Märker, M. (2007) Future long-term changes in global water resources driven by socio-economic and climatic changes, Hydrological Sciences 52(2): 247-275

Aldaya, M.M. and Hoekstra, A.Y. (2010) The water needed for Italians to eat pasta and pizza, Agricultural Systems 103: 351-360.

Aldaya, M.M. and Llamas, M.R. (2008) Water footprint analysis for the Guadiana river basin, Value of Water Research Report Series No. 35, UNESCO-IHE, Delft, The Netherlands.

Aldaya, M.M., Garrido, A., Llamas, M.R., Varelo-Ortega, C., Novo, P., and Casado, R.R. (2010a) Water footprint and virtual water trade in Spain, in Water policy in Spain, edited by A. Garrido and M.R. Llamas, CRC Press, Leiden, The Netherlands, pp. 49-59. 
Aldaya, M.M., Allan, J.A. and Hoekstra, A.Y. (2010b) Strategic importance of green water in international crop trade, Ecological Economics 69(4): 887-894.

Allan, J.A. (1998) Watersheds and problem sheds: Explaining the absence of armed conflict over water in the Middle East. Middle East Review of International Affairs 2: 49-51.

Allan, J.A. (1999) Productive efficiency and allocative efficiency: Why better water management may not solve the Problem, Agricultural Water Management. 40: 71 - 75.

Allan, J.A. (2001) The Middle East Water Question: Hydropolitics and the Global Economy; I.B. Tauris \& Co Ltd: London, UK.

Allan, J.A. (2003) Virtual water - the water, food, and trade nexus: Useful concept or misleading metaphor? Water International 28 (1): 106-113.

Allen, R.G., Pereira, L.S., Raes, D. and Smith, M. (1998) Crop evapotranspiration: guidelines for computing crop water requirements, FAO Drainage and Irrigation Paper 56, Food and Agriculture Organization, Rome.

Alptekin, E. and Canakci, M. (2008) Determination of the density and the viscosities of biodiesel-diesel fuel blends, Renewable Energy 33(12): 2623-2630.

Appelgren, B. and Klohn, W. (1999) Management of water scarcity: a focus on social capacities and options, Physics and Chemistry of the Earth (B), 24(4): 361-373.

ARB (2007) Flowers: Kenya, Africa Research Bulletin 43(11): 17197A-17198A.

Ariga, J., Jayne, T.S., and Nyoro, J. (2006) Factors driving the growth in fertilizer consumption in Kenya, 1990-2005: Sustaining the momentum in Kenya and lessons for broader replicability in Sub-Saharan Africa, Tegemeo Working paper 24/2006, Tegemeo Institute Of Agricultural Policy and Development, Egerton University, Nairobi, Kenya.

Arnot, C., Boxall, P.C., Cash, S.B. (2006) Do ethical consumers care about price? A revealed preference analysis of fair trade coffee purchases, Canadian Journal of Agricultural Economics 54: 555-565.

Baille, M., Baille, A., and Delmon, D. (1994) Microclimate and transpiration of greenhouse rose crops, Agricultural and Forest Meteorology 71: 83-97

Batjes, N. H. (2006) ISRIC-WISE derived soil properties on a 5 by 5 arc-minutes global grid. Report 2006/02, ISRIC - World Soil Information, Wageningen, The Netherlands, www.isric.org. 
Becht, R. (2007) Environmental effects of the floricultural industry on the Lake Naivasha basin, unpublished paper, ITC Naivasha Database, Enschede, The Netherlands.

Becht, R. and Harper, D.M. (2002) Towards an understanding of human impact upon the hydrology of Lake Naivasha, Kenya, Hydrobiologia 488:1-11.

Becht, R. and Nyaoro, J.R. (2006) The influence of groundwater on lake-water management: the Naivasha case, in Proceedings of the 11th world lakes conference, edited by E.O. Odada, et.al., 31 October - 4 November 2005, Nairobi, Kenya, Ministry of Water and Irrigation; International Lake Environment Committee (ILEC), 2006, Vol. II. pp. 384-388.

Becht, R., Odada, O., and Higgins, S. (2005) Lake Naivasha: Experience and lessons learned brief, in Managing lakes and their basins for sustainable use: A report for lake basin managers and stakeholders, edited by International Lake Environment Committee Foundation, Kusatsu, Japan, pp. 277-298

Bergström, S. (1995) The HBV-model, in Computer models for watershed hydrology, edited by V.P. Singh, Water Resources Publications, Highlands Ranch, Colorado, USA, pp. 443-476.

Bouwman, A.F., Van der Hoek, K.W., Eickhout, B. and Soenario, I. (2005) Exploring changes in world ruminant production systems, Agricultural Systems 84: 121-153.

Bouwman, L., Goldewijk, K. K., Van Der Hoek, K.W., Beusen, A.H.W., Van Vuuren, D.P., Willems, J., Rufino, M.C. and Stehfest, E. (2011) Exploring global changes in nitrogen and phosphorus cycles in agriculture induced by livestock production over the 1900- 2050 period, Proceedings of the National Academy of Sciences, doi/10.1073/pnas.1012878108.

Bruinsma, J. (2003) World agriculture: towards 2015/2030: an FAO perspective, Earthscan, London, UK.

Bulsink, F., Hoekstra, A.Y. and Booij, M.J. (2010) The water footprint of Indonesian provinces related to the consumption of crop products, Hydrology and Earth System Sciences 14(1): 119-128.

Calder, I. R. and Neal, C. (1984) Evaporation from saline lakes: A combination equation approach, Hydrological Sciences Journal 29(1): 89-97.

Capper, J.L., Cady, R.A. and Bauman, D.E. (2009) The environmental impact of dairy production: 1944 compared with 2007, Journal of Animal Science 87(6): 2160-2167. 
CBS (2007) Land- en tuinbouwcijfers 2007, Statistics Netherlands, Voorburg.

Chahed, J., Hamdane, A. and Besbes, M. (2008) A comprehensive water balance of Tunisia: blue water, green water and virtual water, Water International, 33(4): 415-424.

Chao, B. F., Wu, Y. H. and Li, Y. S. (2008) Impact of artificial reservoir water impoundment on global sea level, Science 320(5873): 212-214.

Chapagain, A. K. and S. Orr (2008) UK Water Footprint: The impact of the UK's food and fibre consumption on global water resources, Volume 1, WWF-UK, Godalming, UK.

Chapagain, A.K. and Hoekstra, A.Y. (2003) Virtual water flows between nations in relation to trade in livestock and livestock products, Value of Water Research Report Series No. 13, UNESCO-IHE, Delft, the Netherlands.

Chapagain, A.K. and Hoekstra, A.Y. (2004) Water footprints of nations, Value of Water Research Report Series No. 16, UNESCO-IHE, Delft, The Netherlands.

Chapagain, A.K. and Hoekstra, A.Y. (2008) The global component of freshwater demand and supply: An assessment of virtual water flows between nations as a result of trade in agricultural and industrial products, Water International 33(1): 19-32.

Chapagain, A.K., Hoekstra, A.Y. and Savenije, H.H.G. (2006a) Water saving through international trade of agricultural products. Hydrology and Earth System Sciences 10 (3): $455-468$.

Chapagain, A.K., Hoekstra, A.Y., Savenije, H.H.G. and Gautam, R. (2006b) The water footprint of cotton consumption: An assessment of the impact of worldwide consumption of cotton products on the water resources in the cotton producing countries, Ecological Economics 60(1): 186-203.

CIESIN and CIAT (2005) Gridded population of the world version 3 (GPWv3): Population density grids, Socioeconomic Data and Applications Center (SEDAC), Center for International Earth Science Information Network (CIESIN), Columbia University; and International Center for Tropical Agriculture (CIAT), http://sedac.ciesin.columbia.edu/gpw.

Cornish, G., Bosworth, B., Perry, C. and Burke, J. (2004) Water Charging in Irrigated Agriculture: An Analysis of International Experience, FAO Waters Reports 28, FAO, Rome, Italy.

Cosgrove, W.J. and Rijsberman, F.R. (2000a) World Water Vision: Making Water Everybody's Business, Earthscan Publications, London, UK. 
Cosgrove, W.J. and Rijsberman, F.R. (2000b) Challenge for the 21 st century: making water everybody's business, Sustainable Development International 2: 149-156.

Critchley, W. and Siegert, K. (1991) Water harvesting: A manual for the design and construction of water harvesting schemes for plant production, Food and Agriculture Organization, Rome.

De Bruin, H. A. R. (1982) Temperature and energy balance of a water reservoir determined from standard weather data of a land station, Journal of Hydrology 59(3-4): 261-274.

De Fraiture, C., Cai, X., Amarasinghe, U., Rosegrant, M., Molden, D. (2004) Does international cereal trade save water? The impact of virtual water trade on global water use, Comprehensive Assessment Research Report, vol. 4, International Water Management Institute, Colombo, Sri Lanka.

De Fraiture, C., Wichelns, D., Rockström, J., Kemp-Benedict, E., Eriyagama, N., Gordon, L.J., Hanjra, M.A., Hoogeveen, J., Huber-Lee, A. and Karlberg, L. (2007) Looking ahead to 2050: scenarios of alternative investment approaches, in Water for food, water for life: a comprehensive assessment of water management in agriculture, edited by D. Molden, International Water Management Institute, Colombo, Earthscan, London: pp. 91-145.

De Willigen, P. (2000) An analysis of the calculation of leaching and denitrification losses as practised in the NUTMON approach, Plant Research International, Wageningen, The Netherlands.

Dennehy, K.F.: High Plains regional ground-water study (2000) U.S. Geological Survey Fact Sheet

FS-091-00, http://co.water.usgs.gov/nawqa/hpgw/factsheets/DENNEHYFS1.html.

Didier, T. and Lucie, S. (2008) Measuring consumer's willingness to pay for organic and fair trade products, International Journal of Consumer Studies 32 (5): 479-490.

Dinar, A. (1998) Water policy reforms: information needs and implementation obstacles, Water Policy 1(4): 367-382

Dinar, A. and Subramanian, A. (1998) Policy implications from water pricing experiences in various countries, Water Policy 1(2): 239-250.

Döll, P. and Siebert S. (2000). "A digital global map of irrigated areas." ICID Journal 49(2): 55-66. 
Döll, P. and Siebert, S. (2002) Global modelling of irrigation water requirements. Water Resource Research 38 (4), 1037, DOI:10.1029/2001WR000355, 2002.

Doorenboos, J. and Pruitt, W.O. (1977) Crop water requirements, FAO Irrigation and Drainage Paper No. 24. FAO, Rome.

Doorenbos, J. and Kassam, A.H. (1979) Yield response to water, FAO Drainage and Irrigation Paper 33, FAO, Rome.

Dorcey, T., Steiner, A., Acreman, M., and Orlando, B. (Eds.) (1997) Large Dams: Learning from the Past, Looking at the Future, Workshop Proceedings, IUCN, Gland, Switzerland and Cambridge, UK and the World Bank Group, Washington, DC.

Dubcovsky, J. and Dvorak, J. (2007) Genome plasticity a key factor in the success of polyploid wheat under domestication, Science 316(5833), 1862-1866.

Earle, A. and Turton, A. (2003) The virtual water trade amongst countries of SADC, in Virtual Water Trade: Proceedings of the International Expert Meeting on Virtual Water Trade, edited by A.Y. Hoekstra, Research Report Series No. 12. IHE Delft, The Netherlands.

Ekboir, J. (ed.) (2002) CIMMYT 2000-2001 World wheat overview and outlook: Developing no-till packages for small-scale farmers, International Maize and Wheat Improvement Centre, Mexico.

Elferink, E.V. and Nonhebel, S. (2007) Variations in land requirements for meat production, Journal of Cleaner Production, 15(18): 1778.

EPA (2005) List of drinking water contaminants: Ground water and drinking water, US Environmental Protection Agency.

EPZA (2005a) Grain production in Kenya, Export Processing Zones Authority, Nairobi, Kenya.

EPZA (2005b) Horticulture industry in Kenya, Export Processing Zones Authority, Nairobi, Kenya.

EPZA (2005c) Tea and coffee industry in Kenya, Export Processing Zones Authority, Nairobi, Kenya.

EUROSTAT (2011) EUROSTAT online database, European Commission, Luxembourg, http://epp.eurostat.ec.europa.eu/portal/page/portal/statistics/search database, (retrieved 14 January 2011). 
Everard, M., and Harper, D.M. (2002) Towards the sustainability of the Lake Naivasha Ramsar site and its catchment, Hydrobiologia 488:191-202.

Fader, M., Gerten, D., Thammer, M., Heinke, J., Lotze-Campen, H., Lucht, W. and Cramer, W. (2011) Internal and external green-blue agricultural water footprints of nations, and related water and land savings through trade, Hydrology and Earth System Sciences, 15(5): 1641-1660.

Falkenmark, M. (1989) The massive water scarcity now threatening Africa: Why isn't it being addressed? Ambio 18(2): 112-118.

Falkenmark, M. and Rockström, J. (2004) Balancing water for humans and nature: a new approach to ecohydrology, Earthscan, London.

Falkenmark, M., J. Lundqvist and C. Widstrand (1989) Macro-scale water scarcity requires micro-scale approaches: Aspects of vulnerability in semi-arid development, Natural Resources Forum: 258-267.

Falkenmark, M., Berntell, A., Jägerskog, A., Lundqvist, J. Matz, M. and Tropp, H. (2007) On the verge of a new water scarcity: A call for good governance and human ingenuity, SIWI Policy Brief, SIWI.

Falkenmark, M., Rockström, J. and Karlberg, L. (2009) Present and future water requirements for feeding humanity, Food Security, 1(1): 59-69.

FAO (1983) Changing patterns and trends in feed utilization, FAO Economic and Social Development Paper 37, Food and Agriculture Organization, Rome, Italy.

FAO (2003) Technical conversion factors for agricultural commodities, Food and Agriculture Organization, Rome, Italy, www.fao.org/fileadmin/templates/ess/documents/methodology/tcf.pdf.

FAO (2005a) Review of agricultural water use per country, Food and Agriculture Organization, Rome, available at: www.fao.org/nr/water/aquastat/water_use_agr/index.stm.

FAO (2005b) Livestock policy brief 02, Food and Agriculture Organization, Rome, Italy.

FAO (2005c) Kenya Country Report, in: Irrigation in Africa in Figures, by FAO, AQUASTAT Survey 2005, Food and Agriculture Organization Rome, Italy. www.fao.org/nr/water/aquastat/countries/kenya/index.stm.

FAO (2006) Fertilizer by crop, FAO Fertilizer and Plant Nutrition Bulletin 17, Food and Agriculture Organization, Rome. 
FAO (2010a) FAOSTAT database, Food and Agriculture Organization, Rome, Italy, http://faostat.fao.org.

FAO (2010b) AQUASTAT on-line database, Food and Agriculture Organization, Rome, http://faostat.fao.org

FAO (2010c) FertiStat - Fertilizer use statistics. http://www.fao.org/ag/agl/fertistat/

FAO (2010d) Global map of monthly reference evapotranspiration - 10 arc minutes. GeoNetwork: grid database, http://www.fao.org/geonetwork/srv/en/resources.get?id=7416\&fname=ref_evap_fao_10 $\underline{\min . z i p \& a c c e s s=\text { private }}$

FAO (2010e) Global Information and Early Warning System (GIEWS) - Crop calendar tool, Food and Agriculture Organization, Rome, http://lprapp08.fao.org/fenix-portal.

FAO (2010f) CROPWAT model, Food and Agriculture Organization, Rome, Italy. www.fao.org/nr/water/infores_databases_cropwat.html.

FAO (2010g) CLIMWAT database, Food and Agriculture Organization, Rome, Italy, www.fao.org/nr/water/infores_databases_climwat.html .

Fekete, B. M., Vörösmarty, C. J. and Grabs, W. (2002) High-resolution fields of global runoff combining observed river discharge and simulated water balances, Global Biogeochemical Cycles, 16(3), 10.1029/1999GB001254, available at: www.grdc.sr.unh.edu/ last access: 12 April 2010.

Feng, K., Hubacek, K., Minx, J., Siu, Y.L., Chapagain, A., Yu, Y., Guan, D. and Barrett, J. (2011) Spatially explicit analysis of water footprints in the UK, Water, 3(1): 47-63

Finch, J. W. (2001) A comparison between measured and modelled open water evaporation from a reservoir in south-east England, Hydrological Processes 15(14): 2771-2778.

Finch, J. W. and Gash, J. H. C. (2002) Application of a simple finite difference model for estimating evaporation from open water, Journal of Hydrology 255(1-4): 253-259.

Fischer, H. B., List, E. J., Koh, R. C. Y., Imberger, J. and Brooks, N. H. (1979) Mixing in inland and coastal waters, Academic Press, San Diego.

Fraser, D. (2008) Toward a global perspective on farm animal welfare, Applied Animal Behaviour Science 113(4): 330-339.

Galloway, J., Burke, M., Bradford, G. E., Naylor, R., Falcon, W., Chapagain, A.K., Gaskell, J.C., McCullough, E., Mooney, H.A., Oleson, K.L.L., Steinfeld, H., 
Wassenaar, T., Smil, V. (2007) International trade in meat: The tip of the pork chop, Ambio 36: 622-629.

Garrido, A., Llamas, M.R., Varela-Ortega, C., Novo, P., Rodríguez-Casado, R. and Aldaya, M.M. (2010) Water footprint and virtual water trade in Spain, Springer, New York, US.

Gerbens-Leenes, P.W. and Hoekstra, A.Y. (2007) The water footprint of the Netherlands: analysis of international impacts and options for change, Civil Engineering \& Management Research Report 2007R-008, University of Twente, Enschede.

Gerbens-Leenes, P.W., Hoekstra, A.Y. and Van der Meer, T.H. (2008a) The water footprint of bio-energy: Global water use for bio-ethanol, bio-diesel, heat and electricity, Value of Water Research Report Series No. 29, UNESCO-IHE, Delft, The Netherlands.

Gerbens-Leenes, P.W.; Hoekstra, A.Y. and Van der Meer, T.H. (2008b) Water footprint of bio-energy and other primary energy carriers, Value of Water Research Report Series No. 34, UNESCO-IHE, Delft, The Netherlands.

Gerbens-Leenes, W., Hoekstra, A.Y. and Van der Meer, T.H. (2009a) The water footprint of bioenergy, Proceedings of the National Academy of Sciences 106 (25): 10219-10223.

Gerbens-Leenes, P.W. Hoekstra, A.Y. and Van der Meer. Th. (2009b) The water footprint of energy from biomass: A quantitative assessment and consequences of an increasing share of bio-energy in energy supply, Ecological Economics 68(4): 1052-1060.

Gitachi, S. (2005) Lake Naivasha: a case study in IWRM in Kenya, www.netwas.org/newsletter/articles/2005/01/7 (September 5, 2008).

Gleick, P.H. (ed.) (1993) Water in Crisis: A guide to the world's fresh water resources, Oxford University Press.

Gleick, P.H. (1998) Water in Crisis: Paths to Sustainable Water Use, Ecological Applications 8(3): 571-579.

Gleick, P.H. (2000) The changing water paradigm: a look at twenty-first century water resources development, Water Inter., 25(1),127-138.

Gleick, P.H. (2010) Bottled and sold: The story behind our obsession with bottled water, Island Press, Washington, DC, US.

GoK (2007) Vision 2030: A competitive and prosperous Kenya, Government of the Republic of

Kenya, http://www.planning.go.ke/images/stories/downloads/VISION\%202030\%20BROCHU

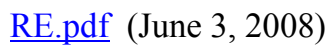


Goulding, K.W.T., Poulton, P.R., Webster, C.P., Howe, M.T. (2000) Nitrate leaching from the Broadbalk Wheat Experiment, Rothamsted, UK, as influenced by fertilizer and manure inputs and weather, Soil Use and Manage. 16(4), 244-250.

GRDC (2007) Major River Basins of the World, Global Runoff Data Centre, Federal Institute of Hydrology, Koblenz, Germany, available at: http://grdc.bafg.de/.

Gupta, S.K. and Deshpande, R.D. (2004) Water for India in 2050: first-order assessment of available options, Current Science 86: 1216-1224.

Gustafson, R.H. and Bowen, R.E. (1997) Antibiotic use in animal agriculture, Journal of Applied Microbiology 83(5): 531-541.

Haileslassie, A., Priess, J.A., Veldkamp, E. and Lesschen, J.P. (2007) Nutrient flows and balances at the field and farm scale: Exploring effects of land-use strategies and access to resources. Agric Syst 94:459-470.

Hanasaki, N., Inuzuka, T., Kanae, S. and Oki, T. (2010) An estimation of global virtual water flow and sources of water withdrawal for major crops and livestock products using a global hydrological model, Journal of Hydrology 384: 232-244.

Harper, D. and Mavuti, K. (2004) Lake Naivasha, Kenya: Ecohydrology to guide the management of a tropical protected area, Ecohydrology and Hydrobiology 4(3): 287305.

HCDA (2007) Horticulture products export volume statistics, Horticultural Crops Development Authority. $\quad$ www.hcda.or.ke/default2.asp?active page id=92 (Aug. 9, 2007).

Heffer, P. (2009) Assessment of Fertilizer Use by Crop at the Global Level 2006/072007/08. International Fertilizer Industry Association, Paris.

Henderson-Sellers, B. (1986) Calculating the surface energy balance for lake and reservoir modelling: A review. Reviews of Geophysics 24(3): 625-649.

Hendy, C.R.C, Kleih, U., Crawshaw, R., Phillips, M. (1995) Livestock and the environment finding a balance: Interactions between livestock production systems and the environment, Impact Domain: concentrate feed demand, Food and Agriculture Organization, Rome, Italy, www.fao.org/wairdocs/lead/x6123e/x6123e00.htm\#Contents

Herrero, M., Thornton, P. K., Gerber, P. and Reid, R. S. (2009) Livestock, livelihoods and the environment: understanding the trade-offs, Current Opinion in Environmental Sustainability 1(2): 111-120. 
Hoekstra, A.Y. (ed.) (2003) Virtual water trade: Proceedings of the International Expert Meeting on Virtual Water Trade, Delft, The Netherlands, 12-13 December 2002, Value of Water Research Report Series No.12, UNESCO-IHE, Delft, The Netherlands, www.waterfootprint.org/Reports/Report12.pdf.

Hoekstra, A.Y. (2006) The global dimension of water governance: nine reasons for global arrangements in order to cope with local water problems, Value of Water Research Report Series No. 20, UNESCO-IHE, Delft, The Netherlands, www.waterfootprint.org/Reports/Report_20_Global_Water_Governance.pdf .

Hoekstra, A.Y. (2010) The water footprint of animal products, in The meat crisis: Developing more sustainable production and consumption, edited by J. D'Silva, and J.Webster, Earthscan, London, UK, pp. 22-33.

Hoekstra, A.Y. (2011) The global dimension of water governance: Why the river basin approach is no longer sufficient and why cooperative action at global level is needed, Water, 3(1):21-46.

Hoekstra, A.Y. and Chapagain, A.K. (2007a) Water footprints of nations: water use by people as a function of their consumption pattern, Water Resources Management, 21(1): $35-48$.

Hoekstra, A.Y. and Chapagain, A.K. (2007b) The water footprints of Morocco and the Netherlands: Global water use as a result of domestic consumption of agricultural commodities, Ecological Economics 64(1): 143-151.

Hoekstra, A.Y. and Chapagain, A.K. (2008) Globalization of water: Sharing the planet's freshwater resources, Blackwell Publishing, Oxford, UK.

Hoekstra, A.Y. and Hung, P.Q. (2002) Virtual water trade: A quantification of virtual water flows between nations in relation to international crop trade, Value of Water Research Report Series No.11, UNESCO-IHE, Delft, The Netherlands, www.waterfootprint.org/Reports/Report11.pdf.

Hoekstra, A. Y. and Hung, P. Q. (2005) Globalisation of water resources: international virtual water flows in relation to crop trade, Global Environmental Change 15(1): 45-56. Hoekstra, A.Y. and Mekonnen, M.M. (2011) Global water scarcity: monthly blue water footprint compared to blue water availability for the world's major river basins, Value of Water Research Report Series No. 53, UNESCO-IHE, Delft, the Netherlands. 
Hoekstra, A.Y., Chapagain, A.K., Aldaya, M.M., Mekonnen, M.M. (2009) Water footprint manual: state of the art 2009, Water Footprint Network, Enschede, The Netherlands, www.waterfootprint.org/downloads/WaterFootprintManual2009.pdf .

Hoekstra, A.Y., Chapagain, A.K., Aldaya, M.M. and Mekonnen, M.M. (2011) The water footprint assessment manual: Setting the global standard, Earthscan, London, UK.

Hoff (2009) Global water resources and their management, Current Opinion in Environmental Sustainability, 1:141-147.

Hoff, H., Falkenmark, M., Gerten, D., Gordon, L., Karlberg, L. and Rockström, J. (2010) Greening the global water system, Journal of Hydrology, 384(3-4): 177-186.

Hubacek, K., Guan, D.B., Barrett, J. and Wiedmann, T. (2009) Environmental implications of urbanization and lifestyle change in China: Ecological and water footprints, Journal of Cleaner Production, 17(14): 1241-1248.

Hutson, S.S., Barber, N.L., Kenny, J.F., Linsey, K.S., Lumia, D.S. and Maupin, M.A. (2004) Estimated Use of Water in the United States in 2000, USGS Circular 1268, US Geological Survey, Reston, USA, "available at: http://water.usgs.gov/watuse, last access: 15 February 2010".

ICID (2006) Experiences with Inter Basin Water Transfers for Irrigation, Drainage and Flood Management, Revised Draft Report of the ICID Task Force on Inter Basin Water Transfers; International Commission on Irrigation and Drainage (ICID), New Delhi, India.

IEA (2010) Key world energy statistics 2010, International Energy Agency, Paris, France.

IFA (2009) International Fertilizer Industry Association Databank, www.fertilizer.org/ifa/ifadata/results, last access: 24 September.

ITC (2007) SITA version 1996-2005 in SITC, [DVD-ROM]. International Trade Centre, Geneva.

Jenkinson, D.S.: The impact of humans on the nitrogen cycle, with focus on temperate arable agriculture, Plant and Soil, 228(1): 3-15, 2001.

Kampman, D.A., Hoekstra, A.Y. and Krol, M.S. (2008) The water footprint of India, Value of Water Research Report Series No.32, UNESCO-IHE, Delft, the Netherlands.

Keller, A.A. and Keller, J. (1995) Effective Efficiency: A water use efficiency concept for allocating freshwater resources, Discussion Paper 22, Centre for Economic Policy Studies, Winrock International, Arlington, USA. 
Keller, J., Keller, A. and Davids, G. (1998) River basin development phases and implications of closure, Journal of Applied Irrigation Science, 33: 145-164.

Keyzer, M.A., Merbis, M.D., Pavel, I.F.P.W. and Van Wesenbeeck, C.F.A. (2005) Diet shifts towards meat and the effects on cereal use: Can we feed the animals in 2030? Ecological Economics 55(2): 187-202.

Kijne, J.W., Barker, R. and Molden, D. (eds.) (2003) Water productivity in agriculture: Limits and opportunities for improvement, CAB International, Wallingford, UK and International Water management Institute, Colombo, Sri Lanka.

King, J.A., Sylvester-Bradley, R., Rochford, A.D.H. (2001) Availability of nitrogen after fertilizer applications to cereals, Journal of Agricultural Sciences 136, 141-157.

Kisima (2007) Will SWAps fix the water sector? Kisima Issue 4 January 2007.

Kitaka, N., Harper, D.M., and Mavuti, K.M. (2002) Phosphorus inputs to Lake Naivasha, Kenya, from its catchments and the trophic state of the lake, Hydrobiologia 488:73-80.

Krier, Jean-Marie (2005) Fair trade in Europe 2005: Facts and figures on fair trade in 25 European countries. www.fairtrade.net/fileadmin/user upload/content/FairTradeinEurope2005.pdf (June 28, 2010).

Kulshreshtha, S.N. (1993) World water resources and regional vulnerability: Impact of future changes, Research Report RR-93-10, International Institute for Applied Systems Analysis, Laxenburg, Austria.

L'vovich, M.I., White, G.F. and Turner, B.L.I. (1990) Use and transformation of terrestrial water systems, in: The earth as transformed by human action: Global and regional changes in the biosphere over the past 300 years edited by: Turner II, B.L., Clark, W.C, Kates, R.W., Richards, J.F., Mathews, J.T. and Meyer, W.B., Cambridge University Press, New York, 235-252.

Leff, B., N. Ramankutty, Foley, J. A. (2004) Geographic distribution of major crops across the world, Global Biogeochemical Cycles 18(1) GB1009, doi:10.1029/2003GB002108.

LEI (2007) Landbouw Economisch Bericht 2007, Landbouw Economisch Instituut.

Lenters, J. D., Kratz, T. K. and Bowser, C. J. (2005) Effects of climate variability on lake evaporation: Results from a long-term energy budget study of sparkling lake, northern Wisconsin (USA), Journal of Hydrology 308(1-4): 168-195. 
Lerer, L. B. and Scudder, T. (1999) Health impacts of large dams, Environmental Impact Assessment Review 19(2): 113-123.

Lesschen, J., Stoorvogel, J., Smaling, E., Heuvelink, G. and Veldkamp, A. (2007) A spatially explicit methodology to quantify soil nutrient balances and their uncertainties at the national level, Nutrient Cycling in Agroecosystems 78:111-131.

Lewis, J.M., Klopfenstein, T.J., Stock, R.A. and Nielsen, M.K. (1990) Evaluation of intensive vs extensive systems of beef production and the effect of level of beef cow milk production on postweaning performance, Journal of Animal Science 68(8): 25172524.

Lidén, R. and Harlin, J. (2000) Analysis of conceptual rainfall-runoff modelling performance in different climates, Journal of Hydrology 238(3-4): 231-247.

Liu, C.M. and Zheng, H.X. (2002) South-to-north water transfer schemes for China, International Journal of Water Resources Development 18(3): 453-471.

Liu, J. and Savenije, H.H.G. (2008) Food consumption patterns and their effect on water requirement in China, Hydrology and Earth System Sciences 12(3): 887-898.

Liu J. and Yang H. (2010) Spatially explicit assessment of global consumptive water uses in cropland: green and blue water, Journal of Hydrology 384: 187-197.

Liu, J., Williams, J.R., Zehnder, A.J.B., and Yang, H. (2007) GEPIC - modelling wheat yield and crop water productivity with high resolution on a global scale, Agricultural Systems 94: 478-493.

Liu, J., Zehnder, A.J.B. and Yang, H. (2007): Historical trends in China's virtual water trade, Water International 32: 78-90.

Liu, J., Yang, H. and Savenije, H. H. G. (2008) China's move to higher-meat diet hits water security, Nature, 454, p. 397.

Liu, J., Zehnder, A.J.B. and Yang, H. (2009) Global consumptive water use for crop production: The importance of green water and virtual water, Water Resources Research 45, W05428, doi:10.1029/2007WR006051.

Liu, J., You, L., Amini, M., Obersteiner, M., Herrero, M., Zehnder, A. J. B. and Yang, H. (2010) A high-resolution assessment on global nitrogen flows in cropland, Proceedings of the National Academy of Sciences 107(17): 8035-8040. 
Ma, J., Hoekstra, A.Y., Wang, H., Chapagain, A.K. and Wang, D. (2006) Virtual versus real water transfers within China, Philosophical Transactions of The Royal Society B. 361 (1469): 835-842.

Ma, W., Li, J., Ma, L., Wang, F., Sisak, I., Cushman, G., and Zhang, F. (2009): Nitrogen flow and use efficiency in production and utilization of wheat, rice and maize in China. Agricultural Systems 99: 53-63.

Mavuti, K.M., Harper, D.M. (2005) The ecological state of Lake Naivasha, Kenya, 2005: Turning 25 years research into an effective Ramsar monitoring programme, www.oceandocs.org/bitstream/1834/2127/1/WLCK-30-34.pdf.

McAlpine, C.A., Etter, A., Fearnside, P.M., Seabrook, L. and Laurance, W.F. (2009) Increasing world consumption of beef as a driver of regional and global change: A call for policy action based on evidence from queensland (australia), colombia and brazil, Global Environmental Change 19(1): 21-33.

McEwen, S.A. (2006) Antibiotic use in animal agriculture: What have we learned and where are we going? Animal Biotechnology 17(2): 239 - 250.

McGuire, V.L. (2007) Water-level changes in the High Plains Aquifer, predevelopment to 2005 and 2003 to 2005: U.S. Geological Survey Scientific Investigations Report 20065324, http://pubs.usgs.gov/sir/2006/5324/.

McJannet, D. L., Webster, I. T., Stenson, M. P. and Sherman, B. S. (2008) Estimating open water evaporation for the Murray Darling basin, Report for CSIRO, Australia.

Mekonnen, M.M. and Hoekstra, A.Y. (2010a) A global and high-resolution assessment of the green, blue and grey water footprint of wheat, Hydrology and Earth System Sciences, 14(7), 1259-1276.

Mekonnen, M.M. and Hoekstra, A.Y. (2010b) A global and high-resolution assessment of the green, blue and grey water footprint of wheat, Value of Water Research Report Series No. 42, UNESCO-IHE, Delft, The Netherlands.

Mekonnen, M.M. and Hoekstra, A.Y. (2010c) Mitigating the water footprint of export cut flowers from the Lake Naivasha Basin, Kenya, Value of Water Research Report Series No. 45, UNESCO-IHE, Delft, The Netherlands.

Mekonnen, M.M. and Hoekstra, A.Y. (2010d) The green, blue and grey water footprint of crops and derived crop products, Value of Water Research Report Series No. 47, UNESCO-IHE, Delft, the Netherlands. 
Mekonnen, M.M. and Hoekstra, A.Y. (2010e) The green, blue and grey water footprint of farm animals and derived animal products, Value of Water Research Report Series No. 48, UNESCO-IHE, Delft, The Netherlands.

Mekonnen, M.M. and Hoekstra, A.Y. (2011a) The green, blue and grey water footprint of crops and derived crop products, Hydrology and Earth System Sciences, 15(5): 15771600.

Mekonnen, M.M. and Hoekstra, A.Y. (2011b) National water footprint accounts: the green, blue and grey water footprint of production and consumption, Value of Water Research Report Series No. 50, UNESCO-IHE, Delft, The Netherlands.

Mekonnen, M.M. and Hoekstra, A.Y. (2011c) The water footprint of electricity from hydropower, Value of Water Research Report Series No. 51, UNESCO-IHE, Delft, The Netherlands.

Mekonnen, M.M. and Hoekstra, A.Y. (2011d) The relation between national water management and international trade: a case study from Kenya, Value of Water Research Report Series No. 52, UNESCO-IHE, Delft, The Netherlands.

Mitchell, T. D. and Jones, P. D. (2005) An improved method of constructing a database of monthly climate observations and associated high-resolution grids. International Journal of Climatology, 25, 693-712. http://cru.csi.cgiar.org/continent_selection.asp.

Mogaka, H., Gichere, S., Davis, R., Hirji, R. (2006) Climate variability and water resources degradation in Kenya: improving water resources development and management, World Bank working paper; no. 69, Washington, USA.

Molden, D. (ed.) (2007) Water for food, water for life: A comprehensive assessment of water management in agriculture, Earthscan, London, UK.

Molden, D.J. and Sakhthivadivel, R. (1999) Water accounting to assess use and productivity of water, International Journal of Water Resources Development 15: 55-71.

Molden, D. Murray-Rust, H., Sakthivadivel, R. and Makin, I. (2003) A water-productivity framework for understanding and action, in Water productivity in agriculture: Limits and opportunities for improvement, edited by Kijne, J.W. et. al., CAB International, Wallingford, UK and International Water management Institute, Colombo, Sri Lanka, pp. 1-18.

Molle, F. (2003) Development trajectories of river basins: a conceptual framework, IWMI Research Report 72, IWMI, Colombo, Sri Lanka. 
Molle, F. and Berkoff, J. (2007) Water pricing in irrigation: The lifetime of an idea, in Irrigation water pricing: the gap between theory and practice, edited by F. Molle and J. Berkoff, Comprehensive Assessment of Water Management in Agriculture Series No. 4, CAB International Publication, Wallingford, UK and Cambridge MA, USA, pp. 1-20.

Monfreda, C., Ramankutty, N., Foley, J.A. (2008) Farming the planet: 2. Geographic distribution of crop areas, yields, physiological types, and net primary production in the year 2000, Global Biogeochemical Cycles, Vol.22, GB1022, doi:10.1029/2007GB002947. www.geog.mcgill.ca/landuse/pub/Data/175crops2000.

Mpusia, P.T.O. (2006) Comparison of water consumption between greenhouse and outdoor cultivation, M.Sc. Thesis, ITC, Enschede, The Netherlands.

Müller and Hennings (2000) CLIMATE 1 - The global Climate Data Atlas on CD-ROM, Univ. Flensburg, Inst. F. Geografie, Flensburg

Mumma, A. (2005) Kenya's new water law: An analysis of the implications for the rural poor. Paper presented at the international workshop on "African water laws: Plural legislative frameworks for rural water management in Africa", Johannesburg, January 26-28, 2005.

Musota, R. (2008) Using WEAP and scenarios to assess sustainability of water resources in a basin. Case study for Lake Naivasha catchment-Kenya, M.Sc. Thesis, ITC, Enschede, The Netherlands.

Myers, N. and Kent, J. (2003) New consumers: The influence of affluence on the environment, Proceedings of the National Academy of Sciences 100(8): 4963-4968.

Naylor, R., Steinfeld, H., Falcon, W., Galloway, J., Smil, V., Bradford, E., Alder, J. and Mooney, H. (2005) Agriculture: Losing the links between livestock and land, Science 310(5754): 1621-1622.

Nazer, D.W., Siebel, M.A., Van der Zaag, P., Mimi, Z. and Gijzen, H.J. (2008) Water footprint of the Palestinians in the West Bank, Journal of the American Water Resources Association 44(2): 449-458.

Nepstad, D.C., Stickler, C.M., and Almeida, O.T. (2006) Globalization of the amazon soy and beef industries: Opportunities for conservation, Conservation Biology 20(6): 15951603.

NCDC (2009) Global surface summary of the day, National Climatic Data Center, ftp://ftp.ncdc.noaa.gov/pub/data/gsod. 


\section{4 / References}

New, M., Lister, D., Hulme, M. and Makin, I. (2002) A high-resolution data set of surface climate over global land areas, Climate Research 21(1): 1-25.

Norse, D.: Non-point pollution from crop production (2005) Global, regional and national issues, Pedosphere 15(4): 499-508.

Noulas, Ch., Stamp, P., Soldati, A., and Liedgens, M. (2004) Nitrogen use efficiency of spring wheat genotypes under field and lysimeter conditions. Journal of Agronomy and Crop Science 190: 111-118.

Nyoro, J. K., Wanzala, M. and Awour, T. (2001) Increasing Kenya's agricultural competitiveness: farm level issues, Tegemeo working Paper No. 4, Tegemeo Institute of Agricultural Policy and Development, Egerton University, Kenya.

Ohlsson, L. (2000) Water conflicts and social resource scarcity, Physics and Chemistry of the Earth 25 (3): 213-200.

Ohlsson, L. and Appelgren, B., (1998) Water and social resource scarcity: Alternative socially based approaches to assessment and management of water scarcity, The Water Page, http://www.africanwater.org/SoicalResourceScarcity.htm.

Oki, T. and Kanae, S., (2004) Virtual water trade and world water resources, Water Science and Technology 49 (7): 203-209.

Oki, T. and Kanae, S. (2006) Global hydrological cycles and world water resources, Science 313(5790): 1068-1072.

Orgaz, F., Ferna'ndez, M.D., Bonachela, S., Gallardo, M., Fereres, E. (2005) Evapotranspiration of horticultural crops in an unheated plastic greenhouse, Agricultural Water Management 72:81-96.

Orr, S. and Chapagain, A. (2006) Virtual water: a case study of green beans and flowers exported to the UK from Africa, Fresh Insights No. 3, www.agrifoodstandards.net/en/filemanager/active fid $=67$.

Owuor, P.O. (1998) Determinants of agricultural productivity in Kenya, Kenya Agricultural Marketing and Policy Analysis Project, Tegemeo Institute of Agricultural Policy and Development/ Egerton University/Kenya Agricultural Research Institute/ Michigan State University

Owuor, S.O. and Foeken, D.W.J. (2009) Water reforms and interventions in urban Kenya : Institutional set-up, emerging impact and challenges, African Studies Centre Working Paper 83, Leiden, The Netherlands. 
Passioura, J. (2006) Increasing crop productivity when water is scarce-from breeding to field management, Agricultural Water Management 80: 176-196.

PDV (2005) Herkomst en samenstelling voer voor de Nederlandse intensieve veehouderij, Productschap Diervoeder.

Peck, J.C. (2007) Groundwater management in the High Plains Aquifer in the USA: Legal problems and innovations, in The agricultural groundwater revolution: Opportunities and threats to development, edited by M. Giordano and K.G. Villholth, CAB International, Wallingford, UK, pp. 296-319.

Peden, D., Tadesse, G., Misra, A.K., Ahmed, F.A., Astatke, A., Ayalneh, W., Herrero, M., Kiwuwa, G., Kumsa, T., Mati, B., Mpairwe, D., Wassenaar, T. and Yimegnuhal, A. (2007) Water and livestock for human development, in Water for food, water for life: a comprehensive assessment of water management in agriculture, edited by D. Molden, International Water Management Institute, Colombo, Earthscan, London: pp. 485-514.

Pelletier, N. and Tyedmers, P. (2010) Forecasting potential global environmental costs of livestock production 2000-2050, Proceedings of the National Academy of Sciences 107 (43): 18371-18374.

Pelsmacker, P. de, Driesen, L., Rayp, G. (2005) Do consumers care about ethics? Willingness to pay for fair-trade coffee, The Journal of Consumer Affairs 39 (2): 369385.

Pena, R.J. (2002) Wheat for bread and other foods, in Bread wheat: Improvement and production, edited by B.C. Curtis, et al., Food and Agriculture Organization, Rome, www.fao.org/docrep/006/y4011e/y4011e00.htm\#Contents.

Perry, C. (2003) Water pricing: some important definitions and assumptions, Occasional Paper No. 59, SOAS Water Issues Study Group, University of London, www.soas.ac.uk/waterissues/papers/file38402.pdf

Perry, C. (2007) Efficient irrigation; inefficient communication; flawed recommendations, Irrigation and Drainage 56(4): 367-378.

Perry, C., Steduto, P., Allen, R. G. and Burt, C. M. (2009) Increasing productivity in irrigated agriculture: Agronomic constraints and hydrological realities, Agricultural Water Management 96(11): 1517-1524.

Peterson, J. and Bernardo, D. (2003) High Plains regional aquifer study revisited: A 20 year retrospective for Western Kansas, Great Plains Studies, Centre for Great Plains 
Research: A Journal of Natural and Social Sciences, http://digitalcommons.unl.edu/greatplainsresearch/662.

Pimentel, D., Houser, J., Preiss, E., White, O. Fang, H., Mesnick, L., Barsky, T., Tariche, S., Schreck, J. and Alpert, S.: Water Resources (1997) Agriculture, the environment, and society, BioScience 47(2): 97-106.

Pimentel, D., Berger, B., Filiberto, D., Newton, M., Wolfe, B., Karabinakis, E., Clark, S., Poon, E., Abbett, E. and Nandagopal, S. (2004) Water resources: Agricultural and environmental issues, BioScience 54(10): 909-918.

Pingali, P.L. (ed.) (1999) CIMMYT 1998-99 World wheat facts and trends. Global wheat research in a changing world: Challenges and achievements, International Maize and Wheat Improvement Centre, Mexico, www.cimmyt.org/research/economics/map/facts trends/wheatft9899/pdf/WheatF\&T99cont.pdf.

Poff, N. L., Allan, J. D., Bain, M. B., Karr, J. R., Prestegaard, K. L., Richter, B. D., Sparks, R. E., and Stromberg, J. C. (1997) The natural flow regime: a paradigm for river conservation and restoration, BioScience 47:769-784.

Poff, N.L., Richter, B.D., Aarthington, A.H., Bunn, S.E., Naiman, R.J., Kendy, E., Acreman, M., Apse, C., Bledsoe, B.P., Freeman, M.C., Henriksen, J., Jacobson, R.B., Kennen, J.G., Merritt, D.M., O’Keeffe, J.H., Olden, J.D., Rogers, K., Tharme, R.E. and Warner, A. (2010) The ecological limits of hydrologic alteration (ELOHA): A new framework for developing regional environmental flow standards, Freshwater Biology, 55(1): 147-170.

Poisot, A.S, Speedy, A., Kueneman, E. (2007) Good agricultural practices - a working concept: background paper for the FAO Internal Workshop on Good Agricultural Practices, FAO GAP Working Paper Series 5, Food and Agriculture Organization, Rome, Italy.

Pontius, D. (1997) Colorado River Basin Study, Report to the Western Water, Policy Review Advisory Commission, New Mexico, US, http://wwa.colorado.edu/colorado_river/docs/pontius\%20colorado.pdf.

Portmann, F., Siebert, S., Bauer, C. \& Döll, P. (2008) Global data set of monthly growing areas of 26 irrigated crops, Frankfurt Hydrology Paper 06, Institute of Physical Geography, University of Frankfurt, Frankfurt am Main, Germany, www.geo.unifrankfurt.de/ipg/ag/dl/f_publikationen/2008/FHP_06_Portmann_et_al_2008.pdf. 
Portmann, F.T., Siebert, S. and Döll, P. (2010) Mirca2000 - global monthly irrigated and rainfed crop areas around the year 2000: A new high-resolution data set for agricultural and hydrological modelling, Global Biogeochemical Cycles, 24(1): GB1011, doi:10.1029/2008GB003435, http://www.geo.unifrankfurt.de/ipg/ag/dl/forschung/MIRCA/data_download/index.html.

Postel, S. L. (1993) Water and agriculture, in Water in crisis: A guide to the world's fresh water resources, edited by P.H. Gleick, Oxford University Press, Oxford, UK, pp.5666.

Postel, S.L. (1998) Water for food production: Will there be enough in 2025? BioScience 48: 629-637.

Postel, S.L. (2000) Entering an era of water scarcity: The challenges ahead, Ecological Applications 10(4): 941-948.

Postel, S.L., Daily, G.C. and Ehrlich, P.R. (1996) Human appropriation of renewable freshwater, Science 271 (5250): 785-788.

Raskin, P.D., E. Hansen and R.M. Margolis (1996) Water and sustainability: global patterns and long-range problems, Natural Resources Forum 20(1): 1-5.

Renault, D. and Wallender, W.W. (2000) Nutritional water productivity and diets, Agricultural Water Management 45: 275-296.

Reynolds, C.A., Yitayew, M., Slack, D.C., Hutchinson, C.F., Huete, A. and Petersen, M.S. (2000) Estimating crop yields and production by integrating the FAO Crop Specific Water Balance model with real-time satellite data and ground-based ancillary data, Int. Journal of Remote Sensing 21 (18): 3487-3508.

Richter, B.D., Davis, M.M., Apse, C. And Konrad, C. (2011) A presumptive standard for environmental flow protection, River Research and Applications, online: doi: 10.1002/rra.1511.

Rijsberman, F. R. (2006) Water scarcity: Fact or fiction? Agricultural Water Management, 80(1-3): 5-22.

Riley, W.J., Ortiz-Monasterio, I., Matson, P.A. (2001) Nitrogen leaching and soil nitrate, and ammonium levels under irrigated wheat in Northern Mexico. Nutr. Cyc. Agroecosys. 61, 223-236.

Riungu, C. (2007) Kenya: Naivasha flower farms win first round in tax war, http://allafrica.com/stories/200708140634.html. 


\section{8 / References}

Rockström, J. (2003) Water for food and nature in drought-prone tropics: Vapour shift in rain-fed agriculture, Philosophical Transactions of the Royal Society of London, Series B, 358(1440): 1997-2009.

Rockström, J. and Barron, J. (2007) Water productivity in rainfed systems: overview of challenges and analysis of opportunities in water scarcity prone savannahs, Irrigation Science 25(3): 299-311.

Rockstrom, J. and Gordon, L. (2001) Assessment of green water flows to sustain major biomes of the world: Implications for future ecohydrological landscape management, Physics and Chemistry of the Earth 26(11-12): 843-851.

Rockström, J., Gordon, L., Falkenmark, M., Folke, C. and Engvall, M. (1999) Linkages among water vapor flows, food production, and terrestrial ecosystem services, Conservation Ecology 3(2), 5, http://www.consecol.org/vol3/iss2/art5/ .

Rockström, J., Barron, J., and Fox, P. (2003) Water productivity in rain-fed agriculture: challenges and opportunities for smallholder farmers in drought-prone tropical agroecosystems, in Water productivity in agriculture: Limits and opportunities for improvement, edited by J.W. Kijne et al., CAB International, Wallingford, UK and International Water management Institute, Colombo, Sri Lanka, pp. 145- 162.

Rockström, J., Hatibu, N., Oweis, T.Y., Wani, S., Barron, J., Bruggeman, A., Farahani, J., Karlberg, L. and Qiang, Z. (2007a) Managing water in rainfed agriculture, in Water for food, water for life: A comprehensive assessment of water management in agriculture, edited by D. Molden, Earthscan, London, 315- 352.

Rockström, J., Lannerstad, M. and Falkenmark, M. (2007b) Assessing the water challenge of a new green revolution in developing countries, Proceedings of the National Academy of Sciences 104(15): 6253-6260.

Rockström, J., Falkenmark, M., Karlberg, L., Hoff, H., Rost, S., and Gerten, D. (2009) Future water availability for global food production: the potential of green water for increasing resilience to global change, Water Resources Research 45: W00A12, doi:10.1029/2007WR006767.

Rodell, M., Velicogna, I. and Famiglietti, J. S. (2009) Satellite-based estimates of groundwater depletion in India, Nature 460 (7258): 999-1002.

Rogers, P., de Silva, R., Bhatia, R. (2002) Water is an economic good: How to use prices to promote equity, efficiency, and sustainability, Water Policy 4(1): 1-17. 
Rohwer, J., Gerten, D. and Lucht, W. (2007) Development of functional types of irrigation for improved global crop modelling, Potsdam Institute for Climate Impact Research, Potsdam, Germany.

Romaguera, M., Hoekstra, A.Y., Su, Z., Krol, M.S. and Salama, M.S. (2010) Potential of using remote sensing techniques to global assessment of the water footprint of crops, Remote Sensing 2(4): 1177-1196.

Rosegrant, M.W. and Cline, S. (2002) The politics and economics of water pricing in developing countries, Water Resources Impact 4(1): 6-8.

Rosegrant, M.W. and Ringler, C. (2000) Impact on food security and rural development of transferring water out of agriculture, Water Policy 1(6): 567-586.

Rosenberg, D.M., Bodaly, R.A. and Usher, P.J. (1995) Environmental and social impacts of large scale hydroelectric development: who is listening? Global Environmental Change 5 (2): $127-148$.

Rost, S., Gerten, D., Bondeau, A., Lucht, W., Rohwer, J., Schaphoff, S. (2008) Agricultural green and blue water consumption and its influence on the global water system, Water Resources Research 44: W09405. doi:10.1029/2007WR006331.

Rost, S., Gerten, D., Hoff, H., Lucht, W., Falkenmark, M., Rockström, J. (2009) Global potential to increase crop production through water management in rainfed agriculture, Environmental Research Letters 4, doi:10.1088/1748-9326/4/4/044002.

Roy, R.N., Misra, R.V, Lesschen, J.P. and Smaling, E.M.A. (2003) Assessment of Soil Nutrient Balance. Approaches and Methodologies, FAO Fertilizer and Plant Nutrition Bulletin 14, FAO, Rome.

SABMiller and WWF-UK (2009) Water footprinting: Identifying and addressing water risks in the value chain, SABMiller, Woking / WWF-UK, Goldalming, UK

Sacks, W.J., D. Deryng, J.A. Foley, and N. Ramankutty (2010) Crop planting dates: An analysis of global patterns, Global Ecology and Biogeography 19 (5): 607-620, http://www.sage.wisc.edu/download/sacks/ArcINFO5min.html.

Savenije, H.H.G. (2000) Water scarcity indicators; the deception of the numbers, Physics and Chemistry of the Earth (B), 25(3): 199-204.

Schuol, J. and Abbaspour, K.C. (2007) Using monthly weather statistics to generate daily data in a SWAT model application to West Africa, Ecological Modelling 201: 301-311. 
Scudder, T. (1997) Social impacts of large dam projects, in Large Dams: Learning from the Past, Looking at the Future, Workshop Proceedings, edited by T. Dorcey et al., IUCN, Gland, Switzerland and Cambridge, UK and the World Bank Group, Washington, DC.

Seckler, D., Amarasinghe, U., Molden, D.J., de Silva, R. and Barker, R.(1998) World water demand and supply, 1990-2025: Scenarios and issues, IWMI Research Report 19, IWMI, Colombo, Sri Lanka.

Seckler, D., Molden, D. and Sakthivadivel, R. (2003) The concept of efficiency in water resource management and policy, in Water productivity in agriculture: Limits and opportunities for improvement, edited by J.W.Kijne et al., CAB International, Wallingford, UK and International Water management Institute, Colombo, Sri Lanka, pp. $37-51$.

Sellers, W. D. (1965) Physical climatology, University of Chicago Press, Chicago, Illinois.

Seré, C. and Steinfeld, H. (1996) World livestock production systems: current status, issues and trends, Animal Production and Health Paper 127, Food and Agriculture Organization, Rome, Italy. www.fao.org/WAIRDOCS/LEAD/X6101E/X6101E00.HTM

Shiklomanov, I.A. (1993) World fresh water resources, in Water in crisis: A guide to the world's fresh water resources, edited by P.H. Gleick, Oxford University Press, Oxford, UK, pp. 13-24.

Shiklomanov, I.A. (2000) Appraisal and assessment of world water resources, Water International 25 (1): 11-32.

Shiklomanov, I.A. and Rodda, J.C. (eds.) (2003) World water resources at the beginning of the twenty-first century, Cambridge University Press, Cambridge, UK.

Siebert, S. and Döll, P. (2008) The global crop water model (GCWM): Documentation and first results for irrigated crops. Frankfurt Hydrology Paper 07, Institute of Physical Geography, University of Frankfurt, Frankfurt am Main, Germany, www.geo.unifrankfurt.de/ipg/ag/dl/f_publikationen/2008/FHP_07_Siebert_and_Doell_2008.pdf.

Siebert, S. and Döll, P. (2010) Quantifying blue and green virtual water contents in global crop production as well as potential production losses without irrigation, Journal of Hydrology 384: 198-207.

Siebert, S., Döll, P., Feick, S., Hoogeveen, J. and Frenken, K. (2007) Global map of irrigation areas version 4.0.1. Johann Wolfgang Goethe University, Frankfurt am Main, 
Germany / Food and Agriculture Organization of the United Nations, Rome, Italy, http:/www.fao.org/nr/water/aquastat/irrigationmap/index10.stm .

Singh, V.P. and Xu, C.-Y. (1997) Evaluation and generalization of 13 mass-transfer equations for determining free water evaporation, Hydrological Processes 11(3): 311323.

Smakhtin, V. (2002) Environmental water needs and impacts of irrigated agriculture in river basins: A framework for a new research program, Working Paper 42, Colombo, Sri Lanka: International Water Management Institute.

Smakhtin, V., Revenga, C. and Döll, P. (2004a) A pilot global assessment of environmental water requirements and scarcity, Water International 29(3): 307-317.

Smakhtin, V., Revenga, C., and Döll, P. (2004b) Taking into account environmental water requirements in global-scale water resources assessments, Comprehensive Assessment Research Report 2, Colombo, Sri Lanka.

Smaling, E.M.A., Roscoe, R., Lesschen, J.P., Bouwman, A.F. and Comunello, E. (2008) From forest to waste: Assessment of the Brazilian soybean chain, using nitrogen as a marker, Agriculture, Ecosystems and Environment 128:185-197.

Smart, A. J., Derner, J. D., Hendrickson, J. R., Gillen, R. L., Dunn, B. H., Mousel, E. M., Johnson, P. S., Gates, R. N., Sedivec, K. K., Harmoney, K. R., Volesky, J. D. and Olson, K. C. (2010) Effects of grazing pressure on efficiency of grazing on North American great plains rangelands, Rangeland Ecology and Management 63(4): 397-406.

Smith, D.L., Harris, A.D., Johnson, J.A., Silbergeld, E.K. and Morris, J.G. (2002) Animal antibiotic use has an early but important impact on the emergence of antibiotic resistance in human commensal bacteria, Proceedings of the National Academy of Sciences 99(9): 6434-6439.

Solley, W.B., Pierce, R.R. and Perlman, H.A. (1998) Estimated Use of Water in the United States in 1995, USGS Circular 1200, US Geological Survey, Reston, USA, http://water.usgs.gov/watuse.

Sonnenberg, A., Chapagain, A., Geiger, M. and August, D. (2009) Der Wasser-Fußabdruck Deutschlands: Woher stammt das Wasser, das in unseren Lebensmitteln steckt? WWF Deutschland, Frankfurt. 
Sonnenberg, A., Chapagain, A., Geiger, M., August, D. and Wagner, W. (2010) Der Wasser-Fußabdruck der Schweiz: Woher stammt das Wasser, das in unseren Landwirtschaftsprodukten steckt? WWF Schweiz, Zürich.

Steinfeld, H., Gerber, P., Wassenaar, T., Castel, V., Rosales, M., de Haan, C. (2006) Livestock's long shadow: environmental issues and options, Food and Agriculture Organization, Rome, Italy, ftp://ftp.fao.org/docrep/fao/010/a0701e/A0701E.pdf.

Sternberg, R. (2008) Hydropower: dimensions of social and environmental coexistence, Renewable and Sustainable Energy Reviews 12(6): 1588-1621.

Sternberg, R. (2010) Hydropower's future, the environment, and global electricity systems, Renewable and Sustainable Energy Reviews 14(2): 713-723.

Sutton, M.A., Oenema, O., Erisman, J.W., Leip, A., Van Grinsven, H. and Winiwarter, W. (2011) Too much of a good thing, Nature 472(7342): 159-161.

Sweers, H. E. (1976) A monogram to estimate the heat-exchange coefficient at the airwater interface as a function of wind speed and temperature; a critical survey of some literature, Journal of Hydrology 30(4): 375-401.

Swinbank, W. C. (1963) Long-wave radiation from clear skies, Quarterly Journal of the Royal Meteorological Society 89 (381): 339-348.

Thenkabail, P. S., Schull, M. and Turral, H. (2005) Ganges and indus river basin land use/land cover (lulc) and irrigated area mapping using continuous streams of modis data, Remote Sensing of Environment 95(3): 317-341.

Thompson, P.B. (ed.) (2008) The ethics of intensification: Agricultural development and cultural change, The International Library of Environmental, Agricultural and Food Ethics Vol. 16, DOI: 10.1007/978-1-4020-8722-6, Springer.

Tilman, D., Fargione, J., Wolff, B., D'antonio, C., Dobson, A., Howarth, R., Schindler, D., Schlesinger, W.H., Simberloff, D. and Swackhamer, D. (2001) Forecasting agriculturally driven global environmental change, Science 292(5515): 281-284.

Tilt, B., Braun, Y. and He, D. (2009) Social impacts of large dam projects: A comparison of international case studies and implications for best practice, Journal of Environmental Management 90 (Supplement 3), S249-S257.

Tiruneh, B.A., (2004) Modelling water quality using soil and water assessment tool SWAT: a case study in Lake Naivasha basin, Kenya. M.Sc. Thesis, ITC, Enschede, The Netherlands. 
Turton, A.R. and Ohlsson, L. (1999) Water scarcity and Social stability: towards a deeper understanding of the key concepts needed to manage water scarcity in developing countries, paper presented at the 9th Stockholm Water Symposium, Sweden, 9-12 August 1999.

UN (1992) Agenda 21: The United Nations programme of action from Rio, United Nations, New York, USA.

UNDP (2006) Beyond scarcity: power, poverty and the global water crisis, Human Development Report 2006, United Nation Development Program.

UNEP (2006) Africa Environment Outlook-2: Our Environment, Our Wealth. Nairobi, Kenya.

UNEP GEMS/Water Programme (2008) Water Quality for Ecosystem and Human Health, $2^{\text {nd }}$ edn., UNEP GEMS/Water Programme, Ontario, Canada.

UNESCO (2009) Water in a changing world: The United Nations World Water Development Report 3, UNESCO Publishing, Paris / Earthscan, London.

UNSD (2010a) UNSD environmental indicators: inland waters resources, UN Statistic Division, http://unstats.un.org/unsd/ENVIRONMENT/wastewater.htm.

UNSD (2010b) Nationals accounts main aggregates database, UN Statistic Division, http://unstats.un.org/unsd/snaama/selectionbasicFast.asp.

USDA 1994) The major world crop areas and climatic profiles, Agricultural Handbook No. 664, World Agricultural Outlook Board, United States Department of Agriculture, www.usda.gov/oce/weather/pubs/Other/MWCACP/MajorWorldCropAreas.pdf.

Van Breugel, P., Herrero, M., Van De Steeg, J. and Peden, D. (2010) Livestock water use and productivity in the Nile Basin, Ecosystems 13(2): 205-221.

Van der Leeden, F., Troise, F.L. and Todd, D.K. (1990) The water encyclopedia, Second edition, CRC Press, Boca Raton, Florida, USA.

Van Oel, P.R., Mekonnen, M.M. and Hoekstra, A.Y. (2008) The external water footprint of the Netherlands: quantification and impact assessment, Value of Water Research Report Series No. 33, UNESCO-IHE, Delft, The Netherlands.

Van Oel, P.R., Mekonnen M.M. and Hoekstra, A.Y. (2009) The external water footprint of the Netherlands: Geographically-explicit quantification and impact assessment, Ecological Economics 69(1): 82-92. 


\section{4 / References}

Verma, S., Kampman, D.A., Van der Zaag, P. and Hoekstra, A.Y. (2009) Going against the flow: A critical analysis of inter-state virtual water trade in the context of India's National River Linking Programme, Physics and Chemistry of the Earth, 34: 261-269.

Vincent, D., De Caritat, A.K., Stijn Bruers, S., Chapagain, A., Weiler, P. and Laurent, A. (2011) Belgium and its water footprint, WWF-Belgium, Brussels.

Vitens (2008) www.verswater.nl

Vörösmarty, C.J., Green, P., Salisbury, J., and Lammers, R.B. (2000) Global water resources: vulnerability from climate change and population growth, Science 289: 284288.

Vörösmarty, C. J., McIntyre, P. B., Gessner, M. O., Dudgeon, D., Prusevich, A., Green, P., Glidden, S., Bunn, S. E., Sullivan, C. A., Liermann, C. R. and Davies, P. M. (2010) Global threats to human water security and river biodiversity, Nature 467(7315): 555561.

Wackernagel, M., Schulz, N.B., Deumling, D., Linares, A.C., Jenkins, M., Kapos, V., Monfreda, C., Loh, J., Myers, N., Norgaard, R. and Randers, J. (2002) Tracking the ecological overshot of the human economy, Proceedings of the National Academy of Science 99 (14): 9266-9271.

Wada, Y., Van Beek, L.P.H., Van Kempen, C.M., Reckman, J.W.T.M., Vasak, S. and Bierkens, M.F.P. (2010) Global depletion of groundwater resources, Geophysical Research Letters, 37, L20402.

Wallace, J.S. (2000) Increasing agricultural water use efficiency to meet future food production Agriculture, Ecosystems and Environment 82: 105-119.

Wallace, J.S. and Batchelor, C.H. (1997) Managing water resources for crop production, Philosophical Transactions of the Royal Society of London, Series B 352: 937-947

Wallace, J.S. and Gregory, P.J. (2002) Water resources and their use in food production systems, Aquatic Sciences 64: 363-375.

Webster, C.P., Poulton, P.R., and Goulding, K.W.T. (1999) Nitrogen leaching from winter cereals grown as part of a 5-year ley-arable rotation, European Journal of Agronomy 10, 99-109.

Wheeler, R.O., Cramer, G.L., Young, K.B., Ospina, E. (1981) The world livestock product, feedstuff, and food grain system, an analysis and evaluation of system interactions throughout the world, with projections to 1985, Winrock Inter., Little Rock, AK, USA. 
Wichelns, D. (2004) The policy relevance of virtual water can be enhanced by considering comparative advantages, Agricultural Water Management 66(1): 49-63.

Williams, J.R., Jones, C.A., Kiniry, J.R., and Spanel, D.A. (1989) The EPIC crop growthmodel, T. ASAE 32(2): 497-511, 1989.

Wint, G.R.W. and Robinson, T.P. (2007) Gridded livestock of the world 2007, Food and Agriculture Organization, Rome, Italy, www.fao.org/docrep/010/a1259e/a1259e00.htm.

Winter, T. C., Rosenberry, D. O. and Sturrock, A. M. (1995) Evaluation of 11 equations for determining evaporation for a small lake in the north central united states, Water Resource Research 31(4): 983-993.

Wirsenius, S. (2000) Human use of land and organic materials: Modelling the turnover of biomass in the global food system, $\mathrm{PhD}$ thesis, Chalmers University of Technology and Göteborg University, Göteborg, Sweden, http://frt.fy.chalmers.se/PDF-docs/SWI_Thesis.pdf.

Witte, W. (1998) Medical consequences of antibiotic use in agriculture, Science 279(5353): 996-997.

Wong, C., Roy, M. and Duraiappah, A.K. (2005) Connecting poverty and ecosystem services: A series of seven country scoping studies, focuses on Kenya, published for UNEP and IISD, Nairobi, Kenya.

World Bank (1996) The World Bank's experience with large dams: a preliminary review of impacts, Operations Evaluation Department, World Bank, Washington, DC.

World Bank (2004) World Bank water resources sector strategy: Strategic directions for World Bank Engagement, World Bank, Washington, DC., USA.

World Commission on Dams (2000) Dams and development: a new framework for decision-making, Earthscan, London, UK.

World Water Commission (2000) A water secure world: Vision for water, life, and the environment, World Water Vision Commission Report. World Water Commission, The Hague, The Netherlands.

WRI (2007) Nature's Benefits in Kenya, an Atlas of ecosystems and human well-being, World Resources Institute, Washington, DC and Nairobi, http://www.wri.org/publication/natures-benefits-in-kenya.

WWAP (2003) The United Nations World Water Development Report 1: Water for people, water for life, World Water Assessment Programme, UNESCO Publishing, Paris / Berghahn Books, New York. 
WWAP (2006) The United Nations World Water Development Report 2: Water a shared responsibility, World Water Assessment Programme, UNESCO Publishing, Paris / Berghahn Books, New York.

WWAP (2009) The United Nations World Water Development Report 3: Water in a changing world, World Water Assessment Programme, UNESCO Publishing, Paris / Earthscan, London.

$\mathrm{Xu}$, T.Z. (1999) Water quality assessment and pesticide fate modelling in the Lake Naivasha area, Kenya. M.Sc. Thesis, ITC, Enschede, The Netherlands.

Yang, H. and Zehnder, A.J.B. (2008) Globalization of water resources through virtual water trade, Rosemberg International Forum on Water Policy, http://rosenberg.ucanr.org/documents/II\%20Yang.pdf

Yang, H., Reichert, P., Abbaspour, K.C. and Zehnder, A. J. B. (2003) A water resources threshold and its implications for food security, Environmental Science and Technology 37(14): 3048-3054.

Yang, H., Wang, L., Abbapour, K.C. and Zehnder, A.J.B. (2006) Virtual water trade: an assessment of water use efficiency in the international food trade, Hydrology and Earth System Sciences 10: 443-454.

Yu, Y., Hubacek, K., Feng, K. and Guan, D. (2010) Assessing regional and global water footprints for the UK, Ecological Economics, 69(5): 1140-1147.

Zhao, X., Chen, B., Yang, Z.F. (2009) National water footprint in an input-output framework - A case study of China 2002, Ecological Modelling 220(2): 245-253

Zimmer, D. and Renault, D. (2003) Virtual water in food production and global trade: review of methodological issues and preliminary results, in Virtual water trade: Proceedings of the International Expert Meeting on Virtual Water Trade, edited by A.Y. Hoekstra, Value of Water Research Report Series No.12, UNESCO-IHE, Delft, The Netherlands, pp. 93-109.

Zwart, S.J. and Bastiaanssen, W.G.M. (2004) Review of measured crop water productivity values for irrigated wheat, rice, cotton and maize, Agricultural Water Management 69(2): 115-133.

Zwart, S.J. and Bastiaanssen, W.G.M. (2007) SEBAL for detecting spatial variation of water productivity and scope for improvement in eight irrigated wheat systems, Agricultural Water Management 89 (3): 287-296. 


\section{List of publications}

\section{Papers in peer-reviewed journals}

- Hoekstra, A.Y. and Mekonnen, M.M. (submitted) The water footprint of humanity, Proceedings of the National Academy of Sciences USA.

- Mekonnen, M.M. and Hoekstra, A.Y. (submitted) The water footprint of farm animal products, Ecosystems.

- Mekonnen, M.M. and Hoekstra, A.Y. (submitted) The water footprint of electricity from hydropower, Energy \& Environmental Science.

- Mekonnen, M.M., Hoekstra, A.Y. and Becht, R. (submitted) Mitigating the water footprint of export cut flowers from the Lake Naivasha Basin, Kenya, Water Resources Management.

- Mekonnen, M.M. and Hoekstra, A.Y. (2011a) The green, blue and grey water footprint of crops and derived crop products, Hydrology and Earth System Sciences, 15(5): 15771600 .

- Mekonnen, M.M. and Hoekstra, A.Y. (2010a) A global and high-resolution assessment of the green, blue and grey water footprint of wheat, Hydrology and Earth System Sciences, 14(7), 1259-1276.

- Van Oel, P.R., Mekonnen, M.M. and Hoekstra, A.Y. (2009) The external water footprint of the Netherlands: Geographically explicit quantification and impact assessment, Ecological Economics 69, 82-92.

\section{Books}

- Hoekstra, A.Y., Chapagain, A.K., Aldaya, M.M. and Mekonnen, M.M. (2011) The water footprint assessment manual: Setting the global standard, Earthscan, London, UK.

\section{Research reports}

- Hoekstra, A.Y. and Mekonnen (2011) Global water scarcity: The monthly blue water footprint compared to blue water availability for the world's major river basins, Value of Water Research Report Series No. 53, UNESCO-IHE, Delft, The Netherlands. 
- Mekonnen, M.M. and Hoekstra, A.Y. (2011b) National water footprint accounts: The green, blue and grey water footprint of production and consumption, Value of Water Research Report Series No. 50, UNESCO-IHE, Delft, The Netherlands.

- Mekonnen, M.M. and Hoekstra, A.Y. (2011c) The water footprint of electricity from hydropower, Value of Water Research Report Series No. 51, UNESCO-IHE, Delft, The Netherlands.

- Mekonnen, M.M. and Hoekstra, A.Y. (2011d) The relation between national water management and international trade: a case study from Kenya, Value of Water Research Report Series No. 52, UNESCO-IHE, Delft, The Netherlands.

- Mekonnen, M.M. and Hoekstra, A.Y. (2010b) A global and high-resolution assessment of the green, blue and grey water footprint of wheat, Value of Water Research Report Series No. 42, UNESCO-IHE, Delft, The Netherlands.

- Mekonnen, M.M. and Hoekstra, A.Y. (2010c) Mitigating the water footprint of export cut flowers from the Lake Naivasha Basin, Kenya, Value of Water Research Report Series No. 45, UNESCO-IHE, Delft, The Netherlands.

- Mekonnen, M.M. and Hoekstra, A.Y. (2010d) The green, blue and grey water footprint of crops and derived crop products, Value of Water Research Report Series No. 47, UNESCO-IHE, Delft, The Netherlands.

- Mekonnen, M.M. and Hoekstra, A.Y. (2010e) The green, blue and grey water footprint of animals and derived animal products, Value of Water Research Report Series No. 48, UNESCO-IHE, Delft, The Netherlands.

- Hoekstra, A.Y., Chapagain, A.K., Aldaya, M.M. and Mekonnen, M.M. (2009) Water footprint manual: state of the art 2009, Water Footprint Network, Enschede, The Netherlands.

- Van Oel, P.R., Mekonnen, M.M. and Hoekstra, A.Y. (2008) The external water footprint of the Netherlands: quantification and impact assessment, Value of Water Research Report Series No. 33, UNESCO-IHE, Delft, The Netherlands.

\section{Conference proceedings}

- Mekonnen, M.M. and Hoekstra, A.Y. (2010) Mitigating the water footprint of export cut flowers from the Lake Naivasha Basin, Kenya, in Proceedings of the IWRM 
conference, edited by H. Steusloff, Karlsruhe, KIT Scientific Publishing (ISBN 978-386644-545-1), pp. 274-381.

- Mekonnen, M.M. and Hoekstra, A.Y. (2008) The relation between national water scarcity and international trade: A case study for Kenya, The 10th Biennial International Society for Ecological Economics Conference Proceeding, Nairobi, Kenya.

- Van Oel, P.R., Mekonnen, M.M., Hoekstra, A.Y. (2008) The external water footprint of the Netherlands: Geographically explicit quantification and impact assessment, The $10^{\text {th }}$ Biennial International Society for Ecological Economics Conference Proceeding, Nairobi, Kenya. 



\section{About the author}

Mesfin Mekonnen was born on 23 November 1966 in Addis Ababa, Ethiopia. He grew up in Addis Ababa where he got his primary and secondary education at the Akaki Adventist School. In 1984 he joined the Addis Ababa University to pursue his study in 'Chemical Engineering' and received the degree of BSc in 1989. After working as a Chemical Engineer for four years, he received a scholarship to follow a Master of Science programme in 'Principles of Renewable Energy' at the University of Oldenburg, Germany and obtained his Master degree in 1994. He has worked at the Ministry of Water and Energy (formerly Ministry of Mines and Energy) as energy expert at various capacities for over 10 years. At the same time he was following the Bachelor degree program in Economics at the Addis Ababa University and obtained his BA degree with distinction in 2003. In the same year, he joined the Master of Science programme at the UNESCO-IHE, the Netherlands. He received his MSc. degree with distinction in 'Environmental Science and Engineering' in March 2005. During his Master of Science thesis project, Mekonnen developed the 'Water footprint calculator' which is still being used at the waterfootprint.org website. In August 2007 Mekonnen started his $\mathrm{PhD}$ at the Water Engineering and Management Department, University of Twente in the Netherlands. Mekonnen is at University of Twente as post-doc working on the EU project (Compiling and Refining Environmental and Economic Accounts - CREEA) and other water footprint related fields. 